Bibliothèque d'Archéologie Méditerranéenne et Africaine - 18

\title{
SIGNA ET TITULI
}

\section{MONUMENTS ET ESPACES DE REPRÉSENTATION EN GAULE MÉRIDIONALE}

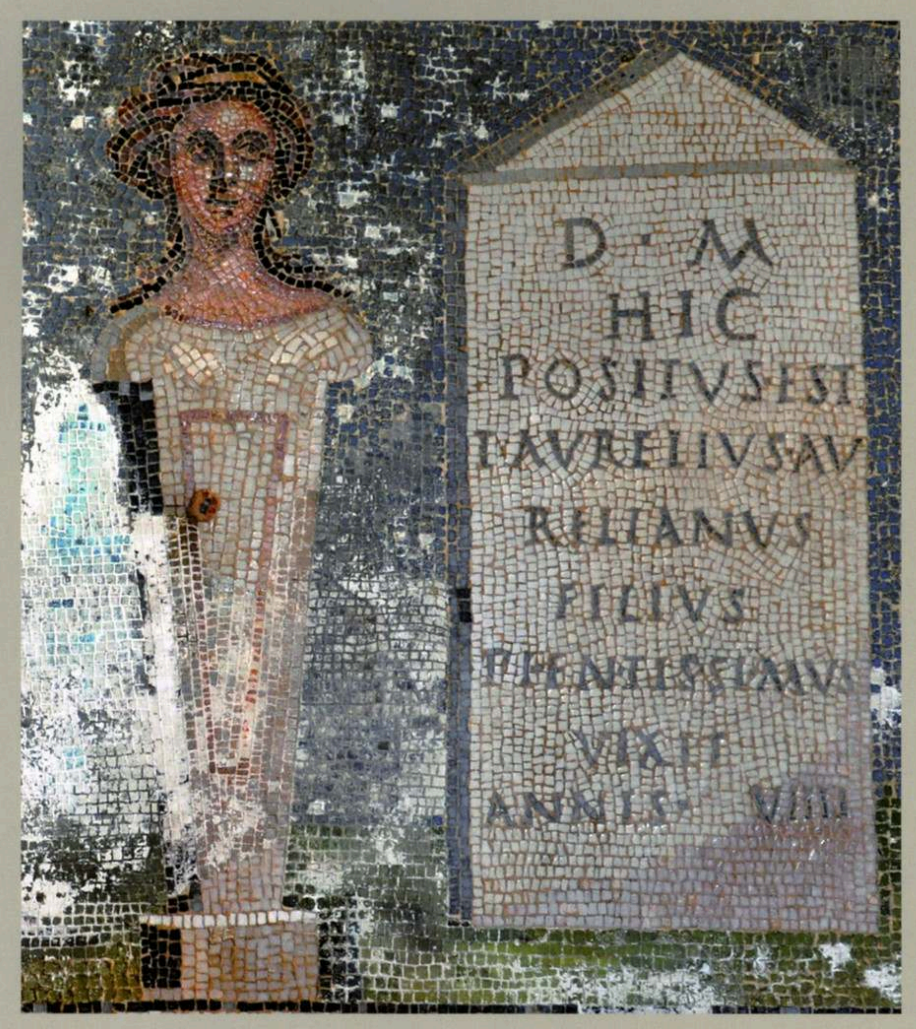

éditions errance | Centre Camille Jullian 


\section{Signa et tituli}

Monuments et espaces de représentation en Gaule méridionale sous le regard croisé de la sculpture et de l'épigraphie

\section{Sandrine Agusta-Boularot et Emmanuelle Rosso (dir.)}

DOI : $10.4000 /$ books.pccj.2288

Éditeur : Publications du Centre Camille Jullian, Éditions Errance

Lieu d'édition : Aix-en-Provence

Année d'édition : 2015

Date de mise en ligne : 6 avril 2020

Collection : Bibliothèque d'archéologie méditerranéenne et africaine

ISBN électronique : 9782491788070

\section{Sobooks}

http://books.openedition.org

\section{Édition imprimée}

Date de publication : 1 mars 2015

ISBN : 9782877725880

Nombre de pages : 239

\section{Référence électronique}

AGUSTA-BOULAROT, Sandrine (dir.) ; ROSSO, Emmanuelle (dir.). Signa et tituli : Monuments et espaces de représentation en Gaule méridionale sous le regard croisé de la sculpture et de l'épigraphie. Nouvelle édition [en ligne]. Aix-en-Provence : Publications du Centre Camille Jullian, 2015 (généré le 08 avril 2020). Disponible sur Internet : <http://books.openedition.org/pccj/2288>. ISBN : 9782491788070. DOI : https://doi.org/10.4000/books.pccj.2288. 


\section{$\mathrm{B}$ ibliothèque d'Archéologie \\ Méditerranéenne et Africaine \\ 18}


Dans la lignée des anciens Travaux du Centre Camille Jullian, la Bibliothèque d'Archéologie Méditerranéenne et Africaine (BiAMA) regroupe des travaux (monographies, actes de colloques, ouvrages collectifs) en relation avec les programmes scientifiques du Centre Camille Jullian, sur l'histoire et l'archéologie de la Gaule méridionale, de l'Afrique du Nord et du bassin méditerranéen. La BiAMA peut comprendre des sous-séries, comme la collection Études massaliètes (EtMassa).

\section{Responsable légal :}

Marie-Brigitte Carre, Directrice du CCJ

Directeurs de la publication :

Sophie Bouffier et Henri Tréziny

Comité de pilotage :

S. Bouffier, M.-Br. Carre, X. Delestre et H. Tréziny

Conception graphique et mise en page :

Véronique Gémonet

\section{Comité de lecture :}

S. Bouffier (CCJ, Aix-Marseille Université), J.-P. Brun (Collège de France), M-Br. Carre (CCJ, CNRS), X. Delestre (CCJ, DRAC PACA), D. Garcia (CCJ, AMU, Inst. Univ. de France), M. Griesheimer (CCJ, AMU), A. Hermary (CCJ, AMU), Ph. Jockey (CCJ, AMU), M. Lombardo (Professeur à l'Université de Lecce), T. S. Loseby (Professeur à l'Université de Sheffield), J.-M. Mignon (Service archéologique départemental du Vaucluse), P. Pomey (CCJ,CNRS), L. Rivet (CCJ, CNRS), J. Sanmarti (Professeur à l'Université de Barcelone), J.-Chr. Sourisseau (CCJ, AMU), H. Tréziny (CCJ, CNRS), C. Virlouvet (École française de Rome), E. Voutiras (Professeur à l'Université de Thessalonique).

(C) 2014 pour tous pays,

Édition Errance, éditeur du groupe Actes Sud,

BP 9003813633 Arles Cédex

Tel. 04-88-65-92-05 / 06-99-30-70-87

Fax : 0143293488

Courriel : contact@editions-errance.fr

http://www.libairie-epona.fr

Centre Camille Jullian

Maison Méditerranéenne des Sciences de l'Homme

5 rue du Château de l'Horloge. BP 647, 13094 Aix-en-Provence Cedex 2

ISBN : 978-2-87772-588-0

ISSN BiAMA : 2101-2849

Illustrations de couverture :

Mosaïque du musée de Split : AE, 2006, 1011 (Croatie) (E. Rosso).

Illustration $4^{\text {ème }}$ de couverture :

Musée départemental d'Arles antique (cliché Centre Camille Jullian-CNRS, Aix-en-Provence).
Publications du Centre Camille Jullian

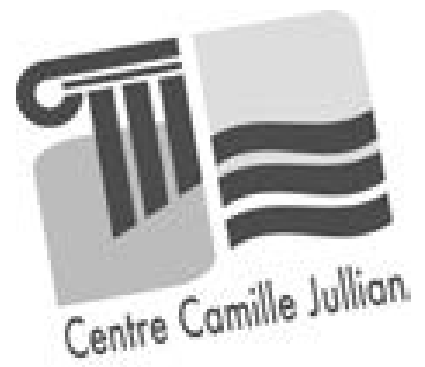

\author{
Ouvrage financé par \\ l'AMU (Aix-Marseille Université) et \\ le labex Montpellier
}

( $\begin{gathered}\text { Aix } * \text { Marseille } \\ \text { universite }\end{gathered}$

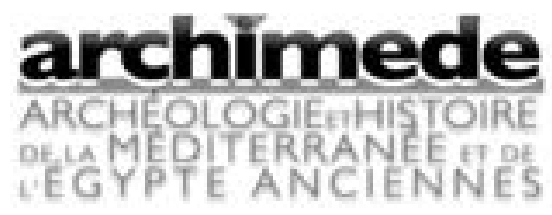

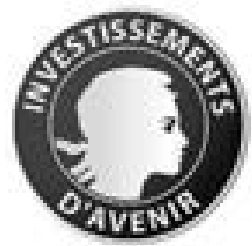

Envoyer les manuscrits à :

Bibliothèque d'Archéologie Méditerranéenne et Africaine Centre Camille Jullian

Maison Méditerranéenne des Sciences de l'Homme

5 rue du Château de l'Horloge. BP 647,

13094 Aix-en-Provence Cedex 2 


\section{SIGNA ET TITULI}

\section{Monuments et espaces de représentation en Gaule Méridionale sous le regard croisé de la sculpture et de l'épigraphie}

Sandrine Agusta-Boularot et Emmanuelle Rosso (éd.)

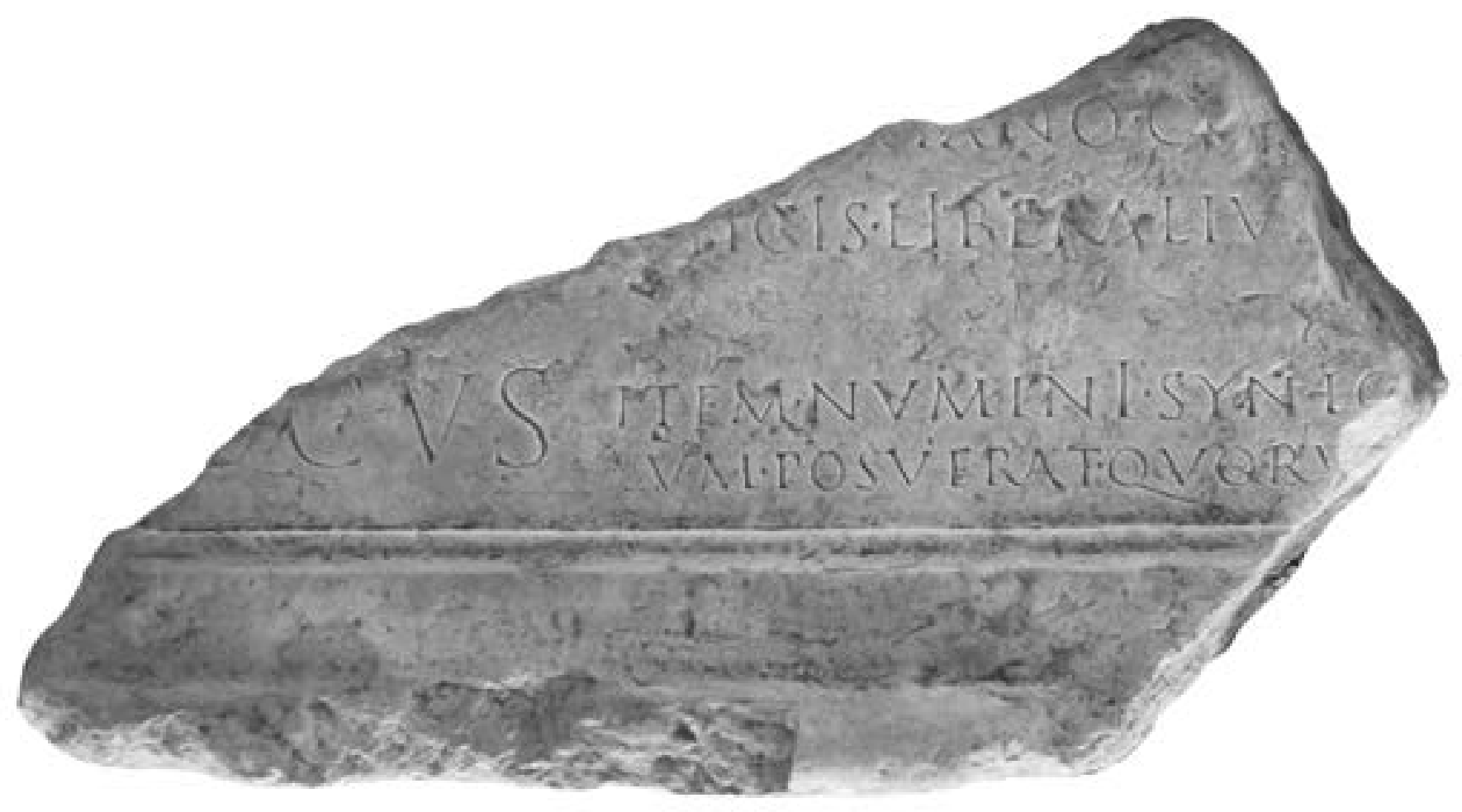




\section{Sommaire}

Hommage à Michel Janon

(Sandrine AGUSTA-BOULAROT, Emmanuelle ROSSO)

Bibliographie de Michel Janon (1937-2010)

\section{Introduction}

(Sandrine AGUSTA-BOULAROT, Emmanuelle ROSSO)

\section{Rapport introductif}

Il volto e la parola nei tituli votivi : ambigue discordanze (Antonio SARTORI)

Statues des dieux, statues des hommes. La mention de statues dans les inscriptions de Gaule Narbonnaise

(Sandrine AGUSTA-BOULAROT)

1. Présentation de la documentation

2. Nature et matériau des supports inscrits

3. Répartition géographique

4. Localisation des statues : espace funéraire, sacré, privé et public

5. Des empereurs, des dieux et des hommes

6. Matériau, poids, prix

Annexe. Catalogue des inscriptions

Signa et tituli dans l'épigraphie de la cité de Vienne au Haut Empire

(Bernard RÉMY, Noëlle GÉROUDET)

1. Répartition géographique

2. Répartition chronologique

3. Les types de monuments

4. Les types de documents

5. Donateurs et receveurs

Annexe 1 : catalogue des inscriptions

Annexe 2: Pline, Histoire Naturelle, 34.16-18

Firme o didascalie. Due contesti narbonensi e qualche riflessione su copie e nomi di artisti

(Fabrizio SLAVAZZI)

1. Mirone a Vienne

2. I busti della villa di Crest

Précisions sur l'Augusteum de Nîmes grâce aux inscriptions de magistrats 
2. Des sénateurs énigmatiques

3. Les chevaliers : le rapport privilégié à l'empereur

4. Pontifes, théâtre et Augusteum

5. Présence fortuite : inscriptions déplacées ou votives des magistrats inférieurs .................................................................... 87

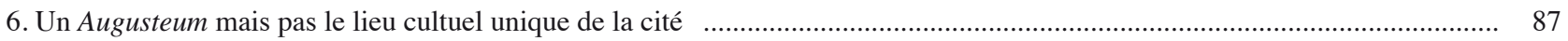

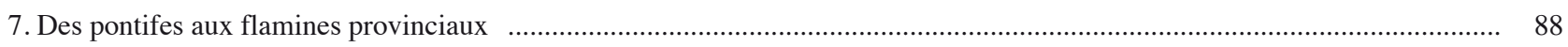

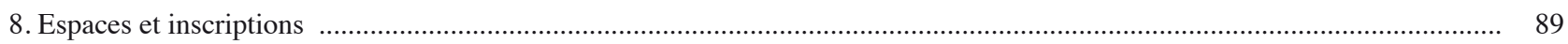

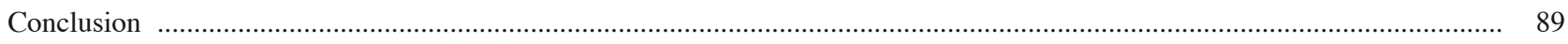

Gli spazi pubblici di rappresentazione tra memoria civica e celebrazione imperiale a Luni e in Cisalpina (Matteo CADARIO)

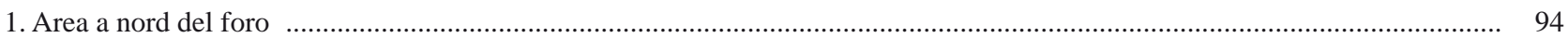

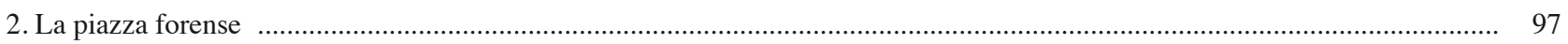

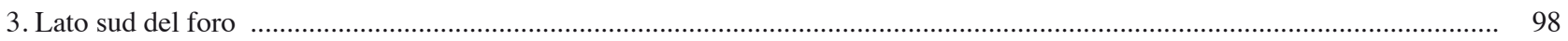

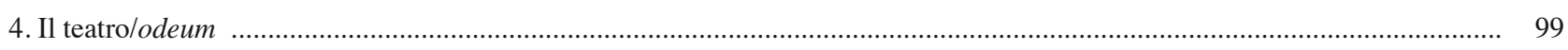

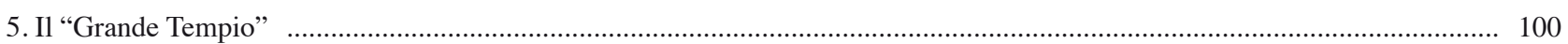

Signa et tituli dans les Alpes maritimae : l'exemple des stèles funéraires en forme de porte (Stéphane MORABITO)

Espaces et monuments funéraires en Arles : autour des stèles à portraits

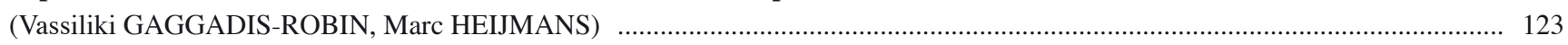

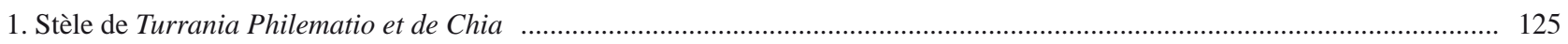

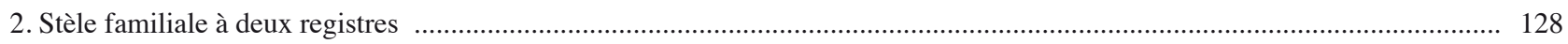

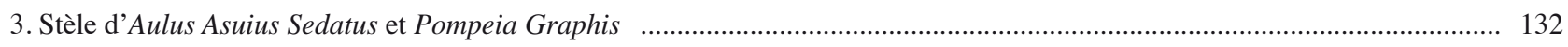

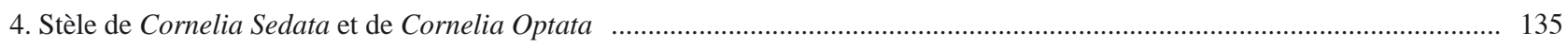

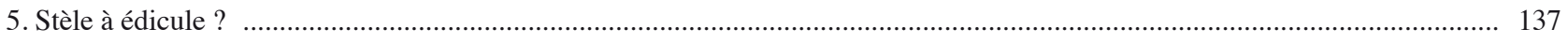

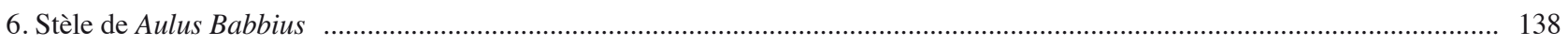

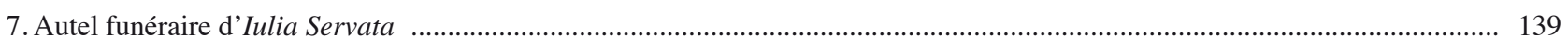

Conclusion

Le cénotaphe de Clarensac : un somptueux décor autour de l'épitaphe de M. ATTIVS PATERNVS

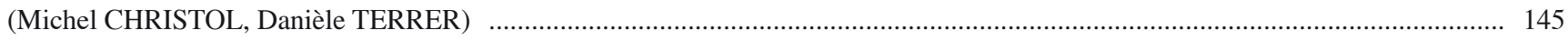

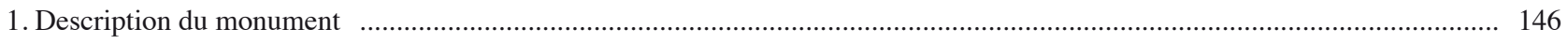

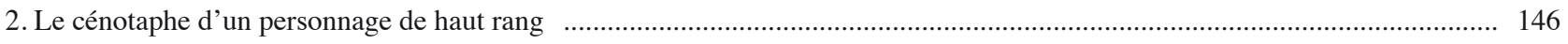

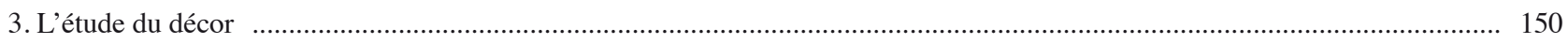

Sepulcrum, signa et tituli : quelques observations sur la «consecratio in formam deorum » et sur l'expression du statut des morts dans la Rome impériale

(Nicolas LAUBRY)

Esculturas e inscripciones del entorno funerario de Barcino

(Montserrat CLAVERIA, Isabel RODÀ)

Épigraphie et mise en scène de la domination sociale dans la Gaule méridionale tardive (IV-VI ${ }^{\mathrm{e}}$ s.) : à propos de la tombe du grand-père de Sidoine Apollinaire

(Christian STEIN)

1. Le corpus épigraphique des élites en Gaule au IVe $\mathrm{s}$.

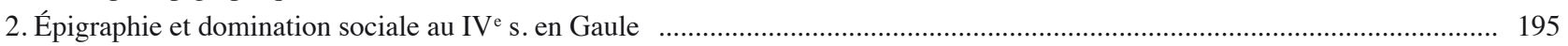


3. Une rupture au $\mathrm{V}^{\mathrm{e}} \mathrm{s}$. : la tombe du grand-père de Sidoine Apollinaire

Signa in templo. Où situer le nouveau groupe statuaire de la famille impériale dans le sanctuaire de la Grange des Dîmes (Avenches, Suisse) ?

(Philippe BRIDEL)

Introduction

1. Le contexte de découverte

2. La restitution dans le cadre du sanctuaire du $2^{\mathrm{e}}$ quart du $\mathrm{I}^{\mathrm{er}} \mathrm{s}$ et de Forum Tiberii (30/40-50/70)

3. La nouvelle présentation dans le cadre du sanctuaire de la fin du $\mathrm{I}^{\mathrm{er}}$ s. et de la Colonia (80/100-120/150)

Conclusion

Deux lieux de culte de domaine foncier sous le regard croisé de l'archéologie, de la sculpture et de l'épigraphie :

\section{Saint-Vincent (Saint-Paul-Trois-Châteaux) et Beauvoir (Allan)}

(Raphaël GOLOSETTI)

Introduction

1. Saint-Vincent : confrontation des sources iconographiques et du contexte archéologique

2. Le lieu de culte du quartier Beauvoir à Allan : un dossier riche

3. Lieux de culte et uillae : démarche comparative

4. Culte des déesses-Mères et uillae 


\title{
Hommage à Michel Janon
}

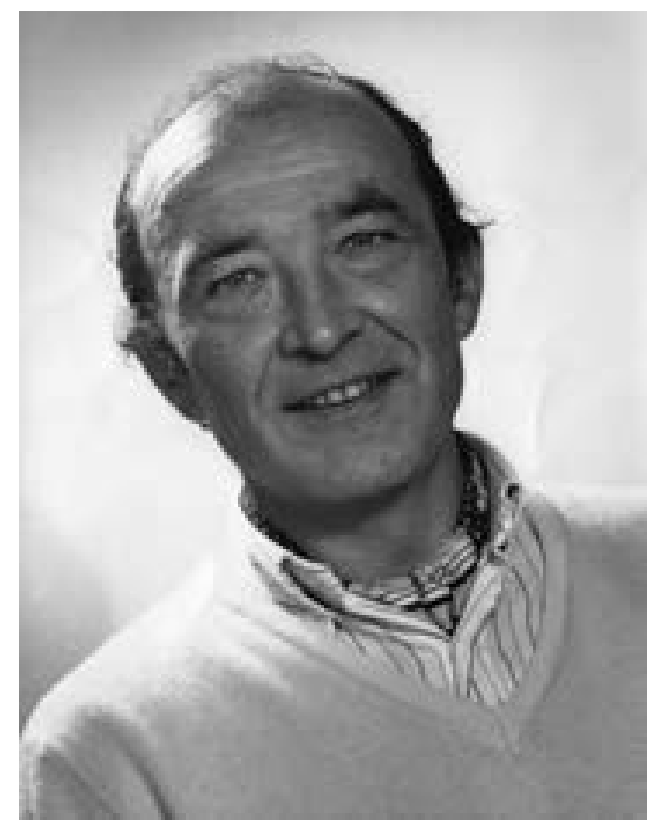

\begin{abstract}
$\mathrm{A}$ près avoir été ingénieur pendant plus de vingt ans au CNRS, d'abord au Centre de Recherches sur l'Afrique Méditerranéenne (CRAM) à Alger, puis à l'Institut d'Archéologie Méditerranéenne (IAM) qui allait devenir le Centre Camille Jullian d'Aix-en-Provence, Michel Janon part enseigner pendant dix ans à l'université d'Ottawa au Canada. En 1995, il revient à Aix-enProvence et rejoint l'Institut de Recherche sur l'Architecture Antique (CNRS) : c'est à ce moment-là que nous avons fait sa connaissance, à un moment décisif de notre formation. C'est avec une grande générosité que Michel nous a associées à ses travaux. Épigraphiste reconnu, mais aussi éminent spécialiste du décor architectural, de la sculpture, de l'urbanisme antique et de la religion romaine, il poursuivait infatigablement ses recherches « de Judée en Narbonnaise », pour reprendre le titre d'un de ses articles les plus stimulants (Janon 1992). Michel a toujours été extrêmement attaché à une approche à la fois pluridisciplinaire et « décloisonnée » des Sciences de l'Antiquité. Curieux de tout, il a eu un rôle pionnier et novateur dans la réflexion sur les apports de l'outil informatique à la recherche en épigraphie, en un temps où l'informatique n'en était qu'à ses balbutiements. Dès 1972, il a animé un groupe de recherches sur ce thème qui a connu
\end{abstract} depuis lors, comme on le sait, une remarquable fortune. Michel était présent lors du sixième colloque des Inscriptions latines de Narbonnaise organisé en décembre 2008 par le Centre Camille Jullian, à Aix-en-Provence : une partie des communications fut consacrée à faire le point sur l'épigraphie et l'informatique et même si Michel ne voulut pas que l'on rappelle ses hauts faits dans ce domaine, ces journées furent organisées comme un hommage à ses travaux. Ce dossier a été publié dans la Revue Archéologique de Narbonnaise $\left(\mathrm{n}^{\circ} 43,2010\right)$.

Son souci de ne pas séparer les images antiques des textes qui leur étaient associés, comme de leur contexte archéologique et historique, fut constant. Cette préoccupation s'exprime de façon particulièrement claire à travers deux de ses travaux majeurs, parus à quelques mois d'intervalle : entre 1985 et 1986, il a publié à la fois le premier volume des Inscriptions Latines de Narbonnaise (cité de Fréjus), avec Jacques Gascou, et les blocs à décor de rinceaux de Narbonne, premier volet d'une série d'études consacrées aux collections lapidaires de la capitale de la Gaule Narbonnaise qu'il projetait de mener à bien ultérieurement. Les nombreuses discussions que nous avons eues avec lui sur ces sujets, d'Aix-en-Provence à Glanum, de Saint-Bertrand-de-Comminges à Orange, ont très puissamment contribué à la réflexion qui a donné naissance au programme Signa et Tituli du Centre Camille Jullian, et au colloque dont nous publions ici les communications. Quelques mois avant sa disparition, Michel nous a fait l'amitié d'assister à ce premier volet du programme et d'en animer les débats avec l'enthousiasme qui le caractérisait : ce projet lui doit beaucoup et nous tenions, à l'occasion de la parution de cet ouvrage, à lui rendre hommage.

Michel nous a quittés le 31 mai 2010 mais nous n'oublions pas ce qu'il nous a appris : regarder inlassablement les blocs, inscrits ou sculptés, avec passion, humilité et esprit critique. 


\section{Bibliographie de Michel Janon (1937-2010)}

Michel JANON, canadien et français, titulaire d'une Licence ès-Lettres (Histoire, Alger, 1964 : Histoire, Archéologie, Antiquité, Moyen Âge, Islam) et d'un Doctorat de $3^{\text {ème }}$ cycle en Histoire sur L'Asclepieium de Lambèse (Paris-Sorbonne, 1970, 177 p.).

\section{EXPÉRIENCE PROFESSIONNELLE}

1964-1965 : Directeur de fouilles archéologiques, Service des Antiquités de l'Algérie ;

1965-1970 : Ingénieur d'études, CRAM-CNRS, Alger ;

1970-1972: Ingénieur d'études, IAM-CNRS, Aix-en-Provence ;

1972-1982 : Ingénieur de recherche IAM-CNRS, Aix-en-Provence ;

1982-1986 : Ingénieur de recherche, CCJ-CNRS, titulaire ;

1986-1995 : Professor of Classical Studies à l'université d'Ottawa, Département d'Études Anciennes.

Directeur des fouilles canadiennes à Saint-Bertrand-de-Comminges ;

1995-2010 : Ingénieur de recherche IRAA-CNRS, Aix-en-Provence.

\section{FOUILLES ARCHÉOLOGIQUES}

Algérie : Cherchell, Tiddis, Lambèse ;

France : Fréjus, Saint-Bertrand-de-Comminges, Gaujac, Orange.

\section{RECHERCHES ÉPIGRAPHIQUES}

Algérie, Numidie méridionale et Confédération cirtéenne ;

France : Fréjus (avec J. Gascou), Nîmes (avec M. Christol), Narbonne, Glanum (Saint-Rémy-de-Provence).

\section{BIBLIOGRAPHIE}

\section{LIVRES :}

JANON (M.), GASCOU (J.) - Inscriptions Latines de Narbonnaise, I. Fréjus, Paris, éd. CNRS, 1985, 225 p., (44 ${ }^{\mathrm{èm}}$ Supplément à Gallia).

JANON (M.) - Le décor architectonique de Narbonne, I. Les rinceaux, Paris, 1986, 96 p., 30 pl. (13 ${ }^{\mathrm{ème}}$ Supplément à la Revue Archéologique de Narbonnaise).

JANON (M.), GASSEND (J.-M.) (aquarelles) - Lambèse, capitale militaire de l'Afrique romaine, Ollioules, éd. de la Nerthe, 2005, $82 \mathrm{p}$.

\section{ÉDITIONS DE LIVRES :}

JANON (M.) - Application à l'épigraphie des méthodes de l'informatique. Actes de la table ronde du CNRS (Marseille, déc. 1972) = Antiquités Africaines, 9, 1975, 150 p. 
JANON (M.) - Inscriptions Latines de Narbonnaise. Actes de la table ronde du CNRS (Montpellier, 23 oct. 1982), Aix-en-Provence, 1983, $51 \mathrm{p}$.

JANON (M.) - Inscriptions Latines de Narbonnaise. Actes de la table ronde de Nîmes (25-26 mai 1987), Nîmes, 1989, 135 p., Préface avec D. Darde.

\section{CHAPITRES DE LIVRES :}

JANON (M.) - Analyse formelle des textes et raisonnement en Histoire. In : Borillo (M.) (éd.), Archéologie et calcul, Paris, 1978, p. 185-224 (avec M. Borillo et alii).

JANON (M.), SOLIER (Y). (dir.) - Narbonne, Paris, 1986 (Guide archéologique de la France), 90 p. : a - Chapitres consacrés au Capitole et au musée lapidaire ;

$\mathrm{b}$ - Supervision de l'illustration.

JANON (M.), Christol (M.) - Étude du matériel épigraphique. In : Bessac (J.-Cl) et al., Vgernum. Beaucaire et le Beaucairois à l'époque romaine, 2 vol., Caveirac : ARALO, 1987, (120, 128 p.) : ill., 226 fig. ; $30 \mathrm{~cm}+1$ plan (Cahiers de l'ARALO ; 15, 16 ; Travaux du Centre Camille Jullian ; 2).

JANON (M.) - Étude du matériel épigraphique de Glanum et de sa région ; confection de l'index. In : Gateau (F.), Gazenbeek (M.), Carte Archéologique de la Gaule. 13/2. Les Alpilles, la Montagnette, Paris, Académie des Inscriptions et Belles-lettres, 1999, p. 435-440.

JANON (M.) - Révision du matériel épigraphique, confection de l'index. In : Brun (J.-P.), Carte Archéologique de la Gaule. 83/1 et 2, Le Var, Paris, Académie des Inscriptions et Belles-Lettres, 1999.

JANON (M.) - Le lapidaire de l'église Lamourguier. In: Dellong (E.), Carte Archéologique de la Gaule. 11/1, Le Narbonnais, Paris, Académie des Inscriptions et Belles Lettres, 2000, p. 150-163 (relevés Gassend (J.-M.), dessins Joulain (J.-M.)).

JANON (M.), LAFON (X.), PAILLET (J.-L.) - Colline Saint-Eutrope. In : Roumegous (A.), Carte Archéologique de la Gaule. 84/3, Orange et sa région, Paris, Académie des Inscriptions et Belles-Lettres, 2009, p. 215-230.

\section{ARTICLES (REVUES, PUBLICATIONS DE COLLOQUES, MÉLANGES) :}

JANON (M.) - Note sur une inscription trouvée à Tobna. Bulletin d’Archéologie Algérienne, t. I, 1962-1965, p. 171-173.

JANON (M.) - Cultures dei Ierhobolis iuniores. Bulletin d'Archéologie Algérienne, t. II, 1966-1967, p. 219-230.

JANON (M.) - Stèles funéraires en bois sculptées de Cherchell. Libyca (Anthropologie, Préhistoire, Ethnologie), 15, 1967, p. 343-355.

JANON (M.) - Cherchell, un musée de mosaïques en plein air. El-Djezaïr, Revue du ministère algérien du tourisme, 7, 1967, p. 24-31.

JANON (M.), Lambèse, capitale de la Numidie. El-Djezaïr, 8, 1968, p. 32-37.

JANON (M.), BONNAL (J.-P.) - Cinq inscriptions funéraires de Sériana. Bulletin d'Archéologie Algérienne, 3, 1968, p. 301-312.

JANON (M.) - Itinéraire aurasien. El-Djezaïr, 9, 1969, p. 18-31.

JANON (M.), FÉVRIER (P.-A.), VAROQUEAUX (Cl.) - Fouilles au Clos du Chapitre à Fréjus (Var). Comptes Rendus de l'Académie des Inscriptions et Belles-Lettres, 1972, p. 355-381.

JANON (M.) - Recherches à Lambèse. 1, La ville et les camps. Antiquités Africaines, 7, 1973, p. 193-221.

JANON (M.) - Recherches à Lambèse. 2, Aquae Lambaesitanae. Antiquités Africaines, 7, 1973, p. 222-254.

JANON (M.), CORBIER (P.) - Projet d'utilisation des ordinateurs pour la recherche épigraphique. In : Beck (C.-H.), Akten des VI Internationalen Kongress für griechische und lateinsche Epigraphik, Munich, 1973, p. 466-469.

JANON (M.), VIRBEL (J.) - Travaux pour l'exploitation automatique du Corpus des Inscriptions Latines. In : Banques de données en archéologie, Paris, éd. du CNRS, 1974, p. 199-218.

JANON (M.), VIRBEL (J.) - Une expérience d'édition et de consultation automatiques du Corpus des Inscriptions Latines : questions de méthode liées au recours à des moyens informatiques pour l'exploitation d'un corpus de textes. In : Flajolet (P.), Informatique et Philologie, Colloque IRIA, Paris, Rocquencourt, 4 et 5 novembre 1974, Le Chesnay : IRIA, 1974 [1975], p. 41-50.

JANON (M.) - Épigraphie et Informatique. Revue du Laboratoire d'Analyse Statistique des Langues Anciennes (Liège), 2, 1974, p. 1-24. 
JANON (M.), CHOURAQUI (E.) et al. - Le SYCIL : un système documentaire pour l'exploitation d'un Corpus d'Inscriptions Latines. Antiquités Africaines, 9, 1975, p. 63-96.

JANON (M.), BORILLO (M.) et al. - Une expérience de recherche historique à partir d'un corpus d'inscriptions funéraires latines. Antiquités Africaines, 9, 1975, p. 127-144.

JANON (M.) - Lambèse et l'occupation militaire de la Numidie méridionale. In : Haupt (D.), Horn (H.G.), Studien $z u$ den Militärgrenzen Rems. II, Vorträge des 10. Internationalen Limeskongresses in der Germania Inferior, Xanten-Nimègues, sept. 1974, Cologne-Bonn, 1977, p. 473-485.

JANON (M.) - Lambaesis, eine Oberblick. Antike Welt, 1977, p. 2-21.

JANON (M.), BUCHSENSCHUTZ (O.), DORION (J.) et al. - Recherche et validation des traces de voies anciennes à l'aide d'un ordinateur. Revue d'Archéométrie, 1, 1977, p. 42-58.

JANON (M.) - À propos de l'Asclepieium de Lambèse (Numidie). In : Fitz (J.), Limes. Akten des XI. Internationalen Limeskongresses (Szekesfehervar, 30. 8.-6. 9. 1976), Budapest, 1977, p. 705-719.

JANON (M.), GASSEND (J.-M.) - La colonne d'Hadrien à Lambèse. Bulletin d'Archéologie Algérienne, 9, 1977 1979, p. 206-239.

JANON (M.) - Note sur un moule bivalve trouvé à Fréjus. Revue Archéologique de Narbonnaise, 11, 1978, p. 251-256.

JANON (M.), GOLVIN (J.-C.) - L'amphithéâtre de Lambèse (Numidie), d'après des documents anciens. Bulletin Archéologique du Comité des Travaux Historiques et Scientifiques, vol. 12-14 fasc. B, 1976-78 [1980], p. 169-193.

JANON (M.) - L'Aurès au VI ${ }^{\mathrm{e}}$ siècle, Note sur le récit de Procope. In : Mélanges offerts à J. Lassus. II = Antiquités Africaines, 15, 1980, p. 345-351.

JANON (M.) - Soldats et agriculteurs (Vanier lectures), Ottawa, mars 1980. Revue de l'Université d'Ottawa, 52, 1982, p. 47-53 ; repris dans Wells (C.) (éd.), L’Afrique romaine, Ottawa, 1982, p. 51-67.

JANON (M.) - Dénombrement des inscriptions dans la partie orientale de la province. In: Inscriptions latines de Narbonnaise. Actes de la table ronde du CNRS, Montpellier, 23 octobre 1982, Aix-en-Provence/Montpellier, 1983, p. 5-7.

JANON (M.) - Recherches à Lambèse. III, Essai sur le temple d'Esculape. Antiquités Africaines, 21, 1985, p. 35-102.

JANON (M.) - Le temple d'Esculape à Lambèse. Archéologia, 201, 1985, p. $42-49$.

JANON (M.) - Compléments carthaginois à un moule de Fréjus. Revue Archéologique de Narbonnaise, 17, 1985, p. 249-252.

JANON (M.), CHRISTOL (M.) - Révision d'inscriptions de Nîmes 1 = CIL XII, 3005. Revue Archéologique de Narbonnaise, 17, 1985, p. 249-255.

JANON (M.), DUVAL (N.) - Le dossier des églises d'Hr Guesseria : redécouverte du rapport Carbuccia (1845) et de l'aquarelle originale de la mosaïque, une fouille partielle en 1908 ?. Mélanges de l'École Française de Rome. Antiquité, 97, 1985, p. 1079-1112.

JANON (M.) - Note préliminaire à l'étude des collections lapidaires de Narbonne. À propos de deux articles récents. Dialogues d'Histoire Ancienne, 9, 1986, p. 171-183.

JANON (M.), CHRISTOL (M.) - Révision d'inscriptions de Nîmes II = CIL XII, 5890. Revue Archéologique de Narbonnaise, 19, 1986, p. 171-183.

JANON (M.), CHRISTOL (M.), GASCOU (J.) - Les Seuiralia ornementa gratuite dans une inscription de Nîmes. Latomus, 46, 1987, p. 388-398.

JANON (M.) - Les rinceaux de Narbonne. Chronologie et symbolique. Bulletin de la Commission Archéologique de Narbonne, 2, 1988, p. 55-62.

JANON (M.), GALLAGHER (J.) - The Theater. Journal of Roman Archaeology, 4, 1991, p. 108-112.

JANON (M.) - Remarques sur la frontière de Numidie. In : Maxfield (V.A.), Dobson (M.J.) (éd.), Roman Frontier Studies 1989. Proceedings of the XVth International Congress of Roman Frontiers Studies, Canterbury, 2-10 September 1989, Exeter, University of Exeter, 1991, p. 482-484.

JANON (M.) - De Judée en Narbonnaise, Contribution à la reconnaissance de quelques sanctuaires du pouvoir. Mélanges de l'École Française de Rome. Antiquité, 103, 1992, p. 735-783.

JANON (M.), JANON (N.), KILMER (M.) - Les frises d'Orange : le pouvoir mis en scène. In : Landes (Chr.), Spectacula. 2, Le théâtre antique et ses spectacles. Actes du colloque tenu au Musée archéologique Henri Prades de Lattes les 27, 28, 29 et 30 avril 1989, Lattes, 1992, p. 149-162.

JANON (M.) - CHARMASSON (J.), CHRISTOL (M.) - Une inscription de Gaujac et les Aemilii nîmois. Cahiers des Musées et des Monuments de Nîmes, 11, 1992, p. 80-95.

JANON (M.) - Les chevaux d'Hadrien. Revue Archéologique de Narbonnaise, 33, 2000, p. 61-68. 
JANON (M.) - CHRISTOL (M.) - Le statut de Glanum à l'époque romaine. Revue Archéologique de Narbonnaise, 33, 2000, p. 47-55.

JANON (M.) - CHRISTOL (M.), GASCOU (J.) - Observations sur les inscriptions d'Aix-en-Provence. Revue Archéologique de Narbonnaise, 33, 2000, p. 24-38.

JANON (M.), LAFON (X.), PAILLET (J.-L.) - Recherches sur le sanctuaire du culte impérial à Orange. Revue Archéologique, 2001, 1, p. 192-195.

JANON (M.), CHRISTOL (M.) - Épigraphie et espaces funéraires en Gaule méridionale. In : Landes (Chr.) (éd.), La mort des notables en Gaule romaine II. Notables, monuments et pratiques funéraires, Lattes, Musée Archéologique Henri Prades, 2002, p. 121-128.

JANON (M.), MILLETTE (D.) - Le théâtre dans Lugdunum des Convènes (Saint-Bertrand-de-Comminges/ Valcabrère, Haute-Garonne), acquis récents de la recherche (1992-2002). Aquitania, 18, 2001-2002 (2003), p. 46-51.

JANON (M.), MILLETTE (D.) - The Gallo-Roman Theatre at Saint-Bertrand-de-Comminges (Haute-Garonne) : an Interim Report. Phonix, 57, 2003, p. 317-326.

JANON (M.), CHRISTOL (M.) - Religio Juxta Aesculapium. Antiquités Africaines, 38-39, 2002-2003 (2004), p. 73-86.

JANON (M.) - Albarinus, dieu indigène dans la cité de Carpentras (Gaule Narbonnaise). Zeitschrift für Papyrologie und Epigraphik, 146, 2004, p. 272-278.

JANON (M.), CARRU (D.), CHRISTOL (M.) - Mercure et les Ateii de Carpentorate (Carpentras, Vaucluse). Note sur une inscription récemment découverte. Revue Archéologique de Narbonnaise, 37, 2004, p. 277-289.

JANON (M.), AGUSTA-BOULAROT (S.), GASSEND (J.-M.) - In Lambaesem defluxit Nilus. In : Lafon (X.), Sauron (G.) (dir.), Théorie et pratique de l'architecture romaine, Études offertes à Pierre Gros, Aix-en-Provence, PUP, 2005, p. 119-131.

JANON (M.), LAFON (X.), PAILLET (J.-L.) - Nouveaux regards sur la zone du grand temple d'Orange dans Christol (M.), Darde (D.) (Textes réunis par), L'expression du pouvoir au début de l'Empire, Autour de la Maison Carrée de Nîmes, Actes du Colloque organisé à l'initiative de la ville de Nîmes et du Musée Archéologique, Nîmes, Carré d'Art, 20-22 octobre 2005, Paris, Errance, 2009, p. 119-130.

JANON (M.) - Notice : Numidie, dans Leclant (J.) (Dir.), Dictionnaire de l'Antiquité, Paris, PUF, 2005, p. 1546-1547.

JANON (M.), CHRISTOL (M.) - Les noms de personnes dans une inscription de Carlisle (Luguualium, Bretagne). Epigraphica, LXXI, 2009, p. 191-201.

JANON (M.), AGUSTA-BOULAROT (S.), CHRISTOL (M.), GOMEZ (E.) - Découverte de blocs architecturaux et d'inscriptions d'époque romaine à Béziers. Epigraphica, LXXI, 2009, p. 438-457.

JANON (M.) - À propos des reliefs figurés du Pont-du-Gard et de l'aqueduc de Fréjus. Revue Archéologique, 50, 2010, 2, p. 309-320. 



\title{
Introduction
}

\author{
Sandrine Agusta-Boularot \\ Université Paul Valéry-Montpellier 3 et Archéologie des Sociétés Méditerranéennes-UMR 5140-CNRS, \\ Labex ARCHIMEDE, programme ANR-11-LABX-0032-01 \\ sandrine.boularot@orange.fr \\ Emmanuelle Rosso \\ Université de Paris IV Sorbonne / EA 4081 - Rome et ses renaissances \\ rosso_emma@yahoo.fr
}

$\mathrm{C}$

et ouvrage regroupe les communications présentées lors du colloque «Signa et tituli. Monuments et espaces de représentation en Gaule Méridionale sous le regard croisé de la sculpture et de l'épigraphie », qui s'est tenu à la Maison Méditerranéenne des Sciences de l'Homme d'Aix-en-Provence, les jeudi 26 et vendredi 27 novembre $2009^{1}$.

L'idée de ce colloque est née d'un constat simple : traditionnellement, sources épigraphiques et sources iconographiques demeurent le plus souvent, en dépit de leur complémentarité, étudiées séparément. Des salles de nos musées aux rayons de nos bibliothèques, documents sculptés et documents inscrits forment des ensembles « disjoints ». Disjoints, ils le sont en raison de leur état de conservation lacunaire, qui nous a livré des membra disjecta : des statues sans leurs bases, des bases inscrites sans leurs statues ou des reliefs privés de leurs inscriptions. Cet état de fait est la seule donnée susceptible d'imposer ou de justifier une telle dichotomie. Elle ne tient pourtant pas exclusivement aux hasards de la conservation et de la transmission des monuments, mais aussi à des questions d'ordre épistémologique et méthodologique, aux logiques inhérentes à chaque entreprise scientifique : au sein des Sciences de l'Antiquité, la constitution des champs disciplinaires, leur spécialisation et donc leur cloisonnement et morcellement progressifs (histoire, histoire de l'art, archéologie...) ont occulté le fait que statuaire et épigraphie, signa et tituli étaient des éléments conçus ensemble comme les deux volets d'un même message, indissociables dès la première formulation. En effet, c'est bien la conjonction d'un texte et d'une image qui définit le monumentum si caractéristique de la pratique commémorative romaine. Un exemple significatif de cette complémentarité est constitué par le portrait, où seule l'inscription permet et valide l'identification du personnage représenté. Si un portrait anonyme perd une grande partie de son message, en revanche les sujets mythologiques ou relevant de la statuaire idéale demeurent plus aisément déchiffrables quand ils ont perdu leurs inscriptions, en raison de leur caractère topique.

La dissociation imposée par l'état des sources est un obstacle majeur, qui ne devrait pas être davantage creusé par une présentation biaisée ou incomplète de nos outils de travail : pourtant, cette séparation a conduit au fil du temps à instaurer, pour la présentation des corpora, des principes de classement parfois fort différents d'une discipline à

1. Nous y avons ajouté, en guise de leçon inaugurale, la communication « Il volto e la parola nei tituli votivi : ambigue discordanze » que le Prof. A. Sartori nous avait fait l'honneur de proposer en introduction au colloque Signa et tituli 3 (29 et 30 novembre 2012, Lattes) sur le thème Les lieux de culte de Gaule Narbonnaise et des régions voisines : sculpture et épigraphie. La pertinence de ses propos nous a semblé particulièrement adaptée à servir de point de départ à toute réflexion sur le croisement des données textuelles et iconographiques antiques. Nous présentons ici nos plus vifs remerciements au Prof. A. Sartori d'avoir accepté de publier sa communication dans ce volume de la BiAMA.

Ce colloque s'inscrivait également dans la continuité de la rencontre consacrée aux Inscriptions Latines de Gaule Narbonnaise, qui s'était tenue à Aix-en-Provence les 4 et 5 décembre 2008 et a fait l'objet d'un dossier publié dans la Revue Archéologique de Narbonnaise, $43,2010$. Il nous faut enfin signaler qu'en revanche certaines communications n'ont pas donné lieu à publication : M.-P. Audoin-Darblade, « L'autel fédéral de Lyon »; P. Thollard, «Espaces et formes de représentation sur le centre monumental du Castellas à Murviel-lès-Montpellier (Hérault) »; G. Di Vita-Evrard et L. Musso, « Statua et titulus à Lepcis Magna : la norme et l'énigme ». 
l'autre. Dans les corpora épigraphiques, le classement par province romaine et par civitas antique est de règle, alors que c'est un classement par agglomération actuelle ou, plus fréquemment encore, par musée, qui prévaut pour les catalogues de sculptures. Jusqu'à une date très récente, il était traditionnel de considérer que la statuaire relevait de l'histoire de l'art tandis que l'épigraphie était plutôt le domaine des historiens. Toutefois, au cours des dernières décennies, la multiplication des fouilles préventives, le développement des outils de géolocalisation des découvertes, mais aussi des réflexions épistémologiques sur les espaces de représentation dans le monde antique ont montré tout l'intérêt de la contextualisation des données iconographiques et épigraphiques et la nécessité dans laquelle nous nous trouvons de considérer fragments sculptés et blocs inscrits sur le même plan que les autres données archéologiques. À titre d'exemple, rappelons combien la terminologie des corpora épigraphiques, depuis le $C I L$ jusqu'aux recueils les plus récents, reste imprécise (cippus, dans le $C I L$ ), voire fautive : il n'est pas rare de trouver le terme d'autel pour désigner ce qui, en l'absence de focus et de puluini, doit être défini comme une base. De même, les catalogues de sculpture se bornent le plus souvent à retranscrire l'éventuelle inscription qui accompagne une statue ou statuette, sans commenter plus avant le lien qui unit message écrit et message figuratif.

Il suffit pour se convaincre de la nécessité de ne pas séparer les deux types de sources d'évoquer le cas de Narbonne, exemplaire par l'ampleur, la qualité de ses témoignages et les circonstances de leur découverte. Les quelque deux mille blocs qui constituent la collection lapidaire de la capitale provinciale ont été dans leur majorité découverts en remploi dans la muraille de la ville. Leur démembrement, fruit du hasard des remplois, ne devrait pas se prolonger, en toute logique, au niveau de leur étude ; certains sont exclusivement sculptés, d'autres exclusivement inscrits et par conséquent étudiés séparément. Or, l'iconographie de nombreux reliefs, qui renvoient à des scènes de la vie civique ou religieuse (processions, banquets, scènes de sacrifice ou de tribunal), pourrait en première lecture les désigner comme appartenant au décor de monuments publics : en réalité, l'écrasante majorité des inscriptions provenant du même contexte sont des inscriptions funéraires, et nous avons probablement affaire au démontage d'une ou plusieurs nécropoles de la cité antique. Cet exemple constitue non seulement un appel à la prudence lorsqu'il s'agit d'interpréter des images devenues en partie muettes car amputées de leur complément inscrit, mais il nous rappelle surtout un fait spécifique à l'art romain : ce dernier est un art éminemment citationnel, un art de l'aemulatio, donc de l'imitatio, dans lequel l'inscription dans une tradition prime sur la volonté d'innover, et en vertu duquel des motifs iconographiques singuliers se sont vus répétés et copiés avec de très faibles variantes pendant des siècles, mais surtout se sont vus transposés sur les supports les plus variés et ainsi réinterprétés et resémantisés périodiquement. Le plus souvent, on a affaire à des figures de répertoire, où une même image ou un même carton, déclinés avec de faibles variantes pendant des siècles, pouvaient servir et porter des messages très différents précisément grâce à l'ancrage dans une actualité (politique ou personnelle) que leur conféraient le texte.

Il en découle une donnée fondamentale pour notre propos : au sein d'un monde saturé d'images volontairement répétitives, dont la récurrence n'a d'ailleurs d'égale que celle des formulaires épigraphiques des tituli, seuls le texte et le contexte permettent d'actualiser les motifs topiques, de les colorer de nouvelles valences et de les charger de nouvelles significations tout en les parant du prestige de référents illustres. Pour reprendre les exemples évoqués précédemment, si les thèmes mythologiques ont connu une si large diffusion dans la sphère publique comme dans la sphère privée chez les Romains, c'est partiellement en raison de la souplesse sémantique que leur emploi permettait dès lors qu'un commanditaire pouvait s'approprier ces images. Mais il faut rappeler aussi, dans le domaine du portrait, un phénomène d'imitations en cascade (les élites imitant l'empereur, les élites locales les élites romaines, les affranchis les élites locales etc.) dû à un désir de reconnaissance sociale, qui tendait à uniformiser considérablement ce qu'il convient d'appeler le patrimoine figuratif des observateurs antiques.

Tout ceci invite à s'interroger tout d'abord, à l'échelle du monumentum comme entité ou « unité de base », sur les modalités de constitution du message, entre sculpture et épigraphie : quelle relation les deux discours entretenaientils ? Etaient-ils superposables, c'est-à-dire équivalents, la traduction ou l'illustration l'un de l'autre - autrement dit redondants?

Étaient-ils au contraire hétérogènes, c'est-à-dire porteurs d'intentions et de messages propres ? Dans ce cas, étaient-ils hétérogènes tout en étant complémentaires, ou bien suivaient-ils des voies indépendantes ? Ainsi, on ne peut qu'être frappé par le caractère très peu descriptif des textes incisés sur les bases de statues : ces dernières ne « disent » pratiquement rien des statues elles-mêmes - de leur format ou de leur aspect. L'indication du type statuaire 
est rare et le matériau n'est précisé que lorsqu'il est précieux. Le plus souvent, seul est mentionné le nom du donateur, plus rarement le prix ou le mode de financement.

Enfin, pouvaient-ils éventuellement délivrer des messages non convergents, voire contradictoires, du moins en apparence - cela pourrait être le cas des monuments remaniés, réexposés, recontextualisés et donc resémantisés ?

Par-delà ces questionnements, il ne paraît cependant pas douteux que la complémentarité des deux types de sources l'emporte sur leurs différences, ce qui invite à envisager les témoignages en fonction d'approches indépendantes des spécialités disciplinaires.

Deux entreprises éditoriales de grande ampleur, à la fois complémentaires et cohérentes dans leur démarche et leur aire géographique, ont pour objet les découvertes issues des provinces gauloises : d'une part la publication des Inscriptions Latines de Narbonnaise ${ }^{2}$, qui ne concerne que la province de Gaule Narbonnaise, d'autre part celle du Recueil Général des Sculptures sur pierre de la Gaule - couramment appelé Nouvel Espérandieu - dirigée par H. Lavagne et complétée par une base de données iconographique, administrée par le Centre Camille Jullian ${ }^{3}$. Elles ont des objectifs scientifiques similaires (la constitution d'ouvrages de référence) et portent, de fait, sur les mêmes monuments. Les conditions étaient donc réunies pour organiser une rencontre réunissant les épigraphistes et les spécialistes de sculpture engagés dans ces projets ou dans des projets similaires, dans le but d'instaurer un dialogue fécond susceptible d'infléchir analyses, conclusions ou restitutions avant l'achèvement définitif des travaux en cours.

Cette première rencontre du cycle Signa et tituli ${ }^{4}$ fut consacrée au thème des espaces de représentation dans la cité gallo-romaine et de leur restitution. Elle avait pour but de susciter des rapprochements entre blocs sculptés et textes épigraphiques provenant d'un même monument, d'un même complexe monumental ou d'un même site, et de reconstituer ainsi des ensembles unitaires. Les questions de typologie monumentale, de formulaire épigraphique et de contenu thématique ont ainsi pu être abordées. La confrontation des données a été envisagée en fonction de deux échelles spatiales différentes : celle du monument singulier d'une part, celle du type d'espace spécifique (espace civique, monument de spectacle, lieu de culte, espace funéraire, espace domestique) d'autre part. Enfin, des synthèses par cité ou par catégorie de monuments, mais aussi des réflexions plus théoriques sur la formulation des messages à travers l'écrit et l'image ont également été proposées.

Si la documentation de Gaule Narbonnaise, par sa richesse et sa cohérence, se prête particulièrement bien à ce type d'analyse, nous avons tenu à faire une place aux réalisations des provinces voisines (Trois Gaules, Germanies, Hispanies, Italie) afin de permettre les comparaisons et de mieux mettre en évidence les éventuelles particularités régionales ainsi que les modalités de circulation des modèles figuratifs ou des formulaires épigraphiques.

Ce colloque a pu être organisé grâce au soutien financier du Centre Camille Jullian (UMR 7299-CNRS), d'AixMarseille Université et du labex Archimede de Montpellier, que nous tenons à remercier.

2. Les volumes de la collection des $I L N$ sont publiés en tant que suppléments à la revue Gallia. Les inscriptions des cités suivantes sont disponibles : Fréjus, Antibes, Riez, Digne, Aix-en-Provence, Apt, Vienne, Alba, Die, Valence.

3. Le Nouvel Espérandieu concerne l'ensemble des Gaules. À ce jour, quatre volumes ont été publiés par l'Académie des Inscriptions et des Belles Lettres : Vienne, Lyon, Toul et la cité des Leuques et Fréjus. La base NEsp (Nouvel Espérandieu) a été créée et administrée par D. Terrer ; elle est désormais sous la responsabilité de St. Satre. On pourra consulter cette base à l'adresse suivante : http://nesp.mmsh.univ-aix.fr/

4. Une deuxième rencontre Signa et tituli 2 s'est tenue au Carré d'Art, à Nîmes, en novembre 2010, sur la question des corpora et des scholae en Gaule méridionale et dans les régions voisines : les actes sont publiés dans le Bulletin de l'École Antique de Nîmes. Une troisième rencontre, Signa et tituli 3, a eu lieu au musée archéologique Henri Prades, à Lattes, en novembre 2012, consacrée aux lieux de culte dans cette même aire géographique. 



\title{
Rapport introductif
}

\section{Il volto e la parola nei tituli votivi : ambigue discordanze}

\author{
Antonio Sartori \\ Già Università degli Studi di Milano (Dipartimento di Scienze dell'Antichità) - UTIU Università \\ Telematica Internazionale Uninettuno \\ antonio.sartori@unimi.it - antonio.sartori@fastwebnet.it
}

$\mathrm{I}$ 1 tema "Signa et tituli" fondante di un binomio suggestivo - divergente e contrapposto o integrantesi e convergente? - è per me di un interesse tutto particolare, perchè esso coincide con almeno due dei temi a cui ho dedicato una parte, che considero non secondaria, della mia attività di ricerca, la quale sta oltrepassando ormai il milliarium del mezzo secolo ahimè, o forse... per buona sorte o per benevolenza di Lassù. Due dei temi che mi sono più cari: e cioè la capacità di comunicazione tutta insieme, sempre e strettamente, di testo e di supporto, o forse anche del supporto che regge un testo o, in breve e in uno, di un intero monumento da intendersi sempre come un corpo unico, in sè e del tutto espressivo e pure eloquente; e, d'altro canto, l'efficacia essa pure comunicativa dell'impaginazione del suo contenuto espresso, e che è già di per sè strumento comunicativo, essa pure eloquente del suo, non fosse altro che perchè coadiuvante la comunicazione.

E dunque proprio su questo vorrei puntare: che anche la realtà indubitabile e salda del tutt'uno físico e comunicativo ed espressivo del monumento epigrafico può avere le sue eccezioni e le sue anomalie: le quali, nonchè porre in discussione o addirittura contrapporsi a quell' assunto fondamentale, lo arricchiscono anzi con varianti complementari.

È per questo che mi permetto di dire di "discordanze" rispetto ad una norma che non è più fissa e immutabile, e di "discordanze ambigue", perchè possono essere interpretate secondo diversi punti di vista.

L'espressività epigrafica si manifesta con caratteri, non so se di vera uniformità, acquisita o per coincidenza inarrestabile di svariati fattori, ma certo di universalità indubbia nello spazio, nel largo spazio del mondo soprattutto imperiale romano come anche per certi versi nel suo arco di tempo: il che, l'universalità, è pur sempre una caratteristica dell'epigrafia tutta, che mi stupisce ancora. Eppure tale espressività, nonché essere monotona o ripetitiva, si complica, ma preferisco dire meglio che si arricchisce, delle mille e mille declinazioni, tante quanti furono i produttori di tale espressività e poi delle sue altrettante interpretazioni da parte dei singoli utenti destinatari più o meno mirati ${ }^{5}$, che la assimilavano, e dunque insieme la assumevano o vi aderivano, attraverso l'adattamento individuale alle proprie esperienze, alle proprie necessità, alle proprie intenzioni e, perchè no, anche ai propri gusti.

È dunque possibile che le presunte discordanze cui mi riferisco, e che ora mostrerò per esempi, non interferissero come disturbo - les bruits de fond, le interferenze o i rumors o meglio i rumores della teoria ${ }^{6}$ - ma contribuissero invece alla comprensione, forse anche persino migliore, di una comunicazione che era ben capace, o si sforzava

5. Da tempo vado meditando sull'efficacia o comunque sugli effetti che il documento comunicativo epigrafico, per sua natura sempre esposto senza veli e senza filtri, possa raggiungere effetti e risultati diversi tanto nei confronti dei destinatari mirati, ai quali fosse espressamente predisposto e rivolto, quanto di tutti coloro che, indefiniti e forse neppure prevedibili (o forse appunto previsti volontariamente a costituire una cosiddetta opinione pubblica, sempre di grande peso nella compagine e nella vitalità sociale), ne erano comunque coinvolti o come semplici osservatori, per quanto distratti, o anche come interessati a ciò che, anche come entità monumentale e per posizione, si imponeva come novità espressiva, una novità, fra l'altro, cui tutti erano predisposti per consuetudine inveterata. Sartori 2007, pp. 47-53; Sartori 2009a, p. 7-14.

6. La possibilità o l'onnipresenza delle interferenze come elementi di disturbo e di inefficacia in ogni forma di comunicazione è un dato ormai generalmente acquisito, per cui si veda e.g., Wolf 2001, p. 106-133. 
quanto meno, di adeguarsi a consuetudini e condizionamenti contingenti e più o meno avvertiti entro ciascun ambiente culturale o sociale, comunque comunitario, in cui si presentasse, e cioè si esponesse visibilmente.

Per definire il problema più rapidamente, propongo una serie di esempi entro il tema del sacro, cui voglio non restringermi, ma attenermi, come il più significativamente complesso di interferenze di interessi e di intenzioni: esempi, che l'esperienza dei lettori potrà facilmente completare con ben altri e più numerosi.

Un primo caso.

Ci sono tituli che in sè, nel loro stretto contenuto esplicativo, hanno differenze puntuali con l'apparato iconografico-decorativo che li accompagna, ma non procede in parallelo.

Porto come primo esempio (fig. 1) un parallelepipedo marmoreo da Augusta Praetoria ${ }^{7}$ : non un'ara, ma forse piuttosto, per le proporzioni e per i contenuti che vi si esprimono, una base con funzioni di appoggio espositivo. È CIL V, 6829: consacrato alla triade, Iovi Iunoni Miner(vae), con un testo dettagliato che elenca quanto è stato offerto e consacrato: oltre al probabile gruppo scultoreo della triade, anche oggetti di culto in metallo probabilmente pregiato, e cioè due recipienti skiphoi, uno specchio e una venus. Ma Venus intesa come altra divinità da fare compartecipe del gesto di devozione, oppure come signum o sigillum religioso? Infatti, se Venus fosse una statuetta di quella specifica divinità aggiunta sulla stessa base, essa sarebbe non compresa fra la triade, ma soltanto una presenza sommatoria per accostamento di icone disparate, come è possibile ritrovare nei bric-à-brac compositi di certi larari o edicole di famiglia: solo un'offerta di omaggio - così sembra dichiarare l'iscrizione - alle altre divinità cui ci si rivolgeva. Forse più opportuno che venus significasse per antonomasia un qualunque simulacro atteggiato in forme di figura femminile e magari pure divina, rientrando nell'insieme degli omaggi concreti offerti e/o consacrati alla triade, raccolti sul monumento e descritti analiticamente nel titulus della base.

Da escludere invece l'ipotesi, pur consueta ma forzata, di un errore - il solito errore del lapicida cui si ricorre per risolvere facilmente certe irregolarità - del tipo di venere $(u) m$ speculum, uno specchio muliebre. E dunque, nell'un caso e nell'altro, statuetta di Venere o una "venerina" o statuetta qualsiasi, comunque una corrispondenza non parallela, o una non corrispondenza, nel binomio testo e monumento.

Un caso analogo può essere quello di tituli soverchiati dall'apparato iconografico-decorativo, e che, quasi costretti ad esserne lo spunto o a farvi riferimento appena accennato, non hanno spazio nè forza per completarne un'opportuna descrizione.

L'esempio è in un curioso monumentino milanese (fig. 2), ritrovato or è un secolo circa, del tutto casualmente (sul carro di un brocanteur) ma con ogni probabilità di origine locale ${ }^{8}$. Scontatane l'autenticità, certo è che il pezzo è insolito per la forma (una piramide tronca a base triangolare) e anche più per gli apparati decorativi ridondanti e fin barocchi, tanto quelli tuttora visibili, quanto quelli descritti nel titulus applicàtivi e ben comprensibilmente scomparsi; e pure nella più totale e fantasiosa incongruenza fra testo iscritto e decorazioni iconografiche complesse, che infatti risultano persino di difficile interpretazione, anche se comunque connesse, ma del tutto simbolicamente, con il termine centrale dell'insieme, la consacrazione Mercurio.

Una tartaruga sulla faccia superiore, grifoni dal lungo collo ora acefali sugli spigoli inferiori, e sui superiori tre teste di ariete con un foro cui si adattavano appariscenti sovrastrutture aggiunte: dracones appunto a far da sostegno tripode ad un proporzionato recipiente, cortina, con una specifica materico-economica, aureos, e ponderale, librarum quinque, di particolare rilievo merceologico e d'apparato. Nell'insieme una decorazione aggiunta, esuberante ma fin qui in parte complementare al testo iscritto, che anzi la descrive in dettaglio.

7. CIL V, 6829; I.I. XI, XI.1, nr. 1; Cavallaro-Walser 1988,nr. 7: Iovi Iunoni Miner(vae) $\mid$ Antonia M. lib\{o\}(erta) |Aphrodisia schyphos (duos) | venerem speculum $\mid$ donum dedit.

8. Risparmio i dubbi persino sulla sua autenticità: nati dal ritrovamento del tutto casuale e dalle fin troppo perfette e fresche condizioni di conservazione, ma da respingersi per la stravaganza dell'oggetto e dei suoi simboli, fuori dalla portata di falsari moderni, che infatti poi vi si cimentarono ma con la copia su lastra del solo titulus. AE 1897, 25; De Marchi 1917, p. 88-96: Mercurio / Sex(tus) Veracilius / Sex(ti) f(ilius) Ouf(entina) tribu / Priscus IIIIvir i(ure) d(icundo) / ex voto don(um) ded(it) / dracones aureos / libr(arum) quinque / adiectis ornament(is) / [e]t cortina. 
Ma a fare del tutto a sé sono i riquadri laterali, che si innestano essi pure sulla semplice consacrazione Mercurio, ma raccolgono in sé una serie numerosa di raffigurazioni simboliche, in parte di persino oscuro significato e comunque estranee al titulus. Che i riferimenti a Mercurio e alle sue epifanie poliformi siano presenti nelle erme su entrambe le facce, è chiaro, di un Mercurio efebico e di un Mercurio maturo; ma meno chiara è la simbologia degli altri particolari, raffigurati con perizia ora a forte rilievo ora stilizzati e rarefatti, suggeriti soltanto sullo sfondo da un palsticismo non più che allusivo.

Ecco dunque, in questo caso, che il monumento epigrafico si complica di diverse valenze: la prima e la più diretta è quella intitolatoria, della divinità onorata e del dedicante, cui non manca l'ambizione di porsi in risalto con tutti i suoi, benchè modesti, orpelli onorifici, componenti comuque della sua visibilità pubblica, che è spesso o sempre intento non ultimo di ogni manifestazione testimoniale epigrafica; la seconda, della descrizione, ma anche dell'enfasi, quasi soddisfatta e compiaciuta, e non certo inefficace nell'intento di visibilità di cui si diceva, di ciò che già doveva essere ben visibile di per sé, dracones aureos et cortina; e invece l'assenza di ogni spiegazione didascalica delle decorazioni, non isolate ma complessivamente articolate e intersecate in veri eídola "difficili", e lasciate alla libera visione del pubblico, non so fino a qual punto in grado di comprenderle e di interpretarle correttamente, senza una guida acculturata, la cui presenza casuale $\mathrm{o}$ voluta non si può neppure escludere ${ }^{9}$ : in una funzione complementare, integrativa ma di fatto quasi estranea, o diretta piuttosto solamente a chi ne avesse complice preconoscenza o ne venisse erudito nell'occasione.

Il che renderebbe necessario pensare ad una volontà/intenzione di esprimersi su registri diversi di comunicazione: quella concretamente visibile, informativa e descrittiva, rivolta indistintamente a tutti e in termini generali; quella velatamente autoritaria o solo superba, che precisa le specifiche merceologiche e di fatto le pone in risalto; quella simbolica infine, mirata di necessità a interlocutori selezionati, ad un ristretto ambiente nelle cui conoscenze condivise poter confidare ${ }^{10}$.

Anche più clamoroso ed evidente lo squilibrio a favore dell'iconografia che la fa da padrona in questa epigrafe (fig. 3).

Proveniente da Angera sul Lago Maggiore, e sicuramente un altare ${ }^{11}$, benchè oggi ridotto a lastra della sola faccia anteriore, ogni attenzione è puntata sulla dilagante scena del sacrificio analizzato con gusto aneddotico e attenta precisione per le fasi formali e gli attori del sacrificio: che è tuttavia un puro accorgimento di distinzione originale e di attenzione, privo di ogni riferimento concreto al titulus: che infatti risulta relegato letteralmente a margine, compresso ed oscurato sotto l'ombra del largo sporto aggettante del coronamento e in un equilibrio compositivo, come dire, ribaltato, nel quale anche la breve iscrizione risulta a sua volta squilibrata, con uno Iuppiter quasi invisibile, sopraffatto dall'esposizione eminente benchè sgrammaticata dei Qurtii, titolari devoti sì ma... in modo esuberante pro domo sua.

In questo caso la discordanza coinvolge, nonché la composizione complessiva e visuale del monumento epigrafico, anche l'intenzione, sua e naturalmente dei suoi promotori: poiché l'appariscenza dei mortali e terreni risulta riconoscibile ben prima e più che la devozione al dio: quasi come una diversione - intenzionale? inavvertita? io propenderei per la prima ipotesi - dal presunto fine primario di un gesto epigrafico espresso nella sfera del sacro. Il che è un secondo scopo - o meglio un altro scopo divergente, perché non so quanto lo si possa interpretare per secondario - che trapela e che si intuisce anche in molti altri dei più tradizionali tituli sacri.

Tituli persino anepigrafi (se posso permettermi questa, ma solo apparente, contradictio, formulati cioè e predisposti per esserlo: in primis gli altari, ma o ancora intatti per incompletezza di semilavorato o completati invece con più effimere addizioni scritte dipinte o in stucco, di appropriazione o per opportunità contingenti), ma in cui la

9. Sartori 2005, p. 89-99: accennai alla possibilità sulla scorta dell'affresco pompeiano, pur di non limpida interpretazione, in cui «personaggi togati leggono un lungo rotulo» (Sampaolo 1991, p. 256) forse soggetti alle spiegazioni (o alla lettura ad alta voce?) di un meglio acculturato.

10. Sartori 2008, p. 71-82; Sartori 2011, p. 35-73.

11. CIL V, 5472: I(ovi) o(ptimo) m(aximo)| P. Qurtius P.f. Victor| P. Qurtius P.f. Primus | (sex)vir iun(ior); Sartori 2009b, pp. 366-367. 


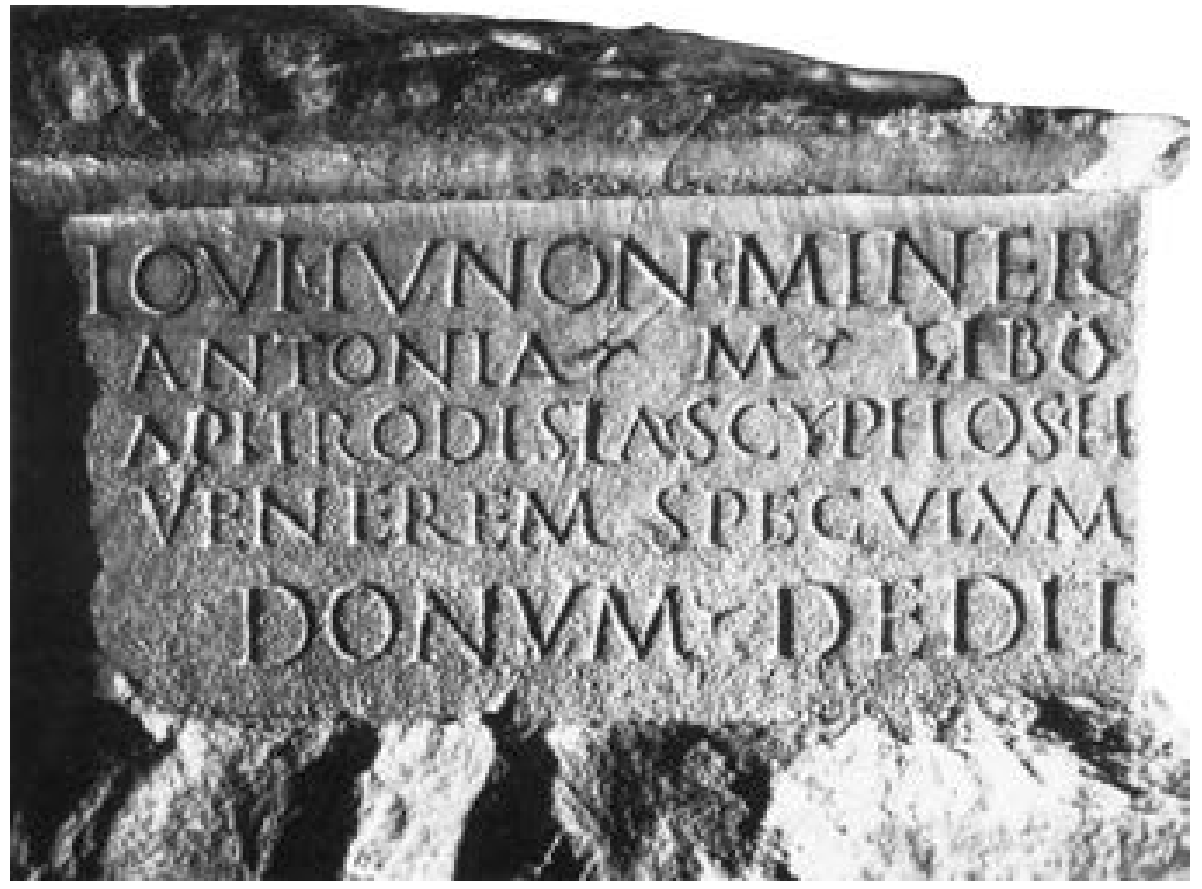

Fig. 1. Base alla triade da Augusta Praetoria (CIL V, 6829), da A.M. Cavallaro-G.Walser, Iscrizioni di Augusta Praetoria. Inscriptions de Augusta Praetoria, Aosta 1988.
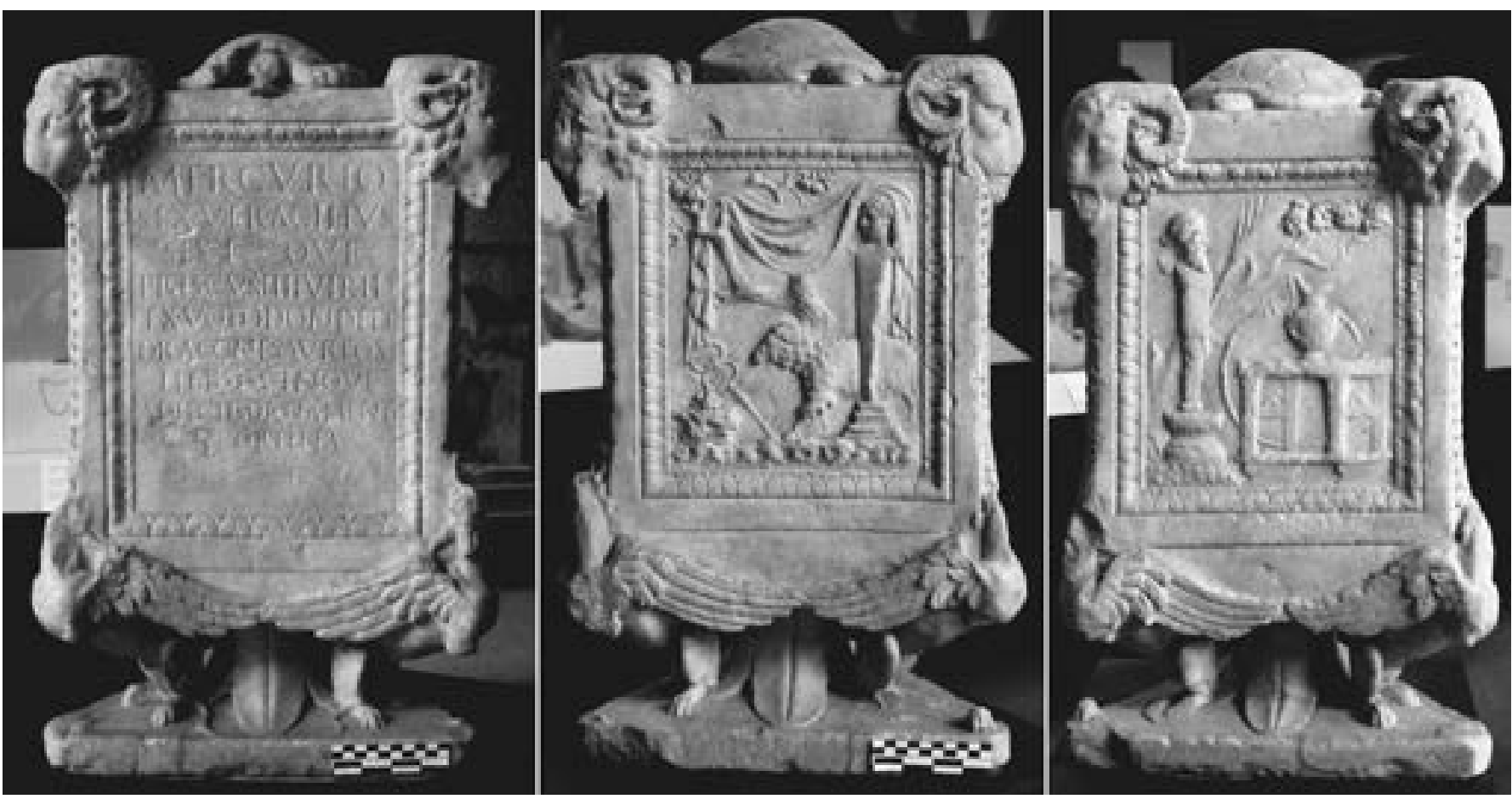

Fig. 2. Base a Mercurio da Milano (AE 1897, 25), foto dell'autore. 


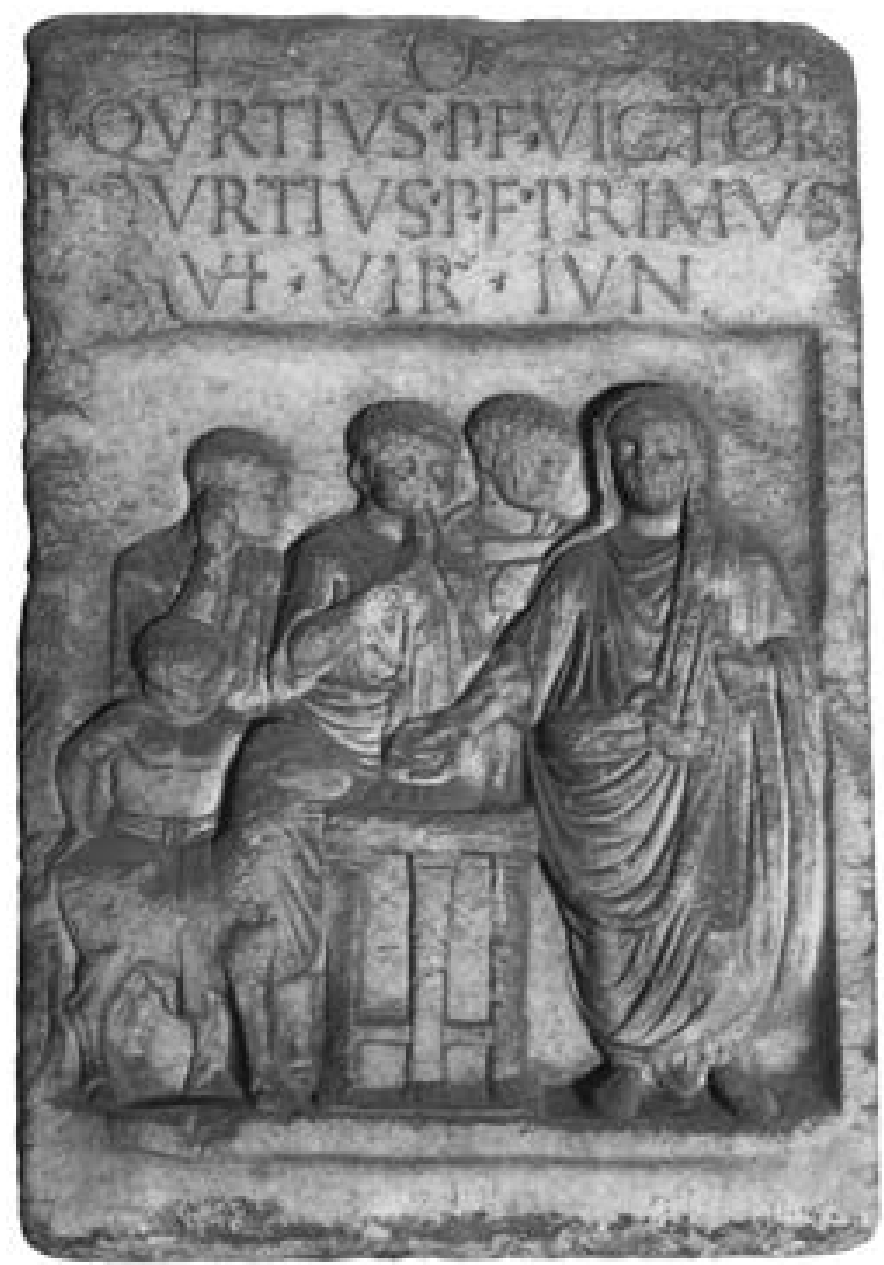

Fig. 3. Fronte di altare dei Qurtii da Angera (CIL V, 5472), foto dell'autore.

discordanza, l'incongruenza, non è nel rapporto testo-eidolon, ma nella destinazione dell'uno o dell'altro: poichè anche l'intenzione di chi vi ha posto mano e il suo fine o i suoi fini fanno parte integrante del gesto epigrafico e della sua comunicazione, lo giustificano e li chiariscono. Infatti la comunicazione non è sempre e soltanto informativa, ma coinvolge in modo più complesso i suoi proponenti come i suoi destinatari, mirati o presunti o occasionali, come si diceva prima.

Un passo avanti sulla via di questa stessa intenzione lo ritrovo infatti neppure in un'epigrafe, ma nel convincimento espresso da Plinio il giovane in una sua lettera ${ }^{12}$ :

1. Ex hereditate quae mihi obvenit, emi proxime Corinthium signum, modicum quidem sed festivum et expressum, quantum ego sapio, qui fortasse in omni re, in hac certe perquam exiguum sapio: hoc tamen signum ego quoque intellego. 2. Est enim nudum, nec aut vitia si qua sunt celat, aut laudes parum ostentat. Effingit senem stantem; ossa musculi nervi, venae rugae etiam ut spirantis apparent; rari et cedentes capilli, lata frons, contracta facies, exile collum; pendent lacerti, papillae iacent, venter recessit; 3. a tergo quoque eadem aetas ut a tergo. Aes ipsum, quantum verus color indicat, vetus et antiquum; talia denique omnia, ut possint artificum oculos tenere, delectare imperitorum. 4. Quod me quamquam tirunculum sollicitavit ad emendum. Emi autem non ut haberem domi - neque enim ullum adhuc Corinthium domi habeo -, verum ut in patria nostra celebri loco ponerem, ac potissimum in Iovis templo; 5. videtur enim dignum templo dignum deo donum. Tu ergo, ut soles omnia quae a me tibi iniunguntur, suscipe hanc curam, et iam nunc iube basim fieri, ex quo voles marmore, quae nomen meum honoresque capiat, si hos quoque putabis addendos.

12. Plin. Epist. 3.6. 
L'illustre personaggio - funzionario attento? uomo di lettere elegante? avvocato di grido? imprenditore agricolo abile? Non è facile definirlo in breve - acquistò una piccola statua di bronzo corinzio, solo perché gli piaceva: pur dichiarandosi inesperto di arte, ne era rimasto attratto per la resa naturalistica dei particolari, persino di quelli meno gradevoli, in un soggetto già di per sé non propriamente bello secondo i più tradizionali canoni estetici: un vecchio macilento, segnato dall'età in ogni parte del corpo, come certi esempi ben noti di mendicanti quasi caricaturali, apprezzati invece da certo ellenismo naturalistico: eppure infatti talia omnia, quae possint artificum oculos tenere, delectare imperitorum come lui stesso.

Tuttavia egli la acquistò non per rimirarsela in privato, ma per esporla in pubblico, per proporla anzi all'attenzione, meglio dire al godimento comune, meglio però se in un tempio, meglio ancora se nel tempio di Giove nella sua Como. E l'iscrizione? Sulla statuetta nulla era inciso, ma Plinio era degno partecipe di una temperie culturale che non può più prescindere da un apparato epigrafico comunque esposto ${ }^{13}$, e chiese pertanto ad un amico residente sul Larius lacus che vi provvedesse: che su una base in buon marmo facesse incidere il suo nome e magari anche i suoi honores, ma solo - eleganza di una falsa modestia - se l'amico lo ritenesse opportuno ${ }^{14}$. Ecco dunque: una statuetta solo esteticamente apprezzabile, che non ha nulla a che fare neppure con il luogo dell'esposizione auspicata, se non come un'addizione estetica, puro oggetto di abbellimento, quasi di arredamento in un contesto estraneo, in quanto sacro. Ma fine ultimo dell'operazione è per via indiretta un ulteriore accrescimento del suo buon nome: neppure vanità, ma autoconsapevolezza del suo valore: autorappresentazione insomma, come oggi piace dire ${ }^{15}$ : ed è l'iscrizione aggiunta che la trasforma e la valorizza in tal senso: la trasforma in una ulteriore manifestazione di presenza, ad accrescere e ad appesantire una serie di altre testimonianze numerose, pretestuosamente intrufolandosi in un contesto sacro con una soluzione neppure appropriata, perché non sacra.

Propongo ora il caso di epigrafi, e cioè - insisto - di insiemi indissolubili e intercomplementari di monumento e di testo, in cui l'iconografia suggerisce e/o completa i contenuti del titulus inscritto. Esempi persino banali talvolta, eppure ricchi di singolari e suggestive variazioni.

È vero, l'epigrafia funeraria non è strettamente compresa nell'ambito del sacro, ma se ne presenta pur sempre come una trasposizione parasacrale, almeno con il riferirsi tanto spesso Dis - Dis appunto, entità divine per quanto impersonali indistinte indefinibili - Manibus. E tra la ricca simbologia che spesso la correda è frequentemente presente la testa di Medusa. Ma con quali funzioni? Apotropaiche? Predeterminanti o illustranti in anteprima lo scopo del monumento? Strumento di attenzione e di riconoscibilità al primo colpo d'occhio anche di lontano o piuttosto di simbolica difesa protettiva ideale per l'integrità dello stesso monumento?

Sono tutte varianti possibili di funzione e di volontà, forse spesso anche concomitanti, che tuttavia non escludono, che valorizzano anzi, la presenza di Medusa, all'apparenza routinière, come segnacolo e distintivo di un monumento già specifico di per sé, per solito una stele, che si presenta dunque secondo definiti stilemi per dimensioni profilo e accessori decorativi evidenzianti, ma soprattutto di una funzione specifica, ove mai vi si potesse equivocare, di essa.

Tant'è vero che se ne possono trovare infinite varianti, declinate secondo gli usi e le disponibilità, o le abitudini, o secondo la tecnica e le abilità dell'operatore e le più diverse opportunità contingenti; eppure tutte collegate con un archetipo di modello materiale, che può trovarsi fianco a fianco o nei pressi o nell'esperienza delle persone coinvoltevi, o anche esserne un, per così dire, modello ideale. Vana e interminabile una descrizione dettagliata e molteplice, è più facile proporne un campionario, tutto solamente dalla mia Milano (fig. 4), che comprende persino due esemplari

13. A riprova di una sensibilità per un'essenziale presenza epigrafica, si ricordi il rammarico espresso dallo stesso Plinio nel ritrovare dopo anni dalla morte dell'amico Virginio Rufo che neglectum cinerem sine titulo sine nomine iacere (Plin. Epist. 6.10. 3-5).

14. Esempio concreto di tale attenzione indiretta, sollecitata o mutuata per l'intervento di altri, può essere la base di Como (AE 1972, 212; 1978, 372; Sartori 1994a, p. 36 Po09): C. Plinio L. f(ilio) Ouf(entina tribu)|Caecilio Secundo| co(n)s(uli) M. Cassius Comic(us), in cui la specifica isolata della detenzione del consolato appare come esornativa e fin superflua nell'attribuzione di un onore gratulatorio in un ambito privato.

15. Per il concetto di autorappresentazione, intesa come il meccanismo con cui vuole dare di sé un'immagine per solito "migliorata" il titolare di un'epigrafe con le opportune strategie comunicative, volute o inavvertite, messe in atto a tale scopo, si vedano, tra gli altri Sartori 1992, p. 423-434; Eck 1996a, p. 271-298; Eck 1996b, p. 319-340; Eck 1996c, p. 347-358; Zaccaria 1997, p. 77-82; Sartori 2003a, p. 283-308; Sartori 2010 [2012], p. 107-116. 


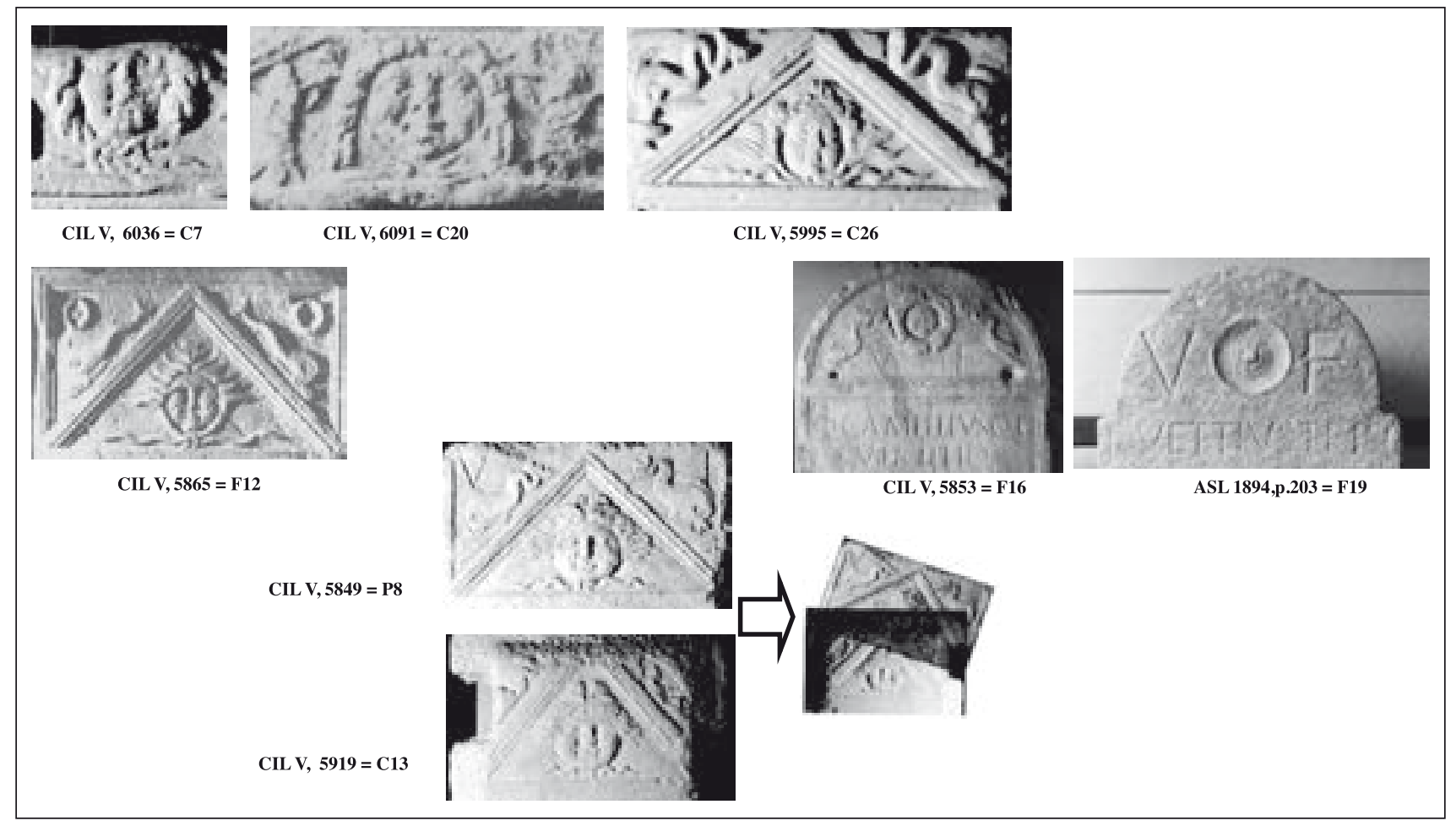

Fig. 4. Comparazione di gorgoneia da Mediolanum (CIL, luoghi vari), fotografie dell'autore.

distinti ma perfettamente sovrapponibili, realizzati senza ombra di dubbio da una stessa officina e per una committenza - ma non è qui il caso di approfondire il caso - socialmente la più disparata ${ }^{16}$.

Ma che cosa mai non è così - tante varianti da un unico modello, oppure coincidenze inattese di esperienze diverse eppure riconducibili ad un unico benchè indistinto patrimonio culturale - in ogni pratica epigrafica, che ogni valenza universale la declina, la interpreta, la fa propria, secondo le circostanze, e le interferenze pure, contingenti e personali?

Una presenza tanto radicata e tanto prevista quella di Medusa, persino attesa e scontata, che può ben tollerare la semplificazione anche estrema o l'accenno soltanto per suggerimento iconografico e persino per allusione letterale.

Che sono appunto, nei termini di questa presentazione, tituli che in sè suggeriscono parvenze o suggestioni di elementi iconografico-decorativi, e che in sè mostrano la massima integrazione, quasi l'identità consustanziale fra testo e monumento; benchè se ne riconoscano le molte varianti per trasposizione: dal fiore che nasconde o ingloba $o$ lascia trapelare i lineamenti di Medusa, alla patera che ne potrebbe surrogare almeno l'essenza rievocandola con un profilo circolare in posizione elevata; sino all'estremo del grafema essenziale ma allusivo (fig. 5) delle sigle letterali (le iniziali di praenomina) ${ }^{17}$ : per le quali osservo infatti che tali sigle dei praenomina, se in posizione isolata del tutto impropria da un punto di vista logico e sintattico, ricorrono molto raramente e soltanto quando abbiano sagoma arrotondata - di fatto solo C di $C$ (aius) e $\mathrm{Q}$ di $Q$ (uintus $)^{18}$ - perseguendo comunque un risultato di estrema rarefazione comunicativa ma efficace, che procede in senso inverso: non più la decorazione che completa il titulus, ma lettere alfabetiche che fanno da surrogato alla decorazione, che esasperano l'allusività solamente di una sagoma arrotondata (e infatti mai si trova un praenomen isolato se non in quella posizione e con quella forma).

16. Sartori 1996,p. 771-785; Sartori 2003b, p. 9-21.

17. Sartori 1995, p. 1353-1361.

18. CIL V, 8923 (Sartori 1994b, p. 40 P10): Q(uintus)| Modius Pelorus $\mid$ (sex)vir sibi et $\mid$ Luciliae C(ai)f(iliae) Pollae | uxori $\mid$ C(aio) Lucilio Sabino | [ - ] Cassio Nigellioni | amico | [ . Jniali Firmo Licoridi | Pupae Cossuroni | libertis; CIL V, 5887 (Sartori 1994b, p. 41 P11: C(aius) | Sentius | C(ai) f(ilius) Ouf(entina tribu)| Flavus | (sex)vir iun(ior). 


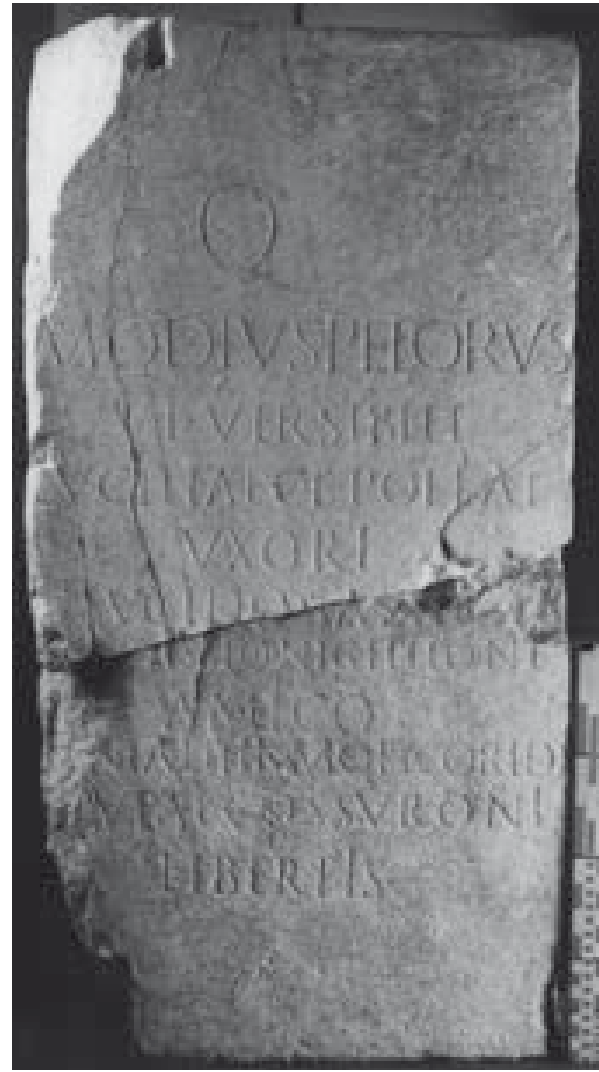

CIL V, 8923 = P10

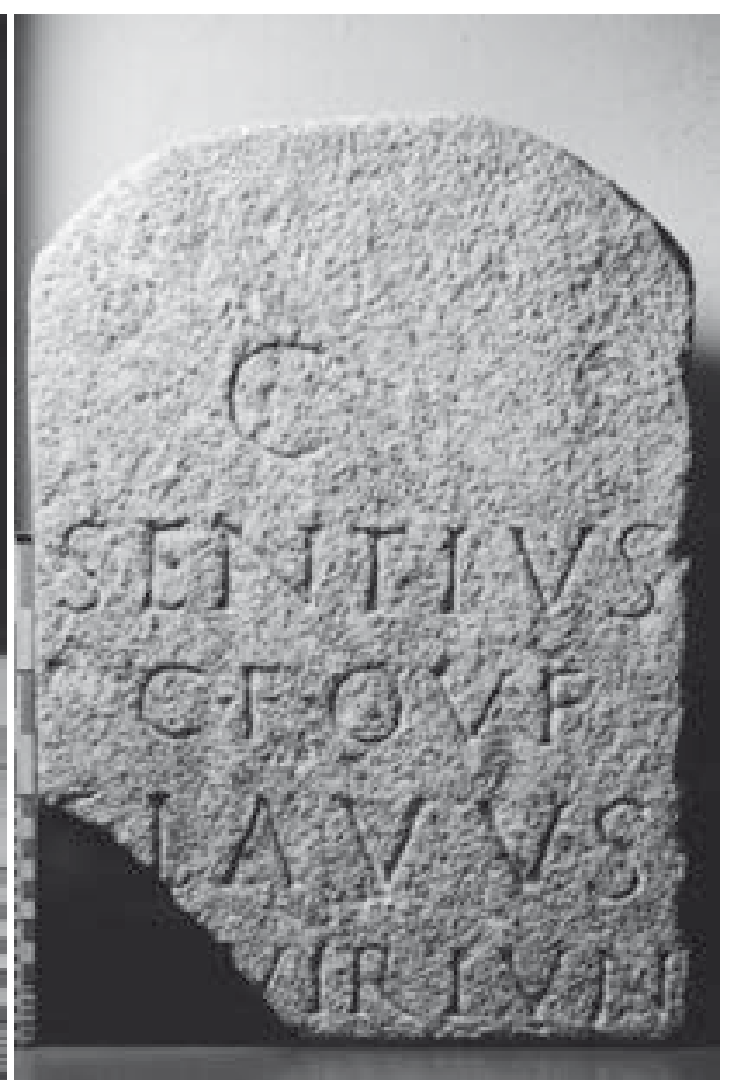

CIL V, 5587 = P11

Fig. 5. Stele da Mediolanum (CIL V, 8923 e 5887), fotografie dell'autore.

Lontano dai signa, ma in simbiosi sempre più stretta tra apparato iconografico-decorativo e tituli è la loro fusione reciproca: tituli che inglobano elementi decorativi, oppure tituli che si inseriscono e non di rado si annullano nell'apparato decorativo.

Dei primi - tituli che inglobano elementi decorativi - un caso tra i molti può ben essere la lastra (fig. 6) da Aquileia ${ }^{19}$, in cui una scena articolata di refrigerium, scomposta nelle sue tre componenti di presenza umana, risulta come intersecata a forza nel testo compatto del titulus, che corre imperterrito da margine a margine in un continuum che le scavalca, utilizzando opportunamente tutti gli spazi, anche i minori e minimi, tra le figure. Che è ben vero che dunque il testo iscritto è stato aggiunto, trapuntato quasi, a raffigurazione iconografica già completata, ma con una tale esuberanza soverchiante, da finire per mostrarsi come un'iscrizione compattamente intessuta con alcuni inserti d'altra natura soltanto.

Dei secondi, dei tituli inseriti invece nell'apparato decorativo, gli esempi più diffusi sono in un ambito più specifico e più latamente epigrafico, quello dei mosaici; nel quale mi sembra di riconoscere due situazioni di ben diverso valore. Infatti, un conto è ritrovare ambientata in una scena musiva, descrittiva di un paesaggio (fig. 7) e che non è in sé comunicazione epigrafica, la riproduzione di un'epigrafe pure accuratamente raffigurata, forse rappresentazione - o surrogato? - di un originale lapideo ${ }^{20}$. Ben altro conto è imbattersi nelle frequenti didascalie che sfregiano molti mosaici ${ }^{21}$, deturpandone la visione complessiva (fig. 8): inestetismi sconvenienti secondo i parametri d'oggi e che

19. Brusin 1948, p. 69-76; Inscr. Aquil. 2913; AE 1991, 772; Vergone 2007, p. 291-295.

20. $A E$ 2006, 1011 (dai pressi di Salona), un mosaico paesaggistico variamente popolato: un giovinetto in toga pretesta con un rotolo, una pernice, l'erma di una giovane, una stele che espone l'iscrizione seguente: $D($ is $)$ M(anibus) | hic | positus est |T(itus) Aurelius Au|relianus / filius / pientissimus / vixit / annis VIIII.

21. Se ne vedano numerosi esempi raccolti in Gómez Pallarès 1997. 


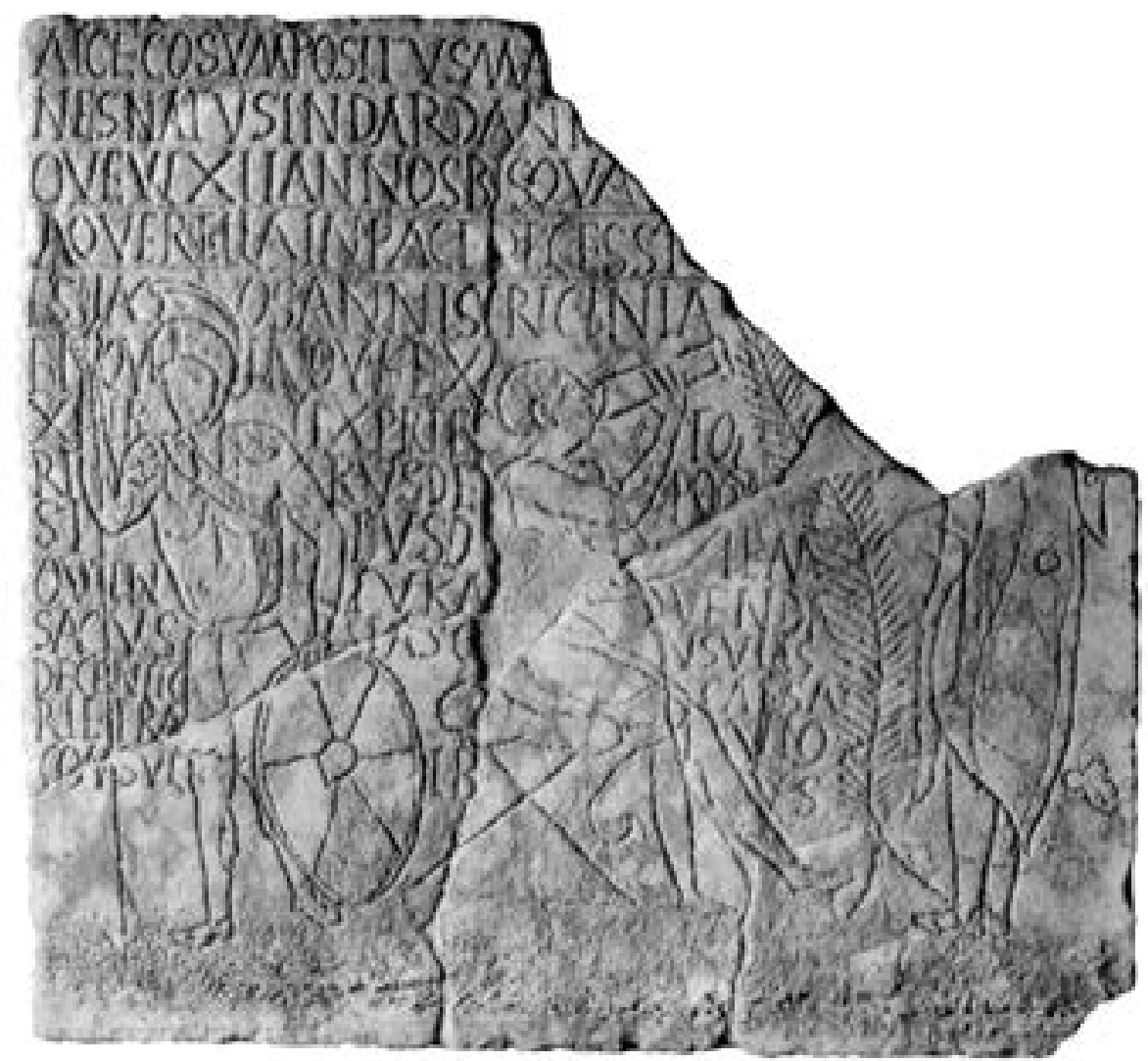

Fig. 6. Lastra funeraria da Aquileia (AE 1982, 383) fotografia da G. Vergone, Le epigrafi lapidarie del Museo paleocristiano di Monastero (Aquileia), Trieste 2007, sch. 139.

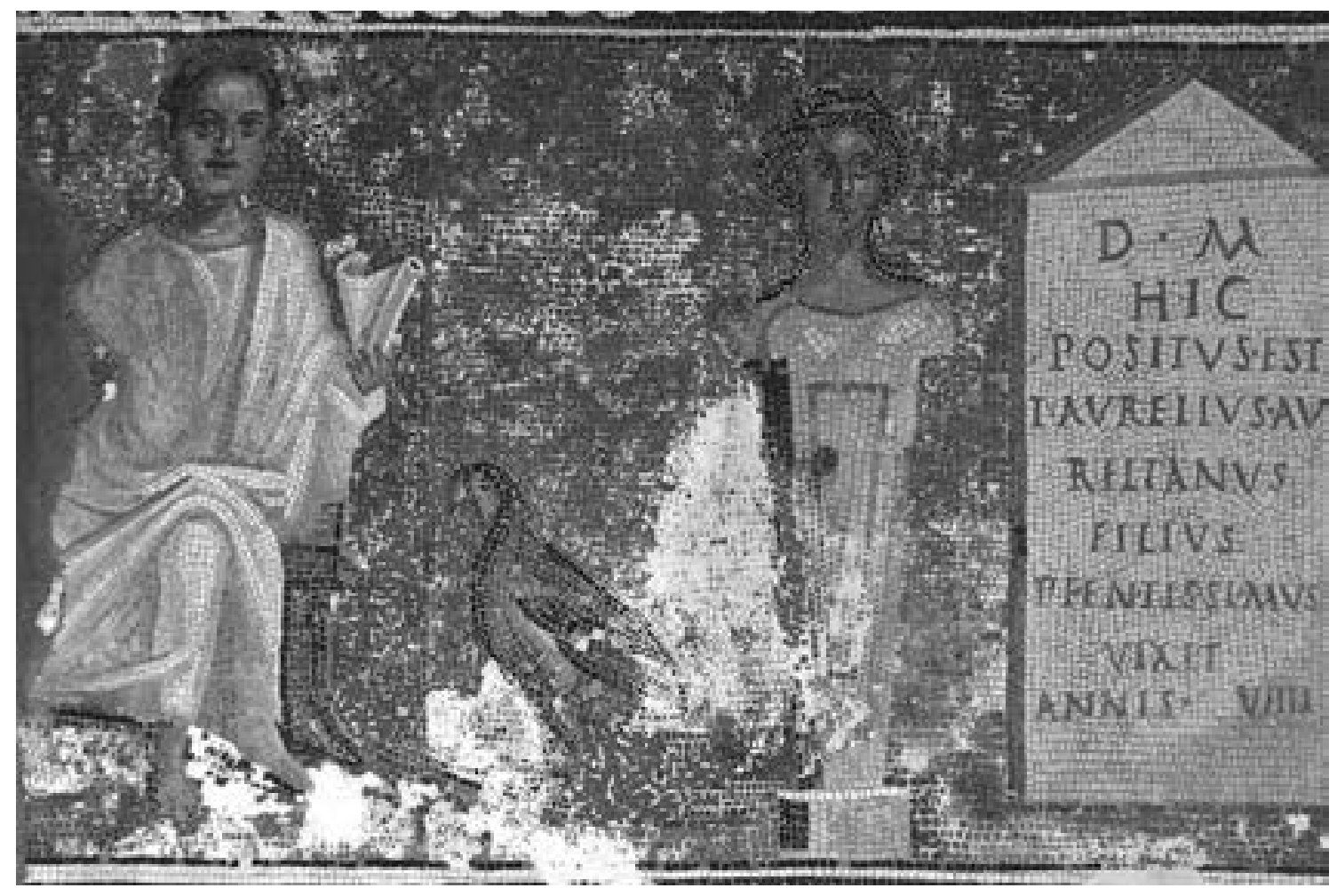

Fig. 7. Mosaico epigrafico da Split (AE 2006, 1011) fotografia da S. Ivčević, Istria Antiqua, 14, 2006, p. 145, n7. 


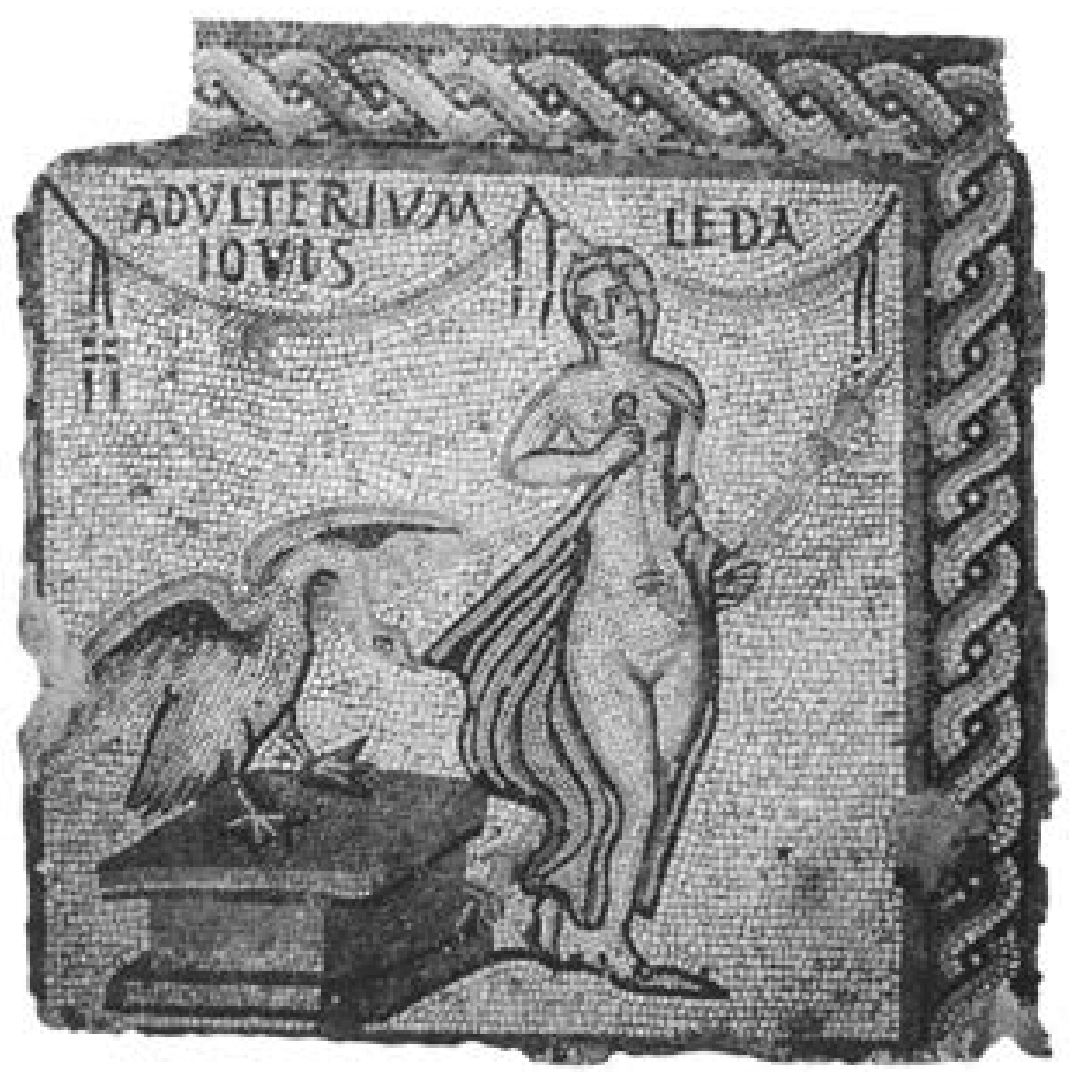

Fig. 8. Mosaico da Alcalá de Henares (Gómez Pallarès 1997, p. 106), fotografia di Fernández-Galiano, EAE 1984.

possono trovare giustificazione soltanto in una presuntiva capacità di lettura "presbite" degli estimatori romani, in grado di scorporarli e di non "vederli" come se fossero trasparenti.

Che è peraltro fenomeno che si manifesta anche - sempre con qualche intolleranza forse tutta nostra, ma inavvertita allora - nelle epigrafi, talvolta sconciate da inserti inaccurati posteriori: completivi per lo più e sia pure motivati, ma sempre per noi sgradevoli, come nelle abbondanti intrusioni aggiuntive, di cui do un solo esempio di sfuggita (fig. 9), pur pregevoli per originalità letteraria, ma esteticamente sgradevoli, negli eleganti monumenti dei Fadieni in un esemplare nucleo necropolare unifamiliare nella bassa regione padana ${ }^{22}$.

Per non dire infine - per completezza, ma un poco a latere rispetto alle manifestazioni epigrafiche - del caso teoricamente forse più avanzato, della figura che si fa titulus, o del titulus che dà forma alla figura.

Che è il caso dei cosiddetti calligrammi ${ }^{23}$, di tradizione colta e piuttosto o solamente manoscritta (e dunque chissà con quali manipolazioni nelle copie della tradizione), in cui il testo letterato si atteggia nelle forme e nei profili di una figura che ne è descritta o che lo ha ispirato, come si sa di componimenti di ambiente ellenistico (Simia Rodio, Teocrito, Dosiada), che perseguivano una ricerca estetica artificiosa, comportante un'accurata composizione prima contenutistica e poi perfino di impaginazione se non grafica con l'uso opportuno di caratteri adatti a contenervisi per riprodurre nel profilo del testo, o meglio della sua trascrizione, la suggestione dell'oggetto citato o cui si riferiva.

Dei quali tuttavia non ho saputo trovare reali esempi epigrafici, ma solo intuirne analogie letterarie, tràdite ovviamente e pure indirette, in pochi cenni della tradizione culturale antica, ad esempio (fig. 10) con un componimento metrico greco in forma fisica, trapezoidale o trigona, di syrinx, forse la più facile, ed uno latino che si atteggia nel

22. Sartori 2010 (2012), p. 107-116.

23. Un'attenta crestomazia, accurata e singolarmente poco nota, è in Massin 1995, spec. alle p. 197-200 e 248-266. 


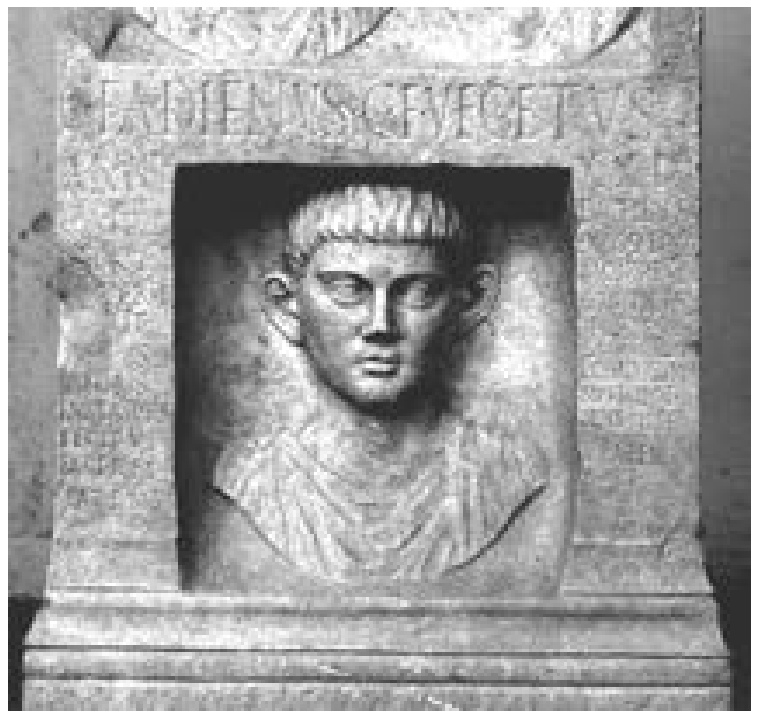

Fig. 9. Stele dei Fadieni dai dintorni di Ferrara (AE 2006, 474; 2008, 264), fotografia dell'autore.

\section{EYPITE.}

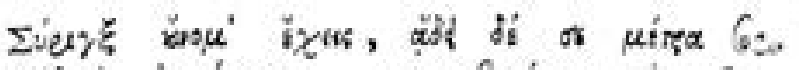

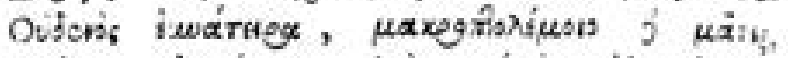
Maixs ainrázos tos rixts iswringa,

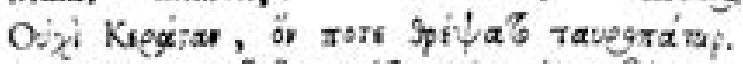

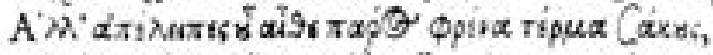

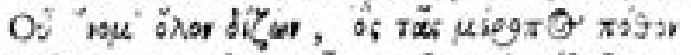

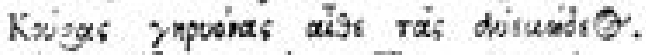

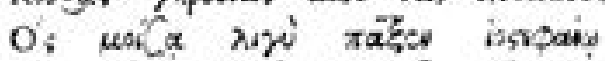

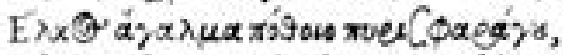

$\mathrm{O}^{\prime}$ Fîtร dingia isaudia

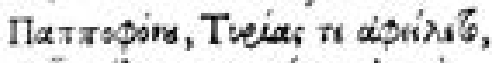

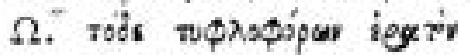

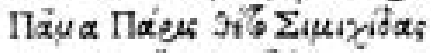

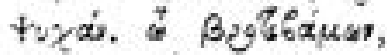

Lings was detas,

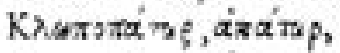

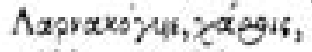

Adi ueligion

L $17: \pi, x \in \rho \alpha$

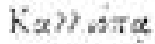

Ningeras.
Vides vt Afa fitem dicata Pythio 1

Fake - polita vatis orte Mufica Sie prolehra facratiflina gens Plocbo decens

His apea templis quis litant vatum choti

Tot compra fertis et Camenae floribus S

Heliconiis locanda lueis camninau

Non caute dura me polinit artifex

Excifa non fum rupe montis albidi

Luna e niteste nec pari de vertice

Non catia duto nee coacha f́piculo

Artare primos etnineates angulos

Et mox fesundos propagure latius

Eosque cxote fingulos fubducte

Gradu mineto per recurtas lineas

Normata vbique fic deinde regala

Vt ora quadrac fit rigente limite

Vel inde ad inum fufa rurfum linea

Teadatur arte latior per ordinem

Me metra pangunt de Canenarun modis

Mutaso ne:squaun numero duataxat pedum 20

Quiae slocha feruat dam peaeceptis rcgula

Elencuta efefount et decrefonat canminum

1L. Photbe fupplex dans metronum iangines

Tonglis chorisquo lactas interite factio

Fig. 10. Calligrammi per impaginato, da Massin, La lettera e l'immagine, Milano 1995 , illustrazioni $n^{\circ} 794$ e $n^{\circ} 796$. 


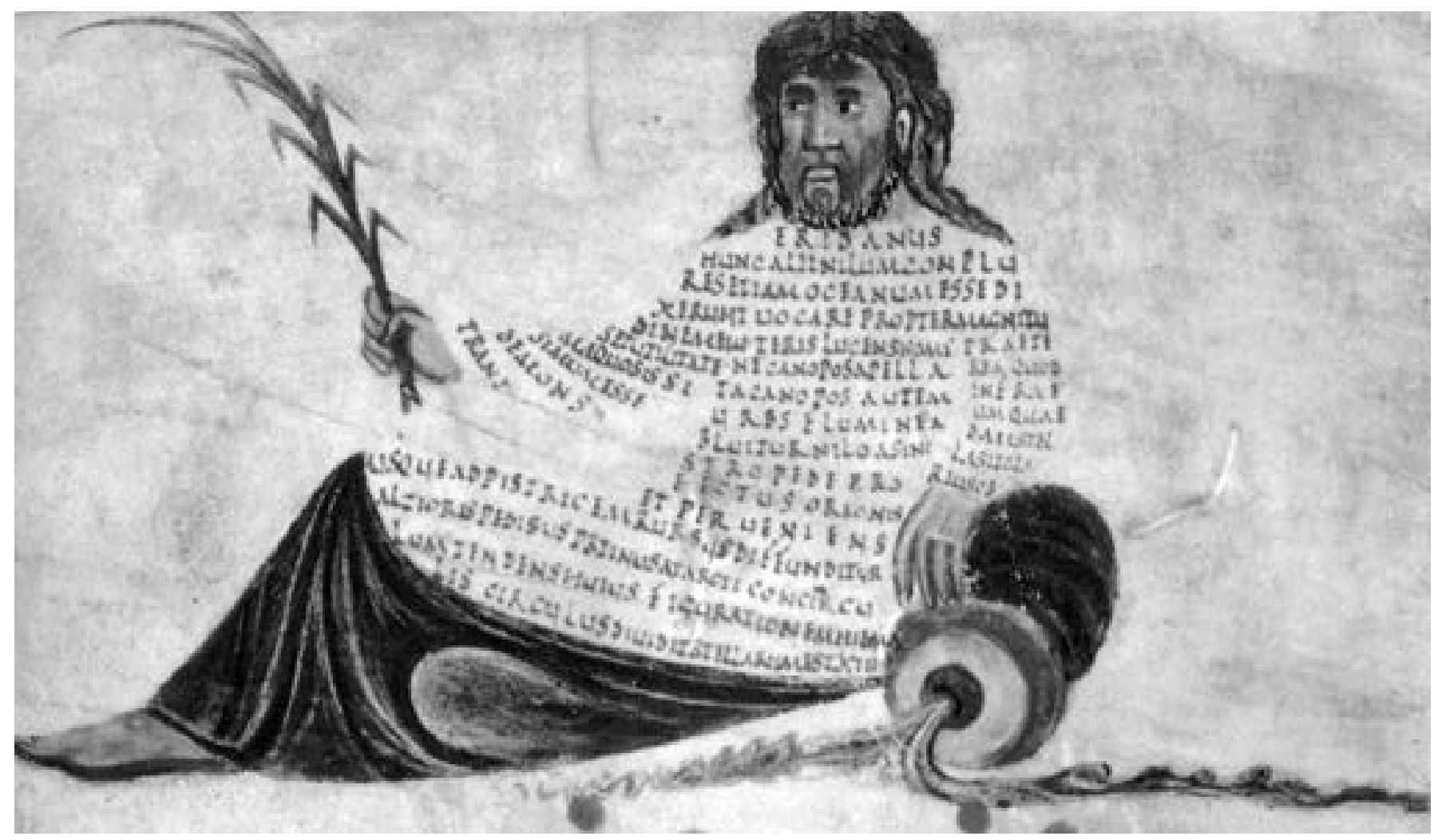

Fig. 11. Calligramma iconografico del fiume Eridano, da Massin, La lettera e l'immagine, Milano 1995 , illustrazione $n^{\circ} 820$.

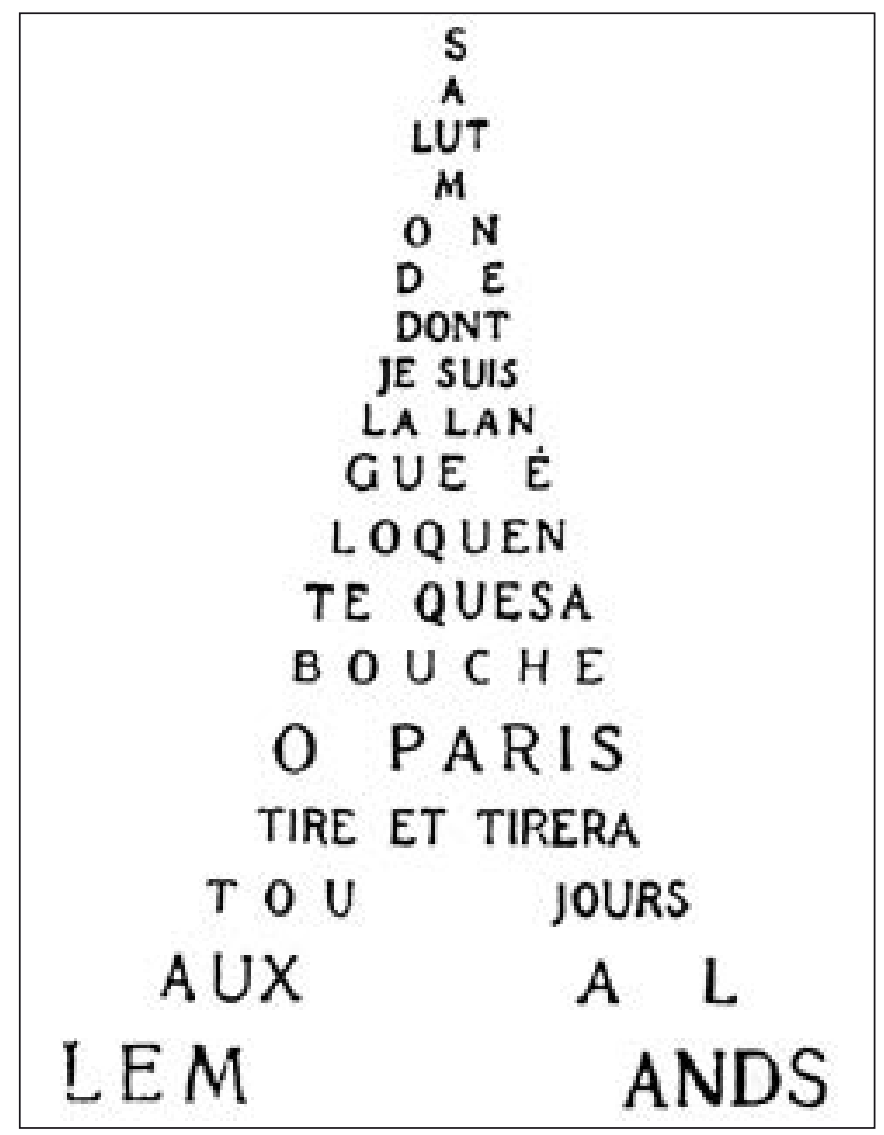

profilo inconfondibile di un'ara "a rocchetto"; e anche più facilmente riconoscibili in certa produzione, manoscritta e non, di veri jeux de plume (fig. 11) di età più avanzate; fino a giungere alle più moderne sperimentazioni poetiche, come la celebre tour Eiffel (fig. 12) di Guillaume Apollinaire, anticipatrice delle molte fantasie del futurismo.

Che dire per concludere? Che anche da questo punto di vista, dell'incontro e del confronto tra signa et tituli, si conferma l'assioma basilare dell'interdipendenza binomia ma indissolubile tra la componente materiale e il complemento ideale che insieme formano l'epigrafe, o meglio la forma della comunicazione epigrafica, dalla quale non può non emergere anche la volontà - intenzione, desiderio, capacità - di chi la volle presentare così, in forme e modi sempre riconoscibili eppure sempre diversi, che è, come sono fermamente convinto, l'essenza più originale di tutta l'epigrafia latina.

Fig. 12. La tour Eiffel in un calligramma simbolista di Guillaume Apollinaire, illustrazione di pubblico domin. 


\section{Bibliographie}

Brusin 1948: BRUSIN (G.) - Epigrafe aquileiese col refrigerium. In : Miscellanea Pio Paschini. Studi Di Storia Ecclesiastica, 2 I, Roma, Pontificia Universitas Lateranensis, 1948, p. 69-76.

Cavallaro, Walser 1988 : CAVALLARO (A.M.), WALSER (G.) - Iscrizioni di Augusta Praetoria. Inscriptions de Augusta Praetoria, Aosta, Musumeci Editore, 1988, $223 \mathrm{p}$.

De Marchi 1917 : DE MARCHI (A.) - Le antiche epigrafi di Milano, Milano, Paravia, 1917, $322 \mathrm{p}$.

Eck 1996a : ECK (W.) - Autorappresentazione senatoria ed epigrafia imperiale. In : Eck (W.) cur., Tra epigrafia prosopografia e archeologia. Scritti scelti, rielaborati ed aggiornati, Roma, Quasar, 1996, 432 p., p. 271-298.

Eck 1996b : ECK (W.) - Tituli honorarii curriculum vitae e autorappresentazione nell'Alto Impero. In : Eck (W.) ed., Tra epigrafia prosopografia e archeologia. Scritti scelti, rielaborati ed aggiornati, Roma, Quasar, 1996, 432 p., p. 319-340.

Eck 1996c : Eck (W.) - Dedicanti di statue ed autorappresentazione nelle città romane. In : Eck (W.) (cur.), Tra epigrafia prosopografia e archeologia. Scritti scelti, rielaborati ed aggiornati, Roma, Quasar, 1996, p. 347-358.

Gómez Pallarès 1997 : GÓMEZ PALLARES (J.) - Edición y comentario de las inscripciones sobre mosaico de Hispania. Inscripciones no Cristianas, Roma, L'Erma di Bretschneider, 1997, 292 p.

I.I. : BAROCELLI (P.) - Inscriptiones Italiae, XI, 1. Augusta Praetoria, Roma, 1932.

Inscr. Aquil. : BRUSIN (J.-B.) - Inscriptiones Aquileiae, Udine, Deputazione di Storia Patria per il Friuli, 1991-1993, 1407 p.

Massin 1995 : MASSIN (R.) - La lettera e l'immagine, Milano, A. Vallardi, 1995 (trad. di La lettre et l'image, Paris 1970 e 1993).

Sampaolo 1991 : SAMPAOLO (V.) - Regio II. Insula 4. In : Pompei, Pitture e mosaici. III, Roma, Istituto della Enciclopedia italiana, 1991, p. 256.

Sartori 1992 : SARTORI (A.) - Epigrafia sacra e appariscenza sociale. In : Mayer (M.), Gómez Pallares (J.) curr., Religio deorum. Actas del Coloquio Internacional de Epigrafía. Culto y sociedad en Occidente (Tarragona, 1988), Sabadell (Barcelona), 1992, editorial AUSA, p. 423-434.

Sartori 1994a : SARTORI (A.) - Le iscrizioni romane. Guida all'esposizione, Como, Comune di Como, 1994, 95 p.

Sartori 1994b : SARTORI (A.) - Guida alla sezione epigrafica delle raccolte archeologiche di Milano, Milano, Comune di Milano, 1994, 148 p.

Sartori 1995 : SARTORI (A.) - Alcuni calligrafismi epigrafici: decorativi o allusivi? In : Miscellània d'estudis dedicats a la memòria del professor Josep Trenchs i Òdena. Estudis Castellonencs, 6, 1994-1995, p. 1353-1361.

Sartori 1996: SARTORI (A.) - I. Il problema, 2. Gli esempi. In : Groppo (E.), Sartori (A), Vai (C.), Schemi compositivi delle iscrizioni latine: le giustificazioni metodologiche. In: III Conv. Intern. di Archeologia e Informatica. Roma 1995. Archeologia e calcolatori 7, 1996, p. 771-785.

Sartori 2003a : SARTORI (A.) - La promozione del consenso : autorappresentazione e modelli epigrafici nelle comunità municipali Cisalpine. In : Castillo García (C.) et al., eds, Sociedad y Economía en el Occidente Romano (Actas del Simposio, Pamplona 2001), Pamplona, 2003, p. 283-308.

Sartori 2003b : SARTORI (A.) - Donne chi/donne di chi? o dell'autoaffermazione femminile. In : Buonopane (A.), Cenerini (F.) (curr.), Donna e lavoro nella documentazione epigrafica. Atti del I semin. sulla condizione femminile. Bologna 2002, Faenza, Fratelli Lega Editore, 2003, 289 p., p. $9-21$.

Sartori 2005 : SARTORI (A.), Tituli da raccontare. In : Sartori (A.) cur. Scripta volant? Atti del $2^{\circ}$ incontro di dipartimento sull'epigrafia (Milano 2004), Milano, Ed. Univ. di Lettere, Economia e Diritto, 2005, p. 89-99.

Sartori 2007 : SARTORI (A.) - Parole per tutti o comunicazione mirata ed esclusiva? In : Sartori (A.) cur., Parole per tutti? Atti del $3^{\circ}$ incontro di dipartimento sull'Epigrafia, Milano, Ed. Univ. di Lettere, Economia e Diritto, 2007, p. 47-53.

Sartori 2008 : SARTORI (A.) - La comunicazione epigrafica: realtà o fantasia? In : Angeli Bertinelli (M.G.), Donati (A.), a cura di, La comunicazione nella storia antica: fantasia e realtà. Atti del III Incontro Internazionale di Storia Antica (Genova, 2006), Roma, Giorgio Bretschneider, 2008, 270 p. e 21 tav., p. 71-82.

Sartori 2009a : SARTORI (A.) - Tra opinione pubblica e comunicazione: quale prima e quale dopo? In: Angeli Bertinelli (M.G.), Donati (A.) (a cura di), Convegno Borghesi 2007. Opinione pubblica e forme di comunicazione a Roma: il linguaggio dell'epigrafia (Bertinoro, 21-23.6.2007), Faenza, Fratelli Lega Editore, 2009, p. 7-14.

Sartori 2009b: SARTORI (A.) - Le pietre iscritte di Angera. In: De Marinis (R.) et al., curr., Alle origini di Varese e del suo territorio. Le collezioni del sistema archeologico provinciale, Roma, L'Erma di Bretschneider, 2009, p. 366-367.

Sartori 2011: SARTORI (A.) - Nuove interpretazioni dell'epigrafia latina. In : Bologna (M.P.), Ornaghi (M.), a cura di, Signa Antiquitatis. Atti dei Seminari di dipartimento 2010 (Quaderni di Acme, 28), Milano 2011, p. 35-73.

Sartori 2012 : SARTORI (A.) - L'autorappresentazione funeraria: abusi in libertà o convenzionalismi sotto controllo? In : Memoriam habeto. Dal sepolcreto dei Fadieni: stele figurate ed iscrizioni in Cisalpina (Gambulaga 19-21 marzo 2009). Ostraka XIX. 1-2, genn.-dic. 2010 [2012], p. 107-116.

Vergone 2007 : VERGONE (G.) - Le epigrafi lapidarie del Museo paleocristiano di Monastero (Aquileia), Trieste, Editreg, 2007, 363 p.

Wolf 2001: WOLF (M.) - Teorie della comunicazione di massa, Milano, Bompiani, 2001.

Zaccaria 1997 : ZACCARIA (C.) - Aspetti sociali del monumento funerario romano. In : Mirabella Roberti (M.), a cura di, Monumenti sepolcrali romani In Aquileia e nella Cisalpina. atti della XXVI Settimana di studi aquileiesi (24-28 aprile 1995), Trieste, 1997, 494 p., p.77-82. 

Première Partie

\author{
Espaces \\ civiques de représentation
}

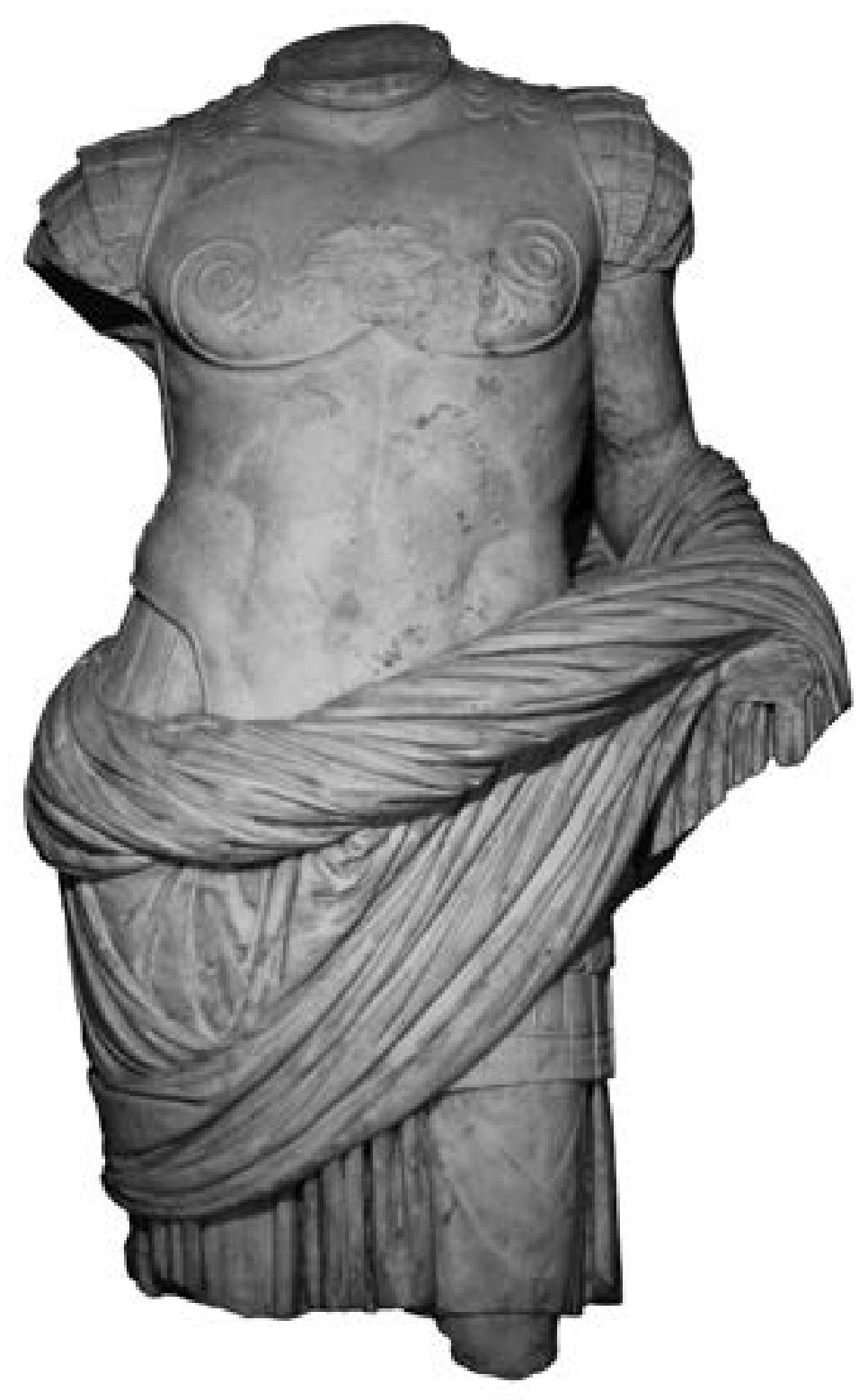





\title{
Statues des dieux, statues des hommes. La mention de statues dans les inscriptions de Gaule Narbonnaise
}

\author{
Sandrine Agusta-Boularot \\ Université Paul Valéry-Montpellier 3 et Archéologie des Sociétés Méditerranéennes-UMR 5140-CNRS \\ Labex ARCHIMEDE, programme ANR-11-LABX-0032-01 \\ sandrine.boularot@orange.fr
}

\begin{abstract}
Résumé
Cet article recense les mentions de statues dans les inscriptions de Gaule Narbonnaise : elles s'élèvent à 36 mentions sur 34 inscriptions, ce qui est fort peu si l'on songe à la multitude de statues qui peuplaient les espaces publics antiques. Le terme de statua est de loin le plus attesté devant signum; imago et simulacrum sont très rares. Aucune des statues mentionnées n'a été conservée. L'étude de cette documentation s'intéresse à la nature des supports et à leur matériau, à leur répartition géographique dans la province et à leur localisation dans l'espace urbain. Ces inscriptions fournissent également des indications sur les sujets représentés (dieux, notables, empereurs), l'origine de leur financement et les mécanismes sociaux qui ont présidé à leur réalisation et à leur mise en place.
\end{abstract}

Mots-clés : Empire romain, Gaule Narbonnaise, épigraphie, inscriptions, statues, sculpture, évergétisme, ex-voto, notables, statua, imago, simulacrum, signum, effigies.

\begin{abstract}
This article presents the inscriptions of Gallia narbonensis in which we find mentions of statues (statua, signum, simulacrum, imago): the number of these inscriptions (34) is quite low when one considers the multitude of statues that populated the ancient public spaces. The terms most attested are signum and statua; simulacrum and imago are very rare. No statue mentioned has been preserved. The study focuses on the type of the inscribed blocks and the material of the statues, their geographical distribution in the province and their location in the urban space. It also provides information about the subjects depicted (gods, "élites locales", emperors), the origin of their funding and social mechanisms that led to their execution and their implementation.
\end{abstract}

Key-words: Roman Empire, Gallia narbonensis, epigraphy, inscriptions, statues, sculpture, evergetism, ex voto, notables, statua, imago, simulacrum, signum, effigies. 
L e vocabulaire de la statuaire, de la sculpture et plus largement de la représentation a déjà fait l'objet de plusieurs études qui ont recensé les termes en usage dans les sources textuelles grecques et latines, tant littéraires qu'épigraphiques ${ }^{\mathbf{1}}$. Néanmoins, si nous disposons d'un cadre général de réflexion, les approches détaillées du sujet demeurent encore en nombre limité. Si l'on ne s'intéresse qu'à la partie occidentale de l'Empire, on constate que les études, finalement peu nombreuses, se limitent souvent à un thème spécifique (les statues des dieux, les images des empereurs, etc.) restreint au cadre d'une cité, d'une province ou d'une région (Rome, les provinces d'Hispanie, l'Afrique du Nord) ${ }^{2}$. L'article qui suit se propose d'apporter une pierre à l'édifice sous la forme d'un dossier, celui des attestations épigraphiques concernant les statues de la province de Narbonnaise, où un tel travail de synthèse, à notre connaissance, n'avait pas encore été conduit. Ces témoignages nous livrent des informations sur le prix des statues, leur nature, leur emplacement, le sujet représenté ou encore les motifs de leur mise en place. Ce travail doit être compris comme un "sondage », au sens archéologique du terme, car cette étude nous est rapidement apparue riche de perspectives. Elle mériterait d'être étendue à d'autres provinces nord-occidentales (Germanies, trois Gaules, etc.) où les données sur le sujet restent peu exploitées.

\section{Présentation de la documentation}

Nous avons relevé, pour la Gaule Narbonnaise, trente-quatre inscriptions correspondant à trente-six mentions de statues ${ }^{3}$, que nous avons rassemblées dans

1. Pour une approche bibliographique générale : Daut 1975. Étude du vocabulaire: Gros 1976, p. 160-161. Pour une étude des données épigraphiques, voir plus particulièrement: Lahusen 1982, Lahusen 1983, Smadja 1995 et Oria Segura 2000a. La bibliographie est ici indicative.

2. Sur les statues des dieux à Rome : Estienne 1997 et Estienne 2000. Sur les représentations des empereurs en Afrique: Smadja 1995 et Hurlet 2000. Sur les provinces d'Hispanie : Alföldy 1979, Oria Segura 2000a, Oria Segura 2000b, Melchor Gil 2006, Melchor Gil 2009 et Melchor Gil 2010. Cette bibliographie n'est en rien exhaustive.

3. Ce corpus comprend des mentions avérées ou des restitutions étayées par des parallèles épigraphiques. Nous avons éliminé certaines hypothèses de restitution trop hasardeuses, comme ce fragment de tablette en marbre d'Arles, aujourd'hui perdu, où la dédicace d'une statue sur le forum nous semble trop incertaine pour être retenue : $C I L$ XII, $5805=C A G 13 / 5,206^{*}, 25$, p. $571:[---]$ nicaea [---] $\mid$ [---]A (?) probante ues[---] [ --- statua]mque (?) in foro. un corpus annexe en fin d'article ${ }^{4}$. Les termes latins attestés sont au nombre de quatre : statua (22 attestations), signum (10), imago (3), simulacrum (1). Statua est le terme le plus fréquent et le plus polyvalent: il renvoie à toute représentation sculptée en pied, qu'il s'agisse d'une divinité, de l'empereur ou d'un notable local, vivant ou mort ${ }^{5}$. Imago est utilisé pour la représentation de l'empereur et correspond à un buste ou à un portrait. Signum et simulacrum désignent une statue de divinité ou d'empereur divinisé, et dans certains cas, simulacrum semble plus précisément faire référence à la statue de culte. Ce vocabulaire n'est pas propre aux inscriptions : les mêmes termes employés dans les mêmes acceptions se retrouvent en littérature ${ }^{6}$. D'autre part, cette terminologie n'est pas figée : il est toujours possible de trouver des contre-exemples à ces définitions.

Ce nombre d'attestations est faible si l'on a à l'esprit les centaines de fragments statuaires conservés dans les musées : il est donc sans commune mesure avec la masse de statues qui ornaient les monuments publics, les espaces urbains, les sanctuaires et les monuments funéraires des villes de la province durant le Haut-Empire. Ce nombre paraît également bien faible si l'on considère toutes les traces d'accrochage, les restes de crampons et autres trous d'ancrage que bon nombre de bases inscrites portent sur leur face supérieure et qui prouvent de façon sûre que des statues surmontaient ces blocs inscrits et entretenaient une relation étroite avec le texte ${ }^{7}$. Une telle étude a été menée à l'échelle réduite de la cité de Vienne (voir l'article de B. Rémy et N. Géroudet). Elle serait riche d'enseignements si elle pouvait être conduite à

4. Le corpus compte trente-quatre inscriptions pour trente-six attestations : deux textes sont cités à deux reprises car ils mentionnent, l'un des signa (6) et une imago $(34=6)$, l'autre des statuae (23) et des imagines $(36=23)$.

5. Statua est « le résultat d'un travail artistique tendant à représenter un modèle réel » (Gros 1976, p. 161, n. 48).

6. Smadja 1995, p. 279-280.

7. Rappelons une fois encore combien le vocabulaire latin utilisé dans le CIL pour désigner les blocs inscrits n'est pas toujours éclairant : cippus, basis, etc. Dans les corpora actuels, il règne encore parfois une certaine imprécision : ainsi le bloc ILN Vienne, 25, qui est désigné comme un "autel de marbre avec base et couronnement moulurés », ne présente en fait ni focus ni puluini. En revanche, l'auteur de la notice signale que «sur la partie supérieure, on remarque trois scellements avec des restes de plomb, sans doute pour fixer une statuette », très certainement celle de Venus Augusta à qui est destiné l'ex-voto. Nous plaidons ici en faveur d'une couverture photographique plus ample de certains blocs, y compris sur les faces non inscrites - de la face supérieure en particulier - ce qui permettrait de distinguer sans ambiguité les autels des bases. L'objet, dont seules les deux côtés inscrits sont reproduits, aurait mérité d'être photographié sous toutes ses faces. 
l'échelle de la province, mais il s'agit là d'un travail de longue haleine qui dépasse le cadre d'un article.

Néanmoins, ce faible nombre d'occurrences ne doit pas surprendre : nul n'était besoin de mentionner la statue offerte puisqu'elle se dressait sur la base inscrite ou à côté de celle-ci. L'inscription n'était là que pour livrer des informations supplémentaires - en particulier le nom du donateur, éventuellement la somme versée, le motif de ce don, etc. - à propos d'une évergésie ou d'une offrande que le passant pouvait aisément voir et identifier. Ce n'est donc que dans quelques cas précis nous verrons lesquels - que le commanditaire tenait à signifier qu'il offrait une statue.

Aucune des inscriptions relevées n'a pu être mise en relation avec une statue ou des fragments sculptés. L'explication en est simple. La grande majorité des inscriptions qui nous intéressent ici ont été trouvées hors de leur contexte archéologique : elles proviennent d'édifices plus récents $\left(\mathrm{n}^{\circ} 3,8,9,20,21\right.$, etc. $\left.^{8}\right)$ comme les remparts de Nîmes ou de Narbonne ( $\mathrm{n}^{\circ} 4,27$, etc.), où elles étaient en remploi, ou résultent de découvertes anciennes, comme l'inscription de Riez trouvée jadis près des «quatre colonnes » $\left(\mathrm{n}^{\circ} 7\right)$. Un seul texte se trouve encore in situ : l'inscription de C. Iunius Priscus gravée sur le podium de l'amphithéâtre d'Arles $\left(\mathrm{n}^{\circ} 2\right)$. Certaines sont aujourd'hui perdues $\left(n^{\circ} 6,10\right.$, etc.). En outre, comme nous le verrons, on prend soin de mentionner que l'on offre une statue quand il s'agit d'un objet de prix, en particulier en bronze, voire en argent. De telles réalisations ont depuis longtemps disparu, refondues et réutilisées.

\section{Nature et matériau des supports inscrits}

Les supports de ces inscriptions, quand ils ont été conservés ou du moins identifiés avant d'être perdus, sont multiples : principalement des bases $\left(\mathrm{n}^{\circ} 3,4,7,12\right.$, $14,15,21,22,24,26,33$ ) qui portaient le texte et une statue, le plus souvent la statue mentionnée par l'inscription, et des plaques $\left(\mathrm{n}^{\circ} 1,5,8,9,11,13,17,30,31,32\right.$, 35) qui pouvaient être insérées dans la base ou affichées à proximité de la statue. L'inscription du podium de l'amphithéâtre d'Arles ( $\left.{ }^{\circ} 2\right)$, toujours en place depuis sa gravure, apparaît comme un cas à part, de même que les colonnes ou colonnettes inscrites $\left(\mathrm{n}^{\circ} 10,20\right)$. La table de bronze de la lex de flamonio de Narbonne $\left(\mathrm{n}^{\circ} 23[=36]\right)$

8. Les numéros renvoient au corpus fourni en annexe. se présente également comme une exception. Notons en fin qu'aucun autel n'est attesté avec certitude.

La proportion de supports en marbre - la moitié des attestations ${ }^{9}$ - contraste avec la place de ce matériau dans les inscriptions de Gaule Narbonnaise, très majoritairement sculptées dans du calcaire. Le meilleur exemple d'une telle prédominance est certainement Narbonne : bien qu'elle soit la capitale de la province, cette ville se distingue par le faible nombre d'inscriptions sur marbre sur les 1100 textes attestés. La place accordée ici au marbre montre que l'on a affaire à des inscriptions d'exception, à la hauteur de la statue de prix qui était offerte et qui le plus souvent se dressait au-dessus du texte.

\section{Répartition géographique}

La répartition géographique de ces mentions montre une prédominance des grands centres urbains (fig. 1). Les inscriptions sont essentiellement attestées dans la capitale de la province, Narbonne (10 attestations), qui livre plus d'un quart des mentions, et dans les chefslieux de cité : Arles (5), Nîmes (5), Vienne (3), Riez (2), Orange (1), Apt (1), Toulouse (1), Aix-en-Provence ${ }^{10}$ (?). D'autres agglomérations, de moindre importance, ont également livré des attestations: Grenoble (Cularo), Castelnau-le-Lez (Sextantio) et Marseille.

En revanche, les inscriptions trouvées à Talloires, sur le territoire de Vienne, à Caissargues, sur le territoire de Nîmes, et à Biot, sur le territoire d'Antibes, pourraient apparaître comme des exceptions dans ce corpus, qu'il faut néanmoins nuancer. Caissargues est une commune située seulement à cinq kilomètres au Sud de Nîmes : les inscriptions qu'elle a livrées proviennent essentiellement de collections privées et peuvent donc avoir été transportées de la cité proche, en particulier de ses nécropoles ${ }^{11}$. Dans le cas de l'inscription qui nous intéresse ici $\left(n^{\circ} 16\right)$, cette provenance nîmoise est certaine car il s'agit d'une épitaphe qui, accompagnée de la statue de la défunte, se dressait nécessairement dans une des nécropoles de Nîmes puisque l'inscription rappelle que c'est « à Nîmes, au nom de la collectivité, (qu') ont été accordés par décret l'emplacement de la sépulture, les frais de l'enterrement et une statue ».

9. $\quad \mathrm{N}^{\circ} 1,4,5,10,12,13,14,20,21,22,25,30,31,32,33,35$ et pierre marbrière (15).

10. Cette provenance n'est pas assurée.

11. Voir les remarques de la $C A G 30 / 2$, p. 280, 60, 8*. 


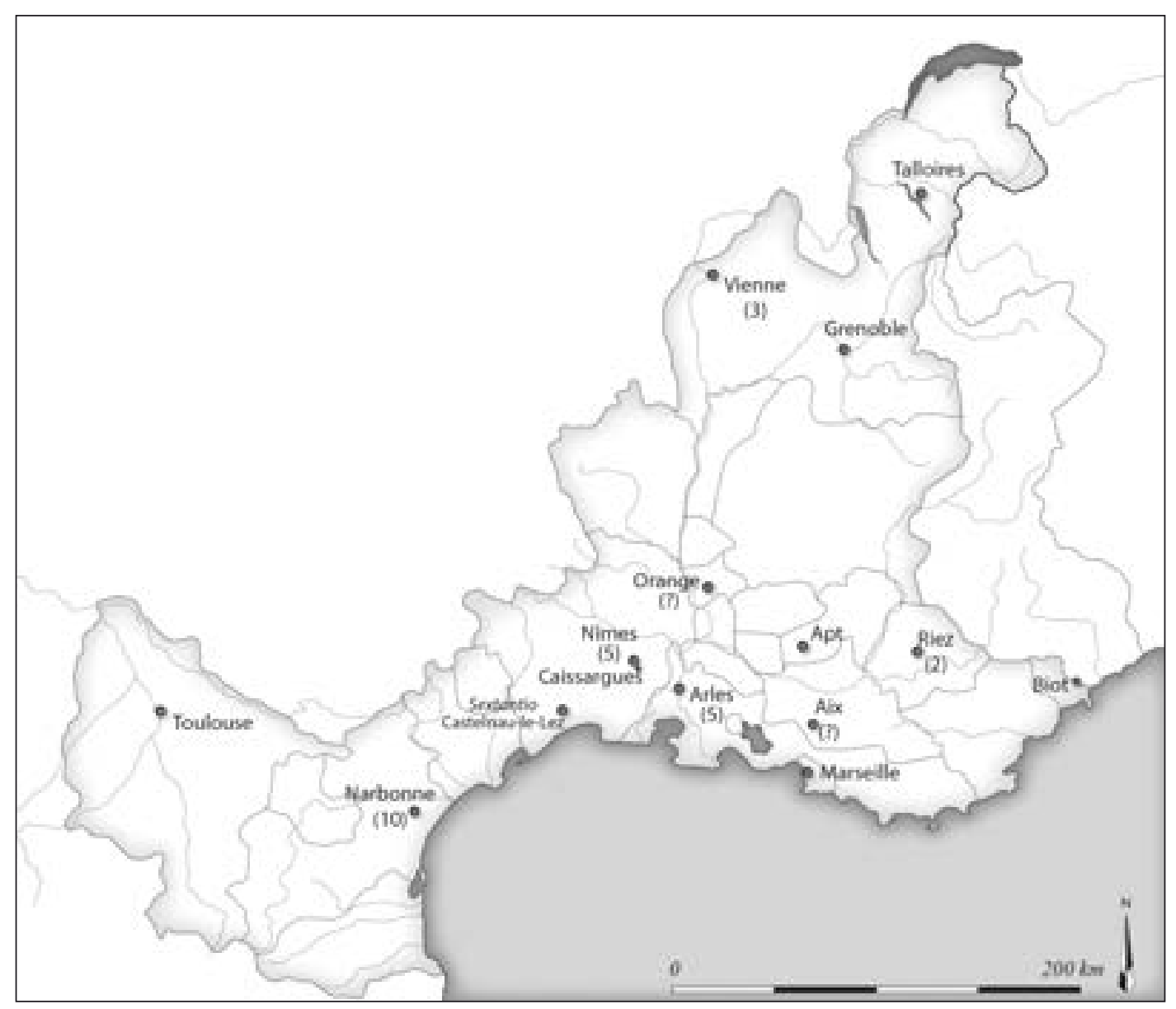

Fig. 1. Carte de répartition des mentions de statues dans les inscriptions de Gaule Narbonnaise (DAO : Stephan Ranchin, Mission Archéologie de la Ville d'Aix-en-Provence).

Si l'on ne connaît pas le nom antique de Biot, l'on sait qu'il s'agissait d'un pagus ${ }^{12}$, dont la proximité avec le chef-lieu de la cité - huit kilomètres - explique certainement le nombre d'inscriptions qui y ont été trouvées ${ }^{13}$. On se sait rien du site de Talloires, qui a livré fort peu de vestiges et d'inscriptions: on ne peut exclure que le texte $\left(n^{\circ} 8\right)$, trouvé au $\mathrm{XVI}^{\mathrm{e}}$ s. dans les murs de l'abbaye bénédictine, ne provienne du uicus d'Annecy (Boutae) distant d'une dizaine de kilomètres.

\section{Localisation des statues : espace funéraire, sacré, privé et public}

Comme nous l'avons signalé, les inscriptions du corpus ont été en majorité retrouvées hors contexte. Néanmoins, grâce à certaines indications livrées par l'inscription elle-même, nous pouvons avoir une idée de

12. Chastagnol 1992, p. 25.

13. Chastagnol 1992, ILN Antibes, 121-129. son emplacement d'origine et du lieu où se dressait la statue.

Ainsi, le contexte funéraire de la statue offerte à Terentia Marcella ne fait aucun doute $\left(\mathrm{n}^{\circ} 16\right)$ : son épitaphe, trouvée à Caissargues, a de fortes chances de provenir en fait d'une des nécropoles nîmoises. En effet, cette femme, qui fut flaminique de l'impératrice dans la colonie de Narbonne, faisait partie des notables nîmois : il lui fut accordé par décret, " au nom de la collectivité » (publice) de Nîmes, "l'emplacement de (sa) sépulture, les frais de (son) enterrement et (sa) statue » qui devait orner le mausolée de la défunte ou l'enclos familial.

Dans l'inscription d'Apt $\left(\mathrm{n}^{\circ} 11\right)$, C. Allius Celer offre après sa mort, par testament, à son oncle le monument sur lequel était gravée l'inscription (et qui portait peut-être aussi une statue de son oncle) ainsi que deux statuae, à son père et à son fils. Pour J. Gascou (ILN Apt, 35), « ce monument s'insérait sûrement dans une sépulture familiale... Sa générosité posthume à l'égard des 
décurions s'explique par le fait que lui-même était un décurion d'Apt». Il s'agirait alors de statues funéraires, et non honorifiques, ce qui impliquerait que l'oncle, le père et le fils de C. Allius Celer étaient déjà morts lors du décès de ce dernier.

Dans cinq cas avérés, une ou des statues sont offertes dans le cadre d'un sanctuaire. La mention VSLM sur l'une des deux inscriptions $\left(\mathrm{n}^{\circ} 4\right)$ rédigées par $\mathrm{Cn}$. Pompeius Hyla atteste sans ambiguïté que la statue d'argent de douze livres qu'il a offerte pour se libérer de son uotum se dressait à Narbonne dans le sanctuaire d'Hercules Inuictus : on ignore tout par ailleurs de ce sanctuaire. Ce que représentait la statue n'est pas mentionné, mais il est facile de le deviner : c'était une statue d'Hercule, dont les attributs (massue, peau de lion) sont représentés sur les côtés de la base inscrite qui servait de support au précieux objet.

À Riez, le sanctuaire d'Esculape n'est également connu que par l'épigraphie. L'abréviation VSLM indique là aussi que la « statue en bronze du Sommeil » (signum Somni aereum) offerte par Valerius Symphorus et Valerius/-a Protis au dieu Esculape était un ex-voto, l'un des nombreux ex-votos précieux déposés dans le sanctuaire du dieu guérisseur par ces deux personnages $\left(\mathrm{n}^{\circ} 7\right)$. Cette statue de Somnus témoignerait en outre de la pratique de l'incubation dans ce lieu de culte.

L'inscription de Nîmes $\left(\mathrm{n}^{\circ} 6\right)$ est certes une inscription honorifique. Mais bien qu'elle soit fragmentaire et aujourd'hui perdue, il est très probable que les différentes statues de divinités (Isis (?), Sérapis, Vesta, Diane, Sommeil), ainsi que «les statues des dieux en argent (telles qu'on en a) dans les camps » offertes par le personnage demeuré anonyme, aient été destinées à orner le temple d'Isis et de Sérapis mentionné dans le texte. Tout ou partie de ces objets pouvait provenir de ses biens personnels puisqu'il est précisé « qu'il (les) ${ }^{14}$ possédait dans sa demeure ».

Dans cette même inscription de Nîmes $\left(\mathrm{n}^{\circ} 6\right)$, les libéralités de l'évergète sont multiples. Outre les différentes statues qu'il offre à Nîmes même, l'inscription signale qu'il «a offert une statue de Mars en argent, d'un poids d'argent de [(?) livres ${ }^{15}$, aux Samnagenses ». C'est donc sur l'actuel site $\mathrm{du}$ Castellas de Murviel-lès-Montpellier (34)

14. Le texte est lacunaire : on ne sait exactement quels sont les biens que possédait le donateur avant qu'il les offre au sanctuaire.

15. Le poids en argent de la statue n'a pas été conservé. que devait se trouver cette statue, peut-être dans l'important sanctuaire qui y a été dégagé ${ }^{16}$.

À Narbonne, la lex de flamonio $\left(\mathrm{n}^{\circ} 23,36\right)$ stipule clairement que sur avis du flamine en fonction et sur décision des décurions, le flamine sortant pourra, s'il le souhaite, faire dresser sa statue «dans les limites du temple de l'empereur divinisé » (intra fines templi diui $A u g(u s t i))$, ce qui désigne l'enceinte du sanctuaire : la cour et les portiques autour du templum et peut-être aussi les basiliques et les thermes que l'on trouve mentionnés dans l'inscription (CIL XII, 4342) rappelant la réfection de ces bâtiments par Antonin le Pieux suite à un incendie, si du moins ce texte doit bien être mis en relation avec le sanctuaire du culte impérial de la province. Dans la lex, un paragraphe prévoit que le flamine qui sort de charge peut employer l'excédent de l'argent destiné aux dépenses sacrées (à ériger) « des statuae ou des imagines de l'Empereur César » et à les dédier « dans ce temple ». L'ensemble du sanctuaire devenait ainsi une vaste galerie où se dressaient les représentations des empereurs et des flamines successifs du culte provincial.

Il faut peut-être y ajouter une sixième attestation. Les deux statues d'argent offertes par le sévir augustal Cornelius Inachus à Iuppiter Optimus Maximus (?) (n²0) pouvaient orner, posées sur leur colonnettes en marbre rouge, un sanctuaire de Narbonne proche du lieu de découverte de l'inscription, peut-être le temple que l'on appelle communément le $«$ capitole ${ }^{17}$.

Quatre, peut-être cinq inscriptions de notre catalogue mentionnent des statues qui se dressaient dans des scholae.

Même si elles ont été trouvées en remploi dans des endroits différents de la ville, trois dédicaces honorifiques de Narbonne $\left(n^{\circ} 21,24,25\right)$, gravées sur les bases des statues qu'elles portaient pour au moins d'eux d'entre elles $\left(\mathrm{n}^{\circ} 21,24\right)^{18}$, se trouvaient à l'origine dans le même local. En effet, dans l'inscription $n^{\circ} 21$, le sévir augustal, L. Aemilius Moschus, verse 4000 sesterces dans la caisse des sévirs, après la mort de son patron L. Aemilius Arcanus, «pour l'emplacement et l'entretien de la statue », «l'emplacement ayant été concédé par un décret des sévirs » (l(ocus) d(atus) d(ecreto) IIIIIIuiror(um)). Cette même formule se retrouve dans l'inscription ${ }^{\circ} 24$, où «Licinia Pallas (...) a porté 10000 sesterces à la

16. Soyris, Escalon, Gassend 1994-95.

17. Selon la proposition de Fishwick 1992. La prudence s'impose néanmoins vu le caractère lacunaire de l'inscription.

18. On ignore la nature du support $n^{\circ} 25$. 
caisse des sévirs, pour la protection de la statue [de son mari]. Emplacement donné par décret des sévirs ». Dans l'inscription $\mathrm{n}^{\circ} 25$, c'est " par décret des sévirs augustaux (dec(reto) IIIIIIuir(orum) | Augustal(ium)) que Publius Olitius Apollonius, sévir augustal lui-même, est autorisé à ériger sa statue à ses frais.

Dans ces trois cas, les formules dec(reto) IIIIIIuir(orum) ou l(ocus) d(atus) d(ecreto) IIIIIIuiror(um) sont simplement «décalquées » sur les expressions officielles $d$ (ecreto) $d$ (ecurionum) ou l(ocus) $d$ (atus) d(ecreto) d(ecurionum). M. Christol a souligné combien ces «phénomènes d'imitation » étaient fréquents dans le monde des associations et des collèges, en particulier dans le «groupe d'élite» que représente le collège des sévirs augustaux. Pour se rapprocher de l'élite politique de leur cité, les sévirs empruntent les modes d'expression (inscriptions et formulaires) et aussi de représentation (statues honorifiques) en usage chez ceux qui dominent la vie politique et institutionnelle de Narbonne ${ }^{19}$. Le collège des sévirs "mime» donc les pratiques en usage chez les décurions mais le lieu d'exposition de ces bases surmontées de statues ne pouvait être public : le décret des sévirs avait valeur dans les limites de leur schola, le siège du collège des sévirs de Narbonne, dont on ignore toujours l'emplacement.

À Marseille, le collège des dendrophores $\left(n^{\circ} 19\right)$ élève une statue à un éminent personnage, certainement un Marseillais, qui exerça le pontificat, le flaminat et d'autres fonctions, à Riez ou à Marseille, et qui fut également le patron de ce collège. Pour remercier les dendrophores de leur geste, le personnage honoré « fit remise des dépenses occasionnées par cette statue et, à l'occasion de la dédicace, versa douze sesterces à titre de sportules à (chacun des membres de) la corporation ». Il est donc assuré que la base inscrite et sa statue se dressaient dans la schola de ce corpus.

À Vienne, c'est peut-être aussi une schola qui accueillait l'offrande spontanée de Namerius Euprepes, qui « donna et dédia une statue du Génie » (sig(num) Genii ... d(edit) d(edicauit)) qui reposait au sommet d'une colonne en marbre ( $\left.\mathrm{n}^{\circ} 10\right)$. Selon D. Fishwick, repris par l'auteur de la notice des ILN Vienne, la statue était destinée à orner soit un sanctuaire de la ville - le sanctuaire de Bellone puisque le collège des hastifères desservait son culte - soit, plus vraisemblablement, la schola des hastifères de Vienne, dont Namerius Euprepes était précisément le président du collège.

19. Christol 2004a.
L'inscription $\mathrm{n}^{\circ} 35$ de Nîmes est fragmentaire mais l'on comprend qu'un personnage demeuré anonyme demande à un collège (corpus) l'autorisation de dédier un buste honorifique (imago) en l'honneur d'un citoyen - également demeuré inconnu - qui s'est montré « dévoué et empressé à l'égard de sa patrie » (in patriam pium ac strenuum). La fin du texte semble indiquer que le donateur a eu recours à une seconde autorisation, celle de l'ordo splendidissimus de Nîmes, qui lui a accordé le droit de réaliser le portrait «à la ressemblance du très noble prince » (sub specie nobilissimi principis). Il est possible que ce portrait ait été destiné à orner le siège du collège mentionné.

La majorité des occurrences à notre disposition montre que les statues mentionnées, et les inscriptions qui les accompagnaient, se dressaient donc dans l'espace public. La raison en est simple : il s'agissait principalement de statues honorifiques ${ }^{20}$. Dans certains cas seulement, il nous est possible de savoir dans quel espace public ou dans quel édifice se dressait la statue : l'amphithéâtre d'Arles ( $\left.\mathrm{n}^{\circ} 2\right)$, le théâtre de Narbonne $\left(\mathrm{n}^{\circ} 5\right)$ ou encore la basilique de Nîmes ( $\left.{ }^{\circ} 27\right)$, qui abritait non seulement la «statue ornée d'argent avec sa base d'un prix de 50000 sesterces » qu'Inveldia Valerilla avait offerte en remerciement du titre de flaminique perpétuelle, mais peut-être aussi sa statue que "le très vénérable sénat (avait) décidé de lui élever» en remerciement. C'est également dans une basilique, peut-être celle d'Aix-enProvence (?), que se dressait aussi la statue offerte par un sévir qui finança une fondation en l'honneur du jour anniversaire de la naissance de Vespasien $\left(n^{\circ} 1\right)$.

Même si l'on ne peut identifier l'édifice, la formule $d$ (ecreto $) d($ ecurionum $)\left(\mathrm{n}^{\circ} 14,15,22,29\right)$ ou la mention de l'autorisation donnée par le sénat local $\left(\mathrm{n}^{\circ} 27\right.$, pour la statue d'Inveldia Valerilla, 33, 35) ou par la colonie (Arles, $\mathrm{n}^{\circ} 12$; Narbonne, $\mathrm{n}^{\circ} 26$ ) assure que la statue de ces évergètes se dressait dans un espace public. À Vienne, la présence de l'abréviation $D D$ dans l'inscription de la flaminique $\left(n^{\circ} 9\right)$ peut laisser planer le doute : soit il faut restituer les différents signa de dieux qu'elle offre sur l'un des espaces publics de la ville, soit il faut les replacer dans l'un des sanctuaires publics de la ville

20. C'est le cas des inscr. $n^{\circ} 8-9,12-15,18,22,26-27,29-33$ et 35 . À Biot, près d'Antibes, en dehors de toute magistrature ou sacerdoce, une famille de notables locaux procède à un acte d'évergétisme $\left(n^{\circ} 3\right)$ : Lucius Amaenius Fronto, Vilbia Marcella, son épouse, Marcus Amaenius Maturus et Marcus Amaenius Optatianus, ses fils, mettent en place une statue d'Arbugio - divinité locale attestée par ce seul texte - qui se dressait sur la base qui portait l'inscription. En l'absence de mention claire de type vslm, ex voto, etc., cette statue devait se dresser dans un lieu public. 
qui étaient sous l'autorité du sénat local. La mention du pagus à la fin de l'inscription de $\operatorname{Biot}\left(\mathrm{n}^{\circ} 3\right)$, dans laquelle une famille de notables locaux offre une statue du dieu local Arbugio, pourrait conduire à la même conclusion.

L'inscription de Talloires $\left(\mathrm{n}^{\circ} 8\right)$ mentionne le don d'un horologium et de toutes les statues qui l'ornaient : «l'esclave de quatre mille sesterces » laissé en sus par l'évergète " pour s'occuper de cette horloge » suggère que l'installation était destinée à servir à tous, vraisemblablement sur le domaine public.

\section{Des empereurs, des dieux et des hommes}

Si l'on s'en tient aux statues mentionnées dans nos inscriptions, la répartition entre les différents types statuaires est nette : les représentations d'individus (53\%) l'emportent sur les statues de divinités (28\%), loin devant les portraits impériaux $(2,7 \%)^{21}$.

Les inscriptions ne mentionnent en effet que très rarement des représentations d'empereurs, constat qui tranche fortement avec celui auquel arrive E. Smadja pour l'Afrique, qui signale que les inscriptions rapportant l'érection de statues impériales sont au contraire très nombreuses ${ }^{22}$. De fait, dans l'ensemble de notre corpus, seule la lex de flamonio cite expressément statu]as imaginesue Imperatoris Caes[aris, que le flamine sortant pouvait faire ériger à l'intérieur du sanctuaire avec l'excédent de l'argent destiné aux dépenses sacrées. Ce texte étant normatif, il édicte ce qu'il était possible de faire : nous ignorons donc tout du nombre de portraits impériaux qui furent réellement exposés dans le sanctuaire, d'autant plus que la fabrication de tels portraits n'étaient envisagée que les années où la trésorerie était excédentaire. Le budget alloué à ces sculptures étant pris sur les fonds destinés aux dépenses sacrées, il faut peutêtre en déduire que ces portraits et statues étaient l'objet du culte impérial et intervenaient, en particulier pour ce qui est des portraits, lors des processions en l'honneur du prince régnant.

Même si aucune indication n'est donnée sur la nature des statues, deux inscriptions nous semblent pouvoir renvoyer à des représentations de l'empereur. Les inscriptions d'Aix-en-Provence (?) $\left(\mathrm{n}^{\circ} 1\right)$ et de Nîmes $\left(\mathrm{n}^{\circ} 28\right)$, qui mentionnent le don d'une statue - l'une dans le cadre

21. Dans plusieurs cas (16,3\%), l'inscription ne livre aucune indication sur l'identification du type statuaire. Il faut tenir compte de cette lacune d'informations qui fausse les statistiques.

22. Smadja 1995, p. 285. d'une fondation en l'honneur du jour anniversaire de la naissance de Vespasien, l'autre à l'occasion de festivités en l'honneur du dies natalis de Marc Aurèle - pourraient en effet faire référence à des statues impériales, en particulier l'inscription aixoise puisque la statue était destinée à orner la basilica, édifice dans lequel il était fréquent de trouver des cycles statuaires comprenant l'empereur et des membres de la domus Augusta ${ }^{23}$.

Viennent ensuite les inscriptions - au nombre de dix - faisant référence à des statues (signum, simulacrum) de divinités. Dans sept inscriptions, le nom des dieux et déesses est même précisé : Neptune $\left(\mathrm{n}^{\circ} 2\right)$, Arbugio ( $\left.{ }^{\circ} 3\right)$, Isis (?), Sérapis, Vesta, Diane, Sommeil et Mars $\left(n^{\circ} 6\right)$, Sommeil $\left(n^{\circ} 7\right)$, Castor et Pollux à cheval, Hercule et Mercure $\left(\mathrm{n}^{\circ} 9\right)$, un Genius $\left(\mathrm{n}^{\circ} 10\right)$ et dea Vienna $\left(\mathrm{n}^{\circ} 33\right)$. Dans certains cas, même si le nom de la divinité n'est pas explicite, on peut aisément l'identifier grâce au décor de la base ou au contenu du texte : l'exvoto à Hercule Ilunnus Andose était à n'en pas douter une statue d'Hercule, dont la massue et la léontè ornent la base inscrite $\left(\mathrm{n}^{\circ} 4\right)$. À Narbonne, il est probable que les deux statues d'argent offertes par le sévir augustal Cornelius Inachus et qui surmontaient, chacune, une colonnette en marbre rouge, représentaient Jupiter si du moins ces colonnettes étaient bien offertes à Iuppiter Optimus Maximus $\left(\mathrm{n}^{\circ} 20\right)$.

Ces représentations de dieux n'étaient pas toutes destinées à des sanctuaires, loin s'en faut ${ }^{24}$. Seules cinq inscriptions peuvent être considérées avec certitude comme des ex-votos $\left(n^{\circ} 4\right.$ et 7$)$ ou des offrandes $\left(n^{\circ} 6,10\right.$ et 20) dans des sanctuaires. La statue du Genius ( ${ }^{\circ} 10$ ) de Vienne était abritée dans une chapelle privée aménagée à l'intérieur de la schola des hastifères : il est possible qu'il se soit agi de la statue de culte, mais ce n'est pas certain. Les représentations divines pouvaient tout aussi bien orner des édifices publics, comme c'est le cas de la statue en argent de Neptune qui décorait, en même temps que d'autres statues en bronze, l'amphithéâtre d'Arles $\left(\mathrm{n}^{\circ} 2\right)$.

Pour les quatre inscriptions restantes, il est difficile de savoir si la statue divine était destinée à un sanctuaire ou à un édifice public. À Biot, lorsque L(ucius) Amaenius Fronto, en compagnie de sa femme et de ses fils, offrent

23. Gros 1996, p. 235-260.

24. Il existe en effet plusieurs types de dédicaces de statues de dieux : une statue de dieu peut-être dédiée publiquement, sans être consacrée religieusement, et placée dans un lieu public, sous l'autorité d'un magistrat ; elle alors une valeur symbolique et non cultuelle. Elle peut-être dédiée dans un temple et donc offerte à la divinité : cf. Estienne 1997. 
une statue d'Arbugio ( $\left.{ }^{\circ} 3\right)$, le verbe employé (ponere) semble davantage renvoyer à un acte d'évergétisme dans un cadre urbain qu'à une offrande dans un sanctuaire, qui aurait certainement entraîné le recours à un terme plus spécifique comme dedicare ${ }^{25}$.

Il est plus délicat de trancher dans le cas de l'inscription de la flaminique viennoise $\left(\mathrm{n}^{\circ} 9\right)$. Ce texte rappelle un acte d'évergétisme ${ }^{26}$ (de sua dedit) : la donation de plusieurs statues divines (Hercule, Mercure), certaines équestres (Dioscures), et d'éléments architecturaux (tuiles en bronze doré, antéfixes et revêtements de bases (?)). La mise en place de l'ensemble a été soumise à autorisation du sénat local (decreto decurionum), ce qui suggère aussi bien un lieu public (forum, basilique, etc.) qu'un sanctuaire de la cité ${ }^{27}$. C'est peut-être aussi dans le cadre d'un grand sanctuaire public de la cité (Isis et Sérapis ?) qu'il faut également replacer les signa deorum argentea offerts par le notable nîmois de l'inscription $n^{\circ} 6$.

En ce qui concerne l'inscription de Vienne relative au don (statue en argent de dea Vienna) des frères Coelii en remerciement de l'octroi du décurionat $\left(n^{\circ} 33\right)$, il est beaucoup plus difficile de proposer un emplacement. Le terme de signum pourrait indiquer néanmoins qu'elle était destinée à un sanctuaire, et peut-être même qu'il s'agissait de la statue de culte (?).

Quant aux statues qui décoraient l'horologium mentionné dans l'inscription retrouvée à Talloires $\left(n^{\circ} 8\right)$, il pouvait s'agir de représentations divines (les Vents, les divinités du zodiaque, etc.) comme le suggère le terme signum. Mais nous manquons de parallèles.

Dans plus de la moitié des occurrences (53\%), nous avons affaire à des portraits d'individus, essentiellement

25. Nous rejoignons ici l'hypothèse déjà avancée par A. Chastagnol (1992, ILN Antibes, 121) : la mention du pagus, dont tout laisse à penser qu'il est également impliqué dans l'acte d'évergétisme, va aussi dans ce sens. Ce pagus désigne le statut de l'agglomération qui se situait sous l'actuelle commune de Biot.

26. F. Bertrandy commente, à tort nous semble-t-il, que la flaminique «a consacré quatre statues à des divinités populaires»: le terme dedicare n'est pas utilisé. Vu la très grande qualité de l'inscription et l'importance du don, ces divinités nous semblent moins «populaires » qu'officielles : il s'agissait manifestement de divinités majeures du panthéon de la cité.

27. Au Grienmatt d'Augst (Augusta Rauricorum, Germanie Sup.), deux inscriptions témoignent de l'intervention des autorités publiques au sein même du sanctuaire : l'emplacement où se dressent les inscriptions que Silv(ius ?) Spart(us ?) et Ti(berius) Cl(audius) Cl[au]di[anus?] offrent, le premier à deus Sucellus, le second à Aesculapius Augustus, leur est conféré par le sénat local (l(ocus) $d($ atus $) d($ ecreto $) d($ ecurionum $))(A E, 1925,5 ; A E, 1993,1221)$. des hommes, puisque dans cette liste on ne trouve mentionnées que deux femmes ( $\mathrm{n}^{\circ} 16$ et 27$)$. En dehors de deux cas, où il est question de statues funéraires, toutes les attestations concernent des statues honorifiques.

Deux inscriptions font référence à des statues élevées dans des enclos funéraires familiaux. Certainement parce qu'il n'a pas eu le temps de le faire de son vivant, C. Allius Celer charge ses héritiers, avec de l'argent laissé par testament, d'élever deux statues à son père et à son fils (?) ( $\left.n^{\circ} 11\right)$. L'absence de toute autorisation de la curie locale suggère qu'il s'agit bien d'un cadre privé, et non de statues honorifiques destinées à l'espace public. Le cas de Terentia Marcella, flaminique de l'impératrice à Narbonne, est différent : la statue funéraire, et aussi l'emplacement de la sépulture et les frais de l'enterrement, sont offerts par la cité de Nîmes. Même si la statue est destinée à orner l'enclos funéraire familial qui se trouvait à Nîmes, d'où cette notable était originaire, il s'agit d'honneurs exceptionnels puisque, pour toute la Gaule, nous ne connaissons que treize exemples de funérailles publiques, dont bénéficièrent quatre femmes et parmi celles-ci, deux flaminiques et une clarissime ${ }^{28}$.

Toutes les autres inscriptions évoquent des statues honorifiques et sont érigées pour remercier un évergète de ses bienfaits. Un premier ensemble de textes comprend les évergètes, souvent des notables de premier plan, dont les libéralités (liberalitates) ont profité à leur cité $\left(\mathrm{n}^{\circ} 12\right.$, $18,22,26,27,29,30,32$, soit $22 \%$ de l'ensemble du corpus) ${ }^{29}$. Ces évergésies, quand elles sont précisées, sont multiples : spectacles de gladiateurs $\left(\mathrm{n}^{\circ} 12\right)$, jeux du cirque ( $\left.\mathrm{n}^{\circ} 29\right)$, ludi et spectacula en général ( $\mathrm{n}^{\circ} 29$ et 30 ), fourniture d'huile pour le bain ( ${ }^{\circ} 29$ et 30), réparation d'édifices publics (la basilique d'Arles : $\mathrm{n}^{\circ} 12$ ), distribution de sportules aux décurions $\left(\mathrm{n}^{\circ} 12\right)$, et bien sûr dons de statues pour orner la cité ( ${ }^{\circ} 18$ et 27$)$.

À l'échelle de la cité, d'autres personnages, à la carrière municipale ou militaire exceptionnelle, reçoivent une statue en raison de leurs mérites (merita) ${ }^{30}$ : c'est le cas de M. Te[...], originaire d'Arles, honoré d'une statue équestre par la colonie d'Arles ( $\left.{ }^{\circ} 14\right)$ ou de M. Precilius Pompeianus $\left(\mathrm{n}^{\circ} 15\right)$, également arlésien d'origine, qui fut patronus de la colonie et se voit honoré d'une statue par les vétérans de la $\mathrm{VI}^{\mathrm{e}}$ légion.

\footnotetext{
28. Lamoine 2009, p. 85.

29. Il faut peut-être y ajouter l'inscr. $\mathrm{n}^{\circ} 31$ (?).

30. C'est certainement dans cette catégorie qu'il faut classer l'inscr. très fragmentaire de Toulouse $\left(\mathrm{n}^{\circ} 31\right)$.
} 
Quand l'information a été conservée, c'est le plus souvent la cité qui apparaît à l'origine de l'honneur accordé (la colonia Iulia Paterna Arelate, $\mathrm{n}^{\circ} 12$; les décurions de la colonie d'Arles, $\mathrm{n}^{\circ} 14$; la colonia Iulia Paterna Claudia Narbone Martio, n²6 ; le «très vénérable sénat de Nîmes », n²7), mais aussi des groupes constitués comme les vétérans de la $\mathrm{VI}^{\mathrm{e}}$ légion à Arles $\left(\mathrm{n}^{\circ} 15\right)$ ou le collège des fabri subaediani de Narbonne ${ }^{31}$ $\left(n^{\circ} 22\right)$. Selon une pratique bien attestée, il n'est pas rare que le personnage honoré fasse remise de la dépense et finance lui-même sa statue $\left(\mathrm{n}^{\circ} 15,19,23,25,27\right)$.

Dans un second ensemble, on trouve, en miroir du premier groupe, les personnages qui se voient octroyer par leur collège une statue à l'intérieur de la schola en raison de leurs bienfaits et/ou de leurs mérites $\left(n^{\circ} 19\right.$ et 25). Nous avons déjà signalé combien il était fréquent que les affranchis miment les pratiques des citoyens magistrats.

Dans tous les cas, il s'agit de personnages de premier plan de leur cité : les citoyens et les citoyennes, en raison de leur place dans la vie politique et religieuse, les affranchis, par leur poids dans la vie économique.

\section{Matériau, poids, prix}

Comme nous l'avons signalé, les mentions de statues sont fort rares eu égard au nombre de statues offertes à la vue des passants des cités de Narbonnaise. Les inscriptions ne les signalent que lorsqu'elles présentent un caractère exceptionnel: statues en bronze, statues en bronze rehaussé d'argent, voire statues en argent. Le matériau employé en faisait des objets particulièrement précieux et onéreux, ce qui explique que l'on trouve à plusieurs reprises mention du poids d'argent ou de bronze utilisé pour les réaliser et du prix que la confection de l'objet a coûté à l'évergète. On apprend ainsi que la statue offerte à Hercules Ilunnus Andose de Narbonne pesait douze livres ( $=3,9$ kilos) d'argent et que Decimus Decmanius Caper, à Grenoble, « sous-préfet des cavaliers de l'aile Agrippiana a laissé par testament cinquante mille sesterces pour des statues » $\left(\mathrm{n}^{\circ} 18\right)$. Les sommes spécifiées sont très conséquentes. La somme la plus élevée est atteinte à Vienne ( $\left.{ }^{\circ} 33\right)$, où deux frères jumeaux, Sextus Coelius Canus et Sextus Coelius Niger, honorés du décurionat par le sénat de la cité, élèvent une statue en argent de dea Vienna, d'une valeur de deux cent mille sesterces, qui est la somme la plus importante jamais

31. Bouet 2001. consacrée à la réalisation d'une statue pour l'ensemble du monde romain ${ }^{32}$.

Le nombre de mentions de statues dans les inscriptions de Gaule Narbonnaise est sans commune mesure avec la réalité des centres urbains et des sanctuaires, où les statues devaient se compter par centaines. Le tableau dressé dans cet article n'avait pour but que de rappeler cette distorsion et de tenter de l'expliquer. Si effectivement, les personnages, hommes ou femmes, qui se voient honorés d'une statue se signalent par leur carrière (politique, religieuse, militaire) exceptionnelle, ce n'est là qu'une partie de l'explication. C'est en effet bien davantage la nature (bronze, argent), le poids et/ou le prix exceptionnels de ces statuae, signa, imagines ou simulacra qui ont jadis justifié la rédaction d'un texte qui, s'il apparaît redondant par rapport à la statue qu'il accompagnait, vient surtout signaler avec ostentation le prix hors norme qu'elle a coûté.

\section{Annexe. Catalogue des inscriptions}

\section{A. Les attestations du terme signum}

\section{AIX-EN-PROVENCE (?)}

Dédicace honorifique pour un sévir qui a financé une fondation en l'honneur du jour anniversaire de la naissance de Vespasien et a orné la basilique d'une statue.

Fragment d'une plaque de marbre, date et lieu de découverte inconnus. CIL XII, $530=I L N$ Aix, 23, où J. Gascou signale que cette inscription, issue d'une collection privée, provient certainement de Narbonnaise, mais peut-être pas nécessairement d'Aix-en-Provence.

\section{--- seui]r Aug(ustalis) corp(oratus) [---] |} [---]um (sestertium) XXX (milia) n(ummum) dedit [--| ex quorum] usuris XV k(alendas) de[c]emb[res --- quotannis] sportulae uescenti[bus ---] | [--- diui] derentur ; qui signo [--- |--- bas]ilicam exorn[auit ---

« ... appartenant au collège des sévirs augustaux... a donné trente mille sesterces... pour que chaque année, le quinzième jour avant les calendes de décembre, avec les intérêts de cette somme des sportules fussent distribuées

32. Sur le prix des donations, et plus particulièrement des statues, l'article de De Kisch 1979 reste fondamental. Il apparaît que sur les cinquante inscriptions qu'il a étudiées (Narbonnaise, Trois Gaules et Germanie), les dépenses mentionnées font état de montants élevés, égaux aux chiffres italiens les plus forts. Il est à noter que dans ces donations, la moitié des textes évoquent le don ou la dédicace de statues. 
pour le banquet des... ; il a en outre orné d'une statue... la basilique... » (trad. J. Gascou).

Datation : après 69 ap. J.-C., ou peut-être plus précisément 69-79 ap. J.-C.

\section{ARLES}

Don de statues dans l'amphithéâtre de la part de Caius Iunius Priscus, candidat au duumuirat quinquennal.

Inscription en double copie sur le podium de l'amphithéâtre. CIL XII, 697 (p. 818) =ILGN, $109=A E$, 1965, 270 = C. Vismara, M.-L. Caldelli, Epigrafia anfiteatrale dell'Occidente romano. V, 2001, p. 34-35, n $7=C A G 13 / 5,29 * 26$, p. 284 . Voir aussi J. Formigé, « L'amphithéâtre d'Arles », Revue Archéologique, 1965, I, (p. 31-46), p. 39-45.

C(aius) Iunius Priscus IIu[ir] quinquen[nalis] cand(idatus) Arelate[nsium] item flam[en Augusta]lis, [postq(uam)] podi[u]m cum [ia]nuis | et signum Nept[uni a]rgenteu[m rei pu]blicae pollicit[us erat], (sestertium) CC (milia) d[e suo adie]c[tis IV ae]nea s[igna] fac[i]en[da cu]rauit, | [du]orum dierum [operas sca]en[i]cas, [uenati]onem edid[it, decur(ionibus)] epulum in XIIII [tricli]n(iis), XXXIIII [biclin(iis) f]orens[ibus it(em) corpo]r(ibus) it(em) IIIIII[uir(is) Aug(ustalibus)] epulum secun[dum discipli]nam mores[que] dedit.

«Caius Iunius Priscus, candidat au duumuirat quinquennal à Arles, et aussi flamine augustal, après avoir promis d'offrir à la res publica (des Arlésiens) le podium (de l'amphithéâtre) avec ses portes et une statue en argent de Neptune, a pris soin d'y ajouter de lui-même quatre statues en bronze et 200000 sesterces, il a donné deux jours de spectacles scéniques et une uenatio, il a offert aux décurions un banquet pour 14 lits de table à trois places et 34 lits de tables à deux places, et aux corporations du forum et aux sévirs augustaux un autre banquet selon les principes et la tradition » (d'après C. Vismara et M.L. Caldelli).

Datation : $\mathrm{I}^{\text {er }}$ siècle-début du $\mathrm{II}^{\mathrm{e}} \mathrm{s}$.

\section{BIOT (territoire d'Antibes)}

Don d'une statue du dieu Arbugio par une famille de notables locaux.

Partie supérieure de la base en calcaire d'une statue. ILN Antibes, $121=C A G$ 06, p. 237.

L(ucius) Amaenius | Fronto | et Vilbia Marcella $\mid$ uxor et M(arcus) Amaeniu[s]| Maturus, M(arcus) Amaeniu[s]
| Optatianus filii, | signum Arbugi|onis posuer(unt). Hoc amplius pagu[s]|[---

«Lucius Amaenius Fronto, Vilbia Marcella, son épouse, Marcus Amaenius Maturus (et) Marcus Amaenius Optatianus, ses fils, ont mis en place cette statue d'Arbugio. En plus de cela, le pagus... » (trad. A. Chastagnol).

En dehors de toute magistrature ou sacerdoce, une famille de notables locaux procède à un acte d'évergétisme. Pour A. Chastagnol (ILN Antibes, 121), cette statue devait se dresser dans un lieu public. Arbugio, divinité locale, trouve ici son unique attestation.

Datation : sur critères paléographiques, deuxième moitié du II ${ }^{\mathrm{e}}$ s., première moitié du III ${ }^{\mathrm{e}} \mathrm{s}$. (A. Chastagnol).

\section{NARBONNE}

Statue d'argent en ex-voto à Hercule Ilunnus Andose de la part d'un affranchi.

Base $^{33}$ en marbre blanc (h : $1 \mathrm{~m}$; larg. : 0,42 m) provenant des remparts de Narbonne, de la zone de la porte Royale (= de Béziers), puis transportée à Toulouse au XVII ${ }^{e}$ s. Ancienne collection de l'Académie des Sciences, Inscriptions et Belles-Lettres de Toulouse. Aujourd'hui conservé au musée Saint-Raymond de Toulouse. À son sommet, cette base présente une cavité rectangulaire destinée, sans nul doute, à l'encastrement de la statue mentionnée dans l'inscription. La base présente deux inscriptions, sur deux faces opposées du bloc. Les deux faces restantes présentent des reliefs : les attributs d'Hercule, la massue et la léontè, sur une face et, sur l'autre, un vase d'où s'échappent des feuilles de lierre.

CIL XII, 4316 (p. 844) $=H G L, X V, \mathrm{n}^{\circ} 151=I L S, 4536=$ $C A G 11 / 1$, p. $212,3^{*}, 1$ et p. $447,261^{*}, 5=$ Rodriguez, Sablayrolles 2008, p. 224-227, $\mathrm{n}^{\circ} 175$.

A. Cn(aeus) Pompeius | Cn(aei) l(ibertus) Hyla | Herculi | Ilunno Andose | u(otum) s(oluit) l(ibens) m(erito).

«Cnaeus Pompeius Hyla, affranchi de Cnaeus, à Hercule Ilunnus Andose, s'est acquitté de son vœu bien volontiers et à juste titre ».

B. Deus $\mid$ Hercul<e=I>s | Inuictus. | Signum argenteum $\mid \boldsymbol{p}$ (endens) $\boldsymbol{p}$ (ondo) (duodecim) de sua $\mid$ pecunia fe|cit.

33. $C A G 11 / 1$, p. $212,3^{*}$ parle à tort d'un autel. 
«Le dieu Hercule invaincu. Statue d'argent (ou ornée d'argent) d'un poids de douze livres ${ }^{34}$, (Cnaeius Pompeius Hyla) l'a fait (ériger) à ses frais ».

Ilunnus ou Ilunus est une divinité indigène attestée chez les Convènes ${ }^{35}$ qui se trouve ici assimilée à l'Hercule romain. Certains linguistes ont proposé de rapprocher Andose d'une racine signifiant « grand » : « and-, ande-, ando- » serait une particule intensive à traduire par « très » ${ }^{36}$. Selon d'autres linguistes ${ }^{37}$, Andose serait une épithète indigène, manifestement originaire de l'Aquitaine proche, où elle est attestée par deux inscriptions, l'une à Deus Basceis* et l'autre à Hercules Toles* 38 : l'équivalent latin de cette épithète serait dominus et il conviendrait donc de la traduire par « souverain».

Datation: début de l'Empire (nom du dédicant avant le nom de la divinité ; affranchi des Pompeii; paléographie).

\section{NARBONNE}

Don d'une statue d'argent et d'objets en bronze pour orner le théâtre.

Fragment de table de marbre (haut. : 0,50 m; larg. : $0,55 \mathrm{~m})$. CIL XII, $4445=H G L, \mathrm{XV}, 73=C A G 11 / 1$, $238 * 1$.

--- et a]mplius [---]|[--- signu]m argent[eum ---] | [---] aeneos [--- | --- ad t]heatri or[na]|[tione]m HS IIII(milia ?) dedit.

«... et en outre une statue d'argent ... et des ? en bronze... et a donné 4000 sesterces pour la décoration du théâtre ».

Par comparaison avec l'inscription d'Arles mentionnée ci-dessus, il est possible que les objets en bronze offerts soient également des statues. Il s'agit de la seule attestation prouvant l'existence d'un théâtre à Narbonne. Sa localisation demeure inconnue.

Datation : $\mathrm{I}^{\mathrm{er}}-\mathrm{II}^{\mathrm{e}} \mathrm{s}$.

34. La libra faisant environ $327 \mathrm{~g}, 12$ livres romaines avoisinent les 3,9 kilos.

35. CIL XIII, 27 (provenance incertaine mais sur le territoire des Convènes), 31 (St-Béat), 371 et 374 (Cadéac) et 11013a (Luchon).

36. Delamarre 2001, p. 39.

37. Hualde et al. 1996, p. 42, repris par Gorrochategui 2011, p. 85 .

38. Deo Bascei Andosso (CIL XIII, 26, à Melles, près de Saint Béat) et Herculi Toli Andosso (CIL XIII, 434, à Saint-Elix-sur-Base).

\section{NÎMES}

Hommage public rappelant les libéralités d'un notable nîmois, parmi lesquelles le don de statues en argent de plusieurs divinités.

Perdue. CIL XII, $3058=$ HGL, XV, $94(=447)=$ SIRIS, 728 = RICIS, II, 605/101 ; cf. CAG 30/1, p. 224, 107, $\mathrm{n}^{\circ} 7$.

[Signa ${ }^{39---}$ Isis (?)] ex [HS ---],| Serapis, Vestae, Dianae, Somni, [ex] | (sestertium) n(ummum) (sex milibus) et phialas II chrysen[g]l[yptas(?)] | [et si]gna deorum argentea castrensia [--- quae in] $\mid$ domo habebat, item [---] || dedicatione templi Isis et Serapis dec[uri]|onibus Nemausensium | et ornamentar[iis] | singulis $\mid$ (denarios) V, ita ut $\mid$ in publico uescerentur, $\mid$ distribui iussit inque eius domus [tu]|telam (sestertium) n(ummum) (decem milia) reliquit, | item [--- im]||aginem Martis argenteam ex [arg(enti) p(ondo $)^{40}$---] | [S]amnagensibus dedit. | [Hui]c ordo Bitur[igum ---].

« ... a offert des statues [d'Isis (?)] pour une somme de [...] sesterces, de Sérapis, de Vesta, de Diane, du Sommeil pour une somme de six mille sesterces, deux phiales enrichies de ciselures en or, et des statues des dieux en argent (telles qu'on en a) dans les camps [...], qu'il possédait dans sa demeure; de même, [...]. Lors de la dédicace du temple d'Isis et de Sérapis, il a donné ordre de distribuer à chacun des décurions et des décurions honoraires de Nîmes cinq deniers pour qu'ils se restaurent lors de cette manifestation officielle et il a laissé pour l'entretien de cette demeure la somme de 10000 sesterces; de même, [...], il a offert une statue de Mars en argent, d'un poids d'argent de [(?) livres], aux Samnagenses. À lui, l'ordo des Bituriges... » (trad. RICIS, II, 605/101).

Datation : Haut-Empire.

\section{RIEZ}

Offrande au dieu Esculape de plusieurs objets en exvotos, dont une statue en bronze du Sommeil.

Petite base en calcaire dur (haut. : $38 \mathrm{~cm}$; larg. : $33 \mathrm{~cm}$; ép. : $32 \mathrm{~cm}$ ). CIL XII, 354 (p. 810) =ILS, $3855=I L N$ Riez, $1=C A G$ 04, p. 366 .

Deo Aesculapio | Val(erii) Symphorus et Protis | signum Somni aereum | torquem aureum ex dracun|culis duobus p(ondo) (?)|, enchiridium | argenti p(ondo) (?)|,

39. Proposition de SIRIS.

40. Proposition de SIRIS. 
anabolium ob in|signem circa se numinis eius $\mid$ effectum $u$ (otum) s(oluerunt) l(ibentes) $m$ (erito).

«Au dieu Esculape, Valerius Symphorus et (Valerius/-a) Protis se sont acquittés de leur vœu de bon gré et à juste titre (en lui offrant) une statue en bronze du Sommeil, un collier d'or formé de deux serpents d'un poids de (?), un enchiridium d'argent d'un poids de (?), et un anabolium en récompense de l'insigne efficacité de sa puissance divine envers eux » (trad. A. Chastagnol).

Il peut s'agir de deux frères ou d'un frère et d'une sœur car Protis est un cognomen autant féminin que masculin ; leurs cognomina hellénisants laisseraient penser qu'ils sont affranchis. Le motif de leurs ex-votos est clair : ils ont été guéris par le dieu Esculape. Si la petite base inscrite portait le signum Somni - ce que nous n'avons pu encore vérifier - il ne pouvait s'agir que d'une statuette vu les faibles dimensions du bloc. L'offrande d'une statuette de Somnus pourrait être une indication de la pratique de l'incubation dans ce sanctuaire.

Datation : $\mathrm{I}^{\mathrm{er}}-\mathrm{II}^{\mathrm{e}} \mathrm{s}$.

\section{TALLOIRES (territoire de Vienne)}

Donation d'une horloge avec toutes ses statues et ses grilles, ainsi que d'un esclave par un particulier.

Plaque de calcaire blanc retaillé de tous côtés. CIL XII, 2522 = ILS, 5624 = ILHSavoie, $105=$ ILN Vienne, 739.

Horologium cum suo aedificio et | signis omnibus et clatris | C(aius) Blaesius C(ai) fil(ius), Voltinia, Gratus ex HS n(ummum) X(milibus) | et eo amplius ad id horologium adminis|trandum seru(u)m HS n(ummum) IIII(millium) d(e) s(ua) p(ecunia) d(edit).

"Cette horloge avec son bâti et toutes ses statues et ses grilles, Caius Blaesius Gratus, fils de Caius, (de la tribu) Voltinia, l'a offerte à ses frais pour un montant de dix mille sesterces et, en plus, pour s'occuper de cette horloge un esclave de quatre mille sesterces » (trad. B. Rémy).

En dépit des détails de l'inscription qui précisent que l'horloge, hydraulique (?) selon la proposition de B. Rémy, était accompagnée de grilles et de décorations statuaires (calcaire? marbre ? métal ?), le don reste modeste par sa somme. En revanche, le prix de l'esclave, deux fois supérieur à la valeur légale, attesterait que l'entretien de la machine devait être complexe et nécessaire au bon fonctionnement du mécanisme (cf. ILN Vienne, 739).

Datation : Haut-Empire.

\section{VIENNE}

Commémoration de la donation de plusieurs statues, et d'autres réalisations, par une flaminique dont le nom est perdu.

Plaque de calcaire, sans doute retaillée de tous les côtés. CIL XII, $1904=I L S, 3400=I L N$ Vienne, 88.

---] | d(ecreto) d(ecurionum) flaminica Viennae, | tegulas aeneas auratas $\mid$ cum carpusculis et $\mid$ vestituris ${ }^{41}$ basium et signa | Castoris et Pollucis cum equis | et signa Herculis et Mercuri $\mid d(e) s($ ua $) d($ edit).

« ...par décret des décurions, flaminique de Vienne, a offert à ses frais, les tuiles en bronze doré, avec les antéfixes et les ornements sculptés des bases, les statues de Castor et Pollux, avec leurs chevaux, et celles d'Hercule et de Mercure » (trad. F. Bertrandy).

Si Mercure est largement attesté par l'épigraphie de la cité, il n'en est pas de même d'Hercule, qui n'apparaît que dans l'iconographie. Les statues des Dioscures étaient des statues équestres.

Datation : fin du ${ }^{\text {er }} \mathrm{s}$. ou début du $\mathrm{II}^{\mathrm{e}} \mathrm{s}$., car cela correspondrait à la période de plus grande expansion du culte impérial (selon F. Bertrandy, dans les ILN Vienne). Cette précision nous parait excessive.

\section{VIENNE}

Dédicace d'une statue au Génie des hastifères par Namerius Euprepes, président du collège.

Colonne ronde de marbre, auj. perdue. CIL XII, $1814=$ ILN Vienne, 6.

Sig(num) Genii $\mid$ Namerius | Euprepes $\mid$ magist(er) | (h)astiferor(um) $\mid d($ edit $), d$ (edicauit) ${ }^{42}$.

« Namerius Euprepes, président du collège des hastifères, a donné et dédié une statue du Génie ».

Datation : deuxième moitié du $\mathrm{II}^{\mathrm{e}} \mathrm{s}$., première moitié du $\mathrm{III}^{\mathrm{e}} \mathrm{s}$. (duo nomina seconde manière).

\section{B. Les attestations du terme statua}

\section{APT}

Inscription mentionnant l'érection de deux statues.

41. Carpusculum est un mot très rare, qui ne connaît qu'un seul parallèle épigraphique (CIL III, 9768) à Aequum, en Dalmatie. Vestitura est un hapax, que N. Blanc (1989, p. 79-80) interprète comme le revêtement des bases des statues.

42. DD peut également être restitué en $d($ ono $) d($ edicauit $)$ ou $d(e)$ $d$ (icauit). 
Plaque de calcaire. CIL XII, 1115 (p. 823) =ILN Apt, 35.

L(ucio) Allio Seuero, C(aius) Al|lius Celer, patruo,| testam(ento) poni iussit,| item statuas duas | patri e[t f]ili[o ?], quar(um) | statuar(um) dedic(atione) hered(es),| ex form(a) testament(i) | decur(ionibus) sing(ulis) (denarios) LXX|deder(unt).

«À Lucius Allius Severus, son oncle paternel, Caius Allius Celer a ordonné par testament d'élever (ce monument), ainsi que deux statues à son père et à son fils (?). Lors de la dédicace de ces statues, les héritiers, conformément aux termes du testament, ont offert à chaque décurion soixante-dix deniers »(trad. J. Gascou et alii).

Même s'il ne mentionne pas ici ses charges, le personnage est certainement à identifier au C. Allius Celer quattuorvir, flamine, augure de la colonie d'Apt et patron du pagus des Vordenses connu par une inscription honorifique (ILN Apt, 22). Cet éminent personnage de la colonie offre après sa mort, par testament, à son oncle le monument qui portait cette inscription (et aussi une statue ?) ainsi que deux statues, à son propre père et à son fils.

Datation : époque julio-claudienne.

\section{ARLES}

Décret honorifique de la colonie d'Arles accordant à un personnage (anonyme), en raison de ses libéralités, l'érection d'une statue en bronze avec sa base.

Partie droite d'une base de statue en marbre. Y. Burnand, J. Gascou, «Une inscription désespérée d'Arles ? », $C R A I, 146,3,2002$, p. 899-915 = AE, 2002, 921; $C A G 13 / 5,283^{*}$, p. 642 ne tient pas compte de l'article Burnand-Gascou.

--- ] | [col(onia) Iul(ia) Pat(erna) Arel]ate ob | [munificentia]m eius | [hanc aeneam st]atuam |[cum base quam o]ptauer(at) | [decreuit quod m]unera | [gladiatorum r]emiser(a)t | [atque ad repa]randam | [nostram basilic]am HS n(ummum) sex (milia) | [ex quorum in]cremento $\mid$ [haec restau]raretur $\mid$ [dederat et eo]dem die | [ab eo dec(urionibus) discu]mbentib(us) | [diuisae sunt spo]rtulae.

« [À... ?], la colonie Iulia Paterna d'Arles, en raison de sa générosité, a accordé par décret cette statue de bronze, avec une base, qu'il avait souhaitée [ou : là où il l'avait souhaité], parce qu'il avait assumé les frais de spectacles de gladiateurs, qu'il avait de plus donné pour la réparation de notre basilique 6000 sesterces pour qu'avec les intérêts de ceux-ci elle fût remise en état, et que le même jour des sportules ont été distribuées par lui aux décurions lors d'un banquet ».

Le personnage que les Arlésiens ont honoré d'une statue était certainement un notable de la colonie.

Datation : $\mathrm{I}^{\mathrm{er}}-\mathrm{II}^{\mathrm{e}} \mathrm{s}$.

\section{ARLES}

Épitaphe d'Aulus Annius Camars, qui a financé sa statue et celle de Titus Annius (... ?).

Fragment de plaque en marbre (haut. : 0,74 m). CIL XII, 670 (p. 817) = M. Heijmans, dans Cl. Sintès (dir.), Musée de l'Arles antique, Arles, 1996, p. 55, n³2 = CAG 13/5, 81*, p. 390-391 ; cf. H.-G. Pflaum 1978, p. $312-313, n^{\circ} 9$.

[? An]nius | [. f(ilius) Te]r(etina tribu)] Camars | [Xuir stlit(ibus)] iud(icandis), trib(unus) mil(itum) | [leg(ionis), --- seui]r eq(uitum) Rom(anorum) turm(ae) | [---, quaest(or), trib(unus) p]leb(is), praet(or), proco $(n) s(u l) \mid[\operatorname{prou}($ inciae)---leg(atus)pr(o)]pr(aetore) prou(inciae) Africae | [ad statuas ponenda]s sibi et T(ito) Annio | [f(ilio) e]x arg(enti) libris [---] ded(it) | [--- ob ] quar(um) manupret(ium) | [---]uit item HS CC(milibus) | [ex quor(um) usur] is omnibus annis | [--ludi] athletar(um) aut circen|[ses ederen]tur | [idem ad me]moriae aeternitat (em) $\mid$ [monumentum] extruxit.

«Aulus Annius Camars, fils de (?), de la tribu Teretina, decemvir pour le jugement des procès, tribun militaire de la (?) légion, sévir de l'escadron (?) des chevaliers romains, questeur, tribun de la plèbe, préteur, proconsul de la province de (?), légat propréteur de la province d'Afrique, a donné (?) pour que des statues lui soient élevées à lui et à Titus Annius (Camars), son fils, (?) livres d'argent a ajoutées pour la main d'œuvre et a légué 200000 sesterces pour que, sur les intérêts, soient donnés tous les ans des concours athlétiques ou des jeux du cirque. Il a également fait élever un monument pour perpétuer son souvenir » (M. Heijmans).

Datation : seconde moitié du ${ }^{\text {er }}$ s. ap. J.-C. (si ce personnage doit bien être identifié à Aulus Annius Camars de l'inscription de Rome $I L S, 3017$, datée de 83 ap. J.-C.).

\section{ARLES}

Décret honorifique accordant à $\mathrm{M}$. Te[---] une statue équestre.

Base de statue (?) en marbre (haut. : 0,82 m ; larg. : 0,48 m ; ép. : 0,29 m). CIL XII, $671=C A G 13 / 5,147^{*}$, p. 455. 
M(arcus) Te[---] | Te[r(etina) ---] prae(fectus) [f]a[brum] | promag(istro) ferr(ariarum) | provinciar(um) | Narbonens(is) Lu[gdun(ensis)] | Aquitanic(ae) Belgi[c(ae)]| adiutor Cassi Maria[ni] | proc(uratoris) Aug(usti) provinci(ae) Narb(onensis) item | Aureli Flacci provinc(iae) Belg(icae) | item Castr[i]ci Saturnin[i] | provinc(iae) Africae item | Metti Rufi praef(ecti) anno[n(ae)] | trib(unus) | militum l(egionis) $X X I \mid$ sacerdos Caeninensiu[m] idem ex d(ecreto) $d$ (ecurionum) honore $p[$ onti]fical $[i] \mid$ et statua equestri exornatus | proc(urator) Aug(usti) epistrat[e]gia[e] | $[P]$ elusi $\mid$ allectus ad census $\mid$ accipiendos in pro(vincia) | Aquitanica.

«Marcus Te[---], fils de Marcus, de la tribu Teretina, préfet des ouvriers, promagister des mines de fer des provinces de Narbonnaise, Lyonnaise, Aquitaine et Belgique ; auxiliaire de Cassius Marianus, procurateur d'Auguste de la province de Narbonnaise ; également d'Aurelius Flaccus, de la province de Belgique, également de Castricius Saturninus, de la province d'Afrique, également de Mettius Rufus, préfet de l'annone; tribun militaire de la $21^{\mathrm{e}}$ légion Rapax, prêtre des Caeninenses $^{43}$; honoré par un décret des décurions de l'honneur de pontifex et d'une statue équestre; procurateur d'Auguste de la surintendance de Péluse ; admis pour recueillir le cens de la province d'Aquitaine ».

Datation : 93 ap. J.-C.

\section{ARLES}

Décret honorifique : les Arlésiens vétérans de la sixième légion honorent d'une statue leur patron Marcus Precilius Pompeianus en raison de ses mérites.

Base de statue en «pierre marbrière ». CIL XII, 701 = $C A G 13 / 5,102 *$, p. 400.

[D(ecreto)] d(ecurionum). | [M(arco)? P]recilio $M($ arci $) \quad f($ ilio $) \quad \mid$ [Tere]t(ina) Pompeiano, | [qui]nqu(ennali)decuri(on)i ${ }^{44}$, | [aed(ili) ?] munerar(io), fl(amini), pontif(ici), | [Sexta]ni, Arelatenses |[muni]cipes optime de |[se me]rito patrono, | [hic s]tatuae honori (!) |[conte]ntus impendium $\mid[r(e i)]$ p(ublicae) remisit.

«Par décret des décurions. À Marcus Precilius Pompeianus, de la tribu Teretina, fils de Marcus, décurion quinquennal, édile (?) munéraire, flamine, pontife, ses concitoyens, les Arlésiens, vétérans de la sixième légion, à leur patron excellent et rempli de mérite ; celui-ci

43. Ce sacerdoce était une prêtrise secondaire de Rome accordée aux membres de l'ordre équestre et qui perpétuait les cultes de Caenina, ancien site du Latium : G. Wissowa, RE, III, 1899, col. 1279. 44. Vismara, Caldelli, 2001, n ${ }^{\circ} 5$ proposent ex qui]nq(ue) decuriis. satisfait de l'honneur de la statue, a fait remise à la cité de la dépense (engagée) ».

Datation : II $\mathrm{e}$.

\section{CAISSARGUES (territoire de Nîmes)}

Épitaphe de Terentia Marcella, flaminique de l'impératrice à Narbonne, rappelant l'érection de sa statue funéraire aux frais de la collectivité.

$I L G N, 429=C A G 30 / 2$, p. 281.

$D($ is $) M($ anibus $) \mid$ Terentiae $M($ arci)f(iliae) $\mid$ Marcellae | [f]lamin(icae) Aug(ustae) | col(onia) Narb(one) | [cui] N[e]m(auso) pub(lice) l(ocus) s(epulturae) f(uneris) impensa $\mid$ [m(onumentum)] statua decr(eta) sunt.

«Aux dieux Mânes, à Terentia Marcella ${ }^{45}$, fille de Marcus, flaminique de l'impératrice dans la colonie de Narbonne, à qui, à Nîmes, au nom de la collectivité, ont été accordés par décret l'emplacement de la sépulture, les frais de l'enterrement et une statue » (M. Christol).

Les flaminiques pouvaient être prêtresses dans plusieurs cités, ce qui explique pourquoi Terentia Marcella a pu exercer son sacerdoce à Narbonne tout en étant originaire de la cité de Nîmes qui, à sa mort, finance les frais de l'enterrement et une statue. L'emplacement de la sépulture est accordé par décret des décurions.

Datation : II ${ }^{\mathrm{e}} \mathrm{s}$.

\section{CASTELNAU-LE-LEZ/SEXTANTIO (Nîmes)}

Remerciement d'un citoyen romain aux coloni et incolae pour une commande relative à des statues (cultuelles ? publiques ?).

Plaque de calcaire. CIL XII, $4189=H G L, \mathrm{XV}, 1861=$ $C A G$ 34/3, p. 147.

Cn(aeus) Plaetorius Macrinus $\mid$ colonis et incolis $\mid$ ex ea pequnia quae ei in | statuas conlata est.

"Cnaeus Plaetorius Macrinus pour les colons et les habitants du lieu, avec l'argent qui a été collecté pour lui (auprès d'eux), en vue de la réalisation des statues » (trad. Christol).

45. Cette flaminique se trouve également mentionnée dans une inscription de Nîmes, dans l'épitaphe qu'elle réalise pour sa mère, porteuse d'un gentilice à consonance gauloise : CIL XII, $3477: D(i s)$ M(anibus) | Boudiae Primulae | Terentia M(arci) fil(ia) | Marcella | matri optimae. Cf. Spickermann 1994, p. 200, n 16. 
Il faut certainement comprendre que dans le troisième quart du Ir s. av. J.-C., des coloni et des incolae se cotisèrent pour réunir la somme nécessaire à la réalisation de statues : il nous est impossible de savoir si ces statues étaient cultuelles ou honorifiques. Cnaeus Plaetorius Macrinus, citoyen romain au gentilice italien, collecta la somme ainsi rassemblée et fit personnellement ériger les statues. Il n'est qualifié ni de magistrat ni de patronus, mais il était tout au moins un notable à qui les donateurs, à la fois des colons italiens et des incolae indigènes, faisaient confiance ${ }^{46}$.

Datation : $3^{\text {e }}$ quart du Ir ${ }^{\text {er }}$ s. av. J.-C. (Christol-Vial).

\section{GRENOBLE}

Épitaphe ou inscription honorifique posthume (?) de Decimus Decmanius Caper, sous-préfet des cavaliers de l'aile Agrippiana qui a laissé par testament cinquante mille sesterces pour des statues.

Perdu. CIL XII, $2231=$ CIL XII, $2232=I L N$ Vienne, 370.

[D(ecimo)] Decmanio | Capro | sub praef(ecto) equit(um) | alae Agrippian(ae) | qui [(sestertium)] L(milia) in sta|tuas [---] | ut [---] et aenearum $|[---]|$ [test(amento) reli]quit.

«À Decimus Decmanius Caper, sous-préfet des cavaliers de l'aile Agrippiana, qui a laissé par testament cinquante mille sesterces pour des statues... et ... en bronze » (trad. Rémy-Dangréaux).

Decimus Decmanius Caper est connu par deux autres inscriptions de Grenoble, des bases de statues dédiées à Mars (ILN Vienne, 357) et à Saturne (ILN Vienne, 363). Ces statues faisaient certainement partie de la donation, 50000 sesterces, une somme importante (De Kisch 1979, p. 259-279). Rappelons que Mars est la divinité la plus attestée dans la cité de Vienne ${ }^{47}$.

Datation : époque julio-claudienne.

\section{MARSEILLE}

Dédicace honorifique du collège des dendrophores rappelant l'érection de la statue d'un personnage en raison de ses mérites.

46. Nous nous appuyons ici sur une communication inédite (Coloni et incolae en Gaule méridionale : une mise en perspective du cas valentinois) que $\mathrm{N}$. Tran a eu la gentillesse de nous faire lire : qu'il en soit ici remercié.

47. Bertrandy 2000 .
Perdue. $C I L$ XII, $411=C A G 13 / 3$, p. $192, n^{\circ} 61$.

---] | [--- ponti]f(ici) flami[ni ---] | [---] col(onia) Re[i]s Apo[l]|[lin]ar[e p]atr(ono) [d]e[ndrophor]orum | [b]e[ne] de se m[-erenti? (ou) -erito? ---] | [de]ndroph[ori] Massil[ienses].| [Cui]us statuae [im]pendium | re[mis(it)] et [ob] dedication(em) (sestertios) XII $\mid$ [n(omine)] spo[rt]ularum corporatis dedi[t].

« À [---], pontife, flamine, [---] de la colonie de Reii Apollinaris, patron des dendrophores, qui a bien mérité d'eux [---], les dendrophores de Marseille (ont élevé cette statue). Mais lui a fait remise des dépenses occasionnées par cette statue et, à l'occasion de la dédicace, a versé douze sesterces à titre de sportules à (chacun des membres de) la corporation » (trad. J. Gascou).

Nous suivons ici J. Gascou qui propose de voir dans le personnage honoré un Marseillais qui a exercé le pontificat et le flaminat, et d'autres fonctions, à Riez ou à Marseille. Ce personnage important a également été patron du collège des dendrophores. Pour le remercier de ses mérites envers eux, les dendrophores lui ont fait élever une statue : il en a assumé la dépense et a en outre donné douze sesterces à chacun des corporati ${ }^{48}$ lors de la dédicace de la statue.

Datation : $\mathrm{II}^{\mathrm{e}} \mathrm{s}$.

\section{NARBONNE}

Offrande de deux statues d'argent par Cornelius Anthus, sévir augustal, à Iuppiter Optimus Maximus (?).

Partie inférieure d'une colonnette cannelée en marbre rougeâtre (brêche rouge d'Italie) trouvée en 1877 sur la butte des Moulinassès; l'inscription est gravée sur le revers. Auj. au musée. CIL XII, 4318 (p. 845) = D. Fishwick, «Un don de statues d'argent à Narbo Martius », CRAI, 1992, p. 381-401 = AE, 1992, 1224.

[I(ovi ?) O(ptimo ?)] M(aximo ?)|[.. Co]rnelius | [An]thus ${ }^{49} \mid$ [VIvi]r Aug(ustalis) $\mid[$ statu $]$ as $^{50}$ arg(enteas) II [---].

« À Jupiter Très Bon Très Grand (?), Cornelius Anthus, sévir augustal, (a offert ?) deux statues d'argent ».

Datation : Haut-Empire.

48. Telle est la proposition de J. Gascou : effectivement, une telle somme ne peut concerner l'ensemble des corporati ; M. Clerc, $1927-$ 29, t. 2, p. 298 comprenait 12000 sesterces.

49. Hirschfeld proposait de restituer [Ina]chus.

50. Hirschfeld proposait de restituer [phial]as; Gayraud (Narbonne antique, 1981, p. 271) puis D. Fishwick, CRAI, 1992, p. 381-401, proposent [statu]as. 


\section{NARBONNE}

Érection d'une statue à L. Aemilius Arcanus, sévir des chevaliers romains, de la part de L. Aemilius Moschus, sévir augustal.

Base de statue en marbre trouvée jadis « dans le jardin du consulat de l'hôtel de la ville », auj. au musée. CIL $\mathrm{XII}, 4354=H G L, \mathrm{XV}, 28=I L S, 1064=C A G$ 11/01, $38^{*}$, p. 308.

L(ucio) Aemilio L(uci) f(ilio) Pap(iria) Arcano, | trib(uno) mil(itum) leg(ionis) XI Gem(inae) et trib(uno) | mil(itum) leg(ionis) I Mineru(iae), item trib(uno) | mil(itum) leg(ionis) II Aug(ustae), omnib(us) hono|ribus in colonia sua funct $(o), \mid$ adlecto in amplissimum $\mid$ ordinem ab Imp(eratore) Caes(are) | Hadriano Aug(usto), IIIIIIuir(o) | equitum Romanor(um), curioni,| quaestori urbano, trib(uno)| plebis, praetori designat(o),| L(ucius) Aemilius Moschus IIIIIIuir | Aug(ustalis), patrono optumo (!), post | obitum eius inlatis arcae | seuiror(um) ob locum et tuitio|nem statuae (sestertium) n(ummum) IIII(millibus). | L(ocus) d(atus) d(ecreto) IIIIIIuiror(um) | et sportulis dedicauit |(denarios) III |(unciam).

«À Lucius Aemilius Arcanus, fils de Lucius, de la tribu Papiria, tribun militaire de la $\mathrm{XI}^{\mathrm{e}}$ légion Gemina, et tribun militaire de la I ${ }^{\text {ère }}$ légion Minervia, et tribun militaire de la $\mathrm{II}^{\mathrm{e}}$ légion Augusta, honoré de toutes les fonctions municipales dans sa colonie, admis dans l'ordre sénatorial par l'empereur César Hadrien Auguste, sévir des chevaliers romains, curion, questeur urbain, tribun du peuple, préteur désigné, Lucius Aemilius Moschus, sévir augustal, à son excellent patron ; après la mort de son patron, Moschus a versé dans la caisse des sévirs, pour l'emplacement et l'entretien de la statue, 4000 sesterces, l'emplacement a été concédé par un décret des sévirs ; il a versé aussi, lors de la dédicace, à titre de sportule trois deniers ».

Datation : règne d'Hadrien ou d'Antonin le Pieux.

\section{NARBONNE}

Érection d'une statue à Sextus Fadius Secundus Musa.

Base de statue en marbre (haut. : 1,90 m ; larg. : 0,63 m) trouvée lors de fouilles dans la rue Droite, en 1826. CIL XII, 4393 (p. 846) $=I L S, 7259=A E, 1978,461=A E$, $1992,1225=C A G 11 / 1$, p. 427-429.

A. Sur la face antérieure. Sex(to) Fadio P[ap(iria)] | Secundo Mu[sae] | omnibus ho[norib(us)] | in colonia N[arbo]|nens[i fu]ncto [curat(ori)] | primo [Aug(usti) templi] | noui Narbo[ne] | fabri subaedia[ni]
| Narbonenses | patrono ob merita | eius l(ocus) d(atus) $d($ ecurionum $) d($ ecreto $)$.

« À Sextus Fadius Secundus Musa, de la tribu Papiria, parvenu à tous les honneurs municipaux dans la colonie de Narbonne, flamine d'Auguste, le premier après la reconstruction du temple de Narbonne, les ouvriers subaediani de Narbonne, à leur patron, en reconnaissance de ses bienfaits. Emplacement donné par décret des décurions ».

B. Sur le côté gauche, est reproduite la longue lettre que le personnage honoré a adressée au collège des fabri subaediani. Il les remercie et demande que les intérêts annuels que le collège pourra tirer de la somme de 16000 sesterces qu'il leur a offerte soient, chaque année, partagés entre les différents membres du collège alors réunis en tenue de cérémonie. Afin que sa demande soit respectée, il en demande gravure sur un des côtés de la base de sa statue :... et in basi statuae quam mihi posuistis | [latere de]xtro scribatis, etc.

Datation : 149 ap. J.-C. (Orfitus et Priscus consuls).

\section{NARBONNE}

Lex de flamonio : loi du flamen augustalis du culte impérial de la province de Narbonnaise.

Tablette de bronze (haut. : $22 \mathrm{~cm}$; ép. : 1,4 cm) trouvée en 1888 lors des dégagements d'une piscine proche de l'amphithéâtre. CIL XII, $6038=I L S, 6964=A E, 1987$, 749 (= C.H. Williamson, A Roman Law from Narbonne, Athenaeum, 65, 1987, p. 173-189) ; CAG 11/1, p. 131132 et p. $388-390,158 *$.

Dans ce long texte de 29 lignes qui règle les droits et les devoirs du flamine de la province, le terme statua apparaît à plusieurs reprises.

A. Dans le paragraphe consacré aux honneurs attribués à l'ancien flamine, il est spécifié que le flamine sortant, peut s'il le souhaite, sur avis du flamine en fonction et sur décision des décurions, faire dresser sa statue dans les limites du temple:

De honoribus eius qui flamen fluerit. Si is qui flamen fue]rit aduersus hanc legem nihilfecerit tum is qui flamen erit c[urato ut ---] [--- per tabell]as iurati decernant placeatne ei qui flamonio abierit permitti sta[tuam intra fines templi diui Aug(usti) ponere si placu]|[erit ius sta]tuae ponendae nomenque suum patrisque et unde sit et quo anno fla[men fuerit inscribendi permitti ei] | [Narbo]ni intra fines eius templi statuae ponendae ius esto nisi cui Imperator [Caesar ---]. 
«À propos des honneurs attribués à l'ancien flamine. Si l'ancien flamine n'a transgressé en rien cette loi, le flamine en fonction avisera, quand les décurions ... assermentés décerneront des statues, à s'informer s'il plaît au flamine qui a quitté son sacerdoce de se laisser ériger une statue. Quand les décurions auront ainsi décrété qu'un flamine a le droit d'avoir une statue avec la mention inscrite de son nom, du nom de son père, de son origine, de l'année de son flaminat, il aura le droit de placer sa statue à Narbonne, dans les limites de ce temple, s'il n'y a pas d'interdiction de l'Empereur César ... » (d'après Hirschfeld et Mommsen).

B. Dans le paragraphe consacré à l'argent [destiné aux dépenses sacrées], il est spécifié que le flamine sortant pourra utiliser l'excédent d'argent de la caisse du concilium à ériger des statues et des imagines de l'empereur :

De pecu[nia ---]. Qui flaminio abierit is ex ea pecunia [--- statu]as ${ }^{51}$ imaginesue Imperatoris Caes[aris --arbitratu? eius qui eo anno pro]|uinciae praeerit intra idem t[empus ---].

« À propos de l'argent [destiné aux dépenses sacrées]. Le flamine qui sortira de charge emploiera l'excédent de l'argent [destiné aux dépenses sacrées] (à ériger) des statues ou des imagines de l'Empereur César ... il les dédiera dans ce temple, en se conformant à la volonté de celui qui, cette année, présidera la province » (d'après Hirschfeld et Mommsen).

Datation : époque flavienne ${ }^{52}$.

\section{NARBONNE}

Don de Licinia Pallas à la caisse des sévirs pour l'entretien de la statue de son mari, Q. Iulius Servandus.

Base de statue. CIL XII, $4397=H G L, \mathrm{XV}, 118=I L S$, $5495=C A G 11 / 1,197^{*}$, p. 412.

Q(uinto) Iulio | Servando | IIIIIIvir(o) Aug(ustali) | c(oloniae) I(uliae) P(aternae) C(laudiae) N(arbonis) M(artii) | Licinia Pallas | marito optimo | inlatis arcae | IIIIIIvir(orum) ob tuitionem | statuae n(ummos) |(mille) | l(ocus) d(atus) d(ecreto) IIIIIIvir(orum).

«À Quintus Iulius Servandus, sévir augustal de la colonie Julia Paterna Claudia Narbo Martius, Licinia Pallas à son excellent mari. Elle a porté 10000 sesterces

51. Cette restitution est assurée par le terme imagines qui suit. 52. Après l'abandon de la datation augustéenne jadis proposée, ce texte a généralement été daté du règne de Vespasien (Gayraud 1981, p. 389-390, qui rappelle la bibliographie antérieure). à la caisse des sévirs, pour la protection de la statue. Emplacement donné par décret des sévirs ».

Datation : 40-60 ap. J.-C.

\section{NARBONNE}

Les sévirs érigent une statue à Publius Olitius Apollonius, sévir augustal et naviculaire de la colonie de Narbonne.

Marbre (?). CIL XII, $4406=C A G$ 11/1, 10*, p. 255.

Dec(reto) IIIIIIvir(orum) | Augustal(ium). P(ublio) Olitio | Apollonio | IIIIIIvir(o) Aug(ustali) et | navic(ulario) c(oloniae) I(uliae) P(aternae) C(laudiae) $N$ (arbonis) $M$ (artii) $\mid$ ob merita et liberali|tates eius qui | honore decreti | usus impendium | remisit et | statuam de suo | posuit.

«Par décret des sévirs augustaux. À Publius Olitius Apollonius, sévir augustal et naviculaire de la colonie Julia Paterna Claudia Narbo Martius, pour ses mérites et ses libéralités. Il a accepté l'honneur que ce décret lui a conféré : il a épargné aux sévirs la dépense qui en résultait et il a érigé la statue à ses frais ».

Datation : $\mathrm{II}^{\mathrm{e}}$ s. ${ }^{53}$

\section{NARBONNE}

Dédicace honorifique mentionnant l'érection de statues pour un personnage en raison de ses libéralités envers la cité.

Partie inférieure d'une base de marbre blanc (haut. : 0,50 m ; larg. : 0,59 m). ILGN, $572=C A G 11 / 1,228 * 28$.

[Col(onia) Iulia Paterna Claud(ia)] | Nar[bon(e) Mart(io) ob merita] | liberalitatesq(ue) [erga] | rem publicam su[am ---] | statuas totidem[q(ue) signa?]| ponenda cen[suerunt].

« La colonie Julia Paterna Claudia Narbo Martius, en raison des mérites et des libéralités [de... ?] envers sa république, a jugé de son devoir de lui ériger des statues et tout autant de...».

Datation : À partir du règne de Claude, date à laquelle Claudia apparaît dans la titulature de la cité.

\section{NÎMES}

Décret honorifique ordonnant l'érection d'une statue honorifique en l'honneur d'une flaminique, Indelvia Valerilla, qui a décoré la basilique d'une statue ornée d'argent.

53. Wierschowski 2001, p. 211. 
G. Barruol, J. Gascou, J.-Cl. Bessac, « Nouvelles inscriptions exhumées d'une enceinte du Bas-Empire à Nîmes », Revue archéologique de Narbonnaise, 15, 1982, (p. 273-318), p. 290-293 = AE, 1982, 682.

Indelviae, T(iti) fil(iae), | Valerillae, | flaminicae | perpetuae, | quae pro eo honore | statuam argenteam cum | basi ex (sestertium) (quinquaginta) m(ilibus) n(ummum) $\mid$ in basilica posuit, | ob quam munificentiam | ordo sanctissimus | statuam ei ponendam | de publico decrevit. $\mid$ Quae honore contenta $\mid$ inpendium remisit.

«Pour Indelvia Valerilla, fille de Titus, flaminique perpétuelle, qui, en retour de cet honneur, a élevé dans la basilique une statue ornée d'argent avec sa base d'un prix de 50000 sesterces. En raison de cette munificence, le très vénérable sénat a décidé de lui élever une statue aux frais de la cité. Mais elle, satisfaite de l'honneur (qui lui était décerné), a pris la dépense à sa charge ».

Datation : $2^{\mathrm{e}}$ moitié du $\mathrm{II}^{\mathrm{e}} \mathrm{s}$.

\section{NîMES}

Festivités en l'honneur du dies natalis de Marc Aurèle (le $6^{\mathrm{e}}$ jour des calendes de mai, soit le 26 avril) marquées par différentes libéralités (banquet, érection d'une statue ...).

Fragment d'un bloc (base ?) en calcaire. CIL XII, 5905.

--- de]dit VIII VII VI K(alendas) M[---] | [---] Augustis co(n)s(ulibus) [---] | [---] decurionibus [---] | [---] collegiis et am[plius ---] [---] epulo IIIIIIuir(is) c[orpor(atis) ---]|[---]us stat[uam ? ---

«...a donné les $8^{\mathrm{e}}, 7^{\mathrm{e}}$ et $6^{\mathrm{e}}$ jours des calendes de mai ..., sous le consulat de ... et de ... Augustes, etc. ».

La première ligne de l'inscription semble attester trois jours de festivités à l'occasion de l'anniversaire de l'empereur (24-26 avril) ${ }^{54}$.

Datation : 161 ap. J.-C., seule année du règne conjoint de Lucius Vérus et Marc Aurèle où ils furent consuls tous les deux, Lucius Vérus pour la seconde fois, Marc Aurèle pour la troisième.

\section{ORANGE}

Dédicace honorifique mentionnant l'érection d'une statue en l'honneur d'un évergète qui a financé des ludi et a fourni l'huile des bains.

54. Fishwick 1991, p. 497 et 587.
Support inconnu. CIL XII, 1236 (p. 824) ; CAG 84/1, p. 312.

--- ]|IIuir ludos fe[cit --- balneum] | et oleum pri[mus in colon(ia) Araus(ione)] | flamen Rom(ae) et d[iui Augusti fact(us) praebuit] | huic d(ecreto) d(ecurionum) sta[tua ---.

Bien que l'inscription soit fragmentaire, on en comprend le sens général grâce à des parallèles connus dans la province et dans les provinces voisines : ce type de fondation ou de donation ponctuelle a déjà fait l'objet d'un recensement par M. Christol ${ }^{55}$.

Datation : Haut-Empire.

\section{RIEZ}

Dédicace honorifique en l'honneur d'un évergète pour ses bienfaits à l'égard de la plèbe des deux sexes et du collège des utriculaires.

Fragment de marbre blanc aujourd'hui perdu. CIL XII, $372=$ ILN Riez, 15 .

---utri]|usquesex[us---colleg(ium)]|utric[ulariorum] | ob liberali[tatem ---] | statuar(um) im[pensam remisit (?)] | adgniton[---] | dedecerun[---] | et oleum p[lebei utriusque] | sexus II P[---] | specta[cul...(?)---

Parmi les bienfaits de cet évergète demeuré anonyme, on compte des jeux (spectacula) et aussi, comme dans l'inscription précédente, la fourniture d'huile très certainement dans le cadre des bains. L'inscription étant fragmentaire, il est malaisé de comprendre la place des statues dans cette liste : soit le personnage a offert des statues à sa ville et celles-ci faisaient partie de ses bienfaits, soit l'inscription rappelle qu'il a reçu des statues en remerciement de sa liberalitas et que l'évergète s'est en outre chargé de cette dépense (statuarum impensam remisit ?). Si la seconde hypothèse est la bonne, l'obtention de plusieurs statues et non d'une seule comme cela est le plus souvent le cas soulignerait l'importance de ce personnage à Riez.

Date : fin ${ }^{\text {er }}$, début du $\mathrm{II}^{\mathrm{e}} \mathrm{s}$.

\section{TOULOUSE}

Dédicace honorifique mentionnant l'érection de statues en l'honneur de Sextus Iulius [---], préfet des ouvriers.

55. Christol 2004b, p. 95, n.47. 
Plaque de marbre. CIL, XII, 5386.

Sex(to) Iu[lio --- praefecto] | fabru[m ---] | statuas $[---] \mid$ Sex(tus) Iulius [---

« À Sextus Iulius [---], préfet des ouvriers, ... des statues... Sextus Iulius...».

Datation : $\mathrm{I}^{\mathrm{er}}-\mathrm{II}^{\mathrm{e}} \mathrm{s}$.

\section{GAULE NARBONNAISE,} de provenance inconnue

Dédicace honorifique mentionnant l'érection d'une statue équestre à un évergète en raison de ses libéralités.

Plaque de marbre. CIL XII, 5386.

$---] R[---] \mid[---i u]$ stitiam $I[---] \mid[---$ libe]ralitatem ex HS [---]|[---] obitum Penates suos [---] [---] semper sibi fuisse [---] [---] coegerunt reponi statuam equ[estrem ---] | [---] ipse ea domo utatur aquam g[ratuitam] | [--d]uci totiusque operis curam et [impendi]um [---]ci| [--- cens]uere omnes [---

Malgré l'état très fragmentaire de cette inscription dont on ne connaît pas la provenance exacte, une certitude s'impose : le personnage était très important comme l'atteste l'octroi, fort rare, d'une statue équestre ainsi que la concession gratuite d'eau dont il a bénéficié. La desserte gratuite d'eau était réservée aux domus des personnages les plus importants d'une ville comme le montre l'étude de la documentation sur le sujet ${ }^{56}$.

Datation : Haut-Empire.

\section{Les attestations du terme simulacrum}

\section{VIENNE}

Don d'une statue en argent de Vienne par les frères Sextus Coelius Canus et Sextus Coelius Niger en remerciement de l'octroi du décurionat.

Bases de statue en marbre. CIL XII, $5864=I L S, 6999=$ ILN Vienne, $72=A E, 2000,898$.

Texte A : Sex(to) Coelio, Volt(inia), Cano|quaest(ori). | Primus, libert(us), sevir. I Hic et frater propter singularem et in $\mid$ suos pietatem et inter se concordiam | quam in consortione iucundissuma | annum LXXVII agunt, ab ordine $\mid$ decurionatu digni iudicati sunt $\mid$ quam

56. Dessales 2008. dexteritatem decurionum | munificentia remuneraverunt | posito simulacro Viennae argenteo | (sestertium) n(ummum) (ducentorum milium).

« À Sextus Coelius Canus, (de la tribu) Voltinia, questeur. Primus, son affranchi, sévir. Lui et son frère, en raison du caractère exceptionnel de leur affection envers les leurs et de l'entente mutuelle qu'ils manifestent dans une vie commune pleine d'agrément depuis soixantedix-sept ans, ont été jugés dignes du décurionat par le sénat (de Vienne). Ils ont répondu à ce procédé obligeant des décurions par leur générosité en élevant une statue en argent de Vienne, d'une valeur de deux cent mille sesterces » (trad. Pelletier).

Texte B : Sex(to) Coelio, Vol(tinia), Nigro, |quaestori. | Primus, libert(us), sevir. | Hic et frater, propter singularem et in $\mid$ suos pietatem et inter se concordiam | quam in consortione iucundissuma | annum LXXVII agunt, ab ordine $\mid$ decurionatu digni iudicati sunt $\mid$ quam dexteritatem decurionum | munificentia remuneraverunt | posito simulacro Viennae argenteo | (sestertium) n(ummum) (ducentorum milium).

« À Sextus Coelius Niger, (de la tribu) Voltinia, questeur. Primus, son affranchi, sévir. Lui et son frère, en raison du caractère exceptionnel de leur affection envers les leurs et de l'entente mutuelle qu'ils manifestent dans une vie commune pleine d'agrément depuis soixantedix-sept ans, ont été jugés dignes du décurionat par le sénat (de Vienne). Ils ont répondu à ce procédé obligeant des décurions par leur générosité en élevant une statue en argent de Vienne, d'une valeur de deux cent mille sesterces » (trad. Pelletier).

Datation : $2^{\mathrm{e}}$ moitié du I ${ }^{\mathrm{er}}$ ou $\mathrm{II}^{\mathrm{e}} \mathrm{s}$.

\section{Les attestations du terme imago}

\section{4 (= 6). NîMES}

Hommage public rappelant les libéralités d'un notable nîmois, parmi lesquelles le don de statues en argent de plusieurs divinités.

Perdue. CIL XII, $3058=$ etc.

\section{NÎMES}

Décret des décurions autorisant le buste d'un personnage éminent sous les traits de l'empereur; le buste devait être destiné à orner le siège d'un collège.

Fragment de plaque marbre (?) provenant du quartier de la Fontaine. $C I L$ XII, 3312 (p. 837) $=H G L, X V, 231=$ $C A G 30 / 1$, p. $304,197, n^{\circ} 7$. 
g]randessum [---]I idus [---]ini[---] | [---]as si quidem hoc non mea sed VESTROFT[---] | [---]ri mihi facere cum splendore uestro et [---]|[--- legibu]s uel principum constitutionibu[s ---] [---]s sub specie nobilissimi prin[cipis ---] | [---]qu(a)e dandas censeatis sub di[uo ---] | [---]m imaginem [---] | [--- i]n patriam pium ac strenuи[m ---] | [--- si] uidebitur illi corpori po[nere ---] | [--- decreto] ordi[nis ---] | [--spl]endi[dissimi ---

Bien que fragmentaire, cette inscription reproduit la requête faite auprès d'un collège (corpus) par un personnage souhaitant dédier un buste honorifique (imago) en l'honneur d'un citoyen qui s'est montré in patriam pium ac strenuum. L'auteur de la requête comme le bénéficiaire de l'imago demeurent inconnus, mais nul doute que ce second personnage devait être éminent puisqu'un décret de l'ordo de la cité de Nîmes autorisa la dédicace de son portrait «à la ressemblance du très noble prince » (sub specie nobilissimi principis) ${ }^{57}$.

Datation: III ${ }^{\mathrm{e}}$ s. ap. J.-C. car nobilissimus désigne soit Commode ${ }^{58}$, soit un César associé à un Auguste dans le courant de ce siècle.

\section{6 (= 23b). NARBONNE}

Lex de flamonio : loi du flamen augustalis du culte impérial de la province de Narbonnaise.

CIL XII, 6038 = etc. (cf. inscr. 23b).

Dans le paragraphe consacré à l'argent [destiné aux dépenses sacrées], il est spécifié que le flamine sortant pourra utiliser l'excédent d'argent de la caisse du concilium à ériger des statues mais aussi des imagines de l'empereur :

De pecu[nia ---]. Qui flaminio abierit is ex ea pecunia [--- statu]as imaginesue Imperatoris Caes[aris --- arbitratu? eius qui eo anno pro]|uinciae praeerit intra idem t[empus ---].

Pour la traduction, voir inscr. $n^{\circ} 23$.

Datation : époque flavienne.

\section{Abréviations}

CAG 11/1: DELlONG (E.), MOULIS (D.), FARRÉ (J.) - Carte Archéologique de la Gaule, 11/1, Narbonne et le Narbonnais, Paris, Académie des Inscriptions et Belles-Lettres, 2002.

\section{Bibliographie}

Alföldy 1981 : ALFÖLDY (G.) - Bildprogramme in den römischen Städten des Conventus Tarraconensis. Das Zeugnis der Statuenpostamente. In: Homenaje García y Bellido, IV. (Revista de la Universidad Complutense de Madrid, 118), Madrid, Universidad Complutense, 1979 [1981], p. 177-275.

Bertrandy 2000 : BERTRANDY (F.) - Le culte de Mars dans la cité de Vienne, RAN, 33, 2000, p. 223-238.

Blanc 1989 : BLANC (N.) - Vocabulaire technique et vocabulaire vitruvien dans les inscriptions de Lyon et de Vienne. In : La Langue des inscriptions latines de la Gaule. Actes de la Table ronde tenue au C.E.R.G.R. les 6 et 7 oct. 1988 (Université de Lyon III). Lyon, de Boccard, 1989, p. 73-85.

Bouet 2001 : BOUET (A.) - Les collèges dans la ville antique : le cas des Subaediani, Revue archéologique, 2001/2, p. 227-278.

Chastagnol 1992: CHASTAGNOL (A.) - Inscriptions Latines de Narbonnaise. II, Antibes, Riez, Digne, (XLIV ${ }^{\mathrm{e}}$ suppl. à Gallia), Paris, éd. CNRS, 1992, $302 \mathrm{p}$.

Christol 2004a : CHRISTOL (M.) - En deçà du monde des notables : la situation en Gaule Narbonnaise. In : Cébeillac-Gervasoni (M.), Lamoine (L.), Trément (F.), Autocélébration des élites locales dans le monde romain: contextes, images, textes ( $\mathrm{II}^{e}$ s. av. J.-C.-III ${ }^{e}$ s. ap. J.-C.). Actes du colloque de Clermont-Ferrand 21-23 nov. 2003, Clermont-Ferrand, Université Blaise Pascal, 2004, p. 59-76.

Christol 2004b : CHRISTOL (M.) - Notes d'épigraphie 7-8, Cahiers $d u$ Centre Gustave Glotz, 15, 2004, p. 85-119.

Daut 1975: DAUT (R.) - Imago. Untersuchungen zum Bildbegriff der Römer, Heidelberg, C. Winter, 1975, 164 p. (Bibliothek der klassischen Altertumswissenschaften. 2. Reihe; Band 56).

De Kisch 1979: DE KISCH (Y.) - Tarifs de donations en Gaule romaine d'après les inscriptions. Ktèma, 4, 1979, p. 259-280.

Delamarre 2001 : DELAMARRE (X.) - Dictionnaire de la langue gauloise : une approche linguistique du vieux-celtique continental, Paris, Errance, 2001.

Dessales 2008 : DESSALES (H.) - Le prix de l'eau dans l'habitat romain : une étude des modes de gestion à Pompéi. In : Hermon (E.) (éd.), Vers une gestion intégrée de l'eau dans l'empire romain. Actes du colloque international, université Laval, octobre 2006, Rome, L'Erma di Bretschneider, 2008, p. 55-66.

Estienne 1997 : ESTIENNE (S.) - Statues de dieux «isolées » et lieux de culte : l'exemple de Rome, Cahiers du Centre Glotz, VIII, 1997, p. 81-96.

Estienne 2000 : ESTIENNE (S.) - Les dieux dans la ville : recherches sur les statues de dieux dans l'espace et les rites publics de Rome, d'Auguste à Sévère Alexandre : (I ${ }^{e r-I I I}{ }^{e}$ s. ap. J.-C.), thèse Paris I (non publiée), 2000.

Gayraud 1981 : GAYRAUD (M.) - Narbonne antique, des origines à la fin du III ${ }^{e}$ s., Paris, éd. CNRS, 1981 (RAN, suppl.8).

58. Selon la proposition de Pflaum 1978, p. 81. 
Gorrochategui 2011: GORROCHATEGUI (J.) - Contactos lingüísticos y epigráficos en la zona vasco-aquitana. In : Ruiz Darasse (C.), Luján Martínez (E.R.) (éd.), Contacts linguistiques dans l'Occident méditerranéen antique, Madrid, Casa de Velázquez, 2011 (Collection de la Casa de Velázquez 126).

Gros 1976 : GROS (P.) - Aurea templa. Recherches sur l'architecture religieuse de Rome à l'époque d'Auguste, Rome, École française de Rome ; Paris, de Boccard, 1976, 282 p.-LXVI p. (BEFAR, 231).

Gros 1996: GROS (P.) - L'architecture romaine: du début du III siècle av. J.-C. à la fin du Haut-Empire, t. I. Les monuments publics, Paris, Picard, 1996 (Manuels d'art et d'archéologie antiques).

Hualde et al. 1996 : HUALDE (J.I.), LAKARRA (J.A.), TRASK (R.L.) - Towards a History of the Basque Language, University of Illinois at UrbanaChampaign/University of the Basque Co, 1996 (Current Issues in Linguistic Theory 131).

Hurlet 2000 : HURLET (F.) - Pouvoir des images, images du pouvoir impérial. La province d'Afrique aux deux premiers siècles de notre ère, MEFRA, $112,1,2000$, p. 297-364.

Lamoine 2009: LAMOINE (L.) - Le pouvoir local en Gaule romaine, Clermont-Ferrand, Presses Univ. Blaise Pascal, 2009.

Lahusen 1982 : LAHUSEN (G.) - Statuae et imagines. In : von Freytag gen. Löringhoff (B.), Mannsperger (D.), Prayon (F.), Praestant interna. Festschrift für U. Hausmann, Tübingen, E. Wasmuth, 1982, p. 101-109.

Lahusen 1983 : LAHUSEN (G.) - Untersuchungen zur Ehrenstatue in Rom. Literarische und epigraphische Zeugnisse, Rome, L'Erma di Bretschneider, 1983, XIV-166 p. (Archaeologica 35).

Melchor Gil 2006 : MELCHOR GIL (E.) - Solo Publico, Solo Suo. Sobre la ubicación de los homenajes estatuarios en las ciudades de la Bética, Cahiers Centre Gustave Glotz, XVII, 2006, p. 201-211.

Melchor Gil 2009: MELCHOR GIL (E.) - Statuas posuerunt: acerca del emplazamiento de los homenajes estatuarios, públicos y privados, en las ciudades de la Bética. In: Espacios, usos y formas de la epigrafía hispana en épocas Antigua y Tardoantigua. Homenaje al Dr. Armin U. Stylow, (Anejos de Archivo Español de Arqueología, XLVIII), Consejo Superior de Investigaciones Científicas, Instituto de Arqueología de Mérida, Mérida, 2009, p. 217-226.

Melchor Gil 2010 : MELCHOR GIL (E.) - Homenajes estatuarios e integración de la mujer en la vida pública municipal de las ciudades de la Bética.
In : Navarro (F.J.) (éd.), Pluralidad e integración en el mundo romano, Pampelune, Eunsa, 2010, p. 221-245.

Oria Segura 2000a : ORIA SEGURA (M.) - Statva, Signvm, Imago : el lenguaje de las dedicatorias en la Bética romana, Spal, 9, 2000, p. 451-463.

Oria Segura 2000b : ORIA SEGURA (M.) - Los dioses y la ciudad en la Bética romana, Cuadernos de Prehistoria y Arqueología, 20, 2000, p. 149-165.

Pflaum 1978 : PFLAUM (H.-G.) - Afrique romaine. Scripta varia, 1, Paris, éd. L’Harmattan, 1978.

Rodriguez, Sablayrolles 2008 : RODRIGUEZ (L.), SABLAYROLLES (R.) - Les autels votifs du musée Saint-Raymond, musée des Antiques de Toulouse. Catalogue raisonné, Toulouse, Musée Saint-Raymond, Musée des Antiques de Toulouse, 2008.

Rosso 2004 : ROSSO (E.) - Elites et imitatio. La reprise par les élites des types statuaires impériaux. In: Cébeillac-Gervasoni (M.), Lamoine (L.), Trément (F.) (éd.), Autocélébration des élites locales dans le monde romain : Contexte, textes, images, $I I^{e}$ s. av. J.-C.-III ${ }^{e}$ s. ap. J.-C., Clermont-Ferrand, Presses Univ. Blaise Pascal, 2004, p. 33-57.

Smadja 1995 : SMADJA (E.) - Statue, image et culte de l'empereur en Afrique. In: Mactoux (M.-M.), Geny (É.) (éd.), Discours religieux dans l'antiquité: actes du colloque, Besançon 27-28 janvier 1995, (Centre de recherches d'histoire ancienne, 150 ; Lire les polythéismes, 4 ; Annales littéraires de l'université de Besançon, 578), Paris, Les Belles lettres, 1995, p. 279-294.

Soyris, Escalon, Gassend 1994-95: SOYRIS (P.), ESCALON (G.), GASSEND (J.-M.) - Un temple du début de l'Empire à Murviel-lèsMontpellier (Hérault). Hypothèse de restitution, Revue archéologique de Narbonnaise, 27-28, 1994-95, p. 57-108.

Spickermann 1994 : SPICKERMANN (W.) - Priesterinnen im römischen Gallien, Germanien und den Alpenprovinzen (1.-3. Jahrhundertn. Chr.), Zeitschrift für Alte Geschichte, 43, 2, 1994, p. 189-240.

Vismara, Caldelli 2001 : VISMARA (C.), CALDELLI (M.L.) - Epigrafia anfiteatrale dell'Occidente romano, V. Alpes maritimae, Gallia narbonensis, Tres Galliae, Germaniae, Britannia, Roma, éd. Quasar, 2001, (Vetera ricerche di storia epigrafia e antichità 14).

Wierschowski 2001: WIERSCHOWSKI (L.) - Fremde in Gallien; "Gallier» in der Fremde. Die epigraphisch bezeugte Mobilität in, von und nach Gallien vom 1. bis 3. Jh. n. Chr. Texte, Übersetzungen, Kommentare, Stuttgart, Franz Steiner Verlag, 2001, (Historia. Einzelschriften 159). 



\title{
Signa et tituli dans l'épigraphie de la cité de Vienne au Haut-Empire
}

\author{
Bernard Rémy \\ Professeur émérite d'histoire romaine de l'université Pierre Mendès France de Grenoble - CRHIPA - \\ CNRS, Centre Camille Jullian, Aix-en-Provence \\ bernard.remy07@orange.fr \\ Noëlle Géroudet \\ Maître de conférences honoraire d'histoire romaine à l'université Pierre Mendès France de Grenoble - \\ CRHIPA \\ noelle.geroudet@wanadoo.fr
}

\section{Résumé}

Sur la base des Inscriptions Latines du territoire de Vienne (ILN Vienne, 935 inscriptions), les auteurs ont relevé 22 textes pouvant mis être mis en relation avec des sculptures (mention dans le texte du terme latin désignant une «statue » ou traces d'accrochage d'une statue). Après avoir examiné les différents termes employés et leur polyvalence, cet article analyse les différents monuments où se dressaient ces statues, ce qu'elles représentaient (dieux, notables), leur statut juridique et l'origine des financements. L'ensemble des textes étudiés est fourni en annexe.

Mots-clés : Empire romain, Gaule Narbonnaise, Vienne, sculpture, épigraphie, inscription, statua, signum, simulacrum, effigies, imago.

\begin{abstract}
On the basis of the Vienna civitas corpus of Latin inscriptions (ILN Vienne 935 inscriptions), the authors noted 22 texts that can be related to statuary (mention in the text of the word which designates a statue or fittings for a statue). The various terms being used and their various meanings are examined in this article then the different monuments where these statues have been erected are described altogether with the subjects represented (gods, local leaders), the legal status and origin of funds. An appendix gives the texts studied above.
\end{abstract}

Key-words: Roman Empire, Gallia Narbonensis, Vienna, sculpture, epigraphy. 
$\mathrm{L}$ a publication du corpus des inscriptions latines de la cité de Vienne (ILN Vienne) a permis de recenser neuf cent trente-cinq inscriptions, dont vingt-neuf bornes milliaires. Malgré ce nombre appréciable de documents, nous avons seulement repéré vingt-deux liaisons certaines de signa et de tituli $^{1}$ dans le vaste territoire viennois. La question de la riche terminologie latine servant à désigner les statues (statua, signum, effigies, imago, simulacrum) a souvent été étudiée ${ }^{2}$. Un texte de Pline l'Ancien ( $H N, 34,16-18$; voir Annexe 2), qui serait d'origine varronienne, semble établir que deux termes paraissent plutôt employés pour désigner des statues de divinités ou d'empereurs divinisés : simulacrum et signum. Simulacrum contient une idée d'ancienneté, donc de vénérabilité et pourrait peut-être s'appliquer à la statue de culte. Statua et imago renverraient plutôt à toutes les statues d'individus, statues en pied ou portraits d'hommes vivants ou morts. Toutefois, si cette constante se révèle assez souvent conforme, il existe autant de contre-exemples. Six inscriptions mentionnent expressément la présence d'une statue. Les termes signum/signa (ILN Vienne, $6 ; 88 ; 739$ ), simulacrum (ILN Vienne, 72 A et B) et enfin statua (ILN Vienne, 370) sont respectivement utilisés. Signum est associé au Génie des hastifères (ILN Vienne, 6), à Castor et Pollux, Hercule et Mercure (ILN Vienne, 88 ) ; simulacrum est utilisé pour une statue de la déesse Vienna (ILN Vienne, 72 A et B). Ici le vocabulaire paraît conforme à la distinction effectuée plus haut. Cependant, l'inscription ILN Vienne, 370 mentionne des statuae. Si ces statues sont celle de Mars et de Saturne dont on a retrouvé la dédicace (ILN, Vienne 357,363 ), alors on le voit, le vocabulaire n'est pas fixé avec une grande rigueur. Cependant, rien ne prouve qu'il s'agisse bien des mêmes.

Enfin, l'inscription de Talloires mentionne des signa en relation avec un horologium. Vitruve évoque à différentes reprises les horologia. En 10, 7, 5 il décrit la machine de Ctésibios, mais ne mentionne aucune statue, pas plus que dans le livre $9,8,2$ où sont décrites diverses horloges à eau. Un texte évoque simplement un sigillum pour désigner la figurine mobile tenant une baguette qui

1. Nous n'avons pas retenu ILN Vienne, 316, une inscription en l'honneur de l'empereur Hadrien par les nautes du Rhône, actuellement conservée à Saint-Jean-de-Muzols (Ardèche), car il semble bien qu'elle ne soit pas viennoise, mais provienne de Tournon, dans le territoire de la rive droite du Rhône de la colonie de Valence (voir ILN Valence, 68).

2. Gros 1976, p. 160-162. Estienne (S.) - Statues de dieux « isolées » et lieux de culte : l'exemple de Rome. Cahier du Centre G. Glotz, 8, 1997, p. 81-96. La terminologie grecque semble poser un peu moins de problème ou plutôt avoir été clarifiée par $\mathrm{Cl}$. Rolley (La sculpture grecque, I, Paris, 1994, p. 22-53). indique les variations du niveau de l'eau sur laquelle elle repose et permet de déterminer l'heure ${ }^{3}$. Ce terme est également utilisé en $9,8,5$ pour désigner des figures mobiles, mues par un mécanisme. Certaines horloges comportaient par exemple un buccinator dont l'effigie surmontait la machine et émettait un son pour annoncer une heure, par le biais de dispositifs ingénieux, proches des automates.

Par ailleurs, Vitruve décrit le mécanisme complet d'une horloge anaphorique qui montre le lever et le coucher des astres, où « [...] les signes célestes étant figurés sur le rebord du grand tambour $»^{4}$. Pour les désigner, Vitruve emploie signa caelestium et précise chaque fois Cancri signum, Arietis signum... ou donne simplement le nom du signe céleste. Le vocabulaire semble exclure qu'à Talloires, il puisse s'agir de ce système extrêmement complexe, même si des fragments d'horloges anaphoriques ont été retrouvés (Museum Carolino Augusteum de Salzburg, Musée des Antiquités Nationales de SaintGermain-en-Laye) et si la présence d'un esclave montre la nécessité d'un entretien spécialisé qui pourrait aussi convenir probablement au type précédent.

C'est un constat décevant puisqu'on ne peut partir du terme pour déduire la nature de l'objet mentionné et qu'à l'inverse, nous ne dispose pas d'éléments suffisants pour préciser la nature de ces signa et statuae indiquées sans plus de précision. La plus grande prudence est donc à conserver dans cet effort de définition.

Nous avons aussi retenu ILN Vienne, 598, où est mentionnée la base (basis) d'une statue de la Victoire impériale, la statue fragmentaire inscrite de Villette-deVienne (ILN Vienne, 291), la base comportant le nom de l'auteur de la statue (ILN Vienne, 91) et les treize monuments inscrits dont l'identification en tant que base ou piédestal est indiscutable (traces ou trous de scellement sur la partie supérieure...). Malgré une fréquente mutilation il est certain que, dans l'Antiquité, ils étaient surmontés soit d'une statue, soit d'une statuette en fonction de leurs dimensions. Il est tout aussi certain que dans le corpus épigraphique viennois d'autres monuments retaillés, mal décrits ou mal conservés, pouvaient être des bases de statues, mais nous n'avons pas réussi à les identifier.

3. Vitruve, 9.8.6. Il faut éventuellement tenir compte du décalage chronologique entre les écrits de Vitruve, de Pline et le vocabulaire des inscriptions ainsi que d'éventuelles nuances géographiques.

4. Vitruve, 9.8.12-14. 
Voici la liste de ces vingt-deux documents classés dans l'ordre géographique des ILN, Vienne, car il n'est guère possible de proposer une date suffisamment précise pour la plupart d'entre eux. (tableau $\left.\mathbf{n}^{\circ} \mathbf{1}\right)$

Un document (ILN, Vienne 28) de ce maigre corpus est inutilisable, car il a été mal décrit par Robert Mowat (Bulletin archéologique, 1888, p. 328), qui n'a pas vu l'objet, mais se fondait sur un dossier retrouvé dans les papiers de Léon Renier. Sa description (« statuette à base hexagonale ») est accompagnée du texte incompréhensible de la dédicace : «PIONI / ACI / DIVI / OANION / IOVA / NI » ${ }^{5}$. Un seul monument de Meyzieu (ILN Vienne, 551 ; Béal 2008, p. 174), aujourd'hui perdu, a été vu quasiment complet par Auguste Allmer (1878), son inventeur: une statuette en bronze posée sur un socle, également en bronze, qui portait la dédicace suivante: «Genio / aerari Diarensium. » Elle n'est actuellement pas localisée.

\section{Répartition géographique}

Les vingt-deux inscriptions ont très majoritairement été retrouvées en milieu urbain (dix-sept occurrences) : huit à Vienne, la capitale ; trois à Grenoble (pour le même homme) et quatre à Genève, deux véritables petites villes, promues chefs-lieux de cité par Dioclétien ${ }^{6}$; une à Aoste, un uicus ; une aux Échelles, une station routière qui était très probablement une agglomération urbaine ${ }^{7}$. Quatre autres ont été découvertes dans des zones rurales : celles de Chambéry/Bissy, Villette-de-Vienne et du Bourget-du-Lac étaient sans doute installées dans des sanctuaires ; trouvée en remploi dans les fondations de l'abbaye des bénédictins, celle de Talloires pourrait éventuellement provenir d'Annecy ${ }^{8}$, un autre uicus. Le dernier document a été mis au jour sur le site de la uilla antique de La Dent, près de Meyzieu (Rhône).

\section{Répartition chronologique}

Longtemps assez peu prise en compte, car il est très difficile d'établir de solides critères chronologiques, la

5. Malgré le DIVI de la ligne 3, la mention d'un empereur divinisé est très loin d'être certaine ; celle de Jupiter (IOVANI) ne l'est pas plus.

6. Voir Rémy (B.), Jospin, (J.-P.) - Cularo, Gratianopolis, Grenoble, Lyon, 2006, p. 28-30.

7. Voir Rémy 2002, p. 173-184.

8. Depuis Annecy, un transport par le lac ne poserait aucun problème, mais il reste à démontrer; l'origine exacte de la pierre demeure inconnue. datation des textes épigraphiques est maintenant devenue l'un des soucis primordiaux des épigraphistes, car une inscription non datée perd l'essentiel de sa valeur historique, même s'il est évident qu'elle garde sa valeur documentaire. En l'absence de critères formels de datation (année consulaire, titulature impériale, contexte archéologique), il faut tenter de trouver d'autres éléments chronologiques en se fondant sur l'analyse des supports (nature de la pierre, typologie du document, éléments du décor, paléographie...) et sur l'étude des caractères internes du texte (onomastique, formulaires funéraires et votifs, ponctuation...). Récemment revus par Marie-Thérèse Raepsaet-Charlier (1993), Monique Dondin-Payre (Dondin-Payre, Raepsaet-Charlier 2006) et Simina Cibu (2003), les critères internes sont les plus utilisables dans une grande cité comme Vienne, où les ateliers de lapicides devaient être assez nombreux et avaient sans doute des «façons de faire » assez différentes et où il ne faut pas exclure l'existence de lapicides itinérants. Si l'analyse des critères internes a permis des avancées non négligeables dans la voie d'une datation assez assurée des épitaphes à condition de retenir de larges plages chronologiques (demi-siècle ou, à défaut, siècle), il reste beaucoup plus délicat de proposer une chronologie même large des dédicaces aux dieux. Du coup, treize documents $(59,5 \%)$ sont indatables et la datation des autres reste seulement hypothétique. (tableau $\mathbf{n}^{\circ}$ 2)

Vu le très faible nombre de documents et le très gros pourcentage de textes indatables, il semble impossible de déterminer si les liaisons signa/tituli ont été plus fréquentes à telle ou telle période du Haut-Empire. Il est seulement certain qu'elles sont attestées tout au long des trois siècles. Le corpus de documents est d'ailleurs tellement mince qu'une telle recherche n'aurait guère de signification.

\section{Les types de monuments}

Les liaisons signa/tituli se retrouvent sur des monuments variés. Trois sont en bronze : une plaque jadis fixée sur le piédestal d'une statue (ILN Vienne, 65), un socle de statuette (ILN Vienne, 551 ; Béal 2008, p. 174) et une tête inscrite de statue (ILN, Vienne 291). À Vienne, la plaque de bronze gravée en l'honneur de C. Iulius Pacatianus (ILN Vienne, 65) a été découverte en même temps qu'une très belle tête de bronze et qu'une statue en bronze, brisée en plus de deux cents morceaux ${ }^{9}$.

9. La statue été reconstituée par le laboratoire des métaux de Nancy (France-Lanord, 1960). 
Tableau 1

\begin{tabular}{|c|c|c|c|c|c|c|}
\hline Provenance & Support & Noms mentionnés & $\begin{array}{c}\text { Type } \\
\text { d' inscription }\end{array}$ & Particularités & Date & Références \\
\hline Vienne & $\begin{array}{c}\text { Colonne ronde } \\
\text { de marbre }\end{array}$ & $\begin{array}{c}\text { Namerius } \\
\text { Euprepes, } \text { magister } \\
\text { hastiferorum }\end{array}$ & $\begin{array}{c}\text { Dédicace au Génie } \\
\text { des hastifères }\end{array}$ & $\begin{array}{c}\text { Donation d'un } \\
\text { signum Genii hastiferorum }\end{array}$ & $150-250$ & ILN, Vienne 6 \\
\hline Vienne & $\begin{array}{c}\text { Base de marbre, avec } \\
\text { traces de scellement }\end{array}$ & L. Rufius Rufinus & Dédicace à Vénus aug. & $\begin{array}{l}\text { Acquittement d'un vœu (donation } \\
\text { de l'inscription et de la statuette) }\end{array}$ & Ind. & $\begin{array}{l}\text { ILN, Vienne } \\
25\end{array}$ \\
\hline Vienne & «base hexagonale » & - & $\begin{array}{c}\text { Dédicace à une } \\
\text { divinité indéterminée }\end{array}$ & $\begin{array}{c}\text { Donation d'une statuette } \\
\text { Inscription incompréhensible }\end{array}$ & Ind. & $\begin{array}{l}\text { ILN, Vienne } \\
28\end{array}$ \\
\hline Vienne & $\begin{array}{l}\text { Plaque de bronze } \\
\text { avec trous de fixation }\end{array}$ & $\begin{array}{l}\text { C. Iulius Pacatianus, } \\
\text { procurateur impérial }\end{array}$ & $\begin{array}{l}\text { Inscription en l'honneur } \\
\text { de Pacatianus }\end{array}$ & $\begin{array}{l}\text { Cursus du chevalier, patron } \\
\text { de la colonie d'Italica qui a } \\
\text { financé l'inscription; découverte } \\
\text { en même temps d'une tête } \\
\text { et d'une statue en bronze }\end{array}$ & Vers 215 & $\begin{array}{l}\text { ILN, Vienne } \\
65\end{array}$ \\
\hline Vienne & $\begin{array}{l}\text { Deux blocs } \\
\text { quadrangulaires } \\
\text { de calcaire }\end{array}$ & $\begin{array}{l}\text { Sex. Coelius } \\
\text { Canus, questeur } \\
\text { Sex. Coelius } \\
\text { Niger, questeur } \\
\text { (Sex.) Coelius) } \\
\text { Primus, libertus } \\
\end{array}$ & $\begin{array}{l}\text { Inscriptions en l'honneur } \\
\text { des deux jumeaux }\end{array}$ & $\begin{array}{l}\text { Commémoration du décurionat } \\
\text { des deux questeurs et de } \\
\text { leur donation d'une statue } \\
\text { (simulacrum) en argent de } \\
\text { Vienne de } 200000 \text { sesterces }\end{array}$ & Ind. & $\begin{array}{l}\text { ILN, Vienne } \\
72 \text { A et B }\end{array}$ \\
\hline Vienne & $\begin{array}{l}\text { Plaque de calcaire, } \\
\text { retaillée de tous côtés }\end{array}$ & $\begin{array}{l}\text { Anonyme, flaminique } \\
\text { de Vienne }\end{array}$ & $\begin{array}{l}\text { Amélioration de } \\
\text { la décoration d'un } \\
\text { sanctuaire }\end{array}$ & $\begin{array}{l}D \text { (ecreto) } d \text { (ecurionum). Donation } \\
\text { de tuiles en bronze doré avec } \\
\text { les antéfixes et les ornements } \\
\text { sculptés, des bases, les statues } \\
\text { (signa) de Castor et Pollux avec } \\
\text { leurs chevaux et les statues } \\
\text { (signa) d'Hercule et Mercure }\end{array}$ & Ind. & $\begin{array}{l}\text { ILN, Vienne } \\
88\end{array}$ \\
\hline Vienne & $\begin{array}{c}\text { Base de statue en } \\
\text { marbre blanc }\end{array}$ & Myron & Signature d'un artiste (?) & - & Ind. & $\begin{array}{l}\text { ILN, Vienne } \\
91\end{array}$ \\
\hline $\begin{array}{l}\text { Villette-de- } \\
\text { Vienne }\end{array}$ & $\begin{array}{l}\text { Diadème d'une tête } \\
\text { de divinité féminine }\end{array}$ & $\begin{array}{l}\text { L. Litugius Laena, } \\
\text { questeur de Vienne }\end{array}$ & $\begin{array}{l}\text { Donation d'une } \\
\text { statue en bronze } \\
\text { plaquée d'argent }\end{array}$ & $\begin{array}{l}\text { L'inscription a été incrustée } \\
\text { après la réalisation de la statue } \\
\text { sur le diadème de la déesse }\end{array}$ & Ind. & $\begin{array}{l}\text { ILN, Vienne } \\
291\end{array}$ \\
\hline Grenoble & $\begin{array}{c}\text { Base de calcaire avec } \\
\text { trous de scellement }\end{array}$ & $\begin{array}{l}\text { D. Decmanius } \\
\text { Caper, chevalier }\end{array}$ & $\begin{array}{l}\text { Donation d'une } \\
\text { statue de Mars }\end{array}$ & $\begin{array}{c}\text { Donation testamentaire } \\
\text { (inscription et statue) }\end{array}$ & $14-68$ & $\begin{array}{l}\text { ILN, Vienne } \\
357\end{array}$ \\
\hline Grenoble & $\begin{array}{l}\text { Base de calcaire avec } \\
\text { trous de scellement }\end{array}$ & $\begin{array}{l}\text { D. Decmanius } \\
\text { Caper, chevalier }\end{array}$ & $\begin{array}{l}\text { Donation d'une } \\
\text { statue de Saturne }\end{array}$ & $\begin{array}{l}\text { Donation testamentaire } \\
\text { (inscription et statue) }\end{array}$ & $14-68$ & $\begin{array}{l}\text { ILN, Vienne } \\
363\end{array}$ \\
\hline Grenoble & Support indéterminé & $\begin{array}{l}\text { D. Decmanius } \\
\text { Caper, sous-préfet } \\
\text { des cavaliers de } \\
\text { l'aile Agrippiana }\end{array}$ & Épitaphe (?) de Caper & $\begin{array}{c}\text { Mention d'une donation } \\
\text { testamentaire de } 50000 \text { HS pour } \\
\text { des statues (statuas) ... et } \\
{[---] \text { en bronze }}\end{array}$ & $14-68$ & $\begin{array}{l}\text { ILN, Vienne } \\
370\end{array}$ \\
\hline Meyzieu & $\begin{array}{l}\text { Statuette et son } \\
\text { socle en bronze }\end{array}$ & - & $\begin{array}{l}\text { Dédicace au Génie des } \\
\text { bronziers Diarenses }\end{array}$ & Donation d'une statuette & Ind. & $\begin{array}{l}\text { ILN, Vienne } \\
551 ; \text { J.-Cl. } \\
\text { Béal, } 2008\end{array}$ \\
\hline Aoste & $\begin{array}{l}\text { Bloc rectangulaire } \\
\text { de calcaire }\end{array}$ & C. Virrius Quartus & $\begin{array}{c}\text { Dédicace à la } \\
\text { Victoire impériale }\end{array}$ & $\begin{array}{c}\text { Financement de l'inscription et } \\
\text { de la statue Basis, ex stipe }\end{array}$ & Ind. & $\begin{array}{l}\text { ILN, Vienne } \\
598\end{array}$ \\
\hline Les Échelles & Base quadrangulaire & T. Silvinius Catullus & $\begin{array}{c}\text { Dédicace à une } \\
\text { divinité indéterminée }\end{array}$ & $\begin{array}{c}\text { Acquittement d'un vœu (donation } \\
\text { de l'inscription et de la statue) }\end{array}$ & Ind. & $\begin{array}{l}\text { ILN, Vienne } \\
624 \\
\end{array}$ \\
\hline Chambéry/Bissy & $\begin{array}{c}\text { Base fragmentaire en } \\
\text { brèche de Vimines }\end{array}$ & $\begin{array}{c}\text { Gratus, fils de } \\
\text { Cassius }\end{array}$ & $\begin{array}{c}\text { Dédicace à une } \\
\text { divinité indéterminée }\end{array}$ & $\begin{array}{c}\text { Acquittement d'un vœu (donation } \\
\text { de l'inscription et de la statue) }\end{array}$ & $\begin{array}{l}\text { Avant } \\
37-41 \\
\end{array}$ & $\begin{array}{c}\text { ILN, Vienne } \\
636 \\
\end{array}$ \\
\hline $\begin{array}{c}\text { Le } \\
\text { Bourget-du-Lac }\end{array}$ & $\begin{array}{c}\text { Base de calcaire avec } \\
\text { trous de scellement }\end{array}$ & L. Catius Lucanus & Dédicace à Mercure & $\begin{array}{c}\text { Acquittement d'un vœu (donation } \\
\text { de l'inscription et de la statue) }\end{array}$ & Ind. & $\begin{array}{c}\text { ILN, Vienne } \\
643 \\
\end{array}$ \\
\hline Talloires & $\begin{array}{l}\text { Plaque de calcaire, } \\
\text { retaillée de partout }\end{array}$ & C. Blaesius Gratus & $\begin{array}{l}\text { Donation d'une horloge } \\
\text { hydraulique et d'un } \\
\text { esclave }\end{array}$ & $\begin{array}{l}\text { Donation du bâti, des statues } \\
\text { (signa), des grilles pour } \\
10000 \text { sesterces et d'un } \\
\text { esclave de } 4000 \text { sesterces }\end{array}$ & Ind. & $\begin{array}{l}\text { ILN, Vienne } \\
739\end{array}$ \\
\hline Genève & $\begin{array}{l}\text { Colonnette de calcaire, } \\
\text { brisée en bas avec } \\
\text { trou de scellement }\end{array}$ & $\begin{array}{l}\text { M. Veratius, } \\
\text { Mercatoris I., Bassus }\end{array}$ & Dédicace à Mercure & $\begin{array}{l}\text { Donation de l'inscription } \\
\quad \text { et de la statue }\end{array}$ & $1-100$ & $\begin{array}{l}\text { ILN, Vienne } \\
834\end{array}$ \\
\hline Genève & $\begin{array}{c}\text { Piédestal de calcaire } \\
\text { avec trou de scellement }\end{array}$ & $\begin{array}{l}\text { Q. Decius Alpinus, } \\
\text { quattuoruir }\end{array}$ & $\begin{array}{l}\text { Inscription et statue en } \\
\text { I'honneur d' Alpinus }\end{array}$ & $\begin{array}{l}\text { Financement de la statue et de l' } \\
\text { inscription par les nautes du Léman }\end{array}$ & $\begin{array}{l}\text { Avant } \\
37-41 \\
\end{array}$ & $\begin{array}{l}\text { ILN, Vienne } \\
850 \\
\end{array}$ \\
\hline Genève & $\begin{array}{c}\text { Piédestal de calcaire } \\
\text { en partie brisé avec } \\
\text { trou de scellement }\end{array}$ & $\begin{array}{l}\text { T. Riccius, T. fil. } \\
\text { Fronto, /l uir aerarii }\end{array}$ & $\begin{array}{l}\text { Inscription et statue en } \\
\text { I'honneur de Fronto }\end{array}$ & $\begin{array}{l}\text { Financement de la statue } \\
\text { et de l' inscription par les } \\
\text { héritiers, ex testamento }\end{array}$ & $50-100$ & $\begin{array}{l}\text { ILN, Vienne } \\
851\end{array}$ \\
\hline Genève & $\begin{array}{l}\text { Bloc de calcaire avec } \\
\text { trou de scellement }\end{array}$ & $\begin{array}{c}\text { [---]biena, C. f., } \\
\text { Montica flaminique, } \\
\text { épouse de [---]roius } \\
\text { Hispanus C. [---] } \\
\text { bienus Bassus, père }\end{array}$ & $\begin{array}{l}\text { Inscription et statue en } \\
\text { I'honneur de Montica }\end{array}$ & $\begin{array}{l}\text { Financement de la statue et } \\
\text { de l' inscription par le père }\end{array}$ & Ind. & $\begin{array}{l}\text { ILN, Vienne } \\
856\end{array}$ \\
\hline
\end{tabular}


Tableau 2

\begin{tabular}{|c|c|c|}
\hline Séquence chronologique & Nombre d'inscriptions & Pourcentage \\
\hline $1-50$ & 2 & $9 \%$ \\
\hline $1-100$ & 4 & $4,5 \%$ \\
\hline $50-100$ & 1 & $9 \%$ \\
\hline $150-250$ & 2 & $59,5 \%$ \\
\hline indéterminée & 13 & $100 \%$ \\
\hline Total & 22 & 100 \\
\hline
\end{tabular}

Il semble que la tête soit contemporaine de l'inscription ; elle pourrait donc être celle de Pacatianus. Le corps de la statue serait antérieur d'au moins un siècle et n'aurait apparemment rien à voir avec le chevalier. Toutefois, nous pouvons nous demander, si, comme c'est courant pour les statues en pierre, les donateurs n'auraient pas réutilisé cette belle statue en la personnalisant avec la tête de Pacatianus. Quoi qu'il en soit de cette hypothèse, il est quasiment certain que le chevalier a été honoré d'une statue, puisque la plaque inscrite était pourvue de trous de fixation. Elle se termine par un fronton triangulaire, décoré «d'un ornement en forme de disque, offrant dans son champ circonscrit par une couronne de petites feuilles le buste d'une Victoire ailée portant de la main droite une couronne et de la gauche une palme. Le disque est suspendu par deux attaches à une espèce de brochette transversale pourvue de crochets à ses extrémités et d'un anneau au milieu » (A. Allmer, Le Journal de Vienne du 31 janvier 1875). Au-dessous de l'inscription, une couronne se termine par des lentisques entre deux palmes. Aucun des autres monuments ne porte la moindre décoration, ce qui est une des caractéristiques de l'épigraphie viennoise, dont les supports sont toujours d'une grande sobriété et n'ont rien à voir avec ceux, largement décorés, de l'épigraphie de la Narbonnaise méridionale (Nîmes...).

À Meyzieu (ILN Vienne, 551 ; Béal 2008, p. 174), la statuette en bronze représentait un jeune homme imberbe debout. Son visage " poupin est encadré d'une chevelure gonflante, que souligne l'anastolè des mèches frontales» (Ibid., p. 172-173). Vêtu d'une tunique courte à col en $\mathrm{V}$ et à manches larges, serrée à la taille par une ceinture, il est chaussé de sandales à lanières. Le personnage tenait de la main gauche « une pièce séparée [disparue], engagée par l'un de ses bouts entre le pouce et les autres doigts comme dans une douille en forme d'anneau » (Allmer 1878) ; le bras droit est cassé au niveau du coude. Une entaille pratiquée transversalement devant les pieds communiquait avec l'intérieur vide du piédestal qui était creux. La statuette et le socle du Génie formaient donc une tirelire, un petit tronc destiné à recevoir les offrandes ${ }^{10}$.

À Villette-de-Vienne (ILN Vienne, 291), a seulement été retrouvée une tête de divinité féminine ${ }^{11}$ en bronze plaquée d'argent, apparemment «arrachée » d'une statue « de grandeur de nature » (A. Allmer, Le Journal de Vienne du 4 mars 1860). Formée de lettres d'argent assez médiocres, l'inscription mentionnant L. Litugius Laena, questeur de Vienne, a été incrustée dans le métal du bandeau du diadème. En certains endroits, il a même fallu procéder à des additions de pièces de métal «afin que l'incrustation en argent puisse être plus facilement réalisée » (Boucher, Tassinari 1976, p. 44).

Les autres supports sont en calcaire, en marbre ou en brèche de Vimines. Nous distinguons deux colonnes rondes (ILN, Vienne 6, 834), un petit autel en marbre (ILN Vienne, 25), deux plaques (ILN Vienne, 88, 739), neuf bases (ILN Vienne, 28, 91 [en marbre], 357, 363, 598, 624, 636 [en brèche de Vimines ${ }^{12}$ ], 643, 856), probablement onze, car deux blocs quadrangulaires (ILN Vienne, 72 A et B) sont sans doute des bases retaillées en vue d'un remploi, et deux piédestaux (ILN Vienne, 850, 851). Un support, aujourd'hui perdu, reste indéterminé (ILN Vienne, 370).

Nous retrouvons la même diversité dans les dimensions des supports épigraphiques. À Vienne, l'arula de marbre $(15,6 \times 13 \times 11,2 \mathrm{~cm})$ devait servir de socle à une statuette de Vénus (ILN, Vienne 25). Haute de $16 \mathrm{~cm}$, la statuette de Meyzieu reposait sur un socle inscrit de $5 \mathrm{~cm}$ de haut. À Villette-de-Vienne, l'inscription

10. Sur ce type d'objets, voir Kaufmann-Heinimann (A.) - Götter und Lararien aus Augusta Raurica, Forschungen in Augst, 26, Augst, 1998.

11. Boucher, Tassinari, 1976, p. $12, n^{\circ} 5$ et p. $41-45, n^{\circ} 34$.

12. Rival (D.), Tritenne (D.) - Marbres savoyards à Grenoble aux époques antique et médiévale : la brèche de Vimines et le conglomérat de Bourdeau. La Pierre et l'Écrit, 17, 2006, p. 59-83. 
était gravée sur le diadème (1. : $46 \mathrm{~cm}$; h. : env. $10 \mathrm{~cm}$ ) d'une divinité indéterminée (h. de la tête : $30 \mathrm{~cm}$ ). Deux autres monuments sont un peu plus grands : à Genève (ILN, Vienne 834), la colonnette en calcaire, retaillée, qui servait de support à une statuette de Mercure, avait une hauteur de $49,5 \mathrm{~cm}$ et un diamètre de $20,5 / 21 \mathrm{~cm}$; la base mutilée de Chambéry/Bissy (ILN, Vienne 636) mesurait $53 \times 38,5 \times 22,5 \mathrm{~cm}$.

À l'opposé, les deux plaques commémorant des donations évergétiques sont de belle taille : 153 x 262 x $40 \mathrm{~cm}$ à Vienne (ILN Vienne, 88) et $86 \times 210 \mathrm{~cm}$ à Talloires (ILN Vienne, 739), par souci d'ostentation. Les dimensions $(79,7 \times 52,4 \times 2,4 \mathrm{~cm})$ de la plaque de bronze de Pacatianus ILN, Vienne 65) et des autres bases et piédestaux attestent qu'elles supportaient des statues ${ }^{13}$.

\section{Les types de documents}

Quatre types de documents comportent une liaison signa-tituli : les dédicaces aux dieux, les hommages aux notables, les actes évergétiques et une signature d'artiste.

\subsection{Les dédicaces aux dieux}

Les dieux sont présents dans quinze des vingt-deux inscriptions de ce corpus (ILN Vienne, 6, 25, 28, 72 A et B, 88, 357, 363, 370, 551, 598, 624, 636, 643, 834) et sur un support (ILN Vienne, 291), mais seulement onze textes épigraphiques sont avant tout ${ }^{14}$ des dédicaces religieuses à telle ou telle divinité (ILN Vienne, 6, 25, 28, $357,363,551,598,624,636,643,834)$. Les cinq autres inscriptions (ILN Vienne, 72 A et B, 88, 291, 370) commémorent des actes d'évergétisme (voir p. 62) où les dieux occupent toute leur place, mais elles n'ont aucun caractère cultuel.

Les cultores ont honoré les dieux selon les complexes modalités cultuelles romaines. Comme partout, le vœu explique une bonne partie des dédicaces. Quatre dévots ont attendu la satisfaction de leur demande — plus exactement l'exécution par le dieu invoqué de sa part du contrat qu'il est réputé avoir accepté — pour s'acquitter de leur vœu, car si la demande n'était pas exaucée dans

13. Voici leurs dimensions en centimètres : $80 \times 64 \times 85$ (ILN Vienne, $643) ; 81,5 \times 66,5 \times 65,5$ (ILN Vienne, 851); $104 \times 68,5 \times 59,5$ (ILN Vienne, 72 bis) ; $108 \times 65 \times 63$ (ILN Vienne, 856$) ; 112 \times 70,5 \times 62,5$ (ILN Vienne, 850); $119 \times 92 \times 45$ (ILN Vienne, 598); 122,5 × 68 × 58 (ILN Vienne, 357$) ; 123$ x 68,5 x 62,5 (ILN Vienne, 363 ).

14. La donation d'une statue à une divinité a aussi un certain caractère évergétique, puisque cette statue ornait le sanctuaire. le délai imparti, le contrat était caduc. Leurs dédicaces sont donc des paiements libératoires, dont les formules sont traditionnelles : ex uoto (ILN Vienne, 624, 636) - u(otum) s(oluit) l(ibens) m(erito) [ILN Vienne, 25]. Nous pouvons noter au Bourget-du-Lac une formulation un peu moins courante : u(t) u(ouerat) s(oluit) l(ibens) $m$ (erito) [ILN Vienne, 643]. Les sept autres dédicaces ne sont apparemment pas votives. ILN Vienne, 6 est un « don gratuit» à la divinité : d(edit), d(edicauit); trois sont des dévotions testamentaires : testamento) $p$ (oni) i(ussit) [ILN Vienne, 357, 363, 598 ${ }^{15}$ ] ; deux ne comportent pas de formulaire religieux (ILN Vienne, 551, 834). Enfin, la dernière est inutilisable (ILN Vienne, 28).

Les dévots ont honoré des divinités variées, dont trois sont indéterminées (ILN Vienne, 28, 624, 636). Traditionnellement, depuis la conquête qui a fait connaître aux Gaulois les dieux du panthéon gréco-romain, on se demande si les dévots qui ont fait une dédicace à une divinité de nom romain priaient le dieu de Rome ou un dieu indigène dont ils avaient latinisé le nom. En fait, comme l'ont montré J. Scheid ${ }^{16}$ et M.-Th. Raepsaet-Charlier ${ }^{17}$, notamment au colloque d'Allonnes, si nous admettons une assimilation organisée et volontaire des cités galloromaines, éventuellement avec des variétés liées à des territoires précis (par exemple, chez les Trévires), il faut aussi admettre qu'il n'existe pas de différence entre des dieux qui seraient romains et des dieux qui seraient indigènes. Ils sont tous un peu des deux. Les divinités des cultes publics et probablement privés ne sont pas de simples transpositions de dieux superficiellement romanisés, car remplacer le nom indigène d'un dieu par un nom romain indique un degré décisif d'intégration dans la religion romaine des divinités et des cultores. Même si les divinités « interprétées » ont conservé une certaine dimension locale, il est probable qu'elles avaient en fait des personnalités et des fonctions très proches de celles des dieux gréco-romains du même nom, ne serait-ce que par leurs origines indo-européennes communes ${ }^{18}$

15. Curieusement, le dévot, C. Virrius Quartio, qui était apparemment un simple particulier, semble n'avoir donné que la statue. La base (basis) a été érigée avec le produit d'une quête. On peut penser que la donation testamentaire était insuffisante.

16. Scheid (J.), Les dévotions en Germanie inférieure : divinités, lieux de culte, fidèles. In : Dondin-Payre, Raepsaet-Charlier 2006, p. 297-346 ; Scheid (J.), Réflexions sur le Mars trévire. In : Mars en Occident, p. 35-44.

17. M.-Th. Raepsaet-Charlier, Les dévots dans les lieux de culte de Germanie supérieure et la géographie sacrée de la province. In : Dondin-Payre, Raepsaet-Charlier 2006, p. 347-435 ; Dondin-Payre, Raepsaet-Charlier, Les cultores de Mars en Gaule Belgique. In : Mars en Occident, p. 45-62.

18. Voir déjà Jullian (J.) - Histoire de la Gaule, III, Paris, 1909, p. 128, n.7. 
Il est probable que, par exemple Mercure, qui semble bien avoir été le dieu le plus populaire de la cité ${ }^{19}$, avait en fait une personnalité et des fonctions très proches de celle du dieu romain du même nom. Comme ses dévots, Mercure s'était largement romanisé. Toutefois, il est très probable qu'un certain nombre de cultores, même très romanisés, honoraient un dieu « indigène » sous un nom latin. Il n'est guère possible de les repérer.

Chaque dévot pouvait se faire sa propre idée de la divinité qu'il célébrait par une inscription ${ }^{20}$, mais il est assez vraisemblable que la plupart priaient à titre privé les dieux officiels de leur cité (Jupiter Optimus Maximus, Vienne, Mars ${ }^{21}$ et peut-être Mercure ${ }^{22}$ ).

Avec deux occurrences (ILN Vienne, 643, 834), Mercure est le dieu est le plus présent dans ce petit corpus. Les autres sont vénérés dans une seule inscription. Vénus a été largement célébrée dans la ville de Vienne où de très nombreux documents figurés de la déesse ont été découverts : statues (NEsp. I, $\left.\mathrm{n}^{\circ} 060-066,123\right)$, statuettes en bronze, mosaïques, médaillons d'applique (Pelletier 1982, p. 403-405). Dieu romain, Saturne (ILN Vienne, 363) ne semble pas avoir été assimilé en Gaule à une divinité de nom indigène, puisque nous ne connaissons pas d'autre dédicace assurée dans les CIL XII et XIII. Attestée à Aoste (ILN, Vienne 598), la Victoire impériale, fondatrice de l'Empire romain, a toujours conservé une importance primordiale dans cette monarchie militaire (J. Gagé, Revue Historique, 171, 1933, p. 353-364). C'est une divinité romaine ${ }^{23}$.

19. Voir Rémy 1994, p. 179-204.

20. Les Gaulois qui faisaient graver des inscriptions disposaient de quelques moyens financiers et avaient peut-être une certaine culture. 21. Prêtres publics de la cité, les flamines de Mars sont attestés à huit reprises dans son territoire (ILN Vienne, 107, 374, 549, 638, 696, 771, 845, 849). Voir Christol (M.) - Mars en Narbonnaise. Quelques remarques. In : Mars en Occident, p. 73-85.

22. À Tournon (Savoie) est attesté un prêtre de Mercure: T(itus) Domitius, T(iti) f(ilius), Montanus, / sacerdos Mercuri [...] (ILN Vienne, 532). Faute d'autres témoignages, il faut peut-être penser à un culte local.

23. Pour le développement, nous pouvons hésiter entre deux hypothèses: Victoria Aug(usti) ou Aug(usta). Dans le premier cas, Aug. est un nom, celui de l'empereur régnant. Il s'agit de la Victoire de l'Auguste. Attribut personnel du fondateur de l'Empire, la Victoire est devenue une déesse dynastique sous les Julio-Claudiens avant de veiller, à partir des Flaviens, sur chaque Auguste. Dans les légendes monétaires, lorsque Aug. est développé, c'est toujours en Victoria Augusti. Dans le second, Aug. est l'adjectif qualificatif auguste, qui accompagne si fréquemment les divinités « augustes ». Il s'agit alors de la Victoire auguste. Au vu de la répartition des inscriptions en toutes lettres (Augusti ou Augustae), il semble préférable d'envisager une dédicace à la Victoire impériale.
Enfin, les cultores ont honoré deux Génies : celui de Meyzieu n'est pas représenté sous les traits classiques d'un Génie, mais plutôt sous l'aspect d'un Lare, comme le note avec raison J.-Cl. Béal (2008, p. 174-175). Il y a donc eu une certaine confusion entre deux divinités, assez proches, il est vrai. Le Génie du collège des hastifères (les porte-lances) protégeait les membres de ce collège qui, avec les cannophores (les porte-roseaux) et les dendrophores (les porte-arbres), était une des trois confréries étroitement liées au culte de Cybèle, la Grande Mère des dieux ${ }^{24}$, qui a été réorganisé et mis en place, comme culte public, dans chaque cité par Antonin le Pieux ${ }^{25}$, mais ils étaient aussi des fournisseurs de bois d'œuvre.

\subsection{Les hommages aux notables}

Six notables ont reçu l'honneur d'une statue et d'une inscription. Le chevalier C. Iulius Pacatianus a parcouru une belle carrière équestre sous les Sévères ${ }^{26}$; il a été honoré à Vienne par la colonie Aelia Augusta Italica de Bétique, dont il était le patron «très méritant», d'une inscription honorifique retraçant son cursus (ILN Vienne, 65 ) et d'une statue en bronze. Il est très probable que les autorités d'Italica avaient souhaité remercier Pacatianus dans sa patrie ${ }^{27} \mathrm{~d}$ 'avoir empêché les tribus maures d'aller piller la Bétique, ce qui était assez fréquent ${ }^{28}$, lorsqu'il était procurateur prolégat de la province de Maurétanie Tingitane. Son titre prouve qu'il avait alors sous ses ordres des troupes régulières ${ }^{29}$.

Toujours à Vienne, (Sex. Coelius) Primus, un affranchi, a fait graver deux inscriptions (ILN, Vienne 72 A et B), au texte identique, en l'honneur de ses

24. Graillot (H.) - Le culte de Cybèle, mère des dieux à Rome et dans l'empire romain, Paris, 1912, p. 265-278 ; Burkert (W.) - Structure and History in greek Mythology and Ritual, Berkeley, 1979, p. 119 et 137. Vermaseren (M.J.), Corpus Cultus Cybelae Attidique, 4 vol., Leyde, 1977-1986. Borgeaud (Ph.) - La Mère des Dieux. De Cybèle à la Vierge Marie, Paris, 1996.

25. Voir Rémy 2005, p. 264-268.

26. Sur la carrière de Pacatianus, voir notamment Pflaum 1978, p. 232-243, n`5 et, en dernier lieu, Burnand 2006, p. 520-528, n 235 E 178 .

27. Aucun des autres documents mentionnant Pacatianus (CIL III, 865, à Napoca, en Dacie ; VI, 1642 add. ; AE 1984, 919, à Kizilburg, en Mésopotamie ; Hérodien, Histoire de l'Empire après Marc Aurèle, 3.6.10) ne précise qu'il était viennois, mais son origine ne fait pas de doute, puisque la colonie Aelia Augusta Italica est venue l'honorer à Vienne.

28. Voir Bénabou (M.) - La résistance africaine à la romanisation, Paris, 1976, p. 179-180 ; M. Christol, Antiquités africaines, 17, 1981, p. 133-141.

29. Voir Pflaum 1950, p. 129-130. 
patrons, les Coelii, frères jumeaux, qui se différenciaient seulement par leur étrange surnom : Sex. Coelius Canus, « le Blanc », et Sex. Coelius Niger, « le Noir. » Au vu des supports (deux blocs quadrangulaires), il est quasiment certain qu'il s'agit de bases retaillées qui supportaient les statues des deux frères. Primus commémorait ainsi deux évènements successifs : l'accès au décurionat de ces anciens questeurs « en raison du caractère exceptionnel de leur affection envers les leurs et de l'entente mutuelle qu'ils manifestent dans une vie commune pleine d'agrément, depuis soixante-dix-sept ans » et leur donation "d'une statue en argent de Vienne divinisée, d'une valeur de deux cent mille sesterces. » Le numen de dea Vienna est attesté dans une inscription de Rome (CIL VI, 36835), gravée par M. Numidius Paternus, un notable viennois ${ }^{30}$ ), et la déesse (Vienna Felix...) est représentée sur plusieurs médaillons d'applique lyonnais (A. Desbat et al., RANarb., 16, 1983, p. 395). C'est la somme la plus importante qui ait été consacrée à la réalisation d'une statue dans le monde romain (De Kisch 1979 ; Rémy 1992). Le passage dans la curie des anciens magistrats, qui n'étaient pas déjà décurions avant leur magistrature, n'était donc pas automatique. Il fallait un vote du sénat local pour l'autoriser ${ }^{31}$.

À Genève, trois notables municipaux ont reçu l'honneur d'une statue ${ }^{32}$. Les nautes du lac Léman, les armateurs ${ }^{33}$ qui se chargeaient notamment du transport des marchandises entre les ports de Genève et de Lousonna-Vidy ${ }^{34}$, ont honoré le quattuorvir Q. Decius Alpinus, dans le premier tiers du I ${ }^{\text {er }}$ s., avant la promotion

30. C'est en fait une base de statue (voir Rémy, Kayser 2005, p. 62-63, n ${ }^{\circ} \mathrm{XXIV)}$. Surprenante à première vue, l'invocation du numen d'un dieu n'est pas exceptionnelle dans les inscriptions du monde romain occidental. Elle est attestée à Rome (ILS, 2095 : numini sancti dei Aesculapi; ILS, 4204: Numini inuicto Soli Mithrae), mais aussi en Gaule : à Nîmes (CIL XII, 3619 : per numina diuum), à Riez [ILN Antibes, Digne, Riez, 1 : numinis (Somni)], à Alan, chez les Convènes d'Aquitaine (CIL XIII, 142 ; Sablayrolles, Schenk, 1988, p. 60 : Lahe Nu[mi]ni.)...

31. Voir la loi d'Irni en Bétique ( $A E$ 1986, 333, rubrique 31, avec une traduction de $\mathrm{P}$. Le Roux) ; Jacques (Fr.) - Le privilège de liberté. Politique impériale et autonomie municipale dans les cités de l'Occident romain, Rome, 1984, p. 394, n.52 et p. 482, n.176. Le conseil comptait un nombre fixe de décurions ; il fallait donc attendre des vacances.

32. Cette répartition est due au seul hasard de la conservation des inscriptions.

33. Voir Tran 2006, p. 103-104.

34. À Lausanne, on a retrouvé trois (?) autres inscriptions mentionnant cette corporation (Howald (E.), Meyer (E.) - Die römische Schweiz. Texte und Inschriften mit Übersetzung, Zurich, 1940, $\mathrm{n}^{\circ} 152$, 154 et peut-être $n^{\circ} 153$ ). Au vu de leur nom, les nautes du Léman devaient travailler sur tout le lac, où ils prenaient le relais des transporteurs terrestres, des nautes du Rhône et des ratiarii superiores du haut Rhône (ILN Vienne, 838). de Vienne au rang de colonie romaine pendant le règne de Caligula ${ }^{35}$, d'une statue et d'une inscription (ILN Vienne, 850). Ils voulaient sans doute remercier ce haut magistrat, qui était probablement originaire de Genève ${ }^{36}$, de sa protection. Dans la seconde moitié du I ${ }^{\text {er }}$ s., un autre magistrat viennois, le duumvir du trésor T. Riccius Fronto a demandé par testament à ses héritiers de perpétuer sa mémoire par une inscription posthume (ILN Vienne, 851) et une statue. Il appartenait à une famille de notables originaire de la région genevoise, comme l'atteste un monument funéraire familial (ILN Vienne, 883). La gens des Riccii possédait aussi des domaines dans la région d'Allinges (Haute-Savoie), où est connue une autre épitaphe familiale (ILN Vienne, 812), mentionnant notamment un personnage homonyme duumvir du trésor, qu'il faut probablement identifier au Fronto de Genève.

Enfin, à une date indéterminée, C. [---]bienus Bassus, le père de [---]biena Montica, une flaminique impériale municipale, épouse de [---]roius Hispanus, a fait graver une inscription (ILN Vienne, 856) et élever une statue à sa fille sur un emplacement donné par décret des décurions. Cette autorisation et le flaminicat de Montica montrent que la famille occupait une place éminente à Genève et même à Vienne et qu'elle savait se montrer généreuse. Bassus n'a pas précisé les raisons de la publicatio de la statue de sa fille. Nous pouvons penser à l'élection au flaminicat ou à un honneur post mortem.

\subsection{Les actes évergétiques ${ }^{37}$}

Cinq notables ont fait à leurs compatriotes d'importantes donations, dont quatre ont un caractère religieux. À Grenoble, D. Decmanius Caper appartenait à l'ordre équestre (ILN Vienne, 370), où il a fait une très courte carrière. Il a occupé le seul poste, fort peu courant (seulement deux autres titulaires à Aquilée ${ }^{38}$ ), de sous-préfet d'une aile de cavalerie. Comme ces trois officiers n'ont pas occupé d'autre fonction militaire, nous ignorons quel était leur rang exact dans la hiérarchie et en quoi consistait leur commandement en second. Caper a servi dans l'ala Agrippiana, une unité très mal connue, puisqu'elle

35. Sur cette promotion voir Gascou (J.) - Introduction. In : ILN Vienne, vol. 1, p. 40. Le nouveau statut a remplacé le collège des quattuorvirs par deux collèges de duumvirs (ibid., p. 43-52).

36. Le plus ancien représentant connu de cette famille est P. Decius Esunertus, fils de Trouceteius Vepus mentionné à Landecy (ILN Vienne, 868) en 8 avant J.-C.

37. Sur l'évergétisme dans la cité, voir Rémy 1992, p. 201-221.

38. Voir Brusin (J.-B.) - Inscriptiones Aquileiae, 3 vol., Udine, 1991-1993, n²813, 2815. 
n'est mentionnée que dans une autre inscription (julioclaudienne ?) de Worms en Germanie supérieure (CIL XIII, 4235) ${ }^{39}$. Dans son testament, il a indiqué que la somme non négligeable de cinquante mille sesterces ${ }^{40}$ devait être consacrée à orner de statues au moins de Mars (ILN Vienne, 357) et de Saturne (ILN, Vienne 363), ainsi que d'objets en bronze, un monument indéterminé et non localisé ${ }^{41}$.

Trois autres documents proviennent de Vienne. Voir, supra p. 62 pour la donation de la statue de Vienne par les frères Coelii. Peut-être pour commémorer son élection au flaminicat (évergétisme ob honorem ${ }^{42}$ ) ou, moins sûrement, dans le cadre d'un évergétisme libre, une flaminique anonyme a fait graver une grande inscription, aujourd'hui très mutilée (ILN Vienne, 88 ), pour perpétuer une importante donation. À une date inconnue, elle a contribué à l'embellissement de l'ensemble cultuel situé sur la partie supérieure du théâtre (au mont Pipet) en offrant « les tuiles en bronze doré, avec les antéfixes et les ornements sculptés des bases, les statues de Castor et Pollux, avec leurs chevaux, et celles d'Hercule et de Mercure. » La mention de tuiles de bronze doré et de carpuscula est unique en Narbonnaise. Très rare, le mot carpusculum se rencontre à Aequum en Dalmatie (CIL III, 9768 ; voir THLL 3, 491). N. Blanc (1989, p. 79-80) considérait que les quatre statues pourraient être des acrotères dont les bases auraient été pourvues d'un revêtement, uestitura; au vu de la taille de l'inscription commémorative, cette vision minimaliste doit rester une hypothèse. Le mot uestitura est un hapax. Les Dioscures semblent avoir joui d'une certaine popularité à Vienne, où a été retrouvé, près du mithraeum, un relief représentant un dieu léontocéphale au centre, Aïon ou Kronos, encadré par les dieux cavaliers (Nouvel Espérandieu I, p. 65-66, $\mathrm{n}^{\circ} 131$ ) et dans la partie orientale de la cité (ILN Vienne, 736, 752, 784, 785). Si Mercure est largement attesté dans l'épigraphie du territoire viennois (B. Rémy,

39. Selon Stein (E.) - Kaiserliche Beamte und Truppenkörper im römischen Deutschland unter dem Prinzipat, mit Benützung von E. Ritterling, Vienne, 1932, p. 121, elle devrait son surnom soit au gendre d'Auguste, soit au roi de Judée, Agrippa I ${ }^{\text {er }}$ qui a pris part en 39-40 à la guerre de Caligula contre les Germains (Dion Cassius, Histoire romaine, 59.24.1).

40. Sur le montant des évergésies, voir De Kisch 1979, p. 259-280.

41. Les trois inscriptions ont été retrouvées en remploi.

42. Au moins à titre d'hypothèse, il semble possible de le déduire du texte de l'inscription : «(Une telle), par décret des décurions, flaminique de Vienne donne... » qui rappelle que cette prêtresse anonyme a été choisie par le conseil municipal, puis nommée par décret des décurions. La donation aurait suivi la désignation.
1994, p. 179-204), Hercule n'est connu que par des statuettes en bronze qui soulignent une piété populaire ${ }^{43}$.

À Villette-de-Vienne (ILN Vienne, 291), c'est sans doute à l'occasion de son élection à la questure que L. Litugius Laena a offert la statue d'une divinité féminine en bronze plaquée d'argent, dont seule la tête a été retrouvée. Afin de perpétuer sa donation, Laena a fait ajouter sur le diadème son nom et son titre. Rien ne permet d'attribuer cette tête à une déesse précise, mais, au vu de l'inscription, St. Boucher et S. Tassinari (1976, p. 44) pensaient à Vienna. Remarquant la qualité exceptionnelle de ce bronze, elles considéraient (ibid.) qu'il avait été importé et proposaient de le dater du début de l'Empire romain, «dans les années les plus prospères de la colonie. » Cet argument (prospérité précoce, suivie d'un déclin) n'est historiquement pas recevable; néanmoins, si Laena a offert une effigie de Vienne, la statue pourrait être de haute époque. En effet, cette statue n'a rien avoir avec la représentation de Vienna sur des médaillons d'applique, découverts à Lyon où la déesse (Vienna felix) tenant une corne d'abondance et un sceptre porte, sur ses cheveux coiffés en rouleaux et ramenés en chignon sur la nuque, une couronne à quatre tours rayonnantes et à trois portes ${ }^{44}$. Laena aurait alors donné la statue à une époque où le type de Vienna n'était pas encore fixé. Toutefois, il est peut-être plus simple de renoncer à cette identification et d'envisager que ce notable a offert la statue d'une déesse qui avait ses faveurs et n'avait rien à voir avec Vienna. Le lieu de trouvaille, hors de Vienne, peut-être dans un sanctuaire rural, semble renforcer cette solution. L'évergète aurait richement doté le sanctuaire local.

À Talloires, C. Blaesius Gratus, qui était apparemment un simple particulier, a offert à ses compatriotes une horloge hydraulique (?) « avec toutes ses statues et ses grilles », c'est-à-dire un ensemble monumental avec des ornements en métal ou en pierre, peints ou gravés, et des barreaux de bois ou de métal formant une clôture ${ }^{45}$. Nous ignorons tout de la nature des statues, mais il est fort peu probable que ce soit des statues divines, car le donateur l'aurait probablement indiqué. L'horloge était

43. Rémy (B.) - Hercule chez les Allobroges et dans la cité de Vienne, $1^{\text {ère }}$ partie. La Pierre et l'Écrit, 13, 2002, p. 9-28; Hercule chez les Allobroges et dans la cité de Vienne, $2^{\mathrm{e}}$ partie. La Pierre et l'Ecrit, 14, 2003, p. 279-293.

44. Audin (A.) - Vienna Felix. Bulletin de la Société des amis de Vienne, 57-58, 1961-1962, p. 65-66 ; voir aussi A. Desbat et al., RANarb., 16, 1983, p. 395.

45. Avec N. Blanc (1989, p. 77-78), il faut noter que le terme clatri est assez rare. L'orthographe sans $h$ pourrait indiquer que ce mot était passé dans la langue populaire (CIL VI, 260 ; ILS, 5448). 
peut-être analogue à celle de Ctesibios (Vitruve, Sur l'architecture, 10.7 ; voir p. 56). À cette donation d'un montant de dix mille sesterces, ce qui est relativement modeste (De Kisch 1979), Gratus a ajouté un esclave de quatre mille sesterces. Ce dernier devait assurer l'entretien de l'horloge qui était peut-être assez compliquée, à en juger par le prix de cet esclave, qui était deux fois supérieur à la valeur légale (Digeste, $1.4 .31 ; 40.4 .47$; 5.2.8.17; 5.2.9 $\left.{ }^{46}\right)$. Gratus a perpétué ce don par une inscription (ILN Vienne, 739), où il détaille ses générosités. Nous pouvons d'ailleurs nous interroger sur la pérennité d'une telle donation si l'évergète n'avait pas pris soin d'instituer une fondation, car la machine était assez fragile et l'esclave n'était pas immortel ${ }^{47}$.

\subsection{La signature d'artiste}

Il est étonnant de trouver une signature d'artiste ici ${ }^{48}$. Les signatures sont rares dans le monde romain en raison de la conception même de l'art qui ne privilégie pas la création, mais le commanditaire, en raison aussi du statut social de l'artiste considéré souvent comme un artisan. Le mépris qui l'entourerait, prolongeant l'attitude des Grecs, dépend en fait des milieux qui s'expriment (Platon représente l'aristocratie et ses préjugés), des époques, ainsi que des préjugés des contemporains, historiens ou sociologues ${ }^{49}$. Pour l'époque romaine, les sculpteurs sont un peu moins anonymes dans la mesure où ayant souvent effectué des copies d'œuvres grecques, ils signèrent leurs œuvres ${ }^{50}$. Mais bien sou-

46. Voir Duncan-Jones (R.) - The Economy of the Roman Empire. Quantitative Studies, Cambridge, 1974, p. 348-350.

47. Nous touchons là un des problèmes de fond de l'évergétisme dans les cités : le suivi des donations de «monuments » qui pouvaient grever lourdement les budgets municipaux.

48. Andreae (B.) - L'art romain, Paris, 1998, p. 603-606 ; BianchiBandinelli (R.) - L'artista nell'antichità Classica. Arch. Class., 9, 1957, p. 1-17 ; Chevalier (R.) - L'artiste, le collectionneur et le faussaire. Pour une sociologie de l'art romain, Paris, 1991 ; Coarelli (F.) - Artista e società nel mondo antico. In : Revixit Ars. Arte e ideologia a Roma dai modelli ellenistici alla tradizione repubblicana, Rome, Quasar, 1996, p. 1-14.

49. Rolley (C.) - La sculpture grecque, I, Paris, 1994, p. 54-57.

50. Les autres secteurs de l'art ne sont guère mieux connus: on connaît quelques noms de mosaïstes tel ce Conculcanus, un Aquitain de Saint-Romain (Inv. I, $\mathrm{n}^{\circ} 688$ ), ou Pythis, qui se dit fils d'Antiochos, un Grec ayant travaillé à Nîmes. En Afrique du Nord, des inscriptions permettent d'entrevoir un travail d'équipe : «de la main de Sabinianus, sans peintre » ou «Sabinianus Senurianus a peint et a réalisé le pavement ». À Lambèse, un mosaïste signe en grec le nom du peintre Aspasios dont il s'est inspiré pour un pavement des Néréides. En revanche, les signatures de potiers ou coroplathes (Sacrillos ou Rextugenos dont la production a donné lieu à des contrefaçons utilisant sa signature ou d'autres noms tels Iulos ou Pestika) sont nombreuses. Lambert (P.-Y.) - RIG, II, 2, Textes vent, ils sont plus connus par les sources littéraires. Pline l'Ancien fournit une liste de noms d'artistes, surtout grecs et énumèrent leurs travaux dont la plupart ne sont pas parvenus jusqu'à nous. Quelques exemples, qui n'épuisent pas le sujet, concernent naturellement Rome, le milieu aristocratique et impérial ${ }^{51}$. C. Avianus Evander, esclave originaire d'Athènes, fut affranchi. Il conseilla Cicéron dans l'acquisition d'œuvres d'art et fut chargé par Auguste de refaire la tête de "l'Artémis » de Timothéos ${ }^{52}$. Horace vante ses qualités en toreutique. Le Naturaliste cite un Scopas comme sculpteur de panneaux représentant un thiase marin ${ }^{53}$. Diogénès, originaire d'Athènes, se chargea du décor du Panthéon d'Agrippa au sein duquel figuraient des caryatides ${ }^{54}$. Le nom d' «Apollonios » apparait sur plusieurs œuvres : un est fils d'Archias ; une tête d'une copie du « Doryphore » de Polyclète porte sa signature. Un autre, fils de Nestor, est l'auteur du «torse du Belvédère » où l'on voit sa signature. On a voulu lire son nom sur le «Pugiliste» en bronze, du Musée des Thermes à Rome, réalité de la signature infirmée par des analyses plus précises. D'autres homonymes apparaissent sans qu'on sache s'il s'agit du même : l'un serait l'auteur d'une statue chryséléphantine de Jupiter Capitolin voulue par Domitien. La signature de C. Vibius Rufus se trouve au bas d'une caryatide du forum d'Auguste ${ }^{55}$. Aristeas et Papias sont les auteurs des deux centaures en marbre noir qui se trouvaient à la villa Hadriana (Musées Capitolins : MC 656). Enfin, Glycon signe une fort mauvaise copie (Glykon Athenaios epoiesen) d'un Héraklès de Lysippe : «L'Hercule Farnèse » (Musée Archéologique de Naples, inv. 6001)! Les empereurs et leur entourage font appel aux plus illustres. Le prestige d'une œuvre peut se mesurer à son prix : la statue de Felicitas exécutée par Arcésilas pour Lucius Lucullus a coûté un million de sesterces et le Mercure sculpté par Zénodoros pour les Arvernes atteint quarante millions de sesterces.

Dans un tel contexte, essayons de mieux cerner la présence d'une éventuelle signature de sculpteur à Vienne, que Claude qualifiait d'ornatissima et que

gallo-latins sur instrumentum, Paris, CNRS éditions, 2002, p. 33-35, 57-59.

51. On possède de rares exemples en Gaule: à Saint-GermainSources-de-la-Seine, le sculpteur Dagolitus a laissé sa signature, de même que Samotalos à Alise-Sainte-Reine ou Itos, auteur d'un très modeste chapiteau.

52. Pline, $H N, 36.32$.

53. Pline, $H N, 36.22$.

54. Pline, $H N, 35.38$.

55. Lesk (A.L.) - Caryatides probantur inter pauca operum : Pliny, Vitruvius, and the Semiotics of the Erechtheion Maidens at Rome. Arethusa, 40, 1, 2007, p. 25-42. 
le $\mathrm{XIX}^{\mathrm{e}}$ s. a appelé « la ville des statues. » Il revient à Nicolas Chorier, appartenant à l'élite du Dauphiné au XVII ${ }^{\mathrm{e}}$ s., un temps avocat à Vienne, d'être un des premiers à porter attention à ces sculptures ${ }^{56}$. Il note la découverte vers 1644-45, dans les restes d'un édifice alors considéré comme des thermes, juste à l'est du Palais des Canaux, d'une tête colossale (athlète nu ? empereur?), d'un pied « d'airain », avec une autre statue d'une déesse "vêtue à la romaine et qui porte une corne d'abondance », sans doute Fortuna, ainsi qu'un socle de marbre blanc avec une inscription en grec au génitif de MYPON, interprétée comme la signature du sculpteur ${ }^{57}$. Cette base était-elle celle de l'athlète (aujourd'hui introuvable), de la statue féminine (détruite) ? On ne saurait le dire. R. Robert ${ }^{58}$ souligne les découvertes dans la ville de plusieurs ensembles de fragments sculpturaux, mais retrouvés dans un même endroit comme le précédent ou l'importante série du "Palais des Miroirs. » Ils témoignent tous d'une qualité rare en Gaule, ce qui permettrait d'envisager l'existence de véritables collections d'art. Dans ces conditions, une signature d'artiste n'est pas incongrue, si elle est authentique ${ }^{59}$. En admettant qu'elle le soit, qui désigne-t-elle ? Il existe plusieurs sculpteurs portant ce nom et non des moindres. Myron d'Athènes, né vers 485 av. J.-C., bronzier, présenté comme le rival de Polyclète ${ }^{60}$, est l'auteur du Discobole et, entre autres sujets animaliers, d'une Génisse qui le rendit très célèbre puisqu'elle est encore connue au $\mathrm{V}^{\mathrm{e}} \mathrm{s}$. ap. J.-C. Un homonyme œuvrait à la cour des Attalides vers 240 av. J.-C. où il collabora aux statues commémorant la victoire sur les Galates. Il est l'auteur aussi de la vieille femme ivre connue par de multiples répliques ${ }^{61}$. Il paraît difficile d'attribuer à l'un ou à l'autre la signature de Vienne. D'autre part, des artistes ultérieurs, recopiant une statue connue pouvaient par déférence signer du nom de ces sculpteurs. Pour R. Robert, il s'agirait, dans ce cas, d'une signature qui aurait fonction d' « étiquettes muséales » permettant d'identifier et classer les œuvres. Elles traduiraient un souci didactique qui en assurerait la qualité. Ces collections contribuaient ainsi à la dignitas

56. Lauxerois (R.) - L'histoire des collections viennoises de sculpture antique: fascination et avatars. In: Nouvel Espérandieu I, p. XXV-XLII.

57. Chorier (N.) - Recherches sur les antiquités de la ville de Vienne (1659), réédité par N. Cochard, Vienne, 1846, p. 401-402; Nouvel Espérandieu I, p. 22, n ${ }^{\circ} 048$ et p. 204 n $^{\circ}$ AI.004.

58. Robert (R.) - Introduction à la sculpture de Vienne. In : Nouvel Espérandieu I, p. XLIII-LII.

59. Opinion réfutée par Loewy (E.M.) - Inschriften Griechischer Bildhauer, Leipzig, 1885, p. 333, n 499.

60. Pline, $H N, 34.57$ avec la liste de ses œuvres 57-58.

61. Pline, $H N, 36.32$. de la cité ${ }^{62}$. Que des thermes ou édifices des eaux aient pu les abriter, il n'y a là rien d'extraordinaire.

Quelle que soit la réponse, la seule présence d'une signature, si elle est authentique, conforterait l'importance de la sculpture à Vienne.

\section{Donateurs et receveurs}

\subsection{Les communautés, les femmes et les hommes}

Les vingt-deux inscriptions mentionnent trois communautés très différentes: la colonie Aelia Augusta Italica de Bétique (voir p. 61), les nautes du lac Léman, une association professionnelle locale (voir p. 62), et les Diarenses.

Dans les ILN Vienne, notamment, l'un de nous (BR) avait suivi l'opinion d'O. Hirschfeld (CIL XII, 2370) et comprenait l'inscription de Meyzieu comme une dédicace Genio aerar(i) Diarensium, au Génie du trésor des Diarenses. Il estimait que l'inscription témoignait de l'existence d'une collectivité du nom de Diarenses, disposant d'un trésor. Bien que Meyzieu soit loin de la région comprise entre Hauteville et Seyssel, où est attesté un pagus Dia... (ILN Vienne, 778, 784), et que nous n'ayons pas de preuve de l'existence dans la cité de communautés de pagani, il proposait, avec prudence, de restituer pagus Diarensis dans les deux inscriptions de Haute-Savoie et d'envisager que les Diarenses, qui portaient un nom indigène, étaient les habitants de ce pagus, car une statuette pouvait facilement voyager ${ }^{63}$. Or dans un récent article, Jean-Claude Béal (2008, p. 173-174) vient de faire remarquer que le terme d'aerarium désigne "les trésors publics de Rome ... ou des capitales régionales ... (mais) ne s'applique pas à des collectivités plus modestes » et qu'il fallait donc revenir à l'hypothèse, trop méconnue, d'Auguste Allmer (1878) : Genio aerar(iorum) Diarensium, au Génie des bronziers Diarenses ${ }^{64}$.

Probablement installés sur le site de La Dent, où ont été retrouvées de nombreuses traces d'activités

62. R. Robert, loc. cit., p. XLIII-LII ; Slavazzi 1996, p. 199-200.

63. Il est quasiment impossible d'envisager que le pagus Dia(-) ait pu s'étendre jusqu'à Meyzieu.

64. Des associations de bronziers sont connues à Rome (CIL VI, 9136), à Milan (CIL V, 5847, 5892)... 
métallurgiques ${ }^{65}$, ces bronziers s'étaient regroupés en une association professionnelle locale. Cette solution explique l'absence du nom des dédicataires. Dès lors, le rapprochement avec le pagus de Haute-Savoie devient nettement plus hasardeux. Il est beaucoup plus probable que les Diarenses étaient les habitants du lieu de découverte de la statuette, mais il est impossible de retrouver le nom exact de ce toponyme (Diar...). Destinée à recueillir de modestes (vu sa taille) offrandes monétaires, la statuette pourrait avoir été placée dans un sanctuaire local, puisqu'au moins trois statuettes religieuses de bronze ont été retrouvées sur le site antique, ce qui est rare (Béal 2008, p. 172).

Les autres textes nous font connaître dix-neuf hommes et seulement deux femmes, dont une anonyme. Cette très importante sous-représentation des femmes est due au seul hasard de la découverte des inscriptions, puisque sur les mille quarante-six citoyennes et citoyens romains de la cité, dont la dénomination est suffisamment bien conservée pour nous permettre de distinguer les hommes et les femmes, nous avons recensé deux cent soixante-sept femmes (soit $25 \%{ }^{66}$ ) et sept cent soixantedix-neuf hommes.

Quatorze hommes et une femme ont pris l'initiative d'offrir une ou plusieurs statues/statuettes ${ }^{67}$. Cinq hommes et une femme ont reçu l'honneur d'une statue ${ }^{68}$. Remarquons que les frères Coelii ont été tour à tour donataires et receveurs. Pour sa part, [---]roius Hispanus est seulement mentionné par son beau-père en tant qu'époux de [---]biena Montica dans ILN, Vienne 856. Nous ignorons quel rôle il a pu jouer dans l'honneur accordé à sa femme.

\subsection{Le statut juridique}

Sauf Myron, un artiste grec (?, voir p. 65), dont nous ignorons le statut juridique, et Gratus, fils de Cassius (ILN Vienne, 636), un pérégrin qui a vécu avant Caligula, alors que la cité était de droit latin, toutes les femmes et

65. Monnier (J.) - La Dent, site gallo-romain à Meyzieu (Rhône), Lyon, 1990.

66. Voir Rémy 2001, p. 56-57.

67. Namerius Euprepes, L. Rufius Rufinus, Sex. Coelius Canus, Sex. Coelius Niger, (Sex. Coelius) Primus, la flaminique anonyme, L. Litugius Laena, D. Decmanius Caper, C. Virrius Quartio, T. Silvinius Catullus, Gratus, fils de Cassius, L. Catius Lucanus, C. Blaesius Gratus, M. Veratius Bassus, [---]roius Hispanus, C. [---] bienus Bassus.

68. C. Iulius Pacatianus, Sex. Coelius Canus, Sex. Coelius Niger, Q. Decius Alpinus, T. Riccius Fronto, [---]biena Montica. tous les hommes mentionnés dans ces documents étaient des citoyennes et des citoyens romains. Ils appartenaient au moins aux couches moyennes de la population et disposaient de solides moyens financiers, car une inscription et une statue ou même une statuette coûtaient cher. En fait, il est probable que ces hommes et ces femmes étaient des notables, au moins locaux ${ }^{69}$, même ceux qui étaient apparemment de simples particuliers, puisqu'ils n'ont indiqué ni magistratures, ni prêtrises, à l'exception de (Sex. Coelius) Primus (ILN Vienne, 72 A et B) et de M. Veratius Bassus (ILN Vienne, 834) deux affranchis de citoyens romains, à tout le moins aisés. À jamais marqués par leur macule servile, ils ne pouvaient prétendre appartenir à la «bonne société. » Pourtant, ils n'étaient pas les affranchis du premier venu. Primus avait reçu la liberté des richissimes frères Coelii et Bassus la devait à M. Veratius Mercator. Contrairement à l'habitude, ce n'est pas par son prénom que ce patron, qui est certainement l'auteur d'une dédicace à Apollon (ILN Vienne, 817), est désigné, mais par son surnom. L'ancien esclave montrait ainsi qu'il n'était pas l'affranchi d'un quelconque Marcus, mais bien d'un personnage important, à la notoriété duquel il participait ${ }^{70}$. Le surnom grec de Namerius Euprepes pourrait indiquer que lui aussi était un affranchi.

\subsection{Les honorati}

Les neuf honorati recensés n'étaient pas tous du même niveau. Deux appartenaient à l'ordre équestre, dans lequel C. Iulius Pacatianus, "procurateur de nos Augustes », a fait une belle carrière au service des Sévères, alors que D. Decmanius Caper a été seulement sous-préfet des cavaliers de l'aile Agrippiana. Six en sont apparemment restés au niveau municipal. En tant que quattuorvir, Q. Decius Alpinus est parvenu au sommet de la hiérarchie des magistratures de la colonie latine ; duumvir du trésor, T. Riccius Fronto n’a pas accédé $\mathrm{au}$ triumvirat locorum publicorum persequendorum qui couronnait la carrière municipale dans la colonie romaine $^{71}$. Les deux jumeaux Coelii ont obtenu la questure et le décurionat; L. Litugius Laena a été au moins questeur. Enfin, l'anonyme de ILN Vienne, 88 et [---]biena Montica furent flaminiques impériales de la

69. Il faut absolument faire la distinction entre notables et honorati. Sur les notables de la cité, voir Rémy 1998, p. 77-120.

70. Cette manière d'indiquer l'affranchissement n'est pas propre à la Gaule romaine. On la trouve déjà dans la Rome républicaine (Eck (W.) - Die Verwaltung des römischen Reiches in der hohen Kaiserzeit, Ausgewählte und erweiterte Beiträge, 2. Band, Cologne, 1998, p. 221-224).

71. Gascou (J.) - Introduction. In : ILN Vienne, vol. 1, p. 43-52. 
Tableau 3

\begin{tabular}{|c|c|c|c|c|}
\hline Provenance & Noms & Gentilices & Surnoms & Datation \\
\hline Vienne & Namerius Euprepes & celtique unique en $\mathrm{N}$ & grec 7 autres en $\mathrm{N}$. & $150-250$ \\
\hline Vienne & L. Rufius Rufinus & « latin régional » 9 autres en N. & « latin italien » assez courant en N. & Ind. \\
\hline Vienne & C. Iulius Pacatianus & « latin italien » courant en N. & « latin italien » unique en $\mathrm{N}$. & ca 215 \\
\hline Vienne & Sex. Coelius Canus & « latin italien » courant en N. & « latin régional » 3 autres en $\mathrm{N}$. & Ind. \\
\hline Vienne & Sex. Coelius Niger & « latin italien » courant en N. & « latin régional » courant en N. & Ind. \\
\hline Vienne & (Sex. Coelius) Primus & « latin italien » courant en N. & « latin régional » courant en $\mathrm{N}$. & Ind. \\
\hline Villette-de-Vienne & L. Litugius Laena & celtique unique en $\mathrm{N}$. & celtique unique en $\mathrm{N}$. & Ind. \\
\hline Grenoble & D. Decmanius Caper & celtique unique en $\mathrm{N}$. & « latin italien » 1 autre en $\mathrm{N}$. & $14-68$ \\
\hline Aoste & C. Virrius Quartio & $\begin{array}{l}\text { « latin régional » assez } \\
\text { courant en N. avec } 2 \mathrm{R}\end{array}$ & « latin régional » ? assez courant en $\mathrm{N}$. & Ind. \\
\hline Les Échelles & T. Silvinius Catullus & « latin italien » (?) 1 autre en N. & « latin italien » 11 autres en N. & Ind. \\
\hline Le Bourget-du-Lac & L. Catius Lucanus & « latin régional » 6 autres en $\mathrm{N}$. & « latin régional » (?) 8 autres en $\mathrm{N}$. & Ind. \\
\hline Talloires & C. Blaesius Gratus & « latin italien » 6 autres en $\mathrm{N}$. & « latin italien » 5 autres en $\mathrm{N}$. & Ind. \\
\hline Genève & M. Veratius Bassus & « latin italien » courant en N. & celtique (?) 12 autres en $\mathrm{N}$. & $1-100$ \\
\hline Genève & Q. Decius Alpinus & « latin italien » 2 ou 3 autres en $\mathrm{N}$. & « latin italien » 4 autres en $\mathrm{N}$. & av. $37-41$ \\
\hline Genève & T. Riccius Fronto & celtique unique en $\mathrm{N}$ & « latin italien » assez courant en N. & $50-100$ \\
\hline Genève & [---]biena Montica & $(?)$ & celtique (?) hapax & Ind. \\
\hline Genève & [---]roius Hispanus & (?) & « latin italien » unique en $\mathrm{N}$. & Ind. \\
\hline Genève & C. [---]bienus Bassus & $(?)$ & celtique (?) 12 autres en $\mathrm{N}$. & Ind. \\
\hline
\end{tabular}

cité. Peut-être affranchi, Namerius Euprepes, un dévot de la Grande Mère des dieux, a eu l'honneur de devenir président du collège des hastifères.

\subsection{La dénomination des hommes et des femmes ${ }^{72}$}

Myron, l'artiste grec (?), peut-être de passage, portait un nom grec fréquent dans la Province, mais rarissime dans la cité (une seule autre occurrence : ILN Vienne, 124, à Vienne). Gratus, fils de Cassius, portait la dénomination officielle des pérégrins (nom unique, suivi de son patronyme). Nom latin, Gratus est courant en Narbonnaise et dans la cité. Très fréquent dans la Province comme gentilice, Cassius, un autre nom latin, y est beaucoup plus rare en tant que cognomen ou nom unique. Il pourrait présenter une consonance indigène et renvoyer à la racine celtique Cassi-, présente dans un adjectif gaulois signifiant «enchevêtré », « touffu » (P.-Y. Lambert, La langue gauloise, $2^{\mathrm{e}}$ éd., Paris 2003, p. 195).

Les dix-huit citoyenn(e)s romain(e)s portaient la dénomination traditionnelle. [---]biena Montica, la seule

72. Pour une étude plus complète, voir Rémy 2001. femme, avait les duo nomina suivis de sa filiation par le prénom de son père. Chez les hommes, quinze portaient les tria nomina, Namerius Euprepes s'est désigné par les seuls duo nomina seconde manière. Nous ignorons si [---]roius Hispanus portait ou non un prénom. Seulement, deux ingénus ont indiqué une dénomination complète, ce qui n'est pas surprenant sous l'Empire : G(aius) Blaesius, G(ai) fil(ius), Voltinia, Gratus et T(itus) Riccius, T(iti) fil(ius), Vol(tinia), Fronto. L(ucius) Litugius, Sex(ti)f(ilius), Laena, un ingénu, n'a pas mentionné sa tribu. Privé de droits politiques, M(arcus) Veratius, Mercatoris l(ibertus), Bassus, un affranchi de citoyen romain, n'était pas inscrit dans une tribu. La dénomination des jumeaux Coelii comporte la tribu, mais non la filiation. Faut-il en déduire qu'ils étaient les premiers citoyens de la famille, ce qui, vu leur âge, daterait leurs inscriptions de la seconde moitié du $\mathrm{I}^{\mathrm{er}} \mathrm{s}$. ? Dans les textes privés, les citoyen(ne)s considéraient que l'indication de la filiation était seulement un moyen de s'inscrire dans une descendance familiale et n'apportait pas de précision sur leur ingénuité. Les affranchis de citoyens romains ne respectaient pas plus l'obligation d'indiquer leur affranchissement. Les inscriptions étaient gravées à l'intention des contemporains qui n'avaient aucun doute sur l'identité et le statut juridique des défunts et des dédicants. La tribu allait de soi dans une colonie romaine. (tableau $\mathbf{n}^{\circ} \mathbf{3}$ ) 


\section{Les gentilices}

Nous connaissons les gentilices de quinze hommes, car nous ne pouvons restituer les noms trop mutilés de [---]biena Montica, [---]roius Hispanus et C. [---] bienus Bassus. Sept hommes portaient un gentilice « latin italien » $(50 \%)$, trois un gentilice « latin régional homonyme » $(21,4 \%)$ et quatre un gentilice indigène $(28,6 \%)^{73}$. Pour Silvinius, il est difficile de trancher entre les trois possibilités ${ }^{74}$. Les gentilices «latins italiens » sont donc à égalité avec les gentilices indigènes ou à tonalité indigène. Sauf Decius, les gentilices «latins italiens » et les gentilices «latins régionaux » sont bien ou assez bien représentés dans la Province, alors que les noms indigènes ne sont pas attestés ailleurs en Narbonnaise ${ }^{75}$.

\section{Les surnoms}

Nous disposons de dix-huit cognomina. Huit hommes portaient un surnom «latin italien» $(44,4 \%)$, quatre peut-être cinq des surnoms qui pourraient être des noms « latins régionaux » (un nom « homonyme »? et quatre noms de traduction?), soit $(27,7 \%)$; deux hommes avaient un surnom qui pourrait être indigène ${ }^{76}$; Laena avait un surnom gaulois. Montica, la seule femme, portait un cognomen qui ne se retrouve pas dans les inscriptions sur pierre du monde romain et semble bien être celtique. C'est en tout cas le nom d'un potier de La Graufesenque (X. Delamarre, 2007, p. 136). Il pourrait donc y avoir quatre cognomina celtiques $(22,2 \%)$. Seul Euprepes avait un surnom grec $(5,7 \%)$. Globalement, à l'exception de Rufinus, Fronto, Niger et Primus, ces surnoms sont relativement peu fréquents dans la Province. Notons que les deux affranchi n'avaient pas un surnom grec: Primus portait un surnom latin, peut-être de traduction ; Bassus, un cognomen peut-être indigène.

Seul, L. Litugius Laena avait une dénomination purement indigène ; trois, peut-être quatre autres (C. Iulius Pacatianus, Q. Decius Alpinus, C. Blaesius Gratus, T. Silvinius Catullus ?) des noms «latins italiens». Enfin, deux (C. Virrius Quartio, L. Catius Lucanus) pourraient avoir porté des noms «latins régionaux».

73. Delamarre 2007 ne range pas Namerius parmi les noms indigènes. Pour Litugius (p. 118), pour Decmanius (p. 83), pour Riccius (p. 153).

74. Delamarre 2007 ne range pas Silvinius parmi les noms indigènes. 75. Nous connaissons seulement d'autres membres de la gens Riccia à Genève (ILN Vienne, 812) et en Haute-Savoie ILN Vienne, 883).

76. Bassus est le nom de potiers gaulois de La Graufesenque et de Lezoux (Delamarre 2007, p. 38).
Les autres avaient une dénomination mixte qui atteste le poids de l'élément indigène dans la dénomination de ces personnages qui avaient reçu ou offert une statue ou une statuette. Néanmoins, dans la vie quotidienne, près d'un sur deux était désigné par un surnom « latin italien »; or, sous l'Empire, les cognomina étaient devenus les véritables noms individuels des citoyen(ne)s romain(e)s. Leur latinisation, comme celle des autres Viennois(es), était donc réellement significative.

$\mathrm{Au}$ total, nous pouvons constater que les trop rares Viennois(e)s attestés dans une liaison signum/tituli ne se distinguent en rien de leurs compatriotes (panthéon, dénomination, évergétisme...). Comme les autres, ils s'étaient très vite et très profondément romanisés.

\section{Annexe 1 : catalogue des inscriptions}

Présentées dans l'ordre géographique des ILN Vienne, les inscriptions de ce catalogue sont un simple instrument de travail ; il vise uniquement à faciliter la lecture de l'article.

\section{ILN Vienne, 6 - VIENNE}

Dédicace au Génie des hastifères par Namerius Euprepes, président du collège.

Colonne ronde de marbre.

Signalée, en 1605, à proximité du couvent des religieuses de Saint-André-le-Haut - Perdue.

Sig(num) Genii, / Namerius / Euprepes, / magis(er) / hastiferor(um), /d(edit), d(edicauit).

Datation : 150-250 (duo nomina seconde manière du dédicant).

\section{ILN Vienne, 25 - VIENNE}

Dédicace à Vénus auguste par un particulier.

Autel de marbre avec base et couronnement moulurés. Sur la partie supérieure, on remarque trois scellements avec des restes de plomb pour fixer une statuette.

Trouvé, en 1873, dans les fouilles du nouveau cimetière, entre le chemin de Pipet et le sentier de Saint-Ignace, sur la partie basse de la colline de Sainte-Blandine Conservé à Vienne (DRAV, n592).

$15,6 \times 13 \times 11,2 \mathrm{~cm}$.

Veneri Aug(ustae), / L(ucius) Rufius / Rufinus / $u$ (otum) s(oluit) l(ibens) m(erito).

Datation indéterminée. 


\section{ILN Vienne, 28 - VIENNE}

Dédicace à une divinité indéterminée.

«Statuette à base hexagonale»(R. Mowat, Bulletin archéologique, 1888, p. 328).

Date et lieu précis de découverte inconnus - Perdue.

\section{PIONI / ACI / DIVI / OANION / IOVA / NI}

Datation indéterminée.

\section{ILN Vienne, 65 - VIENNE}

Inscription en l'honneur de Gaius Iulius Pacatianus, procurateur impérial, par la colonie Aelia Augusta Italica.

Plaque de bronze décorée, brisée en de nombreux fragments et restaurée. Trous de fixation.

Découverte, en 1874, en même temps que les restes d'une tête et d'une statue en bronze dans un jardin entre la place des Allobroges et la gare - Conservé à Vienne, au musée d'archéologie et des Beaux-Arts.

$79,7 \times 52,4 \times 2,4 \mathrm{~cm}$.

G(aio) Iulio Pacatiano, [u(iro) e(gregio)], proc(uratori) / Augustorum nostrorum, militiis / equestribus perfuncto, proc(uratori) prouinc(iae) / Osrhoenae, praefecto legionis Parthi-/cae, proc(uratori) Alpium Cottiarum, adlecto / inter comites Aug(ustorum trium) n(ostrorum), procurator(i) / pro legato prouinc(iae) Mauretaniae Tingi/tanae. Colonia Aelia Aug(usta) Italica, / patrono merentissimo.

Datation : vers 215 (séjour en Maurétanie).

\section{ILN Vienne, 72 - VIENNE}

Inscriptions en l'honneur des jumeaux Sextus Coelius Canus et Sextus Coelius Niger, questeurs et décurions, par Primus, leur affranchi.

Deux blocs quadrangulaires (bases ?) de calcaire dur. Trouvé, en 1882, à l'angle de la rue Victor-Hugo et de la montée Saint-Marcel, dans les vestiges de maisons d'époque romaine - Conservé à Vienne, au musée lapidaire $\left(n^{\circ} 654\right)$.

Dimensions identiques pour les deux blocs : 104 x $68,5 \times 59,5 \mathrm{~cm}$.

Sex(to Coelio, Volt(inia), Cano, / quaest(ori). / Primus, libert(us), seuir. / Hic et frater, propter singularem et in / suos pietatem et inter se concordiam / quam in consortione iucundissuma / annum LXXVII agunt, ab ordine / decurionatu digni iudicati sunt / quam dexteritatem decurionum / munificentia remunerauerunt / posito simulacro Viennae argenteo / (sestertium) n(ummum) (ducentorum milium).
Sex(to Coelio, Volt(inia), Nigro, / quaest(ori). / Primus, liber(tus), seuir. / Hic et frater, propter singularem et in / suos pietatem et inter se concordiam / quam in consortione iucundissuma / annum LXXVII agunt, ab ordine / decurionatu digni iudicati sunt / quam dexteritatem decurionum / munificentia remunerauerunt / posito simulacro Viennae argenteo / (sestertium) n(ummum) (ducentorum milium).

Datation indéterminée.

\section{ILN Vienne, 88 - VIENNE}

Inscription fragmentaire commémorant une donation par une flaminique anonyme.

Plaque de calcaire, sans doute retaillée de tous côtés. Signalée, dans la première moitié du $\mathrm{XVI}^{\mathrm{e}} \mathrm{s}$., dans l'une des portes de la ville - Conservée à Vienne, au musée lapidaire $\left(\mathrm{n}^{\circ} 542\right)$.

$153 \times 262 \times 40 \mathrm{~cm}$.

--- / D(ecreto) d(ecurionum) flaminica Viennae, / tegulas aeneas auratas / cum carpusculis et / uestituris basium et signa / Castoris et Pollucis, cum equis, et signa Herculis et Mercuri, / d(e) s(uo) d(at).

Datation indéterminée.

\section{ILN Vienne, 91 - VIENNE}

Signature d'un artiste grec.

Base de statue en marbre blanc.

Signalée, en 1644-1645, dans un édifice à l'est du Palais des canaux - Perdue.

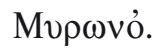

Datation indéterminée.

\section{ILN Vienne, 291 - VILLETTE-DE-VIENNE}

Inscription mentionnant Lucius Litugius Laena, questeur de Vienne.

Tête de divinité féminine en bronze plaquée d'argent. Trouvée, en 1859, dans un champ - Conservé à Lyon, au musée de la civilisation gallo-romaine.

H. : $30 \mathrm{~cm}$.

L(ucius) Litugius, Sex(ti) f(ilius), Laena, q(uaestor) col(oniae) Vianen(sium).

Date indéterminée.

\section{ILN Vienne, 357 - GRENOBLE}

Dédicace testamentaire à Mars par Decimus Decmanius Caper, chevalier. 
Base de statue en calcaire, avec base arasée et corniche moulurée, endommagée dans sa partie supérieure gauche. Les trous de scellement sur le couronnement attestent la présence d'une statue.

Signalée, avant 1808, dans l'ancienne tour de l'évêché, aujourd'hui place Notre-Dame - Conservée à Grenoble, au Musée Dauphinois (inv. ${ }^{\circ} 34.5685$ ).

$122,5 \times 68 \times 58 \mathrm{~cm}$.

Marti, / D(ecimus) Decmanius Caper / testamento) p(oni) i(ussit).

Datation : 1-68 (carrière du dédicant).

\section{ILN Vienne, 363 - GRENOBLE}

Dédicace testamentaire à Saturne par Decimus Decmanius Caper, chevalier.

Base de statue en calcaire, avec base et couronnement moulurés. Des trous de scellement visibles sur la partie supérieure attestent la présence d'une statue.

Signalée, en 1829, dans le mur du lycée, rue Bayard - Conservé à Grenoble, au Musée Dauphinois (inv. $\mathrm{n}^{\circ} 34.5689$ ).

$123 \times 68,5 \times 62,5 \mathrm{~cm}$.

Saturno, / D(ecimus) Decmanius Caper / testamento) p(oni) i(ussit).

Datation : 1-68 (carrière du dédicant).

\section{ILN Vienne, 370 - GRENOBLE}

Épitaphe (?) fragmentaire de Decimus Decmanius Caper, sous-préfet des cavaliers de l'aile Agrippiana.

Support indéterminé.

Découvert, en 1591, lors de la démolition de la porte Iouia, aujourd'hui place Grenette - Perdu.

D(ecimo)Decmanio Capri,/sub praef(ecto) equit(um) / alae Agrippian(ae), / qui (sestertium) ICCC in sta/tuas [---]/ut[---] et aenearum /[---]/[test(amento) reli]quit.

Datation : 1-68 (carrière du dédicant).

ILN Vienne, 551 - J.-Cl. Béal, 2008, p. 174 - MEYZIEU Dédicace au Génie des bronziers des Diarenses ${ }^{77}$. Statuette en bronze sur un socle également en bronze. Trouvé, en 1875, au lieu-dit La Dent - Non localisée, dans une collection particulière.

77. Nous avons adopté la nouvelle interprétation de Béal 2008, qui nous semblé meilleure que celle retenue dans les ILN Vienne.

\section{Genio / aerar(iorum) Diarensium.}

Datation indéterminée.

\section{ILN Vienne, 598 - AOSTE}

Dédicace à la Victoire impériale par un particulier avec le produit d'une quête.

Bloc rectangulaire mouluré de calcaire valanginien.

Trouvé, en 1891, lors de la démolition de l'ancienne église - Remployé dans le mur sud de l'église actuelle. 119 x 92 x 45 .

Victoriae / Aug(usti), / G(aius) Virrius / Quartio / t(estamento) $p$ (oni) i(ussit). / Basis, ex stipe.

Datation indéterminée.

\section{ILN Vienne, 624 - LES ÉCHELLES}

Ex-voto à une divinité indéterminée par un particulier.

Base quadrangulaire de statue.

Découverte, dans la première moitié du XVI ${ }^{\mathrm{e}} \mathrm{s}$., dans une citerne - Perdue.

Titus Siluinius Catullus, ex uoto.

Datation indéterminée.

\section{ILN Vienne, 636 - CHAMBÉRY}

Dédicace, en ex-voto, à une divinité indéterminée par un pérégrin, vivant dans une cité de droit latin.

Base de statue, en brèche de Vimines, avec une base moulurée et un couronnement presque entièrement brisé. Découverte, vers 1850, lors de la démolition de l'ancienne église de Bissy - Conservé à Chambéry, au Musée Savoisien (inv. $\mathrm{n}^{\circ} 899-588$ ).

$53 \times 38,5 \times 22,5 \mathrm{~cm}$.

Datation : avant 37-41 et le changement de constitution (si le cultor était viennois).

Gratus, / Cassi fil(ius), / ex uot(o).

\section{ILN Vienne, 643 - LE BOURGET-DU-LAC}

Dédicace à Mercure par un particulier.

Base de statue, en calcaire, avec un couronnement où se remarquent des trous de scellement.

Découverte, en juillet 1887, dans les fondations du clocher de l'ancienne église - Conservé au Bourget-duLac, dans la crypte de l'église.

$80 \times 64 \times 85 \mathrm{~cm}$.

L(ucius) Catius / Lucanus, / Mercurio, / u(t) u(ouerat) $s$ (oluit) l(ibens) $m$ (erito).

Datation indéterminée. 


\section{ILN Vienne, 739 - TALLOIRES}

Donation d'une horloge hydraulique (?) et d'un esclave par un particulier.

Plaque de calcaire blanc, retaillée de tous côtés.

Découverte, dans la première moitié du $\mathrm{XVI}^{\mathrm{e}} \mathrm{s}$., dans les fondations de l'abbaye des bénédictins - Conservée à Talloires, dans le mur extérieur droit du restaurant de l'abbaye.

$86 \times 210 \mathrm{~cm}$.

Horologium cum suo aedificio et / signis omnibus et clatris / G(aius) Blaesius, G(ai) fil(ius), Voltinia, Gratus ex (sestertium) n(ummum) X (millibus) / et eo amplius ad id horologium adminis-/trandum serum (sestertium) n(ummum) IIII (millium) d(e) s(ua) p(ecunia) d(edit).

Datation indéterminée.

\section{ILN Vienne, 834 - GENÈVE}

Dédicace à Mercure par Marcus Veratius Bassus.

Partie supérieure d'une colonnette en calcaire avec tore de 3,1 cm et astragale de $1,2 \mathrm{~cm}$, présentant des cassures en haut et en bas. La colonnette a été retaillée (face inférieure plane, dressée au ciseau droit). La face supérieure a également été dressée au ciseau droit; elle présente un trou de scellement plus ou moins carré et centré à l'origine, élargi et décentré par la suite.

Découvert, en 1995, à l'angle de la rue de l'Hôtelde-Ville et de la rue Henri-Fazy, lors de fouilles archéologiques - Conservé à Genève, au Service cantonal d'archéologie $\left(\mathrm{n}^{\circ} 47\right)$.

H. : 49,5 cm ; diam. 20,5/21 cm.

M(arcus) Veratius, / Mercatoris l(ibertus), / Bassus / Mercurio.

Datation: 1-100 (formulaire religieux ; abréviation l(ibertus).

\section{ILN Vienne, 850 - GENÈVE}

Inscription en l'honneur de Quintus Decius Alpinus, quattuorvir, par les nautes du Léman.

Piédestal de statue en calcaire en forme de dé, dont l'angle inférieur gauche postérieur est cassé, sans élément de décor. Les côtés sont lissés ; sur la face supérieure, on remarque un cadre d'anathyrose avec trou de scellement central de $9 \times 4 \mathrm{~cm}$, profond de $10 \mathrm{~cm}$, perpendiculaire à la face principale.

Découvert, en 1925, lors de la démolition de la Tour de Boël - Conservé à Genève, au Musée d'Art et d'Histoire (inv. épigr. $\mathrm{n}^{\circ} 728$ ). 112 × $70,5 \times 62,5 \mathrm{~cm}$.
Q(uinto) Decio Alpino, / IIII uir(o). / Nautae lacus / Lemanni.

Datation : avant 37-41 et le changement de constitution.

\section{ILN Vienne, 851 - GENÈVE}

Inscription en l'honneur de Titus Riccius Fronto, duumvir du trésor.

Piédestal en calcaire brisé dans sa partie supérieure, dont l'arête gauche de la face principale et celle du bord inférieur de la face latérale gauche ont été retaillées obliquement (chanfrein), brisé en plusieurs parties, puis recollées. La face supérieure présente, au centre, le fond d'un trou de scellement.

Signalé, au milieu du XVI ${ }^{\mathrm{e}}$ s., en remploi dans un mur de la cathédrale Saint-Pierre - Conservé à Genève, au Musée d'Art et d'Histoire (inv. épigr. $\mathrm{n}^{\circ} 426$ ).

$81,5 \times 66,5 \times 65,5 \mathrm{~cm}$.

[T(ito)] Riccio, T(iti) fil(io), / [V]ol(tinia), Frontoni, /[II] uir(o) aerari. /[He]r(es ou -edes), ex testament(o).

Datation: 50-100 (même personnage que dans ILN, Vienne 812).

\section{ILN Vienne, 856 - GENÈVE}

Base de statue honorifique de [---]biena Montica, flaminique.

Bloc de calcaire, dont le côté gauche a été grossièrement retaillé au pic (avec l'arête arrière et l'arête inférieure retaillées en pan coupé). La face principale et le côté droit présentent une surface plane, lissée, de même que la face arrière. Bien plane, la face supérieure a été dressée au pic fin ; elle présente un trou de scellement centré à l'origine de 12 x 5,5 cm, perpendiculaire à la face principale.

Découvert, en 1890, dans le socle de la tour nord de la cathédrale Saint-Pierre - Conservé à Genève, au Musée d'Art et d'Histoire (inv. épigr. ${ }^{\circ} 329$ ).

$108 \times 65 \times 63 \mathrm{~cm}$.

[--- bi]enae, G(ai) f[il(iae)], / Monticae, / [fla] minic(ae) August(ae), / [---]roi Hispani. / [G(aius) ---] bien(us) Bassus, pater, / [fil]iae dedit. / [L(oco)] d(ato) $d$ (ecurionum) $d($ ecreto $)$.

Datation indéterminée. 


\section{Annexe 2 : Pline, Histoire Naturelle, 34.16-18}

"Transiit deinde ars uulgo ubique ad effigies deorum. Romae simulacrum ex aere factum Cereri primum reperio ex peculio $S p$. Cassi, quem regnum adfectantem pater ipsius interemerit. Transiit et a diis ad hominum statuas atque imagines multis modis. Bitumine antiqui tinguebant eas, quo magis mirum est placuisse auro integere. Hoc nescio an Romanum fuerit inuentum; certe etiam nomen non habet uetustum. Effigies hominum non solebant exprimi nisi aliqua inlustri causa perpetuitatem merentium, primo sacrorum certaminum uictoria maximeque Olympiae, ubi omnium qui uicissent statuas dicari mos erat, eorum uero, qui ter ibi superauissent, ex membris ipsorum similitudine expressa, quas iconicas uocant. Athenienses nescio an primis omnium Harmodio et Aristogitoni tyrannicidis publice posuerint statuas. Hoc actum est eodem anno quo et Romae reges pulsi. Excepta deinde res est a toto orbe terrarum humanissima ambitione, et in omnium municipiorum foris statuae ornamentum esse coepere propagarique memoria hominum et honores legendi aeuo basibus inscribi, ne in sepulcris tantum legerentur. Mox forum et in domibus priuatis factum; atque in atriis honos clientium instituit sic colere patronos».

L'art se mit ensuite, couramment et partout, à représenter les dieux (effigies deorum). Je trouve que la première statue (simulacrum) en bronze, faite à Rome, est celle de Cérès; les dépenses en furent couvertes par les biens de $\mathrm{Sp}$. Cassius, que son propre père avait fait mourir pour le punir d'avoir prétendu à la royauté. Après avoir utilisé le bronze pour la statue des dieux, on en vint à l'utiliser, aussi pour les statues représentant des hommes (statuas atque imagines), et il y en eut bien des variétés. Les Anciens enduisaient les statues de bitume, ce qui rend encore plus étonnant qu'on se soit plu < ensuite > à les recouvrir d'or. Je me demande si ce n'est pas là une invention romaine ; en tout cas, le nom même n'en est pas ancien. On avait l'habitude de reproduire seulement l'image des hommes (effigies hominum) qui méritaient l'immortalité pour quelque action d'éclat ; ce furent d'abord les vainqueurs aux jeux sacrés, surtout à Olympie, où il était d'usage de dédier la statue de tous ceux (statuas) qui avaient remporté une victoire ; quant à ceux qui avaient triomphé trois fois, on leur érigeait des statues faites d'après nature: on appelle iconiques les statues de ce genre. Ce sont sans doute les Athéniens qui ont les premiers érigé des statues (statuas) aux frais de l'État, et cela en l'honneur des tyrannicides, Harmodius et Aristogiton. Cela arriva l'année même où à Rome les rois furent chassés. Le monde entier adopta ensuite cet usage sous l'effet d'une très noble émulation: les statues (statuas) devinrent l'ornement des places publiques dans tous les municipes, on se mit à perpétuer le souvenir des grands hommes et à graver leurs honneurs sur le soc1e de leurs statues, afin que la postérité pût les lire et que leurs tombeaux ne fussent plus seuls à les faire connaître. Plus tard, les maisons particulières devinrent autant de places publiques et l'hommage des clients, prit cette forme pour honorer leurs patrons dans les atriums.

Texte établi et traduit par H. Le Bonniec, Paris, CUF, Les Belles Lettres, 1953, revue.

\section{Bibliographie}

Allmer 1878 : ALLMER (A.) - 2 ${ }^{\mathrm{e}}$ Supplément aux inscriptions antiques et du Moyen Âge de Vienne. Revue du Dauphiné et du Vivarais, 2, 1878, p. 38-44, $\mathrm{n}^{\circ} 2056$.

Béal 2008 : BEAL (J.-Cl.) - Au Génie des bronziers de Diar[---]. RANarb., 41, 2008, p. 169-180.

Blanc 1989 : BLANC (N.) - Vocabulaire technique et vocabulaire vitruvien dans les inscriptions de Lyon et de Vienne. In : La langue des inscriptions latines de la Gaule, actes de la table-ronde tenue au C.E.R.G.R. les 6 et 7 octobre 1988, Université Lyon III, Lyon, CERG, 1989, p. 73-84.

Boucher, Tassinari 1976 : BOUCHER (St.), TASSINARI (S.) - Musée de la civilisation gallo-romaine à Lyon. Bronzes antiques. 1. Inscriptions, statuaire, vaisselle, Paris, De Boccard, 1976.

Burnand 2006 : BURNAND (Y.) - Primores Galliarum. Sénateurs et chevaliers romains originaires de Gaule de la fin de la République au III ${ }^{e}$ siècle, II. Prosopographie, Bruxelles, Editions Latomus, 2006 (Collection Latomus, 302), $630 \mathrm{p}$

Cibu 2003 : CIBU (S.) - Chronologie et formulaire dans les inscriptions religieuses de Narbonnaise et des provinces alpines (Alpes Graies, Pœnines, Cottiennes et Maritimes). RANarb., 36, 2008, p. 335-360.

Delamarre 2007 : DELAMARRE (X.) - Nomina Celtica Antiqua Selecta Inscriptionum. Noms de personnes celtiques dans l'épigraphie classique, Paris, Errance, 2007.

Dondin-Payre, Raepsaet-Charlier 2006: DONDIN PAYRE (M.), RAEPSAET CHARLIER (M.-Th.) eds., Sanctuaires, pratiques cultuelles et territoires civiques dans l'Occident romain, Bruxelles, Le livre Timperman, 2006.

De Kisch 1979 : DE KISCH (Y.) - Tarifs des donations en Gaule romaine d'après les inscriptions. Ktéma, 4, 1979, p. 259-280.

France-Lanord 1960 : France-LANORD (A.) - La statue de bronze reconstituée, dite de Pacatianus, au musée de Vienne. Mémoires de la fondation Eugène Piot, 51, 1960, p. 93-104.

Gros 1976: GROS (P.), Aurea templa: recherches sur l'architecture religieuse de Rome à l'époque d'Auguste, Rome, Ecole Française de Rome, 1976. 
ILN Vienne : REMY (B.) (dir.) - Inscriptions Latines de Narbonnaise. V. Vienne, 3 vol., Paris, CNRS éditions, 2004-2005.

Mars en Occident: BROUQUIER-REDDÉ (V.), BERTRAND (E.), CHARDENOUX (M.-B.), GRUEL (K.) et al., (éd.), Mars en Occident. Actes du colloque international «Autour d'Allones (Sarthe). Les sanctuaires de Mars en Occident », Le Mans, Université du Maine, 4-5-6 juin, 2003, Rennes, PUR, 2006.

Nouvel Espérandieu I: TERRER (D.), LAUXEROIS (R.), ROBERT (R.), GAGGADIS-ROBIN (V.), HERMARY (A.), JOCKEY (P.) - Nouvel Espérandieu : recueil général des sculptures sur pierre de la Gaule. Tome I, Vienne, Isère. Paris, Académie des Inscriptions et Belles-Lettres, Lavagne (H.) dir., 2003, 251 p., 269 p. de pl.

Pelletier 1982: PELLETIER (A.) - Vienne antique, Roanne, éditions Horvath, 1982.

Pflaum 1950 : PFLAUM (H.-G.) - Les procurateurs équestres sous le HautEmpire romain, Paris, Maisonneuve, 1950.

Pflaum 1978 : PFLAUM (H.-G.) - Les fastes de la province de Narbonnaise, Paris, Ed. du CNRS (30e supplément à Gallia), 1978.

Raepsaet-Charlier 1993 : RAEPSAET CHARLIER (M.-Th.)- Diis deabusque sacrum. Formulaire votif et datation dans les Trois Gaules et les deux Germanies, Paris, de Boccard, 1993, 98 p.

Rémy 1992 : REMY (B.) - Un témoignage de la romanisation de la cité de Vienne au Haut-Empire : l'évergétisme. Ktéma, 17, 1992, p. 201-221.

Rémy 1994 : REMY (B.) - Le culte de Mercure dans la cité de Vienne au Haut-Empire. In : Vergé-Franceschi (M.) dir., Mélanges offerts à Bernard Grosperrin, Chambéry, Institut d'Etudes Savoisiennes, 1994, p. 179-204.
Rémy 1998 : REMY (B.) - Les élites locales et municipales de la colonie de Vienne au Haut-Empire. L'Antiquité Classique, 77, 1998, p. 77-120.

Rémy 2001 : REMY (B.) - La dénomination des Viennois à l'époque impériale. In : M. Dondin-Payre, M-Th. Raepsaet-Charlier (éds), Noms, identités culturelles et romanisation sous le Haut-Empire, Bruxelles, Le Livre Timperman, 2001, p. 55-174.

Rémy 2002 : REMY (B.) - L'organisation territoriale de la cité de Vienne, in D. Garcia, Fl. Verdin (dir.), Territoires celtiques. Espaces ethniques et territoires des agglomérations protohistoriques d'Europe occidentale, Paris, Errance, 2002, p. 173-184.

Rémy 2005 : REMY (B.) - Antonin le Pieux. Le siècle d'or de Rome. 138 161, Paris, Fayard, 2005.

Rémy, Kayser 2005 : REMY (B.), KAYSER (F.) - Les Viennois hors de Vienne, Bordeaux, Ausonius, 2005.

Sablayrolles, Schenck 1988 : SABLAYROLLES (R.), SCHENCK (J.-L.) - Collections du musée archéologique départemental de Saint-Bertrand de Comminges. 1. Les autels votifs, Toulouse - Saint-Bertrand de Comminges, Musée archéologique départemental, 1988, 172 p.

Slavazzi 1996 : SLAVAZZI (F.) - Italia verius quam provincia. Diffusione e funzioni delle copie di sculture greche nella Gallia Narbonensis, Perugia, Edizioni scientifiche italiane, 1996.

Tran 2006 : TRAN (N.) - Les membres des associations romaines. Le rang social des collegiati en Italie et en Gaules sous le Haut-Empire, Rome, ÉFR, 2006. 



\title{
Firme o didascalie. Due contesti narbonensi e qualche riflessione su copie e nomi di artisti
}

\author{
Fabrizio Slavazzi \\ Dipartimento di Beni Culturali e Ambientali, università di Milano \\ fabrizio.slavazzi@unimi.it
}

\section{Résumé}

La présence d'inscriptions avec des noms de sculpteurs célèbres est un fait rare à l'époque romaine, et il est plus encore loin de Rome. La situation de la Narbonnaise qui a livré deux inscriptions de cette nature est encore plus significative, car elle est unique pour les provinces occidentales. Il s'agit déjà de cas connus (Myron à Vienne et les bustes de la villa de Crest dans la Drôme), mais qu'il vaut la peine de reconsidérer à la lumière d'études et de découvertes récentes.

Mots-clés : Empire romain, Gaule Narbonnaise, sculpture, Myron, signature, artistes, Vienne, Crest, Philétas.

\section{Riassunto}

La presenza di iscrizioni con nomi di scultori famosi è un fatto raro nell'età romana, e lo è ancora di più lontano da Roma. La situazione della Narbonense, che ha restituito due epigrafi di tale genere, è ancor più significativa, essendo unica per le province occidentali. Si tratta di casi già noti, ma che vale la pena di riconsiderare alla luce di studi e di scoperte recenti.

Parole chiave : Impero romano, Gallia Narbonense, scultura, Mirone, firma, artisti, Vienne, Crest, Filita. 


\section{Mirone a Vienne}

Il primo caso riguarda un'iscrizione con il nome di Mirone. Verso la metà del XVII secolo a Vienne vennero riportati alla luce i resti di un grande monumento di età romana interpretato come un edificio termale (o un ninfeo), denominato dagli studiosi «Palais des Canaux » (Pelletier 1982, p. 150-155; Slavazzi 1996, p. 123-125). Le notizie di questi ritrovamenti sono riferite nella opera di Nicolas Chorier sulle antichità di Vienne, pubblicata nel 1658 (Chorier 1658, p. 400409; Chorier 1828, p. 400-410), che costituisce l'unica fonte al riguardo, dato che quello che fu ritrovato venne in seguito disperso ${ }^{1}$; gli autori successivi hanno ripreso (e talvolta elaborato) tali informazioni ${ }^{2}$. Oltre a diversi frammenti di statue e di elementi architettonici, si rinvenne una base in marmo - pario secondo alcuni autori successivi - che recava l'iscrizione MYPON $\Omega \Sigma$ (Chorier 1658, p. 402-403; Chorier 1828, p. 403). Non è chiaro se sulla base o su un diverso blocco erano attaccati $i$ piedi frammentari di una statua in bronzo: la frase di Chorier - "On trouva auprès la moitié des deux pieds d'airain joints ensemble" (Chorier 1658, p. 403) - è stata intesa da alcuni come se i piedi appartenessero alla base iscritta. Fra le sculture marmoree rinvenute nella stessa occasione, due erano in uno stato di conservazione tale da consentirne una lettura: una figura femminile rappresentante una divinità abbigliata alla romana, che recava una cornucopia, e una statua maschile nuda colossale, di cui si conservavano il torso e la testa; vi erano, inoltre, diversi altri frammenti, fra i quali spiccavano una mano reggente una cornucopia e un piede di elevata fattura.

La base con l'iscrizione dovette scomparire subito perché non è stata più vista da nessuno e tutti gli studiosi successivi si sono basati sulle informazioni di Chorier; molti di loro, rilevando l'errore nel nome, hanno cor-

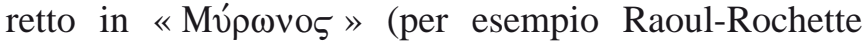
1845 , p. 365) la trascrizione di Chorier, riportata da

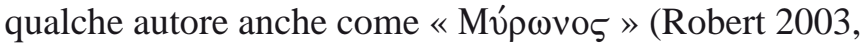
p. XLVII n.13). Principalmente per questo motivo l'epigrafe è stata ritenuta falsa da alcuni studiosi (per esempio Loewy 1885, p. 330 nr. 499), autentica da altri ${ }^{3}$; l'editore più recente, Jean-Claude Decourt, nelle Inscriptions

1. Sul valore dell'opera di Chorier per lo studio delle sculture antiche di Vienne si veda Lauxerois (R.), L'histoire des collections viennoises de sculpture antique : fascinations et avatars. In : Nouvel Esperandieu 1, p. XXV-XLII, in particolare p. XXVII-XXVIII.

2. Liste di autori che si sono occupati della questione sono in Loewy 1885, p. 330; Decourt 2004, p. 294.

3. Guerrini (L.), Myron (5). In: Enciclopedia dell'arte antica classica e orientale, V, Roma, Istituto dell'Enciclopedia Italiana, 1963, grecques de la France (Decourt 2004, p. 294-295 nr. 201), esamina le varie possibilità e, rifiutando comunque che si tratti di una iscrizione relativa a un originale di Mirone scultore del V secolo a.C., pensa a una copia di un'opera dell' artista, o a un lavoro di uno scultore anonimo nobilitato attraverso il nome famoso, o all'opera di un omonimo; se però la trascrizione di Chorier fosse corretta, si tratterebbe di un falso.

A mio avviso l'iscrizione può essere giudicata autentica: non si vede per quale motivo l'autore che riferisce la scoperta debba avere inventato una falsa notizia riguardo a una testimonianza che poi scomparve immediatamente, per di più senza associarla puntualmente con una delle sculture rinvenute nella stessa occasione. Si può pensare che l'errore relativo alla sostituzione di omicron con omega fosse dovuto allo stato di conservazione o delle condizioni del manufatto, al cui proposito nel testo di Chorier non viene detto nulla; o si è semplicemente trattato di una scorretta trascrizione del testo da parte dell'autore.

Riguardo al tipo di epigrafe, la presenza del solo nome al genitivo è insolita, ma il testo può essere incompleto, mancando forse del sostantivo ěpyov come nell'esempio

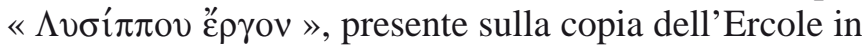
riposo con il ritratto di Commodo, rinvenuta a Roma sul Palatino e ora conservata a Palazzo Pitti a Firenze (IGUR IV, 1574). In altri casi, sempre limitatamente alle epigrafi romane su basi di opere di scultori greci di età più antica, o nel caso di iscrizioni relative a copie, il nome dello scultore compare al genitivo, come su un'erma con

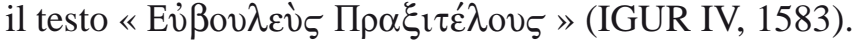

Anche la serie delle basi dal Templum Pacis a Roma, recentemente ristudiate da Eugenio La Rocca in occasione del ritrovamento di tre nuove basi iscritte nell' area del foro imperiale flavio (La Rocca 2001, p. 196-201), presenta il nome dello scultore al genitivo, preceduto dal titolo dell'opera e seguito dall'aggettivo di origine etnica. Si vedano i casi già noti del Ganimede di Leocare

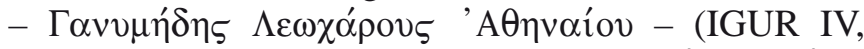

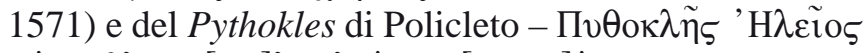

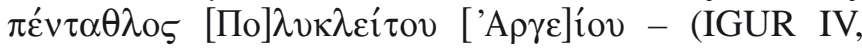
1580). In un caso almeno, però, quello di Parthenokles, di recente ritrovamento, il testo epigrafico è composto solamente dal nome dello scultore al genitivo e dall'et-

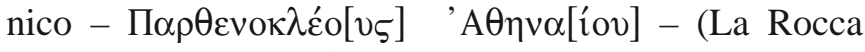
2001, p. 198-199, fig. 19a), secondo una soluzione molto simile a quella della base perduta di Vienne.

p. 315; Moreno (P.), Lisippo, volume I, Bari, Dedalo Libri, 1974, p. 135. 
Il testo dunque presenta qualche possibilità di confronto in iscrizioni di simile funzione e si può, al limite, presumere che fosse incompleto al momento del ritrovamento $^{4}$. Si tratta di una didascalia, una "etichetta museale" (Robert 2003, p. XLVI) posta per ricordare allo spettatore l' autore (e/o il titolo) dell'opera (Gualandi 1984, p. 72-74).

Rimane aperta la questione se i piedi frammentari in bronzo fossero connessi con la base o meno, che, naturalmente, non è risolvibile; d'altra parte, se anche non fossero pertinenti al blocco iscritto, avrebbero comunque potuto appartenere alla stessa opera (come hanno ipotizzato già diversi studiosi $)^{5}$, dato che la scultura poteva essere fissata su un blocco, o una cimasa, a sua volta posto sopra quello che recava l'iscrizione.

Pur in assenza di ogni testimonianza materiale e dovendosi solamente basare su notizie molto vecchie e non più verificabili, si tratta senza dubbio di un contesto molto interessante, come già notato da Emile Espérandieu (Espérandieu 1910, p. 398-399 nr. 2598). L'edificio rinvenuto nel XVII secolo era probabilmente una struttura termale, situata nell' area centrale dell'abitato, che, per l'apparato scultoreo e la posizione, doveva essere il più rilevante di Vienne, che era una delle maggiori e più ricche città della Narbonense ${ }^{6}$. Fra i frammenti di sculture ricordati dal Chorier si possono identificare una statua di divinità femminile che, per l'attributo della cornucopia, pare interpretabile come Cerere o come Fortuna-Tyche - in questo caso in parallelo con la presenza di una immagine dello stesso soggetto nell'altro importante edificio termale della città, il «Palais de Miroir », dove venne rinvenuta la grande statua della « Tyche di Vienne » (Will 1952, p. 16 nr. 12; Slavazzi 1996, p. 212 nr. 51, fig. 48; Nouvel Espérandieu 1, p. 36-37 nr. 72, tav. 84-85) -; oppure poteva essere una statua-ritratto di un membro femminile della famiglia imperiale assimilata a una delle divinità recanti la cornucopia, iconografia per la quale sono noti diversi esempi ${ }^{7}$.

4. Per altre iscrizioni recanti il nome dello scultore Mirone al genitivo si veda IGUR IV, 1578-1579.

5. Per esempio Raoul-Rochette 1845, p. 365-366 nr. 255, che, pur distinguendo i due elementi (blocco con iscrizione e base con piedi), li associa considerandoli parte di una stessa statua.

6. Il caso delle terme centrali di Vienne non è stato considerato in Manderscheid 1981.

7. Si veda Alexandridis (A.), Die Frauen des römischen Kaiserhauses. Eine Untersuchung ihrer bildlichen Darstellung von Livia bis Iulia Domna, Mainz am Rhein, Zabern, 2004, che discute dei tipi di Cerere e Tyche-Fortuna impiegati per i ritratti delle principesse della casa imperiale.
La seconda statua allora recuperata, la cui testa venne inviata a Parigi al Sieur de la Verrerie, era di grandezza superiore al naturale (Nouvel Espérandieu 1, p. 22 nr. 48): questo rende difficile pensare alla immagine di un atleta (originale o copia che fosse), mentre è più verosimile che si trattasse di una rappresentazione divina (Hermes, Herakles), oppure di una statua-ritratto di tipo eroico, forse anche imperiale; in questo ultimo caso, il riferimento più immediato è con l'Adriano dal teatro di Vaison-la-Romaine ${ }^{8}$.

In tale contesto, se la presenza di un originale greco di età classica sembra molto difficile, l'esistenza della copia di un'opera del famoso scultore greco Mirone appare del tutto possibile, anche in considerazione dei soggetti prevalenti delle opere dello scultore ateniese, atleti e divinità ${ }^{9}$, in entrambi i casi tema appropriato per un edificio termale.

Un ulteriore importante supporto all'ipotesi che la base con l'iscrizione appartenesse a una copia di un'opera di Mirone deriva dal confronto con le già ricordate terme del « Palais de Miroir », nel quartiere suburbano di Sainte-Colombe, un ricchissimo complesso monumentale confrontabile con esempi urbani, oltre che per la pianta, anche per la decorazione scultorea (Manderscheid 1981, p. 70-71; Slavazzi 1996, p. 125-129), dove erano collocate, fra l'altro, oltre alla già ricordata immagine di Tyche e a una di Igea del tipo Broadlands, copie di un'opera celebre come l'Afrodite accovacciata di Doidalsas di Bitinia (al museo del Louvre) e di figure atletiche come quella attribuita a uno scultore anonimo dello Stile Severo (oggi conservata a Budapest) e quella di un atleta di ambito policleteo, forse il Dyskophoros (Espérandieu 1910, nr. 2592, 2599, 2601, 2604-2606; Will 1952, nr. 4, 12; Slavazzi 1996, p. 209-216 nr. 49-54, figg. 46-51; Nouvel Espérandieu 1, nr. 43, 47, 60, 72, 79). Si ritrovano, dunque, gli stessi temi - divinità, figure virili nude atletiche, copie di opere famose dell'arte greca -, con caratteristiche simili di gusto nella scelta dei prototipi, in particolare la presenza di opere della prima età classica.

Infine, si ricorda che nella provincia narbonense erano effettivamente presenti copie di opere dello scultore ateniese, come il Discobolo rinvenuto a Carcassonne e la Atena del gruppo con Marsia nella villa di Chiragan (Slavazzi 1996, p. 168-169 nr. 11, fig. 12; 182-183

8. Goudineau (Ch.), de Kisch (Y.), Vaison-la Romaine, Paris, Errance, 1991, p. 135.

9. Sui soggetti delle opere dello scultore si veda Arias (P.E.) cur., Mirone, Firenze, Sansoni 1940 (Quaderni per lo studio dell'archeologia, 2). 
nr. 24, fig. 25); di tali copie si è già rilevata la rarità nelle province occidentali (Slavazzi 1996, p. 29-31) e la loro concentrazione in Narbonense appare significativa.

\section{I busti della villa di Crest}

Nel 1770 in un terreno in aperta campagna a Crest, a non grande distanza da Valence sulla strada per Die, fu scoperto per caso un busto antico che recava iscritto

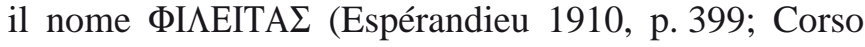
1988, p. 31-32; Slavazzi 1996, p. 198-199 nr. 37). Circa sessanta anni dopo, nello stesso luogo, in seguito a scavi mirati, si recuperarono altre sculture: un ritratto virile, un busto anepigrafe e un secondo busto con l'iscrizione

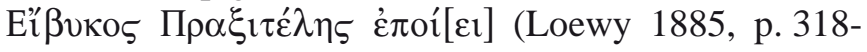
319 nr. 488; Slavazzi 1996, p. 196-197 nr. 36; Decourt 2004, p. 292 nr. 198). Infine, in un successivo e ultimo intervento di scavo nel 1839, fu rinvenuta una testa di bambino ${ }^{10}$.

Sul gruppo di opere fino a poco tempo fa si poteva ragionare su scarsi elementi: tutti i pezzi erano considerati perduti e, riguardo ai due busti iscritti, vi erano notevoli dubbi interpretativi sulle iscrizioni e sui soggetti, per la loro grande rarità, rappresentando due poeti non certo fra i maggiori e per i quali non si avevano quasi testimonianze relative a opere che li raffigurassero; anche la presenza del nome di Prassitele complicava la questione, dato che un ritratto del poeta di Reggio non è ricordato nelle fonti antiche fra le opere dello scultore ateniese (Corso 1988, p. 31-32 nr. 20).

Ma due scoperte recenti hanno cambiato la situazione. Nel 2001 la pubblicazione del Papiro Milanese Vogl. VIII, $309^{11}$, contenente una raccolta di epigrammi del poeta ellenistico Posidippo di Pella, porta alla conoscenza dell'esistenza di un ritratto del poeta Filita di Cos, opera del bronzista Ecateo (Slavazzi 2007; Prioux 2008, p. 66-68); dall'epigramma si possono ricavare anche alcune indicazioni sulle caratteristiche dell'opera: si trattava di una statua in bronzo, improntata a un forte realismo e alla verità nella resa dei tratti del soggetto, che raffigurava Filita in età avanzata, ed era stata commissionata da Tolomeo Filadelfo, che del poeta era stato allievo. In un lavoro presentato a un convegno tenuto a Perugia nel 2004, avevo ipotizzato che la statua fosse

10. Sui ritrovamenti e sulla bibliografia relativa si vedano Slavazzi 1996, p. 116-118; Prioux 2008, p. 69-70.

11. Bastianini (G.), Gallazzi (C.), Austin (C.) edd., Posidippo di Pella, Epigrammi (P. Mil. Vogl. VIII 309), Milano, LED, 2001 (Papiri dell'Università degli Studi di Milano, VIII, Il Filarete, 200). stata eretta nel Museo di Alessandria (Slavazzi 2007, p. 398-399); inoltre, avevo suggerito un collegamento con il busto di Crest, unica testimonianza reale di un ritratto del poeta ellenistico.

La seconda scoperta è stata il recupero del busto, recentemente identificato in una collezione privata e pubblicato da Evelyne Prioux (Prioux 2008, p. 68-71) ${ }^{12}$. La studiosa, sulla base dell'epigramma e grazie al ritrovamento del busto, che precedentemente era noto solamente da un'incisione, di difficile reperimento ${ }^{13}$, propone che tale busto sia effettivamente una copia del ritratto di Ecateo noto dai versi di Posidippo.

In effetti, il busto, sulla base delle immagini pubblicate, mostra le caratteristiche di un'opera del primo ellenismo, anche se, apparentemente, non risultano così evidenti i tratti realistici esaltati nell'epigramma. Si tratta, in ogni caso, di una acquisizione importante, che recupera una pregevole testimonianza della scultura narbonense.

Alla luce dei nuovi dati, il riesame del contesto appare di un certo interesse. In passato si è ipotizzato, sulla base delle notizie ottocentesche, che le sculture rinvenute nella villa di Crest dovevano costituire una galleria di busti di epoca tarda, del III secolo d.C. (da ultimo Corso 1988, p. 31; Slavazzi 1996, pp. 117-118).

In realtà, della villa non si sa nulla, anche se il raffinato gruppo di scultore rinvenutovi deve far ritenere che si trattasse di una costruzione di un notevole impegno. Il recupero del busto di Filita ha permesso una sua datazione agli inizi del II secolo d.C. (Prioux 2008, p. 69); si può ora presumere che a questa data vadano riferiti anche gli altri busti perduti. La scelta, da parte di chi ha commissionato il programma scultoreo, di almeno due ritratti di poeti greci, un lirico di età arcaica e un elegiaco del primo ellenismo, fanno ritenere che il proprietario fosse un uomo di grande e raffinata cultura, sia letteraria, come dimostrato dalle preferenze poetiche non banali, sia artistica, dato che entrambi i busti erano copie di opere di artisti greci, l'uno famosissimo, l'altro celebrato nell'epigramma di del poeta ellenistico. Che valore hanno le due iscrizioni? La loro presenza permetteva l'identificazione di due personaggi la cui notorietà in età imperiale doveva essere molto ridotta (Gualandi 1984, p. 71-74), ma, almeno nel caso della copia prassitelica,

12. Il pezzo, che è conservato a Lione, è già ricordato in Chorier 1828 (p. 404 n. 1) presso M. Girardon nella stessa città.

13. L'incisione, riprodotta in Decourt 2004, fig. 197, mi era sfuggita nello studio sulle copie della Narbonense (Slavazzi 1996). 
sembra comunicare e affermare quasi con orgoglio il possesso di un'opera rara e di alto valore simbolico.

Se si concorda, come credo sia corretto, che ci si trovi di fronte a una galleria di busti di poeti (o di letterati) greci - rispetto alle ipotesi precedenti di una galleria mista greco-latina, poiché uno dei ritratti anonimi era stato identificato dubitativamente con Cicerone -, un aspetto interessante è la differenza dell' apparato epigrafico nei tre esemplari di busti appartenevano al gruppo: nel caso dell' Ibico l'iscrizione informa sul soggetto, sul nome dello scultore e sulla sua patria; nel caso di Filita, compare il solo nome del personaggio, cioè il soggetto dell'opera, mentre del suo autore si era forse persa memoria; infine il terzo busto era anepigrafe, come affermato esplicitamente da chi vide il pezzo al momento della scoperta, forse perché il personaggio raffigurato era talmente noto da non richiedere una "didascalia".

Che poi, come è stato scritto da diversi studiosi (da ultimo Prioux 2008, p. 70-71), si tratti proprio di opere per la decorazione di una biblioteca, in mancanza di ogni altro dato oggettivo rimane una interessante ipotesi, anche se senza riscontro documentario. La dimensione del ritratto di Filita, la cui sola testa è alta 15,5 centimetri, è circa $2 / 3$ della grandezza naturale, una misura decisamente superiore rispetto a quella dei piccoli busti che, sulla base degli esemplari ritrovati nella Villa dei Papiri, sono considerati solitamente "ritratti da biblioteca", caratterizzati, inoltre, dal materiale bronzeo ${ }^{14}$. Si può, in alternativa, pensare più genericamente e in mancanza di informazioni più precise a supporto della ipotesi precedente - ad esempio la presenza di una biblioteca nella villa, su cui peraltro non si hanno informazioni puntuali e di cui si sta ancora cercando la esatta localizzazione - a una raffinata galleria di busti dove il tema letterario e quello artistico si intrecciavano e dove la rarità dei soggetti dovette avere una parte consistente nella scelta.

Gallerie di letterati greci nelle ville sono note, oltre al caso di Ercolano, attraverso esempi nei dintorni di Roma,

14. Wojcik (M.R.), La Villa dei Papiri ad Ercolano. Contributo alla ricostruzione dell'ideologia della nobilitas tardorepubblicana, Roma, «L'Erma» dei Bretschneider, 1986 (Soprintendenza Archeologica di Pompei. Monografie, 1), p. 157-170, tav. LXXXXIII-LXXXVIII. Su questo genere di sculture si veda anche il piccolo ritratto bronzeo di Crisippo, recentemente rinvenuto nel Templum Pacis a Roma: Papini (M.), Ritratto di Crisippo. In: La Regina (A.), Fuksas (M.), Mandrelli (D.) cur., Forma. La città moderna e il suo passato, catalogo della mostra (Roma 2004), Milano, Electa, 2004, p. 50-55. come nella villa dei Volusii Saturnini a Lucus Feroniae ${ }^{15}$, in quella dei Bruttii Praesentes presso Rieti ${ }^{16}$, in quella cosiddetta dei Pisoni a Tivoli e nella Villa Adriana ${ }^{17}$, ma in quest'ultimo caso siamo in un contesto imperiale e dunque in una situazione ben diversa per ampiezza, mezzi e significato.

La presenza delle iscrizioni, soprattutto quella con il nome di uno scultore, per di più molto famoso, fa del gruppo di Crest un caso molto significativo nel panorama generale, non solo limitatamente alla Narbonense. Ancora una volta, gli esempi di iscrizioni di questo genere nelle ville sono rari, e sono circoscritti alla sola area dei dintorni di Roma. Si possono ricordare una base di statua con il nome di Boupalos, ritrovata nel XVIII secolo nella villa di Prato Bagnato, sulla Via Prenestina, insieme a copie di opera nobilia (Neudecker 1988, p. 214); oppure la base con il nome di Teisikrates, allievo di Lisippo, recuperata in una villa sulle sponde del Lago di Albano nel 1796 (Raoul-Rochette 1845, p. 419 nr. 363).

Riguardo al soggetto, nella Narbonense e nelle zone limitrofe sono stati rinvenuti altri ritratti di letterati greci. Ricordo solamente il Platone di Aix-en-Provence, lo Pseudo Seneca di Auch, il Sofocle di Beziers, il Demostene di Chiragan, lo Zenone di Lione ${ }^{18}$. Ancora una volta, occorre rilevare che questo interesse per tali soggetti è unico nel panorama delle province occidentali e i confronti si ritrovano solamente in area campano-laziale e in Oriente (Slavazzi 1996, p. 134-135).

Sulla base di quanto esposto credo si possano apprezzare meglio i testi epigrafici esaminati e le opere a essi relative. Si tratta, una volta di più, di testimonianze preziose, che sottolineano la assoluta vicinanza della Narbonense a Roma e all'Italia centrale dal punto di vista di tali manifestazioni artistiche, nel gusto che governa le scelte e nelle modalità espositive delle opere, come non avviene, in misura paragonabile, in nessuna altra provincia dell'Occidente. Come già sottolineato

15. Torelli (M.), Una galleria della villa. Qualche nota sulla decorazione del complesso. In: I Volusii Saturnini. Una famiglia romana della prima età imperiale, Bari, De Donato, 1982 (Archeologia. Materiali e problemi, 6), p. 97-104.

16. Neudecker 1988, p. 180-184; Brusini (S.), La decorazione scultorea della villa romana di Monte Calvo, numero monografico di RIASA, 55, 2000.

17. Palma Venetucci (B.) cur., Pirro Ligorio e le erme tiburtine, Roma, Leonardo-De Luca, 1992 (Uomini illustri dell'antichità, I.1), p. $15-85$.

18. Su tali pezzi si vedano Slavazzi 1996, p. 160-161 nr. 4, fig. 5 (Aix); Id., p. 167 nr. 10, fig. 11; Esperandieu 1910, p. 23 nr. 1768; Richter (G.M.A.), The portraits of the Greeks, I, London, Phaidon, 1965, p. 61 nr. 29, figg. 195-197. 
altrove (Slavazzi 1996), tale consonanza dipende, prima di tutto, dagli stretti legami con Roma della classe dirigente locale, che si è integrata in fretta ed è giunta ai vertici delle carriere magistratuali e al senato con numerosi rappresentanti, generando una situazione del tutto privilegiata anche sul piano culturale.

\section{Bibliographie}

Chorier 1658: CHORIER (N.) - Les recherches du Sieur Chorier sur les antiquitéz de la ville de Vienne, metropole des Allobroges, capitale de l'Empire Romain dans les Gaules, des deux Royaumes de Bourgogne, et presentement du Dauphiné, première partie, Lyon, chez Claude Baudrand, 1658.

Chorier 1828 : CHORIER (N.) - Recherches sur les antiquités de la ville de Vienne, metropole des Allobroges, capitale de l'Empire Romain dans les Gaules, des deux Royaumes de Bourgogne, nouvelle edition, Lyon, chez Millon Jeune, 1828.

Corso 1988 : CORSO (A.) - Prassitele. Fonti epigrafiche e letterarie. Vita e opere, tomo I, Roma, De Luca, 1988 (Xenia Quaderni, 10).

Decourt 2004: DECOURT (J.-C.) - Inscriptions grecques de la France $(I G F)$, Paris, 2004 (Travaux de la Maison de l'Orient et de la Méditerranée, $38)$.

Esperandieu 1910 : ESPERANDIEU (E.) - Recueil général des bas-reliefs, statues et bustes de la Gaule romaine, III, Lyonnaise - Premier partie, Paris, Imprimerie Nationale, 1910.

Gualandi 1984: GUALANDI (G.), Il testo epigrafico come didascalia delle opere d'arte greca nei complessi monumentali e nelle raccolte collezionistiche di antichità. In: Il museo epigrafico, Faenza 1984 (Colloquio AIEGL-Borghesi, 83; Epigrafia e antichità, 7), p. 51-84.

IGUR IV : Inscriptiones Grecae Urbis Romae, curavit L. Moretti, fasciculus quartus, Roma, Istituto Italiano per la Storia Antica, 1990 (Studi pubblicati dall' Istituto Italiano per la Storia Antica, 47).

La Rocca 2001 : LA ROCCA (E.) - La nuova immagine dei fori imperiali. Appunti in margine agli scavi. RM, 108, 2001, p. 171-213.
Loewy 1885: LOEWY (E.) - Inschriften griechischer Bildhauer, mit Facsimiles heraugegeben, Wien 1885.

Manderscheid 1981 : MANDERSCHEID (H.) - Die Skulpturenausstattung der kaiserzeitlichen Thermeanlagen, Berlin, Mann, 1981, 142 p. (Monumenta Artis Romanae, 15).

Moreno 1974 : MORENO (P.), Lisippo, volume I, Bari, Dedalo Libri, 1974.

Neudecker 1988 : NEUDECKER (R.) - Die Skulpturenausstattung römischer Villen in Italien, Mainz am Rhein, Zabern, 1988 (Beiträge zur Erschliessung hellenistischer und kaiserzeitlicher Skulptur und Architektur, 9).

Nouvel Espérandieu 1 : TERRER (D.), LAUXEROIS (R.), ROBERT (R.), GAGGADIS-ROBIN (V.), HERMARY (A.), JOCKEY (P.) - Nouvel Espérandieu : recueil général des sculptures sur pierre de la Gaule. Tome I, Vienne, Isère. Paris, Académie des Inscriptions et Belles-Lettres, Lavagne (H.) dir., 2003, 251 p., 269 p. de pl.

Pelletier 1982 : PELLETIER (A.) - Vienne antique de la conquête romaine aux invasions alamanniques (II siècle avant - III e siècle après J.-C., Le Coteu-Roanne, 1982.

Prioux 2008 : PRIOUX (E.) - Le portrait perdu et retrouvé du poète Philitas de Cos: Posidippe 63 A.-B. et IG XIV, 2486. ZPE, 166, 2008, p. 66-72.

Raoul-Rochette 1845 : RAOUL-ROCHETTE (D.) - Lettre à M. Schorn; supplément au catalogue des artistes de l'antiquité grecque et romaine, Paris, Imprimerie de Crapelette, 1845

Robert 2003 : ROBERT (R.) - Introduction à la sculpture de Vienne. In: Nouvel Espérandieu 1, pp. XLIII-LII.

Slavazzi 1996 : SLAVAZZI (F.) - Italia verius quam provincia. Diffusione e funzioni delle copie di sculture greche nella Gallia Narbonensis, Napoli, Edizioni Scientifiche Italiane, 1996, (Pubblicazioni dell'Università degli Studi di Perugia. Aucnus. Collana di studi di antichità dell'Istituto di studi comparati sulle società antiche, VI)

Slavazzi 2007 : SLAVAZZI (F.) - Un epigramma di Posidippo, il bronzista Ecateo e il ritratto di Filita. In: Fortunelli (S.) cur., Sertum perusinum Gemmae oblatum, Docenti e allievi del Dottorato di Perugia in onore di Gemma Sena Chiesa, Napoli, Loffredo, 2007 (Quaderni di “Ostraka”, 13), p. 393-401.

Will 1952 : WILL (E.) - La sculpture romaine au Musée Lapidaire de Vienne, Vienne, 1952. 


\title{
Précisions sur l'Augusteum de Nîmes grâce aux inscriptions de magistrats
}

\author{
Céline Chulsky \\ Doctorante à l'Université Paris 1 Sorbonne, UMR 8210 (ANHIMA) \\ celine.chulsky@numericable.fr
}

\begin{abstract}
Résumé
La source qui coule au pied du Mont Cavalier, à Nîmes (Gard), est le lieu principal de rassemblement des inscriptions aux membres de l'élite nîmoise, dans ce qu'on interprète désormais comme un Augusteum. Il s'agit principalement de monuments honorifiques élevés à des chevaliers, dont une majorité furent flamines provinciaux. Les chevaliers étant des desservants essentiels du culte provincial, ils expriment un lien particulier au Prince, ce qui expliquerait leur présence. Les autres magistrats de la cité ne sont représentés qu'occasionnellement. Il faut ajouter à ce constat celui d'une évolution dans le temps : si le lieu semble réservé aux manifestations collectives envers l'empereur au $\mathrm{I}^{\mathrm{e}} \mathrm{s}$., il se transforme dès les Flaviens, pour devenir au $\mathrm{II}^{\mathrm{e}} \mathrm{s}$. un espace où sont honorés les grands de la cité, ce qui peut refléter un changement de perspective, notamment la plus grande importance pour l'élite de sa place locale.

Mots-clés : Empire romain, provinces romaines, Nîmes, Augusteum, épigraphie, élite, magistrats, chevaliers, flamines, théâtre.

Abstract

The spring that flows out of the Mont Cavalier in Nîmes (Gard) is the main location where inscriptions to the local elite are found. This complex is now believed to be an Augusteum. The inscriptions are mainly honorific monuments to equites, a majority of whom were provincial priests. The equites were essential ministers of the provincial cult with a deep bond with the Prince, which would explain their presence. Other members of the local ruling elite are only occasionally found. The nature of the inscriptions evolves over time. In the first century, collective displays of loyalty towards the Emperor are most common. Change appears to begin in the time of the Flavian emperors and in the Second century. The sanctuary increasingly becomes a place where the elite is honored by the city. This may reflect new horizons, with the elite being more interested in its local impact than before.
\end{abstract}

Key-words: Roman Empire, Roman provinces, Nîmes, Augusteum, epigraphy, local ruling elite, equites, flamines, theatre. 
$\mathrm{L}$ 'ensemble monumental d'époque romaine entourant la source de Nîmes pose des problèmes d'interprétation depuis sa redécouverte. Considéré d'abord comme un complexe thermal ${ }^{1}$, il n'était donné aucune explication à la concentration d'inscriptions découvertes en ce lieu, concernant notamment de nombreux membres de l'élite nîmoise. Au début du XX $X^{\mathrm{e}}$ s., R. Naumann (1937) rassembla les différents éléments des environs de la source et les identifia à un sanctuaire. Cette hypothèse très cohérente ne permettait toujours pas d'expliquer la présence des inscriptions honorifiques en ce lieu. Plus récemment, P. Gros (1984) proposa d'identifier le complexe à un Augusteum. L'idée fut suivie par M. Janon (1991), qui en étendit les conclusions. Permet-elle d'expliquer la présence des inscriptions?

\section{La concentration d'inscriptions à des membres de l'élite nîmoise autour de la source}

La source est le lieu principal de rassemblement des inscriptions de magistrats et de membres de l'élite nîmoise, alors même qu'il s'agit de découvertes sur le lieu originel et non de déplacements (fig. 1). En effet, le site fut fouillé seulement au XVIII ${ }^{\mathrm{e}} \mathrm{s}$, à l'exception du bâtiment appelé Temple de Diane qui ne fut pas enfoui mais réutilisé et où furent déposées des pierres à des dates variées (Fiches, Veyrac 1996, p. 241-268). Vingtet-un membres de la haute élite nîmoise sont honorés à proximité de la source, ce qui représente presque le cinquième des magistrats nîmois.

La répartition est toutefois variée en fonction de la hiérarchie sociale (fig. 2). En dehors des sénateurs, les catégories supérieures de l'élite sont les mieux représentées. Presque 40 \% des chevaliers nîmois ont leur inscription à la source (fig. 3). Il s'agit uniquement d'inscriptions honorifiques ; elles représentent plus de la moitié des inscriptions honorifiques établies à des chevaliers (7 sur 12), dont toutes celles qui furent trouvées en place. Le chiffre est moins élevé pour les magistrats supérieurs, dont plus de $10 \%$ tout de même y ont une inscription, mais là encore, il semble que les inscriptions honorifiques y soient prioritairement établies (trois sur les six connues, c'est-à-dire toutes les inscriptions honorifiques bien localisées pour des magistrats supérieurs, le lieu d'origine des trois autres étant indéterminé ou semblant marquer un remploi). Les inscriptions à des magistrats inférieurs sont apparemment différentes,

1. Encore par Pelet (1852), qui prétendait reconnaître dans le Temple de Diane un temple aux Nymphes auprès des bains. puisqu'il ne s'agit pas d'inscriptions honorifiques, mais de deux inscriptions votives et d'une inscription funéraire.

\section{Des sénateurs énigmatiques}

Deux sénateurs sont représentés, un Nîmois (CIL XII, 3172) et un sénateur d'origine incertaine (CIL XII $3171 b)^{2}$. Les fragments furent découverts vers 1850 lors de fouilles à proximité du temple de Diane (HGL XV, $\mathrm{n}^{\circ} 187$ et $\left.H G L \mathrm{XV}, \mathrm{n}^{\circ} 193\right)$. Le sénateur d'origine incertaine a pu être gouverneur de Narbonnaise ; dans ce cas, sa présence s'expliquerait par la fonction de l'Augusteum, les cérémonies annuelles du culte municipal étant peut-être l'occasion d'inviter le représentant du pouvoir impérial (Fishwick II 1 1987-1992, p. 529), ou du moins, de l'y honorer, en tant qu'image de l'Empereur dans la province. Toutefois, la plaque étant incomplète, il peut s'agir d'un Nîmois. L'inscription se rapportant à un sénateur de Nîmes est également fragmentaire, et il est très difficile d'expliquer sa présence à cet endroit.

\section{Les chevaliers : le rapport privilégié à l'empereur}

Sept chevaliers sont connus à la source, exclusivement par des bases honorifiques ${ }^{3}$. P. Gros indique que les inscriptions des prêtres du culte provincial sont toutes concentrées à cet endroit, consacré par excellence au culte impérial (Gros 1998, p. 18). Cette assertion paraît contestable à première vue : sur quatre flamines provinciaux ${ }^{4}$, tous des chevaliers, deux d'entre eux ont des inscriptions ailleurs. Toutefois, l'hommage à Q. Solonius Severinus, découvert place de la Madeleine, est gravé sur une inscription déplacée dont on ne connaît pas la provenance exacte. D'autre part, l'une des inscriptions à M. Cominius Aemilianus fut découverte place Gabriel Péri, mais il s'agissait d'un remploi, sur un socle de croix puis dans un puits. Pourquoi cette concentration ? En effet, le culte provincial avait lieu dans la

\footnotetext{
2. L'inscription CIL XII, 3173 est trop incomplète pour pouvoir être prise en compte.

3. C. Aemilius Postumus (CIL XII, 3176), M. Cominius Aemilianus (CIL XII, 3213), L. Sammius Aemilianus (CIL XII 3183), Q. Soillius Valerianus (CIL XII 3274-3275) et trois anonymes (CIL XII, 3185, 3187 et 5899). Un huitième fut peut-être chevalier, [---] Paetinus (CIL XII, 3160), mais l'identification n'est pas assurée : il pourrait s'agir d'un magistrat de rang inférieur.

4. M. Cominius Aemilianus (CIL XII, 3212-3213), Q. Soillius Valerianus (CIL XII, 3274-3275), L. Sammius Aemilianus (CIL XII, 3183 ) et Q. Solonius Seuerinus (CIL XII, 3184).
} 
capitale provinciale, Narbonne, et non pas à Nîmes. On peut tout de même mettre en relation leur fonction et la présence de leur statue à l'Augusteum : ce sont les représentants de la province face à l'empereur, des témoins de sa loyauté, de même que l'Augusteum est un témoin de la loyauté de Nîmes envers le Prince. Une place particulière est donc réservée aux anciens flamines provinciaux dans l'Augusteum local, non pas directement en raison de leur fonction puisqu'ils ne sont plus en charge, mais peut-être plutôt en raison de la dignité qu'ils avaient acquise par ce sacerdoce et qui les liait plus directement à l'empereur. Comment alors expliquer les inscriptions de chevaliers n'étant pas passés par le flaminat provincial ? Il faut d'abord invoquer le caractère incomplet des inscriptions: sur quatre chevaliers qui ne furent pas flamines, trois sont connus par des inscriptions anonymes incomplètes; le flaminat a donc pu être revêtu. Toutefois, dans l'inscription complète, le flaminat provincial n'apparaît pas, et les carrières des anonymes n'incitent pas nécessairement à le restituer. Il faut chercher une autre raison à leur présence. Il ne s'agit pas de l'exercice de fonctions sacerdotales: quatre sur sept seulement semblent avoir été pontifes, et cela est mentionné avec le reste de leur carrière municipale. Une statue fut offerte par la cité d'Apt à son patron ${ }^{5}$; toutefois, d'autres inscriptions consacrées à des patrons sont situées en d'autres lieux ${ }^{6}$, et il ne faut pas voir dans le sanctuaire un espace privilégié de remerciement à des patrons. L'inscription de l'Ara Numinis Augusti municipal de Narbonne (CIL XII, 4333) donne un indice : elle précise que les sacrifices au numen de l'empereur doivent être offerts par trois chevaliers et trois affranchis, ainsi que par les colons et les habitants (Fishwick II 1 19871992, p. 502 ; Van Andringa 2002, p. 222). Il existe donc un rapport particulier entre les chevaliers et l'empereur. Cela pourrait expliquer une localisation préférentielle des dédicaces à l'Augusteum, même lorsqu'elle ne concerne pas des flamines provinciaux. Une inscription put se trouver en un lieu plus spécifique de l'Augusteum : la statue élevée à $M$. Cominius Aemilianus par les sévirs augustaux (CIL XII, 3213), peut-être aux abords de leur collège à proximité du sanctuaire, puisque M. Janon (1991, p. 772) y souligne la présence d'un autre collège, celui des utriculaires. Toutefois, comme il s'agit d'un ancien flamine provincial, cela n'est pas certain.

\footnotetext{
5. CIL XII, 3275 (Q. Soillius Valerianus).

6. CIL XII, 3169 au couvent des Ursulines (rue Sainte-Ursule), par les Avignonnais; deux inscriptions à L. Iulius Niger par les sévirs augustaux, découvertes en des lieux indéterminés de Nîmes ; inscription de Q. Solonius Severinus (CIL XII, 3184) par la cité de Forum Iulii, découverte à Nîmes en un lieu indéterminé ; inscription CIL XII, 3212 à M. Cominius Aemilianus par les Voconces, découverte en remploi place des Carmes.
}

\section{Pontifes, théâtre et Augusteum}

Les quatre magistrats supérieurs ${ }^{7}$ connus par des inscriptions à la source mentionnent tous le pontificat (dont un sous la forme « ayant accompli tous les honneurs ») ; trois d'entre eux ne mentionnent que cette fonction sur l'inscription. Cela est particulièrement remarquable puisque la mention du pontificat seul est rare, indiquée seulement cinq fois de manière isolée dans la cité de Nîmes, ce sacerdoce faisant partie du cursus municipal (Gascou 1997, p. 112-113) et étant donc généralement mentionné avec d'autres magistratures. Les deux cas recensés hors de l'Augusteum sont une inscription très lacunaire sur laquelle manque quasiment tout le cursus du personnage ${ }^{8}$ et une inscription funéraire à la sœur d'un pontife, effectuée donc dans un cadre privé pour une autre personne que le pontife ${ }^{9}$. À la source, les fragments consacrés à T. Iulius Dolabella (CIL XII, 3232) donnent le cursus complet du personnage. Ce n'est donc pas le pontificat qui explique la présence de l'inscription à cet endroit. P. Gros a émis l'hypothèse qu'elle se situait au théâtre. En effet, l'inscription est offerte par l'association thymélique sacrée de Naples. L'emplacement originel de cet hommage au théâtre n'est pas certain (Janon 1991, p. 772); toutefois, puisque quasiment aucun magistrat n'est honoré aux abords de la source en dehors des chevaliers, cela invite à placer le personnage un peu à l'écart, dans un lieu en rapport avec l'association qui l'honore. Cela n'est évidemment pas une certitude, puisque la notoriété de cet homme remarquable «non seulement dans sa splendide patrie, par sa famille de grande réputation et par son genre de vie modéré, mais également par sa raison et sa grande âme » selon les termes du décret peut expliquer, malgré l'emphase convenue, qu'il ait exceptionnellement eu le droit de recevoir un hommage à l'Augusteum. Selon H. Lavagne (1986, p. 139), l'association serait une des pièces maîtresses du culte impérial à Nîmes et $\mathrm{P}$. Gros (1984, p. 132) ajoute que cet endroit était celui on l'on conservait les traces officielles des concours et témoignages de loyalisme à l'égard des empereurs. Le lien entre ludi scaenici et culte impérial est attesté par Suétone, qui indique que la plupart des provinces établirent des jeux quinquennaux en l'honneur de l'empereur ${ }^{10}$; des prêtres du culte impérial offraient également des jeux au

7. T. Iulius Dolabella (CIL XII, 3232), M. Valerius Severus (CIL XII, 3134) et deux pontifes mentionnés sur la même inscription (CIL XII, 3142), [-] Clodius Iunior et [...] Varenus.

8. CIL XII 3220 : C. [.] Latr[.]

9. CIL XII 2759 : Flavius.

10. Suétone Aug. 59,3. 


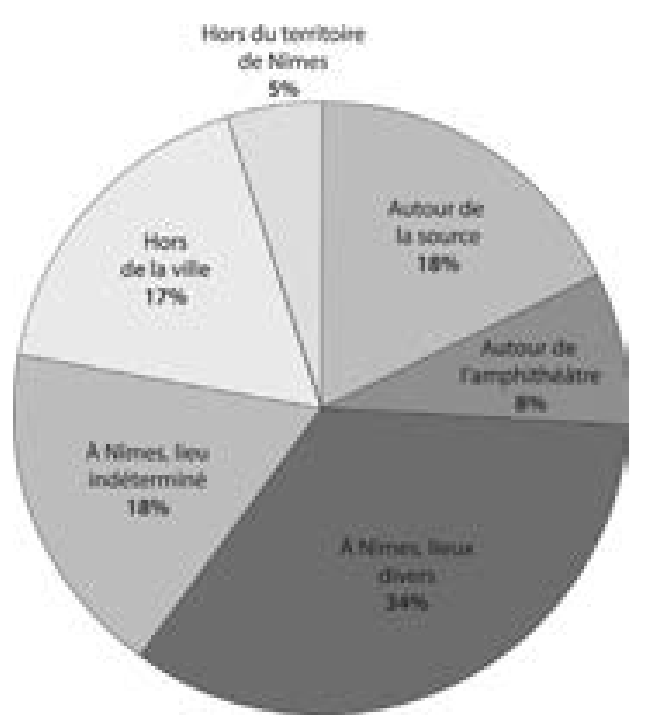

Fig. 1. Lieux de découverte d'inscriptions à des magistrats nîmois.

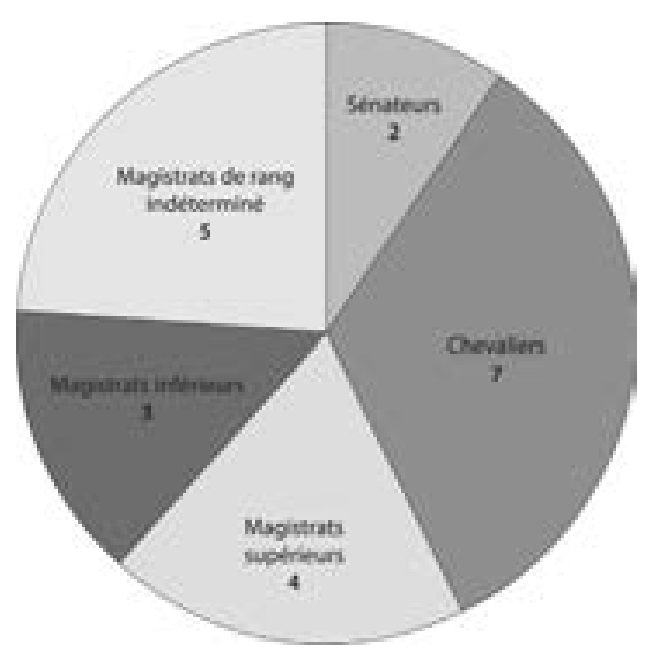

Fig. 2. Répartition hiérarchique des témoignages à la source.

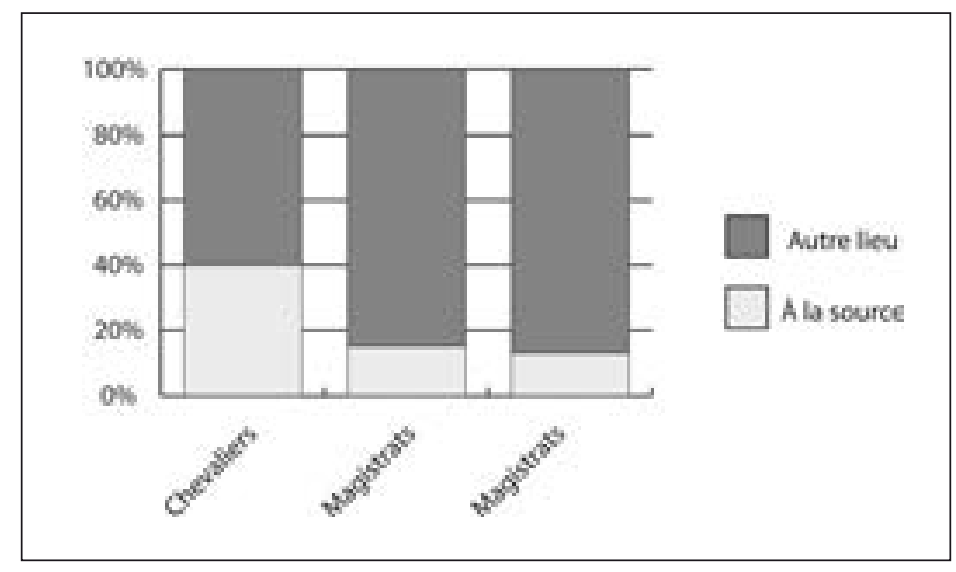

Fig. 3. Proportion des magistrats nîmois présents à la source par catégorie.

théâtre (Fishwick II 1, 1987-1992, p. 583 n. 664). Nous ne pensons pas que l'inscription, si elle était proche du théâtre, indiquait le siège de l'association thymélique. Le siège de l'association pourrait s'être situé à un tout autre endroit de la ville ${ }^{11}$; il semble en effet inapproprié qu'une association se réunisse à l'intérieur même de l'Augusteum. Il vaudrait donc mieux situer l'inscription (fig. 4) au théâtre, à moins qu' elle n'ait été affichée juste à l'extérieur du sanctuaire, puisque un fragment retrouvé récemment à proximité (Fiches, Veyrac 1996, n¹84) indique un possible rapport entre T. Iulius Dolabella et l'association des utriculaires, qui pourrait avoir son

11. Contre P. Ghiron-Bistagne (1990-1991, p. 71), qui propose la source comme siège de l'association des technites. siège à cet endroit, comme d'autres associations favorisées par l'empereur (Janon 1991, p. 772-774).

Or, ce décret mentionne deux associations, celle des centonaires et celle des synagonistes. Une deuxième inscription à un magistrat supérieur est de nature votive, s'adressant à la Victoire Auguste ; elle mentionne un autel et des vela restaurés par le pontife en charge, M. Valerius Severus (CIL XII, 3134). L'interprétation traditionnelle fut d'y voir des tentures, des rideaux autour d'un petit temple ${ }^{12}$. La mention conjointe d'un autel peut inciter à y reconnaître, selon une hypothèse émise par M. Christol, des rideaux cachant l'emplacement des

12. $H G L X V, \mathrm{n}^{\circ} 100=303, \operatorname{IAN}, \mathrm{n}^{\circ} 47=148$. 


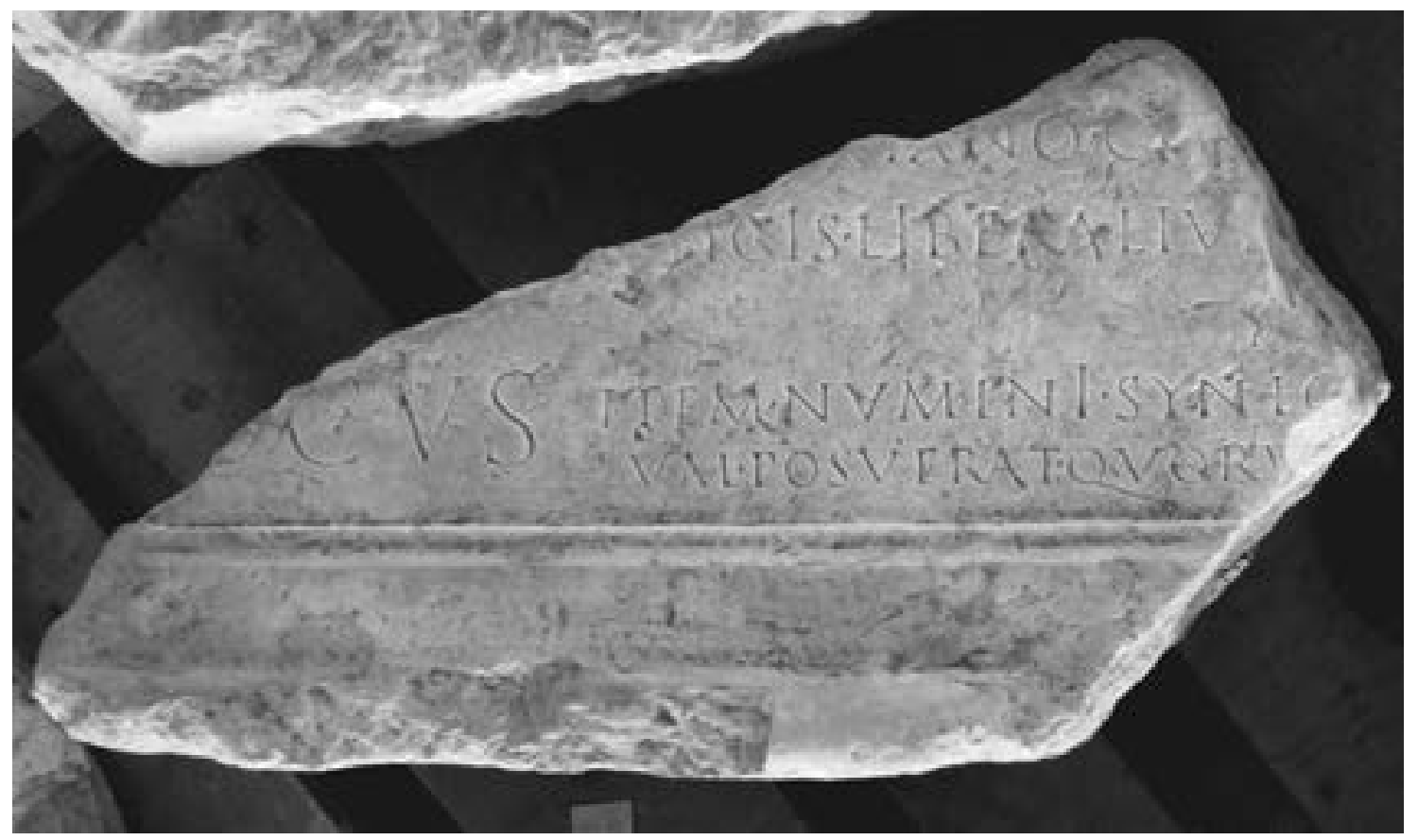

Fig. 4. CIL XII, 3232 (๔ Céline Chulsky).

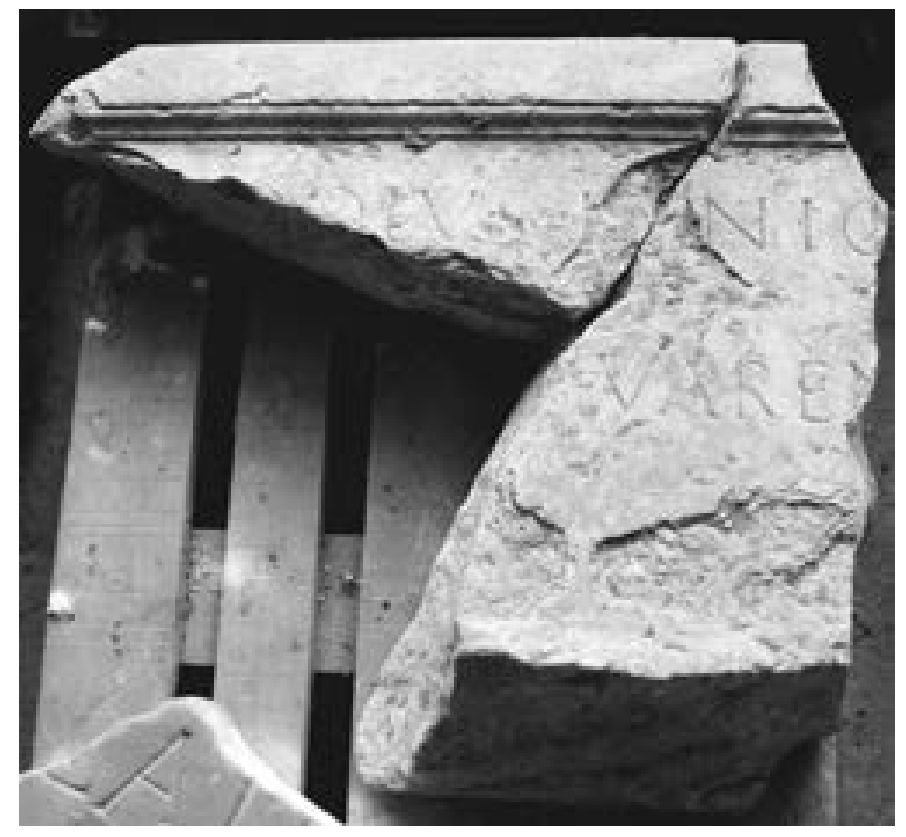

Fig. 5. a CIL XII 3142, fragment 1 (๔ Céline Chulsky).

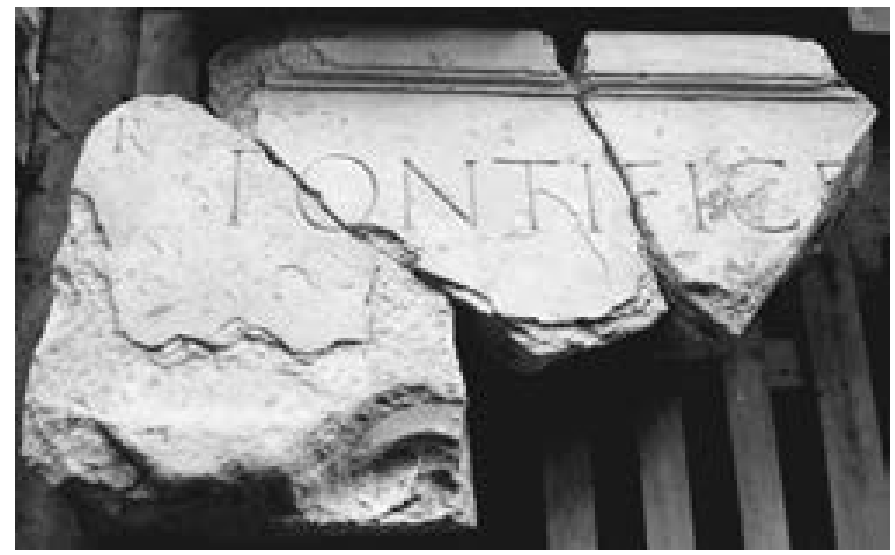

Fig. 5. b CIL XII 3142, fragment 2 (@ Céline Chulsky)

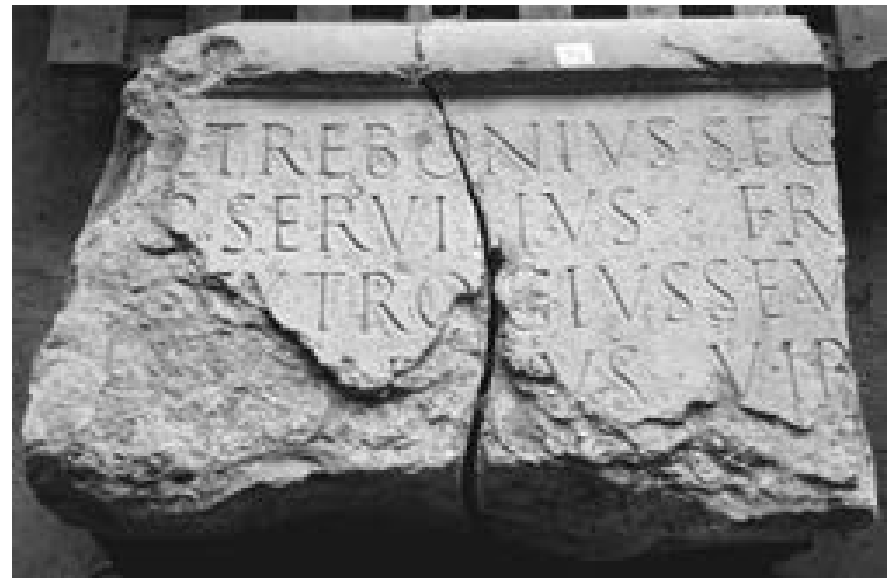

Fig. 5. c CIL XII 3142a (๑ Céline Chulsky). 
statues impériales du mur de scène ou d'un autre endroit du théâtre, amenées en procession lors des grandes fêtes (Fishwick II 1 1987-1992, p. 522-523 et 555-557) ${ }^{13}$. Nous resterons prudent malgré la pertinence de cette idée, car la Victoire est un thème très lié à Auguste (Fears 1981 p. 812 ; Fishwick II 1 1987-1992, p. 463 ; Acomoli 1999-2000, p. 288), et elle trouverait peut-être mieux sa place non loin de l'autel impérial, malgré l'évidence du lien entre culte à l'empereur et cérémonies au théâtre. Selon l'étude de E. Smadja concernant l'Afrique (1986), la Victoire Auguste, " garante de l'ordre social et du maintien de l'Empire », symbolisant l'autonomie locale sous la protection de l'empereur, est généralement un culte civique ; elle n'est liée à un aspect plus militaire que dans des zones où la présence de soldats est importante, et les dédicaces sont alors faites par des individus. Toutefois, l'Augusteum de Nîmes a été mis en place à l'époque augustéenne, alors que le prince était encore en guerre. L'empereur fit de la Victoire Auguste le pilier du système des vertus impériales, élément qui perdura jusqu'à Constantin et qui est presque inévitablement présent auprès de l'empereur (Fears 1981, p. 812) ${ }^{14}$. Le thème a pu se perpétuer à Nîmes. La dernière inscription semble être une liste de pontifes (CIL XII, 3142). La plaque, mentionnant deux à quatre personnes ${ }^{15}$, est incomplète (fig. 5). Il s'agit d'une pierre divisée par des encadrements de moulures en plusieurs compartiments, qui faisait plusieurs mètres de long lors de sa découverte $^{\mathbf{1 6}}$. Le caractère massif de l'inscription, s'étendant en largeur et non en hauteur, incite à y voir le bandeau d'un grand édifice. Cette inscription fut peut-être retrouvée en place, car J. Teissier-Rolland (1851, p. 183) et J.-F. Séguier (Msc. 110 , p. $40=$ p. 1 et p. $46=$ p. 8 ) indiquent qu'elle fut découverte sur la face antérieure de la margelle d'un bassin du complexe. Ce serait

13. D. Fishwick cite Tacite, Ann. IV,2 et Sénèque, De cons. ad Marciam 22,4, mais il s'agit de cas controversés et critiqués.

14. S. Acomoli (1999-2000, p. 288) rappelle que la première mention du culte à Victoria Augusta date de 14 de n. è. (CIL X 8375 à Cumes).

15. L'inscription mentionne $[\mathrm{Cl}]$ oduis $\mathrm{I}[\mathrm{u}]$ nior et $[---] \mathrm{s}$ Varenus. Deux fragments, hono et us ont été découverts au même endroit. Les commentateurs anciens ont refusé de les rassembler (Pelet Msc. 503, p. $8 \mathrm{n}^{\circ} 26 ; H G L \mathrm{XV}, \mathrm{n}^{\circ} 302$ ). $H G L \mathrm{XV}$ fait toutefois de l'un d'eux un nom, [---] Hono[ratus], et le place à la suite de [---] Varenus, ce qui est peu probable étant donné la configuration de la pierre. J. Gascou (1997, p. 113 n.209) place un nom sur une colonne plus à gauche, ce qui semble la meilleure solution, mais il n'est pas certain alors qu'il se soit agi d'un pontife. Il vaut mieux abandonner ce nom, même si on doit probablement postuler deux autres pontifes.

16. Selon $I A N \mathrm{n}^{\circ} 147$, il y aurait eu trois fragments, dont l'un était perdu déjà de son temps et les deux autres furent brisés pour en donner quatre. Ils mesuraient alors 2,3 m de long réunis. Aujourd'hui, l'inscription est brisée en cinq fragments et conservée à la réserve du musée de Nîmes. alors le bandeau d'un podium, peut-être pour l'autel du culte impérial, ou plutôt pour le portique aquatique qui entoure cet espace. Nous disposons d'une seconde liste (CIL XII, 3142a ), découverte au même endroit, ne précisant pas la fonction des probables magistrats concernés, mais ressemblant à cette liste des pontifes (fig. 5). Les caractères sont de taille un peu différente, la moulure supérieure est plus simple et la disposition des noms plus resserrée ; J. Teissier-Rolland (1851, p. 183) a rapproché les inscriptions, indiquant qu'il s'agissait d'une plaque unique de 5 mètres de long. O. Hirschfeld (CIL XII, 3142a) cite A. Allmer pour dire qu'elle est gravée d'une autre main, ce avec quoi nous ne sommes pas d'accord: les lettres sont réalisées avec les mêmes courbes ${ }^{17}$, mais cette liste, qui mentionne quatre personnes, est moins effacée et les caractères sont plus resserrés. J.-F. Séguier aurait d'ailleurs vu les lettres po- en dessous des quatre noms ${ }^{18}$, mais $\mathrm{O}$. Hirschfeld conclut à posuerunt et non à pontifices. Il peut s'agir soit d'une autre liste de pontifes, soit d'une liste d'autres magistrats, soit, selon l'hypothèse d'O. Hirshfeld, d'une liste des dédicants en raison du caractère réduit des lettres par rapport à l'autre inscription. Dans le cas d'une liste de pontifes uniquement, elle pourrait avoir un lien avec l'autel situé au-dessus. Le collège des pontifes de Rome avait un rôle pendant les jeux ${ }^{19}$, notamment lors des ludi scaenici se déroulant au théâtre; il pourrait en avoir été de même dans les provinces. Or, les jeux, particulièrement à Nîmes où le théâtre est à l'intérieur de l'Augusteum (Gros 1984, p. 131 ; Fishwick II 1 1987-1992, p. 584), ont un lien avec le culte impérial (Fishwick II 1 1987-1992, p. 575576). Les pontifes seraient mentionnés à l'Augusteum en raison du rôle des pontifes dans la célébration du culte. Toutefois, on comprendrait mal que les noms soient différents alors que la gravure est de la même main, à moins qu'elle ait été faite peu après. Dans le cas d'une liste de tous les magistrats de la cité, le fait que nous n'ayons conservé que la mention sûre de pontifes serait un hasard et il faudrait alors relativiser la présence quasi exclusive des pontifes à l'Augusteum. Une dernière inscription concerne le théâtre : l'hommage à L. Sammius Aemilianus (CIL XII, 3183), dédié par le « grand-prêtre du synode », indique un lien particulier avec les synagonistes. Toutefois, ce n'est peut-être pas en raison de ce

17. Voir la ressemblance entre les $\mathrm{E}$ ou les $\mathrm{R}$ des deux inscriptions, particulièrement frappante. Les $\mathrm{N}$ et les $\mathrm{O}$ sont également similaires, mais plus communs. Les $\mathrm{V}$ sont un peu plus resserrés sur l'inscription CIL XII, 3142a pour des raisons de place.

18. Cité par CIL XII, 3142a. Une bonne copie est disponible dans Tersan Msc.6954, n²62.

19. North (J.A.) - Article «Pontifex». In : Hornblower (S.) et Spawforth (A.) dir., The Oxford Classical Dictionary, Oxford, $3^{\mathrm{e}}$ édition, Oxford University Press, 1999, 1640p, p. 1219. 
lien que la statue fut élevée à l'Augusteum, mais parce que le personnage était flamine provincial.

\section{Présence fortuite : inscriptions déplacées ou votives des magistrats inférieurs}

La présence de magistrats inférieurs à l'Augusteum semble de nature différente. L'un d'entre eux, T. Caecilius Guttur (CIL XII, 3206), a reçu une inscription honorifique de la part de ses affranchis; il s'agit donc d'un monument privé (fig. 6). Selon F. GermerDurand (IAN, $\left.\mathrm{n}^{\circ} 141\right)$, elle s'intégrait dans un ensemble, dans une galerie proche de la source. Elle ne dut pas être découverte dans l'Augusteum proprement dit car l'inscription ne mentionne pas que l'endroit a été octroyé par décret des décurions, ce qui aurait été le cas si l'emplacement avait été public. De plus, l'hypothèse de l'appartenance à un ensemble n'est pas certaine, et on ne sait pas si l'inscription fut découverte dans la fontaine ou au Temple de Diane ; dans ce dernier cas, il pourrait s'agir d'une inscription déplacée, les inscriptions du pseudo-temple ayant quasiment toutes été déplacées. Emile Espérandieu (1924, p. 92 n³18) l'a identifiée à une inscription funéraire, ce qui est très probable. En effet, le nom du personnage est au datif, caractéristique des épitaphes du I $\mathrm{I}^{\mathrm{e}}$ s. de n. è. (Pelet 1863, p. 50 n ${ }^{\circ} 33$; Dondin-Payre, Raepsaet-Charlier 2001, p. IX). Dans ce cas, l'hypothèse d'un déplacement est cohérente, puisqu'il ne pouvait pas se trouver d'espace funéraire dans l'Augusteum. Les deux autres documents ${ }^{20}$ sont des inscriptions votives privées, dédiées à la divinité topique, Nemausus; ils ne sont donc pas sur les lieux pour des raisons liées à la fonction des magistrats évoqués.

\section{Un Augusteum mais pas le lieu cultuel unique de la cité}

Nous connaissons huit flamines de la cité à Nîmes ${ }^{21}$, dont la fonction sacerdotale pourrait avoir un lien avec les abords de la fontaine puisque la formule complète du sacerdoce est « flamine de Rome et d'Auguste » ${ }^{22} \mathrm{ou}$

20. CIL XII, 3094 (Q. Crassius Secundinus) et CIL XII, 3095 (Q. Iulius Bucca).

21. CIL XII, 3180 (Sex. Iulius Maximus), 3186 (anonyme), 3190 (Aemilius), 3207 ([---] Capito), 3212-3213 (M. Cominius Aemilianus), 3275 (Q. Soillius Valerianus) ; AE 1904, 147 (Publius), AE 1969-1970 376 (C. Sergius Respectus).

22. AE 1969-1970 376; CIL XII, 3212 (mais l'autre inscription au même personnage, CIL XII, 3213, le mentionne comme «flamine de Rome et du divin Auguste » ${ }^{23}$. Il s'agit de cinq chevaliers et de trois magistrats supérieurs, certainement l'élite de la cité, juste en dessous des flamines provinciaux, fonction que deux d'entre eux ont d'ailleurs exercée. Toutefois, seules les deux inscriptions se rapportant aux flamines provinciaux ${ }^{24}$ sont situées aux abords de la source. Il semble donc que l'Augusteum n'était pas l'endroit où étaient honorées ces personnes, si elles l'étaient d'ailleurs, car les inscriptions honorifiques les concernent rarement. Bien que les flamines aient apparemment été les desservants du culte impérial local, ils n'y recevaient aucun hommage. On peut émettre l'hypothèse que ces flamines avaient un lien moindre avec l'empereur. Ils n'étaient en effet nommés à cette position que pour un an, et n'étaient pas nécessairement des chevaliers, catégorie dont on a vu qu'elle était proche du Prince. Le flamine provincial, outre son statut de chevalier, conservait toute sa vie de nombreux privilèges acquis pendant sa charge, comme le droit de porter le vêtement du flamine lors des jours de fêtes (Fishwick II 1 1987-1992, p. 479) ou celui de siéger à l'assemblée provinciale et dans sa curie municipale (Fishwick III 2, p. 9). Il était donc étroitement associé au sacerdoce qu'il avait revêtu. D'autre part, les flaminicae Augustae municipales sont totalement absentes de cet espace. Nous ne connaissons aucune inscription effectuée par des flaminiques dans l'exercice de leurs fonctions, ce qui ne relevait probablement pas de leurs attributions. Elles sont connues par des inscriptions funéraires voire honorifiques élevées en remerciement de dons, mais ne récompensant pas leur fonction civique, contrairement aux magistrats honorés pour leur rôle dans la cité. Enfin, on ne relève aucune inscription de sévir augustal à la source, alors même que leur nom et leur fonction semblent y inviter. Les sévirs sont connus uniquement par des inscriptions funéraires, ce qui n'a pas sa place à la source, voire par des dédicaces votives, et le hasard a voulu qu'on n'ait retrouvé aucune dédicace faite par un sévir à cet endroit. De plus, leur statut d'affranchis était peu prestigieux, alors même qu'on honorait très peu de magistrats municipaux dans cet endroit. Les abords de la source sont donc bien un lieu spécialisé, où les magistrats n'ont pas nécessairement leur place, mais où le lien avec l'empereur est mis en valeur.

«flamine de la colonie »); CIL XII, 3186 si l'on accepte la restitution habituelle.

23. CIL XII ,3180 et CIL XII, 3207, qui furent aussi flamines de Drusus et de Germanicus.

24. M. Cominius Aemilianus et Q. Soillius Valerianus. 


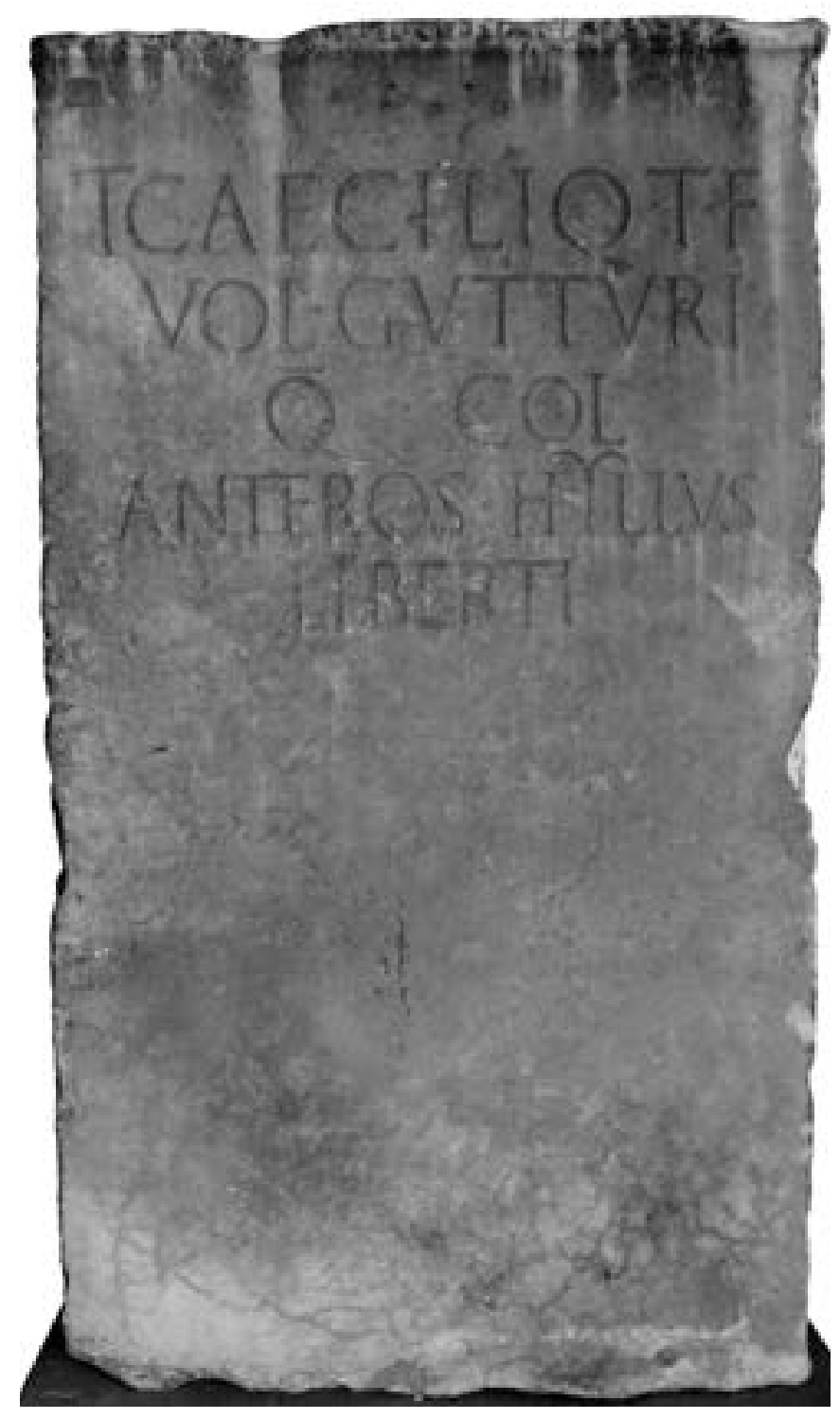

Fig. 6. CIL XII, 3206 (@ Céline Chulsky).

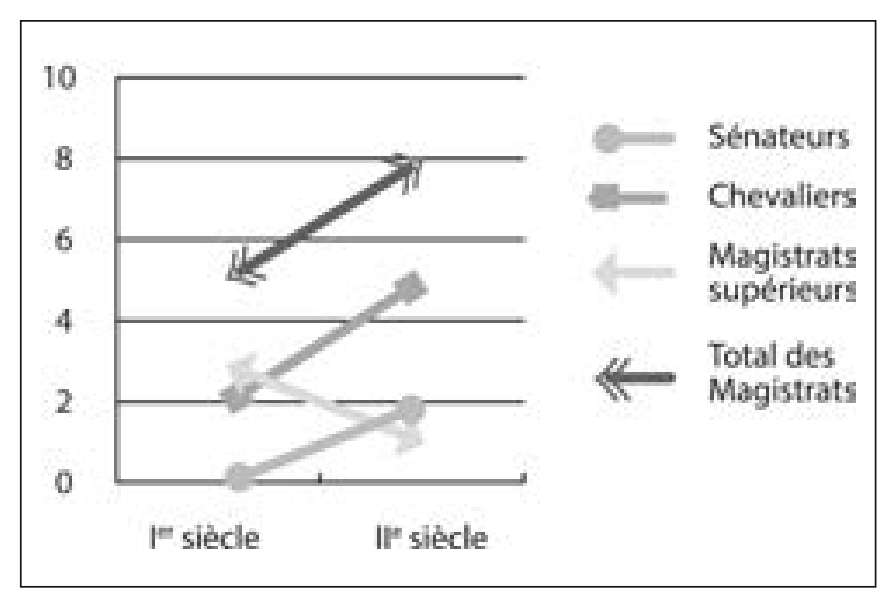

Fig. 7. Evolution du nombre de membres de l'élite connus à la source.

\section{Des pontifes aux flamines provinciaux}

L'évolution chronologique montre une augmentation globale du nombre d'inscriptions découvertes aux abords de la source, sans compter les magistrats inférieurs dont les inscriptions semblent être de nature privée (fig. 7). Le nombre de témoignages de magistrats supérieurs, qui sont en général des pontifes, diminue au deuxième siècle de n. è., alors que cette fonction fait toujours partie du cursus nîmois. Il ne me semble pas qu'il faille y voir un déplacement ou une modification de leur activité, mais plutôt des pratiques commémoratives un peu différentes, les témoignages plus ou moins collectifs du premier siècle ne trouvant plus leur place à l'Augusteum à l'époque suivante. Le seul pontife recensé au deuxième siècle, T. Iulius Dolabella, ne mentionne d'ailleurs ce sacerdoce qu'au milieu de sa carrière. À l'opposé, le nombre d'inscriptions de chevaliers augmente, en lien avec le flaminat provincial. En effet, les flamines de la province, à Nîmes, ne sont connus qu'au deuxième siècle, le sacerdoce ayant été créé sous Vespasien (Fishwick III 2 p. 4 et $8{ }^{25}$. Cela suffit à expliquer l'augmentation. Le sanctuaire, lieu du culte impérial, c'est-à-dire de la fidélité à l'empereur, y met en valeur les flamines provinciaux, représentants privilégiés du lien entre la cité et l'empereur. Nous pouvons ainsi relativiser l'hypothèse que le sanctuaire deviendrait, au deuxième siècle, un lieu plurifonctionnel (Gros 1998, p. 18). Deux sénateurs y apparaissent certes, mais plus des deux tiers environ sont désormais d'anciens flamines provinciaux. Il semble y avoir une meilleure définition du rôle des inscriptions dans ce lieu. Si, au premier siècle, les monuments sont liés à des occasions particulières (dédicace à la Victoire Auguste, liste de pontifes autour de l'autel impérial, peut-être à l'occasion d'une dédicace ou d'une restauration) et concerner les magistrats dans un sens collectif (pontife dans l'exercice de sa charge, somme des pontifes ou des magistrats en charge), au deuxième siècle, ils récompensent des individus particulièrement liés à l'empereur voire aux activités du sanctuaire, et se présentent sous la forme de piédestaux de statues, qui sont toutefois offerts par des entités très diverses. Le changement commence probablement sous les Flaviens, avec les inscriptions de C. Aemilius Postumus et de l'anonyme CIL XII 3187, mais prend toute son ampleur au $\mathrm{II}^{\mathrm{e}}$ s., au travers des statues aux anciens flamines provinciaux.

25. J.-M. Pailler (1989) propose Domitien, ce qui ne modifie pas notre propos. 


\section{Espaces et inscriptions}

Les inscriptions des magistrats renvoient donc à plusieurs espaces très différents constituant le sanctuaire :

- l'autel du culte impérial, autour duquel ou auprès duquel se serait trouvée la liste des pontifes voire des magistrats en charge

- des autels à des divinités associées au culte impérial, notamment Victoria Augusta

- le théâtre, lié au culte impérial, près duquel fut peutêtre placé le décret thymélique en faveur de T. Iulius Dolabella

- des espaces consacrés à diverses divinités, dont Nemausus, à qui sont adressés les vœux des questeurs Q. Crassius Secundinus et Q. Iulius Bucca ; c'est peutêtre l'originalité de l'Augusteum nîmois, en raison de sa localisation sur un sanctuaire pré-romain qu'il a intégré dans sa disposition

- un ou des espaces recevant les statues honorifiques de certains chevaliers, puis des anciens flamines provinciaux, voire de quelques sénateurs, probablement sous des portiques ; cette composante resterait difficile à percevoir sans l'épigraphie

- en bordure de l'Augusteum, des sièges d'associations, peut-être les utriculaires, mais aussi les centonaires ou des synagonistes.

\section{Conclusion}

L'interprétation de cet ensemble comme Augusteum proposée par P. Gros éclaire la présence des inscriptions, et l'épigraphie confirme le lien entre cet espace et l'empereur. Ce sont bien les représentants de l'Empereur, et non les Nîmois en tant que tels, qui y sont honorés. Toutefois, on peut relativiser l'affirmation selon laquelle il s'agit du site le plus important pour les habitants et pour le pouvoir (Gros 1991, p. 139) : une partie des activités et cérémonies municipales se déroulent ailleurs, et les magistrats municipaux ou les grands évergètes de la cité sont remerciés à d'autres endroits. Il semble que le sanctuaire gagne de l'importance au $\mathrm{II}^{\mathrm{e}} \mathrm{s}$., en relation avec la mise en place du culte impérial provincial ; il se transforme en tout cas pour devenir le lieu où sont honorés d'anciens flamines provinciaux originaires de Nîmes, alors que les hommages, à cet endroit, n'étaient jamais individuels avant les Flaviens. Rien de systématique, toutefois, les dédicants étant d'origine et de nature très variées. Le recentrage de l'élite nîmoise sur la province de Narbonnaise pourrait en tout cas se lire jusque dans l'utilisation de l'Augusteum.

\section{Bibliographie}

CIL XII : HIRSCHFELD (O.) - Inscriptiones Galliae Narbonensis Latinae. Berlin, G. Reimer, 1888, 976 p. (Corpus inscriptionum Latinarum, XII).

$\boldsymbol{H} \boldsymbol{G L}$ XV = ALLMER (A.), GERMER-DURAND (F.) et LEBÈGUE (A.), Recueil des inscriptions antiques de la province de Languedoc. Toulouse, Privat, 1892, 1251 p. (Histoire générale de Languedoc, XV).

$\boldsymbol{I A N}$ : GERMER-DURAND (E.) et (F.) et ALLMER (A.) dir., Inscriptions Antiques de Nîmes. Toulouse, Privat, 1893, 1100 p.

Acomoli 1999-2000 : ACOMOLI (S.) - Il pontificato municipale nella Gallia Narbonese. Atti dell'Istituto Veneto di Scienze, Lettere ed Arti, CLVIII, 1999 2000, p. 201-303.

Espérandieu 1924 : ESPERANDIEU (E.) - Le musée lapidaire de Nimes. Guide sommaire. Nîmes, Imprimerie générale, 1924, 160 p.

Fears 1981 : FEARS (J.R.) -The Theology of Victory at Rome: Approaches and Problems. Temporini (H.) et Haase (W.) dir., ANRW II, 17, 2, Berlin/New York, W. de Gruyter, 1981, p. 736-826.

Fiches, Veyrac 1996 : FICHES (J.-L.) et VEYRAC (A.) - Nîmes. Carte archéologique de la Gaule 30/1. Paris, Académie des Inscriptions et BellesLettres, 1996, 634 p.

Fishwick 1987-1992 : FISHWICK (D.) - The Imperial Cult in the Latin West. Leyde/New York/Cologne, Brill, 1987-1992, 2 tomes en 4 vol., 867 p.

Gascou 1997 : GASCOU (J.) - Magistratures et sacerdoces municipaux dans les cités de Gaule Narbonnaise. In : Christol (M.) et Masson (O.) dir., Actes du $X^{e}$ congrès international d'épigraphie grecque et latine, Nîmes (4-9 octobre 1992), Paris/Nîmes, Publications de la Sorbonne/Ville de Nîmes, 1997, 499 p., p. $75-140$

Ghiron-Bistagne 1990-1991 : GHIRON-BISTAGNE (P.) - Les artistes dionysiaques de Nîmes à l'époque impériale. Cahiers du GITA 6, 1990-1991, p. $57-78$.

Gros 1984 : GROS (P.) - L'Augusteum de Nîmes. RAN, 17, 1984, p. 123-134.

Gros 1991: GROS (P.) - Nouveau paysage urbain et cultes dynastiques : remarques sur l'idéologie de la ville augustéenne à partir des centres monumentaux d'Athènes, Thasos, Arles et Nîmes. In: Rebourg (A.) et Goudineau (C.) dir., Les villes augustéennes de Gaule, colloque d'Autun (6-8 juin 1985), Autun, Société éduenne des lettres, sciences et arts/Ville d'Autun, 1991, 152 p., p. 127-140.

Gros 1998 : GROS (P.) - Villes et «non-villes » : les ambiguités de la hiérarchie juridique et de l'aménagement urbain. In: Gros (P.) dir, Villes et campagnes en Gaule romaine, $120^{\mathrm{e}}$ Congrès national des sociétés historiques et scientifiques, Aix-en-Provence (23-39 octobre 1995), Paris, Ed. du CTHS, 1998, 204 p., p. 11-25.

Janon 1991 : JANON (M.) - De Judée en Narbonnaise, reconnaissance de quelques sanctuaires du pouvoir. MEFRA, 103-2, 1991, p. 735-783.

Lavagne 1986 : LAVAGNE (H.) - Rome et les associations dionysiaques en Gaule (Vienne et Nîmes). In : L'association dionysiaque dans les sociétés anciennes, actes de la table ronde de l'Ecole française de Rome, Rome (24-25 mai 1984), Rome, Ecole française de Rome, 1986, 318 p., p. 129-148.

Naumann 1937 : NAUMANN (R.) - Der Quellbezirk von Nîmes. Berlin/ Leipzig, W. de Gruyter, 1937, 60 p. 
Pailler 1989 : PAILLER (J.-M.) - Domitien, la loi des Narbonnais et le culte impérial dans les provinces sénatoriales d'Occident. RAN, 22, 1989, p. 171-189.

Pelet Msc. 503 : PELET (A.) - Nymphée à Nîmes, inscriptions antiques recueillies par A. Pelet, Msc.503, cahier 3, BM Nîmes.

Pelet 1852 : PELET (A.) - Essai sur le nymphée de Nîmes. Mémoires de l'Académie du Gard, 1851-1852, p. 83-152.

Pelet 1863 : PELET (A.) - Catalogue du musée de Nîmes. Nîmes, $6^{e}$ édition, Clavel-Ballivet, 1863, $267 \mathrm{p}$.

Dondin-Payre, Raepsaet-Charlier 2001: DONDIN-PAYRE (M.) et RAEPSAET-CHARLIER (M.-T.) - Critères de datation épigraphique pour les Gaules et les Germanies. In : Id. dir., Noms, identités culturelles et romanisation sous le Haut-Empire, Bruxelles, Le livre Timperman, 2001, 774 p., p. IX.
Smadja 1986 : SMADJA (E.) - La Victoire et la religion impériale dans les cités d'Afrique du Nord sous l'Empire romain. In : Les grandes figures religieuses : fonctionnement, pratique et symbolique dans l'Antiquité, rencontres internationales de Besançon (25-26 avril 1984), Paris/Besançon, Belles Lettres/Imprimerie de la Faculté des lettres et sciences humaines, 1986, 607 p., p. 503-516.

Tersan Msc.6954 : CAMPION DE TERSAN (C.-P.) - Msc. FR 6954, BNF Paris.

Teissier-Rolland 1851 : TEISSIER-ROLLAND (J.) - Histoire des eaux de Nîmes et de l'aqueduc du Gard III. Nîmes, Ballivet et Fabre, 1851.

Séguier Msc.110 : SEGUIER (J.-F.) - Msc.110 (=13802), Fascicule 4 : Notes relatives aux découvertes faites à la fontaine et au temple de Diane, BM Nîmes.

Van Andringa 2002 : VAN ANDRINGA(W.) - La religion en Gaule romaine : piété et politique, Ir-III $^{e}$ siècles ap. J.-C. Paris, Errance, 2002, 335 p. 


\title{
Gli spazi pubblici di rappresentazione tra memoria civica e celebrazione imperiale a Luni e in Cisalpina
}

\author{
Dr. Matteo Cadario \\ Università degli Studi di Milano \\ matteo.cadario@gmail.com
}

\begin{abstract}
Résumé
L'article propose une réflexion sur les espaces de représentation en Italie du Nord à partir de la ville de Luni. À Luni, il est possible d'obtenir une vue d'ensemble de la présence des statues impériales et des statues des élites locales dans une ville romaine de taille moyenne. Après la présentation des statues et des dédicaces découvertes dans les loca publica (area Capitolina, Basilique, Forum, Curie, Area con fontane, théâtre, « Grande Tempio »), le celeberrimus locus de Luni a été reconnu sur le côté nord du forum. Il était dédié à la construction de la mémoire civique à travers la conservation des anciens monuments honorifiques. Il été également possible de reconnaître l'espace choisi pour l'auto-représentation des élites municipales dans la porticus qui entoure le Capitolium. La répartition des portraits impériaux a finalement permis de suivre l'évolution de la hiérarchie des espaces de représentation dans la ville : la zone nord du forum était la seule à recevoir des honneurs pendant toute l'histoire de Luni. Vers le milieu du I ${ }^{\mathrm{er}} \mathrm{s}$. ap. J.-C., il y avait une prolifération de lieux de représentation que conduirait à attribuer à la famille impériale au moins trois espaces privilégiés : l'odéon, la basilique et «l'Area con fontane ». L'image impériale était devenue omniprésente dans la ville. Au troisième siècle les espaces de représentation étaient réduits et les dédicaces étaient concentrées de nouveau dans l'area Capitolina.
\end{abstract}

Mots-clés : Basilique, Cisalpine, Luni, portrait impérial, portrait privé, statues honorifiques, culte impérial, Capitole, simulacre, théâtre, odéon, forum, statues équestres, Aquilée, Velleia, statues cuirassées.

\section{Riassunto}

L'articolo propone una riflessione sugli spazi di rappresentazione in Italia settentrionale a partire dalla città di Luni. Luni consente infatti di ricostruire il quadro di insieme della presenza delle statue imperiali e di quelle delle élites locali in una città romana di medie dimensioni. Dopo aver presentato i loca publica (area Capitolina, basilica, foro, curia, Area con fontane, teatro, "Grande Tempio") e i relativi rinvenimenti di statue e dediche onorarie, nell'area a nord del foro è stato riconosciuto il celeberrimus locus cittadino, dedicato anche alla costruzione della memoria civica mediante la conservazione dei più antichi monumenti onorari cittadini. È stato inoltre possibile riconoscere nel porticato lo spazio scelto dall'élite locale per la propria autorappresentazione La distribuzione dei ritratti imperiali ha permesso infine di seguire l'evoluzione della gerarchia degli spazi di rappresentazione nella città: l'area a nord del foro fu l'unica ad accogliere onori per tutto il corso della storia lunense. Intorno alla metà del I sec. d.C. vi fu però una moltiplicazione dei luoghi di rappresentazione che comportò l'assegnazione alla famiglia imperiale di almeno tre spazi privilegiati: odeum, basilica e l'Area con fontane. L'immagine imperiale era diventata veramente onnipresente nella città. Nel III sec. d.C., comunque ricco di dediche, gli spazi di rappresentazione si contrassero di nuovo, limitandosi all'area Capitolina.

Parole Chiave : Basilica, Cisalpina, Luni, ritratto imperiale, ritratto privato, statue onorarie, culto imperiale, statue di culto, teatro, odeion, statue equestri, Aquileia, Velleia, statue loricate. 
I nuna città romanai luoghi pubblici servivano come spazio per la celebrazione e la rappresentazione dei poteri impegnati nella tutela e nella garanzia del buon funzionamento della comunità civica, dalla famiglia imperiale ai notabili locali. Quello della perpetuazione concreta della memoria mediante le statue e i monumenti onorari era un aspetto molto scenografico e "appariscente" della vita politica municipale in tutto l'impero, attinente alla coesione stessa della comunità locale e utile oggi per comprendere i legami esistenti al suo interno e i rapporti con il potere imperiale. Le statue onorarie erano, almeno idealmente, destinate a durare nel tempo, o almeno così si auguravano, con una certa dose di ottimismo, onorati e dedicanti; esse presumevano di conseguenza anche un pubblico vasto, formato dai concittadini presenti e futuri e attento a decifrare il messaggio contenuto nelle iscrizioni e nei tipi statuari ${ }^{1}$. Un ritratto forense significava infatti una presenza quotidiana nella memoria della città e l'onore della rappresentazione era quindi spesso oggetto di una complessa trattativa tra il benefattore e gli organismi municipali, in cui il primo concedeva un beneficio e i secondi contraccambiavano i suoi merita decretando/ accettando il monumento e decidendo anche dove e come erigerlo in base al rango dell'onorato e al prestigio della collocazione $^{2}$. La scelta del locus risultava così decisiva per valutare l'importanza simbolica dell'onore ricevuto: si pensi per esempio alla statua di M. Claudius Fronto, la cui morte in battaglia contro Iazigi e Germani fu tradotta dal Senato (e da Marco Aurelio) nella scelta sia del tipo statuario (statua armata) sia della collocazione (il foro di Traiano, divenuto ormai nel II sec. d.C. una sorta di "santuario" degli "eroi" dell'esercito romano) più appropriate alla motivazione dell'onore (pro rei publicae fortiter pugnans ceciderit) ${ }^{3}$.

Pur in un quadro generale condiviso all'interno dell'impero, ciascuna città sembra aver goduto di una certa autonomia nelle scelte specifiche dei luoghi di rappresentazione privilegiati, come suggeriscono i casi più conosciuti (per esempio Pompei, Ostia, Augusta Emerita, Tarraco, Conimbriga, Segobriga, Lepcis Magna, Cuicul, Thamugadi e Afrodisia ${ }^{4}$ ). Il foro, la basilica, il teatro, le vie più frequentate erano le collocazioni più ovvie

1. La bibliografia è aggiornata al 2010. Ringrazio Giuseppina Legrottaglie per i proficui scambi di opinioni sulle statue lunensi. In generale: Fejfer 2008, p. 16-72 e Lefebvre 2004. Si vedano anche Abascal 2009 ed Eck 1996.

2. Lefebvre 2004; Eck 1996, p. 298.

3. ILS 1098.

4. Vedi Lefebvre 2004. Nello specifico cfr. Zimmer 1989 (Cuicul e Thamugadi); Smith 2006 (Afrodisia); Bejor 1986 (Lepcis Magna); Abascal 2004 e Noguera 2008 (Segobriga); Rodrigues Conçalves e consuete, ma talora anche luoghi o edifici più specifici, come l'edificio di Eumachia a Pompei, divennero spazi ricercati ${ }^{5}$. In effetti ogni città disponeva di più loca publica designati ad accogliere onori e sottoposti al controllo delle autorità municipali, loca che spesso avevano "specializzazioni" differenti, come dimostrano per esempio le accorte distribuzioni dei ritratti di L. Volusio Saturnino a Roma e di M. Nonio Balbo a Ercolano ${ }^{6}$, rispettose anche della stretta relazione tra ubicazione e tipo statuario. Questo legame è stato affermato come principio generale anche da Vitruvio, per il quale la committenza dell' arredo scultoreo era chiamata a rispettare la convenienza (decor) tra atteggiamento delle statue (status signorum = tipo statuario) e funzione dei luoghi pubblici (proprietates locorum) e ogni violazione era rimarcata dagli osservatori ${ }^{7}$.

Sebbene la documentazione sia spesso lacunosa e sia raro poter disporre di una quantità ragionevole di elementi utili a valutare l'ubicazione esatta delle statue in una città e le loro relazioni reciproche, l'analisi del legame esistente tra lo spazio urbano e le immagini che ospitava costituisce un approccio stimolante al fine di comprendere sia la funzione dei monumenti onorari nel mondo romano e la percezione che ne aveva lo spettatore sia la storia locale, visto che molto spesso le statue onorarie raccontano proprio le microstorie della comunità che le avevano decretate ${ }^{8}$. La scelta dei luoghi della memoria civica, ovvero delle modalità di espressione della propria lealtà nei confronti dell'autorità imperiale e della connessa (auto) celebrazione della propria classe dirigente, era infatti impegnativa per una comunità e serviva a costruire l'immagine che essa intendeva offrire di sé.

In proposito molti studi si sono concentrati soprattutto sulla presenza delle statue imperiali nelle città ${ }^{9}$, mentre sono più rare le ricerche sulla collocazione delle statue dei notabili e sulla dialettica che si creava tra i due poli, imperiale e "municipale" ${ }^{10}$, della celebrazione civica, che non sempre coincidevano ${ }^{11}$. Una rifles-

2007, 2, p. 168-171 (Conimbriga); Pensabene 2007, p. 560-581 (Ostia); Rodá 2009 (Tarraco).

5. Eck 1996, p. 309-311.

6. Fejfer 2008, p. 213-227 e 439-447.

7. In Vitr., 7.5.6 (dialogo tra Apaturio di Alabanda e Licinio di Tralles).

8. Vedi Smith 2006.

9. Per esempio Nogales Basarrate 2007 su Augusta Emerita oppure Rosso 2006 sulla Gallia romana.

10. Sève 2004 sul foro di Philippi.

11. Tuttavia l'iscrizione di una statua in onore di un imperatore menzionava, e quindi tramandava, anche la memoria del dedicante, che risultava così coinvolto nell'onore e nella (auto)rappresentazione. 


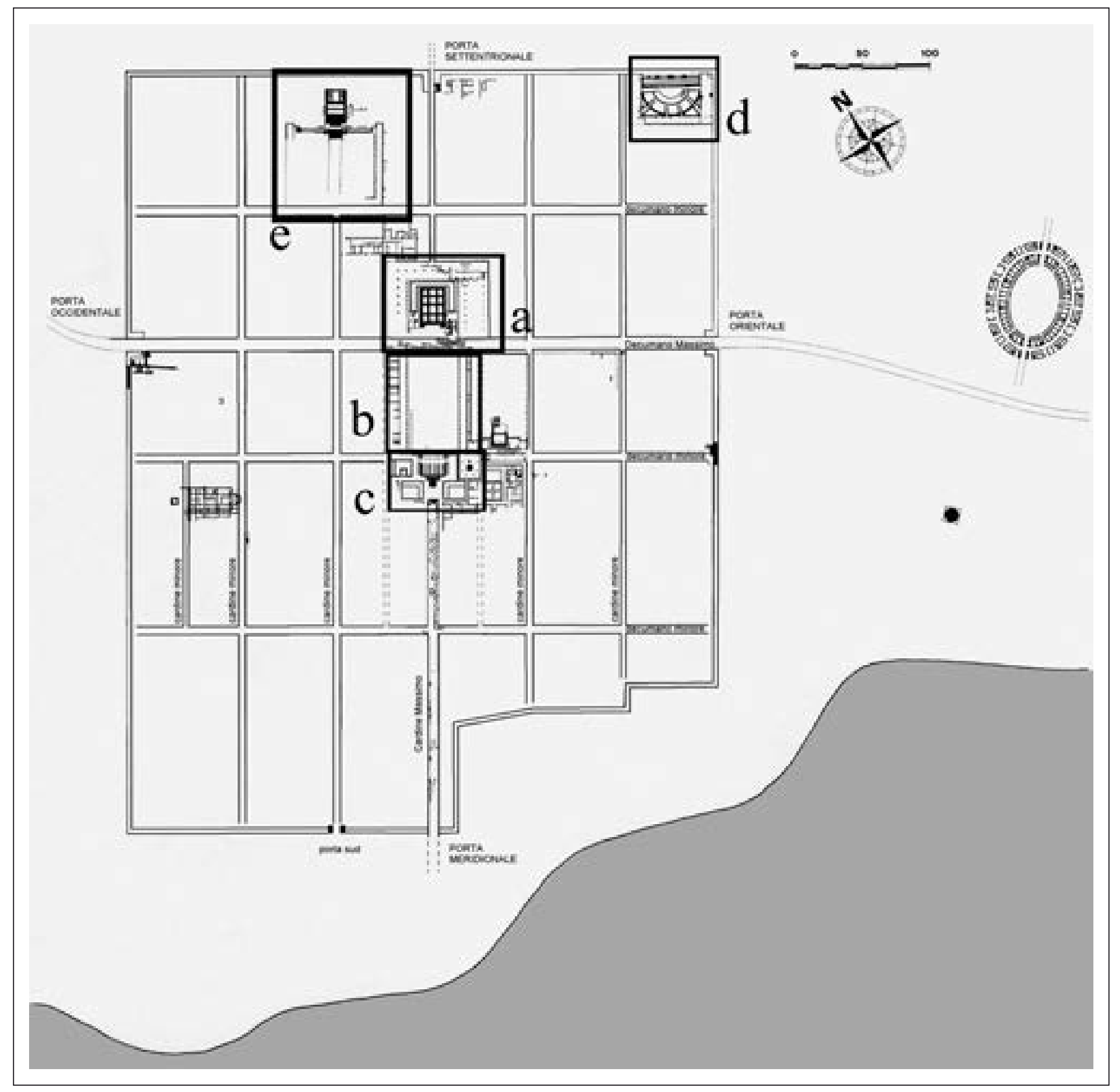

Fig. 1. Pianta di Luni e dei suoi spazi pubblici di rappresentazione.

a: Area a nord del foro - b: piazza forense - c: Area a sud del foro - d: Teatro - e: «Grande Tempio» (Luni Guida, rielaborato da Matteo Cadario). 
sione sugli spazi pubblici di rappresentazione e sulle modalità della presenza degli imperatori e delle classi dirigenti locali risulterà però tanto più affidabile quanto più sarà diretta a città romane il cui impianto urbano sia globalmente noto, così da poter ricostruire al meglio i rapporti reciproci esistenti tra i loca usati per le statue e di cogliere al meglio le dinamiche locali ${ }^{12}$. In questo senso Luni è un caso di studio promettente, perché il suo assetto urbano è conosciuto in maniera soddisfacente e i suoi edifici pubblici hanno conservato numerose testimonianze di monumenti onorari dall'età repubblicana a quella tardoantica. Inoltre la città svolse probabilmente un ruolo nella diffusione del modello cittadino in Italia settentrionale, alla quale cercherò quindi, se possibile, di allargare il discorso, visto che la continuità moderna della maggior parte degli abitati ha reso in Cisalpina più che altrove molto difficile affrontare il problema della collocazione delle statue ${ }^{13}$.

Luna fu fondata nel 177 a.C. ma il suo porto era stato già usato dai romani almeno da qualche decennio come punto di imbarco verso la Spagna. Nata per controllare i liguri, la colonia visse una vita più tranquilla da quando nel 155 a.C. M. Claudio Marcello li sconfisse definitivamente. Fu una città ricca, soprattutto a partire dal I sec. d.C. quando cominciò lo sfruttamento intensivo delle cave di marmo delle Apuane, ebbe un forte incremento dell'attività edilizia in età claudia e si mantenne vitale almeno fino alla fine del IV sec. d.C., quando verosimilmente un terremoto ne favorì la decadenza ${ }^{14}$, che proseguì poi nel corso dell'altomedioevo fino al definitivo abbandono. A partire dal 1970 Luni è stata oggetto di una serie di campagne di scavi che, sotto la guida di Antonio Frova e di Maria Pia Rossignani, hanno indagato scientificamente buona parte degli edifici pubblici, dove sono state scoperte molte statue e iscrizioni. In precedenza la città era stata già oggetto di diversi scavi, soprattutto ottocenteschi, dei quali esiste una minima documentazione che consente di riferire almeno una parte dei rivenimenti epigrafici e scultorei ai loro edifici di appartenenza ${ }^{15}$. Le informazioni sembrano

12. Cfr. le riflessioni di Le Roux 2008 su Baelo Claudia, su cui cfr. anche Silliéres 1997. Si vedano anche Abascal 2004 e Noguera 2008 sul foro di Segobriga e Moreno Pérez 2007, p. 91-92 su Pollentia (Alcudia).

13. In generale vedi De Maria 2008; De Maria 2005 e De Maria 1988.

14. Durante 2001, p. 22-23.

15. Su Luni: Rossignani, Rossi 2009, p. 63-94; Durante 2001; Durante, Gervasini 2000; Luni Guida. Sugli scavi: Luni I e Luni II. Sulla ritrattistica e scultura lunense: Spadea 2008, p. 225-231; Frova 1987; Frova 1987a; Frova 1983. Sull'importanza di Luni: Rossignani 1995. Per le strutture amministrative ed élite locale: Angeli Bertinelli 2002; Angeli Bertinelli 1983. quindi sufficienti a impostare un'analisi più specifica degli spazi pubblici di rappresentazione ${ }^{16}$. Prenderò in considerazione l'area Capitolina, la piazza forense, gli edifici a sud del foro, il teatro e il cosiddetto "Grande Tempio", attingendo alla documentazione edita (fig. 1).

\section{Area a nord del foro}

Tra le aree pubbliche l'area Capitolina, che la via Aurelia separava dalla piazza forense, ebbe sicuramente il ruolo di primo piano (fig. 2) ${ }^{17}$. Il Capitolium fu costruito nei primi decenni di vita della colonia; distrutto da un fulmine, fu riedificato nei primi decenni del I sec. a.C., quando fu costruito anche il triportico intorno al tempio. L'aspetto attuale è determinato da una complessa serie di interventi databili intorno alla metà del I sec. d.C. La porticus triplex fu profondamente rimaneggiata: il pavimento dei bracci ovest e nord del portico fu rifatto, mentre il braccio est fu sostituito da una grande basilica rettangolare. Ai due lati del pronao del tempio furono inoltre costruiti due tempietti mentre intorno al tempio fu inserito un grande bacino-fontana che rese di fatto impraticabile lo spazio aperto che lo circondava e contribuì a isolare il Capitolium dai due edifici circostanti, raggiungibili solo dalla via Aurelia ${ }^{18}$. $\mathrm{Nel}$ frattempo anche il culto imperiale potrebbe essere stato accolto nell'area, come suggerisce un'iscrizione di età neroniana del patrono locale L. Titinio Glauco Lucreziano, che, associando a Giove, Giunone e Minerva anche Felicitas, Roma e il Divo Augusto, potrebbe essersi conformato alla situazione topografica dell'area Capitolina lunense ${ }^{19}$.

Il tempio, i portici e la basilica sono stati indagati a più riprese da Remedi e da Promis tra il 1837 e il triennio 1857-1859, poi ancora negli anni cinquanta del secolo scorso, quando fu costruito il museo, e infine negli anni settanta $^{20}$. Riassumendo i risultati degli scavi, l'edificio

16. In proposito resta fondamentale Saletti 1993, p. 276-284, anche se non è possibile accettare tutti i cicli statuari da lui proposti, cfr. Boschung 2002, p. 3-4. Su Luni cfr. anche Rose 1997, p. 93-95; Wohlmayr 2004, p. 205-210. Non ho preso in considerazione i ritrovamenti in ambito privato (un busto di Tiberio Gemello) e quelli riferibili alle necropoli.

17. A.M. Durante in: Città antica, p. 75-88; Luni guida, p. 55-63.

18. Rossi 1998, p. 43-64.

19. CIL XI,1331e Marmora Lunensia, n. 33, p. 113-116 (M.G. Angeli Bertinelli). Sarebbe suggestivo riferire l'epigrafe all'area del Capitolium, anche perché l'enfasi sulla discendenza di Nerone farebbe pensare a un gruppo dinastico: Saletti 1993, p. 283 e cfr. Rose 1997, cat. 22, p. 95. Su Lucreziano: Gregori 2000.

20. Sulla storia degli scavi: Frova 1998; Frova 1983, p. 11-34 e in Luni I, p. 3. Per le sculture: Saletti 1993, p. 278-280. 
di culto non ha dato rinvenimenti scultorei significativi, ma la presenza di statue è suggerita perlomeno dai due simmetrici basamenti quadrati posti ai lati del tempio (2.U-V), di fianco ai sacelli aggiunti in età giulioclaudia $^{21}$. L'area della basilica si è rivelata molto più ricca di scoperte ${ }^{22}$ : da reimpieghi in strutture più tarde o dallo strato di abbandono provengono infatti il ritratto veristico "repubblicano" di un uomo maturo (2B), quello di Germanico (2A), una statua togata giulioclaudia capite velato priva del volto (2D) e un giovane principe (Nerone?) con indosso toga e bulla (2C) ${ }^{23}$; alle statue vanno aggiunti i frammenti dei cosiddetti Fasti $^{24}$, alcune iscrizioni in onore di duoviri ${ }^{25}$ e una serie consistente di dediche in onore degli imperatori del III sec. d.C. (Treboniano Gallo, Volusiano, Salonino e altri tre anonimi, di cui uno colpito da damnatio $\left.=2 \mathrm{E}^{26}\right)$. Inoltre il grande basamento (2T) aggiunto in uno degli intercolumni settentrionali della basilica potrebbe aver ospitato un gruppo statuario posteriore all'età giulioclaudia. Dall'adiacente braccio orientale del bacino fontana provengono infine una coppia di statue acefale giulio-claudie (2F-G) trovate dal Promis (un adulto togato e una donna che la cornucopia assimilava a Fortuna $)^{27}$ e un ritratto in bronzo giulio-claudio di un privato cittadino $(2 \mathrm{H})^{28}$. Mentre le due statue in marmo potrebbero essere attribuite anch'esse alla basilica, il ritratto in bronzo va accostato al ritrovamento nella stessa area di altri frammenti di bronzi (due piedi) da parte ancora del Promis, da riferire probabilmente allo smantellamento sistematico delle statue in metallo del porticato.

Nei due bracci della porticus sopravvissuti dopo la costruzione della basilica sono state infatti trovate a più riprese numerose cimase di basi destinate in origine a

21. Per il possibile confronto con la situazione veronese, cfr. Legrottaglie 2008, p. 257.

22. In generale sui programmi decorativi delle basiliche: Cavalieri 2000 .

23. Frova 1987, p. 233-245; Frova 1987a, p. 310-314; Frova 1983, p. $42-46$ e $48-52$; Luni I, c. $540-541$; c. 592 , n.145. Sul ritratto di anziano: Papini 2004, p. 341-342; Frova 1998; Frova 1983, p. 42-43. 24. Nei Fasti lunensi, che non implicano la presenza di statue, erano stati riportati i nomi dei titolari della tribunicia potestas almeno fino a Traiano. Documenti simili sono noti in altri due Capitolia cisalpini, ossia a Brescia e Verona, oltre che nel foro di Cuma e a Castelporziano: Capaldi 2007; Di Vita Évrard 1991 e Buonopane 2008, n. 2, p. 277. Cfr. anche Mennella 2008.

25. Per esempio la dedica di coloni et incolae a L. Titinio Petriniano in $C I L$ XI, 1347.

26. Angeli Bertinelli 1987.

27. Frova 1983, p. 73-74 e 76-77; Marmora Lunensia, n.5-6 (A. Frova), p. 51-55. In Saletti 1993, p. 279 le tre statue sono invece riferite alla decorazione del porticato.

28. Frova 1983, p. 52-53 e Luni II, p. 405-407 (A. Frova). sostenere statue in bronzo e oggi conservate in parte sul posto e in parte nel cortile del Palazzo Municipale di Sarzana, per un totale di circa una ventina di pezzi anepigrafi $(2 \mathrm{~K}-\mathrm{J})^{29}$. Della loro collocazione esatta non c'è una documentazione puntuale, ma nella pianta degli scavi del Promis molte basi di statue sono poste sia negli intercolumni esterni sia addossate ai pilastri interni del porticato (fig. 3), un'indicazione confermata dagli scavi più recenti che hanno riconosciuto alcune loro impronte nell'allettamento del pavimento giulio-claudio del portico. In effetti dopo la costruzione del bacino-fontana, la porticus risultava un edificio semichiuso, accessibile solo dalla via Aurelia e perciò protetto e adatto a ospitare una fitta galleria di statue (cfr. la porticus meridionale del foro di Segobriga ${ }^{30}$ ), che la presenza del bacinofontana doveva rendere assai scenografica. La funzione di spazio di rappresentazione doveva comunque risalire già all'età repubblicana, come suggeriscono la cimasa della statua di M. Claudio Marcello (2L), il vincitore dei liguri nel 155 a.C., trovata dal Remedi nel $1857^{31}$, e le due basi di statue facenti parte della preda etolica di cui nel 191 a.C. M'. Acilio Glabrione si era impadronito a Heraclea (lastra reimpiegata in un basamento antistante il Capitolium = 2.I) e a Scarphea (base non in situ dalla zona sud del foro). L'area Capitolina, a imitazione di quella di Roma, ospitava quindi ornamenta urbis fin dalla prima fase della colonia ${ }^{32} \mathrm{e}$, come in altre città repubblicane, i monumenti trionfali e gli spolia hostium furono collocati nei pressi degli edifici di culto più importanti: ricordo il titulus mummiano proveniente dal portico del tempio di Apollo a Pompei e le basi firmate da scultori greci trovate a Ostia nell'area dei templi di via della Foce ${ }^{33}$.

Tra i materiali rinvenuti nel triportico mancano i piedistalli iscritti che dovevano congiungersi alle numerose cimase anepigrafi presenti. Gli unici scoperti da Remedi e Promis furono quelli di L. Helvius e di L. Titius Philargurus nel 1837 (2.M) ${ }^{34}$. Nel 1889 durante gli scavi Podestà nell' area della Basilica paleocristiana furono però trovate ben nove basi iscritte e due anepigrafi,

\footnotetext{
29. Frova 1984, p. 10-20.

30. Abascal 2004.

31. S. Landi in: Città antica, p. 55-56; Cadario 2005; Frova 1984, p. 7-10; CIL XI, 1339.

32. De Maria 2005, p. 169-170; Angeli Bertinelli 1993; Frova 1984, p. 5-7.

33. Lippolis 2004 e Pensabene 2007, p. 560-561.

34. Frova 1984, p. 18-19; Marmora Lunensia, n.16, p. 74 (M.A. Angeli Bertinelli); CIL XI, 1353 e 1373. Il riferimento del CIL all' anfiteatro (cfr. anche CIL XI 1341, dedica al duoviro M. Turtellius Rufus) è errato, visto che il Promis indica chiaramente nel porticato il luogo del ritrovamento: Frova 1998, p. 180.
} 


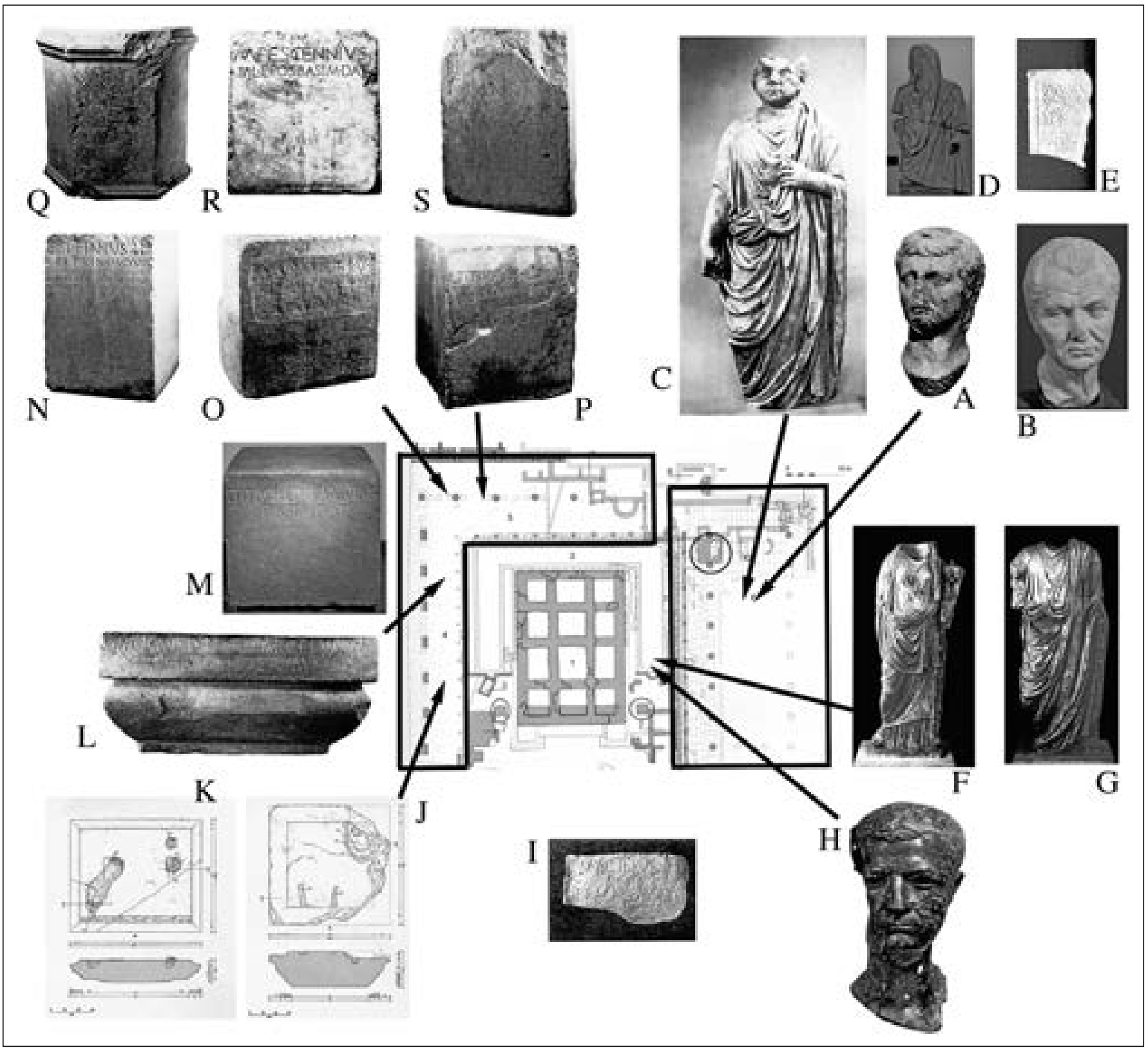

Fig. 2. Gli edifici a nord del foro: Capitolium, porticus e basilica (Rielaborazione di Matteo Cadario da Luni Guida).

tutte reimpiegate nel nuovo edificio realizzato all'inizio del V sec. d.C. $(2 . \mathrm{N}-\mathrm{S})^{35}$. Si tratta di parallelepipedi appartenenti sicuramente a basi di statue che dovevano trovarsi insieme in un edificio smantellato alla fine del IV sec. d.C., visto che l'epigrafe più recente ricorda Lucilius Constantius, che fu consolare della Tuscia nel 366 d.C. (CIL XI 6958). Tutte le altre iscrizioni (otto

35. Frova 1998, p. 180; Frova 1984, p. 20-23; Marmora Lunensia (M.A. Angeli Bertinelli), nn.59-67, p. 69-70 e 171-197. Cfr. anche Angeli Bertinelli 2002, p. 138-139. Nella chiesa di S. Maria era reimpiegata anche la base dedicata a Ottaviano, trovata però nel 1706 (Marmora Lunensia, n.14, p. 69-70). più le due trovate dal Promis) si riferivano in origine a notabili locali, ma due basi furono riusate per la coppia imperiale Carino e Magna Urbica (e poi ancora per Diocleziano e Galerio/Massenzio) ${ }^{36}$. Dimensioni e materiali sono spesso compatibili con le cimase rinvenute nel porticato e una base, quella dedicata da L. Titius Philomusus (2P), è la gemella di quella del suo colliberto Philargurus tanto che è logico pensare che le due basi in origine fossero nello stesso edificio. Credo quindi che sia possibile attribuire con un buon margine

36. Frova 1984, p. 22-23 e CIL XI, 6956-6957. 


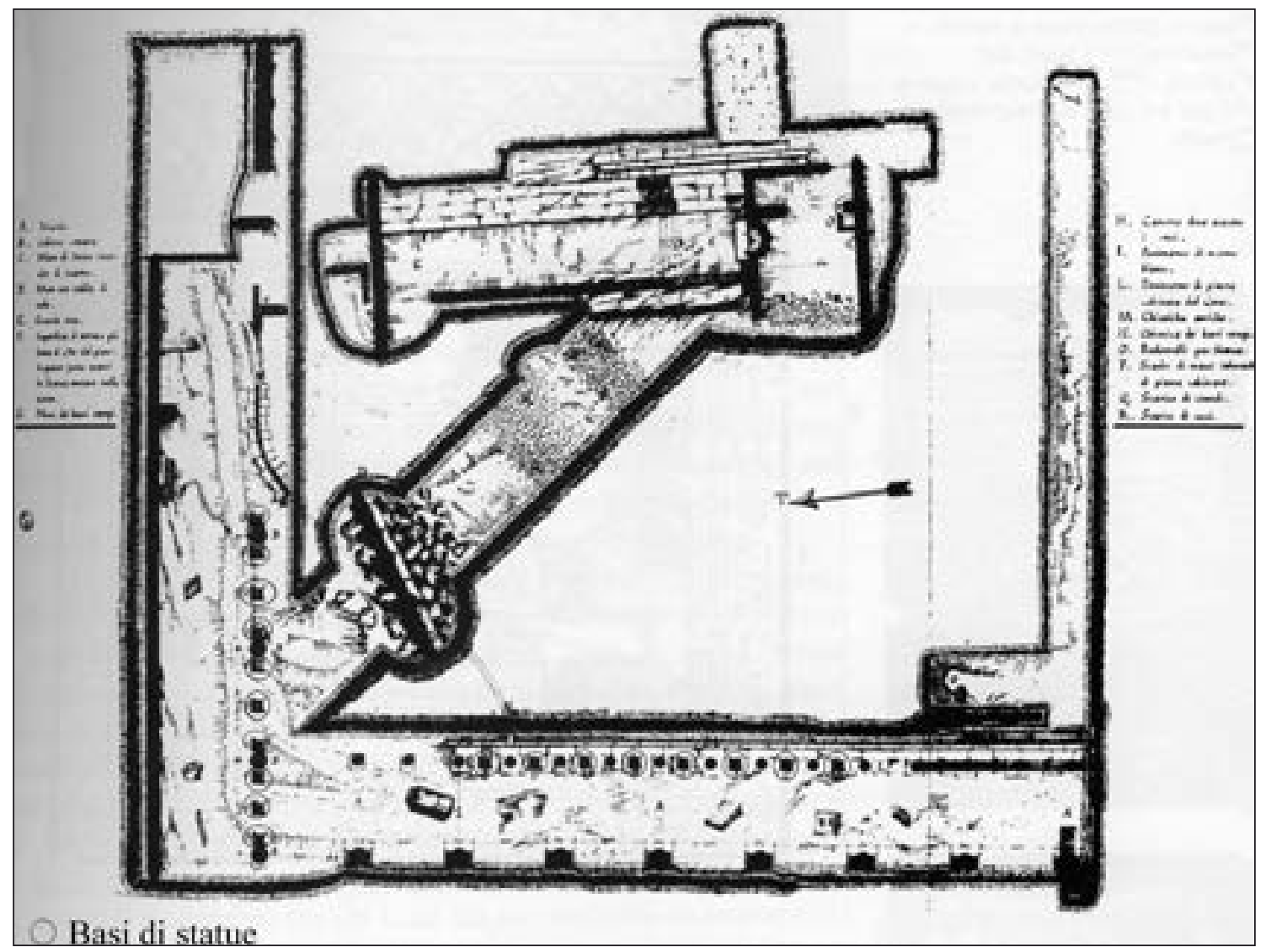

Fig. 3. Pianta degli scavi del Promis, con indicazione delle le basi di statue (da Marmora Lunensia).

di sicurezza queste basi alla spoliazione dell'area a nord del foro, area che alla fine del IV sec. d.C. era ormai abbandonata, e in particolare ai due bracci del triportico, come suggeriscono anche i ritrovamenti del Promis. Alla fine del IV sec. d.C. i dadi erano stati recuperati perché adatti al riuso come basi di colonne nella nuova Basilica, mentre le cimase furono lasciate sul posto, ovviamente dopo aver scalzato le statue in bronzo.

Se questa ricostruzione fosse corretta, si potrebbe riconoscere anche una differenza d'uso tra il triportico e la basilica, confermata anche dal fatto che i due edifici avevano percorsi di visita separati: nel primo la maggior parte delle epigrafi celebrava i membri dell'élite locale, mentre nella basilica prevalevano, come d'abitudine, i ritratti imperiali. Questa separazione potrebbe essersi attenuata nel pieno III sec. d.C., quando il reimpiego per Carino e Magna Urbica di due basi di notabili segna l'inserimento degli imperatori nella galleria del porticato, determinato forse dalla mancanza di spazio nella basilica ${ }^{37}$. L'adozione di un criterio topografico

37. Cfr. però Lefebvre 2006, p. 2138-2139 sull'abbandono "relativo" delle zone del foro di Cuicul in cui erano poste le epigrafi dei damnati, che per questo non erano sostituite. razionale, tendenzialmente coerente e attento soprattutto a distinguere le zone a vocazione imperiale (ma non solo quelle) nel raggruppamento delle statue era del resto frequente nelle città romane, sia nei fori (cfr. Cuicul, Thamugadi, Segobriga e Lepcis Magna) sia all'interno di edifici pubblici più importanti ${ }^{38}$.

\section{La piazza forense}

Passando alla grande piazza forense, che fu risistemata nella prima metà del I sec. d.C. insieme alle tabernae circostanti, in parte rimaneggiate nel corso del II sec. d.C. ${ }^{39}$, essa non ha dato molti rinvenimenti di iscrizioni o sculture, a parte una testa minore del vero di Agrippina Minore, trovata lungo il lato occidentale ${ }^{40}$.

38. Su Cuicul e Thamugadi: Fejfer 2008, p. 382, pl. 40 ; Lefebvre 2004, p. 383-384 ; Zimmer 1989. Nell'agorà di Palmira, per esempio, le statue degli ufficiali romani erano concentrate nell' angolo NE: Delplace, Dentzer-Feidy 2005. Per lo spazio riservato alla statua di Traiano nella basilica di Baelo Claudia: Sillières 1995, p. 111; nel foro di Segobriga era l'altare di Augusto a definire un locus privilegiato: Abascal 2007, p. 695-699.

39. Luni guida 1985 , p. 63-68.

40. Frova 1987a, p. 315. 


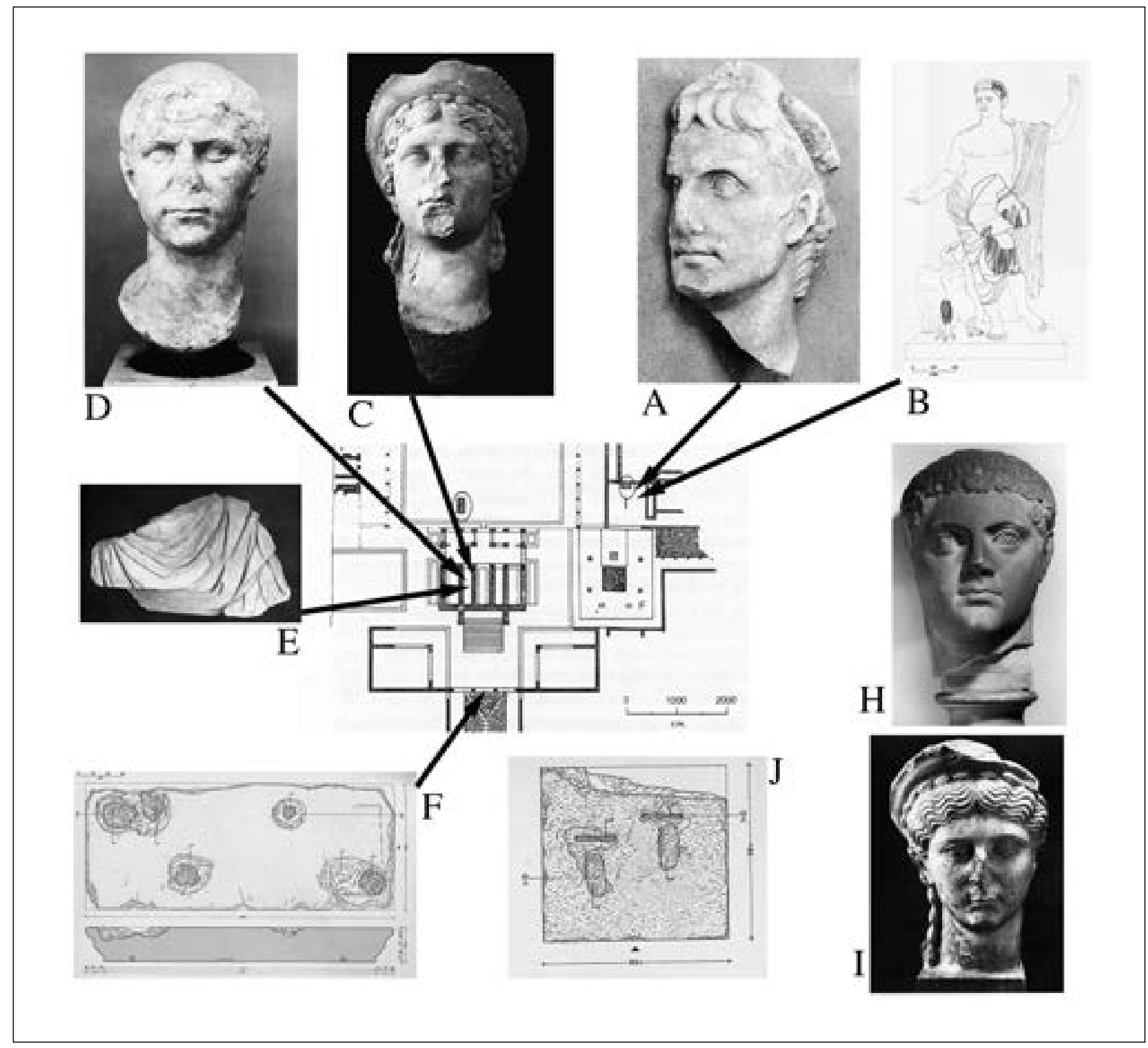

Fig. 4. Gli edifici a sud del foro: "Curia" e Area con fontane (Rielaborazione di Matteo Cadario da Sacchi 2000).

Le testimonianze più significative di monumenti onorari sono le due grandi basi equestri ancora visibili presso i lati corti del foro, in una collocazione enfatica simile a quelle di Velleia e di Pompei ${ }^{41}$, che farebbe pensare a una simile cronologia nell'ambito del I sec. d.C. Ai monumenti equestri forensi potrebbero appartenere anche la cimasa di statua riusata come copertura dell'imbocco della cloaca del cardo maximus (4F) e forse le appliques di balteo trovate nell'Ottocento nell'area Capitolina ${ }^{42}$.

\section{Lato sud del foro}

Anche l'area a sud del foro è stata più ricca di scoperte rispetto alla piazza e ai suoi portici laterali (fig. 4) ${ }^{43}$. Il lato corto è occupato da un edificio monumentale porticato dubitativamente identificato con la curia; alle sue spalle si trovano due aree lastricate in marmo aggiunte successivamente. Nella prima metà del II sec. d.C. l'edificio fu profondamente ristrutturato,

43. Luni guida 1985 , p. $68-78$.

41. De Maria 1988, p. 48-57.

42. Frova 1983, p. 30-31. 
trasformando il porticato in un ambiente chiuso. Immediatamente a est si trova la cosiddetta Area con fontane, un complesso realizzato in età claudia, formato da una piazzetta occupata da un grande basamento e da un altare su cui si affacciava un'aula (aula 1) con un podio addossato al muro di fondo. Una seconda piazza rettangolare, parallela a quella forense e dominata dal cosiddetto "tempio di Diana", è stata identificata di recente a est del foro ${ }^{44}$, ma dall'area non risultano per ora rinvenimenti significativi di statue ed epigrafi. Dall'Area con fontane provengono, insieme a diversi frammenti minori, una testa radiata del Divo Augusto $(4 \mathrm{~A})^{45}$ e una statua (frammentaria) raffigurante Claudio assimilato a Giove dall'Hüftmantel e dal sostegno in forma di aquila (4B) ${ }^{46}$. I due probabili simulacra ${ }^{47}$, entrambi colossali e simili nella resa, dovevano trovarsi nell'aula coperta, che, come proposto da Furio Sacchi, andrebbe quindi identificata con uno spazio riservato al culto imperiale e realizzato in età claudia (si è pensato alla sede degli Augustali, sebbene le dimensioni dell' edificio lascino poco spazio alle riunioni di un collegio). Nella zona a sud del foro sono state trovate altre statue e diversi frammenti scultorei, tra cui un bel ritratto di Agrippina Maggiore (4C), un frammento di pteryges di statua loricata, un ritratto privato datato in età flavia (4D) e un busto loricato rilavorato verosimilmente più tardo $(4 \mathrm{E})^{48}$. Per resa e dimensioni la testa di Agrippina è molto simile ad altri due ritratti lunensi, oggi conservati a Genova senza che si conosca la loro collocazione originaria e raffiguranti Caligola $(4 \mathrm{H})$ e una principessa, forse la Diva Drusilla (4I) ${ }^{49}$. I tre ritratti potrebbero aver formato un vero e proprio ciclo dinastico, eretto al tempo di Caligola e probabilmente ubicato proprio nella zona meridionale del foro, forse nella cd. curia, visto che l'Area con fontane fu costruita in età claudia ${ }^{50}$.

44. Durante, Gervasini 2000.

45. Ritengo più probabile che si trattasse di una statua a tutto tondo, cfr. Saletti 2000; per un altorilievo: Valeri 2005, p. 157-158, nota 573 e Legrottaglie 1995a. I grandi occhi fanno pensare a una statua postuma, escludendo la rilavorazione da un ritratto di Nerone, su cui invece: Varner 2004, p. 62-63 e cat. 2.8, p. 239. Vedi anche Saletti 1993, p. 281; Frova 1983, p. 53-54; Luni I, cc. 536-537.

46. Sacchi 1997 e Sacchi 2000. Sono stati trovati anche alcuni frammenti di statue togate e un frammento di collo maschile con taenia.

47. Applico la distinzione in Suet. Tib. 26 e cfr. Rosso 2006, p. 159.

48. Saletti 1993, p. 280; Luni I, c. 537 (Agrippina); cc. 540-541 (ritratto flavio); c. 546 (busto e pteryges). Sull'Agrippina : Wood 1999, p. 223-225; Rose 1997, p. 94 ; Legrottaglie 1995b ; Frova 1983, p. 47-48.

49. Per Drusilla: Varner 2004, p. 43 ; Wood 1999, p. 239-240 ; Rose 1997, cat. 20, p. 94 ; per Antonia Minore: Kokkinos 1992, p. 113-120; per Livia : Saletti 2001 e Zana 1995.

50. Sul ciclo: Saletti 2001; Frova 1987a, p. 308-309; Marmora Lunensia (A. Frova), nn.34-35, p. 117-120 ; Frova 1983, p. 55-58;

\section{Il teatro/odeum}

Il teatro si trova nell'angolo NE della città, vicino alle mura (fig. 5) ${ }^{51}$. Fu probabilmente costruito nella tarda età augustea, quando la cavea doveva essere a vista, e fu ricostruito tra l'età claudia e neroniana da L. Titinio Glauco Lucreziano che ne fece un edificio coperto, come a Cosa, dove aveva trasformato la basilica in un odeum poco dopo il 51 d.C., facendovi collocare un ciclo statuario imperiale e una propria statua, di cui resta solo la base ${ }^{52}$. L'edificio lunense fu scavato alla fine dell'ottocento dal Fabbricotti, che ha lasciato un elenco delle statue iconiche, privo però di indicazioni sul luogo esatto di rinvenimento; si potrebbe però pensare che esse si trovassero nel frontescena e nella porticus meridionale, alle spalle della cavea, dove sono state riconosciute alcune basi. Nel teatro furono trovati una coppia di busti databili nei primi due decenni del I sec. d.C. e raffiguranti Tiberio (5B) e un giovane principe (Germanico o Nero Germanici $=5 \mathrm{~A}$ ); una bella statua femminile acefala $(5 \mathrm{C})$ e un togato "declamante" (5D), ossia ritratto nel raro gesto di interrompere la lettura (vedi infra e fig. 6), entrambi di piena età giulio-claudia; e una statua loricata più tarda, verosimilmente flavia $(5 \mathrm{E})^{53}$ (i loricati sono una presenza costante nei frontescena dei teatri: solo in Cisalpina ricordo Nerone a Bologna, un imperatore giulio-claudio a Vicenza e uno antonino a Pola ${ }^{54}$ ). Inoltre nell'edificio è stata rinvenuta una dedica di Lucreziano a Nerone, Poppea Augusta e alla figlia Diva Claudia che suggerisce la presenza dei rispettivi ritratti ${ }^{55}$. Il teatro ospitò quindi una ricca serie di immagini della famiglia imperiale, integrate in momenti successivi: i due busti appartenevano alla prima fase della storia

Saletti 1973 ; Marmi antichi, nn.33-34, p. 99-103 (B.M. Giannattasio, che pensa a Druso Maggiore e Antonia Minore per le statue genovesi). 51. Luni guida, p. 110-114 ; Frova 1980. Per le statue : Saletti 1993, p. 277-278 e Fuchs 1987, p. 97-99. I busti furono trovati vicino al loricato e alla statua femminile : Luni I, c. 50.

52. Per l'iscrizione di dedica, vedi CIL XI, 6955 e Marmora Lunensia (M.G. Angeli Bertinelli), n. 57, p. 167-168. Su Cosa : Fentress 2003, p. 56-62 ; Collins Clinton 2000.

53. Vedi Marmora Lunensia (A. Frova), nn.19-20, p. 78-81, nn 41-42, p. 132-136, n.46, p. 143-144; Fuchs 1987, p. 97. Sul loricato: Stemmer 1978, II a6, p. 29 ; sulla statua femminile: Frova 1983, p. 75-76; sul togato: Cadario 2001 ; sui busti : Frova 1983, p. 59-61.

54. Cadario 2004, p. 151-152 (Vicenza) ; 335-336 (Bologna); 359360 (Pola).

55. Rose 1997, cat. 21, p. 94-95, che non riferisce però il gruppo al teatro. Penserei a imagines secondo la distinzione statua vs imago in CIL XII, 6038. 


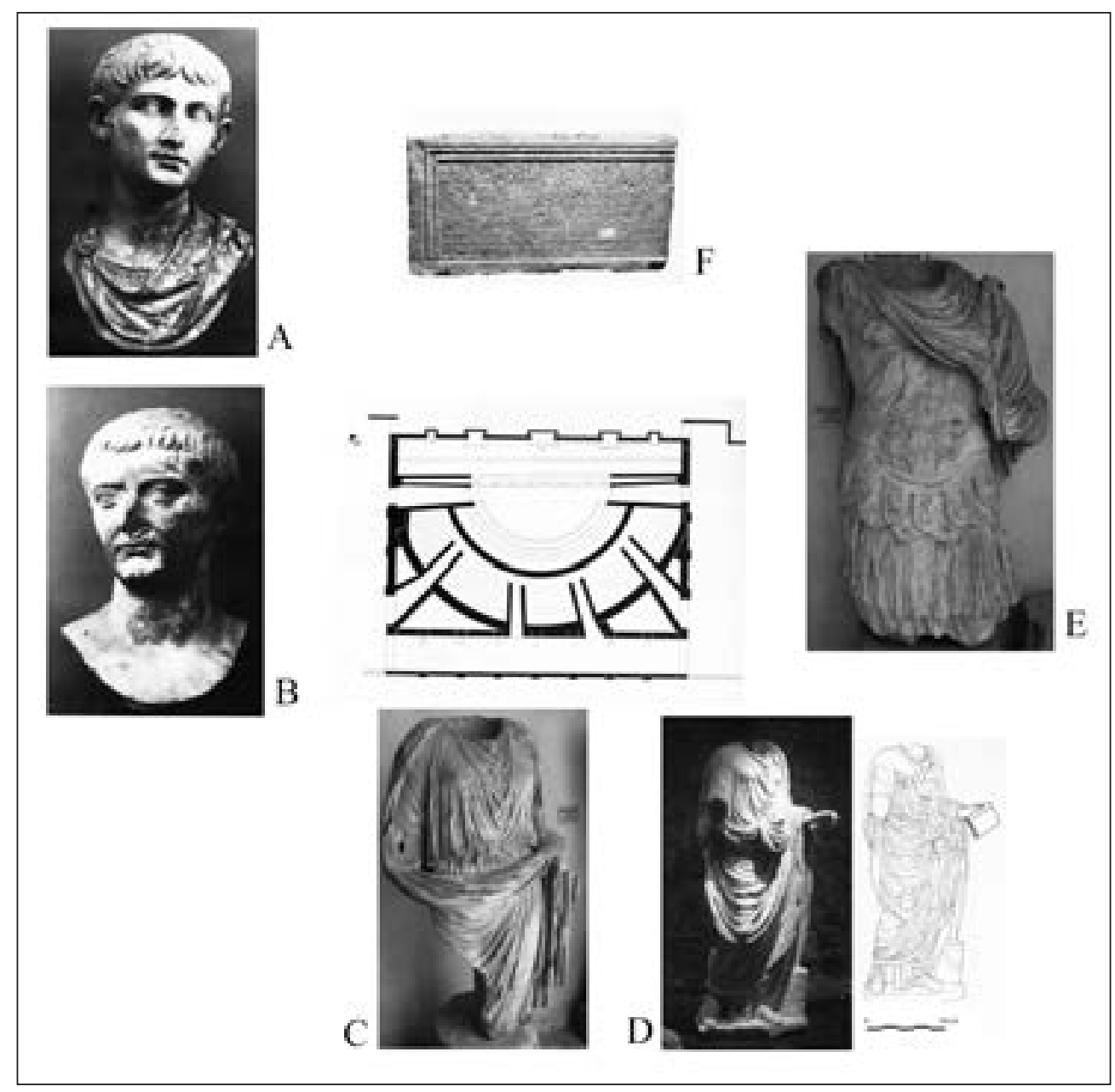

Fig. 5. Il teatro/odeum (Rielaborazione di Matteo Cadario da Luni guida).

dell'edificio ${ }^{56}$, mentre le statue stanti furono aggiunte in seguito. Vista la datazione intorno alla metà del I sec. d.C., il togato e la statua muliebre potrebbero avere come committente lo stesso Lucreziano, che si era comportato allo stesso modo nell'odeum di Cosa; il loricato andrebbe invece attribuito a un imperatore (flavio?), come suggerisce la decorazione figurata della lorica, che sfrutta nella corazza il tema della vittoria terra marique, introducendo nelle pteryges anche quello più esclusivo dell'omen imperii, realizzato associando due teste di aquila al motivo dei serpenti intrecciati.

\section{Il "Grande Tempio"}

Il cosiddetto "Grande Tempio" era dedicato alla dea Luna e fu costruito già nella prima fase della

56. Boschung 2002, p. 92 ; Rose 1997, cat. 19, p. 93-94. Secondo Fuchs 1987, p. 98 i busti sarebbero stati spostati nel teatro in età neroniana. colonia (fig. 7). L'edificio conobbe una prima ristrutturazione all'inizio dell'età augustea, quando vi fu integrato il culto imperiale, come ha dimostrato Giuseppina Legrottaglie ${ }^{57}$, e fu poi ricostruito probabilmente nella prima metà del III sec. d.C. da Caracalla (o Elagabalo), che ricordò il suo intervento in una iscrizione apposta sulla trabeazione ${ }^{58}$. Il tempio si affacciava su una grande piazza porticata che esisteva probabilmente già in età augustea, ma che si presenta oggi nella fase medioimperiale, con la grande scalinata di accesso al podio e le scale laterali che permettevano il passaggio verso i portici. All'estremità di entrambi i portici era ricavato un vano accessibile direttamente dalle scale laterali. Nel vano orientale, pavimentato con lastre di marmi colorati e con emblema (perduto) al centro, è stata rinvenuta una statua loricata protoaugustea (7.A) ${ }^{59}$,

57. Vedi Legrottaglie 1995.

58. Horster 2001, VII 6, p. 323-324 ; Luni guida, p. 104-109.

59. Lo suggeriscono i confronti con i loricati di Tuscolo e di Alcudia: Laube 2006, p. 145 ; Cadario 2004, p. 116-120; Mannino 


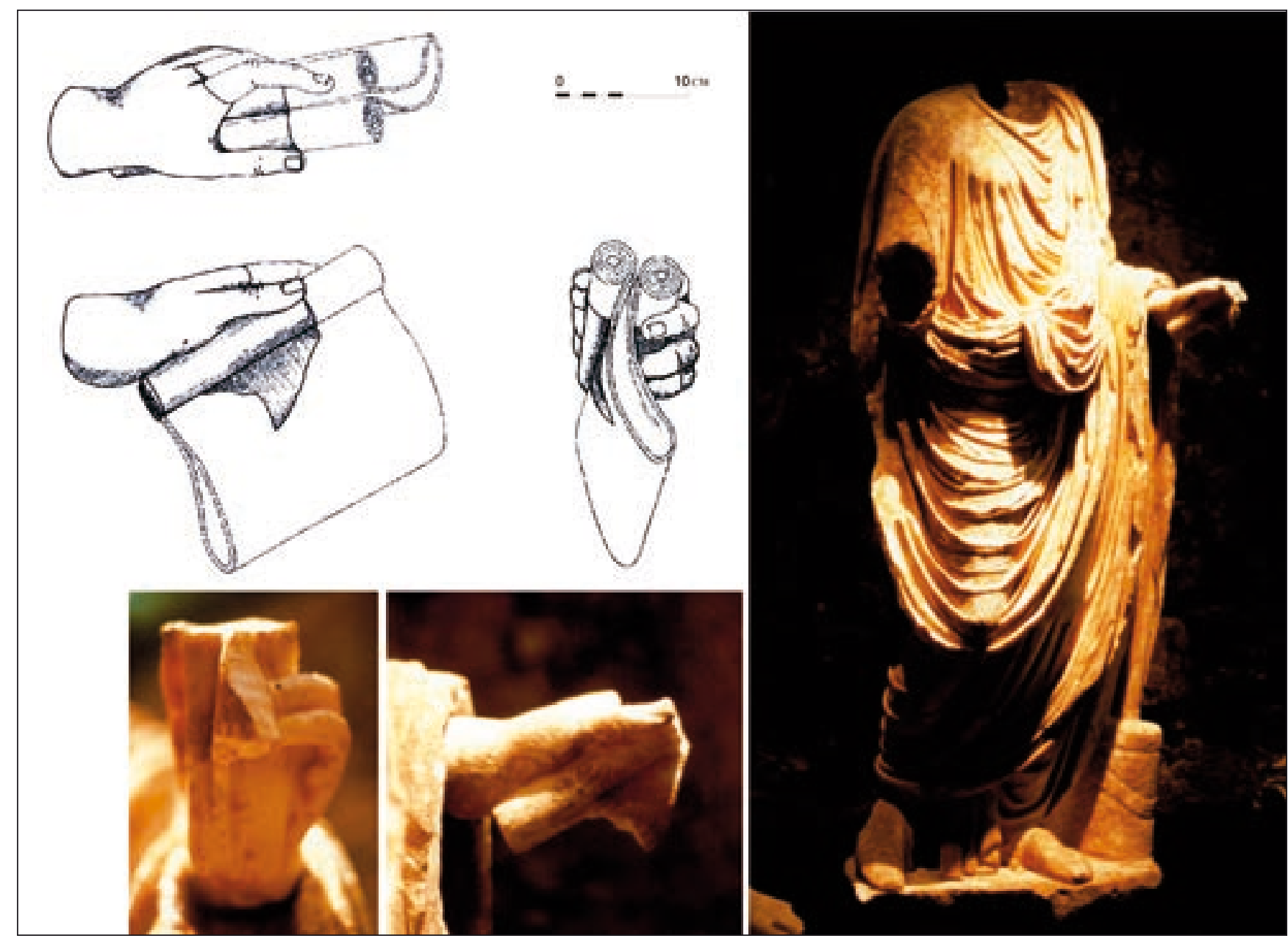

Fig. 6. Statua togata dal teatro e ricostruzione del gesto della lettura interrotta (disegno di Remo Rachini, foto di Matteo Cadario).

posta probabilmente sul piedistallo in conglomerato aggiunto in un momento successivo alla costruzione del vano in modo da essere subito visibile anche da chi giungeva dalle scale laterali ${ }^{60}$. La conservazione e l'isolamento nel rifacimento medioimperiale (si noti che nel simmetrico vano occidentale non ci sono segni di un apprestamento simile) provano che il loricato era ritenuto anche a distanza di secoli un monumento insigne, ragion per cui sembra verosimile che fosse stato eretto per onorare il princeps stesso in occasione del restauro protoaugusteo del "Grande Tempio" " 1 . Sebbene enfatica, la collocazione nel portico e non nell'edificio di culto sembra però escludere che la statua fosse considerata, almeno nel III sec. d.C., un vero e proprio simulacrum.

1999 ; Saletti 1993, p. 281 ; Frova 1983, p. 79-80.

60. Per il luogo ritrovamento, vedi Luni II, p. 579; Luni guida, p. 79. 61. Tra gli onori di Ottaviano nel 36 a.C. ci fu la dedica di sue statue nei templi delle città italiane App. B.C. 5.132.
Una volta esaminati i singoli edifici è possibile riflettere sugli spazi di rappresentazione lunensi confrontandoli anche con quanto sappiamo del resto dell'Italia settentrionale. Sebbene sotto molti aspetti esemplare, Luni offre comunque un quadro parziale delle possibilità di collocazione pubblica delle statue, come dimostra per esempio l'assenza di testimonianze relative all'arredo scultoreo degli ingressi in città, che erano invece luoghi privilegiati per la celebrazione in primis della famiglia imperiale. La presenza di cicli statuari in connessione con le porte urbane è probabile per molte città cisalpine $^{62}$ e ad Aquileia fu probabilmente valorizzato anche

62. De Maria 2008, p. 102-104 ; De Maria 2005, p. 168-169. Mi riferisco alle porte di Rimini, Parma (dedica di Munatius Apsyrtus in CIL XI, 1062), Pavia (il ciclo giulio-claudio in Carmen Einsiedeln 326), Verona (Porta di via del Redentore), forse Laus Pompeia (dedica di Tiberio e Druso Minore in CIL V, 6358) e Aosta (base di Augusto presso la porta Principalis dextera). Vedi Saletti 2002 e Saletti 1993, p. 285; Arrigoni Bertini 2002, p. 122-123. 


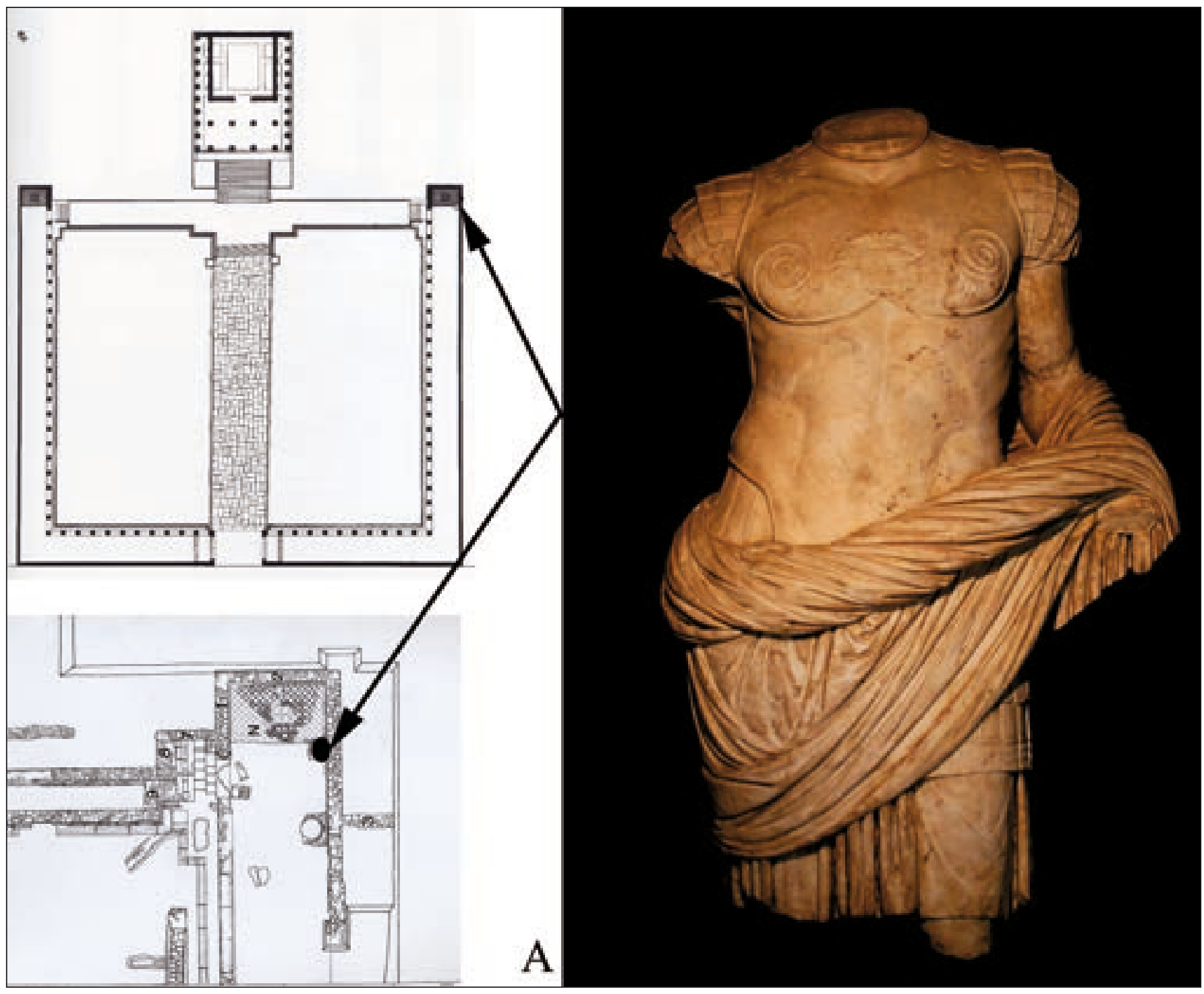

Fig. 7. II "Grande Tempio" e il contesto della statua loricata (rielaborazione di Matteo Cadario da Luni II).

l'ingresso in città dal porto ${ }^{63}$. È verosimile che anche a Luni vi fossero "allestimenti" analoghi, che non sono però documentati.

Fatta questa premessa e tenuto conto della spoliazione della città antica, il numero e la continuità delle dediche insieme alla frequente committenza pubblica, consentono di riconoscere il celeberrimus locus nella zona a nord del foro, ossia negli edifici adiacenti il Capitolium e affacciati sulla trafficata via Aurelia. La presenza di ritratti nei Capitolia o nelle loro immediate vicinanze

63. Il ritratto di Gaio Cesare, una base in forma di prua e un torso in nudità eroica del I sec. a.C. sono stati rinvenuti tra il fiume Natissa e la vicina banchina del porto: Mian 2009, p. 208. è del resto attestata per gli imperatori ${ }^{64} \mathrm{e}$, sebbene più raramente, anche per i notabili locali ${ }^{65}$, ma nel caso di Luni colpisce soprattutto il contrasto con la carenza di monumenti onorari eretti nella piazza forense vera e propria, con l'eccezione delle due statue equestri. In

64. Ricordo le statue di Traiano a Roma (Plin. Pan., 52.3); la base di statua di Adriano a Ostia (Pensabene 1997, p. 567-568); il togato nel tempietto centrale del Capitolium di Baelo Claudia (Sillières 1997, p. 95-96) ; un frammento di loricato a Verona (Legrottaglie 2008, n.13, p. 263) ; a Brescia i sei ritratti in bronzo datati tra l'età flavia e il pieno III sec. d.C. e le basi di Vespasiano e Nerva dall'Aula dei pilastrini (De Maria 1988, p. 35-36).

65. Il grammatico L. Orbilius Pupillus a Benevento (Suet. Gram. et Rhet. 9), il magistrato P. Marcius Crescens a Uzelis/Udjel (CIL VIII, 6339) e un anonimo a Hispalis (Lefebvre 2004, p. 384). Cfr. Legrottaglie 2008, p. 255. 
effetti la zona del Capitolium (con il porticato e la basilica) fu l'unica a servire da punto di aggregazione per le statue durante tutta la storia della città. Il diaframma rappresentato dalla via Aurelia potrebbe spiegare questa specializzazione di un' area oggettivamente più frequentata e percepita perciò come privilegiata fin dall'età repubblicana, come è suggerito dalla presenza di statue e dediche sicuramente più antiche della basilica ${ }^{66}$. Proprio l'inserimento di quest'ultima non fece altro che rafforzare il favore di cui godeva la zona, anche se ne modificò radicalmente l'aspetto, creando una separazione tra l'antico porticato e il nuovo edificio pubblico, destinati a ospitare due ambiti diversi ma complementari degli onori pubblici: quello epicorio dei notabili e quello "universale" degli imperatori. In ogni caso, soprattutto nel portico, le statue erano molto numerose e sembrano quasi illustrare gli inconvenienti descritti dalla celebre iscrizione antonina di Cirta/Constantina in cui si lamentava l'intralcio delle statue alla circolazione pedonale negli spazi pubblici (iter fori angustabant) ${ }^{67}$.

L'area intorno al Capitolium fu inoltre usata anche per tenere in vita la memoria dell'identità civica urbana mediante la conservazione di monumenti legati alle origini o alla storia stessa della città. Essa si presentava così come una sorta di archivio visivo offerto ad abitanti e visitatori. Ai primordia della colonia di Luna appartenevano almeno la base di M. Claudio Marcello e forse le dediche di M.' Acilio Glabrione, mentre la restituzione dei signa da parte del duoviro L. Titinio Petriniano $(2 . \mathrm{N})^{68}$ prova che la cura dei propri ornamenta urbis era un merito che l'élite locale amava ostentare per celebrare se stessa ${ }^{69}$, mostrando così anche di condividere quello stesso ideale di vita civica legato anche al decoro del kosmos urbano che era di norma più radicato nelle province greche dell'impero ${ }^{70}$. Anche la conservazione nella basilica del bel ritratto veristico di tradizione repubblicana, un'opera originale del 100 a.C. ca. oppure una sua replica della fine del I sec. a.C. ${ }^{71}$, come suggerisce il probabile uso del marmo lunense ${ }^{72}$, conferma che la zona ospitava monumenti importanti per la storia

66. De Maria 2005, p. 170.

67. CIL VIII, 7046 e cfr. Abascal 2009, p. 96.

68. Vedi CIL XI, 6959 e 6960 (iscrizione in onore di Titinia). La cronologia di Petrinianus è discussa: per il II/III sec. d.C. : Angeli Bertinelli 1995, p. 48-49; per l'età augustea: Mennella 2006; Gregori 2000, p. 167-168. La prima ipotesi sembra più adatta alla situazione del triportico.

69. Per due iscrizioni analoghe di Cirta: CIL VIII, 7063 e 7068 e cfr. Abascal 2009, p. 101.

70. In generale, vedi Pont 2010, p. 223-347.

71. Papini 2004, p. 342-343; Frova 1998.

72. Sul marmo: Frova 1998, p. 181, nota 12. della comunità, ai quali apparteneva forse anche la base dedicata a Ottaviano patrono di Luni, che fu trovata nel 1706 reimpiegata nella Chiesa di S. Maria, come le basi scoperte alla fine dell'ottocento ${ }^{73}$.

Come ha scritto Sandro De Maria, situazioni analoghe si riconoscono anche altrove in Cisalpina, sebbene di solito riguardino tutto il foro e non solo l'area Capitolina $^{74}$. La conservazione delle statue onorarie, erette proprio per perpetuare la memoria dei benefattori $^{75}$, faceva parte dei doveri di una comunità, anche quando poteva sembrare politicamente inopportuno, come per la statua di Bruto nel foro di Milano, che suscitò un commento acido di Augusto in visita ${ }^{76}$. Bruto aveva però governato la Cisalpina nel $46 / 45$ a.C. ed è significativo che la "doverosa" espressione della gratitudine conseguente abbia giustificato i milanesi anche agli occhi del princeps. L'uso consapevole del foro come spazio espositivo di antichi monumenti si riconosce soprattutto nel tardoantico, per esempio a Verona, dove intorno al 380 d.C. il corrector Venetiae et Histriae Palladius decise la traslatio di una statua (probabilmente divina) dal Capitolium nel celeberrimus locus del foro proprio perché fosse ancora fruibile come ornamentum $^{77}$. Ma è ad Aquileia che osserviamo la situazione più simile a quella lunense, sebbene caratterizzata da una scansione di interventi più complessa ${ }^{78}$. Le basi delle statue di L. Manlius Acidinus, uno dei triumviri fondatori della colonia, e di T. Annius Luscus, che partecipò all'invio del supplemento del 169 a.C., ancora visibili nel foro tardoantico, costituivano delle vere e proprie reliquie del passato, come le dediche lunensi di Marcello e Glabrione. La serie di iscrizioni realizzate intorno al 300 d.C. nell'attico dei portici forensi come didascalie di statue o immagini per commemorare sia personaggi della storia locale (Acidino e Laberius, che fu uno dei primi quattuorviri della colonia), sia imperatori (forse Claudio e Massimiano) era invece il frutto di un'operazione antiquaria di ricostruzione della storia locale ${ }^{79}$; e lo stesso si può dire della più tarda statua del patrigno di Virgilio Publius Valerius Maro (definito pater Vergili), che suggerisce la dedica nel foro di un gruppo familiare comprendente anche il poeta, celebrato in un modo non

73. Marmora Lunensia, n.14, p. 69-70.

74. De Maria 2005, p. 169-171; Zaccaria 2000, p. 101-106.

75. Plin. N.H., 34.17; Fejfer 2008, p. 63-72.

76. Plut. Comp. Dion. et Brut. 5 e Suet. Gramm. et Rhet. 30.

77. Buonopane 2008, p. 287-288; Lepelley 1994; CIL, V 3332.

78. Su Aquileia, cfr. Mian 2009, p. 206-207; De Maria 2005 ; Sotinel 2005, p. 36-41 ; Zaccaria 2000 ; De Maria 1988.

79. Zaccaria 2000 , p. 93-94. 


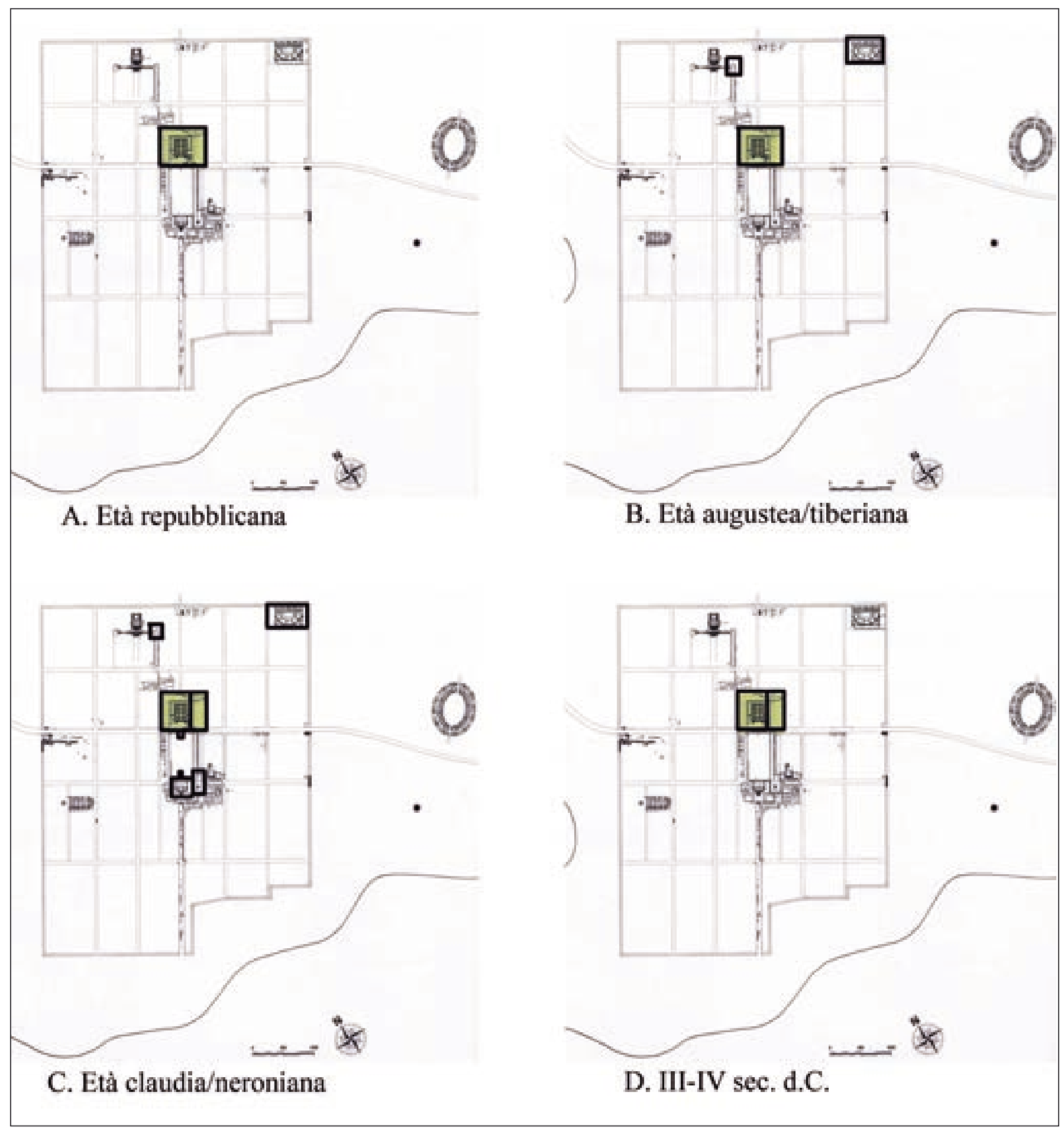

Fig. 8. Evoluzione degli spazi di rappresentazione a Luni dal II sec. a.C. al IV sec. d.C. (Rielaborazione di Matteo Cadario da Città antica). 


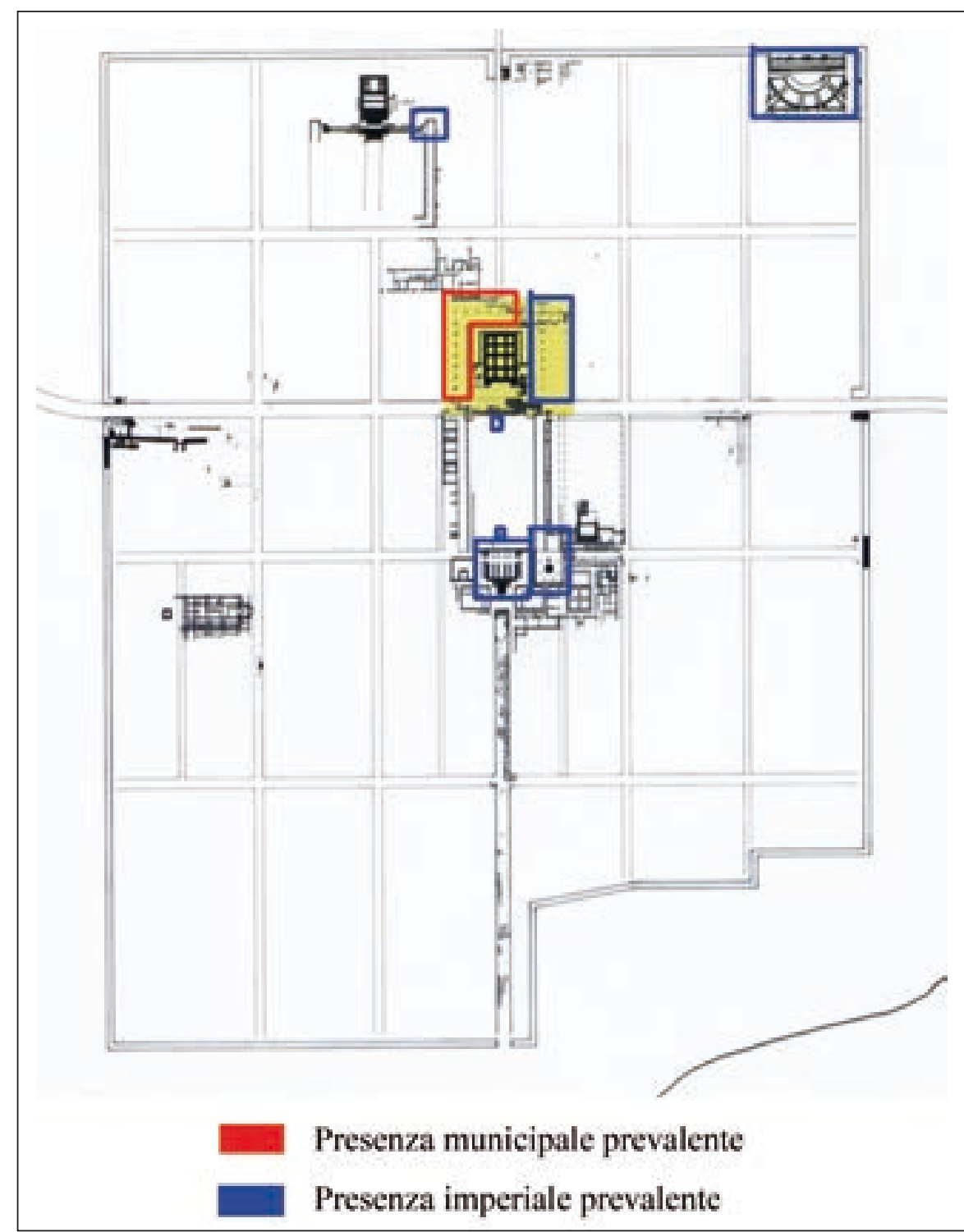

Fig. 9. Gli spazi di rappresentazione a prevalenza imperiale e municipale (rielaborazione di Matteo Cadario da Luni guida).

troppo diverso dai fondatori o rifondatori della città ${ }^{80}$. Nell'insieme anche il foro di Aquileia, come l'area Capitolina a Luni, si presentava dunque come il luogo destinato a mantenere vive le tradizioni civiche, con la differenza che la città friulana nel IV sec. d.C. era ancora in grado di integrare con nuovi e impegnativi monumenti l'illustrazione della propria storia.

La zona a nord del foro non era però l'unico luogo di rappresentazione lunense, vista l'onnipresenza imperiale nei luoghi pubblici. A Luni nel I sec. d.C. gli imperatori erano ritratti perlomeno nella basilica e nell'adiacente porticato, nella piazza forense (le due

80. La base farebbe parte del programma di abbellimento del foro voluto da Septimius Theodulus, corrector Venetiae et Histriae poco prima del 361 d.C. : Zaccaria 2000, p. 95-100. statue equestri), nel teatro, nel complesso del Grande Tempio, nell'Area con fontane e forse anche nella cd. curia (fig. 8), ossia in tutti gli spazi di rappresentazione individuati, corrispondenti alla quasi totalità dei luoghi di riunione della comunità a fini politici, cultuali e ludici (manca solo l'anfiteatro). Sono attestati anche più gruppi statuari: quello familiare neroniano dedicato da Titinio Glauco Lucreziano nel teatro; i due busti di Tiberio e di un giovane principe provenienti sempre dal teatro; i ritratti di Claudio e del Divo Augusto riferiti all'Area con fontane; il ciclo giulio-claudio della basilica (se non altro per accumulo) ${ }^{81}$; i ritratti di Caligola, Drusilla (?) e Agrippina Maggiore, posti probabilmente nella zona sud

81. Per il ciclo: De Maria 2005, p. 172. il ritratto di Germanico, il togato velato capite e il giovane principe potrebbero appartenere alla stessa dedica. 
del foro; le statue di Carino e Magna Urbica (283 d.C. ca.). La dedica di questi gruppi è connessa nel I sec. d.C. alla storia degli edifici che li ospitano, dei quali accompagna la costruzione (teatro $1^{\circ}$ fase, basilica, Area con fontane) o un rifacimento (teatro/odeum - ma anche per il Grande Tempio la statua loricata coincide con il restauro augusteo): la trasformazione monumentale di Luni e la sua "occupazione" da parte della domus Augusta procedettero dunque in parallelo.

Le altre città cisalpine offrono molte situazioni analoghe, soprattutto in età giulio-claudia ${ }^{82}$, come dimostrano i casi più eclatanti del teatro di Vicenza e della basilica di Velleia $^{83}$, da integrare con quelli più frammentari delle basiliche di Bononia e Verona ${ }^{84}$, ma solamente Luni consente di ricostruire il quadro di insieme dell'articolazione e della profusione delle immagini imperiali in una città romana di medie dimensioni. La distribuzione dei ritratti imperiali permette infatti di seguire anche l'evoluzione della gerarchia degli spazi di rappresentazione (fig. 9): se l'area a nord del foro fu l'unica ad accogliere onori per tutto il corso della storia lunense e la basilica vi svolse un ruolo di primo piano dall'età claudia al III sec. d.C., nel I sec. d.C. il teatro non fu da meno, visto che fu oggetto di dediche ripetute almeno fino all'età flavia, e anche la zona sud del foro, che ospitò nell'Area con Fontane anche il culto imperiale ${ }^{85}$, proponendosi così verso la metà del I sec. d.C. come un polo di attrazione simmetrico rispetto al Capitolium $^{86}$. Nella Luni di età claudia si ebbe dunque una moltiplicazione dei luoghi di rappresentazione che comportò l'assegnazione alla domus divina di almeno tre spazi privilegiati per theatra ('odeum) et fora (la basilica, l'Area con fontane e forse la Curia) ${ }^{87}$, una scelta coerente con le nuove esigenze del culto imperiale, che aveva trovato nei ludi teatrali

82. Oltre ai lavori più ampi di Boschung 2002 e Rose 1997 sui cicli statuari giulio-claudi in Cisalpina si rimanda a Saletti 1993 ; Denti 1991 e Denti 1991a.

83. Su Velleia: De Maria 1988 e Saletti 1993. Su Vicenza : Legrottaglie 2008.

84. Su Bononia: De Maria 2008, p. 105 ; su Verona: Frova, Cavalieri Manasse 2005.

85. Lo suggeriscono l'altare e la scelta dei tipi statuari. A Luni il culto imperiale era probabilmente presente sia nel Grande Tempio sia nel Capitolium, ma per questi due edifici mancano testimonianze concrete di simulacra, visto che la collocazione della statua loricata era marginale (almeno nel III sec. d.C.) e che per nessuna delle statue rinvenute nella zona a nord del foro è possibile ipotizzare la provenienza dall'edificio templare. Per il teatro, cfr. Rosso 2009 sulla condizione di per sé vicina a quella dei simulacra dei ritratti imperiali nei frontescena.

86. Per esempio nel foro di Segobriga i due poli di attrazione furono l'altare di Augusto a sud e a nord l'esedra in cui era onorata Agrippina Maggiore : Abascal 2004, p. 242.

87. Cfr. Tac. Ann., 4.2.4 su Seiano. e nell'attività degli Augustali media molto efficaci e apprezzati dal potere centrale.

Proprio in questa fase emerse la figura di L. Titinio Glauco Lucreziano, che impersonò il ruolo del notabile "di successo" il quale, godendo di ottime relazioni con la corte imperiale (Nerone), poteva guidare (anche in quanto patrono) le forme della celebrazione dinastica nella comunità locale, a Luni (almeno l'odeum) come a Cosa (Capitolium e basilica/odeum), curando anche l'arredo scultoreo degli edifici mediante cicli statuari dinastici e proprie statue ${ }^{88}$. La preferenza accordata all'odeum è coerente con l'entusiasmo dell'élite urbana del tempo per il teatro ma soprattutto con l'importanza acquisita dalla recitatio di panegirici nella liturgia imperiale intorno alla metà del I sec. d.C., come testimoniato dal certamen di Lugdunum al tempo di Caligola ${ }^{89}$ e poi dai Neronia con le loro laudes Neronis ${ }^{90}$. La collocazione nell'odeum lunense della statua di un togato declamante può quindi essere vista come un caso ideale di coerenza tra locus e tipo statuario "intellettuale". In uno spazio riservato alla celebrazione dinastica (cfr. la presenza di più immagini imperiali) essa poteva infatti ritrarre un cittadino impegnato in una performance encomiastica (una sorta di sebastologos lunense ${ }^{91}$ ) oppure - meno probabilmente - un imperatore/oratore (Nerone) on stage, modello di chi lo avrebbe elogiato in quello stesso edificio.

Dopo la profusione di onori del I sec. d.C., la situazione cambiò e almeno nel pieno III sec. d.C. ${ }^{92}$ vi fu una netta contrazione degli spazi di rappresentazione con le nuove dediche (e i riusi di basi più antiche) concentrate di nuovo intorno al Capitolium, come in età repubblicana. Il dossier di dediche imperiali della seconda metà del III sec. d.C. a Luni è però molto ricco: sono ben otto e in totale onoravano undici imperatori/imperatrici (sei nella basilica e i doppi e tripli riusi di due basi più antiche nel porticato). Questa iperattività si inserisce in un fenomeno esteso a tutta la Cisalpina, dove epigrafi e ritratti degli stessi imperatori sono segnalati ad Aquileia, Brescia, Velleia, Modena, Trieste, Vicenza e Benacum superando nei numeri le testimonianze di età flavia, antonina e severiana provenienti dalla stessa regione ${ }^{\mathbf{9 3}}$.

88. Fentress 2003, p. 58-61.

89. Fishwick 1991, p. 571-573 e Suet. Gaius, 20.

90. Champlin 2003, p. 70-83.

91. Su questa carica a Mileto al tempo di Caligola: I Didyma 148 e Robert 1949, p. 210.

92. Purtroppo il II sec. d.C. è privo di testimonianze scultoree significative.

93. In proposito, cfr. Slavazzi 2008, p. 137. Vedi anche De Maria 2008; Deppmeyer 2008, n.7, p. 20-30 (Velleia); n.209, p. 402-404 
La spiegazione va cercata nella frequente presenza degli imperatori sul territorio, impegnati sul campo in quell'Italia settentrionale posta ormai sotto pressione dalle incursioni barbariche. Onorare gli imperatori nel III sec. d.C. non significava più mostrare la propria adesione e lealtà per benefici lontani, ma ringraziare o esortare i nuovi principi a interventi contro pericoli ormai vicini.

La caratteristica forse più peculiare della documentazione lunense resta però la possibilità di riconoscere nella porticus che circondava il Capitolium lo spazio scelto dall'élite cittadina per celebrarsi (fig. 8), così come, per esempio, a Labitolosa era avvenuto con la curia/tempio forense del Genio municipale o come è possibile ipotizzare anche per il grande edificio porticato/ basilica di Piazza Mattej a Formia tra I e II sec. d.C. ${ }^{94}$. A Luni i notabili furono onorati anche altrove, come nella basilica (e nella cd. curia), dove ebbero l'opportunità di condividere lo spazio di rappresentazione con gli imperatori proprio così come ne imitavano i tipi statuari ${ }^{95}$. Questi onori dovevano però essere eccezionali, spesso determinati anche dal patrocinio personale o gentilizio dell'edificio, come fu il caso di Lucreziano nell'odeum di Cosa ${ }^{96}$. Il porticato che circondava il tempio cittadino più importante sembra invece essere stato riservato dai notabili lunensi alla propria autorappresentazione, creando così per accumulo un vero e proprio "gruppo" di dediche che tramandavano i loro nomi insieme agli antichi monumenti repubblicani come quello di M. Claudio Marcello. La vicinanza al Capitolium (e alla basilica riservata all'omaggio dinastico) dava inoltre un rilievo eccezionale alla classe dirigente locale ed è un indizio del forte orgoglio civico degli abitanti della splendida civitas di Luna.

(Brixia); n.210, p. 404-405 (Aquileia).

94. Su Labitolosa: Jordán 2004-2005; Sillières 1995. Cfr. anche Balty 2005, p. 141-142 che identifica l'edificio con la curia. Per Formia ricordo almeno un ritratto muliebre e cinque/sei statue virili private tra età augustea e giulio-claudia e la serie di nove piedistalli eretti nel II sec. d.C. per i notabili locali: Cassieri 2001, p. 13-16 e Cadario 2010a.

95. Rosso 2004, p. 35-39. Era un problema solo se la statua di un privato sovrastava quella di un imperatore, come nel celebre caso della lesa maestà di Granius Marcellus: Tac. Ann., 1.74.3 e Mainardis 2006, p. 276-277.

96. Casi analoghi potrebbero essere quelli di Q. Petronius Modestus nel teatro di Trieste (Aberson 1991), C. Baebius Atticus a Iulium Carnicum (Mainardis 2006) e Q. Baienius Blassianus nella basilica di Trieste (il suo rapporto con le fasi dell'edificio è però discusso: Zaccaria 1988 e Mainardis, Zaccaria 2005).

\section{Bibliographie}

Abascal 2004: ABASCAL (J.M.), CEBRIÁN (R.) et TRUNK (M.) Epigrafía, arquitectura y decoración arquitectónica del foro de Segobriga, in La decoración arquitectónica en las ciudades romanas de Occidente, S.F. Ramallo (ed.), Actas del Congreso Cartagena (2003), Murcia, p. $219-244$.

Abascal 2007 : ABASCAL (J.M.) et al., Segobriga. Culto imperial en una ciudad romana de la Celtiberia, in Culto imperial, p. 685-704.

Abascal 2009 : ABASCAL (J.M.) - Programas epigraficos en los foros romanos de Hispania. In : Fora Hispaniae, 2009, p. 89-104.

Aberson 1991 : ABERSON (M.) - Le formule dell'iscrizione di «Petronius Modestus» e la datazione del teatro di Trieste. In : Il teatro romano di Trieste. Monumento, storia e funzione, a cura di M. Verzár Bass, Roma, 1991 (Biblioteca Helvetica romana, 25).

Angeli Bertinelli 1983 : ANGELI BERTINELLI (M.G.) - Ordo populusque Lunensium. Le strutture politiche e amministrative dell'antica Luni. QuadLun, 8, 1983, p. 39-52.

Angeli Bertinelli 1987 : ANGELI BERTINELLI (M.G.) - Gli imperatori del III secolo nelle iscrizioni onorarie lunensi. Studi Lunensi, 1987, p. 525-540.

Angeli Bertinelli 1988 : ANGELI BERTINELLI (M.G.) - Frammenti di fasti imperiali inediti da Luni. MEFRA, 100, 1, p. 100-116.

Angeli Bertinelli 1990 : ANGELI BERTINELLI (M.G.) - Ancora a proposito di L. Titinius Glaucus Lucretianus. Athenaeum, n. s. 78, 1990, p. 541-542.

Angeli Bertinelli 1993 : ANGELI BERTINELLI (M.G.) - Un titulus inedito di M'. Acilio Glabrione da Luni. MEFRA, 105, 1993, p. 7-31.

Angeli Bertinelli 1995 : Angeli Bertinelli (M.G.) - Il ricordo epigrafico dell'evergetismo a Luna. In : Splendida civitas nostra, 1995, p. 45-60.

Angeli Bertinelli 2002 : ANGELI BERTINELLI (M.G.) - Il ceto medio nella colonia romana di Luna. In : Ceti medi in Cisalpina, p. 131-149.

Arrigoni Bertini 2002 : ARRIGONI BERTINI (M.G.) - I "ceti intermedi" nell'Emilia Occidentale: Parma. In : Ceti medi in Cisalpina, p. 119-129.

Augusto in Cisalpina : SENA CHIESA (G.) a cura di - Augusto in Cisalpina. Ritratti augustei e giulio-claudi in Italia settentrionale, Milano, 1995.

Autocélébration des élites: CEBEILLAC GERVASONI (M.), LAMOINE (L.), TREMENT (Fr.) edd., Autocélébration des élites locales dans le monde romain. Contextes, images, textes (II ${ }^{e}$ s. av. J.-C.-III ${ }^{e}$ s. ap. J.-C.), Clermont Ferrand, 2004 (Coll. Erga 7).

Balty 2005 : BALTY (J.-C.) - Curia et bouleutérion, nouveaux exemples: confirmations et problèmes. In: Théorie et pratique de l'architecture romaine, p. 141-152.

Bejor 1987 : BEJOR (G.) - Documentazione epigrafica di complessi statuarii nell'Africa romana: alcuni esempi. Africa Romana IV, Atti Sassari (1986), Sassari, 1987, 1, p. 101-116.

Boschung 2002: BOSCHUNG (D.) - Gens Augusta. Untersuchungen zu Aufstellung, Wirkung und Bedeutung der Statuengruppen des julischclaudischen Kaiserhauses, Mainz am Rhein, 2002 (Monumenta Artis Romanae 32). 
Buonopane 2008 : BUONOPANE (M.) - Il materiale epigrafico. In : L'area del Capitolium, p. 269-288.

Cadario 2001 : CADARIO (M.) - Un intellettuale a teatro. Una statua togata lunense nel gesto della lettura interrotta. QuadLun, n.s. 7, 2001, p. 83-114.

Cadario 2004 : CADARIO (M.) - La corazza di Alessandro. Loricati di tipo ellenistico dal IV secolo a.C. al II d.C., Milano, 2004 (Il Filarete, 218).

Cadario 2005 : CADARIO (M.) - I Claudi Marcelli: strategie di propaganda in monumenti onorari e dediche votive tra III e I sec. a.C.. Ostraka, 14, 2, 2005, p. 147-177.

Cadario 2010 : CADARIO (M.) - Le basiliche civili. Da luogo della memoria gentilizia a scenario della storia di Roma e del potere imperiale. In: TOMEI (M.A), a cura di, Memorie di Roma. Gli Aemilii e la basilica del foro, Milano, 2010, p. 58-107.

Cadario 2010a : CADARIO (M.) - II 26. Statua eroica di rango militare. In : La Rocca (E.), Parisi Presicce (C.), Lo Monaco (A.), a cura di, I giorni di Roma. L'età della conquista, (mostra Roma), Milano, 2010, p. 293-294.

Capaldi 2007 : CAPALDI (C.) - Una nuova attestazione da Cuma dei cosiddetti fasti imperiali. In : Gasparri (C.), Greco (G.), a cura di, Cuma. Il Foro. Scavi dell'Università di Napoli Federico II 2000-2001, Napoli, 2007, p. $177-$ 198 (Studi Cumani, 1).

Cassieri 2001 : CASSIERI (N.) - Museo Archeologico Formia, Marina di Minturno, 2001.

Cavalieri 2000 : CAVALIERI (M.) - La basilica in Italia. Decorazione scultorea e sue valenze politico-culturali. Athenaeum, n.s. 88, 2000, p. $465-476$.

Ceti medi in Cisalpina : Ceti medi in Cisalpina, Atti Milano (2000), a cura di A. Sartori, A. Valvo, Milano, 2002.

Città antica : DURANTE (A.M.) a cura di, Città antica di Luna. Lavori in corso 2, Genova 2010

Champlin 2003 : CHAMPLIN (E.) - Nero, Harvard, 2003.

Collins Clinton 2000 : COLLINS CLINTON (J.) - The Neronian odeum at Cosa and its sculptural program: a new Julio-claudian Group. MAAR, 45, 2000, p. 99-130.

Culto imperial: Culto imperial: política y poder, Actas Mérida (2006), T. Nogáles, J. Gonzáles eds., Roma, 2007 (Hispania Antigua. Serie Arqueológica, 1).

De Maria 1988 : DE MARIA (S.) - Iscrizioni e monumenti nei fori della Cisalpina romana. Brixia, Aquileia, Veleia e Iulium Carnicum. MEFRA, 100, 1988, p. 27-62.

De Maria 2005 : DE MARIA (S.) - I fora della Cisalpina romana come luoghi della celebrazione. In : Théorie et pratique 2005, p. 166-177.

De Maria 2008 : DE MARIA (S.) - Immagini e spazi della celebrazione nelle città dell'Emilia romana. In : Scultura romana, p. 101-109.

Delplace, Dentzer-Feidy 2005 : DELPLACE (C.), DENTZER-FEYDY (j.) L'agora de Palmyre, Bordeaux-Beyrouth, 2005.

Denti 1991 : DENTI (M.) - Ellenismo e romanizzazione nella X regio. La scultura delle élites locali dall'età repubblicana ai giulio-claudi, Roma, 1991 (Archaeologica, 97).
Denti 1991a : DENTI (M.) - I Romani a Nord del Po, Milano, 1991.

Deppmeyer 2008 : DEPPMEYER (K.) - Kaisergruppen von Vespasian bis Konstantin. Eine Untersuchung zu Aufstellungkontexten und Intentionen der statuarischen Präsentation kaiserlicher Familien, Hamburg, 2008.

Di Vita Évrard 1991 : DI VITA ÉVRARD (G.) - Les « Fastes impériaux » de Brescia, in Epigrafia. Actes du colloque international en mémoire de Attilio Degrassi, Actes Roma (1988), Roma, 1991, p. 92-117.

Durante, Gervasini 2000 : DURANTE (A.M.), GERVASINI (L.) - Zona archeologica e Museo Nazionale di Luni, Roma, 2000.

Durante 2001 : DURANTE (A.M.) - Urbanistica lunense. Note di aggiornamento. In : Durante (A.M.), a cura di, Città antica di Luna. Lavori in corso, Luni, 2001, p. 8-27.

Eck 1996 : ECK (W.) - Tra epigrafia, prosopografia e archeologia. Scritti scelti, rielaborati e aggiornati, Roma, 1996.

Fejfer 2008 : FEJFER (J.) - Roman Portraits in Context, Berlin, New York, 2008.

Fentress et al. 2003 : FENTRESS (E.) et al. - Cosa V: An intermittent town. Excavations 1991-1997, Ann Arbor, 2003 (MAAR, Suppl. 2).

Fishwick 1991 : FISHWICK (D.) - The Imperial Cult in the Latin West. Studies in the Ruler Cult of the Western Provinces of the Roman Empire, II, 1-2, Leiden et al., 1991.

Fora Hispaniae : Fora Hispaniae. Paisaje urbano, arquitectura, programas decorativos y culto imperial en los foros de las ciudades hispanorromanas, Actas Murcia (2002), J.M. Noguera Celdrán (ed.), Murcia, 2009 (Monografías MAM 3).

Frova 1980 : FROVA (A.) - Sul teatro di Luni. $R S L, 46,1980$, p. 7-24.

Frova 1983 : FROVA (A.) - Ritrattistica e scultura a Luni. RSL, 49, 1983, p. $37-84$.

Frova 1983A : FROVA (A.) - Gli scavi di Luni e il collezionismo. In : Marmora Lunensia, p. 11-34.

Frova 1984 : FROVA(A.) - De statuarum basibus. QuadLun, 4, 1984, p. 5-34.

Frova 1987 : FROVA (A.) - La produzione di scultura a Luni. Studi Lunensi, p. $223-250$.

Frova 1987A : FROVA (A.) - Ritrattistica romana a Luni. In : Atti della II conferenza internazionale sul ritratto romano (Roma 1985), Roma, 1987, p. 303-312.

Frova 1998 : FROVA (A.) - Un ritratto romano a Luni. In : In memoria di Enrico Paribeni, a cura di G. Capecchi et al., Roma, 1998, 1, p. 179-187 (Archaeologica, 125).

Frova, Cavalieri Manasse 2005 : FROVA(A.), CAVALIERI MANASSE (G.) - La basilica forense di Verona alla luce dei nuovi scavi. In : Théorie et pratique, p. 179-201.

Fuchs 1987 : FUCHS (M.) - Untersuchungen zur Ausstattung römischen Theater, Mainz, 1987.

Gregori 2000 : GREGORI (G.) - In margine alla carriera di L. Titinius Glaucus Lucretianus. In : Les Élites municipales de l'Italie péninsulaire da la 
mort de César à la mort de Domitien entre continuité et rupture, Atti Napoli (1997), Roma, 2000, p. 160-169 (CÉFr., 271).

Horster 2001: HORSTER (M.) - Bauinschriften römischer Kaiser. Untersuchungen zu Inschriftenpraxis und Bautätigkeit in Städten des westlichen Imperium Romanum in der Zeit des Prinzipats, Stuttgart, 2001 (Historia Einzel. 157).

Jordán 2004-2005 : JORDÁN (Á.A.) - Curia ordinis. Uso epigráfico de un edificio singular, in Espacio, Tiempo y Forma, Serie II, Historia Antigua 17-18, 2004-2005, p. 361-373

Kokkinos 1992 : KOKKINOS (N.) - Antonia Augusta, London, New York, 1992.

L'area del Capitolium : CAVALIERI MANASSE (G.) a cura di, L'area del Capitolium di Verona. Ricerche storiche e archeologiche, Milano, 2008.

Laube 2006: LAUBE (I.) - Thorakophoroi. Gestalt und Semantik des Brustpanzers in der Darstellung des 4. bis 1. Jhs v. Chr., Rahden/Westfalia, 2006.

Le Roux 2008 : LE ROUX (P.) - Dans les centres monumentaux des cités de la péninsule Ibérique au Haute-Empire : à propos de statues. In : Le Quotidien municipal dans l'Occident romain, Actes Clermont-Ferrand (2007), Paris, 2008, p. 569-594.

Lefebvre 2004 : LEFEBVRE (S.) - Espace et pouvoir local dans les provinces occidentales: quelques remarques. In: Au jardin des Hespérides. Histoire, société et épigraphie des mondes anciens. Mélanges offerts à Alain Tranoy, Rennes, 2004, p. 379-406.

Lefebvre 2006 : LEFEBVRE (S.) - Le forum de Cuicul: un exemple de la gestion de l'espace public à travers l'étude des inscriptions martelées. In : L'Africa Romana XVI, Atti Rabat (2004), Roma, 2006, 4, p. $2125-2140$

Legrottaglie 1995 : LEGROTTAGLIE (G.) - Culto e divinità eponima e Veneratio Augusti nel 'Grande Tempio' di Luni. QuadLun, n.s. 1, 1995, p. 19-82.

Legrottaglie 1995a : LEGROTTAGLIE (G.) - Frammento di altorilievo con ritratto di Augusto. In : Augusto in Cisalpina, p. 155-165.

Legrottaglie 1995b : LEGROTTAGLIE (G.) - Frammento di altorilievo con ritratto di Augusto. In : Augusto in Cisalpina, p. 173-187.

Legrottaglie 2008 : LEGROTTAGLIE (G.) - La decorazione scultorea. In : L'area del Capitolium, p. 255-265.

Legrottaglie 2008a : LEGROTTAGLIE (G.) - Il ciclo statuario del teatro di Vicenza. Qualche considerazione alla luce dell'analisi dei marmi. In : Scultura romana, p. 161-167.

Lepelley 1994 : LEPELLEY (C.) - Le musée des statues divines. La volonté de sauvegarder le patrimoine artistique païen à l'époque théodosienne. $C A r c h$, 42, 1994, p. 5-15.

Lippolis 2004 : LIPPOLIS (E.) - Triumphata Coryntho: la preda bellica e $i$ doni di Lucio Mummio Acaico. ArchClass, 55, 2004, p. 25-82.

Luni I : FROVA (A.) a cura di - Scavi di Luni. Relazione preliminare delle campagne di scavo 1970-1971, Roma, 1973.

Luni II : FROVA (A.) a cura di - Scavi di Luni. Relazione preliminare delle campagne di scavo 1972-1973-1974, Roma, 1977.
Luni guida : Luni. Guida Archeologica, Sarzana, 1985.

Mainardis, Zaccaria 2005 : MAINARDIS (B.A.), ZACCARIA (C.) - Tra epigrafia e papirologia. Q. Baienus Blassianus, cavaliere tergestino e prefetto d'Egitto. In: Scrivere, leggere, interpretare. Studi di antichità in onore di Sergio Daris, a cura di F. Crevatin, G. Tedeschi, Trieste, 2005, p. 1-25 (edizione elettronica:

http://www.sslmit.units.it/crevatin/franco_crevatin_homepage.htm)

Mainardis 2006 : MAINARDIS 2006 - Un ciclo imperiale da (ri)considerare? Onori alla casa imperiale e a un cavaliere illustre di Iulium Carnicum (Italia, Regio X). ZPE, 156, 2006, p. 267-283.

Mannino 1999 : MANNINO (K.) - La statua del complesso monumentale del Grande Tempio di Luni: alcune note. QuadLun, n.s. 5, 1999, p. 3-22.

Marmi antichi : BETTINI (a.) et al. - Marmi antichi delle Raccolte Civiche Genovesi, Ospedaletto, 1998

Marmora Lunensia : Marmora Lunensia Erratica. Mostra fotografica delle opere lunensi disperse (Sarzana 1983), Sarzana, 1983.

Mennella 2006 : MENNELLA (G.) - Un esponente della gens Titinia ad Aulla. Epigraphica, 68, 2006, p. 414-420.

Mennella 2008 : MENNELLA (G.) - La conservazione delle memorie imperiali negli spazi espositivi: una prospettiva lunense. In: Nuove ricerche sul culto imperiale in Italia, a cura di L. GASPERINI G. PACI (Atti Ancona 2004 = Ichnia, n. 7), Tivoli 2008, p. 173-192.

Mian 2009 : MIAN (G.) - I programmi decorativi nell'edilizia pubblica. In : Ghedini (F.), Bueno (M.), Novello (M.) a cura di, Moenibus et portu celeberrima. Aquileia: storia di una città, Roma, 2009, p. 204-210.

Moreno Pérez 2007 : MORENO PÉREZ (S.) - Contexto y funcionalidad de las representaciones escultóricas pétreas de Pollentia. Arqueologia y Territorio, 4, 2007, p. 87-106.

Nogales Basarrate 2007 : NOGALES BASARRATE (T.) - Culto Imperial en Augusta Emerita: imágenes y programas urbanos. In : Culto imperial, p. 449-539.

Noguera 2008 : NOGUERA (J.M.), ABASCAL (J.M.) et CEBRIÁN (R.) El programa escultórico del foro de Segobriga. In : Escultura Romana en Hispania V, Atti Murcia (2005), J.M. Noguera, E. Conde Guerri éds., Murcia, 2008, p. 283-343.

Papini 2004 : PAPINI (M.) - Antichi volti della repubblica. La ritrattistica in Italia centrale tra IV e II sec. a.C., Roma, 2004 (BCAR Suppl., 13).

Pensabene 2007: PENSABENE (P.) - Ostiensium marmorum decus et décor. Studi architettonici, decorativi e archeometrici, Roma, 2007 (Studi Miscellanei, 33).

Pont 2010 : PONT (A.V.) - Orner la cité. Enjeux culturels et politiques du paysage urbain dans l'Asie gréco-romaine, Paris, 2010 (Scripta Antiqua, 24).

Robert 1949 : ROBERT (L.) - Le culte de Caligula à Milet et la Province d'Asie. Hellenica, VII, Paris, 1949, p. 206-238

Rodá 2009 : RodÁ (I.) - Espacios de representación en los foros de Hispania. In : Fora Hispaniae, 2009, p. 69-87.

Rodrigues Conçalves 2007: RODRIGUES CONÇALVES (L.G.) Escultura romana em Portugal: uma arte do quotidiano, Mérida, 2007 (Studia Lusitana, 3). 
Rose 1997: ROSE (C.B.) - Dynastic Commemoration and Imperial Portraiture in the Julio-Claudian Period, Cambridge, Melbourne, New-York 1997.

Rossi 1998: ROSSI (A.M.) - Un'indagine sul bacino-fontana del «Capitolium» di Luni: primi risultati. QuadLun, n.s. 4, 1998, p. 43-64.

Rossignani 1995 : ROSSIGNANI (M.P.) - Gli Aemilii e l'Italia del Nord. In : Splendida Civitas Nostra, p. 61-74.

Rossignani 1995A : ROSSIGNANI (M.P.) - Foro e basilica a Luni. In : Mirabella Roberti (M.), a cura di, «Forum et Basilica» in Aquileia e nella Cisalpina romana, Atti Aquileia 1994, Udine, p. 443-459 (AAAd, 42).

Rossignani, Rossi 2009 : ROSSIGNANI (M.P.), ROSSI (A.M.) - Liguria, Roma, Bari, 2009 (Guide Archeologiche).

Rosso 2004 : ROSSO (E.) - Élites et imitatio : la reprise par les élites des types statuaires impériaux. In : Autocélébration des élites, p. 33-45.

Rosso 2006: ROSSO (E.) - L'image de l'empereur en Gaule romaine. Portraits et inscriptions, Paris 2006.

Rosso 2009: ROSSO (E.) - Le message religieux des statues divines et impériales dans les théatres romains. Approche contextuelle et typologique. In: Fronts de scène et lieux de culte dans le théâtre antique, Lyon, 2009, p. 89-126 (TMO, 52)

Sacchi 1998 : SACCHI (F.) - L'imperatore Claudio a Luni. Una breve nota. QuadLun, n.s. 3, 1998, p. 3-26.

Sacchi 1998 : SACCHI (F.) - Un frontone marmoreo dall'area con fontane del Foro di Luni. Considerazioni preliminari. QuadLun, n.s. 6, 2000, p. 11-28.

Saletti 1973 : SALETTI (C.) - Tre ritratti imperiali da Luni : Tiberio, Livia e Caligola. Athenaeum, n.s. 51, 1973, p. 34-48.

Saletti 1993 : SALETTI (C.) - I cicli statuari giulio-claudi della Cisalpina. Presenza, ipotesi, suggestioni. Athenaeum, n.s. 81, p. 365-390.

Saletti 2000 : SALETTI (C.) - Ritratti di Augusto in Cisalpina: il grande frammento di Luni. QuadLun, n.s. 6, 2000, p. 3-10.

Saletti 2001 : SALETTI (C.) - Nuove osservazioni su un gruppo giulio-claudio di Luni. QuadLun, n.s. 7, 2001, p. 17-27.

Saletti 2002 : SALETTI (C.) - Ritratti di Augusto in Cisalpina: la documentazione epigrafica. Athenaeum, 1995, 90, p. 331-338.

Scultura romana :La scultura romana dell'Italia settentrionale. Quarant'anni dopo la mostra di Bologna, Atti Pavia (2005), a cura di S. Maggi e F. Slavazzi, Firenze, 2008 (Flos Italiae, 8).

Sève 2004 : SÈVE (M.) - Le forum de Philippes, lieu d'autocélébration de lélite municipale ? In: Autocélébration des élites, p. 107-119.
Sillières 1995 : SILLIÈRES (P.), MAGALLÓN BOTAYA (M.Á.) ; NAVARO CABALLERO (M.) - El Municipium Labitvlosanvm y sus notables: novedades arqueólogicas y epigráficas. AEA, 68, 1995, p. 107-130.

Sillières 1997 : SILLIÈRES (P.) - Baelo Claudia. Una ciudad romana de la Bética, Madrid 1997.

Slavazzi 2008 : SLAVAZZI (F.) - Ritratti imperiali in Italia settentrionale. Premesse per una ricerca. In : Scultura romana, p. 133-142.

Smith 2006: SMITH (R.R.R.) - Aphrodisias II. Roman Portraits from Aphrodisias, Mainz am Rhein, 2006.

Sotinel 2005 : SOTINEL (C.) - Identité civique et christianisme. Aquilée du III ${ }^{e}$ au $\mathrm{VI}^{e}$ siècle, Rome, 2005 (BEFAR, 324).

Spadea 2008 : SPADEA (G.) - Presenze scultoree nell'odierna Liguria. In : La scultura romana, p. 225-237.

Splendida civitas nostra: CAVALIERI MANASSE (G.), ROFFIA (E.), a cura di, Splendida civitas nostra. Studi archeologici in onore di A. Frova, Roma 1995.

Stemmer 1978: STEMMER (K.) - Untersuchungen zur Typologie, Chronologie und Iconographie der Panzerstatuen, Berlin 1978.

Studi Lunensi : Studi Lunensi e prospettive sull'occidente romano 2, Atti Lerici (1985). QuadLun, 11, 1987.

Théorie et pratique : Théorie et pratique de l'architecture romaine: la norme et l'expérimentation: études offertes à Pierre Gros, Aix-en-Provence 2005.

Valeri 2005 : VALERI (C.) - Marmora Phlegraea. Sculture dal Rione Terra di Pozzuoli, Roma, 2005.

Varner 2004 : VARNER (E.R.) - Mutilation and Transformation. Damnatio memoriae and Roman Imperial Portrait, Leiden, Boston 2004.

Wohlmayr 2004 : WOHLMAYR (W.) - Kaisersaal. Kultlagen der Augustalen und munizipale Einrichtungen für das Herrscherhaus in Italien, Wien, 2004.

Wood 1999 : WOOD (S.E.) - Imperial Women: a Study in public images 40 b.C.- A.D. 68, Leiden, Boston, Köln, 1999 (Mnemosyne Suppl. 194).

Zaccaria 1988 : ZACCARIA (C.) - Problemi epigrafici del foro di Trieste. MEFRA, 100, 1, 1988, p. 63-85.

Zaccaria 2000 : ZACCARIA (C.) - Permanenza dell'ideale civico romano in epoca tardoantica: nuove evidenze da Aquileia. In : Bandelli (G.), Aquileia romana e cristiana fra II e V secolo, Atti Aquileia (1991), Trieste, 2000, p. 91-113 (AAAd, 47).

Zana 1995 : ZANA (L.) - Ritratto di Livia. In : Augusto in Cisalpina, p. $167-171$

Zimmer 1989: ZIMMER (G.) - Locus datus decreto decurionum. Zur Statuenaufstellung zweier Forumsanlagen in römischen Afrika, München, 1989 (Bayerische Akademie Abhandlungen, 102). 
Deuxième Partie

\section{Espaces et monuments funéraires}

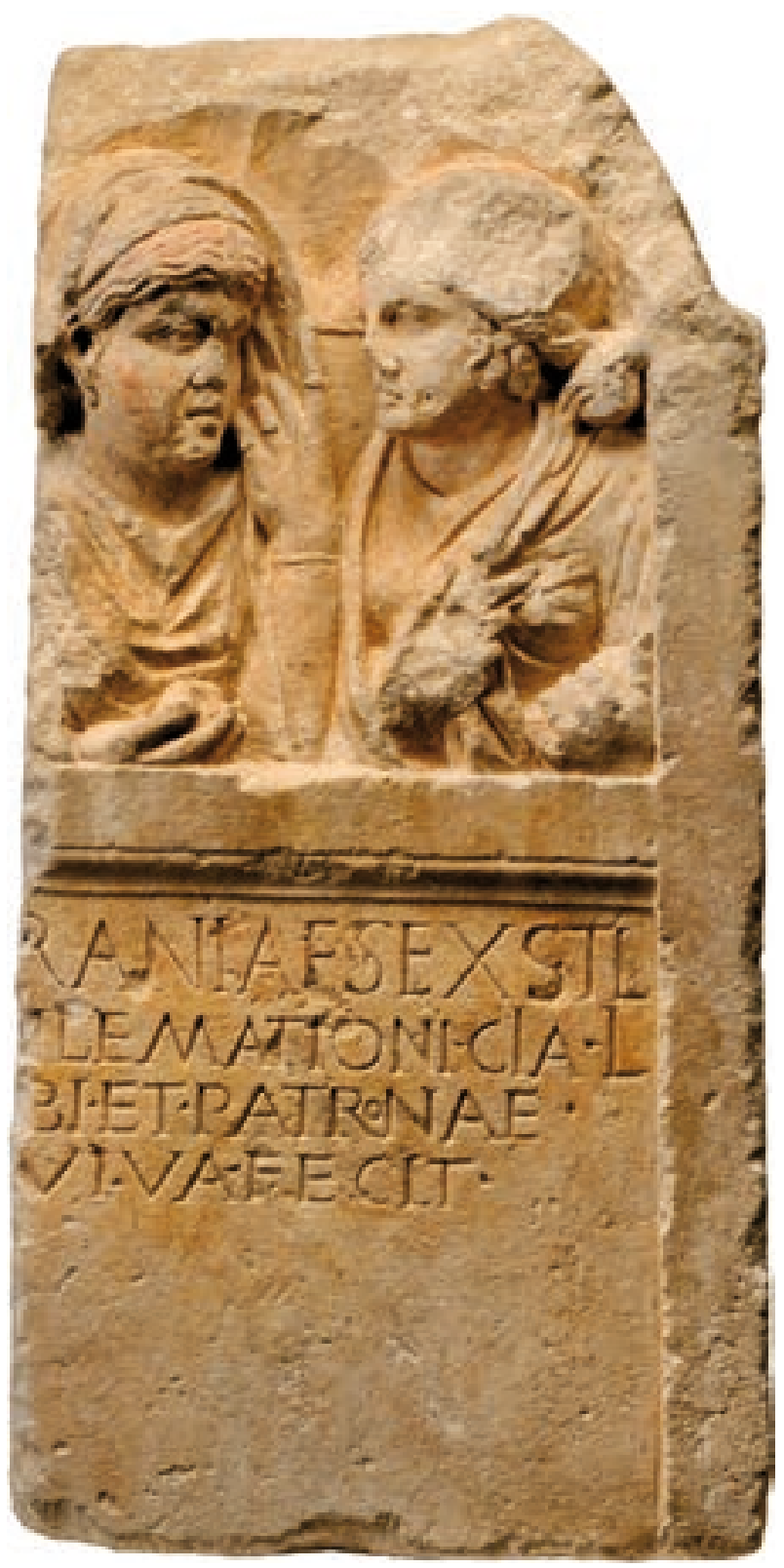





\title{
Signa et tituli dans les Alpes maritimae : l'exemple des stèles funéraires en forme de porte
}

\section{Stéphane Morabito}

Service archéologie de la Ville de Nice, Chercheur associé Centre Camille Jullian, Aix-en-Provence stephane.morabito@ville-nice.fr

\section{Résumé}

Cet article s'est attaché à un ensemble de cinq stèles cohérent et original des Alpes maritimes : les stèles en forme de porte. La présence de symboles militaires gravés sous les inscriptions, appréciée également dans le milieu militaire du littoral dalmate, permet à l'auteur de remonter une des pistes possibles qui expliquerait l'origine de ce motif iconographique : la présence d'auxiliaires originaires de Dalmatie dans la province des Alpes maritimes.

Mots-clés : Empire romain, Alpes maritimes, stèles funéraires, épitaphe, auxiliaires, Danube.

\begin{abstract}
This article highlights a coherent and original set of five steles from the area of Alpes Maritimes: door shaped ones. The presence of military symbols engraved under the inscriptions, also met in military context on the dalmatian coast, allows the author to trace those iconographical motifs possible roots linked to the presence of dalmatian natives as military auxiliaries in the Alpes maritimes.
\end{abstract}

Key-words: Roman Empire, Alpes maritimae, funeral steles, epitaphs, auxiliaries, Danube. 


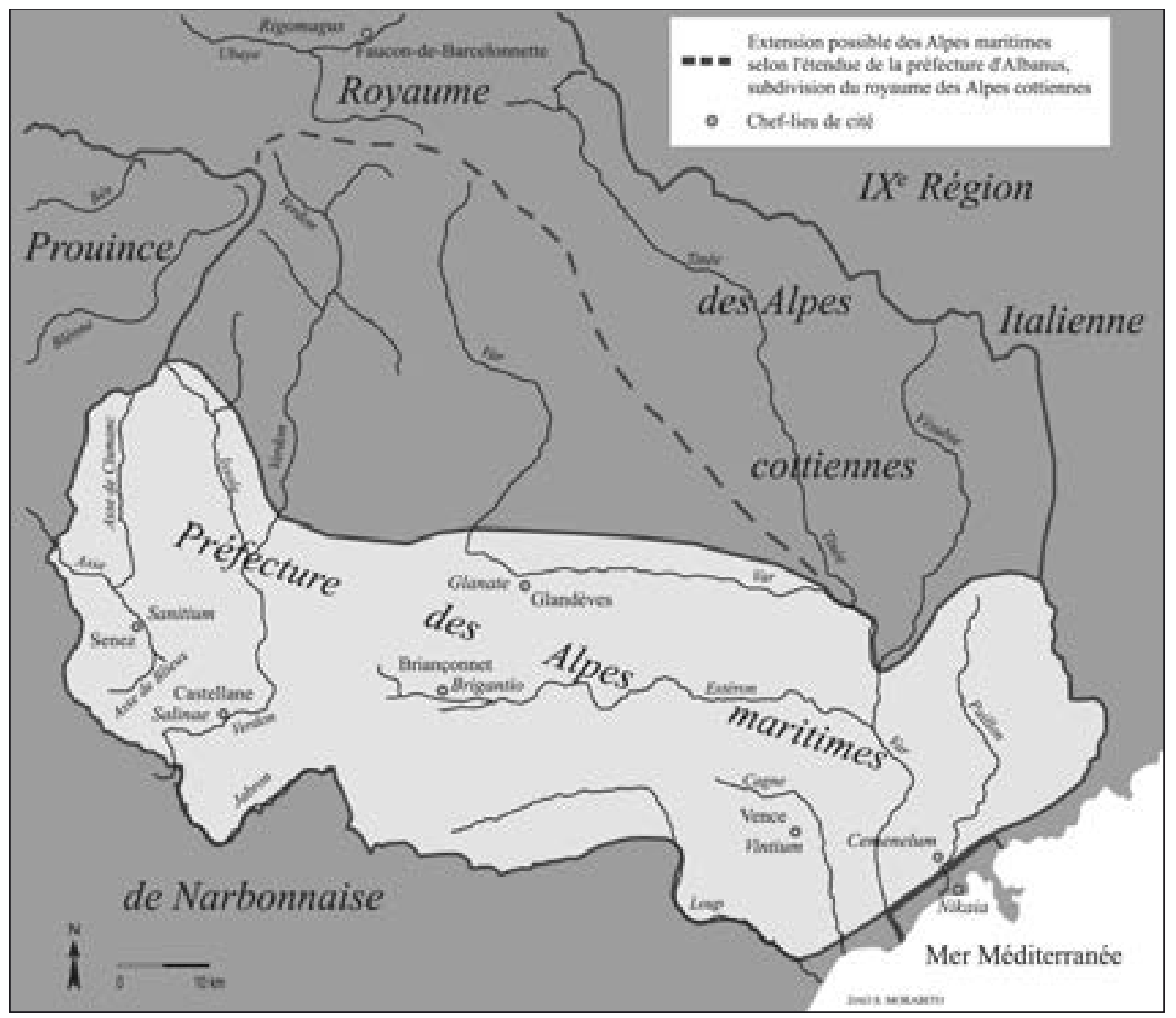

Fig. 1. Limites de la préfecture des Alpes maritimes dans la première moitié du ler $\mathrm{s}$.

L a reprise du matériel épigraphique des Alpes maritimae nécessaire à la constitution du corpus de cette province a permis de relever parmi les quelques quatre cents inscriptions formant ce corpus provincial $^{1}$, un type de monument particulier, les stèles funéraires en forme de porte. L'organisation d'un colloque rassemblant épigraphistes et spécialistes de la sculpture nous offre l'occasion d'étudier ces documents sous un angle nouveau.

Quelques mots au préalable sur la géographie administrative de ce secteur méridional du massif alpin mal connue si l'on en croit encore certaines études concernant les provinces occidentales.

$\mathrm{Au}$ lendemain de la pacification du massif alpin par Auguste, une partie du massif méridional a été érigée en préfecture sous la responsabilité d'un membre de

1. Morabito, 2010b. l'ordre équestre. La préfecture des Alpes maritimes s'est concentrée dès l'origine sur le versant occidental du massif alpin, enserrée entre la $\mathrm{IX}^{\mathrm{e}}$ région pour l'est et le sud-est, Nikaia sous la responsabilité de Marseille pour le sud-ouest, la province de Narbonnaise pour l'ouest et les Alpes cottiennes au nord et au nord-est (fig. 1).

L'évolution des Alpes maritimae du rang de préfecture à celui de province, sans doute durant le règne de Néron, marque une évolution de leurs limites territoriales. La capitale Cemenelum a vraisemblablement étendue son territoire aux vallées de la Vésubie et de la Tinée, placée précédemment dans le royaume cottien. La province est alors formée de six ciuitates (fig. 2).

Avant la fin du $\mathrm{II}^{\mathrm{e}} \mathrm{s}$. de notre ère, les Alpes maritimae vont connaître un accroissement de leur territoire en direction du nord avec l'intégration de Dinia / Digne, localité de la province de Narbonnaise, et celles de Caturigomagus / Chorges, d'Eburodunum / Embrun et de 


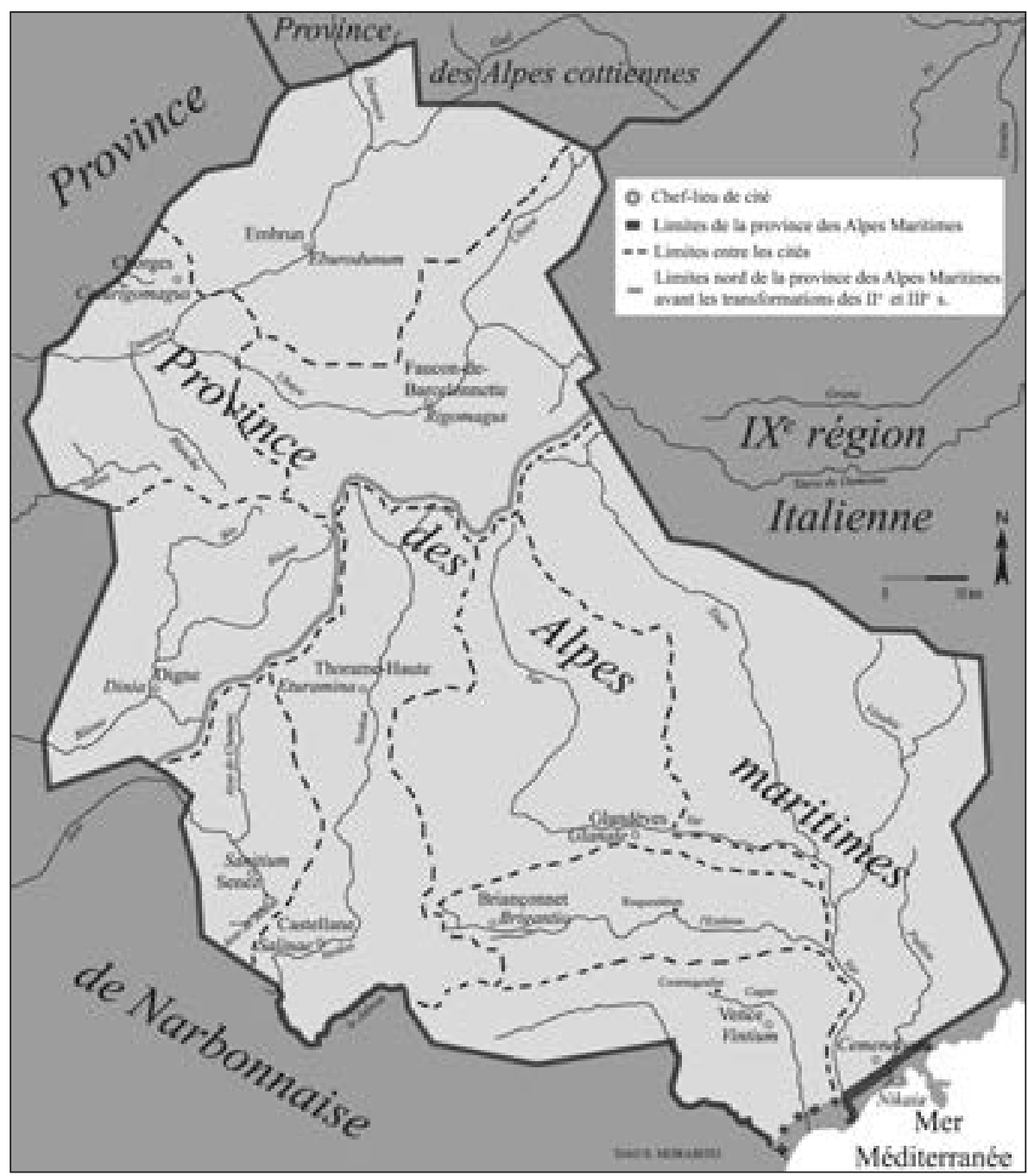

Fig. 2. Limites de la province des Alpes maritimes à la fin du IIe $s$.

Rigomagus / Faucon-de-Barcelonnette antérieurement dans la province des Alpes cottiennes.

Durant l'Antiquité tardive, la cité de Caturigomagus perd son rang de ciuitas et se retrouve intégrée dans le territoire d'Eburodunum. Nous ne pouvons préciser si ce remaniement à accompagner l'élévation d'Embrun au rang de métropole des Alpes maritimes, ceci étant assuré pour le début du $\mathrm{V}^{\mathrm{e}} \mathrm{s}$. Brigantio semble avoir connu le même sort que Caturigomagus, son territoire étant ajouté à celui de Glanate. Enfin, dans la première moitié du $\mathrm{V}^{\mathrm{e}}$ s., une localité secondaire de la haute vallée du Verdon, Eturamina / Thorame-Haute, obtient le statut de ciuitas et le rang d'évêché ${ }^{2}$.

Le nombre de stèles en forme de porte relevé dans les Alpes maritimae, cinq individus, peut apparaître faible.

2. Sur ce point et les informations précédentes, voir Morabito, 2010a.
Cependant, nos recherches préliminaires sur ce type de monument à travers les corpora des autres provinces occidentales et des régions italiennes ont rapidement démontré le contraire. Nous avons trouvé une vingtaine d'exemples pour l'Occident.

Intéressons-nous en premier lieu à la localisation de ces monuments dans l'aire géographique retenue. Honneur à la capitale provinciale, Cemenelum / Cimiez (fig. 3). Deux stèles de ce type ont été mises au jour dans cette cité et plus particulièrement dans la nécropole dite « suburbaine du Nord » qui marque, par son ampleur, les confins septentrionaux de Cemenelum. Ces deux stèles ont été découvertes lors de l'édification des fondations d'un immeuble en 1962 et transférées dans le musée d'archéologie de Nice - Cemenelum où elles sont présentées au public ${ }^{3}$ (fig. 4 et $\mathbf{5}$ ).

3. Morabito, $2010 \mathrm{~b}, \mathrm{n}^{\circ} 189$ et 192. 


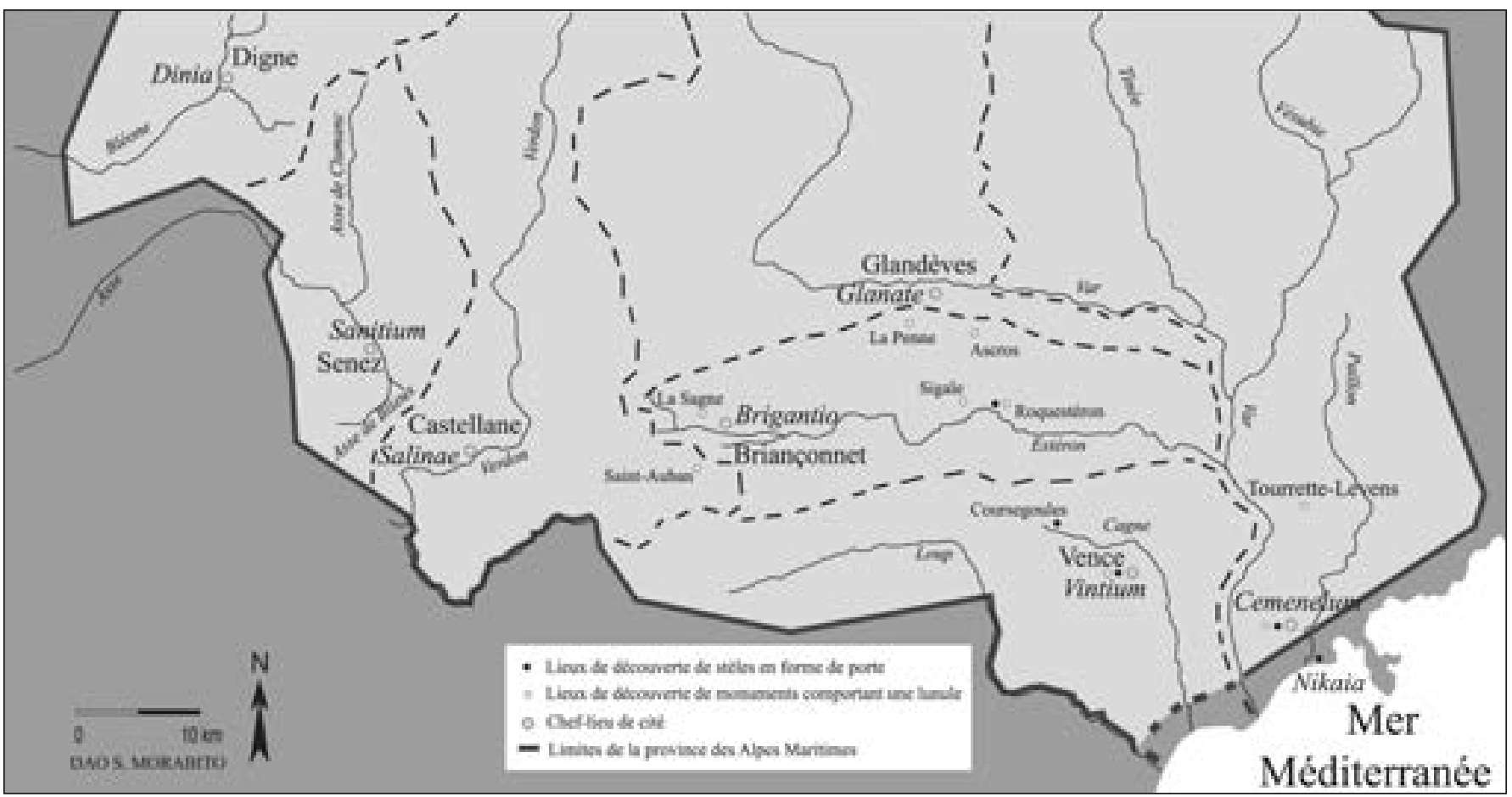

Fig. 3. Localisation des stèles en forme de porte et des monuments à lunule dans la province des Alpes maritimes

Limitrophe de Cemenelum à l'ouest, la cité de Vintium / Vence (fig. 3) possède également dans son territoire deux exemples de ce type de stèles. Mises au jour dans le quartier de l'Autreville, dans la commune de Coursegoules, dans la seconde moitié du XIX ${ }^{\mathrm{e}}$ s., elles ont été détruites par le propriétaire du terrain peu de temps après leur découverte ${ }^{4}$. Nous possédons heureusement un dessin de l'abbé Tisserand qui, s'il offre un détail des monuments et permet de les rattacher à la catégorie des stèles en forme de porte, fait cependant naître des questions quant aux inscriptions qu'ils comportaient (fig. 6). Le dessin de Tisserand a malheureusement été réalisé avant un déterrement complet des stèles et nous prive d'informations supplémentaires.

$\mathrm{Au}$ nord du territoire de Vintium, le municipe de Brigantio / Briançonnet (fig. 3) conserve la dernière stèle en forme de porte découverte à ce jour dans la province des Alpes maritimae. Le lieu exact de trouvaille de cette stèle est inconnu. Elle se situe aujourd'hui sous une voûte encastrée dans le mur d'une maison du village de Roquestéron, dans la vallée de l'Estéron ${ }^{5}$. L'inscription est pratiquement illisible, quelques lettres tout au plus, et une grande partie de la partie inférieure de la stèle a disparu, cachée par les différents rehaussements du niveau de circulation de la ruelle (fig. 7).

Outre la représentation de deux ou quatre caissons superposés et séparés par un trait vertical, symbolisant ainsi les battants d'une porte, nous relevons que trois des cinq stèles possèdent un fronton triangulaire. Nous ne pouvons le préciser pour les deux stèles de Coursegoules (fig. 6), celles-ci n'ayant pas été totalement déterrées au moment de la visite de l'abbé Tisserand, seul auteur à avoir pu les observer ${ }^{6}$.

Deux de ces trois frontons possèdent comme décor une lunule, symbole que l'on rencontre fréquemment sur les monuments funéraires des Alpes maritimae puisque onze monuments ont ce symbole gravé, accompagné parfois d'étoiles comme pour la stèle de Roquestéron. La carte de répartition des monuments comportant des lunules établit qu'ils se concentrent majoritairement dans les mêmes cités que les monuments en forme de porte (fig. 3): Briançonnet avec cinq monuments; Vence avec trois monuments et Cimiez avec deux monuments. Seul un monument comportant une lunule apparaît dans un autre territoire, celui de Castellane, à proximité immédiate de la limite entre cette cité et celle de Briançonnet.

6. Tisserand, 1860, p. 7 et 1862 , p. 48

4. Morabito, $2010 \mathrm{~b}, \mathrm{n}^{\circ} 138$.

5. Morabito, $2010 \mathrm{~b}, \mathrm{n}^{\circ} 57$. 


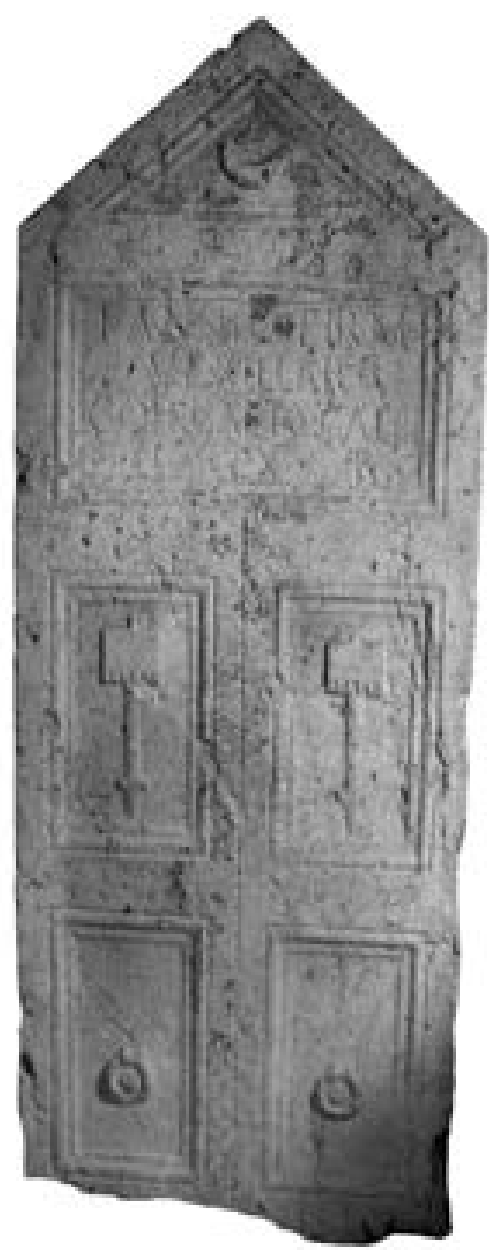

Fig. 4. Stèle en forme de porte dédiée à T. Annius Firmus, découverte à Cemenelum (Cl. S. Morabito).

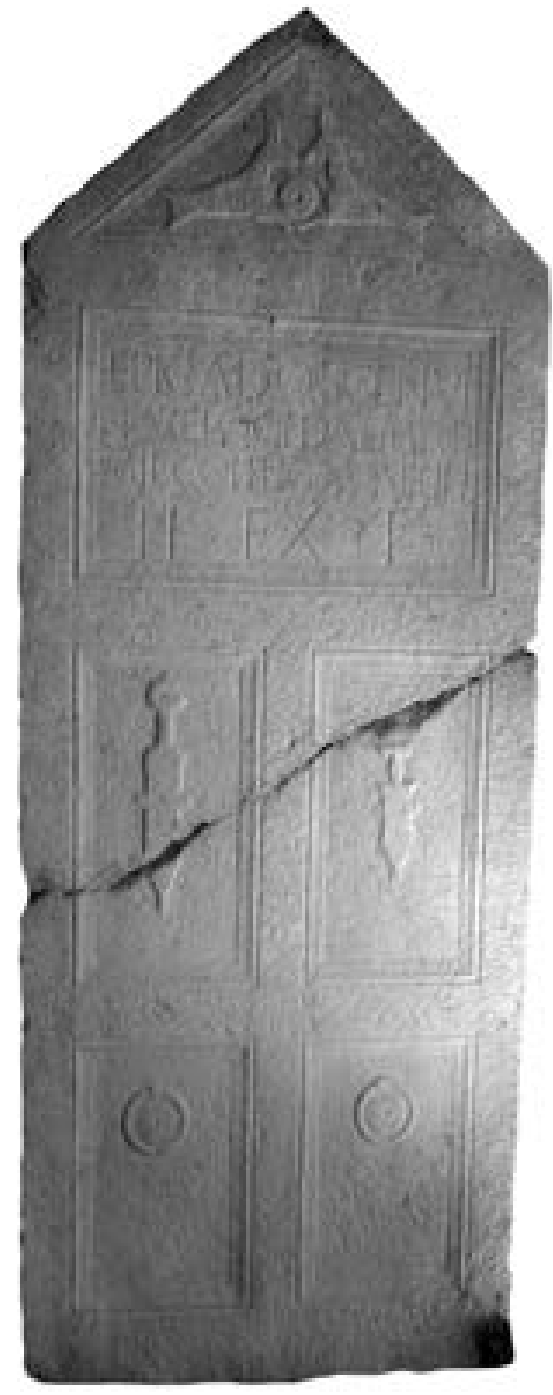

Fig. 5. Stèle en forme de porte dédiée à Epicadus Velox, découverte à Cemenelum (Cl. S. Morabito).

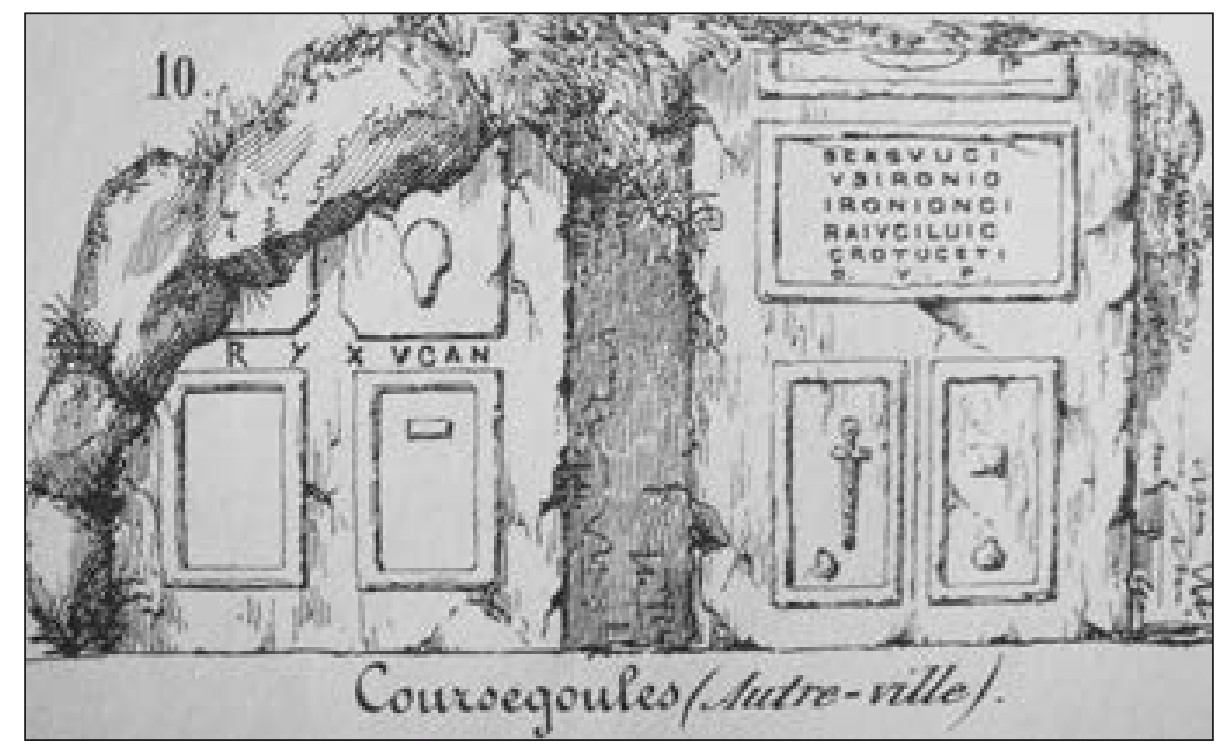

Fig. 6. Reproduction dessin des stèles découvertes à Coursegoules (abbé Tisserand, 1862). 
Autre point commun entre quatre des cinq monuments en forme de porte, la présence de symboles militaires gravés dans les différents caissons présents sous les inscriptions.

La conquête de 14 avant notre ère marque le début du stationnement de cohortes auxiliaires dans les Alpes maritimae avec Cemenelum comme lieu de garnison. Préalablement formée de la cohors Nauticorum et de la cohors Gaetulorum, la garnison a été très tôt augmentée d'une cohorte recrutée localement, la cohors Ligurum. Au plus tard durant le règne de Tibère, les troupes stationnées dans le chef-lieu des Alpes maritimes atteignent un nombre de 1500 hommes. Sous Néron, dans une province où la romanisation est désormais enracinée, la décision a été prise de retirer les cohortes Nauticorum et Gaetulorum et de laisser, seule, la cohors Ligurum. Sans doute durant le règne de Vespasien, cette cohors Ligurum est scindée en deux unités, la cohors prima Ligurum et la cohors secunda Ligurum, avec l'adjonction de contingents extérieurs après une courte durée d'existence. La cohors II Gemina Ligurum et Corsorum a reçu alors un cantonnement en Sardaigne, tandis que la cohors I Ligurum et Hispanorum Ciuium Romanorum va demeurer un temps à Cimiez. Vers la fin du règne de Trajan, la cohors I Ligurum et Hispanorum Ciuium Romanorum est déplacée en Germanie Supérieure, signe que la province et ses habitants ne nécessitaient plus désormais la présence d'une troupe ${ }^{7}$.

Pour les stèles de Cemenelum (fig. 4 et 5), l'une conserve des enseignes ou uexilla pour les caissons supérieurs quand l'autre possède un glaive ou gladius dans le caisson de gauche et un poignard ou pugio dans celui de droite. Les uexilla sont reproduits avec une grande précision : l'étoffe carrée terminée par des franges est placée sur une lance dont la partie inférieure possède un cran d'arrêt servant à limiter l'introduction de la lance en terre. En ce qui concerne les deux épées, la précision est également là : elles sont représentées dans leur fourreau avec les attaches pour les glisser sur un cingulum. Elles sont à pommeau et les cannelures de la poignée du gladius sont également représentées. Les caissons inférieurs de ces deux stèles sont occupés chacun par un décor circulaire évidé qui peut-être un collier ou torquis ou une phalera, ces insignes entrant dans la catégorie des dona militaria. Si les décors de ces stèles ne laissent aucun doute quant à l'appartenance des défunts à la catégorie des militaires, les épitaphes l'assurent. Le premier

7. Morabito, 2010b, p. 56-57. défunt, T. Annius Firmus ${ }^{8}$, était membre de la cohors Gaetulorum. Son rôle de uexillarius au sein de cette cohorte a amené la gravure des uexilla sur sa stèle pour rappeler sa fonction. Le second défunt, Epicadus Velox, fils de Scenus, dont l'onomastique offre peut-être un cas de dénomination pérégrine bi-membre, était membre de la cohorte des Ligures ${ }^{9}$.

En ce qui concerne les autres stèles, celle découverte dans le territoire de Briançonnet (fig. 7) comporte un pugio ainsi que le manche avec pommeau d'une épée indéterminée, le reste des décors étant désormais illisible. Celle mise au jour dans le territoire de Vence (fig. 6) présentait un gladius ainsi que des décors circulaires et un petit rectangle qui rappellent une patera et un uexillum. La dégradation des inscriptions de ces stèles voire la disparition presque totale de celle gravée sur la stèle de Briançonnet ne permet pas d'assurer que ces monuments ont été élevés en l'honneur de militaires, même si nous le supposons fortement.

L'existence dans le territoire marseillais de Nikaia, au sud de la province des Alpes maritimae, d'une stèle en forme de porte comportant un fronton triangulaire, de nombreux attributs militaires et une épitaphe d'un membre de la cohors I Ligurum et Hispanorum Ciuium Romanorum ${ }^{\mathbf{1 0}}$, stationnée dans la cité voisine de Cemenelum, confirme à nouveau la prédilection des auxiliaires stationnés dans les Alpes maritimes pour ce type de monument. Malheureusement, une nouvelle fois, ce monument n'a pu parvenir jusqu'à nous. Inséré dans le pavement d'une église dans le quartier dit du Vieux-Nice, il a été détruit lors de la réfection du sol. Seul un dessin fait par l'abbé Bonifassi ${ }^{11}$ au début du $\mathrm{XIX}^{\mathrm{e}}$ s. permet de connaître ce monument (fig. 8). Une nouvelle fois ce monument comporte une lunule et des

8. T(ito) Annio Firmo, | uexillar(io) | coh(ortis) Gaet(ulorum), (centuria) Galli. | H(eres) ex t(estamento). À Titus Annius Firmus, vexillaire de la cohorte des Gétules, de la centurie de Gallus. Son héritier (fit élever ce monument) selon le testament (Morabito, 2010b, n¹89).

9. Epicado, Scenutis $\mid$ f(ilio), Veloci, Dalmat(ae), $\mid$ mil(iti) coh(ortis) Lig(urum), (centuria) Maelini. |H(eres) ex t(estamento). À Epicadus Velox, fils de Scenus, Dalmate (par son origine), soldat de la cohorte des Ligures, de la centurie de Maelinus. Son héritier (fit élever ce monument) selon le testament (Morabito, 2010b, $\mathrm{n}^{\circ} 192$ ).

10. Sex(to) Vibio C(aii) [f(ilio)] | Seuero, (domo) Suetrio, | militi | coh(ortis) I $\operatorname{Lig}$ (urum) et Hisp(anorum) | C(iuium) R(omanorum), (centuria) Muci(i). Stip(endiorum) XI. | H(eres) ex t(estamento) $\mathrm{f}(\mathrm{ecit})$. À Sextus Vibius Severus, fils de Caius, Suetrius par son origine, soldat de la I $I^{\mathrm{re}}$ cohorte de Ligures et d'Espagnols Citoyens Romains, de la centurie de Mucius. Il a servi onze ans. Son héritier a fait (ce monument) en vertu du testament (CIL V, 7900).

11. Bonifassi, $1808, n^{\circ} 86$ et 105. 


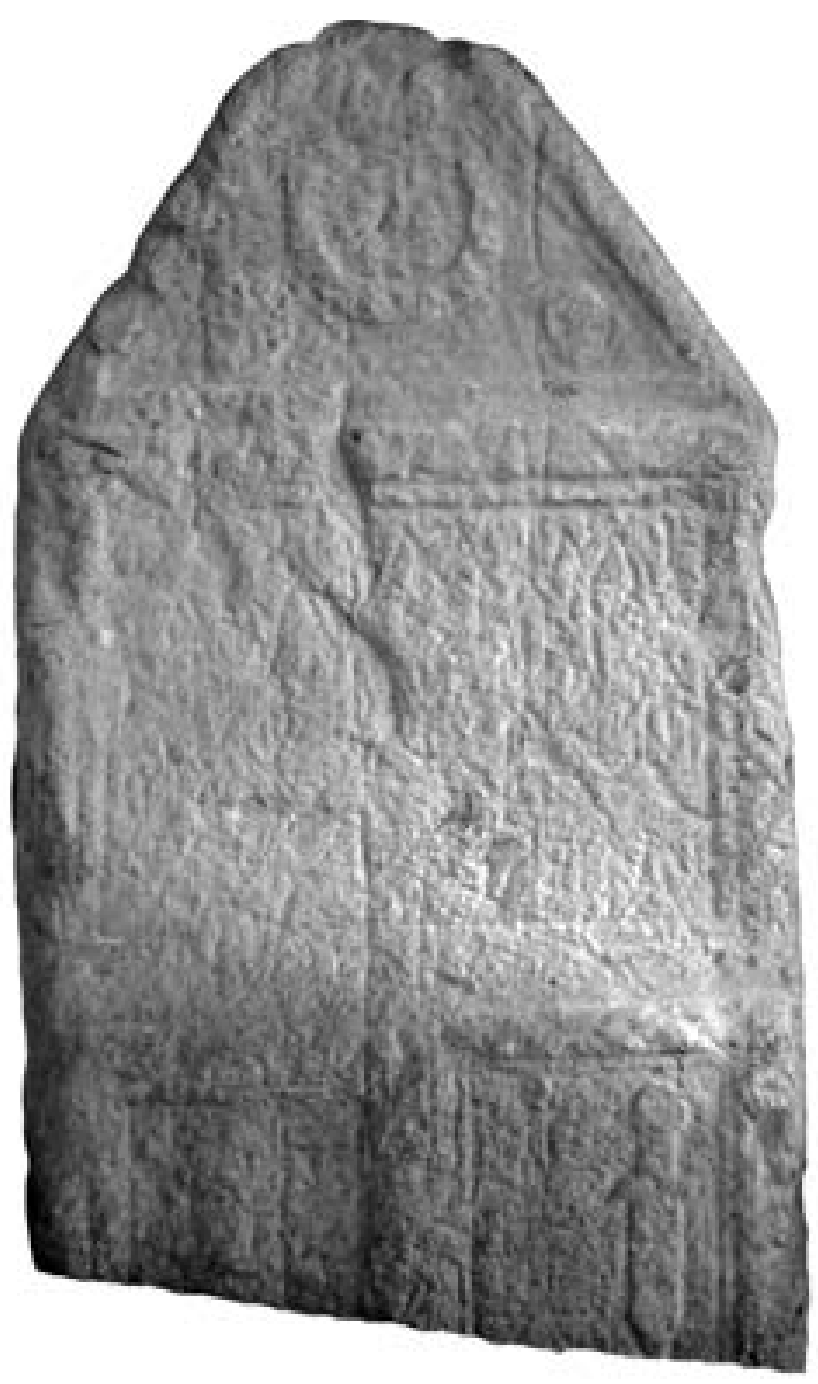

Fig. 7. Stèle présente dans le village de Roquestéron (Cl. S. Morabito).

étoiles dans le fronton, un gladius et un pugio dans les premiers caissons positionnés sous l'inscription, ainsi que des torques et peut-être des uexilla dans les caissons inférieurs. Une originalité apparaît cependant par rapport aux autres stèles, la présence de lances et de flèches de part et d'autre des caissons et du cartouche de l'inscription. Les flèches séparant les caissons dans la partie inférieure ne sont peut-être que l'extrapolation par l'abbé Bonifassi du trait symbolisant la séparation des vantaux de la porte.

Quelles informations est-il possible de retenir de l'étude de ces différentes stèles ?

En premier lieu, ce style de monuments était particulièrement privilégié dans le milieu des auxiliaires originaires ou stationnés dans les Alpes maritimes, même si la disparition totale ou partielle de certaines épitaphes ne permet pas de conclure définitivement pour l'ensemble de ces stèles.

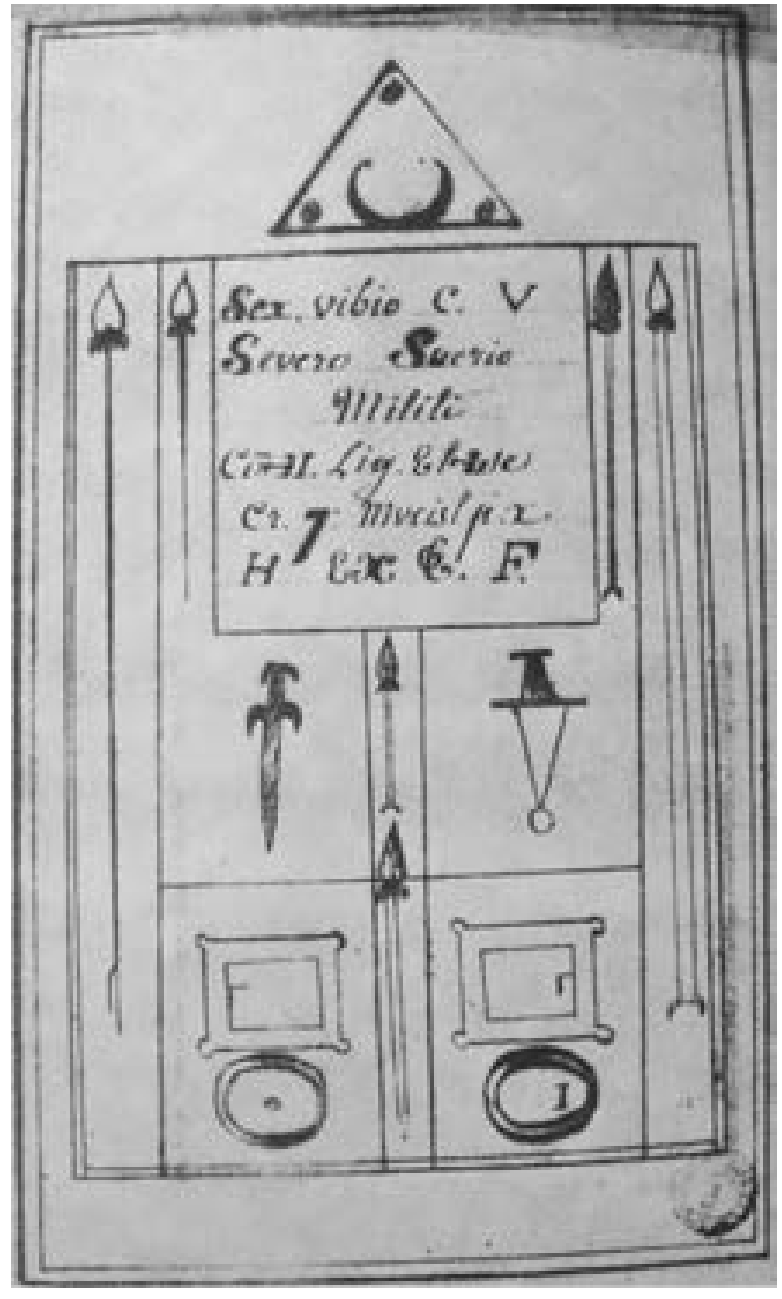

Fig. 8. Reproduction dessin de la stèle découverte dans le pavement de l'église Saint-François, quartier du Vieux-Nice (abbé Bonifassi, 1808).

L'absence de stèles en forme de porte dans les cités mitoyennes des Alpes maritimae, si ce n'est à Nikaia mais pour un auxiliaire engagé dans une cohorte stationnée à Cemenelum, interroge sur l'arrivée de ce type de décor dans notre région. L'origine dalmate d'Epicadus, membre de la cohorte des Ligures, incite à examiner les monuments de sa région d'origine. Les divers corpora et études sur la Dalmatie comportent plusieurs exemples de stèles en forme de fausse porte telles que celles exhumées à Narona ${ }^{12}$, colonie romaine proche du littoral de l'Adriatique et siège d'un conuentus rassemblant treize ciuitates, ou celles découvertes à Tilurium ${ }^{13}$, cité située au nord-ouest de Narona, qui fut le siège de la VII légion dans la première moitié du $\mathrm{I}^{\mathrm{er}} \mathrm{s}$., dont le corpus comporte des stèles de légionnaires de ce type datées des années 40 de notre ère.

12. Dodig, 2005

13. Sanader, 2003 ; Cambi, 2005 et Tončinić, 2007. 
L'observation de quelques-unes des stèles dalmates dévoile une parenté évidente avec celles des Alpes maritimae: fronton triangulaire, inscription dans un cartouche et quatre caissons, superposés deux par deux. Cependant, les stèles dalmates sont plus stylisées. Elles comportent parfois une représentation du défunt. Les épitaphes sont régulièrement encadrées par deux colonnettes et les décors présents dans les frontons et les caissons sont quelque peu différents de ceux observés sur les stèles de notre province: animaux; personnages ; tête de Gorgone, des végétaux, outil ou poignées de porte en forme de tête de lion.

Cette parenté, complétée par l'absence de ces stèles dans le voisinage immédiat de la province des Alpes maritimes, entraînent à envisager une possible transmission de ce style de la Dalmatie vers notre province, par l'intermédiaire d'auxiliaires originaires de la côte orientale de l'Adriatique. Outre une différence de style entre les stèles des Alpes maritimes et de Dalmatie d'une part et celles d'Italie d'autre part, de la $\mathrm{X}^{\mathrm{e}}$ région par exemple (Aquilée, Vérone, Brescia ou Parenzo) ${ }^{14}$ ou de la $\mathrm{VI}^{\mathrm{e}}$ région qui rassemble les cités d'Ombrie ${ }^{15}$, une autre différence apparaît dans l'origine des défunts. Si ceuxci sont en majorité voire exclusivement des militaires pour les Alpes maritimes et la Dalmatie, auxiliaires ou légionnaires, nous observons essentiellement des civils pour les stèles italiennes avec, par exemple dans la cité de Sentinum dans la $\mathrm{VI}^{\mathrm{e}}$ région, cinq femmes sur les six défunts connus par l'intermédiaire de stèle en forme de porte ${ }^{16}$.

Il n'est nullement question d'aller au-delà dans la détermination de l'origine des stèles en forme de porte. L'existence du symbole de la porte dans différentes cultures depuis l'Egypte des pharaons en passant par l'Etrurie, puis l'Italie durant la fin de la période républicaine et la période impériale, avec toujours la symbolisation du transfert de la vie vers le monde des morts, rend plus que difficile la résolution de cette question et dépasse largement ce travail et la documentation étudiée. Nous pouvons seulement envisager qu'une transmission du style apprécié dans le milieu militaire du littoral dalmatien a pu avoir lieu vers le milieu militaire de la plus méridionale des provinces alpines, par l'intermédiaire d'auxiliaires originaires du territoire de l'ancienne peuplade des dalmatae comme Epicadus Velox, membre de la cohorte des Ligures. La période de réalisation des stèles dalmates, dans le courant des

14. Tramunto, 2008a et Verzár, 2009.

15. Antolini, 2000, p. 369-370 et Pentiti, 2000, p. 272-273.

16. Tramunto, 2008b. années 40 de notre ère, contemporaine de celles des Alpes maritimes, élevées entre les règnes de Claude et des Flaviens, sans être un indice incontestable autorise à envisager cette hypothèse.

L'adoption de ce style de stèle pour honorer certains auxiliaires stationnés et décédés à Cemenelum a pu s'accompagner de l'ajout de décors présents dans les monuments funéraires en milieu celtique et particulièrement dans les Alpes maritimes, à savoir la lunule, parfois accompagnée d'étoiles.

L'étude de quelques stèles de la province des Alpes maritimae, sous le regard croisé de la sculpture et de l'épigraphie, est un nouvel exemple de l'intérêt d'associer ces deux spécialités, permettant ainsi de faire apparaître de nouvelles perspectives de recherche.

\section{Bibliographie}

Antolini 2000 : ANTOLINI (S.) - Regio VI - Umbria, Suasa. Supplementa Italica, nuova serie, XVIII, 2000, p. 317-394.

Bonifassi 1808 : BONIFASSI (J.) - Nicienses inscriptiones tum veteres tum recentiores a J. B. collectae, manuscrit, 2 vol., Bibliothèque de Cessole, Nice, 1808 .

Cambi 2005: CAMBI (N.) - Attis or someone else on funerary monuments from Dalmatia? In : Sanader (M.), Miocevic (A.R.) et Toncinic (D.) dir., Religija I mit kao poticaj rimskoj provincijalnoj plastici, Akti VIII Medunarodnog kolokvija o problemima rimskog provincijalnog umjetničkog stvaralaštva, Zagreb (5-8 mai 2003), Zagreb, Golden marketing-Tehnicka knjiga, 2005, p. 511-520.

Dodig 2005 : DODIG (R.) - Afterlife on military monuments in Narona hinterland. In : Sanader (M.), Miocevic (A.R.) et Toncinic (D.) dir., Religija I mit kao poticaj rimskoj provincijalnoj plastici, Akti VIII - Medunarodnog kolokvija o problemima rimskog provincijalnog umjetničkog stvaralaštva, Zagreb (5-8 mai 2003), Zagreb, Golden marketing-Tehnicka knjiga, 2005, p. 205-211.

Morabito 2010a : MORABITO (S.) - Entre Narbonnaise et Italie : le territoire de la province des Alpes maritimes à travers l'antiquité romaine ( ${ }^{\text {er }} \mathrm{s}$. av. n. è. - Ve s. de n. è.). Gallia, 67-2, p. 99-124.

Morabito 2010b : MORABITO (S.) - Inscriptions latines des Alpes maritimes (ILAM), Nice/Montpellier, IPAAM/CERCAM, 2010, 530 p. (Mémoires IPAAM, Hors série VI).

Pentiti 2000 : PENTITI (G.A.) - Regio VI - Umbria, America. Supplementa Italica, nuova serie, XVIII, 2000, p. 191-315.

Sanader 2003 : SANADER (M.) - Grabsteine der legio VII aus Tilurium - Versuch einer Typologie. In : Noelke (P.), Schneider (B.) et NaumannSteckner (F.) dir., Romanisation und Resistenz : in Plastik, Architektur und Inschriften der Provinzen des Imperium Romanum, Akten des VII. internationalen Colloquiums über Probleme des provinzialrömischen Kunstschaffens, Köln (2-6 Mai 2001), Mainz am Rhein, Éd. Ph. Von Zabern, 2003, p. 501-510. 
Tisserand 1860 : TISSERAND (E.) - Histoire de Vence, Paris, Éd. E. Belin, $1860,311 \mathrm{p}$.

Tisserand 1862 : TISSERAND (E.) - Histoire civile et religieuse de la cité de Nice et du département des Alpes-Maritimes, 2 tomes, Nice, Éd. Visconti et Delbecchi, 1862, 320 p.

Tončinić 2007 : TONCINIC (D.) - Werkzeugdarstellungen auf einer Grabstele aus Tilurium. In : Walde (E.) et Kainrath (B.) dir., Die Selbstdarstellung der römischen Gesellschaft in den Provinzen im Spiegel der Steindenkmäler, IX. Internationales Kolloquium über Probleme des provinzialrömischen Kunstschaffens, Innsbruck (25-28 mai2005), Innsbruck, Éd. Innsbruck university press, 2007, p. 259-264.

Tramunto 2008a: TRAMUNTO (M.) - Le Ianuae Ditis della decima regio augustea: una puntualizzazione. In: Basso (P.), Buonopane (A.), Cavarzere (A.) et Pesavento Mattioli (S.) dir., Est enim ille flos italiae... Vita economica e sociale nella Cisalpina romana, Atti delle Giornate di studi in onore di Ezio Buchi, Verona (30 novembre - 1 dicembre 2006), Verona, Éd. QuiEdit, 2008, p. 521-525.

Tramunto 2008b: TRAMUNTO (M.) - Le portae Ditis di Sentinum. Bertinelli (A.), Gabriella (M.) et Donati (A.) dir., La comunicazione nella Storia antica : fantasia e realtà, Atti del III Incontro Internazionale di Storia Antica, Genova (23-24 novembre 2006), Roma, Éd. G. Bretschneider, 2008, p. 255-258.

Verzár 2009 : VERZAR (M.) - La produzione di scultura calcarea di Aquileia e il rapporto con le province limitrofi : l'esempio delle stelle. In : GaggadisRobin (V.), Hermary (A.), Redde (M.) et Sintes (C.) dir., Les ateliers de sculpture régionaux: techniques, styles et iconographie, Actes du $\mathrm{X}^{\mathrm{e}}$ colloque international sur l'art provincial romain, Arles et Aix-en-Provence (21-23 mai 2007), Aix-en-Provence / Arles, Centre Camille Jullian / Musée départemental Arles antique, 2009, p. 169-178. 



\title{
Espaces et monuments funéraires en Arles : autour des stèles à portraits ${ }^{1}$
}

\author{
À la mémoire de notre collègue et ami, Gilles Ghiringhelli, \\ responsable des réserves lourdes au M.D.A.A., disparu en janvier 2014, à qui cette étude doit tant.
}

\author{
Vassiliki Gaggadis-Robin \\ CNRS - Centre Camille Jullian - MMSH \\ Gaggadis@mmsh.univ-aix.fr \\ Marc Heijmans \\ CNRS - Centre Camille Jullian - MMSH \\ heijmans@wanadoo.fr
}

\section{Résumé}

Cette étude concerne un petit nombre de stèles ( $\left.\mathrm{n}^{\mathrm{os}} 1-6\right)$ et un autel funéraires $\left(\mathrm{n}^{\circ} 7\right)$, avec portraits et inscriptions. Ces documents ont été découverts en remploi à Arles ou dans son territoire et ne peuvent pas être mis en relation avec une nécropole. Au point de vue typologique prédomine la stèle à édicule et fronton ouvert en forme de coquille. Le portrait du défunt seul, en couple ou en famille figure sur la stèle qui peut avoir plusieurs registres $\left(\mathrm{n}^{\circ} 2\right)$. Ce type, présent également à Nîmes, semble proche des productions de l'Italie du Nord. La majorité des documents peut être datée dans la première moitié du Ir $\mathrm{s}$. de n. è. et représente pour certains les premiers portraits de citoyens d'Arles.

Mots-clés : Sculpture, épigraphie, iconographie, portrait, attribut professionnel, Arles, Narbonnaise, Haut-Empire.

\begin{abstract}
This study concerns a small number of funeral stelai (nr.1-6) and a funeral altar (nr.7) with portraits and inscriptions. These documents were discovered in re-use in Arles, or in its territory and cannot be put in connection with a necropolis. In the typological point of view prevails the stele with aedicula and opened pediment in the shape of a shell. The portrait of the deceased alone, in couple, or in family appears on the stele which can have several registers (nr.2). This type, present also in Nimes, seems close to the productions from North Italy. The major part of these documents can be dated in the first half of 1st c. A. D., some of them represent the first portraits of citizens of Arles.

Key-words: Sculpture, epigraphy, iconography, portrait, professional attribute, Arles, Narbonnaise, the Early Roman Empire.
\end{abstract}

1. Nous remercions très vivement les collègues qui nous ont aidés dans notre étude : Alain Charon, Conservateur du Patrimoine au M.D.A.A. ainsi que Dominique Darde, Conservateur et Cécile Carrier, Attachée de conservation, au Musée Archéologique de Nîmes. 


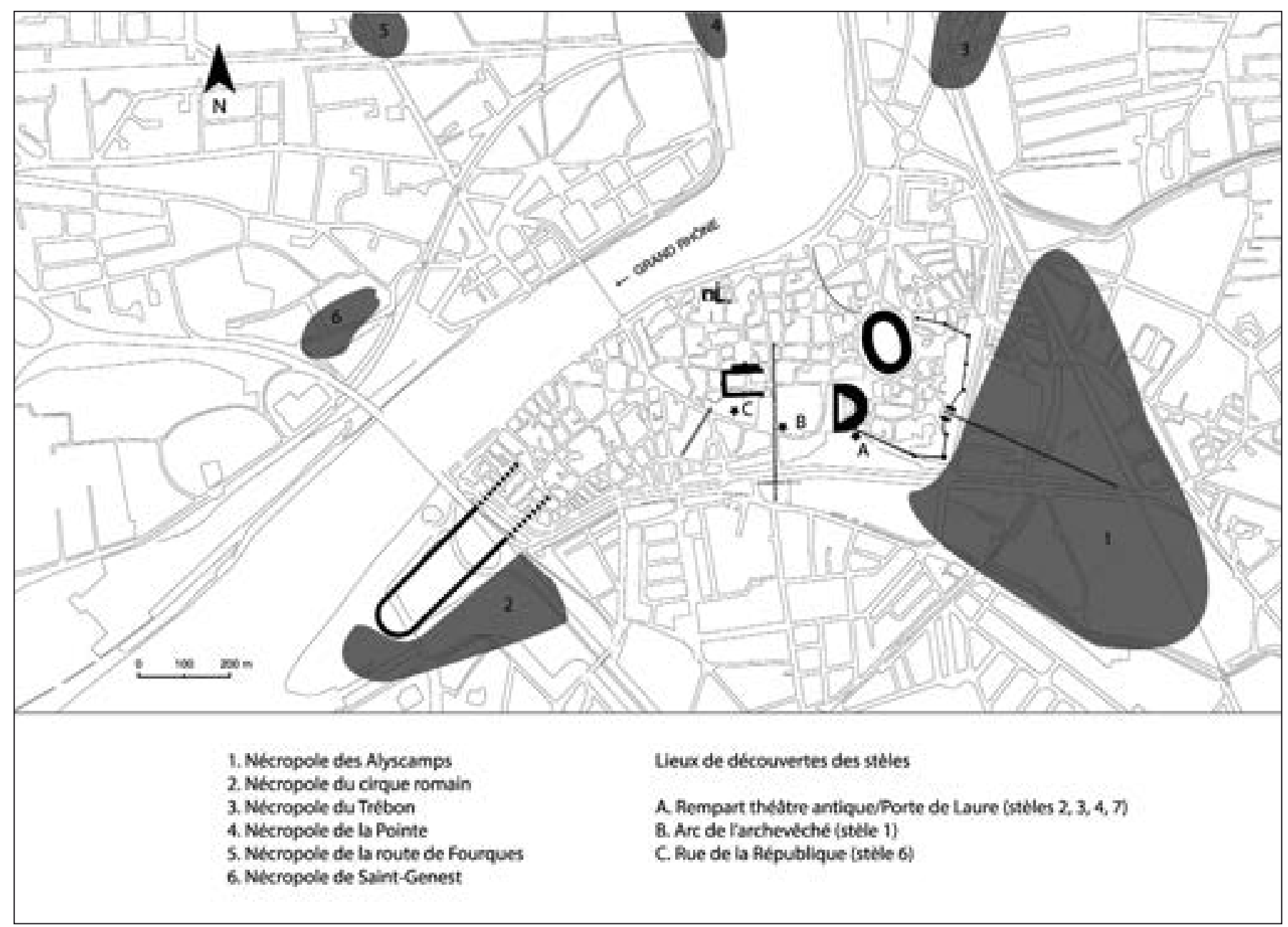

Fig. 1. Nécropoles d'Arles (৫ M. Heijmans).

L e petit nombre de stèles funéraires (six) analysées ici forme un groupe homogène par leurs matériaux, le calcaire local, ainsi que par leur iconographie, groupe auquel on peut associer un autel funéraire en marbre. Ces documents sont de forme simple, pour la plupart à édicule et comportent un ou plusieurs bustes-portraits, ainsi qu'une inscription. D'exécution plus ou moins raffinée, ils ont été probablement produits par des ateliers locaux. Bien que tous aient été répertoriés par E. Espérandieu, ils n’ont jamais fait l'objet d'une étude particulière.

Comme la majorité des inscriptions et stèles funéraires du Musée d'Arles, les pièces présentées ici n'ont pas été trouvées in situ, mais ont été remployées dans le rempart qui relie, depuis la fin de l'Antiquité, la tour d'angle (tour des Mourgues) au théâtre antique, donc au sud de la ville (fig. 1). On ignore par conséquent où elles se trouvaient à l'origine. Toutefois, il est probable que ces stèles proviennent de la vaste nécropole des Alyscamps, qui se développe depuis la fin du $\mathrm{I}^{\text {er }}$ s. av. J.-C. au sud-est de la ville, le long de la voie Aurélienne. Cette nécropole a particulièrement souffert depuis le $\mathrm{XVIII}^{\mathrm{e}} \mathrm{s}$. des aménagements divers et variés, qui ont certes livré quantité d'objets lapidaires, mais qui ont détruit à jamais les vestiges des mausolées ou des enclos funéraires, dans lesquels il faut sans doute restituer ces stèles. Les autres nécropoles arlésiennes, celle dite du Plan-du-Bourg ou du Cirque romain, au sud-ouest de la ville, ou les nécropoles situées rive droite, dans le quartier de Trinquetaille, ne sont guère mieux connues. Seule la fouille préalable à la construction du Musée archéologique, en 1989, a permis d'étudier sur une superficie importante l'extrémité sud-ouest de la nécropole du Cirque. Si cette fouille a bien livré des restes de monuments funéraires, les éléments lapidaires sont assez pauvres.

On ne peut pour l'instant qu'étudier ces stèles pour elles-mêmes, avec le décor et le texte qui les accompagnent. Nous avons joint à cette présentation une stèle 

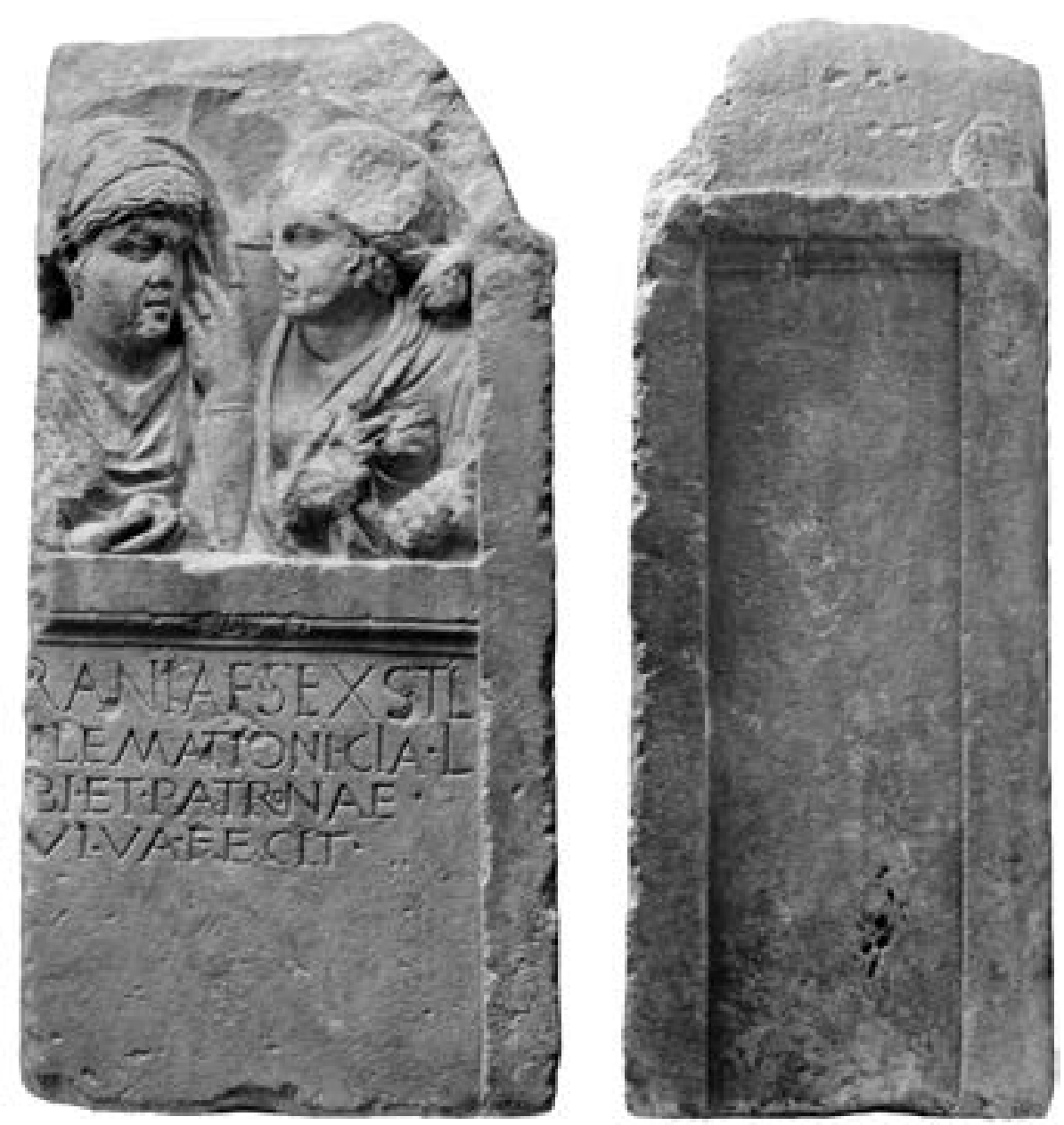

Fig. 2. Stèle de Turrania Philematio et de Chia. Face principale (ci-dessus à gauche). Fig. 3. Côté droit (ci-dessus à droite). Arles, M.D.A.A. (๔) Loïc Damelet, CNRS, CCJ).

qui ne provient pas de la ville d'Arles, mais de son territoire, montrant ainsi que les modèles urbains sont également repris à la campagne.

\section{Stèle de Turrania Philematio et de Chia (fig. 2-6)}

La première stèle ${ }^{2}$ appartient au type à édicule et fronton ouvert en forme de coquille Saint-Jacques, et est en calcaire beige assez fin (fig. 2). Très endommagée, seule la partie droite est conservée, puisque la stèle a été sciée à gauche verticalement, probablement lors d'un remploi. Pour avoir la largeur d'origine, on pourrait rajouter à

2. Elle a été découverte en remploi dans l'arc de l'Archevêché en 1810. Au M.D.A.A. Inv. FAN.92.00.149. H. : $117 \mathrm{~cm}$, L. : 54, 1. : $39 \mathrm{~cm}$ : CIL XII, 891, Espérandieu 1907, p. 155 n 197 ; CAG $13 / 5$, p. $268 n^{\circ} 4$, fig. 140. gauche $17 \mathrm{~cm}$. Un bandeau plat ${ }^{3}$, assez large qui encadre la stèle sépare le champ figuré du champ épigraphique. Sur le petit côté droit (fig. 3) où il se retrouve également, il est décoré sur sa partie supérieure d'une moulure à baguette soulignée d'un filet. La stèle semble endommagée sur sa partie inférieure. De même de nombreuses épaufrures se retrouvent sur les vêtements, les visages, les mains des personnages. Des traces de polychromie sont encore conservées sur les visages et les cheveux. Sur le petit côté restent quelques traces des chapiteaux et des acrotères qui donnent une allure davantage architectonique au monument.

Deux femmes représentées en buste côte à côte échangent un regard (fig. 4). Celle de gauche, vue de trois quarts vers la droite, semble être la plus âgée. Elle est habillée d'une tunique et d'un manteau qui

3. Largeur: $8 \mathrm{~cm}$. 


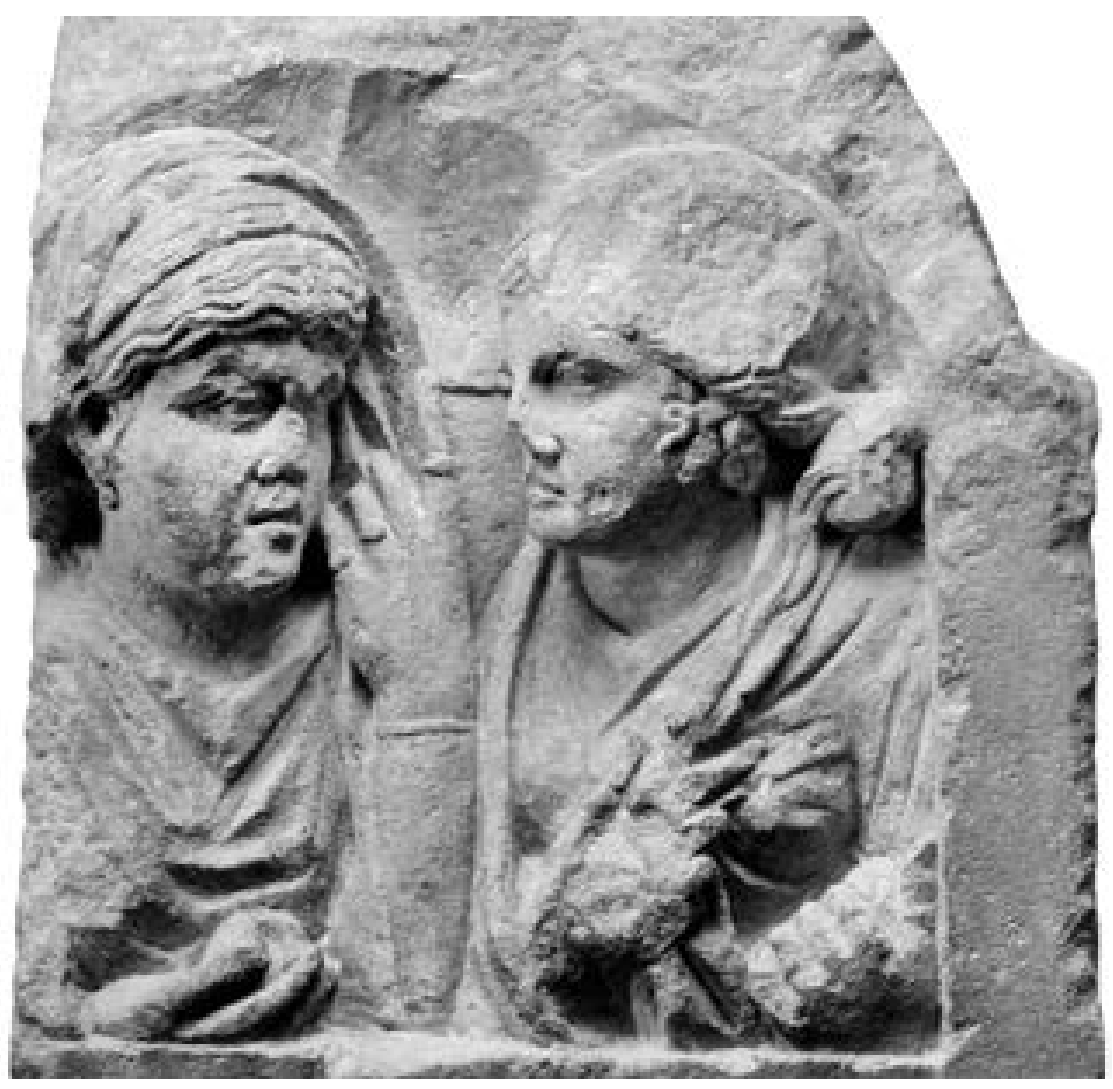

Fig. 4. Stèle de Turrania Philematio et de Chia. Détail des bustes. Arles, M.D.A.A.

(๔ Loïc Damelet, CNRS, CCJ).
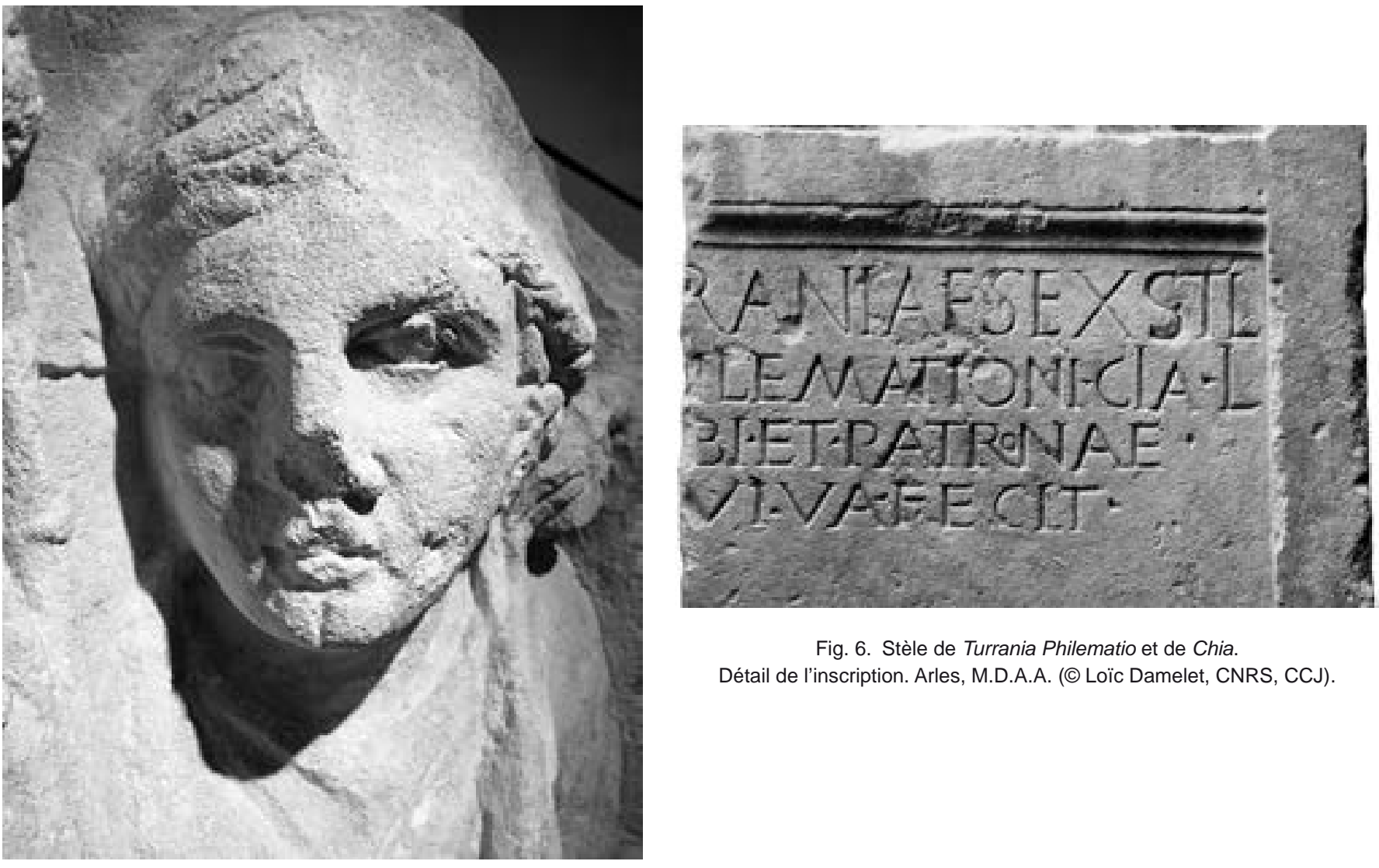

Fig. 6. Stèle de Turrania Philematio et de Chia.

Détail de l'inscription. Arles, M.D.A.A. (৫) Loïc Damelet, CNRS, CCJ).

Fig. 5. Stèle de Turrania Philematio et de Chia. Détail du visage de la femme de droite (Chia). Arles, M.D.A.A. (৫) Loïc Damelet, CNRS, CCJ). 
remonte sur sa tête comme un voile, dont, de sa main gauche, elle écarte un pan de son visage, suivant un schéma qu'on retrouve dès l'époque classique sur les stèles grecques ; ce geste indique une femme mariée. Elle porte des boucles d'oreille de forme circulaire, à son bras gauche un bracelet simple et à sa main trois bagues ${ }^{4}$. Elle tient dans sa main droite un fruit, peut-être une pomme ${ }^{5}$. Son visage est ovale avec des joues bien en chair, la bouche petite et charnue est entrouverte, le menton est petit et arrondi. Les yeux en amande ont des paupières ourlées. Un sillon doux part des narines vers le menton. Les arcades sourcilières épaisses, aujourd'hui abimées, voilaient d'ombre les yeux. Ses cheveux volumineux, ondulés, se partagent de part et d'autre d'une tresse assez large au milieu du front. Entre le voile qui couvre la partie supérieure de la tête et la masse de cheveux figure un autre élément assez volumineux occupant toute la largueur de la tête, traité par des stries horizontales assez profondes. Il s'agit peut-être d'une tresse qui ceint le haut de la tête. Ce type de coiffure assemblant des cheveux probablement attachés en chignon et ornée de tresses se retrouve au début du ${ }^{\text {er }}$ s. ${ }^{6}$

La femme de droite semble plus jeune (fig. 4). Elle est habillée également d'une tunique et d'un manteau qui ne lui couvre pas la tête. Son visage est de plus petite taille et les traits sont moins marqués. La fossette du menton est indiquée par une incision verticale. Ses cheveux longs serrés par un bandeau (visible au niveau du chignon), sont ramenés en deux rouleaux qui se rejoignent en un chignon bas sur la nuque. Trois mèches folles couvrent l'oreille gauche. Elle tient dans sa main droite un pan de son manteau qui couvre ses épaules, et dans l'autre elle tient un objet indéfinissable, peut-être un bout de son manteau. Elle porte également trois bagues sur sa main gauche. La partie droite du visage (fig. 5) vers le fond de la stèle, certainement à cause du manque de place qui ne permettait pas de sculpter la forme entièrement, est un peu déséquilibrée, l'œil droit est plus large que l'œil gauche. De telles maladresses sont courantes même sur des stèles funéraires de meilleure exécution, comme par ex. sur une stèle funéraire de Frascati ${ }^{7}$. Malgré l'aspect aplati des vêtements, le traitement des visages témoigne

4. Sur l'index, l'annulaire et le petit doigt.

5. La pomme, tout comme la grenade, tenue souvent par les défuntes, est un symbole de fertilité : Pflug 1989, p. 101. Voir la stèle d'Aquilée, Musée National 5149: Pflug 1989, p. 192-193 $\mathrm{n}^{\circ} 91$, pl. 19, 3 .

6. Musée du Louvre Ma 3469 : Kersauson 1986, p. 116 n52.

7. Au musée du Louvre Ma 3493 : Kersauson 1986, p. 40-41 $\mathrm{n}^{\circ} 15$. Il s'agit d'une stèle à trois personnages. Une oreille manque à l'homme du centre, celui de gauche a son oreille gauche sculptée à plat sur le fond du relief. d'une très bonne maîtrise de la taille. Elégance, sobriété, ainsi qu'un certain 'classicisme' se dégagent de cette œuvre.

Les quatre lignes de l'inscription (fig. 6) ont été gravées dans la partie supérieure du champ préparé. La hauteur des lettres ${ }^{8}$ diminue entre la première et la dernière ligne. La gravure est de bonne qualité et ne pose pas de problème de lecture.

\section{[Tur]RANIAE*SEXST(i) L(ibertae) [Ph]ILEMATIONI C(h)IA*L(iberta) [si]BI*ET*PATRONAE}

\section{VIVA*FECIT}

A Turrania Philematio, affranchie de Sextus. Chia, son affranchie, a fait ce tombeau de son vivant pour ellemême et pour sa patronne.

Il s'agit d'une épitaphe érigée par Chia à sa patronne, qu'il faut probablement reconnaître en la personne de gauche sur la stèle, celle qui est la plus âgée. Les noms des deux femmes, d'origine grecque, les situent bien dans le monde servile. Philematio est un nom dérivé du mot philema $(\phi i ́ \lambda \eta \mu \alpha)$ «baiser », utilisé en latin par Lucrèce (De rerum natura, IV, 1169), alors que la courtisane Philematium est l'un des personnages importants dans la Mostellaria de Plaute. Ce cognomen n'est pas inconnu en Narbonnaise, où on connaît une Titia Philematio, à Uzès (CIL XII, 2958) et peut-être une autre à Nîmes (ILGN, 499), alors qu'à Rome, on dénombre au moins 57 attestations ${ }^{9}$.

Quant au nom de son affranchie, Cia, il est aussi d'origine grecque. En supposant que le lapicide a omis un « $\mathrm{h}$ », comme on fait depuis l'édition du CIL, on restitue Chia, nom dérivé de l'île de Chios, d'où serait originaire la jeune fille. Le nom est bien attesté, en particulier en Italie ${ }^{\mathbf{1 0}}$. Enfin, le nom du patron de Philematio, Sexstus Turannius, n'est pas inconnu à Arles, où on trouve ce nom deux autres fois (CIL XII, 821 et 892). En Narbonnaise, ce nom est attesté, en dehors d'Arles, uniquement à Narbonne, également deux fois (CIL XII, 4522 et 4552 ), mais il est fréquent en Italie ou en Dalmatie $^{11}$. On peut rapprocher à ce nom le cognomen d'Iulia Tyrannia (CIL XII, 832) qui semble être un cas

8. H. des lettres : $1^{\mathrm{e}}$ ligne $: 5,5 \mathrm{~cm}, 2^{\mathrm{e}}: 4 \mathrm{~cm}, 3^{\mathrm{e}}$ et $4^{\mathrm{e}}: 3 \mathrm{~cm}$.

9. Solin 1982, p. 1258.

10. OPEL II, p. 53 ; Solin 1982, p. 596.

11. OPEL IV, p. 134. 
unique dans les provinces occidentales de l'empire ${ }^{\mathbf{1 2}}$, alors qu'on connaît quelques personnes de ce nom à Rome ${ }^{13}$.

Date : Ce type de stèle, à fronton ouvert, se retrouve fréquemment en Italie du Nord, plus particulièrement une petite série issue d'Altino ${ }^{14}$ datée dans la première moitié du Ir $\mathrm{s}$., présente les mêmes caractéristiques. La stèle représentant deux femmes se retrouve ailleurs en Narbonnaise, à Nîmes et aux environs ${ }^{15}$, mais sans que la relation entre les personnages y soit exprimée par la position ou le regard. La coiffure peut dater la stèle d'Arles des premières décennies du ${ }^{\text {er }} \mathrm{s}$., car elle est proche des celles des impératrices Julio-Claudiennes et pour la femme de droite notamment d'Agrippine la Jeune. Cette datation n'est pas contredite par l'inscription, comme le montre la graphie qui présente certains archaïsmes (Sexstus au lieu de Sextus).

\section{Stèle familiale à deux registres (fig. 7-10)}

Cette stèle ${ }^{16}$ est taillée dans un calcaire coquillier, comme on le voit clairement sur le visage de la femme. Il s'agit d'une stèle familiale à niches et fronton ouvert en forme de coquille, mais présentant deux registres à portraits et inscriptions (fig. 7). Le petit côté gauche a été retaillé. Le bandeau plat ${ }^{17}$ de la face principale et la moulure ${ }^{18}$ continuent également sur le petit côté droit et sur l'arrière. Si on observe la direction des cannelures de la coquille, la femme paraît être placée à son centre. Étant donné que la stèle a été sciée à gauche, on peut restituer à cette partie manquante un troisième buste, probablement celui d'une femme comme l'inscription semble nous l'autoriser ${ }^{19}$. À côté de l'épaule de la femme restent les plis assez larges d'un manteau, comme celui de l'homme de droite. Il semble que la figure n'était pas voilée.

12. OPEL IV, p. 136.

13. Solin 1982, p. 1006.

14. Pflug 1989 , p. $220-221$ n $^{\text {os }} 162-165$, pl. 25,$3 ; 27,4$.

15. Stèle de Nîmes, sur laquelle les femmes sont placées côte à côte : CIL XII, 3498 ; Espérandieu 1907, p. 317 n475 ; et Espérandieu 1925, p. 147 n $^{\circ} 6803$. La même remarque vaut pour une stèle découverte à Saint-Geniès-de-Malgoires (Gard) : CIL XII, 3031 ; Espérandieu 1907, p. 330 n503.

16. Découverte en 1908 dans un ancien mur du rempart, situé en face du théâtre antique. Au M.D.A.A. Inv. FAN.92.00.159. H. : $173 \mathrm{~cm}$, L. : $58 \mathrm{~cm}, 1$. : $49 \mathrm{~cm}$ : Espérandieu 1908, p. 453 n ${ }^{\circ} 1695$; CAG 13/5, p. $264 \mathrm{n}^{\circ} 52$, fig. 130 .

17. Largeur : $8 \mathrm{~cm}$.

18. Largeur : $3 \mathrm{~cm}$.

19. La stèle devait avoir plus de $16 \mathrm{~cm}$ ( 8 pour le corps +8 pour le bandeau).

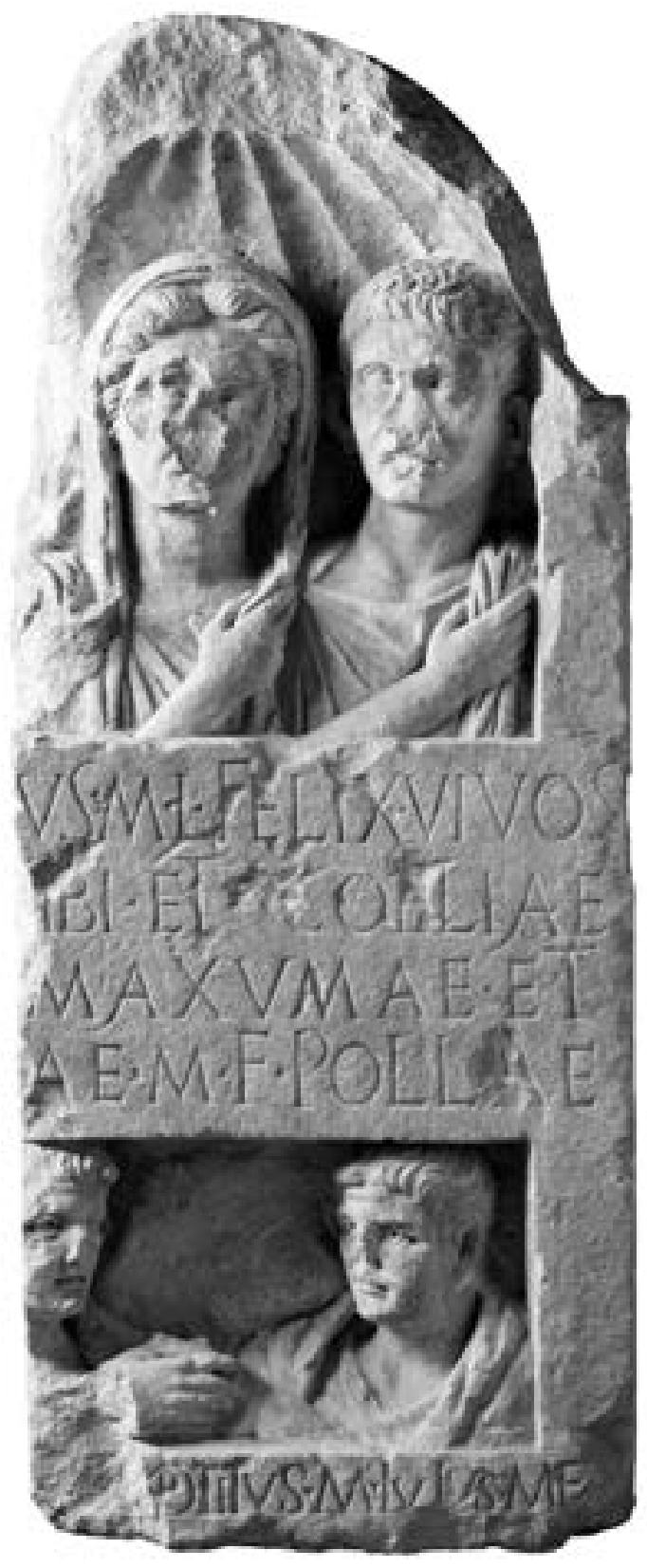

Fig. 7. Stèle familiale à deux registres. Arles, M.D.A.A. (๑) Philippe Groscaux, CNRS, CCJ).

Un couple figure dans le registre supérieur (fig. 8). Tous deux, vus de face, sont habillés d'une tunique et d'un manteau. (H. des têtes, en haut $24 \mathrm{~cm}$, en bas : $16 \mathrm{~cm})$. La femme voilée pose sa main droite, tenant un pan de son manteau, sur son épaule gauche. L'homme fait exactement le même geste de sa main droite. Leurs bras assez plats semblent surgir du cadre. La femme a un visage large, marqué par deux rides sur le front ; ses joues et son menton sont assez plats et géométriques. Ses yeux sont grands, les paupières sont ourlées. Sa tunique forme un pli doux triangulaire au niveau du cou. 


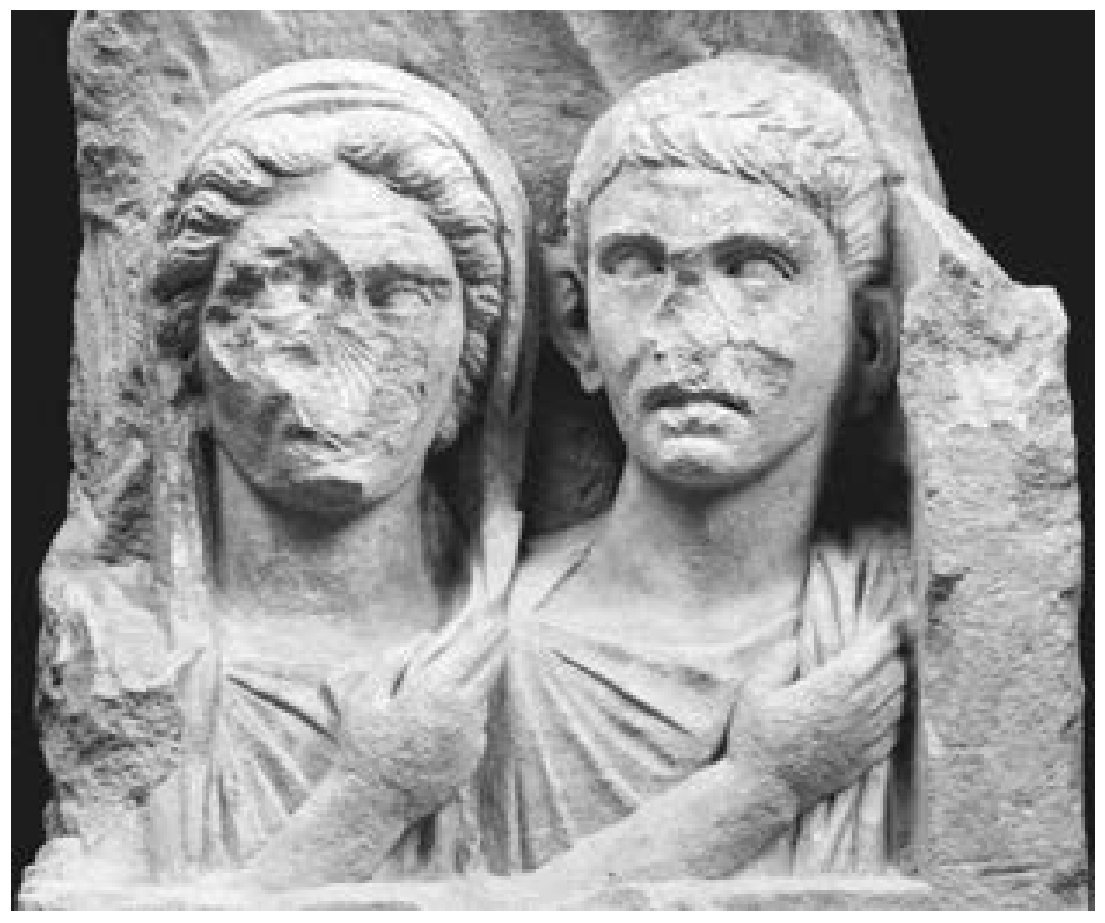

Fig. 8. Stèle familiale à deux registres.

Détail du registre supérieur. Arles, M.D.A.A. (৫) Philippe Groscaux, CNRS, CCJ).

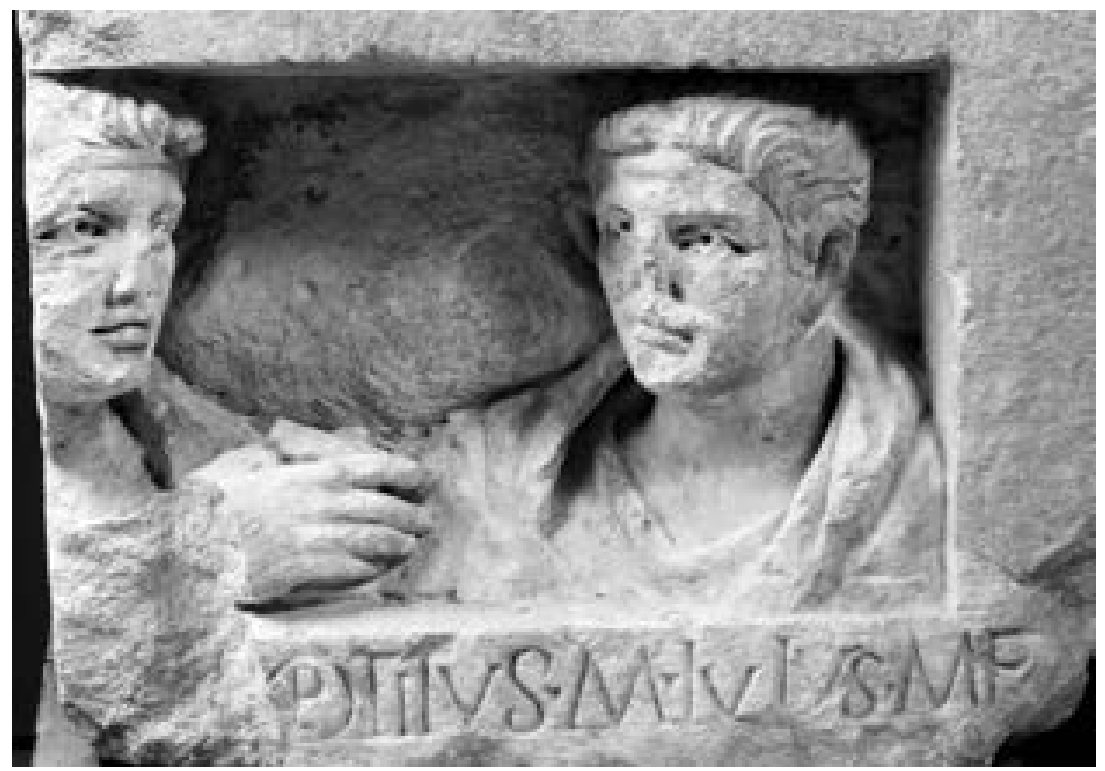

Fig. 9. Stèle familiale à deux registres. Détail du registre inférieur. Arles, M.D.A.A. (๑) Philippe Groscaux, CNRS, CCJ).

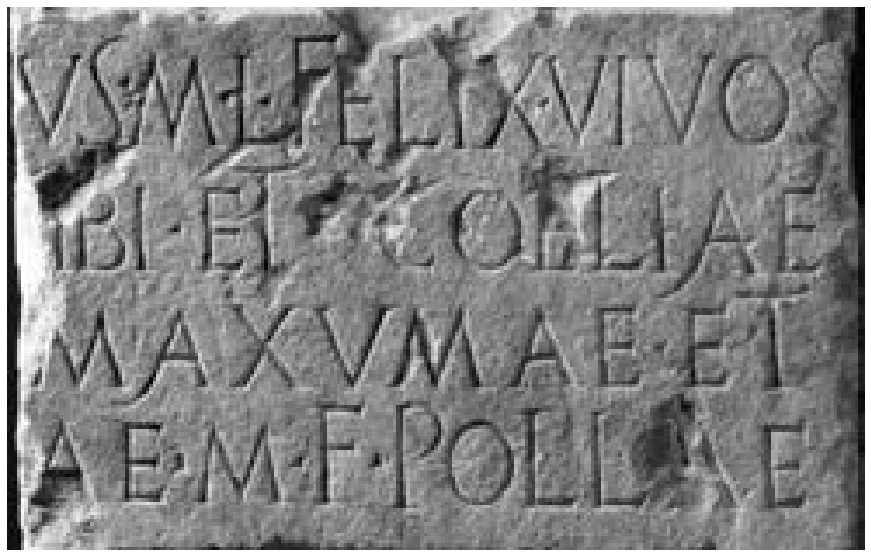

Fig. 10. A. Stèle familiale à deux registres. Détail de l'inscription supérieure. Arles, M.D.A.A.

(๔ Philippe Groscaux, CNRS, CCJ).

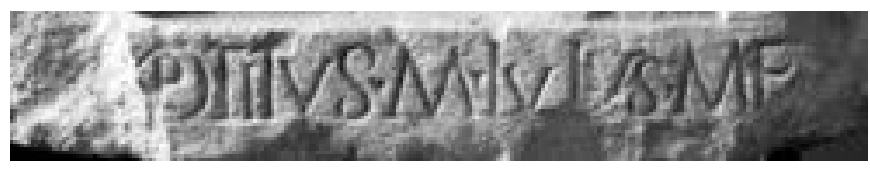

Fig. 10. B. Stèle familiale à deux registres. Détail de l'inscription inférieure. Arles, M.D.A.A. (@ Philippe Groscaux, CNRS, CCJ). 
Sa coiffure présente des petites mèches striées en petites touffes encadrant le visage à partir du milieu du front. En fait il s'agit d'une coiffure augustéenne, où les cheveux longs sont ramenés vers l'avant du visage et répartis en deux mèches enroulées autour d'un bandeau qui reste invisible, et encadrent le visage ${ }^{20}$. Une des sphinges du mausolée carré de Fourches-Vieilles à Orange présentant la même coiffure ${ }^{21}$ est un autre exemple régional.

L'homme dont la tête est tournée légèrement vers sa droite, a un visage jeune, ovale, aux joues larges, au menton petit et arrondi, une petite ride discrète sillonne son front. Ses yeux en forme d'amande ont une pupille globulaire, la paupière supérieure est ourlée. Sa bouche est petite, ses lèvres semblent entrouvertes, les oreilles sont grandes et décollées. Sur le cou assez fin les muscles sont indiqués. La coiffure est courte, traitée en plusieurs rangées de petites mèches fines dirigées vers le front, où elles sont disposées de part et d'autre d'une petite fourche située au-dessus de l'œil droit. Cette coiffure, proche de celle d'un portrait d'Auguste ${ }^{22}$, nous autoriserait à dater la stèle du début du I ${ }^{\mathrm{er}}$ s., vers $10-20$ de notre ère. Sur certaines stèles de l'Italie du Nord ${ }^{23}$, les figures en toge avec des plis larges et assez plats, sont datés également du début du $\mathrm{I}^{\mathrm{er}} \mathrm{s}$. en comparaison à des togati des monuments publics.

Dans le registre inférieur (fig. 9) se trouvent les bustes des deux jeunes hommes, qui se donnent la main, en échangeant un regard. Ils portent tunique et manteau, les plis d'un manteau épais, certainement une toge, enveloppent largement le dos de l'homme de droite. Leurs visages sont larges, les bouches petites aux lèvres sinueuses et entrouvertes, laissant apparaître les dents, (à gauche). Les iris sont percés d'un coup de foret. Les oreilles du personnage de droite sont grandes, son oreille droite est sculptée en partie sur le fond de la plaque. La coiffure est courte également, traitée en petites mèches, portées vers le front, mais plus aplaties et sèches. Une ride assez profonde et large barre le front de chaque personnage. Ces éléments peuvent dater ces deux portraits un peu plus tard que les portraits de la niche supérieure,

20. Voir le portrait du Louvre Ma 3445 : Kersauson 1986, p. 72 $\mathrm{n}^{\circ} 31$, mais qui présente un nodus frontal des cheveux qui n'existe pas sur la stèle.

21. Gaggadis-Robin, Mignon, Zugmeyer 2009.

22. Louvre Ma 1276 : Kersauson 1986, p. 88-89 n³8.

23. Pflug 1989, p. 23, voir la stèle de Gavaseto, au musée de Bologne : Pflug 1989, p. 170-171 n45, pl. 10, 1-2. vers 40-50 de notre ère. Cela pourrait indiquer une deuxième phase de décor pour la même stèle.

Sous chaque registre se trouve une inscription (fig. 10 A-B) :

\section{Régistre supérieur (fig. 10 A)}

$[\mathrm{M}($ arcus $) * I u l i]$ VS $* \mathrm{M}($ arci)*L(ibertus)*FELIX * VIVOS [s]IBI*ET*COELIAE

[...f(iliae ] MAXVMAE*ET

[Iuli] $\mathrm{AE}^{*} \mathrm{M}(\operatorname{arci}) * \mathrm{~F}(\mathrm{iliae}) * \mathrm{POLLAE}$

\section{Régistre inférieur (fig. 10 B)}

[M(arcus) Iulius] OPTITVS*M(arcus)*IVLIVS*M(arci)*F(ilii)

M. Iulius Felix, affranchi de Marcus, a posé (ce monument) de son vivant pour lui-même et pour Coelia Maxuma, fille de [ ] et pour Iulia Polla, fille de Marcus,

\section{[ ] Optitus, M. Iulius, fils de Marcus}

La gravure est élégante et la disposition du texte sur la pierre équilibrée. On note un archaïsme (uiuos pour uiuus) ; les T et les I dépassent la ligne et dans la dernière ligne, se trouve une imbrication d'un $\mathrm{P}$ et d'un $\mathrm{O}$. Tous ces éléments permettent de proposer une date assez haute pour ce texte, qui n'est toutefois pas sans poser de problème. On identifie aisément l'homme du registre supérieur avec [- - -]us Felix. Le peu d'espace disponible dans la partie gauche de la stèle réduit le nombre de possibilités pour le nom, et la lecture de Iulius, que l'on trouve dans la dernière ligne de l'inscription paraît s'imposer. La femme à ses côtés doit être Coelia Maxuma ou Iulia (?) Polla, mais le lien de parenté n'est pas exprimé ; on peut supposer que Coelia Maxuma est la femme de Iulius Felix et qu'elle se trouve au centre, alors que Iulia Polla peut être leur fille, puisqu' elle porte probablement le même gentilice que Iulius Felix. Son portrait se trouvait probablement à gauche.

Quant aux noms, le gentilice Coelius est très fréquent en Narbonnaise, où on le rencontre au mois cinquante fois, dont au moins deux autres fois à Arles (CIL XII, 723 et 750). Le cognomen de sa fille, Polla, est moins fréquent, sans être inconnu, puisqu'il est attesté à Nîmes (CIL XII, 3471), alors qu'on connaît au moins une trentaine d'attestations en Italie ${ }^{24}$.

24. OPEL III, p. 148. 


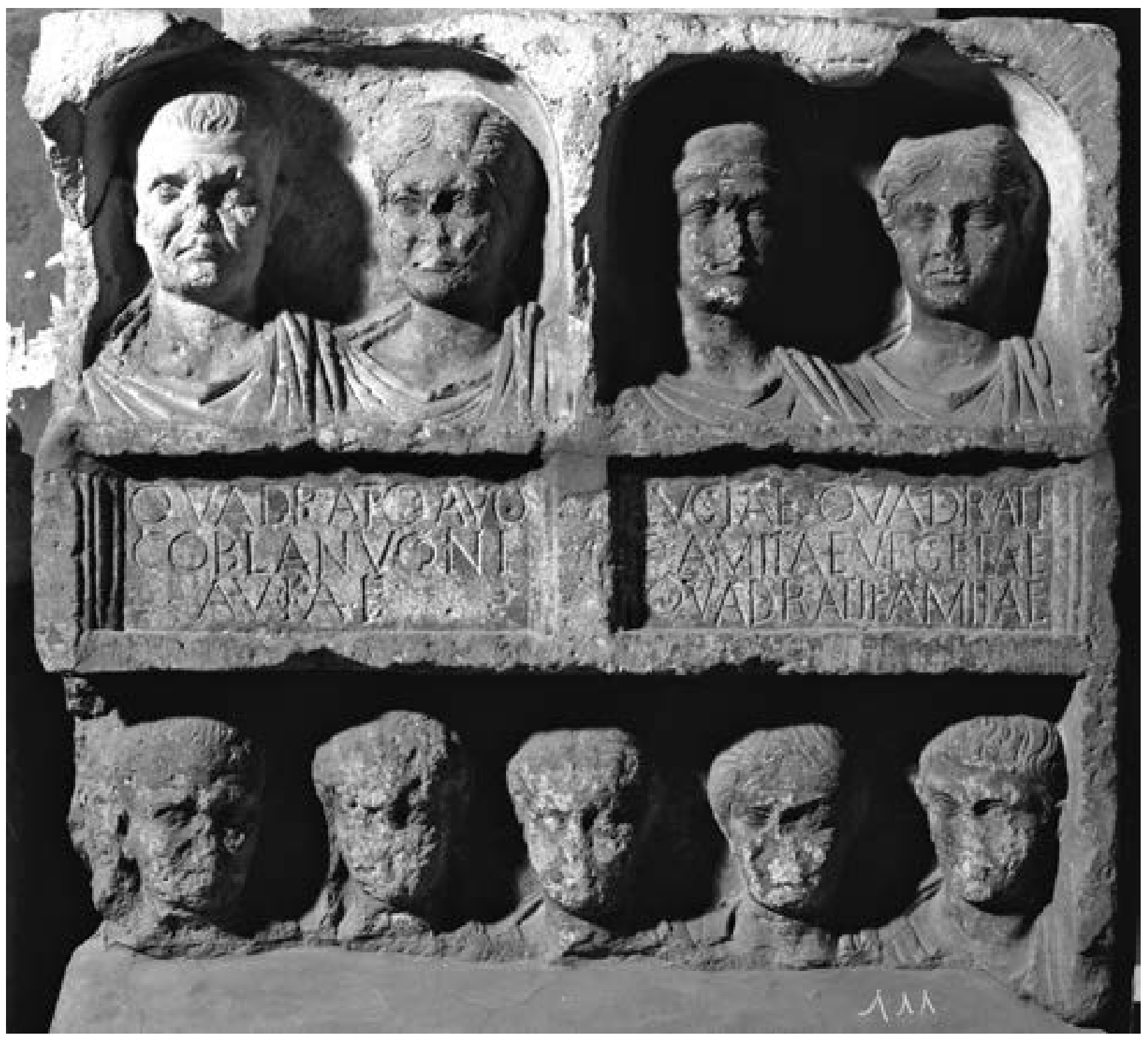

Fig. 11. Stèle familiale à deux registres. Nîmes musée archéologique (๔ Philippe Foliot, CNRS, CCJ).

En ce qui concerne les deux hommes du registre inférieur, du premier, on n'a que le cognomen, Optitus, un nom qui paraît bien latin mais qui n'est pas attesté par ailleurs. S'agit-il d'une confusion entre Optatus et Optimus ? On ne saurait retenir l'hypothèse d'E. Lacaze Dutiers, qui évoque, sans trop y croire, la possibilité de lire dans la dernière phrase OP pour obiit, puis le prénom Titus ${ }^{25}$. Dans la lacune devant ce nom, on peut restituer la filiation $\mathrm{M}$ (arcus) Iulius $\mathrm{M}$ (arci) f(ilius), qu'on retrouve pour le deuxième personnage, qui, lui, ne porte pas de cognomen, ce qui est assez surprenant ; par manque de place?

25. Lacaze Duthier 1908.
Date : Cette stèle à deux registres présente donc deux générations. L'espace relativement restreint ne permet pas d'y sculpter des bustes plus grands. Les stèles familiales à plusieurs registres se retrouvent en Italie du Nord, mais également à Nîmes ${ }^{26}$ (fig. 11). Notons la hiérarchie familiale exprimée de manière verticale, les personnes les plus âgées et plus respectées figurent en haut, cet agencement se remarque aussi sur les stèles de l'Italie du Nord ${ }^{27}$.

26. 1. = CIL XII, 3564 ; Espérandieu 1907, p. 316-317 n473. 2. = CIL XII, 3015 ; Espérandieu 1907, p. 324 n490. 3. Inv. 862. 1.1 Fig. 11 = CIL XII, 3030 ; Espérandieu 1907, p. 326 n494.

27. Pflug 1989, p. 107. 


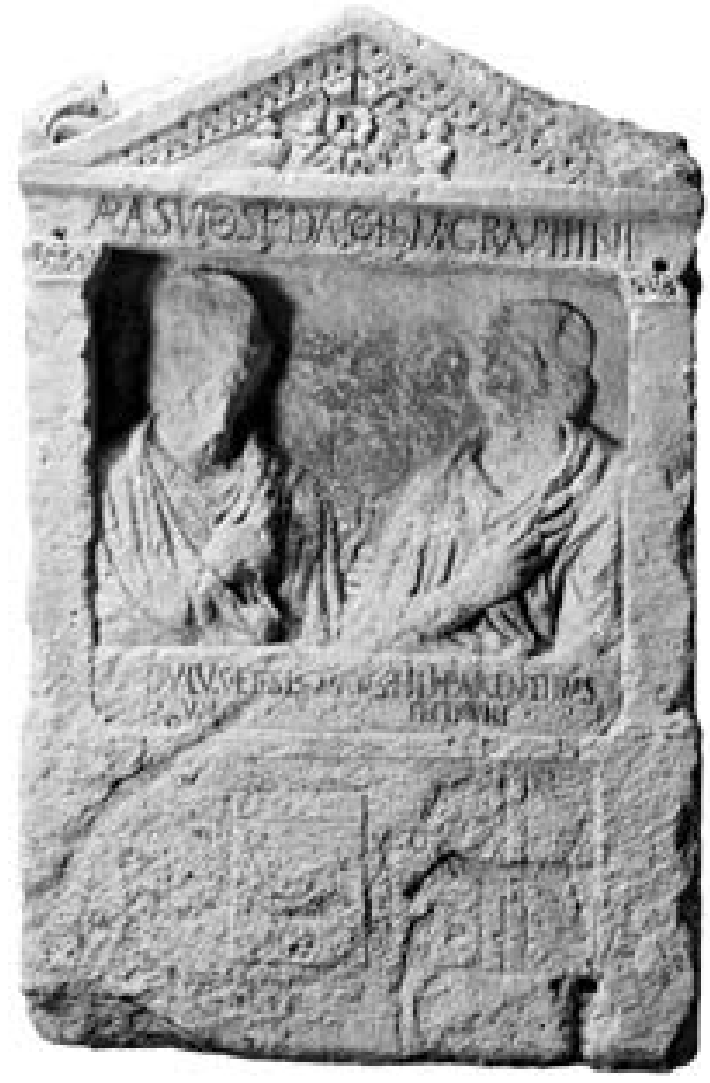

Fig. 12. Stèle d'Aulus Asuius Sedatus et Pompeia Graphis. Arles, M.D.A.A. (C) Philippe Groscaux, CNRS, CCJ).

\section{Stèle d'Aulus Asuius Sedatus et Pompeia Graphis (fig. 12-16)}

Cette stèle ${ }^{28}$, également en calcaire, prend la forme d'un édicule. Les deux corniches rampantes du fronton sont ornées de rais de cœur, motif qui se retrouve également sur les petits côtés, alors qu'à l'intérieur du fronton figure un fleuron à double corolle de feuilles, encadré par deux petits vases. Les pilastres à chapiteau et base de la façade se retrouvent aussi sur les petits côtés. Un acrotère en forme de palmette ouverte se trouvait sur chaque angle de la stèle, il était peint, des traces de couleur violacée sont encore visibles sur l'acrotère de la face arrière. On remarque une forte utilisation du foret sur les chapiteaux et le fronton. Sur les petits côtés (fig. 13-14) qui reprennent la forme de l'édicule, entre les pilastres figure un bouclier accroché par une courroie à un clou, à gauche (fig. 13) une pelta appelée aussi

28. Découverte en 1561 dans le rempart porte de Laure. Au M.D.A.A. Inv. FAN.92.00.161. H. : $136 \mathrm{~cm}$, L. : $96 \mathrm{~cm}, 1 .: 52 \mathrm{~cm}$ : CIL XII, 762, Espérandieu 1907, p. 153-154 n¹94; CAG 13/5, p. $262 \mathrm{n}^{\circ} 40$, fig. 125 .
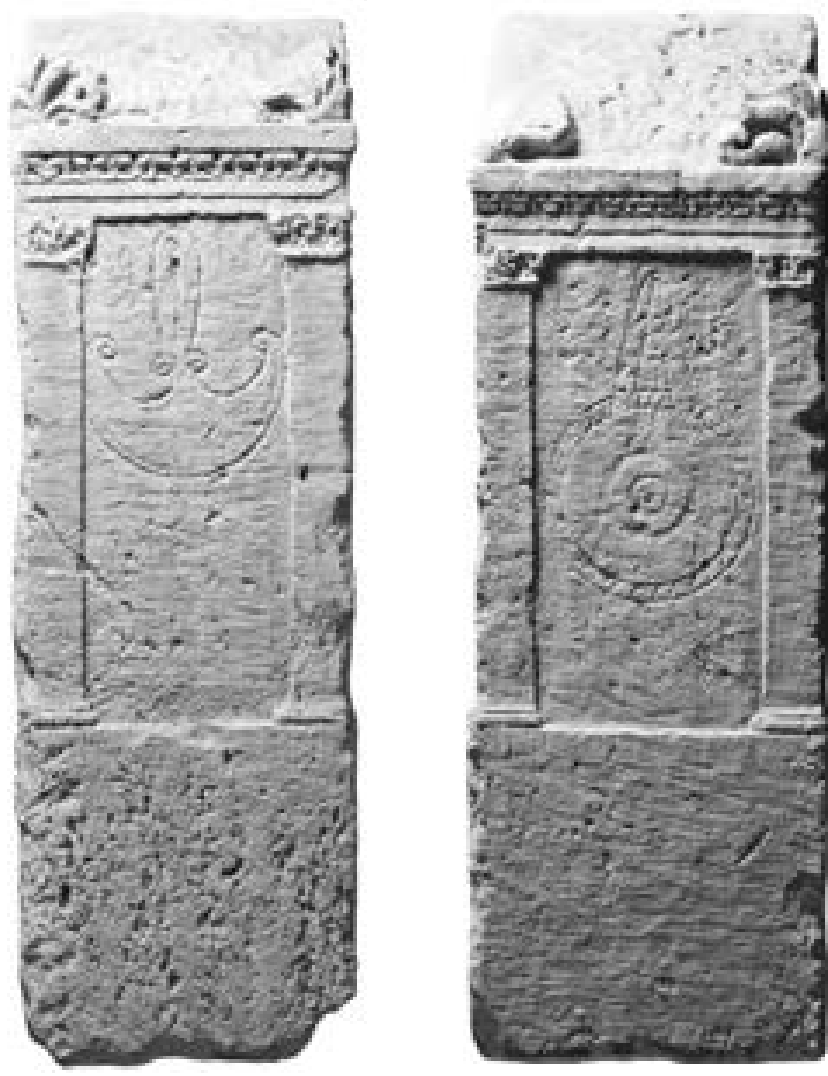

Fig. 13. Coté gauche de la stèle d'Aulus Asuius Sedatus et Pompeia Graphis (ci-dessus à gauche).

Fig. 14. Coté droit de la stèle, (ci-dessus à droite). Arles, M.D.A.A. (@ Philippe Groscaux, CNRS, CCJ).

bouclier d'Amazone ${ }^{29}$ et à droite (fig. 14) un bouclier rond. Des boucliers de même forme se retrouvent sur des cippes funéraires de petites dimensions de l'Italie centrale, datés par l'épigraphie du milieu du ${ }^{\mathrm{er}} \mathrm{s}$. av. J.-C. ${ }^{30}$

Deux personnages en buste (fig. 15) figurent dans la niche rectangulaire, dont les visages sont arrachés. Ils portent tous deux le même type de vêtement: une tunique, visible au niveau du cou, et un manteau qui couvre leurs épaules et entoure le corps, la main droite ${ }^{31}$ de chacun se place sur la poitrine, en tenant un pli du

29. Les Amazones apparaissent dès le IV ${ }^{\mathrm{e}}$ s. av. J.-C. sur des monuments funéraires, par ailleurs la présence très fréquente de ce type de bouclier sur des cippes, des sarcophages, des stèles etc. incite à attribuer à ce motif un sens funéraire en plus de sa valeur décorative : Gaggadis-Robin et Gascou 1996, p. 158 n.86-87.

30. Ces cippes en travertin ont été découverts à Carsoli (Carsulae) en Ombrie et sont conservés au musée de Terni. Sur le long côté dans l'entrecolonnement de ces petits monuments en forme d'édicule à fronton, figurent deux peltes, alors qu'un bouclier rond décore le petit côté : Coarelli et Sisani 2008, p. 204 n²33 ; p. 206 n²36.

31. Le personnage de droite porte une bague sur l'annulaire de sa main droite. 


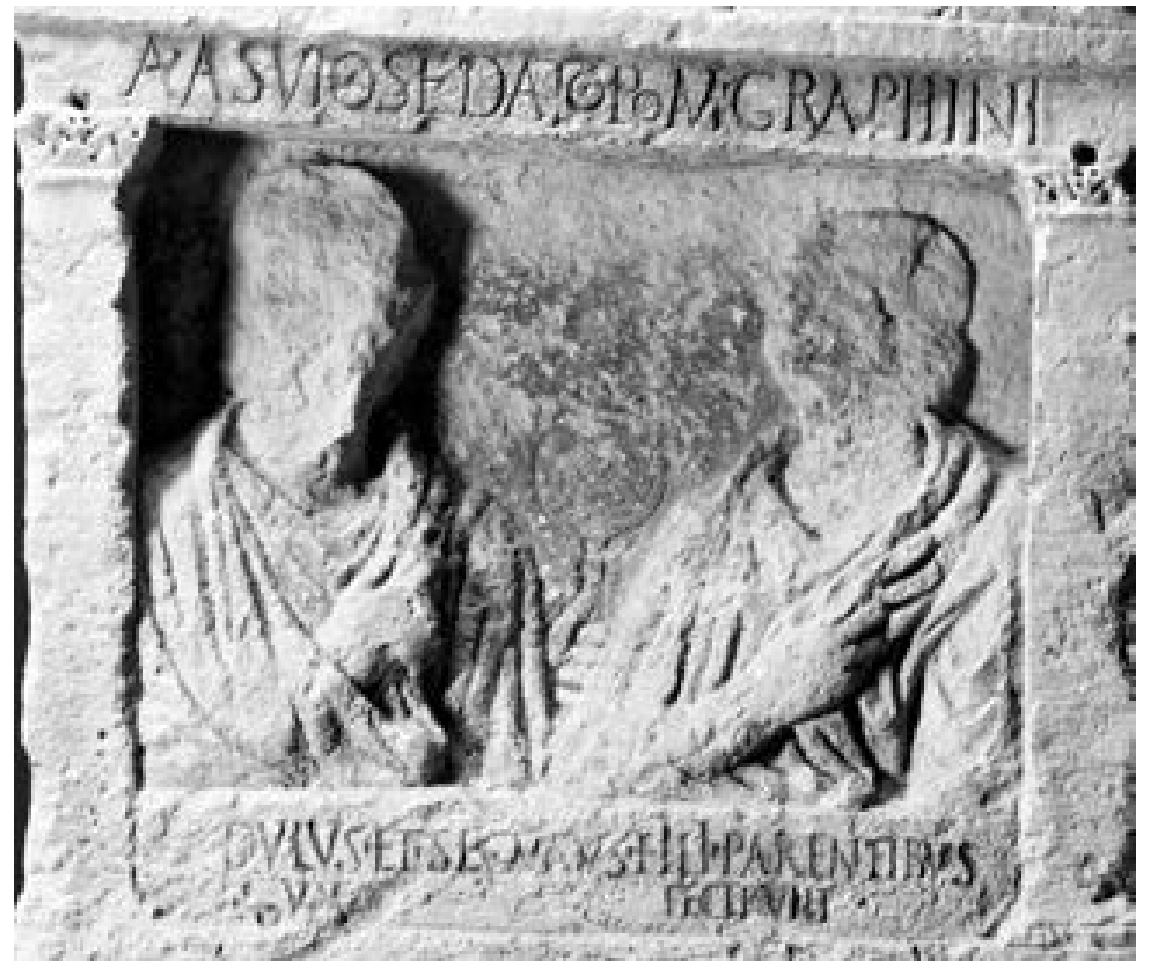

Fig. 15. Stèle d'Aulus Asuius Sedatus et Pompeia Graphis. Détail des bustes et de l'inscription. Arles, M.D.A.A. (@ Philippe Groscaux, CNRS, CCJ).

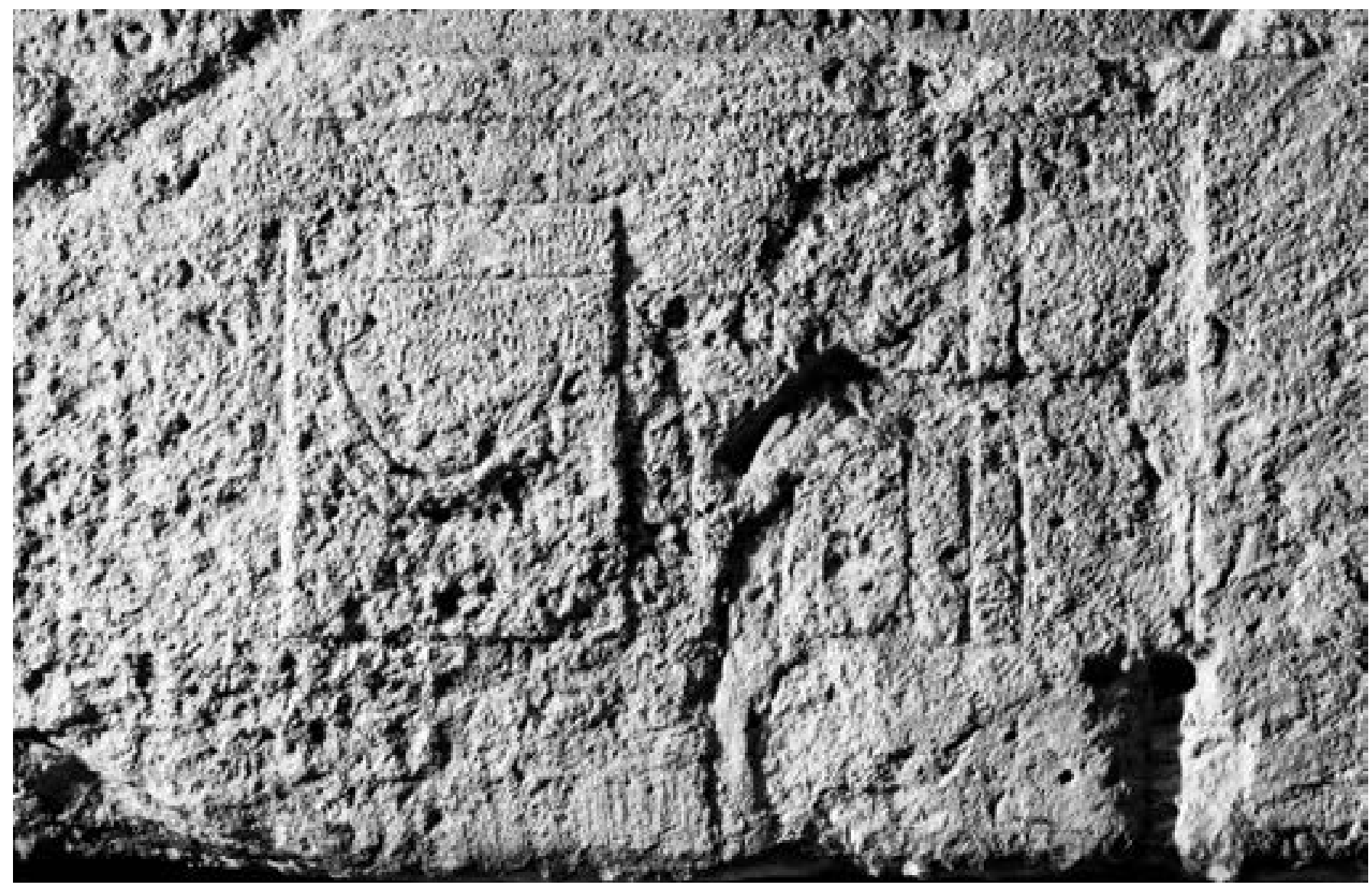

Fig. 16. Stèle d'Aulus Asuius Sedatus et Pompeia Graphis. Détail du panneau décoré sous les bustes. Arles, M.D.A.A. (@ Philippe Groscaux, CNRS, CCJ). 
manteau. Le vêtement et le geste donc sont identiques. La trace arrondie de la coiffure, qui pourrait être un chignon, peut indiquer que la figure de droite est féminine. Sur des nombreuses stèles d'Italie du nord, une femme pose sa main sur la poitrine de la même manière. Mais les visages très abimés ne permettent pas d'approfondir davantage l'identité du personnage. Entre eux, au centre, on aperçoit les doigts d'une main gauche qui tiennent un objet circulaire à manche, représenté en faible relief, fort probablement un miroir, dont le disque est décoré de cercles concentriques. Cette main est représentée de manière maladroite, alors qu'on distingue bien le contour précis du corps et du bras. Le miroir, objet de la toilette féminine et du quotidien, est un attribut fréquent dans l'iconographie funéraire ${ }^{32}$, et il finit parfois par devenir un symbole ${ }^{33}$.

Au-dessous du champ figuré dans un panneau (fig. 16) et en faible relief sont sculptées deux formes, mal dessinées et mal conservées. À gauche il s'agit d'un coffret à couvercle. À droite on distingue deux objets longs et fins, figurés à la verticale. Il s'agit peut-être des volumina posés verticalement, dans le champ à côté d'un scrinium, ou capsa, sorte de grosse boite qui servait à leur rangement. Sur des nombreuses stèles ${ }^{34}$ le défunt tient un volumen dans la main, ce qui a été supposé le qualifier comme un lettré. Ce rouleau a été aussi interprété comme un testament, un contrat de mariage, ou bien comme l'attribut du citoyen ${ }^{35}$. Un grand nombre de statues des togati, ou même sur des stèles ${ }^{36}$, présentent aux pieds de la figure masculine, un lot de volumina attachés ensemble, ou bien placés dans un scrinium. $\mathrm{Si}$ on compare le coffret de notre stèle au scrinium figurant aux pieds d'une statue conservée à Rome ${ }^{37}$, on s'aperçoit que le relief de forme arrondie qui décore le scrinium sur la stèle d'Arles, et qu'on pourrait interpréter de prime abord comme une guirlande, pourrait être la courroie en cuir

32. Sur un grand nombre de stèles de Bordeaux la défunte tient un miroir : Braemer 1959, p. $120 \mathrm{n}^{\text {os }}$ 20, 22 pl. VI ; 33, pl. X ; 49 pl. XIV, 50, pl. XV ; 57, pl. XVII. Breamer 1959, p. 120 n.4-6 voir la liste des stèles d'une autre provenance avec le même sujet.

33. Sur la stèle de Poitiers : Espérandieu 1908, p. 298 n¹393 un miroir seul est gravé sur la partie supérieure de la stèle.

34. Voir par ex. celle de Modena, Musée Lapidaire 101 : Pflug 1989, p. 174 n 52 , pl. 11, 1-2.

35. Pflug 1989, p. 94.

36. Voir par ex. deux stèles d'Athènes: Céramique P262, et une autre dans une collection privée: Von Moock 1998, p. 109 n 130 , pl. 15 d ; p. 190 n`551, pl. 67 d.

37. Le scrinium a été gravé d'une inscription commémorative concernant une corporation : Nista (L.) - Statua togata con testa ritratto non pertinente (Inv. 124472). In : Giuliano (A.) dir., Museo Nazionale Romano, Le sculture, I, 2, Rome, De Luca, 1981, 369 p., p. 41-42 n³0, inv. 124472 . qui servait à le transporter. Ceci indique que le sculpteur d'Arles avait le souci de représenter la réalité des choses dans leur détail. Par ailleurs dans le cas où notre interprétation comme volumen et scrinium serait exacte, ces deux formes, maladroitement mais intentionnellement sculptées, pourraient être expliquées comme des attributs professionnels ${ }^{38} \mathrm{du}$ défunt. Sur un certain nombre de stèles de l'Italie du Nord on remarque que sous le panneau réservé à la représentation du défunt, figurent des objets qui peuvent se référer à ses activités. Par exemple, les outils (équerre, fil à plomb, marteaux), qui figurent sur le socle de la stèle d'un marmorarius de Reggio Emilia ${ }^{39}$ ont été interprétés comme des attributs professionnels. Sur une autre stèle d'Aquilée ${ }^{40}$, probablement d'un marin, on y trouve une ancre et un gouvernail. Ces deux stèles sont datées vers la fin du I ${ }^{\mathrm{er}} \mathrm{s}$. Comparés à ces exemples, ces deux objets sur la stèle d'Arles pourraient peut-être s'expliquer dans le sens d'un attribut professionnel. Alors dans ce cas il s'agirait peut-être de la stèle d'un secrétaire, un librarius, ou un scriba ${ }^{41}$, comme nous en connaissons par ex. en Pannonie ${ }^{42}$. Dernière hypothèse possible, ces objets font peut-être allusion au nom de la défunte Graphis, cognomen repris du nom grec qui désigne un stylet pour écrire.

L'épitaphe (fig. 15) se trouve de part et d'autre du champ figuré ; l'écriture est soignée et on lit sans difficulté :

\section{A(ulo)*ASVIO*SEDATO*POM(peiae)*GRAPHINI [Se]DVLVS*ET*SECVRVS*FILI*PARENTIBVS $\mathrm{V}(\mathrm{i}) \mathrm{V}(\mathrm{i}) \quad$ FECERVNT}

À Aulus Asuius Sedatus et Pompeia Graphis (?). Sedulus et Securus, leurs enfants, ont posé ce tombeau de leur vivant à leurs parents.

Il s'agit d'une stèle dédiée par deux enfants, uniquement indiqués par leur cognomina, Sedulus et Securus, à leurs parents, dont les portraits figurent au centre de la stèle. Le père porte un nom, Asuius, très rare, uniquement attesté en Narbonnaise, car on ne le retrouve qu'une autre fois, sur une inscription nîmoise datable du $\mathrm{II}^{\mathrm{e}}$ s. (CIL XII, 3429). Son cognomen, Sedatus, est mieux

38. Pflug 1989, p. 96-98.

39. Museo Civico 150 : CIL XI, 961 ; Pflug 1989, p. 96-98 n56, pl. 13,1.

40. Museo Nazionale 262 : Pflug 1989, p. 190 n86, pl. 19,2.

41. Le terme librarius désigne aussi bien un copiste travaillant sous les ordres et pour l'usage d'un particulier, dont il était le plus souvent l'esclave, qu'un secrétaire employé par les fonctionnaires, l'administration ou bien par des particuliers.

42. Hainzmann 1991 a examiné des documents figurés et épigraphiques qui font référence à ce métier. 
attesté en Gaule (six fois en Narbonnaise, huit fois en Belgique/Germanie ; trois fois en Aquitaine et deux fois en Lyonnaise), mais très rare ailleurs ${ }^{43}$. L'influence celtique est encore plus importante pour ses fils, en tout cas pour l'aîné, puisque le cognomen Sedulus n'est pas connu en dehors de la Gaule, où on connaît une dizaine d'attestations ${ }^{44}$. Contrairement à ce que pensait I. Kajanto ${ }^{45}$, l'origine de ce nom pourrait donc bien être celtique $^{46}$. Enfin, le nom de l'autre fils, Securus, est uniquement attesté en Narbonnaise par cette inscription, mais il est mieux connu dans le nord de la Gaule et dans les Balkans ${ }^{47}$.

Si le gentilice de son épouse est des plus classiques (plus de 230 attestations en Narbonnaise), son cognomen est en revanche très rare. L'index du CIL XII ne mentionne qu'une autre Graphis, à Toulouse (CIL XII, 5389), et deux attestations sont signalées dans les provinces alpines d'Italie (CIL V, 3536 et 7111$)$ alors qu'on en connaît seize à Rome ${ }^{48}$. Toutefois, il est possible que le nom au nominatif ne soit pas Graphis, mais Graphe, comme signalé dans OPEL ${ }^{49}$. En fait, le datif devrait être Graphidi et non pas Graphini. Dans ce cas, le nombre d'attestations est légèrement supérieur, bien que le choix entre les deux solutions soit parfois arbitraire. Ainsi, pour le CIL XII, 4822, où le nom est lacunaire, rien ne permet de trancher en faveur de l'une ou de l'autre interprétation. Quoi qu'il en soit, il s'agit d'un cognomen grec, qui tranche avec les noms celtiques de l'époux et de leurs fils.

Date: La graphie, avec les hederae dans les $\mathrm{O}$ de Asuio et Sedato, la taille réduite des $\mathrm{O}$ de Sedato et Pom, et les I qui dépassent la ligne, permettent de dater l'inscription de l'époque Julio-claudienne. Les visages disparus du monument d'Arles ne permettent pas d'en tirer de conclusions chronologiques, pourtant les attitudes des personnages et l'exécution des draperies les rapprochent de la date suggérée par l'épitaphe. Le type de stèle à édicule, avec les défunts figurant dans une niche rectangulaire couronnée par un fronton se retrouve au Nord de l'Italie (Vénétie et Istrie), où certains exemplaires ${ }^{50}$ datent de la première moitié du ${ }^{\mathrm{er}} \mathrm{s}$.

43. OPEL IV, p. 61-62.

44. OPEL IV, p. 62.

45. Kajanto 1965 , p. 259.

46. Cf. Hölder 1896-1913, II, col. 1433-1335.

47. OPEL IV, p. 61.

48. Solin 1982, p. 1158.

49. OPEL II, p. 170

50. Trieste : Pflug 1989, p. 188 n $^{\circ} 81$, pl. 19, 1; Portogruaro : Pflug 1989, p. 198 n $^{\circ} 103$, pl. 21, 1-3; Altino: Pflug 1989, p. $214 \mathrm{n}^{\circ} 147$, pl. 24, 1; Gologorica à Pula : Pflug 1989, p. 188 n75, pl. 18, 1.

\section{Stèle de Cornelia Sedata et de Cornelia Optata (fig. 17-18)}

Cette stèle ${ }^{51}$ est du type à édicule avec fronton ouvert en forme d'une coquille. Malgré l'état de conservation assez médiocre et la mauvaise qualité du calcaire coquillier dans lequel elle est taillée, on distingue à gauche le chapiteau qui couronnait le pilastre engagé. Sur le devant au niveau du haut du crâne, reste de chaque côté de chaque personnage un trou bien régulier, rempli encore de restes de fer. Ces trous servaient certainement à accrocher des guirlandes ${ }^{52}$, lors de visites de la tombe. De tels dispositifs ont été observés également

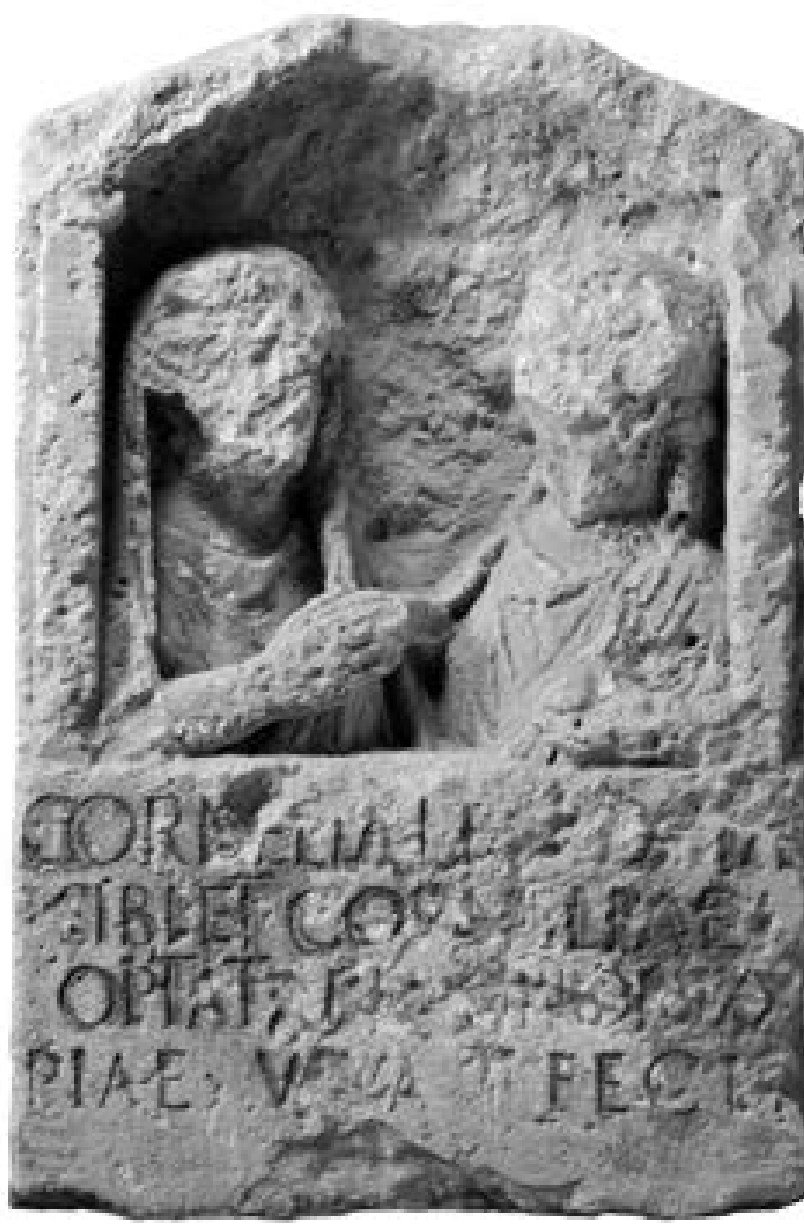

Fig. 17. Stèle de Cornelia Sedata, et de Cornelia Optata. Arles, M.D.A.A. (C Philippe Groscaux, CNRS, CCJ).

51. Découverte en 1561 dans le rempart porte de Laure. Au M.D.A.A. Inv. FAN.92.00.147. H. : $113 \mathrm{~cm}$, L. : $76 \mathrm{~cm}, 1 .: 53 \mathrm{~cm}$ : CIL XII, 793, Espérandieu 1907, p. 154 n 195 ; CAG 13/5, p. 262 $\mathrm{n}^{\circ} 41$, fig. 126.

52. Pflug 1989, p. 113-117. 


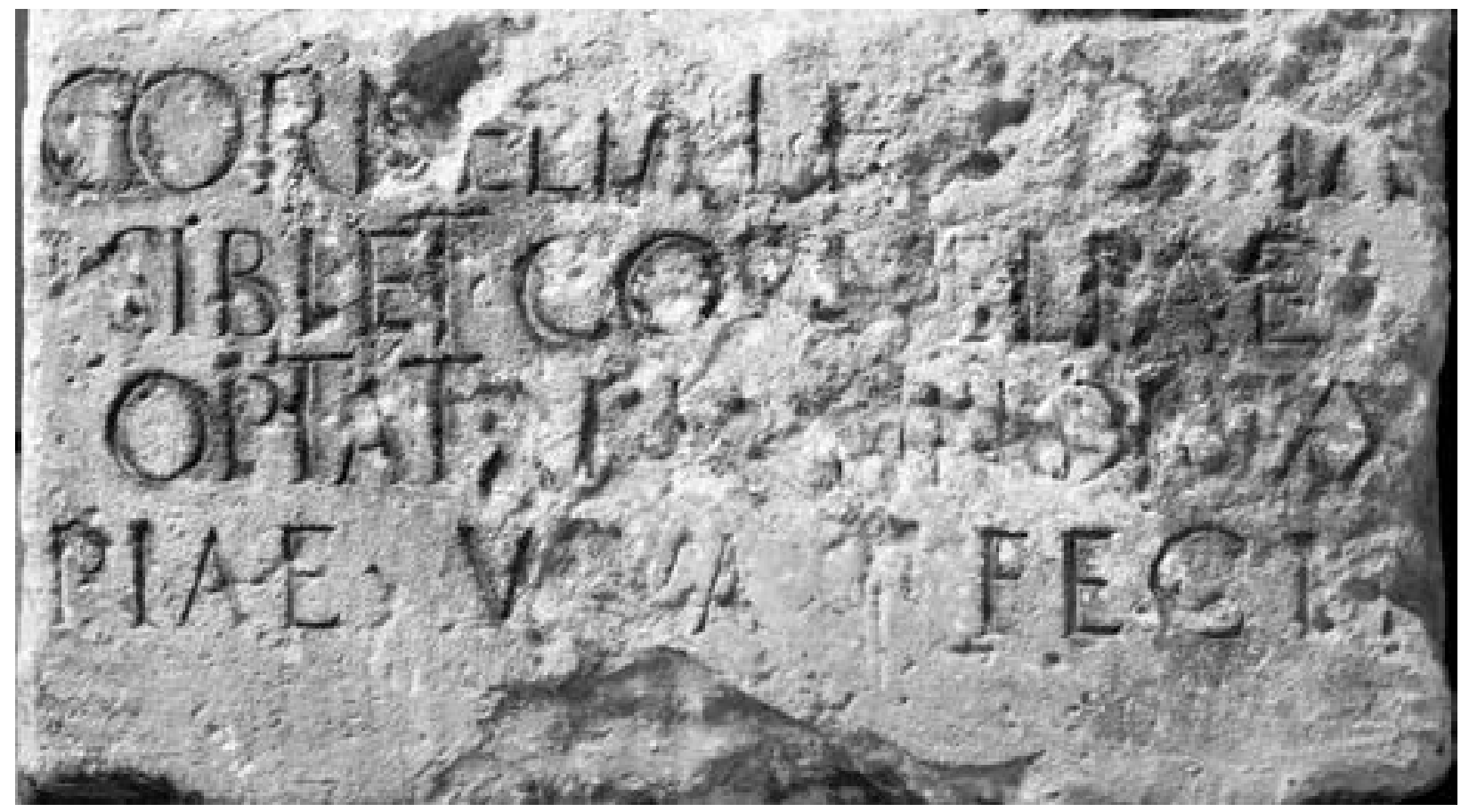

Fig. 18. Stèle de Cornelia Sedata, et de Cornelia Optata. Détail de l'inscription. Arles, M.D.A.A. (@ Philippe Groscaux, CNRS, CCJ).

sur des stèles d'Italie du Nord ${ }^{53}$; sur certaines d'entre elles les crochets $^{54}$ qui servaient à attacher des guirlandes sont même conservés. On aperçoit aussi un petit trou, rempli également de fer de chaque côté du cou de la femme de gauche, peut-être pour y accrocher une guirlande en guise de collier?

Deux femmes (fig. 17) figurent dans la niche, celle de gauche a la tête voilée. Le relief est très endommagé et ne facilite pas la compréhension de la scène. Les visages sont brisés. On aperçoit la coiffure en nattes longues attachées en chignon de la femme de droite. Elle porte dans la paume ouverte de sa main droite un objet, peutêtre un fruit. La femme de gauche avance sa main droite (ornée probablement de bagues) vers l'autre femme. Il s'agit certainement d'une poignée de main, la dextrarum iunctio très fréquente dans l'iconographie funéraire, mais ici elle est très maladroitement représentée.

Malgré le médiocre état de conservation de la pierre, l'inscription (fig. 18) qui se trouve sous les portraits est relativement bien lisible.

\section{CORNELIA*L(uci)*F(ilia)*SEDATA SIBI*ET*CORNELIAE}

53. Stèle de Cesena: Pflug 1989, p. 159 n $^{\circ} 19$, pl. 4, 1-2; stèle d'Alba : Pflug 1989, p. 287-288 n³27, pl. 51, 1.

54. Stèle de Ravenne : Pflug 1989, p. 151 n5, pl. 1, 2.4.

\section{OPTATAE [f(iliae ?)*an]NORV(m) XX PIAE * V[i]VA * FECIT}

Cornelia Sedata, fille de Lucius, a élevé(ce monument) de son vivant pour elle-même et pour Cornelia Optata sa fille ?, femme dévouée, morte à l'âge de 20 ans.

L'inscription nous donne les noms des deux femmes représentées sur la stèle. La stèle a été érigée par Cornelia Sedata, fille de Lucius, de son vivant pour elle-même et pour une autre femme, également appelée Cornelia. L'identification de cette personne est moins certaine, sauf qu'on peut comprendre qu'elle est décédée à l'âge de vingt ans. Le problème est de savoir ce qu'il faut restituer dans la lacune de la ligne 3. Si l'on lit, comme fait le CIL, Corneliae Optatae [l(ibertae)] / Piae, la défunte s'appelle Cornelia Pia, et elle est l'affranchie d'une (Cornelia) Optata, ce qui n'est en soit pas impossible. On s'étonnera toutefois de trouver l'âge de la défunte entre cette filiation et le cognomen et on comprend mal quel est le lien entre les deux femmes. Il semble préférable de suivre la proposition de Th. Mommsen, cité par le CIL, et de lire Corneliae Optatae [f(iliae)] / Piae, donc « à Cornelia Optata, sa fille ». Pia n'est donc pas, dans ce cas, un cognomen, mais une épithète, équivalente à piissima, une femme pieuse, dévouée.

Date : la coiffure de la femme de droite pourrait situer la stèle à la période Julio-Claudienne, date qui convient également à l'épitaphe. 


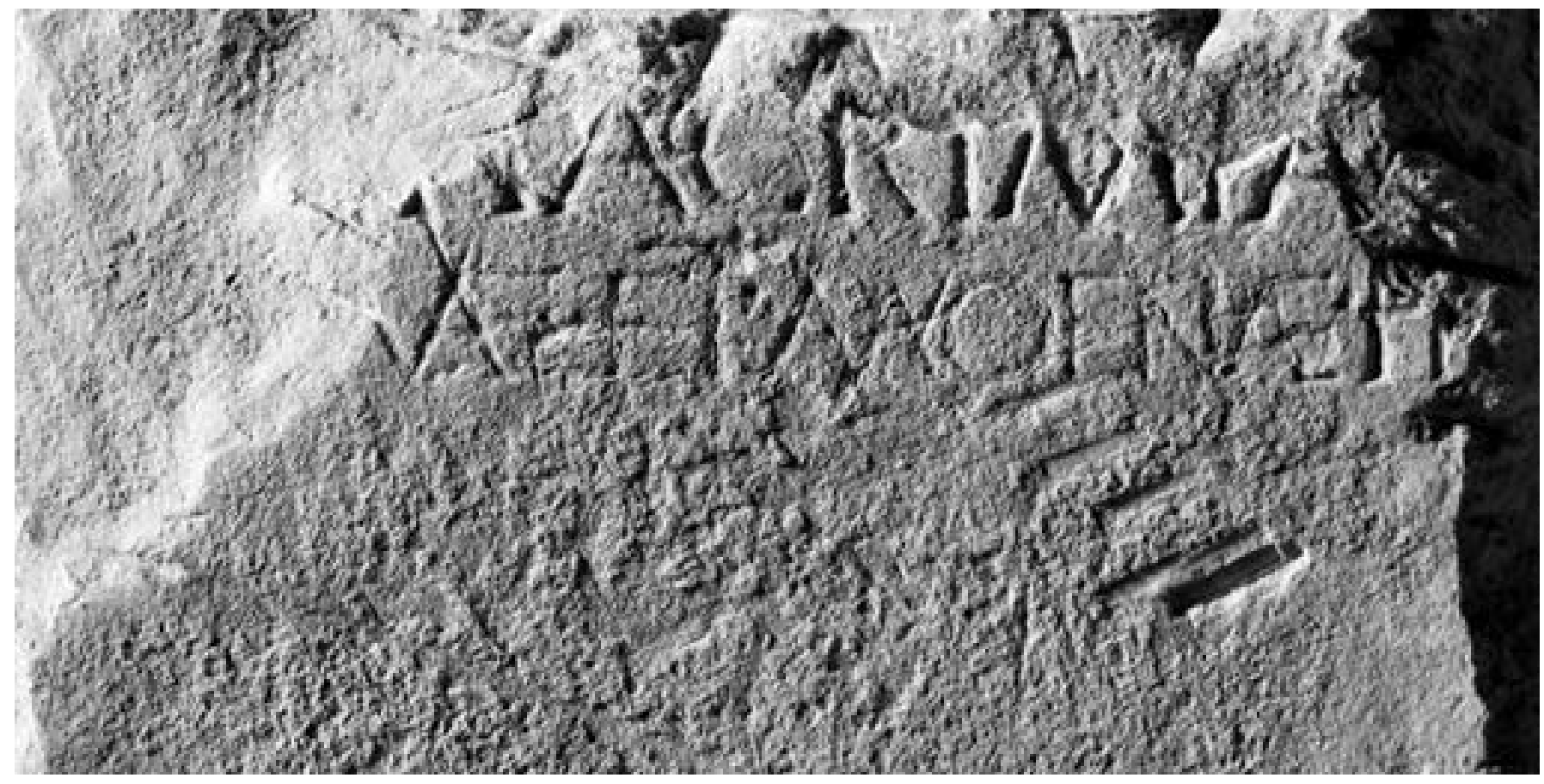

Fig. 20. Stèle à édicule ? Détail de l'inscription (๔ Philippe Groscaux, CNRS, CCJ).

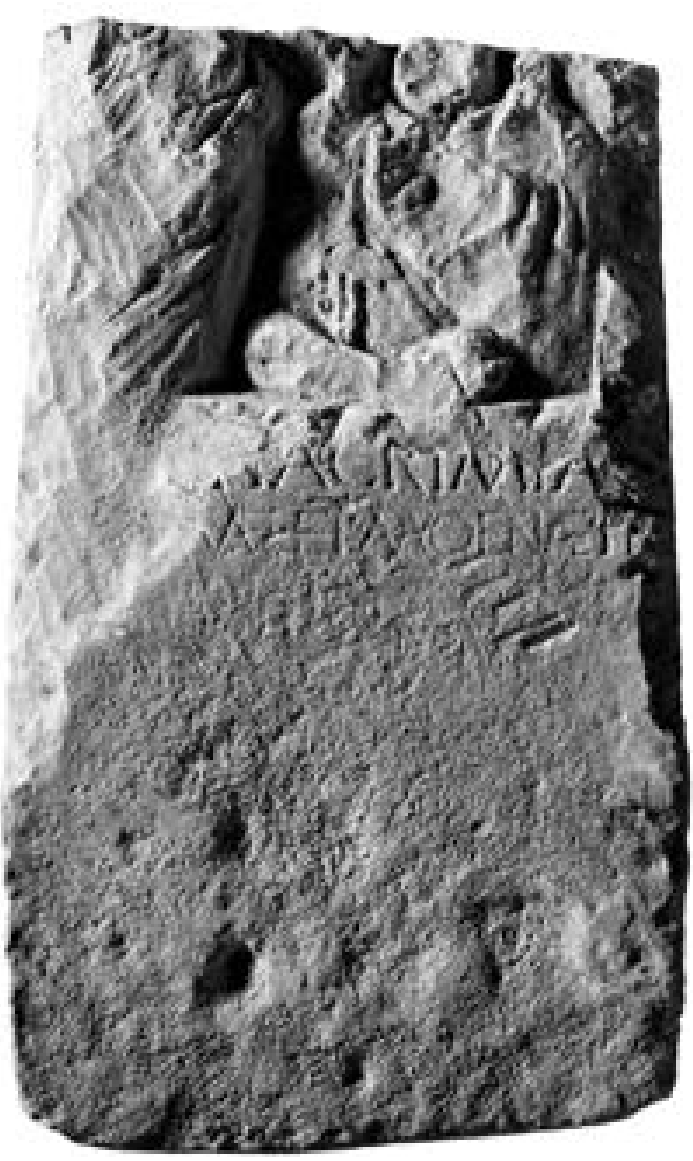

Fig. 19. Stèle à édicule ? Arles, M.D.A.A. (৫) Philippe Groscaux, CNRS, CCJ).

\section{Stèle à édicule ? (fig. 19-20)}

Cette stèle ${ }^{55}$ a été découverte en 1891 à Mouriès, en bordure du chemin des Baumettes, sur le versant méridional des Alpilles, elle provient donc de la campagne d'Arles. Elle est aussi en calcaire coquillier, très abîmée, et semble avoir été retaillée en haut et à gauche. Le champ décoré était encadré d'un bandeau, visible à droite, ce qui peut indiquer également une stèle à édicule.

Les bustes de deux personnages (fig. 19) au moins, figuraient dans la partie supérieure de la stèle. Ils sont très détériorés. Le personnage de gauche semble être de taille plus grande que celui de droite. Ce dernier a le bras droit plié sur le ventre et était peut-être voilé, ce qui indiquerait évidemment une figure féminine. Le personnage de gauche était peut-être également une femme, dont on aperçoit une partie du vêtement (un manteau ?) rejeté sur son épaule gauche. Bien que Allmer ${ }^{56}$ qui publia le premier cette stèle en 1894 ait interprété ces deux figures comme étant un couple, il se peut qu'il s'agisse de deux femmes.

55. $\mathrm{Au}$ M.D.A.A. Inv. FAN.92.00.479 : H. : $116 \mathrm{~cm}$, L. : $68 \mathrm{~cm}$, 1. $19 \mathrm{~cm}$ : Espérandieu 1929, nº ; CAG 13/2, p. 219 n³267; Heijmans 2003, p. 333-334, 6.3.2.

56. Allmer, Revue Épigraphique du Midi, $1894, \mathrm{n}^{\circ} 1042$. 
L'inscription (fig. 20)

$$
\begin{aligned}
& \text { [- - - ] . ACRIMIA. } \\
& \text { [- - -]VAE ET AMOENAE [- - - }
\end{aligned}
$$

L'écriture est assez soignée. Le T de la ligne 2 dépasse les autres lettres, et l'on observe plusieurs ligatures dans la ligne 2 : VAE, AM et AE; les mots sont séparés par des points. Il reste des traces de lettres avant le premier mot, probablement un I ou un T; il reste éventuellement la place pour une dernière lettre après le $\mathrm{A}$, où se trouve une lacune.

Pour la ligne 2, le premier mot après la cassure est certainement - - -]VAE et non pas - - - ]MA, comme lisait E. Espérandieu. Les deux lettres à la fin sont probablement un $\mathrm{F}$ et un $\mathrm{I}$.

L'état de dégradation de la pierre interdit de restituer le sens du texte, qui semble pourtant dédié à deux personnes, dont les noms, mutilés, apparaissent dans la seconde ligne. Le premier élément conservé, - - -]VA, peut être une partie d'un cognomen, comme [Ner]va ou [Scae $] v a$, mais on peut aussi penser à [Cal] va ou [Sil] va ${ }^{57}$. Le cognomen Amoena/us, particulièrement répandu en Espagne, est attesté neuf fois en Narbonnaise. À côté de Narbonne, où il apparaît quatre fois (CIL XII, 4511, $4571,4799,4851)$, on le trouve également à Lambesc (territoire d'Aix) (ILN Aix, 252) et dans la moyenne vallée du Rhône (ILGN, 377 : Apt ; AE 1965, 175 : Valence), un dernier cas étant attesté dans les Alpes (ILN Vienne, 799 : Saint-Julien-en-Genevois). Les deux surnoms, placés au même niveau, peuvent indiquer qu'il s'agissait de deux membres de la même famille, dont on n'a pas senti le besoin de répéter le gentilice ${ }^{58}$. Quant à la première ligne, - - ]ACRIMIA peut correspondre à une partie d'un gentilice, qui n'est pas attesté par ailleurs.

Il y a évidemment peu de choses à tirer de l'inscription ; si ce n'est qu'elle semble de bonne qualité et qu'elle peut dater du I ${ }^{\text {er }} \mathrm{s}$.; on a peut-être les noms Acrimia et Amoena (ILN Antibes, 121).

\section{Stèle de Aulus Babbius (fig. 21-22)}

Une autre stèle ${ }^{59}$ de forme simple, sans encadrement, représente un homme seul dans une niche au

57. Cf. Solin, Solomies 1994, p. 437.

58. Comme par ex. dans une autre inscription arlésienne, CIL XII, 897. 59. Elle se trouvait au XVII ${ }^{\mathrm{e}} \mathrm{s}$. contre le mur du réfectoire des Pères de l'Oratoire. Au M.D.A.A. Inv. FAN.92.00.144. H. : 154 cm,

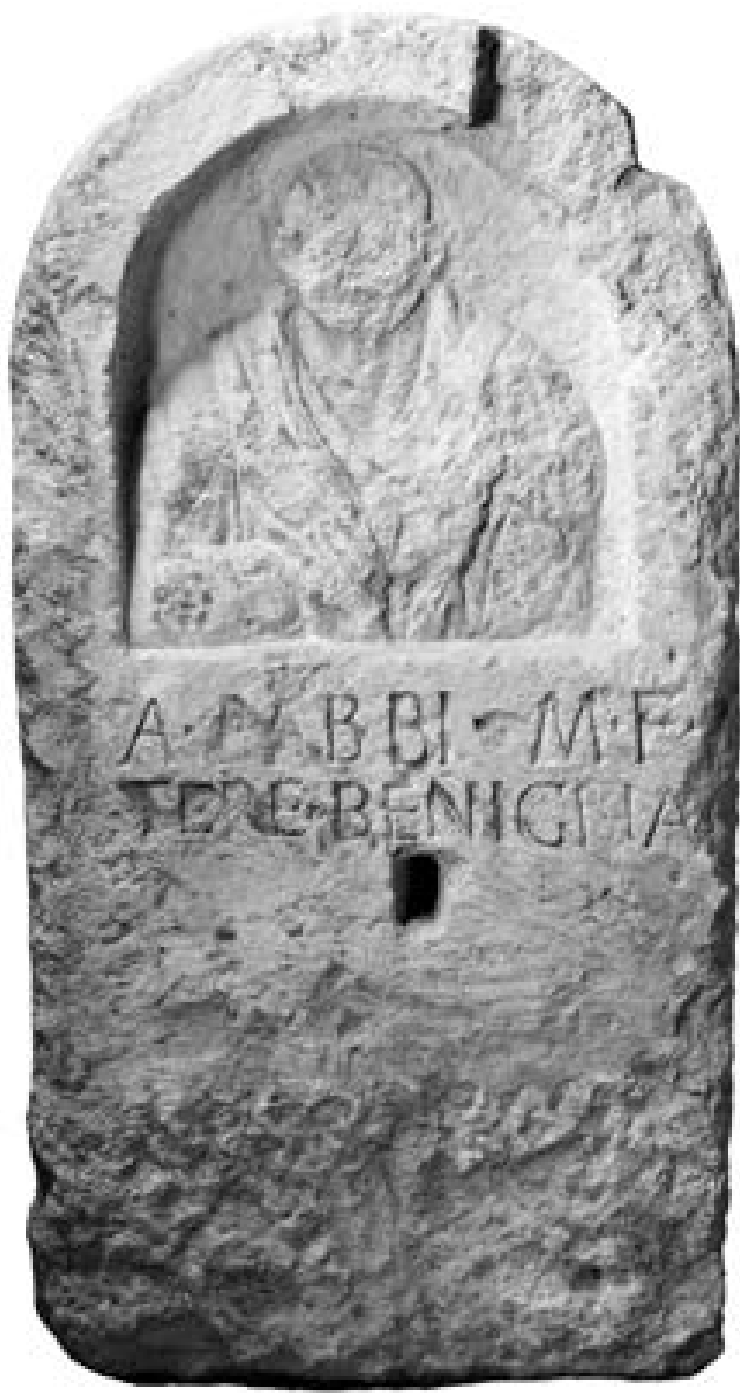

Fig. 21. Stèle d'Aulus Babbius. Arles, M.D.A.A. (C Philippe Groscaux, CNRS, CCJ).

sommet arrondi. Un large espace est laissé libre sous l'inscription. La partie inférieure de la stèle, bûchée, était certainement enfouie dans le sol. Le personnage, de taille importante, est drapé dans un manteau à larges bords, certainement une toge. Sa main droite placée sur sa poitrine tient les plis du manteau, et non un objet, comme le pensait Espérandieu. Du visage très abimé, ne restent plus que les oreilles, grandes et décollées. Le cou est aussi cylindrique et puissant. Les cheveux étaient peut-être coiffés vers l'avant. Il se peut que le visage ne soit pas abimé par le temps, mais qu'on ait cherché volontairement à le retailler.

L. : $80 \mathrm{~cm}, 1$. : $35 \mathrm{~cm}$ : CIL XII, 767, Espérandieu 1907, p. 156-157 $\mathrm{n}^{\circ} 201$; $C A G 13 / 5$, p. 405 n$^{\circ} 116$, fig. 428. 


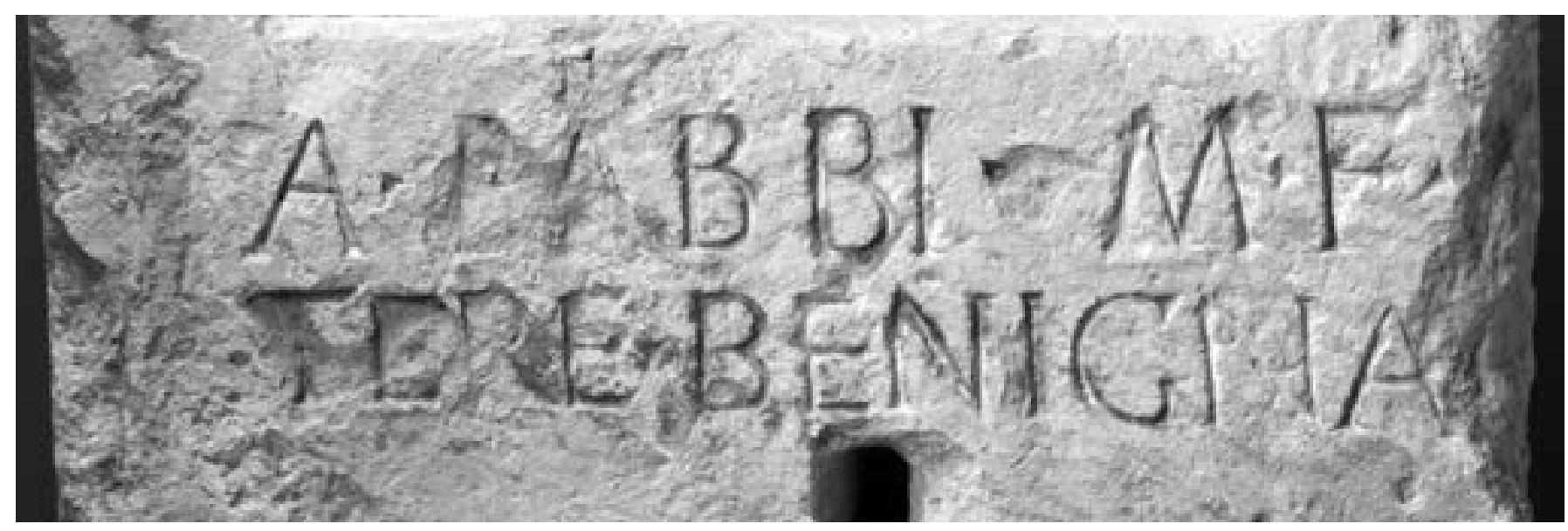

Fig. 22. Stèle d'Aulus Babbius. Détail de l'inscription. Arles, M.D.A.A. (@ Philippe Groscaux, CNRS, CCJ).

Notons que les stèles de cette même forme, mais de plus petites dimensions apparaissent à l'époque de Trajan à Bordeaux ${ }^{60}$.

L'inscription sous le portrait est très simple (fig. 22) :

$$
\begin{gathered}
\text { A(uli)*BABBI*M(arci)*F(ilii) } \\
\text { TERE(tina tribu)*BENIGNA }
\end{gathered}
$$

(stèle de) Aulus Babbius, fils de Marcus, de la tribu Teretina. Benigna (a fait ce monument)

L'inscription avec la mention de la tribu Teretina, qui est celle d'Arles, montre qu'il s'agit d'un citoyen, ce qui est corroboré par le port de la toge. Le nom, Babbius, est unique sous cette forme ; il s'agit peut-être d'une variante du gentilice Baebius, bien plus courant (une trentaine d'attestations en Narbonnaise) ${ }^{61}$. La stèle a été dédiée par une femme, nommée Benigna, dont on ignore les liens avec Babbius. Ce nom latin ${ }^{62}$ est peu fréquent et on le trouve, en Narbonnaise, quatre autres fois (CIL XII, 722 (Arles) ; 3516 (Nîmes); 5137 (Narbonne); ILN Vienne, 132).

Date: L'absence d'un cognomen pour le défunt plaide en faveur d'une date haute (première moitie du $\mathrm{I}^{\text {er }} \mathrm{s}$.). Le type de la stèle se retrouve également en Italie $\mathrm{du}$ Nord, où les quelques exemplaires proches ${ }^{63}$ sont datés de la première moitié du $\mathrm{I}^{\mathrm{er}} \mathrm{s}$. Le type de la toge se

60. Braemer 1959, p. $31 \mathrm{n}^{\circ} 7$, pl. 11.

61. OPEL I, p. 259-260.

62. Kajanto 1965, p. 255.

63. Voir trois stèles de Mantoue figurant un buste: Pflug 1989, p. 261-262 nos262-264, pl. 42, 1-3 ; stèle de Brescia avec une figure entière : Pflug 1989, p. 265 n $^{\circ} 273$. retrouve également sur les stèles ${ }^{64}$ de la même origine datant du début de ce même siècle. Une stèle épigraphe de Béziers ${ }^{65}$, qui peut être datée du ${ }^{\mathrm{er}} \mathrm{s}$. également, présente dans une niche à arcade supportée par deux pilastres le buste d'un homme drapé, la main droite sur la poitrine tenant les plis du manteau, jeté sur l'épaule gauche seulement.

\section{Autel funéraire d'Iulia Servata (fig. 23-24)}

Le dernier document analysé est un autel funéraire ${ }^{66}$ en marbre blanc à gros grains. La partie centrale d'une des faces principales a été partiellement évidée en forme de niche arrondie pour recevoir le portrait de la défunte, une jeune femme vêtue d'une tunique agrafée à chaque épaule. Malgré l'état du visage très abimé, on aperçoit sa structure solide ovale, le cou cylindrique, les joues larges, les yeux en amande aux paupières ourlées. Les cheveux partagés par une raie médiane, encadrent le visage en vagues striées et ramenés vers l'arrière de la tête, recouvrent en partie les oreilles. Sous le personnage a été gravée l'inscription. La face arrière porte dans un cartouche mouluré la même épitaphe, gravée avec plus de soins, avec des lettres de taille plus importante. Les petits côtés sont restés sans décor.

64. Stèle du musée de Bologne : Pflug 1989, p. 170 n $^{\circ} 45$, pl. 10 , 1-2; stèle du musée de Parme : Pflug 1989, p. 181 n 62 , pl. 16,1.

65. CIL XII, 4286, Espérandieu 1907, p. 346-347 n536.

66. Découverte en 1561 dans le rempart porte de Laure. Au M.D.A.A. Inv. FAN.92.00.198. H. : $91 \mathrm{~cm}$, L. : $58 \mathrm{~cm}, 1$. : $44 \mathrm{~cm}$ : CIL XII, 830, Espérandieu 1907, p. $155-156^{\circ} 198$; CAG 13/5, p. 262 $\mathrm{n}^{\circ} 42$, fig. 127. 


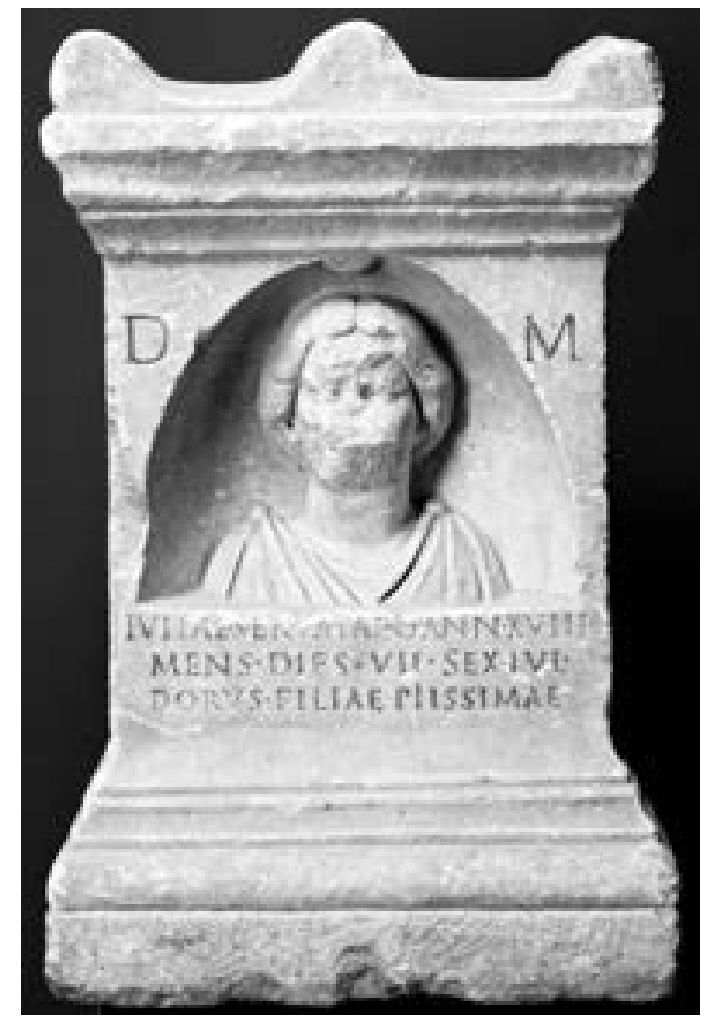

Fig. 23. Autel funéraire d'Iulia Servata. Face A : buste et inscription. Arles, M.D.A.A.

(๑) Philippe Groscaux, CNRS, CCJ).

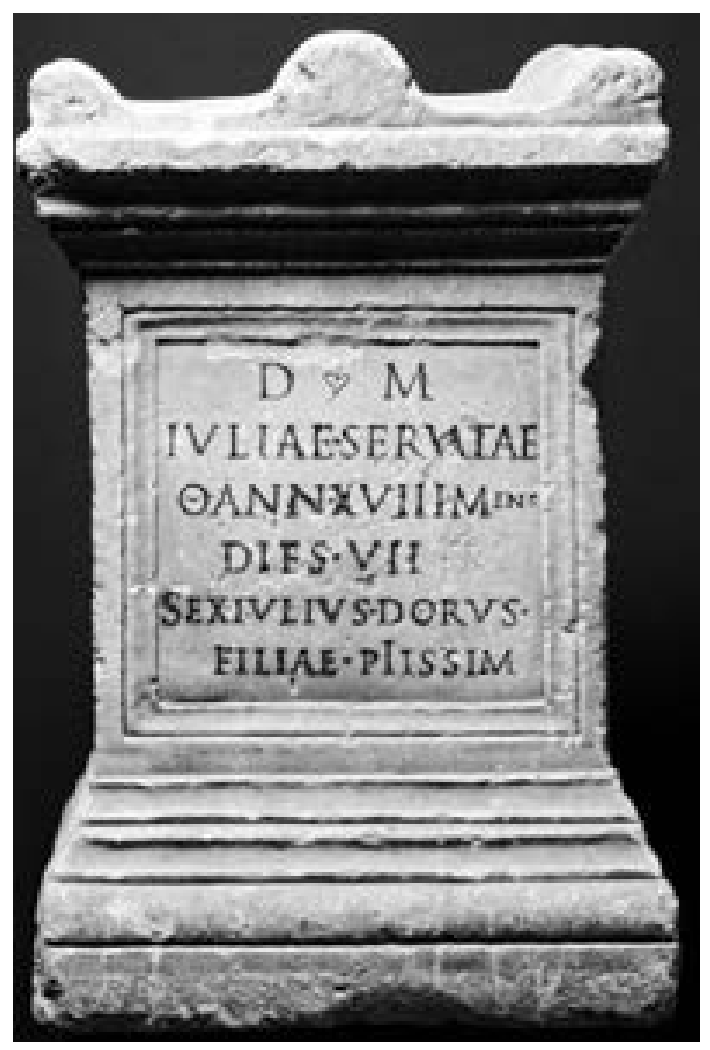

Fig. 24. Autel funéraire d'lulia Servata. Face B : inscription. Arles, M.D.A.A. (๔ Philippe Groscaux, CNRS, CCJ).
L'autel porte sur les deux faces la même inscription (fig. 23-24) avec seulement d'infimes différences dans la mise en page du texte :

1. face $^{67}$ :
$\mathrm{D}(\mathrm{is})$
M(anibus)
IVLIAE*SERVATAE* $\theta *$ ANN(os)*XVIII MENS(em)*DIES*VII*SEX(tus)*IVL(ius)* DORVS*FILIAE*PIISSIMAE

revers ${ }^{68}$.

D(is) $*$ M(anibus)
IVLIAE*SERVATAE
$\Theta *$ ANN(os)*XVIII*MENS(em)
DIES*VII
SEX(tus)*IVLIVS*DORVS
FILIAE*PIISSIM(ae)

Aux Dieux Mânes. A Iulia Servata, morte à l'âge de 18 ans, un mois et 7 jour. Sextus Iulius Dorus (a élevé ce monument) à sa fille très dévouée

La graphie est soignée, surtout sur la face principale. Sur le revers, 1. 2, on note la ligature VA, et une hedera se trouve au début entre le $\mathrm{D}$ et le $\mathrm{M}$.

Le nom de la jeune fille est des plus classiques, comme celui de son père, puisque le gentilice Iulius est parmi les plus fréquents en Narbonnaise ${ }^{69}$, alors que le cognomen Servatus/a est également bien attesté et paraît même particulier à la Province ${ }^{70}$. Seul le cognomen Dorus du père de la défunte fait exception, puisqu'il s'agit de la seule attestation en Narbonnaise. On le rencontre en revanche à plusieurs reprises à Rome ${ }^{71}$.

Sur les deux faces, on observe un thêta entre le nom de la défunte et l'indication de l'âge au moment du décès. Si cette abréviation, que l'on comprend traditionnellement comme obiit ou obitus/a, est en soi courante, surtout à Narbonne, l'emplacement avant l'indication de l'âge semble typiquement arlésien ; en effet, sur les 14 cas signalés dans l'index du CIL XII, 12 proviennent d'Arles, un de Beaucaire et un de la cité d'Alba. Cette dernière inscription est gravée sur

67. H. des lettres : $2 \mathrm{~cm}$.

68. H. des lettres : $4 \mathrm{~cm}$.

69. OPEL II, p. 201-207.

70. Pas moins de 57 attestations, d'après $O P E L$ IV, p. 57.

71. Solin 1982, p. 472. 


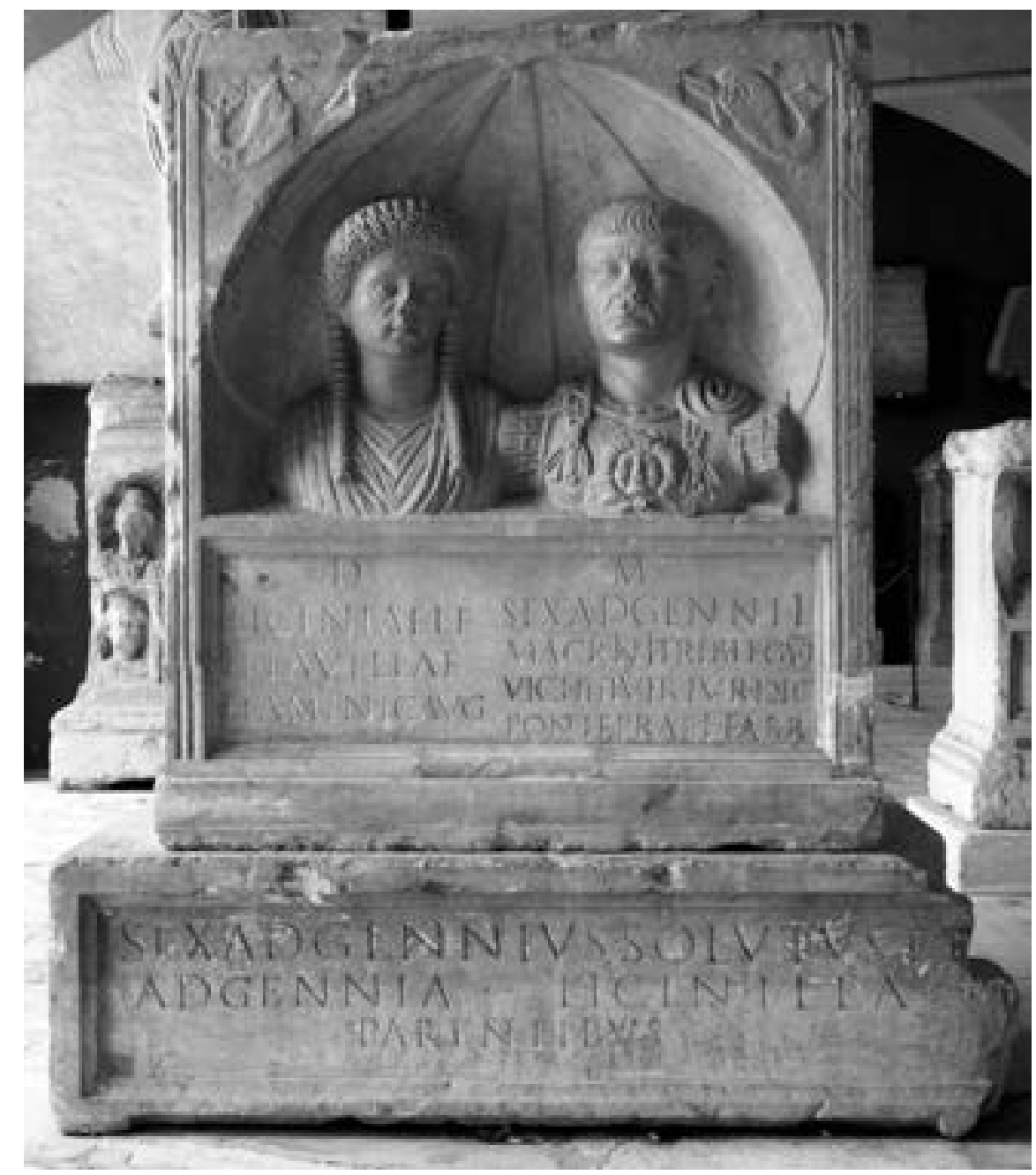

Fig. 25. Stèle de Licinia Flavilla et de Sextus Adgennius Macrinus. Nîmes musée archéologique (๑ Dejan Stokic, Musée archéologique de Nîmes).

un sarcophage d'enfant en marbre ${ }^{72}$ décoré d'Amours volants, très proche de certains exemplaires arlésiens ${ }^{73}$, et pour lequel on pourrait proposer une fabrication arlésienne sans grand risque d'erreur.

Date : Plusieurs indications permettent de dater cette inscription d'une période plus tardive que celle des stèles précédentes. L'invocation des Dieux Mânes, surtout abrégée, n'est pas antérieure à la fin du $\mathrm{I}^{\mathrm{er}} \mathrm{s}$. et se généralise après. Cela vaut également pour des épithètes laudatives, comme piissimus, alors que les inscriptions arlésiennes avec le thêta semblent dater du $\mathrm{II}^{\mathrm{e}} \mathrm{s}$., datation qui convient également pour cette stèle.

72. CIL XII, 2708 ; Espérandieu 1907, p. 287-289 n423. Lors d'un remploi au $\mathrm{IX}^{\mathrm{e}} \mathrm{s}$. pour Saint-Andéol, on a sculpté un décor chrétien à la face arrière du sarcophage.

73. Pour ce type de sarcophages produits à Arles voir : GaggadisRobin 2009.
Il s'agit d'un exemplaire produit par un atelier local, peut-être le même qui quelques décennies plus tard produisit des sarcophages. La coiffure reflète une mode capillaire des années du milieu du $\mathrm{II}^{\mathrm{e}} \mathrm{s}$. et semble être inspirée de celle de Faustine l'Ancienne ${ }^{74}$.

\section{Conclusion}

Fidèles au thème du colloque, nous avons présenté les stèles funéraires d'Arles qui assemblent sculpture et épigraphie ${ }^{75}$. Malgré le fait que nous ne pouvons pas rattacher cette petite série de stèles à un espace funéraire

74. Comme par ex. le portrait d'une inconnue du Louvre Ma 4572 : Kersauson 1996, p. $210 \mathrm{n}^{\circ} 90$.

75. Au M.D.A.A. existent trois autres stèles à portraits qui n'ont pas conservé leur inscription : Espérandieu 1907, p. 153-154 nºs 193, 196 et Espérandieu, Lantier 1947, p. 24 n7955. 
précis, leur intérêt est évident étant donné que pour la première fois, on procède à leur analyse technique et stylistique, ainsi qu'à l'étude de leurs inscriptions. En guise de conclusion quelques remarques s'imposent qui soulignent l'apport innovant de cette étude.

Au point de vue typologique la stèle à édicule prédomine $\left(\mathrm{n}^{\mathrm{os}} 1,2,4\right)$ couronnée d'une coquille, motif à forte symbolique funéraire, fréquemment et longtemps utilisé dans l'antiquité. La coquille est souvent clairement sculptée, mais parfois les rayons qui sont à peine indiqués, comme sur le document $\mathrm{n}^{\circ} 4$ servaient peut-être de repère au peintre, comme Espérandieu l'a également remarqué pour une stèle de Bonn ${ }^{76}$. Sur l'autel funéraire de Iulia Servata $\left(\mathrm{n}^{\circ} 7\right)$ les rayons étaient probablement suggérés par la couleur qui a disparu, alors que le crochet de la coquille est clairement sculpté.

Ce type de stèle à édicule semble avoir été assez courant dans la Narbonnaise. Nous avons évoqué des documents très proches conservés au musée archéologique de Nîmes, datables aussi dans le $\mathrm{I}^{\mathrm{er}} \mathrm{s}$. À cette collection appartient d'ailleurs un exemplaire de très belle facture ${ }^{77}$, en calcaire jaune (fig. 25). Il s'agit du monument de Licinia Flavilla, flaminique et de Sextus Adgennius Macrinus, tribun de légion et préfet des ouvriers qui a conservé sa base, portant également une inscription ${ }^{78}$. Le fond de la niche est constitué par une coquille bien ouverte et clairement sculptée. Le couple figure solennel en buste côté à côte, le mari portant une cuirasse sculptée dans le détail, l'épouse aux traits de jeune fille, mais les personnages ne sont pas représentés de manière expressive et vivante, comme sur les stèles d'Arles ${ }^{79}$.

Pour l'édicule, le sculpteur emprunte des éléments au répertoire du décor architectural, pour suggérer au mieux la monumentalité de la stèle. Le défunt y figure seul $\left(n^{\circ} 6,7\right)$, en couple $\left(n^{\circ} 3\right)$, ou bien en famille $\left(n^{\circ} 2\right)$. Les femmes ${ }^{80}\left(\mathrm{n}^{\text {os }} 1,4\right)$ figurent ornées de bijoux, portant

76. Espérandieu 1925, p. $247 n^{\circ} 6270$.

77. CIL XII, 3175 ; Espérandieu 1907, p. 318 n 478 ; Espérandieu 1924, p. 84 n²90, pl. 24 ; CAG 30/1, p. 347, (311) n ${ }^{\circ} 6$.

78. CIL XII, 3368 ; CAG 30/1, p. 361 (329) n6, il s'agit de la partie inférieure du tombeau par Sextus Adgennius Solutus et Adgennia Licinilla : Darde, Lassalle 1993, p. 60-61.

79. Sur la photo récente du monument que nous publions ici, après restitution de l'angle supérieur gauche, jadis refait en ciment comme le mentionne Espérandieu, il est clair que la tige à gauche, qu'Espérandieu interprétait comme une lance (Espérandieu 1907, p. $318 n^{\circ} 478$ ), est un épi de blé.

80. Sur une stèle du même type que les monuments examinés, mais qui n'a pas conservé son épitaphe, figure aussi un enfant accompagné de ses parents : Espérandieu 1907,p. 154 n 196. parfois une pomme. Elles sont accompagnées de leur mari, parfois elles ont élevé la stèle pour une sœur, ou bien pour leur patronne. Quant aux hommes portant la toge, ils font partie certainement des premières représentations des citoyens romains d'Arles. Enfin la stèle $\mathrm{n}^{\circ} 3$ comporte peut-être des attributs professionnels du défunt (ou même de la défunte ?). Une des stèles $\left(\mathrm{n}^{\circ} 4\right)$ qui a conservé des traces de crochets métalliques servant à accrocher des guirlandes, témoigne de la pratique familiale du rituel funéraire de la visite et de la décoration de la tombe.

Les nombreux documents issus d'Italie du Nord auxquels nous avons fait appel à titre de comparaison, mettent en évidence leurs liens avec les monuments arlésiens. Seul l'autel funéraire $\left(\mathrm{n}^{\circ} 7\right)$ peut être daté du II $\mathrm{e}$ s., la majorité des documents ( $\left.{ }^{\text {os }} 1-6\right)$ se situent dans la première moitié du I ${ }^{\mathrm{er}} \mathrm{s}$. La stèle de Philematio et de Chia $\left(\mathrm{n}^{\circ} 1\right)$, ainsi que la stèle familiale $\left(\mathrm{n}^{\circ} 2\right)$ ont été probablement sculptées dans les premières décennies du siècle et il est possible que cette dernière présente une deuxième phase de décor, environ deux décennies après. Ces deux stèles d'ailleurs attestent à Arles la présence dès le $\mathrm{I}^{\mathrm{er}} \mathrm{s}$. des sculpteurs très expérimentés, liés avec les ateliers d'Italie du Nord, d'où ils étaient peut-être originaires.

\section{Bibliographie}

Braemer 1959 : BRAEMER (Fr.) - Les stèles funéraires à personnages de Bordeaux. I I $-I I I^{e}$ siècles; contribution à l'histoire de l'art provincial sous l'Empire romain, Paris, A. et J. Picard, 1959, 157 p., 36 pl.

CAG 13/2 : GATEAU (F.), GAZENBEEK (M.), éd. - Les Alpilles et la Montagnette 13, 2, Paris, 1999, 464 p., Académie des Inscriptions et Belleslettres, (Carte archéologique de la Gaule).

CAG 13/5 : ROTHÉ (M.-P.), HEIJMANS (M.), éd. - Arles, Crau, Camargue 13/5, Paris, 2008, 906 p., Académie des Inscriptions et Belles Lettres, (Carte Archéologique de la Gaule).

Coarelli, Sisani 2008 : COARELLI (F.), SISANI (S.) - Museo comunale di Terni. Raccolta archeologica. Sezione romana, Perugia: Electa Editori Umbri; Milano: Electa, 2008, 254 p. (Catalogo regionale dei beni culturali dell'Umbria ).

Darde, Lassalle 1993 : DARDE (D.), LASSALLE (V.) - Nîmes antique. Monuments et sites, Paris, Imprimerie Nationale éditions, 1993, 123 p., (Guides archéologiques de Grance).

Espérandieu 1907 : ESPÉRANDIEU (É.) - Recueil général des bas-reliefs de la Gaule, I, Paris, 1907, 489 p., (réimpr. Anast. The Gregg Press Inc. 1965).

Espérandieu 1908 : ESPÉRANDIEU (É.) - Recueil général des bas-reliefs de la Gaule, II, Paris, 1908, 478 p., (réimpr. Anast. The Gregg Press Inc. 1965). 
Espérandieu 1925 : ESPÉRANDIEU (É.) - Recueil général des bas-reliefs de la Gaule, IX, Paris, 1925, 437 p., (réimpr. Anast. The Gregg Press Inc. 1965).

Espérandieu, Lantier 1947 : ESPÉRANDIEU (É.), LANTIER (R.) - Recueil général des bas-reliefs de la Gaule, XII, Paris,1947, 47 p., 48 pl.

Gaggadis-Robin 2009 : GAGGADIS-ROBIN (V.) - Ateliers de sculpture d'Arles: nouvelles recherches sur la série des sarcophages avec Amours. Histria Antiqua, 18-1, 2009, p. 381-388.

Gaggadis-Robin, Gascou 1996 : GAGGADIS-ROBIN (V.), GASCOU (J.) - Les sarcophages décorés du Musée de Vienne (Isère). RAN, 29, 1996, p. $145-171$.

Gaggadis-Robin, Mignon, Zugmeyer 2009: GAGGADIS-ROBIN (V.), MIGNON (J.-M.), ZUGMEYER (S.) - La grande sphinge restaurée du Mausolée carré de Fourches-Vieilles à Orange (Vaucluse). In : GaggadisRobin (V.), Hermary (A.), Reddé (M.), Sintes (C.) éd., Les ateliers de sculpture régionaux: techniques, style et iconographie, Actes du $\mathrm{X}^{\mathrm{e}}$ Colloque International sur l'art provincial romain, Arles et Aix-en-Provence, (21-23 Mai 2007), Arles, 2009, 840 p. (Centre Camille Jullian, Musée départemental Arles Antique), p. 33-39.

Hainzmann 1991: HAINZMANN (M.), Schriftrolle und Schwurgestus. Neue Beobachtungen zu einem alten Bildmotiv. In : Hainzmann (M.), Kramer (D.), Pochmarski (E.) éd., Akten des 1. Internationalen Kolloquiums über Probleme des Provinzialrömischen Kunstschaffens (Graz 27.-30. April 1989). Teil II, (Mitteilungen der Archäologischen Gesellschaft Steiermark, Jg. 5, 1991), Vienne, 1991, 174 p, 52 pl., (VWGÖ), p. 120-146.

Heijmans 2003 : HEIJMANS (M.) - Les stèles inscrites. In : Marcadal (N.), Marcadal (Y.), Paillet (J.-L.) éd., La nécropole protohistorique et gallo-romaine de Servanes - Cagalou ( ${ }^{\text {er }}$ s. av. J.-C. - III ${ }^{\mathrm{e}}$ s. ap. J.-C.) à Mouriès (Bouchesdu-Rhône) : sépultures et monuments funéraires. DAM, 26, 2003, p. 251-348.

Hölder 1896-1913 : HÖLDER (A.) - Altkeltischer Sprachschatz, 3 vol., Leipzig 1896-1913, 1035 p. + 1013 p. + 640 p., (réimpr. Anast. Graz, 19611962), Akademische Druck.

ILGN : ESPÉRANDIEU (É.) - Inscriptions latines de Gaule (Narbonnaise), Paris 1929, 224 p., E. Leroux.

Kajanto 1965 : KAJANTO (I.) - The Latin Cognomina, Helsinki 1965, 417 p. (Commentationes humanorum litterarum 36, 2).
Kersauson 1986 : DE KERSAUSON (K.) - Musée du Louvre. Catalogue des portraits romains, I. Portraits de la République et d'époque Julio-Claudienne, Paris, 1986, 246 p. (Editions de la Réunion des musées nationaux).

Kersauson 1996 : DE KERSAUSON (K.) - Musée du Louvre. Catalogue des portraits romains, II, De l'année de la guerre civile (68-69 après J.-C.) à la fin de l'Empire, Paris, 1996, 582 p. (Editions de la Réunion des musées nationaux).

Lacaze Duthiers 1908 : LACAZE DUTHIERS (E.) - Nos vieilles pierres. La stèle funéraire trouvée dans l'ancien rempart d'Arles dit de la Porte de Laure. Bulletin des Amis du Vieil Arles, 1908, p. 206-220.

OPEL I : LÖRINCZ (B.), REDÖ (Fr.) - Onomasticon prouinciarum Europae Latinarum, vol. I : Aba-Bysanus, Budapest, Archaeolingua Alapítvány, 1994, 364 p., (Archaeolingua 3).

OPEL II : LÖRINCZ (B.) - Onomasticon prouinciarum Europae Latinarum, vol. II : Cabalicius-Ixus, Vienne, Forschungsgesellschaft Wiener Stadtarchäologie, 1999, 232 p.

OPEL III : LÖRINCZ (B.) - Onomasticon Prouinciarum Europae Latinarum, III : Labareus-Pythea, Vienne, Forschungsgesellschaft Wiener Stadtarchäologie, 2000, 190 p.

OPEL IV: LÖRINCZ (B.) - Onomasticon Prouinciarum Europae Latinarum, IV : Quadratia-Zures, Vienne, Forschungsgesellschaft Wiener Stadtarchäologie, 2002, 210 p.

Pflug 1989 : PFLUG (H.) - Römische Porträtstellen in Oberitalien, Mayence, Philipp von Zabern, 1989, 320 p., 52 pl. (DAI).

Solin 1982 : SOLIN (H.) - Die griechischen Personennamen in Rom. Ein Namenbuch, Berlin - New-York, 1982, 1584 p. W. de Gruyter.

Solin, Solomies 1994: SOLIN (H.), SOLOMIES (O.) - Repertorium nominum gentilium et cognominum Latinorum, Hildesheim, 1994, 508 p. Olms-Weidenmann.

Von Moock 1998 : VON MOOCK (D.) - Die figürlichen Grabstelen Attikas in der Kaiserzeit. Studien zur Verbreitung, Chronologie, Typologie und Ikonographie, Mayence, Philipp von Zabern, 1998, 217 p.-76 pl. (Beiträge zur Erschließung hellenistischer und kaiserzeitlicher Skulptur und Architektur). 



\title{
Le cénotaphe de Clarensac : un somptueux décor autour de l'épitaphe de M. ATTIVS PATERNVS
}

\author{
Michel Christol \\ Professeur émérite, Université Paris I-Panthéon Sorbonne, ANHIMA (UMR 8210) \\ christolmichel@yahoo.fr \\ Danièle Terrer \\ Centre Camille Jullian (UMR 7299-CNRS, Aix-en-Provence) \\ Terrer@mmsh.univ-aix.fr
}

\section{Résumé}

Cet article est consacré à un autel de marbre blanc aux dimensions imposantes et à la riche décoration (CIL XII, 3200) provenant de Clarensac, situé sur le territoire antique de Nîmes. Cet autel ne signalait pas une sépulture, mais un cénotaphe dressé en l'honneur d'un personnage de haut rang, M. Attius Paternus, originaire de la cité de Riez.

Mots-clés: Gaule Narbonnaise, Nîmes, Riez, épigraphie, inscription latine, ordre équestre, chevalier, décurion, Attii.

\begin{abstract}
This article is devoted to a white marble altar of imposing dimensions and rich decoration (CIL XII, 3200) from Clarensac, located on the territory of Nimes during Roman times. This altar did not report a burial, but a cenotaph: it has been erected in honor of a person of high rank, M. Attius Paternus, borned in the city of Riez.
\end{abstract}

Key-words: Gallia narbonensis, Nîmes, Riez, epigraphy, Latin inscription, equestrian order, decurio, Attii. 
$\mathrm{L}$ e monument a été mis au jour à Clarensac en janvier 1758, à proximité du village, sur la route conduisant à Nîmes. Lorsque Léon Ménard rédigeait le dernier ouvrage de l'Histoire civile, ecclésiastique et littéraire de la Ville de Nîmes, qui parut en 1758 (VII, p. 279) = éd. de 1875, VII, p. 333, nXXX de la dissertation II (« sur les inscriptions des empereurs et des magistrats »), il indiquait que le monument avait été «trouvé depuis peu». Il fut d'abord recueilli au château du village, puis il fut transporté à Nîmes en novembre 1824, et déposé à la Maison Carrée qui venait d'être établie comme Musée (l'inauguration eut lieu le 11 mars 1824). L'autel fut placé sous le portique, puis il fut installé à l'intérieur. Il a fait l'objet de plusieurs éditions : CIL XII, $3200(=I L S, 6983)=I A N, 116=$ HGL XV, 234.

\section{Description du monument}

Il s'agit d'un cippe de marbre blanc aux dimensions imposantes ${ }^{1}$. Sous un fronton cintré entre deux volutes et sur lequel nous reviendrons, la partie supérieure comprend: un linteau entre les pilastres d'angle ${ }^{2}$; une corniche reposant sur les chapiteaux ; un attique en deux registres séparés par une moulure, composé de deux frises superposées.

Les faces latérales sont ornées. En revanche, l'arrière est piqueté, mais non travaillé.

Les pilastres sur les deux côtés verticaux et le linteau qui les couronne, encadrent l'inscription à la mémoire de Marcus Attius Paternus. Celle-ci se présente de la sorte:

\section{MEMORIAE \\ $\mathrm{M} \bullet \mathrm{ATTI} \bullet \mathrm{M} \bullet \mathrm{FIL} \bullet \mathrm{VOLT}$ \\ PATERNI•EQVO•PVBLIC \\ HONORATO $\bullet$ ITEM・DECV \\ RIONI•COL・APOLLINARE \\ REIORVM•DECURIONI \\ ORNAMENTARIO•COL・AVG \\ NEMAVSI•AN•XXV•AGENTI \\ COELIA $\bullet$ SEX $\bullet$ FILIA \\ PATERNA \\ FILIO•PIISSIMO}

1. Ht. 2,10 m ; 1. 0,95-1,15 m ; ép. 0,68 m.

2. «Le caractère architectonique est souligné par les pilastres d'angle et l'agencement de la partie supérieure... » (Burnand 1975, p. 750-751).
Memoriae M(arci) Atti M(arci) fil(ii) Volt(inia) Paterni, equo publico honorato, item decurioni col(onia) Apollinare Reiorum, decurioni ornamentario col(oniae) Aug(ustae) Nemausi, an(nos) XXV agenti, Coelia Sex(ti) filia Paterna filio piissimo. (fig. 1)

\section{Le cénotaphe d'un personnage de haut rang}

Une clef d'interprétation est donnée par le premier mot du texte: memoriae. L'absence de référence aux divinités mânes du défunt indique qu'il ne s'agit pas de la tombe du personnage ${ }^{3}$, même si, dans quelques cas, elle est appelée memoria, comme le relève déjà l'index du CIL, XII, p. 964 lorsqu'on y écrit : memoria = sepulcrum $^{4}$. La tombe se trouvait ailleurs ${ }^{5}$. À Clarensac, à l'initiative de la mère du défunt, on se contentait de rappeler sa mémoire et d'organiser un culte funéraire auprès de l'autel, alors que les restes du défunt étaient ensevelis dans un autre lieu qui se trouvait dans la cité de Riez vraisemblablement.

Il faut s'accommoder des changements de cas qui se produisent tout au long du texte : passage du génitif au datif après la dénomination de la personne (on attendrait plutôt equo publico honorati, puis decurionis etc.), ensuite, dans la localisation des honneurs, le passage de l'ablatif pour ce qui concerne Riez au locatif pour ce qui concerne Nîmes. On traduira : «À la mémoire de Marcus Attius Paternus, fils de Marcus, de la tribu Voltinia, honoré du cheval public, et aussi décurion dans la colonie Apollinaris Reiorum, honoré des ornements de décurion dans la colonie Augusta Nemausus, mort à l'âge de vingt-cinq ans ; Coelia Paterna, fille de Sextus, pour le plus pieux des fils ».

On a longtemps hésité sur la cité de rattachement de M(arcus) Attius Paternus, la communauté de citoyens à laquelle le liait son origo. Mais Y. Burnand, qui avait argumenté en faveur de Nîmes, à partir des attestations épigraphiques du gentilice Attius ${ }^{6}$, est revenu sur son point de vue et sa retractatio du sujet apporte à présent une claire démonstration de la question, à

3. Contrairement à l'avis des commentateurs dans $H G L \mathrm{XV}, 234$ et d'Allmer 1883.

4. Voir aussi ILN Antibes, 8 (Chastagnol 1992, p. 48), 94 (Chastagnol 1992, p. 130) et 97 ; ILN Riez, 25 (Chastagnol 1992, p. 228).

5. Pour l'usage de memoria dans l'inscription d'un cénotaphe : CIL XIV, 3602 (ILS, 950) = Inscr. Ital. IV, 1, 18 (Tibur), et plus généralement sur le sujet, Ricci 2006 (qui, cependant, ne relève pas l'exemple fourni dans la cité de Nîmes par l'inscription de Clarensac).

6. Burnand 1975,p. 749-751. 


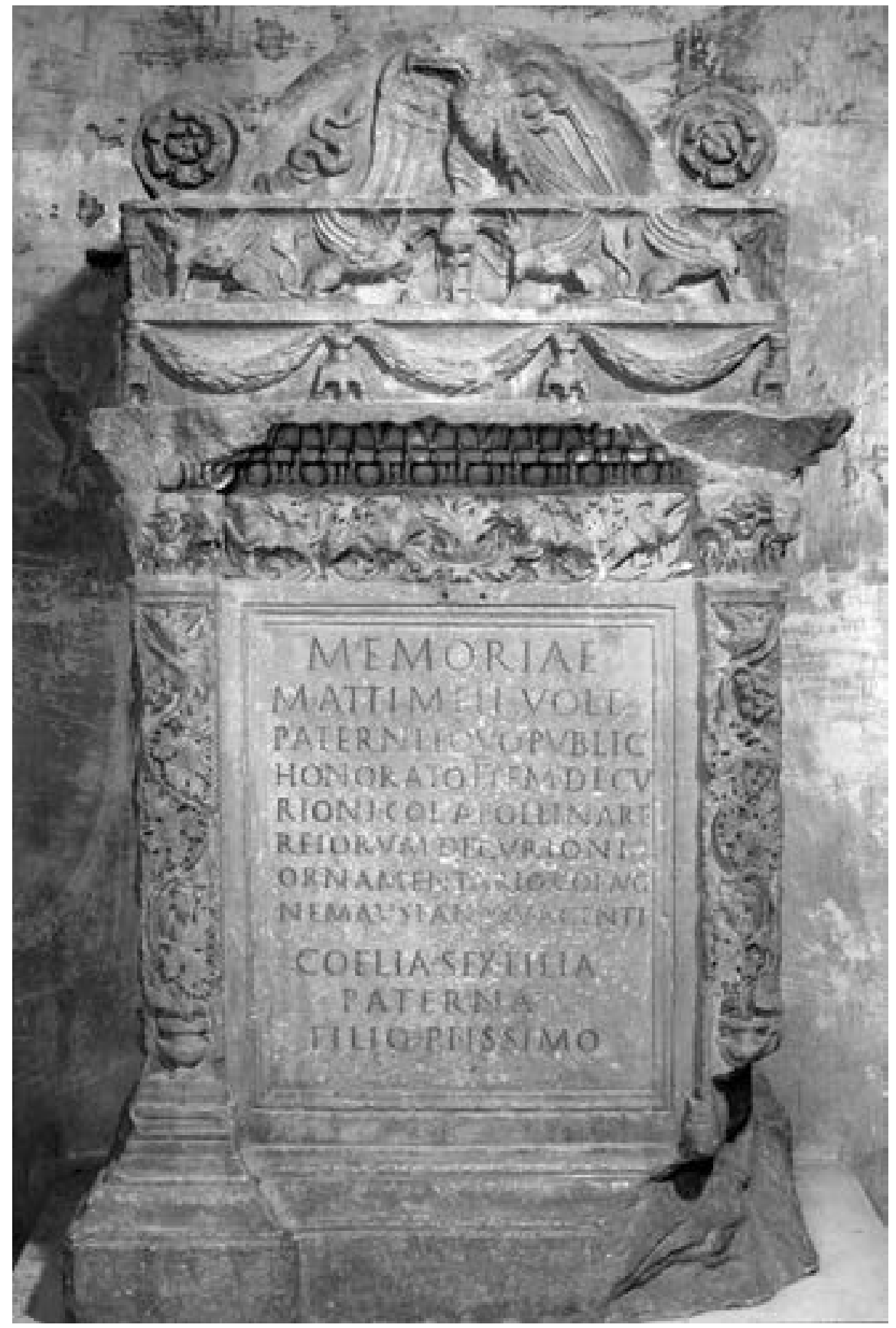

Fig. 1. Le cénotaphe de Clarensac. Inscription CIL XII, 3200 (๑) Centre Camille Jullian, UMR 7299-CNRS).

laquelle on ne peut que se rallier ${ }^{7}$. En effet, Paternus était décurion à Riez, colonie de droit latin, la colonia Apollinaris Reiorum ${ }^{8}$, ce qui signifie qu'il était lié à cette cité par son origo $^{9}$, et c'est là qu'il devait ses obligations d'honoratus ou d'honestior: membre de l'ordo municipal, il devait y parcourir la carrière des

7. Burnand 2006, p. 262-263 ; voir aussi Burnand 2005, p. 102 pour la datation du $\mathrm{I}^{\text {er }}$ siècle.

8. Dénomination : Hirschfeld dans CIL, XII, p. 49 ; Barruol 1968, p. 273-277; Chastagnol 1992, p. 188.

9. Jacques 1984, p. 648-649, p. 652-653 ; Thomas 1996, p. 61-68. magistratures locales (Jacques 1984, p. 321-336, p. 352357), y assumer les éventuelles charges inhérentes à cette position honorifique (les munera) et soutenir plus généralement sa dignitas (Garnsey 1970, p. 224225 ; Jacques 1984, p. 571), car celle-ci et la position acquise en conséquence procédaient vraisemblablement d'une histoire familiale établie localement. A contrario, l'origine extérieure à la cité de Nîmes, autre cité de droit latin, est révélée par sa qualité de decurio ornamentarius. $\mathrm{Ce}$ point de vue avait été implicitement admis par A. Chastagnol qui, dans l'introduction de l'édition des inscriptions de Riez, considérait que le gentilice Attius 
faisait partie des " noms connus en dehors de la cité ${ }^{\mathbf{1 0}}$. Mais il faut remarquer, si le texte ne nous trompe pas par des omissions, que l'âge au décès, vingt-cinq ans, établit que le défunt n' avait pas encore entamé la carrière municipale dans la cité provençale de ses ancêtres, alors qu'il avait atteint l'âge d'accès aux magistratures ${ }^{11}$. En effet, le statut de chevalier romain le prédisposait à un parcours brillant, car il était placé au niveau le plus élevé dans la société politique, celui qui fournissait les prêtres du culte impérial, tant dans les cités qu'au niveau provincial. Mais on n' oubliera pas que soutenir la dignité familiale dans plusieurs cités était onéreux ${ }^{12}$, et que déjà l'entrée dans l'ordo de Riez impliquait un réel engagement financier ${ }^{13}$.

Une des particularités de l'épigraphie nîmoise est de fournir plusieurs exemples de personnes ayant été distinguées par l'honneur des ornements décurionaux. Ce qui ailleurs se découvre isolément et rarement ${ }^{14}$, prend ici d'autres dimensions, car le phénomène apparaît dans toute sa réalité : il n'était pas occasionnel comme on pourrait le croire ; il était bien apparent dans le déroulement de la vie municipale et une place bien visible lui est assignée par la documentation. En effet, cette marque d'honneur conférait à ceux qui l'avaient reçue quelques avantages des décurions, par exemple la participation à des distributions ${ }^{15}$ : on peut ajouter le placement dans les lieux de fêtes et de spectacles ${ }^{16}$. Pris dans leur ensemble, les personnages connus constituaient assurément un groupe mixte. Les témoignages les plus nombreux concernent des sévirs augustaux pour qui cet honneur, qui impliquait le versement d'une summa honoraria ${ }^{17}$,

10. Chastagnol 1992, p. 188 ; nous avons défendu cette interprétation en évoquant le mariage de personnes issues de deux cités différentes (Christol 2005, p. 564 n.32).

11. Sur l'âge d'accès aux magistratures et sur les pratiques qui l'adaptent aux circonstances, Jacques 1984, p. 463-465 (avec la n.102 de la p. 464, sur les particularités), p. 472-473.

12. Jacques 1984, p. 656-658; Thomas 1996, p. 76.

13. Sur le fils de décurion, Jacques 1984 , p. 579-580, p. 603-618; sur les engagements de fortune, servant de garantie, Garnsey 1970, p. 243-244.

14. Par exemple $A E, 1957,21$ en Bétique : Jacques 1984, p. 407 ; CIL X, 4643 en Italie : Jacques 1984, p. 404-405 ; nous avons repris la question dans une communication à paraître : Christol (à paraître), avec une bibliographie plus étendue.

15. CIL XII, $3058=H G L \mathrm{XV}, 94=447$, où l'on prévoit d'honorer de la sorte [decuri]onibus Nemausensium et ornamentar[iis].

16. Garnsey 1970, p. 244-245 ; mêmes avantages pour les incolae, les consistentes, « résidents » plus ou moins stables (Pavis d'Escurac 1988, p. 62, p. 64).

17. On doit le déduire de la mention de la gratuité de l'honneur dans le cas de C(aius) Aurelius Parthenius : CIL XII, $3203=H G L$ XV, 238 : C(aius) Aurelius Parthenius, ornamentis dec(urionalibus) honoratus col(oniae) Aug(ustae) Nemausi, sevir Aug(ustalis) col(onia) Copia apportait un surcroît d'élévation sociale et de prestige : il pouvait venir couronner une participation évergétique à la vie municipale ${ }^{18}$. Un plus petit nombre se rapporte à des personnes qui signalaient aussi leur appartenance au monde des notables dans une autre cité que celle de Nîmes. Pour eux l'honneur était avant tout une confirmation de leur statut, mais sans aucun doute coûteux. L'index du volume XII du CIL distingue déjà soigneusement ces deux groupes ${ }^{19}$.

On connaît ainsi, parmi ces derniers, trois exemples, y compris M(arcus) Attius Paternus. Avec lui sont attestés M(arcus) Verius Victor ${ }^{20}$, également décurion à Riez, et M(arcus) Velloudius Statutus qui, lui, avait été décurion à Senez, cité des Alpes-Maritimes ${ }^{21}$. Y. Burnand a souligné les rapports qu'avaient les cités de l'intérieur provençal avec Nîmes, qui sont aussi importants que ceux qu'entretenaient ces mêmes cités avec la colonie d'Arles.

Il faut donc admettre l'existence d'une gens Attia à Riez, parvenue à la dignité équestre soit à la génération de notre jeune nîmois, soit antérieurement à lui. Mais elle n'est pas autrement connue : il n'y a pas de témoignage épigraphique du gentilice Attius à Riez, mais ce n'est pas une raison suffisante ${ }^{22}$, comme l'avait envisagé

Claudia Lugud(uno) item Narbone Martio item Fir(ma) Iul(ia) Secund(anorum) Arausione et Foro Iulii Pacato, ubique gratuitis honoribus. Il faut vraisemblablement étendre l'octroi de la gratuité à tous les honneurs reçus et pas seulement au sévirat augustal : on connaît à Nîmes un exemple d'ornamenta seviralia obtenus avec la gratuité (Christol, Gascou, Janon 1987). Pour les ornements de décurion, CIL X, 5348 (ILS, 5648), (cf. Jacques 1984, p. 409).

18. CIL X, 4643 : Jacques 1984, p. 404-405 ; AE, 1957, 21 : Jacques 1984, p. 407.

19. CIL XII, p. 935 ; voir aussi Christol 1990, p. 76. Le cas étudié dans cet article se rapporte à C(aius) Sergius Respectus ( $A E$ 1969$1970,376=A E 1992,1216$ ), qui offre une situation inversée, puisque, notable de Nîmes, il fut decur(io) or[nam(entarius) C]abal(lione), c'est-à-dire dans la colonie latine de Cavaillon.

20. CIL, XII, $3291=H G L, \mathrm{XV}, 235:[D($ is $) m($ anibus $)] M(\operatorname{arci})$ Verii Victoris decurion(is) col(onia) Iul(ia) Aug(usta) Apollinar(e) Reiorum item col(onia) Aug(usta) Nem(auso) ornam(entario) vivos sibi et suis fecit. Il ne manque que la première ligne du texte, placée en dehors du cadre principal qui est pour sa part conservé. On ajoutera, même si elle est incomplète, une inscription de Bellegarde, encore dans ce lieu, qui faisait connaître aussi, indirectement, un personnage appartenant à la cité de Riez (CIL XII, $4082=H G L$ XV, 1419) : [---] col. Iul. August. Apollon. fratris.

21. CIL XII, $3288=H G L \mathrm{XV}, 236: D$ (is) m(anibus) L(ucii) Velloudi Statuti dec(urioni) Sanit(iensium) et dec(urionis) orn(amentarii) col(onia) Aug(usta) N(emauso), Sempronia Statuta patris piissimi.

22. C'est ce que montre la liste des noms de familles connus hors du territoire de la cité (Chastagnol 1992, p. 194, cf. p. 191) : il n'y a pas de véritable corrélation entre les gentilices attestés dans l'épigraphie locale et ceux qui apparaissent à l'extérieur. 
un temps Y. Burnand, pour récuser que son origo l'ait rattaché à cette cité.

Pour ces notables issus d'une autre cité, une alliance avec une famille nîmoise faisait entrer dans un milieu plus élevé : elle pouvait apporter un peu plus de prestige et surtout davantage d'appuis ${ }^{23}$. Mais il fallait aussi acquérir la reconnaissance d'une position dans une autre cité que celle de l'origine, sans pour autant bénéficier pleinement d'une double appartenance, qui était exclue. Il faut donc rechercher les raisons de la présence de ce cénotaphe aux environs du village de Clarensac dans le déroulement de l'histoire familiale, puisqu'il s'agit d'un milieu où nouer des alliances pouvait conduire à l'extérieur de la cité. En effet, tant Y. Burnand ${ }^{24}$ que L. Wierschowski ${ }^{25}$ ne se sont pas prononcés sur cet aspect du problème et le second d'entre eux se demande quel est l'arrière-plan de la présence de ce décurion honoraire dans le territoire nîmois. Sans aucun doute c'est parce que la mère, Coelia Sex(ti) filia Paterna, était d'une famille nîmoise. Certes le nombre des attestations sur la gens Coelia, à Nîmes, est assez réduit ${ }^{26}$. Mais c'est par rapport à des dossiers très bien fournis que l'on pourrait considérer ce groupe familial comme mineur. Il convient de tenir compte des effets de la constitution de la documentation épigraphique et admettre que bien des familles de notables ne sont encore connues qu'imparfaitement. De toute façon, dans le cas de M(arcus) Attius Paternus, le rang équestre vient indiquer aussi un niveau de fortune plutôt élevé, qui plaçait le personnage au-dessus du commun des décurions, même si la formulation retenue peut laisser supposer une entrée de fraîche date parmi les chevaliers romains (Demougin 1988, p. 201-202). Le dossier épigraphique montre une implantation dans la ville de Nîmes elle-même ${ }^{27}$, comme on peut s'attendre de personnes qui étaient contraintes par la législation d'avoir une résidence urbaine, au chef-lieu de la cité, au lieu où se concentrait la vie politique (Strabon, Géogr., IV, 1, 12), et aux alentours de Nîmes, en quelques points du territoire. L'inscription de Saint-Hippolytede-Montaigu, dans l'Uzège est isolée ${ }^{28}$, tout comme, dans la Vaunage, celle de Clarensac. Mais celle-ci,

23. Sur l'hétérogénéité du monde des décurions et des notables des cités (Jacques 1984, p. 562-570). À Nîmes Christol 1990, p. 73-77.

24. Qui évoque la situation d'incola dans sa notice de 2006 (voir n.7).

25. Wierschowski 2001, p. 177-178, n²18.

26. Il est en train de s'étoffer toutefois avec les nouvelles découvertes épigraphiques de P. Thollard sur le site de Murviel-les-Montpellier.

27. CIL XII, $3704=H G L \mathrm{XV}, 948$; CIL XII, $3524=H G L, \mathrm{XV}$, $757 ;$ CIL XII, $3523=H G L$ XV, 756.

28. CIL XII, $3704=H G L \mathrm{XV}, 1645$. vraisemblablement, par son contenu et par sa fonction vient orienter l'attention sur la situation du principal domaine familial maternel : c'est une problématique du genre de vie des notables qui a déjà été bien étudiée, à partir de la documentation archéologique comme à partir de la documentation épigraphique ${ }^{29}$.

S'il y a mobilité des personnes ${ }^{30}$, elle est ici d'un genre particulier ${ }^{31}$. À l'origine de la célébration de la mémoire du personnage et de la situation juridique que fait apparaître l'inscription, il y a une alliance matrimoniale. Elle avait créé une situation juridique originale. Le défunt ne peut être totalement assimilé à un incola, à qui on demandait une résidence durable pour considérer qu'il avait fait le choix d'un nouveau domicile ${ }^{32}$. Cette situation juridiquement bien définie pourrait se concevoir pour les deux autres personnages qui reçurent les ornements de décurion à Nîmes, $\mathrm{M}$ (arcus) Verius Victor et L(ucius) Velloudius Statutus : n'ont-ils pas reçu leur sépulture dans cette cité ? Ils avaient établi leur résidence hors de leur cité d'origine et ils s'étaient fixés à Nîmes, sans que l'on puisse aller jusqu'à leur attribuer le bénéfice d'un changement de cité, privilège réservé à l'empereur ${ }^{33}$. Mais elle ne peut être envisagée dans le cas de M(arcus) Attius Paternus, en raison de sa jeunesse d'abord et parce que, de fait, son contexte familial ne donnait pas - ou pas encore, semble-t-il - priorité au domicile nîmois. Issu du mariage d'un père rattaché à la cité de Riez et d'une mère rattachée à la cité de Nîmes, ayant sa sépulture à Riez dans la cité paternelle, il avait reçu toutefois un cénotaphe dans la cité de sa mère, à Clarensac, dans la Vaunage, ce qui devrait nous signaler le lieu où s'enracinait du côté maternel la mémoire familiale.

29. Travaux pionniers de Burnand 1975a et de Février 1981 ; on se référera aussi aux actes d'un colloque portant sur le sujet (Ferdière 1993) et plus particulièrement, pour des contextes de Gaule méridionale, aux contributions de J.-C. Meffre et d'A. Roth-Congès ; à propos de Nîmes la contribution de Fiches 1993 ; et enfin Christol 2003.

30. Elle touche aussi la cité d'Apt (colonia Iulia Apta), comme le montre l'inscription $A E, 1982,680$, revue par Christol 2005, p. 562.

31. Dans les remarques de Jacques 1984, p. 656-657, d'ailleurs limitées au cas de C(aius) Aurelius Parthenius (n.17) en ce qui concerne Nîmes. Pour lui, il semble qu'il y ait à l'arrière-plan la mobilité pour affaires ou une mobilité liée aux affaires (voir aussi, généralement Pavis d'Escurac 1988). Le cas des personnages connus dans l'épigraphie de Nîmes, qui appartiennent aux élites provençales, n'est pas pris en compte, et il est à notre avis différent des quelques exemples présentés.

32. Pavis d'Escurac 1988, p. 63-65; Thomas 1996, p. 30-34, p. 43-44.

33. Pavis d'Escurac 1988, p. 65-67 ; Thomas 1996, p. 89-92. 

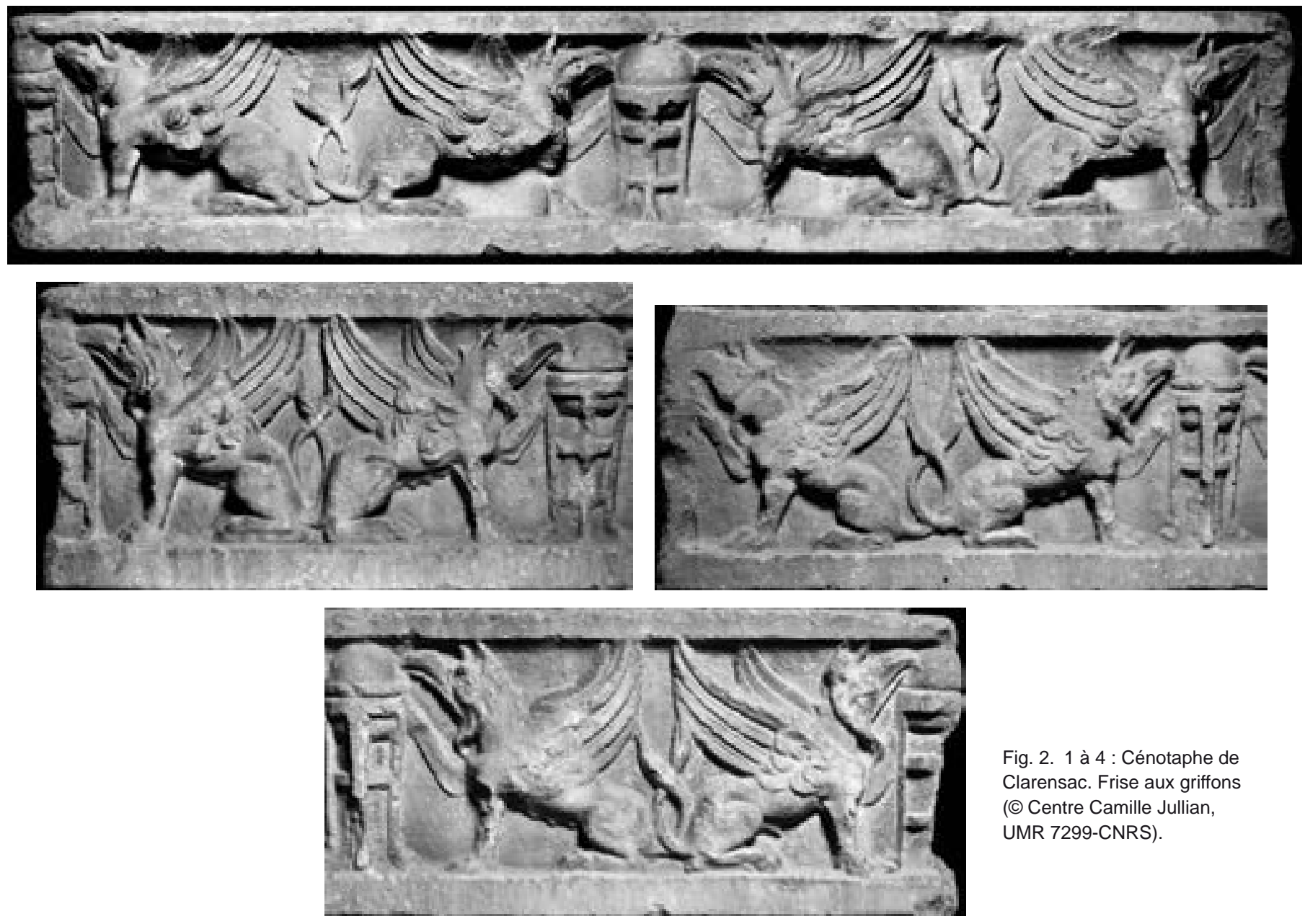

Fig. 2. 1 à 4 : Cénotaphe de Clarensac. Frise aux griffons (C) Centre Camille Jullian, UMR 7299-CNRS).

\section{L'étude du décor}

L'étude du décor du monument ${ }^{34}$ devrait confirmer ce que la lecture du texte a pu révéler.

Si l'on reprend l'ordre des registres, le premier registre de l'attique se compose d'une première frise sous le fronton, alternant griffons assis dans une composition antithétique et trépieds delphiques surmontés de l'ombilic.

La frise de façade comprend quatre griffons adossés, mâles et femelles, selon une composition assez souvent reproduite sur les monuments funéraires galloromains ${ }^{35}$. Ces griffons, à la fois « animaux funéraires,

34. Espérandieu (E.) - Recueil général des bas-reliefs, statues et bustes de la Gaule romaine, tomes I-XI, Paris Imprimerie Nationale, 1907-1938. Pour le monument de Clarensac, Espérandieu 1-491; 3, p. $422 ; 9$, p. 145 , p. $325-326$.

35. Delplace 1980, p. 288. gardiens de la tombe et symboles de résurrection ${ }^{36}$, ont une tête d'aigle au bec fermé ${ }^{37}$, une crête de coq, un corps de félin, des ailes de dragon ${ }^{38}$. Ces animaux fabuleux accompagnent souvent le culte d'Apollon ${ }^{39}$, ce qui est renforcé ici par la présence de trépieds delphiques où, sur la partie supérieure, chaque griffon vient appuyer une patte ${ }^{40}$. C'est la patte en fond de frise, simplement gravée, qui est sollicitée pour ce geste. Nul besoin ici d'une représentation d'Apollon; les attributs

36. Prieur 1986, p. 158-159.

37. Delplace 1980 , p. 287-289

38. Tels ceux du mausolée de l'Ile du Comte, décrits par Anne RothCongès et repris dans Landes 2002, p. 146, n ${ }^{\circ} 6-7$.

39. Prieur 1986, p. 159 « les griffons gardaient les trésors d'Apollon au pays des Hyperboréens, où ils se battaient fréquemment avec les représentants de la peuplade des Arimaspes ; selon une autre légende, toujours au service d'Apollon qui l'avait attelé à son quadrige, le griffon se dessèche, puis se renouvelle en se plongeant dans l'eau du Nil ».

40. Delplace 1980 , p. 287-289. 

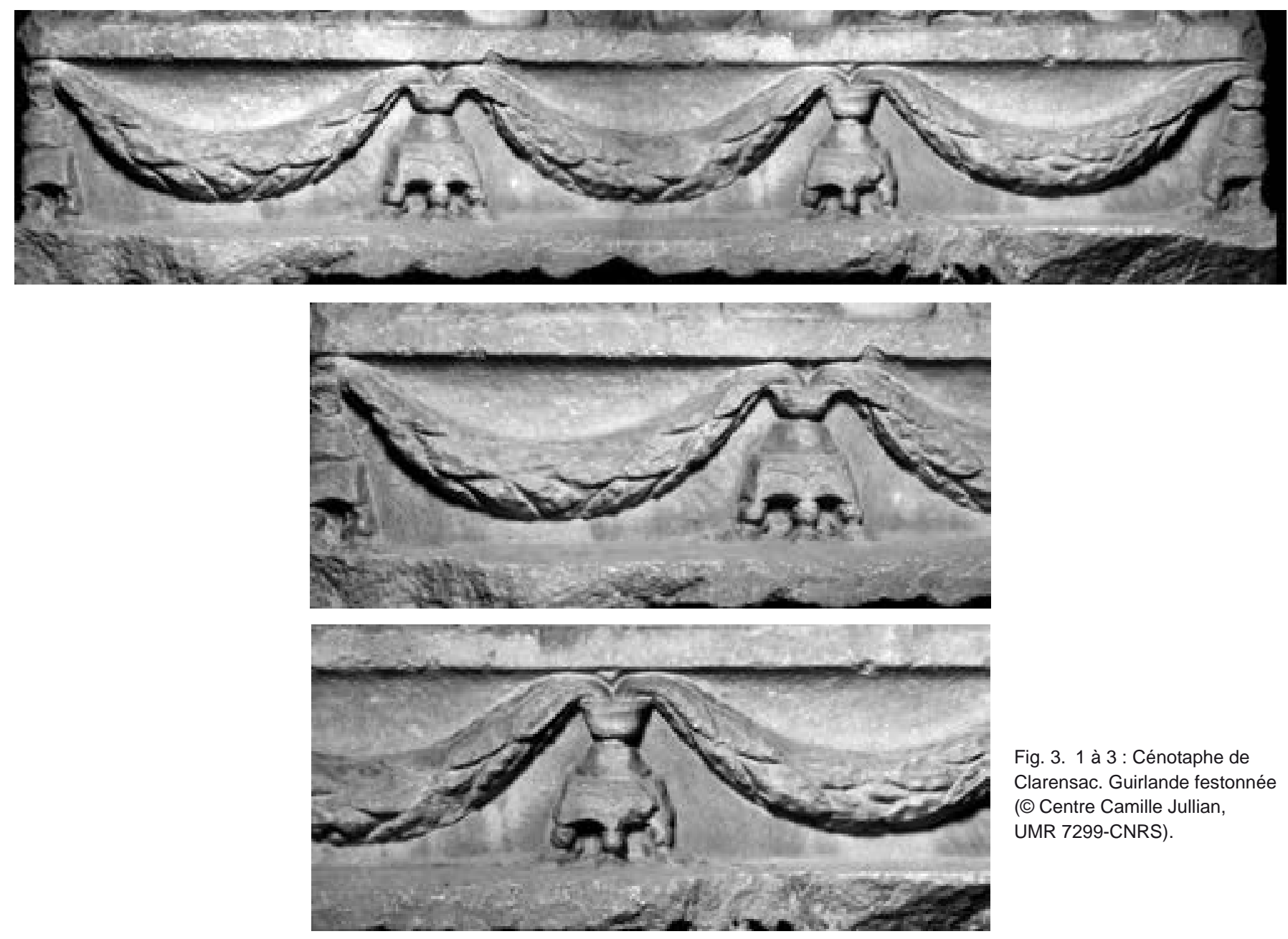

Fig. 3. 1 à 3 : Cénotaphe de Clarensac. Guirlande festonnée (๔ Centre Camille Jullian, UMR 7299-CNRS).

accompagnant communément le dieu semblent suffire à son évocation ${ }^{41}$.

Le motif du trépied est répété aux angles du monument. La frise se prolonge sur les faces latérales. (fig. 2, 1 à 4)

Le $2^{\mathrm{e}}$ registre montre une frise constituée d'une guirlande festonnée ${ }^{42}$, tresse de feuilles, suspendue entre des trépieds et supportée par eux, dont deux en façade

41. «Dans la religion apollinienne, l'iconographie de l'Apollon au griffon se transforme. De plus en plus, le dieu est remplacé par un élément aniconique, tel le trépied delphique ou la lyre, faisant traditionnellement partie de ses attributs. Exemple, frise du temple d'Apollon à Didyme. Cette composition symbolique sera fréquente sur les autels funéraires du $\mathrm{I}^{\mathrm{er}}$ s. ap. J.-C. » (Delplace 1980, p. 376). J. Gagé le constatait déjà " c'est une tradition insistante du culte romain que la représentation des dieux par leurs attributs ou leurs symboles cultuels » (Gagé 1955, p. 175).

42. «Quand le motif est répété (à partir de l'époque hellénistique), il constitue une frise de guirlandes festonnées. Au lieu d'être pendantes, elles sont suspendues. Ce type de présentation est de loin le plus populaire et le plus banal » (Turcan 1971, p. 93). pour trois festons et deux aux angles, le motif se répétant sur les faces latérales. La guirlande apparaît composée de feuilles de laurier, le laurier, emblème du triomphe du juste sur la mort ${ }^{43}$, mais encore l'arbre consacré à Apollon. (fig. 3, 1 à 3)

Une corniche repose sur des chapiteaux corinthiens. Ici, oves et denticules sont agrémentés de perles et de pirouettes.

Un linteau entre les pilastres d'angle représente une chasse. Deux trous de louve marquent le centre de la plinthe.

Au centre du linteau, un lion et un sanglier - l'identification traditionnelle est celle d'un taureau - se font face, séparés par un culot d'acanthe sur couronne de sépales. À chaque extrémité, un chien dressé sur ses pattes avant ;

43. «La guirlande de laurier est solidaire aussi de la symbolique victorieuse qui a pris dans l'art sépulcral romain une place énorme, sinon prépondérante ; elle est inséparable d'une perspective de la victoire sur la mort et de l'héroïsation par la « virtus » (Turcan 1971, p. 129). 

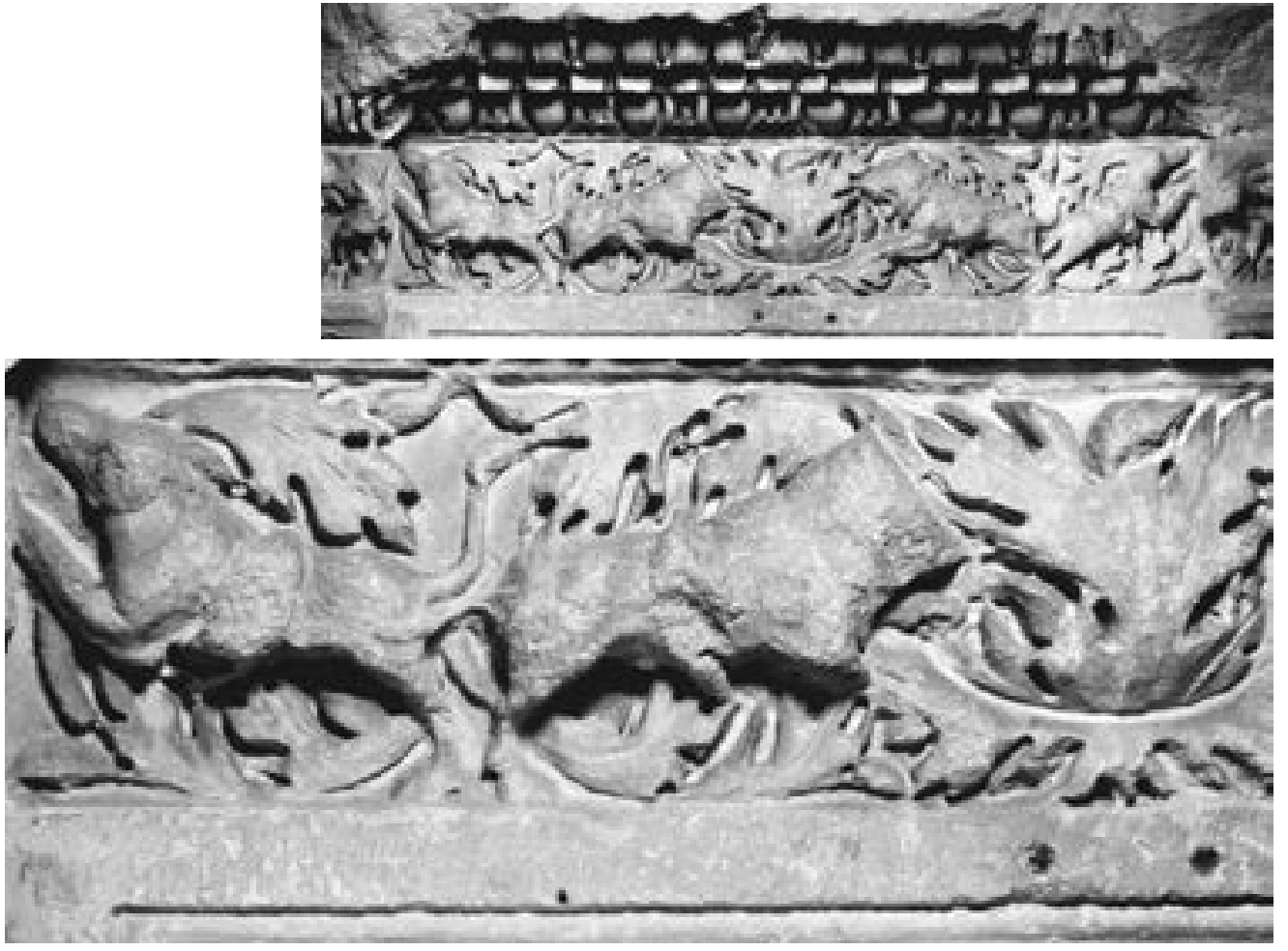

Fig. 4. 1 à 3 : Cénotaphe de Clarensac. Linteau portant une scène de chasse (C) Centre Camille Jullian, UMR 7299-CNRS).

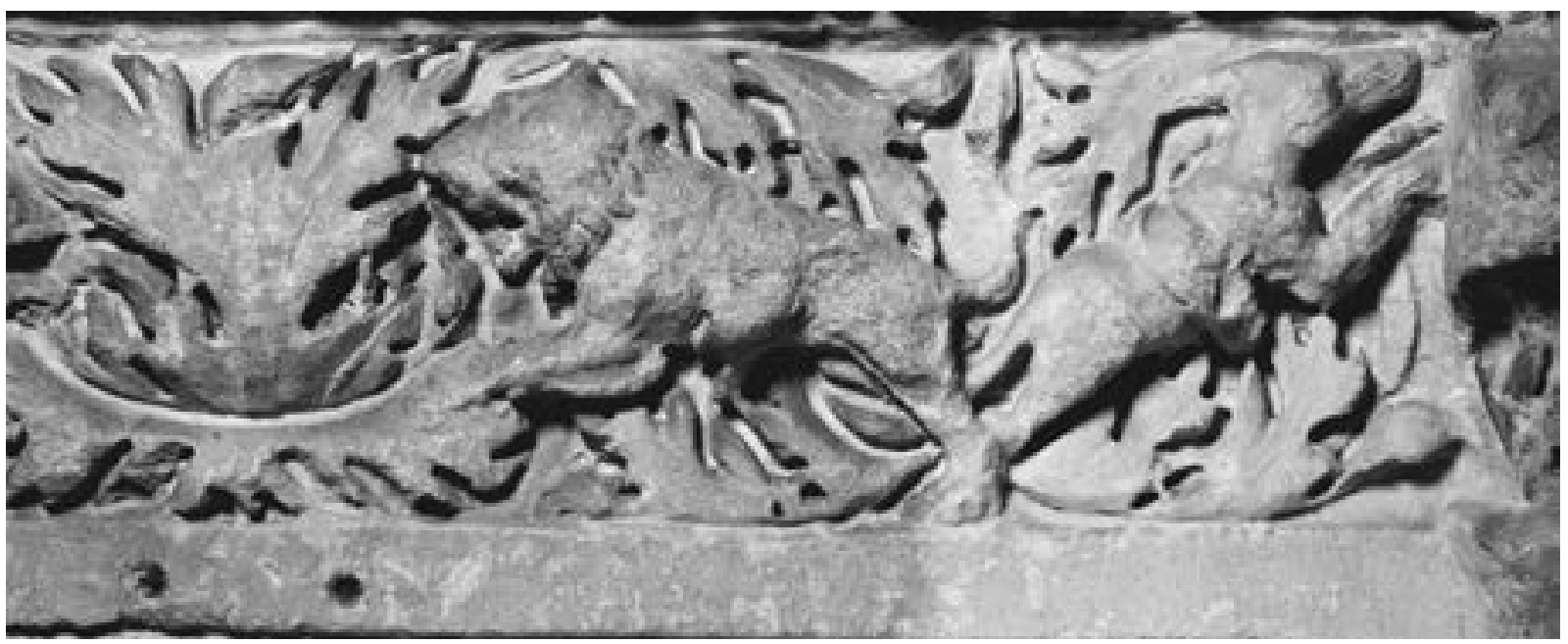

il s'agit vraisemblablement de lévriers. Cumont évoque le caractère religieux de la chasse dans l'antiquité ${ }^{44}$, et en même temps, la décrit comme un sport d'endurance. La chasse, d'après lui, pouvait être, en temps de paix, un service commandé destiné à débarrasser les campagnes d'animaux nuisibles, comme le sanglier, et de fournir des bêtes sauvages aux venationes de l'amphithéâtre.

44. Cumont 1942, p. $438-440$ repris par Aymard 1951, p. 514 et p. 469, 513, 551 qui rappelle Platon mettant sur le même pied la chasse aux animaux et la chasse à l'homme : la guerre, ainsi qu'Aristote pour qui la cynégétique est l'une des parties de la science militaire. La chasse, dans l'éthique de Rome, n'est pas éloignée de la romana virtus nécessaire au guerrier.
Camille Jullian ${ }^{45}$ assimile la chasse celtique à « une sorte de guerre rustique, savante et religieuse ».

Mais il s'agit bien, ici, de remémorer un défunt adroit aux pratiques de la chasse, qui compte parmi les activités nobles de l'aristocratie et remplace l'évocation d'actions de guerre ${ }^{46}$; elle revêt donc une grande importance dans

45. Jullian 1908, p. 289.

46. Au tableau militaire, se substitue une scène de chasse comme le soulignait Cumont.... On se reportera à Aymard 1951, p. 62-63 : d'après Caton, la chasse est un exercice physique, propre à faire de son fils un soldat entraîné, l'autre conception cynégétique étant d'après Polybe une activité désintéressée, un jeu digne des fils de la grande aristocratie romaine. 

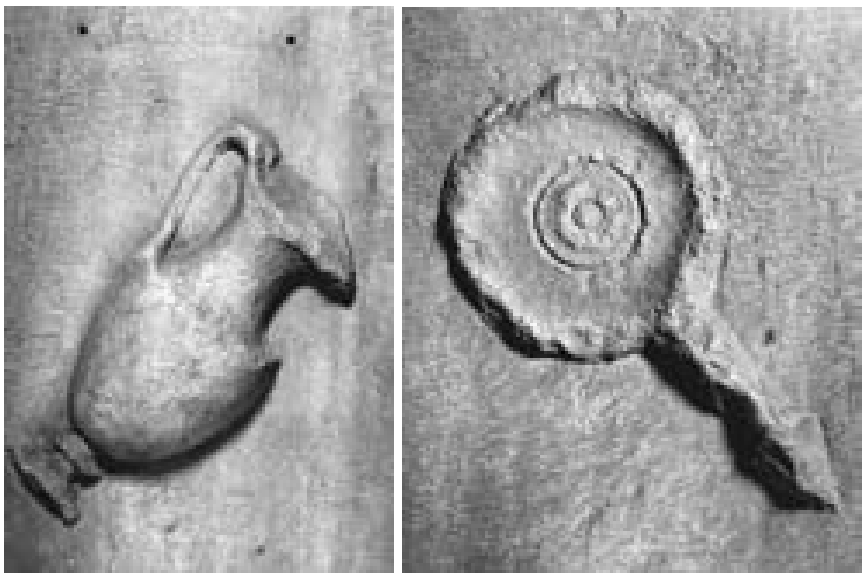

Fig. 5.1 à 2 : Cénotaphe de Clarensac. Faces latérales. Guttus et patère à ombilic (C Centre Camille Jullian, UMR 7299-CNRS).

ce contexte où le chevalier, mort trop jeune, n'a pu faire ses preuves comme guerrier. En outre, il s'agit de l'évocation d'une chasse dangereuse, exigeant force et courage, à cause de la présence conjointe du lion et du sanglier ${ }^{47}$.

La chasse se substitue ici, comme marque de la virtus équestre, à la représentation des symboles classiques des chevaliers romains (la parma et les lances). Le défunt n'avait pu encore manifester, par un commandement équestre, une militia, la virtus qui était exigée par son statut. (fig. 4, 1 à 3)

Sur les faces latérales, la présence d'un guttus et d'une patère à ombilic avec son manche, répondent à un impératif de représenter sur les monuments funéraires les instruments du sacrifice. On satisfait ici à une tradition religieuse destinée à accompagner la mémoire du défunt. (fig. 5, 1 à 2)

Des pilastres d'angle soutiennent la corniche : encadrant l'inscription, deux piliers angulaires surmontés de chapiteaux sont décorés d'un rinceau de vigne sortant d'un canthare. Dans la partie inférieure du pilastre, l'oiseau perché sur le canthare, tête en bas, s'abreuve au vase. Au sommet des pilastres angulaires, des passereaux se répondent dans la profusion des pampres. (fig. 6, 1 à 4)

47. Badel dans Trinquier 2009 « la chasse n'engageait pas la virtus, à l'exception des chasses dangereuses, celle au sanglier et celle au lion ». On verra aussi Baratte dans Trinquier 2009 «Le succès à la chasse, sur un fauve notamment, annonce le triomphe sur la mort ». On retrouvera mention du lion et du sanglier, désignés comme chasse dangereuse et comme gibier de choix de l'équipage impérial (Aymard 1951 , p. 328 , p. 355$)$.

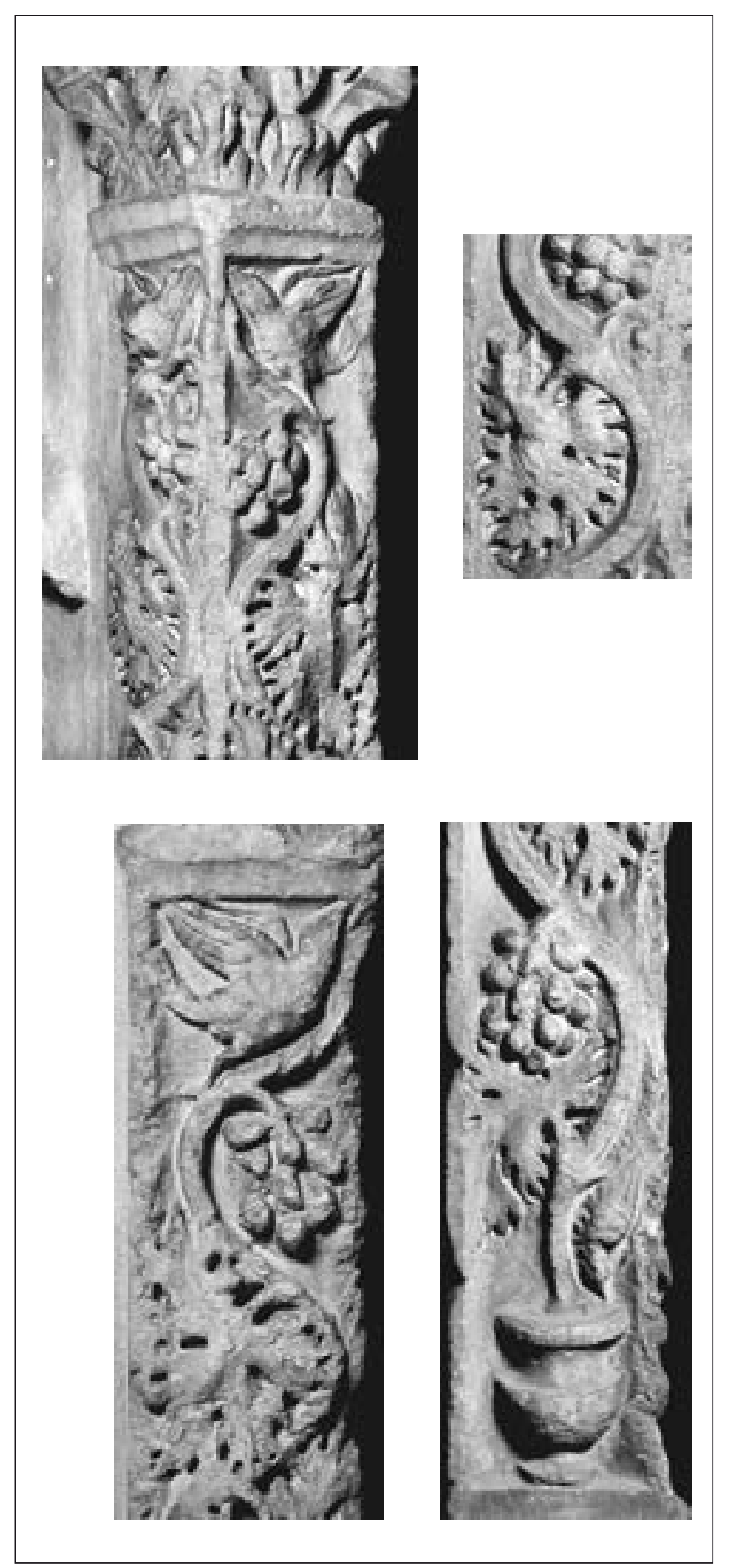

Fig. 6.1 à 4 : Cénotaphe de Clarensac.

Pilastres ornés de rinceaux peuplés (C) Centre Camille Jullian, UMR 7299-CNRS). 


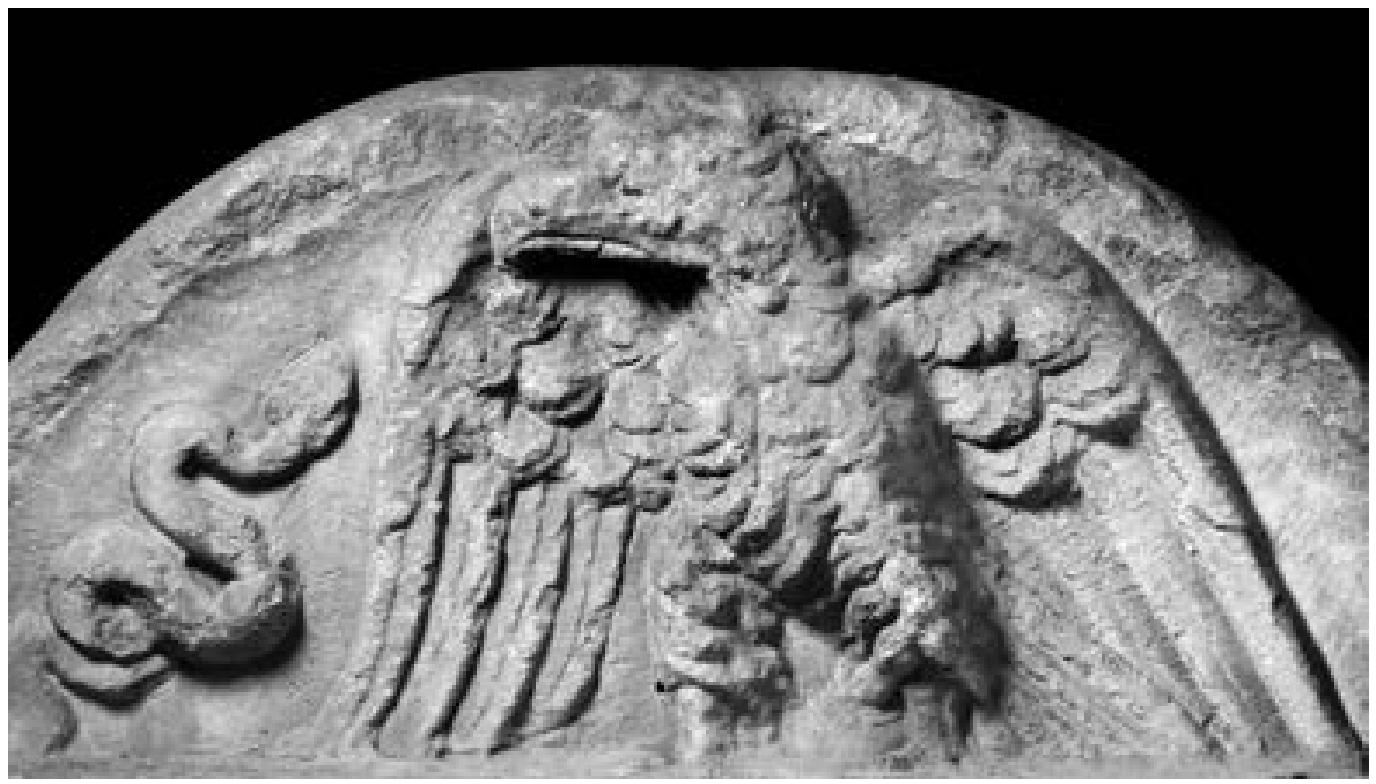

Fig. 7. Cénotaphe de Clarensac. Le couronnement (๑ Centre Camille Jullian, UMR 7299-CNRS).

Un soin particulier a été apporté au couronnement de l'autel ; aux angles, des rouleaux décorés de feuilles lancéolées, du laurier encore, sont ponctués à l'avant d'une rosace, On revient à un peu de sobriété dans le traitement du fronton de couronnement cintré, mais même si, dans la lunette du fronton, l'espace paraît moins envahi que dans les parties plus basses, les deux antagonistes, l'aigle et le serpent affrontés, sont fastueusement représentés dans un champ dépouillé de tout autre décor pour conserver à la scène toute sa charge symbolique.

L'oiseau de l'apothéose aux ailes éployées annonce son envol et prend davantage d'envergure devant le serpent qui l'affronte. L'aigle porte en lui mille significations : c'est en Orient l'oiseau du soleil psychopompe « chargé de porter vers cet astre les âmes qu'on en croyait issues ${ }^{48}$, c'est $~ «$ l'envol triomphal de l'âme libérée ${ }^{49}$. Les références sont nombreuses et lointaines. Ce thème familier de l'aigle et du serpent est commun aux représentations figurées et à la littérature : il figure dans le répertoire décoratif des tombes aux époques hellénistique et romaine. La signification funéraire du motif paraît évidente. Le tombeau d'Alkétas à Termessos de Pisidie $^{50}$ en est orné ; on le retrouve à Babylone sur le tombeau d'Héphaistion dont Diodore décrit le bûcher d'apothéose $^{51}$ : l'aigle dévorant un serpent, signe de la

48. Cumont 1917, p. 63, cité dans Symbolisme 1942, p. 154.

49. Picard 1964, p. 218.

50. Picard 1964, p. 216-228.

51. Diodore, XVII, 115,3 . victoire promise au guerrier malgré sa mort ${ }^{52}$. La grande mosaïque palatiale d'Istanbul reprend le même thème iconographique ${ }^{53}$ que l'on retrouvera plus près de nous sur un chapiteau historié de Vienne (Isère) ${ }^{54}$. (fig. 7)

Dédicace et représentations figurant sur le cénotaphe de Clarensac pour évoquer la mémoire du jeune chevalier ont été soigneusement choisis pour ne rien omettre et tout valoriser.

C'est ainsi que se croisent dans cette iconographie des symboles de vie et de mort, car, tandis que les passereaux se répondent dans les rinceaux qu'ils viennent peupler, et que se côtoient dans un chant de vie les pampres et les raisins surgissant des canthares, la patère et le guttus évoquent, de façon rituelle, les instruments sacrificiels rappelant le défunt à la bienveillance des dieux; la présence du serpent et de l'aigle renvoie à l'immortalité et au triomphe. Le religieux et le politique se mêlent dans cette iconographie. Les griffons, en particulier, figurent souvent dans le répertoire décoratif, soit qu'ils apparaissent dans un contexte funéraire, gardiens de la tombe et symboles de protection et de résurrection, soit que, conjugués à un ensemble de symboles apolliniens,

52. Le motif est largement représenté dans la littérature : augure funeste chez Homère (Iliade XII, 200-215) que ce serpent qu'un aigle laisse retomber au milieu des combattants troyens. Le récit en est repris chez Virgile (Enéide, XI, 750-754).

53. Toynbee 1973, p. 242-243.

54. Recueil général des sculptures sur pierre de la Gaule, Nouvel Espérandieu, I, Vienne (Isère), dir. H. Lavagne, Paris, 2003, p. 140, 323 B (R. Robert). 


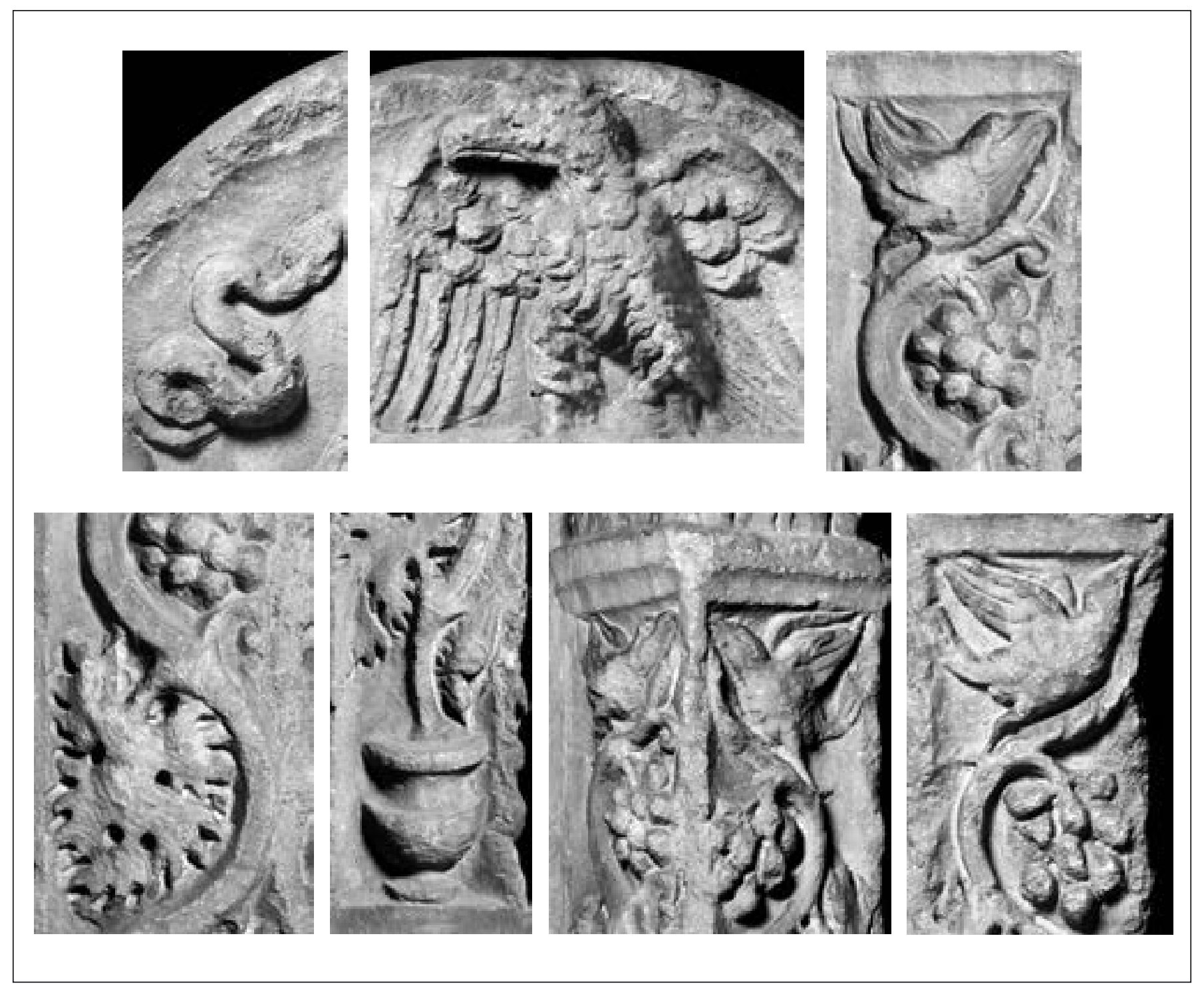

Fig. 8.1 à 7 : Cénotaphe de Clarensac. Détails du décor (@ Centre Camille Jullian, UMR 7299-CNRS).

ils s'intègrent dans une iconographie à la louange de l'empereur qu'a initiée la période augustéenne ${ }^{55}$. (fig. 8, 1 à 7)

Le croisement des données fournies par la lecture de l'inscription et la description du monument apportent un éclairage neuf sur le somptueux cénotaphe de Clarensac longtemps oublié dans des réserves archéologiques. L'examen du décor, récemment mis en valeur par une

55. «Autre choix virgilien: la récupération des monstres légués par la tradition séculaire de la mythologie et de l'iconographie grecques », en particulier les griffons et le symbolisme apollinien qu'ils incarnent utilisés dans les décors de la Rome augustéenne (Sauron 2000, p. 197-199). nouvelle couverture photographique, vient appuyer le contenu du texte.

Sur les deux frises que comporte l'attique, on retrouve la représentation associée du griffon et du trépied delphique sur l'une, la présence symbolique des guirlandes constituées de feuilles de laurier et des trépieds sur l'autre, tous symboles éminemment représentatifs du culte d'Apollon. Le laurier figure aussi sur les rouleaux de la partie supérieure. La présence emblématique des uns et des autres ajoute aux symboles pythiens qui s'accumulent sur cet autel. On peut envisager qu'une relation serait établie entre ces symboles apolliniens et la cité de Riez, Apollinaris Reiorum, qui figure dans la dédicace et qui vient indiquer - de façon très claire l'origo de Paternus. 


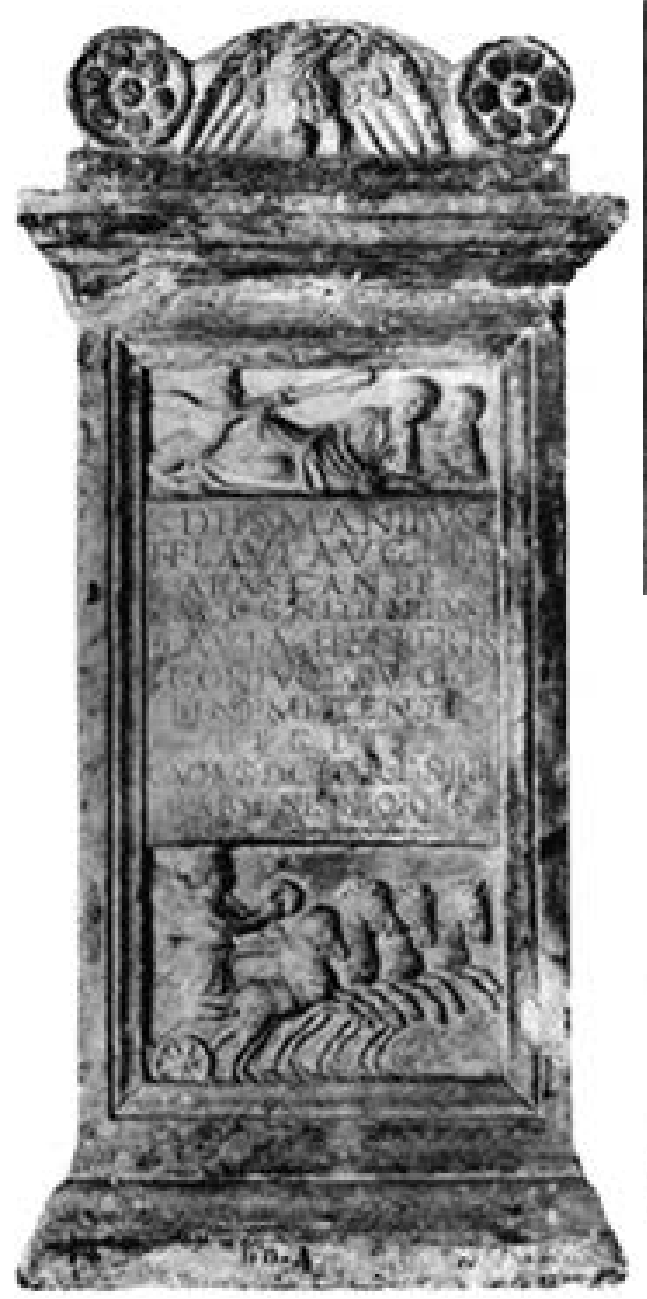

Fig. 9. 1 : Cippe de Titus Flavius Abascantus (๔ Centre Camille Jullian, UMR 7299-CNRS).

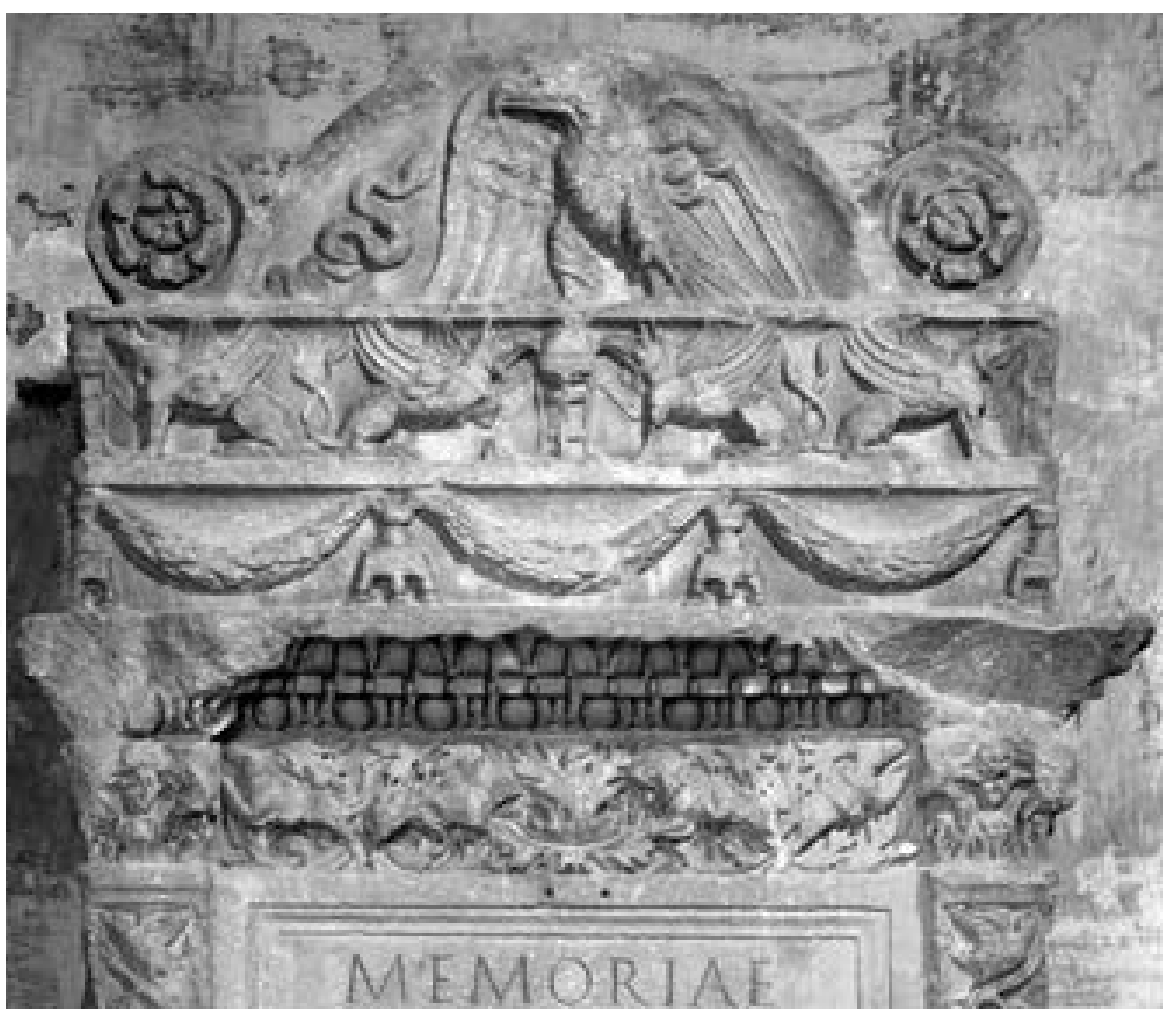

Fig. 9. 2 : Couronnement du cénotaphe de Clarensac (৫) Centre Camille Jullian, UMR 7299-CNRS).

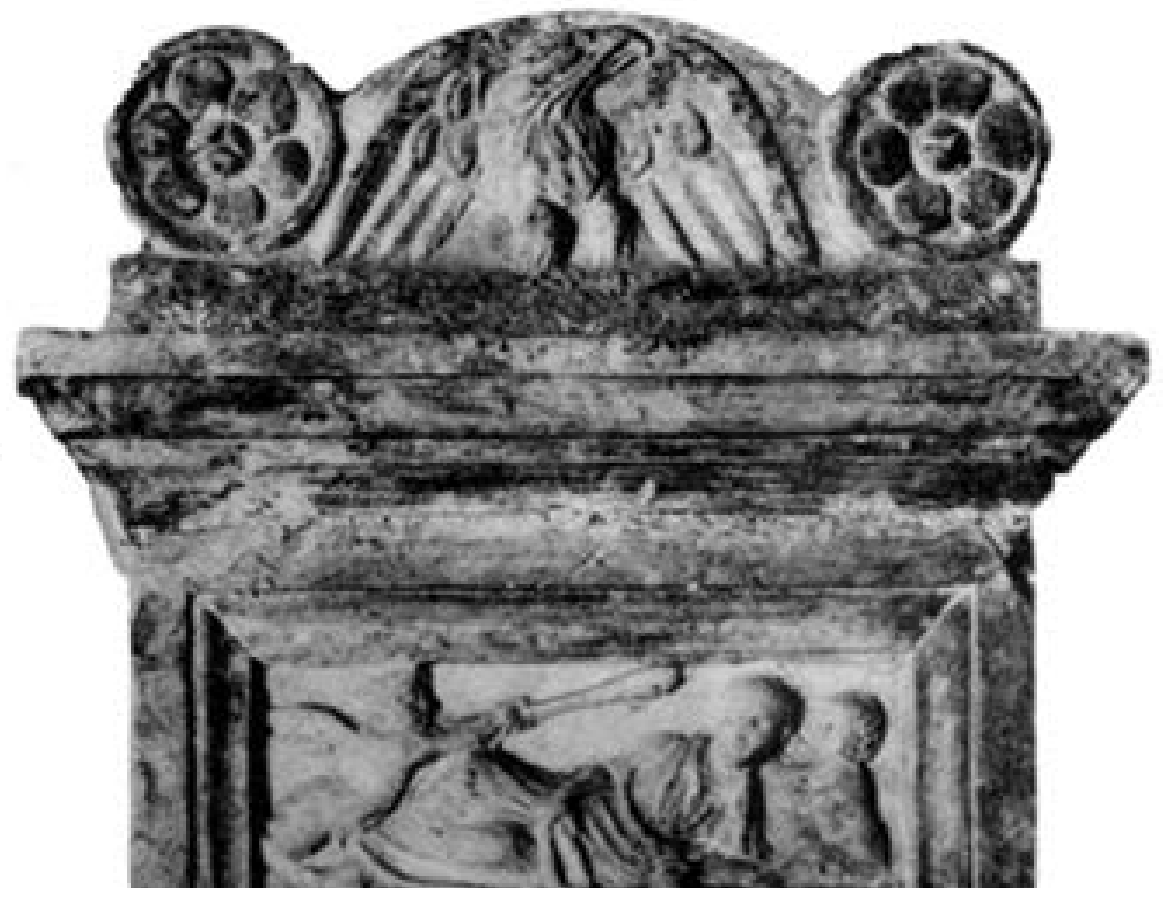

Fig. 9. 3 : Couronnement du cippe de Titus Flavius Abascantus (c Centre Camille Jullian, UMR 7299-CNRS). 
Quant à la datation du cénotaphe, on trouve un parallèle dans le cippe, découvert à Rome et conservé au Palais ducal d'Urbino, de Titus Flavius Abascantus, fonctionnaire impérial, affranchi de l'un des Flaviens, probablement Domitien. Si l'inscription en est connue (CIL, VI, 8628), le monument lui-même a été rarement représenté ${ }^{56}$. Dans ce cas toutefois, à la différence de Nîmes, l'épitaphe fait référence aux divinités mânes et non à la memoria: elle était donc liée à la sépulture. Mais le thème de l'aigle de l'apothéose couronnant le monument entre deux rouleaux ponctués de rosaces, rappelle le couronnement du monument du Gard. La datation claire du cippe romain, des similitudes dans le décor, nous orientent vers une même datation pour le cippe de Clarensac. (fig. 9, 1 à 3)

Pour ce qui est de la provenance de ce monument au fastueux décor, nous pouvons penser, en le mettant en relation avec les autres monuments nîmois, et en observant tout ce qui les différencie, que c'est une oeuvre importée ${ }^{57}$.

On peut remarquer que, dans l'ensemble, le travail au foret y est très accentué. Même si les registres dédiés aux griffons et à la guirlande, ainsi qu'au guttus et à la patère des faces latérales, apparaissent plutôt sobres, sculptés sur un fond lisse profondément ravalé, le reste du décor se montre exubérant ${ }^{58}$ comme on peut le voir dans les dentelles des pampres, les digitations des végétaux - vigne et acanthe - les rinceaux peuplés d'oiseaux, la profusion dans le décor des chapiteaux. Tout témoigne d'une «tendance certaine à l'horreur du vide »-pour citer Burnand ${ }^{59}$ - ce qui est en accord avec « les caractères d'un certain baroque flavien» où se révèle un clair-obscur favorisé par le traitement du décor. À l'opposé de la rigueur sèche de l'art augustéen, s'égrène ici tout le vocabulaire de l'art flavien finissant «...una fantasia vasta e delicata ${ }^{60} »$.

56. Étude et représentation dans Cumont 1942, p. 457-458 et pl. XLV.

57. « Nîmes n'a livré que fort peu de stèles funéraires à encadrement de vigne, et les seuls exemplaires connus (stèle de Vettitia Dubitata, Espérandieu (E.), Recueil des bas-reliefs, statues et bustes de la Gaule romaine, IX, Paris, $\mathrm{n}^{\circ} 6823$, et cippe de M. Attius Paternus, Espérandieu (E.), Recueil des bas-reliefs, statues et bustes de la Gaule romaine, I, Paris, 1907, n491 rompent avec tous ces types de monuments connus à Nîmes, et ont été probablement importés » (Sauron 1983, p. 99).

58. «La richesse exubérante » du style décoratif romain de la fin du $\mathrm{I}^{\mathrm{er}}$ siècle «les rinceaux de l'autel funéraire de Clarensac marquent l'apogée du décor ornemental flavien » (Hatt 1951, p. 126).

59. Burnand 1975, p. 749-751.

60. «Flavian illusionism, spacing and delicate fancy... » (Strong 1923 [New-York 1971], p. 130).

\section{Bibliographie}

Allmer 1883 : ALLMER (A.) - Magnifique tombeau et épitaphe d'un décurion ornementarius. Rev. épigraphique, I (22), janvier-mars 1883, p. 340-341, nº381.

Aymard 1951 : AYMARD (J.) - Essai sur les chasses romaines des origines à la fin du siècle des Antonins, Paris, de Boccard, 1951.

Burnand 1975 : BURNAND (Y.) - Sénateurs et chevaliers romains originaires de la cité de Nîmes. MEFRA, 87, 1975, p. 681-791.

Burnand 1975 a : BURNAND (Y.) - Domitii Aquenses, Une famille de chevaliers romains de la région d'Aix-en-Provence. Mausolée et domaine, Paris, 1975.

Burnand 2005 : BURNAND (Y.) - Primores Galliarum, I. Méthodologie : Sénateurs et chevaliers romains originaires de Gaule de la fin de la République au III ${ }^{\mathrm{e}}$ siècle, Bruxelles, 2005 (Collection Latomus, 290).

Burnand 2006 : BURNAND (Y.) - Primores Galliarum, II. Prosopographie, Bruxelles, 2006 (Collection Latomus, 302).

Chastagnol 1992: CHASTAGNOL (A.) - Inscriptions latines de Narbonnaise, II. Antibes, Riez, Digne, Paris, 1992.

Christol 1990 : CHRISTOL (M.) - L'inscription funéraire de Caius Sergius Respectus. Remarques sur le milieu des notables gallo-romains de Nîmes (AE, 1969-1970, 376). In: Mélanges Pierre Lévêque, 5. Anthropologie et société, Paris-Besançon, 1990, p. 65-83.

Christol 2002 : CHRISTOL (M.) - Elites, épigraphie et mémoire en Gaule méridionale. In : Landes 2002, Lattes 2002, p. 129-139. [Catalogue de l'exposition « La mort des notables en Gaule romaine»].

Christol 2003 : CHRISTOL (M.) - Le patrimoine des notables en Gaule méridionale. Apport et limites de l'épigraphie. Histoire et sociétés rurales, 19, 2003, p. 133-150

Christol 2005: CHRISTOL (M.) - A propos d'hommages publics en Narbonnaise. MEFRA, 117, 2005, p. 555-566.

Christol 2010 : CHRISTOL (M.) - «S'approcher de l'ordo, entrer dans l'ordo : le cas de Nîmes ». In : Lamoine (L.), Berrendonner (C.) et CebeillacGervasoni (M.) dir., La Praxis municipale dans l'Occident romain, Clermont-Ferrand, Presses Universitaires Blaise-Pascal, 2010, p. 327-345.

Christol, Gascou, Janon 1987: CHRISTOL (M.), GASCOU (J.), JANON (M.) - Les seviralia ornamenta gratuita dans une inscription de Nîmes. Latomus, 46, 1987, p. 388-398.

Cumont 1942 : CUMONT (F.) - Recherches sur le symbolisme funéraire des Romains, Paris, 1942 [1966].

Delplace 1980 : DELPLACE (C.) - Le griffon de l'archaïsme à l'époque impériale. Etude iconographique et essai d'interprétation symbolique, Bruxelles-Rome Institut Historique Belge de Rome 1980 [Etudes de Philologie, d'Archéologie et d'Histoire Anciennes t. XX].

Demougin 1988: DEMOUGIN (S.) - L'ordre équestre sous les JulioClaudiens, Rome, 1988.

Ferdière 1993 : FERDIERE (A.) dir. - Monde des morts, monde des vivants en Gaule rurale, Actes du colloque ARCHEA/AGER, Orléans (7-9 février 1992), Tours, 1993 
Février 1981 : FEVRIER (P.-A.) - Villes et campagnes des Gaules sous l’Empire. Ktèma, 6, 1981, p. 359-372.

Fiches 1993 : FICHES (J.-L.) - Les élites nîmoises et les campagnes du Haut Empire : caractérisation, place et signification de leurs sépultures. In : Ferdière 1993, p. 333-339.

Gagé 1955 : GAGE (J.) - Apollon romain. Essai sur le culte d'Apollon et le développement du «ritus Graecus » à Rome des origines à Auguste, Paris, de Boccard, 1955 (BEFAR, fasc. 182).

Garnsey 1970 : GARNSEY (P.) - Social Status and Legal Privilege in the Roman Empire, Oxford, 1970.

Hatt 1951 : HATT (J.-J.) - La tombe gallo-romaine, Paris 1951 [Paris 1986].

Jacques 1984 : JACQUES (Fr.) - Le privilège de liberté. Politique impériale et autonomie municipale dans les cités de l'Occident romain (161-244), Rome, 1984.

Jullian 1908 : JULLIAN (C.) - Histoire de la Gaule, II, 1908

Landes 2002 : LANDES (C.) - La mort des notables en Gaule romaine, Lattes, Imago, Musée archéologique Henri Prades 2002 (Catalogue de l'Exposition).

Pavis d'Escurac 1988 : PAVIS D'ESCURAC (H.) - Origo et résidence dans le monde du commerce sous le Haut-Empire. Ktèma, 13, 1988, p. 57-68.

Picard 1964 : PICARD (Ch.) - Sépultures des compagnons de guerre ou successeurs macédoniens d'Alexandre le Grand. Journal des Savants, 1964, vol. $3, n^{\circ} 3$, pp. 215-228.
Prieur 1986 : PRIEUR (J.) - La mort dans l'antiquité romaine, Ouest-France, 1986.

Ricci 2006 : RICCI (C.) - Qui non riposa. Cenatofi antichi e moderni fra memoria e rappresentazione, Rome, 2006.

Sauron 1983 : SAURON (G.) - Les cippes funéraires gallo-romains à décor de rinceaux de Nîmes et de sa région. Gallia 41, 1983, fasc. 1, p. 59-110.

Sauron 2000 : SAURON (G.) - L'histoire végétalisée. Ornement et politique à Rome, Paris, Picard, coll. « Antiqua », 2000.

Strong 1923-1926: Roman Sculpture from Augustus to Constantine, Florence, 1923-1926 [New-York, 1971].

Thomas 1996 : THOMAS (Y.) - «Origine » et « commune patrie ». Etude de droit public romain (89 av. J.-C.-212 ap. J.-C.), Rome, 1996.

Trinquier 2009 : TRINQUIER (J), VENDRIES (C.) dir. - Chasses antiques. Pratiques et représentations dans le monde gréco-romain (III ${ }^{e}$ siècle av.IVe siècle ap. J.-C.), Rennes, Presses universitaires, 2009.

Turcan 1971 : TURCAN (R.) - Les guirlandes dans l'antiquité classique. Jahrbuch für Antike und Christentum, 14, 1971, p. 92-139.

Wierschowski 2001 : WIERSCHOWSKI (L.) - Fremde in Gallien "Gallier» in der Fremde. Die epigraphisch bezeugte Mobilität in, von und nach Gallien vom 1. bis 3. Jh. n. Chr., Stuttgart, 2001 (Historia Einzelschriften, H.159). 


\title{
Sepulcrum, signa et tituli : quelques observations sur la «consecratio in formam deorum » et sur l'expression du statut des morts dans la Rome impériale
}

\author{
Nicolas Laubry \\ Université Paris Est Créteil/Centre de recherches en Histoire européenne comparée (EA 4392) \\ nicolas.laubry@u-pec.fr \\ nicolas.laubry@gmail.com
}

\section{Résumé}

Le phénomène désigné comme apothéose privée ou consecratio in formam deorum par les études modernes est une manifestation originale de la sphère funéraire à Rome à partir de la fin du $\mathrm{I}^{\mathrm{er}} \mathrm{s}$. ap. J.-C. Perceptible surtout à travers la sculpture ou l'architecture, il a été interprété comme l'expression de croyances relatives au sort post mortem ou comme une forme particulière de commémoration des défunts. Cet article revient sur certains de ses aspects religieux en le resituant au sein du ritualisme propre au culte romain des morts. Il s'attache plus particulièrement à deux exemples privilégiés, le tombeau de Claudia Semne à Rome et une dédicace de Gabies. Malgré l'ambiguïté ou les limites des sources, il est ainsi possible de formuler quelques hypothèses sur les implications religieuses de ces pratiques qui, selon des modalités variables, participent à la construction du statut des morts, moins dans l'au-delà que dans la communauté des vivants.

Mots-clés : Tombeaux, statuaire funéraire, dédicace, apothéose privée, culte des morts, divinisation, Claudia Semne, Gabies, Vénus.

\begin{abstract}
The so-called private apotheosis or consecratio in formam deorum is an original phenomenon among funerary practices in Rome from the late 1st century A.D. Mostly visible through tomb sculpture and architecture, it was interpreted as the expression of beliefs relating to post mortem destiny or alternatively as a peculiar way of commemorating the dead. This paper goes back over some of its religious aspects, by replacing them into the frame of the ritualism proper to Roman cult of the dead. It deals especially with two famous cases, Claudia Semne's mausoleum in Rome and a dedication from Gabii. Despite equivocal and limited sources, we can put forward some hypothesis about the religious implications of these practices, which, in different ways, were aiming at the construction of the status of the dead, not so much in the hereafter as in the community of the living.
\end{abstract}

Key-words: Tombs, funerary statuary, dedication, private apotheosis, cult of the dead, divinisation, Claudia Semne, Gabii, Venus. 
$\mathrm{V}$ ers la fin du $\mathrm{I}^{\mathrm{er}} \mathrm{S}$. ap. J.-C. se diffuse à Rome l'usage de représenter les défunts avec les attributs de divinités ${ }^{1}$. S'observant dans certains milieux de la société romaine et plus particulièrement chez les affranchis, ce phénomène, quelquefois désigné comme «apothéose privée » ou par l'expression consecratio in formam deorum selon le titre d'un ouvrage désormais ancien mais toujours fondamental de $\mathrm{H}$. Wrede, s'est manifesté selon des modalités variables. Il a aussi été diversement compris par les études modernes dont il a fait l'objet. S'il est impossible de résumer ici la totalité et les nuances des interprétations proposées, on peut cependant regrouper les approches selon deux perspectives majeures. Selon la première, cette pratique touchait aux conceptions eschatologiques sur la destinée d'un individu après sa mort et marquait, sinon son identification directe avec le dieu, du moins sa participation à la sphère divine (dans des perspectives différentes, Brelich 1937, p. 69-71 et Cumont 1942, p. 414-416). Un second courant s'est attaché à montrer que cet usage était avant tout une forme de commémoration. L'assimilation plastique d'un défunt à une divinité est alors appréhendée comme un mode spécifique d'évocation du mort et de son individualité par référence à des attributions propres au dieu choisi (Wrede 1981 ; Zanker, Ewald 2008, p. 193-301). C'est cette dernière interprétation qui tend désormais à recevoir la préférence (Turcan 1982; Rothenhöfer 2010 ; Lo Monaco 2011 ; cf. aussi de Maria 1992, plus nuancé). Pour reprendre des catégories jadis formalisées par E. Panofsky, l'aspect rétrospectif de cette iconographie aurait été largement prédominant par rapport à sa dimension prospective (Panfosky 1964, passim). En conséquence, les aspects plus proprement en lien avec la religion ont été relégués au second plan, au point qu'on s'est demandé si ce phénomène pouvait être considéré comme révélateur de la mentalité religieuse des anciens Romains et de ses évolutions (North 1983, p. 172).

Ce sont certains de ces aspects que je voudrais aborder ici, sans avoir la prétention de reprendre de fond en comble les interprétations précédemment signalées, mais en déplaçant quelque peu le questionnement. En effet, dans le sillage des thèses illustrées magistralement par Fr. Cumont, la discussion s'est généralement concentrée sur les croyances ou sur les représentations de l'au-delà et l'eschatologie individuelle que ces

1. Les abréviations des recueils épigraphiques cités dans cette étude sont celles recommandées dans Bérard, Feissel, Laubry et al. 2010. pratiques auraient exprimées ${ }^{2}$. Or, leurs implications plus spécificiquement rituelles n'ont guère fait l'objet de toute la considération qu'elles méritent, à plus forte raison parce qu'elles sont cruciales dans la définition de la religion des Romains ${ }^{3}$. Cette dimension n' avait pourtant pas échappé à Tertullien, comme le montre un passage souvent cité de son opuscule Ad nationes, composé à la fin du II ${ }^{\mathrm{e}}$ s. ap. J.-C. :

Quid enim omnino ad honorandos eos (sc. deos) facitis, quod non etiam mortuis uestris ex aequo praebeatis? Exstruitis deis templa: aeque mortuis templa; exstruitis aras deis: aeque mortuis aras; easdem titulis superscribitis litteras, easdem statuis inducitis formas, ut cuique ars aut negotium aut aetas fuit : senex de Saturno, imberbis de Apolline, uirgo de Diana figuratur, et miles in Marte et in Vulcano faber ferri consecratur. Nihil itaque mirum, si hostias easdem mortuis, quas et deis, caeditis eosdemque odores excrematis.

« Car que faites-vous pour les honorer que vous ne donniez pas de la même façon à vos morts ? Vous bâtissez des temples aux dieux : vous faites aussi des temples pour les morts ; vous bâtissez des autels aux dieux : vous faites aussi des autels pour les morts ; ce sont les mêmes lettres que vous écrivez sur les inscriptions, les mêmes formes que vous donnez aux statues, selon l'art, le métier ou l'âge de chacun : un vieillard est représenté sur le modèle de Saturne, un imberbe sur celui d'Apollon, une jeune fille sur celui de Diane ; le soldat est consacré en Mars, le forgeron en Vulcain : il n'y a donc rien d'étonnant si vous abattez les mêmes victimes et si vous brûlez les mêmes parfums pour vos morts et pour vos dieux ${ }^{4}$.

Les propos de Tertullien sont évidemment polémiques: l'identification entre les honneurs rendus aux morts et ceux rendus aux dieux est à ses yeux une marque de mépris pour ces derniers et contribue à les

2. Un cas particulièrement bien connu est l'apothéose de Tullia, la fille de Cicéron, à travers le témoignage d'une série de lettres adressées par l'écrivain à Atticus (Att., 12, $12 ; 12,18,1 ; 12,19 ; 12,35-37 ; 12$, $41 ; 12,43 ; 13,29$. Le commentaire le plus complet demeure celui de J. Beaujeu dans le tome VIII de l'édition de la correspondance de Cicéron dans la CUF (appendice I, « le sanctuaire de Tullia », p. 275299). Voir aussi Boyancé 1944. On sait que le monument fut pensé moins comme un tombeau que comme un fanum. Important aussi le passage cité par Lactance (Inst., 1, 15, 18), qui signale l'existence d'une statue (imaginem filiae eodem se modo consecraturum esse profitetur quo illi (sc. dei) a ueteribus consecrati sunt).

3. L'unique exception à ma connaissance est formée par Wrede 1981, p. 88-90.

4. Tert., Nat., 1, 10, 26-28. Cf. également Tert., Apol., 13, 7 et Spect., 13, 2, et, dans un autre contexte, Lact., Inst., 5, 15, 4-6. 
déconsidérer. Ils font néanmoins entrevoir les différentes facettes de ce phénomène: monumentales et plastiques d'abord, qui incluent d'ailleurs les inscriptions ; rituelles ensuite, c'est-à-dire, les formes prises par le culte. Contrairement à ce que laisse entendre l'apologiste chrétien, la similitude apparente des gestes accomplis n'implique pas nécessairement une homologie dans leur signification. Dans la mesure où les données archéologiques font généralement défaut, ce n'est donc qu'en partant de l'examen attentif des inscriptions, de leur contenu et de leur contexte que l'on peut espérer apporter quelque éclairage sur la caractérisation de ces pratiques. La confrontation des messages de l'architecture, de l'iconographie et de l'épigraphie qui se fondent en une seule et même entité monumentale, est à ce titre primordiale, car on y décèle en creux des éléments rituels demeurant souvent largement implicites. Les implications de l'assimilation plastique ou discursive d'un défunt à une divinité sont nombreuses et multiformes et ne peuvent pas être toutes reprises dans le cadre de cette étude. En particulier, l'un des domaines les plus discutés et qui sera laissé à part dans les pages qu'on va lire est celui des sarcophages et de leur iconographie (Gabelmann 1978 ; Wrede 1981, p. 139-157 ; Zanker, Ewald 2008). Je me contenterai d'examiner ici quelques cas pour lesquels les informations disponibles sont assez nombreuses, dans l'intention de déterminer si ce phénomène est une forme particulière d'hommage symbolique rendu au mort ou s'il engage des actes proprement religieux pour évaluer l'écart avec des modalités plus communes du culte des morts.

Les exemples suffisamment complets et éclairants ne sont guère nombreux et il est presque inévitable de commencer par le plus fameux d'entre eux : le tombeau de Claudia Semnè (Altmann 1905, p. 280 ; Wrede 1971 ; Wrede 1981, p. 87-88). Localisé près de San Sebastiano sur la via Appia, il fut dédié par un affranchi impérial, M. Vlpius Crotonensis, à son épouse. Il n'est aujourd'hui connu que sous la forme de membra disiecta. Quatre inscriptions lui sont rattachées: la dédicace du tombeau $(C I L$, VI, $15593=I L S, 8063 \mathrm{c})$, un autel consacré à Fortune, Spes, Vénus et la mémoire de la défunte (CIL, VI, $15594=I L S, 8063 \mathrm{~b})$, une dédicace à la défunte gravée sur une frise $(C I L$, VI, $15592=I L S, 8063 \mathrm{a})$ et enfin une dédicace aujourd'hui disparue qui était adressée au fils de Crotonensis et de Claudia Semnè (CIL, VI, 15595). En faisaient également partie cinq éléments statuaires : un buste de la morte dans un fronton, une statue d'elle allongée sur une klinè, une statue de Spes, ainsi que deux statues en pied et un buste figurant le jeune M. Vlpius Crotonensis. Il faut enfin ajouter divers fragments architecturaux, au nombre desquels trois frontons en marbre (Wrede 1971, p. 126-138). L'ensemble a pu être daté sur critères épigraphiques et stylistiques des années 120-130 de notre ère.

Les comptes rendus de découverte de la fin du XVIII ${ }^{\mathrm{e}}$ et du début du XIX ${ }^{\mathrm{e}} \mathrm{s}$. ne sont pas suffisamment détaillés pour se faire une idée exacte du monument. Les inventeurs signalent l'existence d'un édifice de 3,80 x 3,10 m possédant des niches qui auraient pu accueillir des statues (Altmann 1905, p. 280-281; Wrede 1971, p. 126). À partir de ces quelques données et en s'appuyant surtout sur une publication antérieure de W. Uhden ${ }^{5}, \mathrm{H}$. Wrede a proposé une reconstitution du tombeau. Celui-ci aurait adopté la forme d'une chambre funéraire, dont la façade aurait comporté la dédicace principale et l'architrave inscrite, ainsi que le fronton orné du buste de la défunte. À l'intérieur, trois niches surmontées des frontons décorés des attributs divins auraient accueilli des statues de Claudia Semnè sous les traits de déesses : face à l'entrée, celle de Fortune et, sur chacun des côtés, celles de Spes et de Vénus. Il plaçait en outre les deux statues de togatus de M. Vlpius Crotonensis fils de chaque côté de la porte d'entrée. L'autel funéraire se serait trouvé en face, tandis que la représentation de la défunte sur la klinè pouvait être disposée contre l'une des parois. Enfin, des niches secondaires devaient accueillir les bustes restants, ainsi que des urnes cinéraires qui ne sont pas signalées.

Dans l'ensemble, cette reconstitution s'avère plausible. Une telle organisation de l'espace trouve en effet des confrontations dans divers tombeaux contemporains comme, entre autres, le mausolée H des Valerii de la nécropole païenne de Saint Pierre à Rome (Mielsch, von Hesberg 1995, p. 143-208). Certains éléments sont pourtant dissonnants avec cette hypothèse. Selon l'inscription principale du monument en effet (fig. 1) ${ }^{6}$, le complexe comportait également un jardin (hortus), une pergola (triclia pour trichila $)^{7}$, une petite vigne

5. W. Uhden dans F. Wolf et Ph. Buttmann (dir.), Museum der Alterthums-Wissenschaft, I, 1807, p. 534 sq. (non vidi), cité par Wrede 1981, p. 125.

6. CIL, VI, 15593 (ILS, 8063c) : Claudiae Semne uxori et $\mid$ M(arco) Vlpio Crotonensi fil(io) | Crotonensis Aug(usti) lib(erto) fecit. | Huic monumento cedet $\left.\right|^{5}$ hortus in quo tricliae uiniola $\mid$ puteum aediculae | in quibus simulacra Claudiae | Semnes in formam deorum, ita uti $\mid$ cum maceria a me circumstructa est. $\mid{ }^{10} H(o c)$ m(onumentum) h(eredes) $n$ (on) s(equetur).

7. Pour cette orthographe, voir CIL, VI, $52=25990$ (ILS 4335), 4305 (ILS 1732), 29394, 29958 et 29959 (ILMN, 1, 415). Cf. également CIL, XIV, 1636 (ILS 7926, Portus). H. Thylander (Inscriptions du Port d'Ostie, Lund, C.W. K. Gleerup, 1952, 562 p., B 152) traduit, sans doute à juste titre, par «salle d'été ». Certaines des inscriptions citées montrent que des emplacements pour des sépultures étaient aménagés dans ces trichila. 


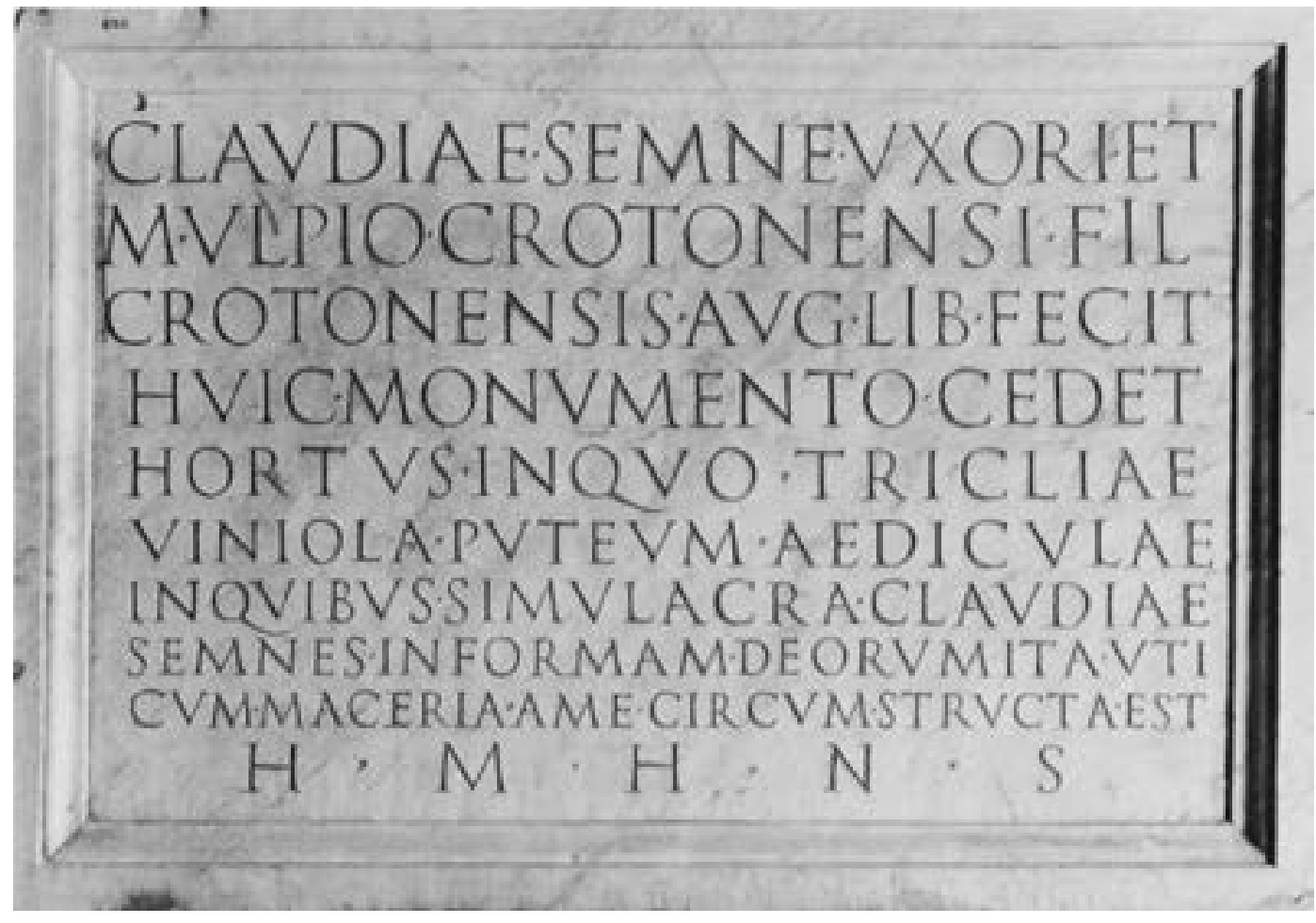

Fig. 1. Rome, dédicace du mausolée de Claudia Semnè (d'après Wrede 1971, pl. 77).

(uiniola) et un puits (puteum, sic). L'ensemble formait un cépotaphe qui était délimité par un enclos (maceria). M. Vlpius Crotonensis en avait fait une annexe du tombeau proprement dit et il avait cherché à lui assurer le même statut juridique afin de garantir sinon son inviolabilité, du moins son affectation ${ }^{8}$. Ce jardin pouvait en outre fournir un modeste revenu destiné à financer l'entretien du tombeau et à servir de lieu d'agrément à l'occasion des cérémonies du culte des morts (Toynbee 1971, p. 94-100 ; Gregori 1987-1988). Si on lit de près ce texte, il ne s'accorde pas exactement avec la reconstruction évoquée plus haut. Il indique en effet que les adicula renfermant les statues de Claudia Semnè in formam deorum se trouvaient non pas dans le monumentum proprement dit - c'est-à-dire dans la chambre funéraire - mais dans le jardin ${ }^{9}$. L'énumération fournie

8. C'est le sens de la formule huic monumento cedet, qui trouve plusieurs parallèles épigraphiques : CIL, VI, 7803 (ILS 7899), 10673, 13823 (ILS 8352), 13876, 14823, 17979, 17992, 23090, 24374, 2743, 29961 et, hors de Rome, CIL, V, 3072 (ILS, 8339 : Padoue), CIL, IX, 3437 (ILS, 5063 : Alba Fucens), CIL, X, 3750 (ILS, 8351 : Atella), 6144 (Formiae), CIL, XI, 3895 (ILS, 8347 : Capène), CIL, XIV, 396 (ILS 8346: Ostie) et 715 (Ostie), 3857 (InscrIt, IV, 1, 466 et ILS, 8350 : Tivoli). Sur ces annexes et leur statut dans le droit romain, voir de Visscher 1963, p. 58-59 et 212-217. Pour la formule finale réservant l'affectation familiale et soustrayant le tombeau au patrimoine transmis aux héritiers, voir Orlandi 2004.

9. Le sens même du mot aedicula, employé par le rédacteur sans doute à dessein, ne vient pas éclairer la question : il peut désigner à la par l'inscription, dont la formulation syntaxique est par ailleurs maladroite, se devait d'être aussi précise et exhaustive que possible afin d'être pleinement efficace pour valoir comme attestation en cas de litige ${ }^{10}$. Certes, il n'est pas pas dit qu'elle puisse être considérée comme livrant une description exacte du complexe funéraire. Mais ce n'est pas l'unique détail qui incite à douter de cette hypothèse. H. Kammerer-Grothaus s'est effet interrogée sur la présence des frontons de marbres à l'intérieur de la chambre funéraire. Selon elle, c'est en effet un type de décor qui serait plutôt atypique pour cette époque où prévalait dans les tombeaux la simplicité des éléments en stuc. Il serait donc possible que ces fragments soient à attribuer à de petits édicules édifiés à l'extérieur, c'est-à-dire, précisément, dans le jardin (Kammerer-Grothaus 1978, p. 134-135).

fois une petite chapelle, généralement pour la statue d'une divinité, mais également, de manière courante, la niche dans laquelle étaient logée les urnes funéraires. Cf. TLL, s.v. et Ginouvès 1998, p. 37. Pour le sens sépulcral, voir entre autres CIL, VI, 9910 (ILS 7624), 18019 et 25359, ainsi que CIL, VI, 16624, très parlant (aedicula ossuaria). Cette localisation des statues a été vue par De Maria 1992, p. 297.

10. Signalons que le droit romain ne reconnaissait pas la validité de telles clauses et que, en tout cas, la législation et la jurisprudence ont souvent refusé d'attribuer aux annexes le même statut qu'au tombeau proprement dit, qui était res religiosa - ce qui n'empêchait pas les fondateurs de chercher à les protéger par ces dispositions. Cf. De Visscher 1963, p. 58-60. 
Quels que fussent son organisation et son aménagement originels, le monument possédait une vocation familiale. Les inscriptions ne mentionnent que deux destinataires, Claudia Semnè et son fils. Pourtant, bien que cela ne soit pas explicitement précisé, il est probable que M. Vlpius Crotonensis, le dédicant, y ait également reçu une sépulture. Le tombeau frappe aussi par la pluralité des évocations des défunts qu'il renfermait. Claudia Semnè était figurée en matrone romaine sur le buste du fronton et dans le sommeil de la mort sur la klinè, mais elle apparaissait aussi sous la mise de Fortune, de Spes et de Vénus. Autant que nous puissions en juger, son fils était quant à lui représenté uniquement en togatus et par un buste. Le registre divin semble donc avoir été réservé à sa mère. L'épigraphie et l'iconographie se complètent, mais les inscriptions se contentent de fournir l'identité des défunts ou se limitent à quelques caractéristiques biographiques et à des clauses juridiques. Bien qu'elles soient indissociables, c'est donc la seconde qui occupe la place centrale parce qu'elle présente un éventail beaucoup plus suggestif et varié de représentations. Pareille situation se retrouve ailleurs, par exemple dans le tombeau des Munatii (tombeau 106) à l' Isola Sacra de Portus (Hommel 1956 ; Helttula 2007, p. 172-182).

Claudia Semnè prêtait donc ses traits aux statues de trois divinités. Le choix de multiples figurations théomorphes pour un même individu n'est pas si fréquent. Un second exemple, également fameux, est celui de Priscilla, qui fut l'épouse de T. Flauius Abascantus, un affranchi $a b$ epistulis de Domitien. Même s'il n'est connu qu'à travers un poème de consolation (epicedion) composé par Stace, il décrit une situation tout à fait comparable à celle du monument de Claudia Semnè. Le tombeau était lui aussi bâti aux abords de la via Appia, aux environs de l'Almo, et il renfermait quatre effigies de la défunte :

(...) Mox in uarias mutata nouaris / effigies : hoc aere Ceres, hoc lucida Gnosis, / illo Maia tholo, Venus hoc improba saxo. / Accipiunt uultus haud indignata decoros / numina.

« Bientôt te voilà transformée en images multiples : tu es Cérès dans ce bronze, la brillante fille de Gnosse dans cet autre, sous ce dôme Maïa, une Vénus chaste dans ce marbre. Les divinités acceptent volontiers de recevoir tes traits gracieux ${ }^{\mathbf{1 1}}$.

11. Stace, Silu., 5, 1, 231-235. Traduction H.J. Izaac, CUF. La leçon tholos au vers 233 n'a pas été retenue par tous les éditeurs, le plus ancien manuscrit conservant le texte des Silves portant tolo. Certains ont préféré la correction en luto proposée dans l'apparat
Comme Claudia Semnè, Priscilla fut figurée avec les attributs de Vénus, mais aussi avec ceux de Céres, de Maïa ${ }^{12}$ et d'une quatrième divinité identifié tantôt à Ariane, tantôt à Diane ${ }^{13}$. Le recours à plusieurs divinités pour évoquer le souvenir d'une même défunte suggère donc qu'il s'agit dans les deux cas de «formules iconographiques » servant à la caractériser (Zanker, Ewald 2008, p. 196). Il n'est pas toujours possible d'expliquer les choix opérés par les commanditaires, mais ces représentations s'inscrivent pour la plupart dans une véritable topique visant à célébrer les qualités physiques ou morales du mort, ou encore sa relation avec le dédicant. Ainsi, la référence à Vénus exprimait une exaltation métaphorique de la beauté. Pour Claudia Semnè, les choix de Spes et de Fortuna trouvent leur probable justification dans la volonté de signifier les bienfaits qu'elle apportait à son époux (Wrede 1981, p. 110-111). Le sens de l'identification de Priscilla à Cérès est moins claire, mais elle a été comprise comme une référence à la fécondité voire à la maternité ${ }^{14}$. La représentation théomorphe doit ainsi se concevoir comme un moyen concret pour exprimer métaphoriquement des notions abstraites tout en exaltant la mémoire du mort. Dans ce cas précis, on ne décèle dans l'assimilation aucune référence à une éventuelle apothéose, à moins de donner à ce dernier terme une signification vague.

La dédicace gravée sur l'autel renforce l'impression d'une distinction entre la morte et les divinités choisies par le commanditaire (fig. 2). On y lit en effet que le monument a été « consacré à Fortune, à Spes, à Vénus

par Baehrens (E.), ed., P. Papinii Siluae, Leipzig, Teubner, 1874, ce qui explique que des commentateurs modernes aient considéré que les statues étaient réalisées dans trois matériaux différents : le bronze, l'argile et le marbre. Lutus possède cependant une connotation négative qui convient mal au passage. En dernier lieu, Leofranc Holford-Strevens a proposé nites ou nitet : voir la mise au point dans Gibson 2006, p. 163-164. Sur le tombeau de Priscilla, voir Wrede 1981, p. 75.

12. Sur Maïa, voir Wissowa 1912, p. 229 et 305 et $R E, 26,1928$, col. 527-533. Divinité plutôt obscure, elle était honorée avec Mercure et recevait un sacrifice accompli par le flamine de Vulcain aux calendes de mai. Elle fut aussi assimilée parfois à la Bona Dea (Macr., Sat., 1, 12, 21).

13. On a généralement compris qu'il s'agissait d'Ariane, qui est demeurée à Rome un personnage mythologique sans jamais recevoir de culte. La présence de l'épithète lucida, souvent attribuée à Diane, a conduit $\mathrm{H}$. Wrede à y voir de préférence une allusion à la Diane crétoise Diktynna (Wrede 1981, p. 75-76). Cette identification n'emporte pas entièrement la conviction, même si cette déesse fut souvent choisie pour représenter des défuntes. Ce fut également le cas pour Ariane, notamment sur les sarcophages, et si c'est bien cette hypothèse qu'il faut retenir, il est intéressant de noter la diversité des registres dans lesquels est venu puiser Flauius Abascantus.

14. C'est en tout cas l'interprétation suggérée par H. Wrede 1981, p. 111. 


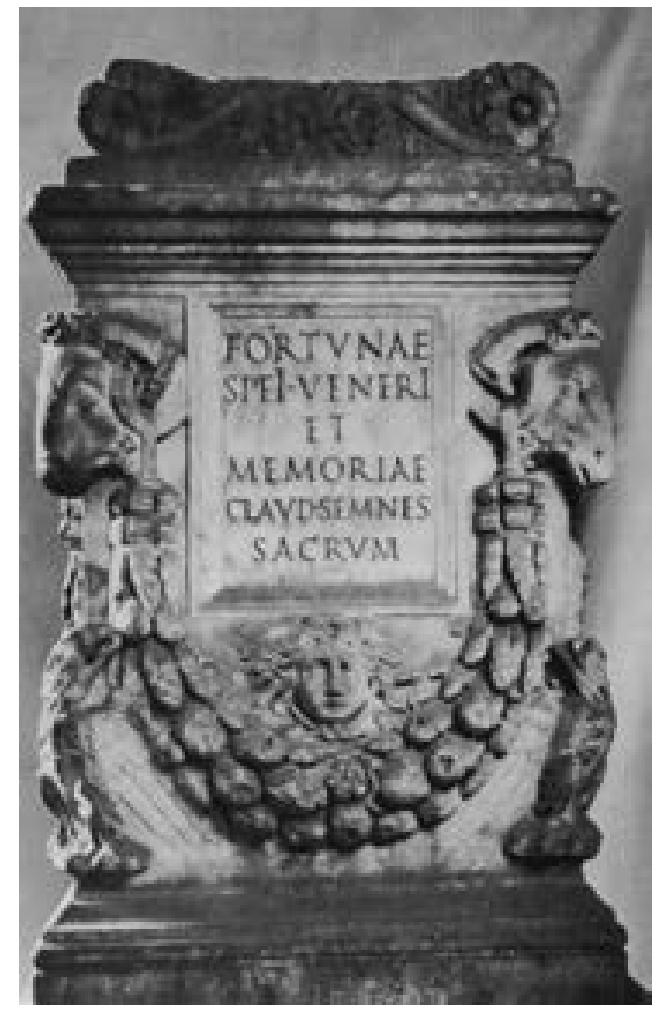

Fig. 2. Rome, autel du mausolée de Claudia Semnè (d'après Wrede 1971, pl. 77).

et à la mémoire de Claudia Semnè ${ }^{15}$. Selon une ambivalence qui a jadis été soulignée par P. Veyne, l'autel est à la fois une offrande et l'objet commémorant l'acte de consécration lui-même et les gestes rituels qui ont accompagné la dédicace (Veyne 1983, p. 288). La formulation qui fait apparaître la mémoire de la défunte au tout dernier rang des dédicataires respecte la hiérarchie entre les entités à qui M. Vlpius Crotonensis a souhaité vouer le monument. En outre, celles-ci ne rentrent pas dans la même catégorie et ne se situent pas sur le même plan. D'un côté sont invoquées des divinités appartenant au panthéon romain que l'on peut qualifier de traditionnel et dont la sphère d'action ne possède pas de lien apparent ou direct avec le monde des morts; de l'autre, le souvenir de la disparue. L'interprétation de la memoria dans la formulation de la dédicace n'est pas totalement dépourvue d'équivoque. Celle-ci, comme on sait, fut parfois associée aux dieux Mânes dans les dédicaces d'épitaphes, au point de devenir dans certaines régions de l'Empire un élément à part entière du formulaire conventionnel. Il n'est pourtant pas complètement certain, comme on l'a parfois sugéré et en dépit de certaines formulations amphibologiques, qu'il se soit

15. CIL, VI, $15594=I L S, 8063 \mathrm{~b}:$ Fortunae $\mid$ Spei Veneri $\mid$ et $\mid$ memoriae $\left.\right|^{5}$ Claud(iae) Semnes | sacrum. agi d'une forme divinisée du souvenir (Brelich 1937, p. 69-71 ; cf. Ricci 2010, p. 166-167). Celles-ci laissent néanmoins entrevoir des interprétations personnelles d'autant plus ouvertes qu'il n'existait aucun dogme en la matière.

La formulation de la dédicace de l'autel n'est pas isolée. Nous connaissons en effet, le plus souvent par la seule inscription, une série de monuments qui furent dédiés conjointement à une voire à plusieurs divinités et à la mémoire du mort. Toutefois, bien qu'ils aient été érigés à titre posthume, le formulaire votif et l'absence d'informations propres aux épitaphes - par exemple l'indication de l'âge - laissent penser qu'ils ne provenaient pas d'un contexte funéraire. Voués par des particuliers ou, plus rarement, par des collectivités, ils prenaient place dans des temples ou des chapelles publics ou privés, comme les espaces cultuels attenants aux scholae de collèges (Wrede 1981, p. 188 ; Arnaldi 2003 ; pour l'Espagne, cf. Rothenhöfer 2010) ${ }^{16}$. Lorsque le support est connu ou a été étudié, on constate qu'il s'agit souvent de bases qui devaient supporter une statue de la divinité honorée dont on peut imaginer qu'elle adoptait les traits du disparu. Une statue de Fortuna retrouvée via San Lorenzo à Rome possède ainsi une dédicace qui nomme conjointement, sur le même mode que pour Claudia Semnè, la divinité à qui est consacrée l'effigie et une femme, Claudia Iusta, qui prêtait ses traits à la déesse (Wrede 1981, kat. 107) ${ }^{17}$. Bien que le texte ne fasse pas explicitement mention de la memoria, il est assez probable que ce soit un honneur posthume. La découverte au cours des mêmes fouilles d'une dédicace adressée par un vétéran du nom de C. Iulius Germanus à la Fortuna Primigenia avait conduit leur premier éditeur à les mettre en relation avec un temple de la Fortune (Visconti 1872) ${ }^{18}$. On s'accorde toutefois aujourd'hui à localiser les aedes Fortunce tres plus au nord, à proximité de la porta Collina, à l'intérieur de l'enceinte servienne, et il n'est donc pas certain que ces deux monuments aient été originellement situés dans l'un de ces sanctuaires (F. Coarelli, LTUR, II, p. 285-287).

16. Cesari 1998 propose aussi une synthèse sur cette documentation pour l'Italie mais considère à tort que ces dédicaces sont funéraires et traduisent une divinisation de l'individu honoré.

17. CIL, VI, $3679=30873:$ Fortunae sacrum, $\mid$ Claudiae Iustae.

18. CIL, VI, $3681=30875$ (cf. SupplIt Imagines, Roma (CIL, VI), 1. Musei Capitolini, n'89). C(aius) Iulius | Germanus | ueter(anus) Aug(usti) n(ostri) | et Aur(elia) Gratta $\left.\right|^{5}$ et Iul(ia) Germana | filia eorum | Fortunae Primigeni|ae aram ex uoto posueru|nt numini $\left.\right|^{10}$ eius INB eius | priuato. Les trois lettres de l'avant dernière ligne font problème. Th. Mommsen proposait de lire $(C I L)$ in b(alneo) eius priuato, qui ne paraît pas satisfaisant à cause du démonstratif. C. Visconti avait compris imp(erio) eius, qui oblige à supposer une erreur du lapicide. 
Les attestations de ce type de dédicaces sont nettement plus sporadiques en contexte funéraire. Il faut compter au nombre de ces dernières l'autel romain d'Auidia Eutychia, qui est de provenance inconnue. L'origine sépulcrale est indiquée à la fois par la forme de la dédicace et par la présence des dimensions de l'enclos gravées sur la base. Le monument était consacré à Diane $(C I L$, VI, $12892=I L S 9064){ }^{19}$. Un second texte est plus révélateur encore et, fruit du hasard des découvertes, il fut mis au jour dans les environs immédiats du tombeau de Claudia Semnè. Il est également inscrit sur un autel dont la destination funéraire est indéniable en raison de la présence de la dédicace aux dieux Mânes (CIL, VI, $10958=I L S, 8065)$ :

$D($ is $) M($ anibus $) \mid$ sacrum $\mid$ Deanae (!) et $\mid$ memoriae $\left.\right|^{5}$ Aeliae | Proculae. | P(ublius) Aelius Asclepiacus | Aug(usti) lib(ertus) | et Vlpia Priscilla filiae $\left.\right|^{10}$ dulcissimae fecerunt.

À y regarder de près, l'articulation syntaxique des trois premières lignes n'est pas des plus claires. On peut hésiter à les traduire : " consacré aux dieux Mânes, à Diane et à la mémoire d'Aelia Procula » ou bien « aux dieux Mânes, consacré à Diane et à la mémoire d'Aelia Procula ». La distinction, de toute façon, n'est pas cruciale, car le rédacteur du texte a très bien pu vouloir mettre ce mot en facteur commun. L'autel d'Aelia Procula demeure digne d'intérêt, car il est une sorte de parallèle en modèle réduit du complexe de Claudia Semnè. Il est en effet décoré d'une niche où est sculptée une petite effigie de Diane suivant le type de l'Artémis de Versailles, mais dont le visage évoque plutôt celui d'une petite fille -évidemment pour rappeler la défunte (Wrede 1981, p. 189 et kat 91). Cependant, le rapprochement s'arrête là, car l'autel d' Aelia Procula fut trouvé en relation avec un tombeau qui, à l'origine,

19. Cf. SupplIt Imagines Roma, VI, 3, 3464 et Wrede 1981, p. 187. Le texte est le suivant: Dianae sacrum; | Auidiae Eutychiae | coniugi sanctissim(ae) | et C(aio) Auidio Karo f(ilio). $\left.\right|^{5} C$ (aius) Auidius Gelos | fecit. | In fr(onte) p(edes) XXV, in agr(o) p(edes) $X X V$. L'autel, conservé au musée des Offices à Florence, est daté vers la moitié du $\mathrm{II}^{\mathrm{e}} \mathrm{s}$. p. C. Notons qu'il y a deux destinataires, mais la principale semble bien Avidia Eutychia. Une autre dédicace du même genre, elle aussi adressée à Diane, a été découverte à Terracina $(C I L, X, 6300$ et p. $984=I L S, 8066 a)$. Elle était gravée sous un édicule sculpté directement dans la roche. On peut cependant avoir des doutes sur sa nature funéraire : cf. en dernier lieu Solin (H.), Kajava (M.) 1992, p. 342-345 et fig. 2 et 9. Il faut exclure de la série l'inscription CIL, IX, 6314 (regio IV, Iuvanum), rapprochée des deux précédentes par Wrede 1981, p. 187. On doit lire en effet: Deanae sacr(um) $\mid$ Seruandus Ob|idiae Maximae $\mid p$ (osuit) et non $p($ ater) pour la dernière ligne. Obidia Maxima n'est pas une dédicataire, mais le nom au génitif de la maîtresse de Servandus, qui était sans doute un esclave. Il s'agit donc d'un autel votif classique. ne lui était apparemment pas destiné. Situé sur l'Appia, le mausolée en question fut édifié vers le milieu du $\mathrm{I}^{\mathrm{er}}$ s. ap. J.-C. par un Q. Ateius Eutyches (?) pour son fils Apollonius, pour ses descendants et pour sa familia (AE, 1977, 106 ; Kammerer-Grothaus 1978, p. 116119 ; Feraudi-Gruénais 2001, p. 120, kat. 157). Il est impossible d'établir comment P. Aelius Asclepiacus, un affranchi impérial, aurait pu obtenir le droit d'y installer une sépulture à sa fille, puisqu'aucun lien de parenté manifeste ne l'unissait aux Ateii. Mais à supposer qu'il s'agisse bien de l'emplacement initial de l'autel - ce qui est loin d'être assuré ${ }^{20}$-, nous n'aurions pas affaire alors à un complexe funéraire aménagé pour honorer le souvenir d'une unique défunte ou, à tout le moins, centré sur elle ${ }^{21}$.

On peut s'interroger sur la valeur de pareilles dédicaces en contexte funéraire. Les formules épigraphiques attestent en effet l'accomplissement d'une consécration, c'est-à-dire qu'elles rappellent un acte rituel qui transfère un objet dans la propriété d'un dieu et, par là-même, cherche à lui rendre hommage. Même si du point de vue du droit sacré, il n'est de consécration au sens strict que dans le cadre du culte public, il n'en reste pas moins que, par homologie, l'acte prend la même signification dans le cadre privé comme le montre largement l'épigraphie $^{22}$. Pour les inscriptions qui ne proviennent pas de tombeaux, le sens de ce geste est relativement évident. L'offrande à la divinité, probablement titulaire du lieu où elle était déposée, constituait un acte de piété à son égard mais aussi un moyen pour rappeler le souvenir d'un être cher. On saisissait en quelque sorte l'occasion du geste religieux pour honorer également un défunt. Or, les choses étaient théoriquement différentes dans les tombeaux, qui sont normalement consacrés aux dieux Mânes. Cette dédicace se fait jour dans l'épigraphie de Rome à partir du règne d'Auguste et se diffuse surtout

20. La relation a été établie par Kammerer-Grothaus 1978, p. 136, suivant des observations de Wrede 1971, p. 125 et 138, mais elle est mise en doute, avec des raisons non dénuées de fondement, par Feraudi-Gruénais 2003, p. 102 et n.179 p. 149.

21. Une seconde épitaphe, assignable à la même époque que celle d'Aelia Procula (milieu du II ${ }^{\mathrm{e}} \mathrm{s}$. ap. J.-C.), a été attribuée au même mausolée (CIL, VI, 10818). Elle fut vouée pour un C. Aelius Urbicus par sa femme, Aelia Priscilla. Si l'onomastique des différents personnages suggère un rapport avec ceux mentionnés dans l'inscription qui nous intéresse ici, on ne peut tisser aucun lien précis entre eux. Son appartenance au tombeau des Ateii est également incertaine. Sur la documentation épigraphique de celui-ci, voir en dernier lieu Feraudi-Gruénais 2003, p. 98-103.

22. Les définitions classiques se trouvent chez Festus 424 L. citant Aelius Gallus (fin de l'époque républicaine), ainsi que Marcian., Inst., 3 (Dig., 1, 8, 6, 3) et Gaius, Inst., 3. Voir la synthèse proposée par Estienne 2008 ainsi que Laubry 2012 [cf. bibliographie]. 
à partir de celui de Claude. Il est cependant manifeste qu'elle fait référence à un acte plus ancien mais qu'on ne jugeait pas nécessaire de transcrire jusqu'alors dans la pierre. Derrière cette expression réside une réalité rituelle et des gestes qui aboutissaient à la constitution de la tombe et à la définition de son statut religieux. Le droit les définissait comme des loca religiosa, qualification qui les distinguait à la fois des espaces disponibles pour les activités humaines, mais aussi de ceux voués par la communauté aux dieux (De Visscher 1963, p. 52-60 ; Ducos 1995 ; Thomas 1999). La dédicace aux Mânes était un moyen d'affirmer que le lieu ou la sépulture avaient été constitués de manière rituelle (Estienne 2008, p. 692 ; Laubry 2012).

Le formulaire de l'autel du tombeau de Claudia Semnè révèle ainsi une logique qui est atypique et même inattendue dans un espace funéraire. Contrairement au petit monument d'Aelia Procula, il ne comporte pas de dédicace aux Mânes. On ne saurait bien sûr en déduire que celle-ci n'a pas eu lieu. Elle peut très bien avoir été rappelée par une autre inscription non conservée, ou éventuellement ne pas avoir reçu de transcription épigraphique. Il n'y a bien sûr aucun doute sur la dimension funéraire du monument. Par sa forme et sa décoration, l'autel lui-même s'inscrit dans le répertoire sépulcral plus que dans celui des monuments votifs, même si la distinction entre les deux ne va pas toujours de soi (Altmann 1905, p. 280 ; Boschung 1987, p. 27). Mais la consécration à Fortune, Spes et Vénus vient introduire un registre différent qui confère à cet espace une dimension supplémentaire. La référence aux divinités auxquelles Claudia Semnè était comparée ne se limite donc pas aux seuls aspects plastiques ou métaphoriques auxquels on a parfois tendu à la restreindre : elle a en effet reçu une sorte d'ancrage religieux. Celui-ci reposait essentiellement sur des gestes rituels accomplis probablement à l'occasion de la constitution du tombeau et qui associaient des divinités aux destinataires traditionnels des rites de fondation. Le lieu était donc marqué par une certaine ambivalence délibérément recherchée par M. Vlpius Crotonensis.

Il y a d'autres indices de cette ambivalence religieuse du tombeau de Claudia Semnè. Les statues de la défunte sous les traits des divinités sont qualifiées dans l'inscription principale déjà citée de simulacra. Or, ce terme désigne généralement les statues cultuelles, par opposition aux statues consacrées ou à celles possédant une valeur décorative ${ }^{23}$. L'utilisation de ce mot dans

23. Ainsi, Suét., Tib., 26 (par opposition aux ornamenta). Cf. également Estienne 1997, p. 83-89. un contexte funéraire est, à ma connaissance, pratiquement un hapax - une seconde occurrence apparaissant dans une épitaphe probablement plus tardive d'Auzia en Maurétanie césarienne (CIL, VIII, $8124=I L S, 8084$.). L'interprétation de ces usages lexicaux recommande toutefois la prudence, car ils ne sont pas toujours probants. Dans le cas présent, il est parfaitement envisageable que le recours à simulacrum ait été appelé par le syntagme in formam deorum, sans pour autant qu'il se soit agi d'images cultuelles au sens strict. Par ailleurs, il est douteux que ce dernier qualificatif puisse s'appliquer en tant que tel aux représentations statuaires des défunts qui revêtaient essentiellement une fonction commémorative et ce en dépit du contexte dans lequel elles se trouvaient, puisqu'il est indubitable que la tombe est un lieu de culte.

Le fondateur a voulu concevoir un ensemble qui se démarquait de tombeaux plus conventionnels. À partir du $\mathrm{I}^{\text {er }}$ s. ap. J.-C. et surtout dans le courant du II ${ }^{\mathrm{e}}$ s. ap. J.-C. se diffusent à Rome des mausolées qui, par leurs caractéristiques architecturales et formelles, sont apparentés à des temples (Wrede 1978 ; von Hesberg 1992, p. 182201 ; Gros 2001, p. 444-451). Les exemples les plus fameux car les mieux conservés sont ceux du temple dit du Deus Rediculus sur la via Appia ou du mausolée dit des Valerii sur la via Latina. Une illustration très suggestive s'en trouve sur l'un des reliefs du complexe funéraire des Haterii (Sinn, Freyberger 1996, kat. 6 et pl. 11-16). Il représente un édifice tétrastyle construit sur un podium qui renfermait la chambre funéraire figurée dans la partie supérieure du relief. On a souligné à juste titre que ces solutions architecturales traduisaient la volonté d'assimiler certains tombeaux aux édifices cultuels des divinités. Cette identification paraît ainsi avoir été délibérée dans le cas du mausolée de Priscilla. Aucun vestige n'en a été retrouvé, mais Stace le compare au templum gentis Flauice. Surtout, une épitaphe urbaine mentionne un aedituus répondant au nom de T. Flauius Epaphroditus, affranchi d'un T. Flauius Abascantus et d'une Priscilla. Cet ancien esclave était très probablement préposé à la surveillance et à l'entretien de leur tombeau. Le recours à ce terme rend explicite l'assimilation du monumentum à une acdes ${ }^{24}$.

Le mausolée de Claudia Semnè a quelquefois été rapproché de ces tombeaux-temples, mais il est difficile

24. CIL, VI, 2214: M(anibus) | dis sacr(um). | Aphrodisio uernae suo dulc(issimo) $\left.\right|^{5}$ fec(it) T(itus) Flauius | Epaphroditus | aedituus | Abascanti et Priscil|laes (!) patronor(um) $\left.\right|^{10}$ et sibi suis ; $b$ (onis) b(ene). Sur cette inscription et le terme adituus, voir De Ruggiero (E.), dir., Dizionario epigrafico di antichità romane, I, Roma, L. Pasqualucci editore, 1895, p. 271-273. C'est apparemment l'unique occurrence de ce terme en contexte funéraire. 
de vérifier la validité de cette hypothèse en l'absence de toute trace architecturale qui permettrait de la corroborer. Ce que nous avons pu en voir à travers un examen des membra disiecta et d'une lecture attentive des inscriptions le fait sortir du cadre d'une définition trop étroite ou trop restrictive. D'une certaine manière, il ne se résumait pas dans l'idée de son fondateur à seule dimension funéraire et n'était pas voué uniquement à la mémoire de la défunte. L'introduction dans un lieu de culte pour les morts d'objets dédiés à des divinités n'est guère conforme à la logique de la religion romaine qui marquait une différenciation assez nette sur le plan rituel et conceptuel entre les morts et les autres divinités. Ainsi, lors des dies parentales célébrés en février ou à l'occasion des parentationes en l'honneur des princes défunts de la famille impériale, les temples devaient demeurer portes closes ${ }^{25}$. La cohabitation dans un même espace d'un culte aux Mânes ou à la défunte Claudia Semnè et de statues vouées à Fortune, Spes ou Vénus paraît de ce point de vue difficilement envisageable. Remarquons en passant que l'idée d'une différenciation spatiale dans l'organisation du complexe pourrait recevoir ici un appui supplémentaire : aux défunts aurait été réservée la chambre funéraire, tandis que les autres divinités auraient été installées dans le cépotaphe. Ce genre de configuration n'est guère attesté pour des monuments de particuliers, mais il n'est pas sans faire penser à des espaces collégiaux où la chapelle vouée au culte de la divinité patronne jouxtait souvent une aire destinée aux sépultures des membres de l'association ${ }^{26}$. Cependant, il ne faut sans doute pas chercher à pousser trop loin le raffinement et appliquer des distinctions ou des différenciations qui étaient opératoires essentiellement dans le culte public. Nous nous trouvons ici dans le cadre de dévotions et de pratiques privées, qui étaient soumises à des interprétations personnelles donnant lieu à des constructions ou à des innovations plus libres.

Le tombeau de Claudia Semnè, si souvent cité en exemple dans les études modernes, laisse en définitive apercevoir des usages peu communs. Nous n'avons aucune preuve explicite que l'identification plastique à Fortune, Spes et Vénus ait cherché à exprimer l'apothéose à la défunte, et encore moins une identification de la morte avec ces divinités ${ }^{27}$. En se concentrant sur

25. Ov., Fast., 2, 563-564 et CIL XI, 1421, 1. 32-33. Ce principe est formulé de manière particulièrement claire par Cic., Phil., 1, 13. Cf. Fraschetti 2000, p. 150.

26. Une confrontation possible se trouve par exemple dans la donation de Salvia Marcellina au collège d'Esculape et Hygie (CIL, VI, $10234=I L S, 7213):$ locum aediculae cum pergula et signum marmoreum Aesculapi et solarium tectum iunctum.

27. Contra, par exemple, Picard 1939, p. 124-125. quelques détails, on constate plutôt une évidente différenciation. Mais tout aussi intéressant me semble le fait que le rapprochement exprimé par la statuaire a trouvé une forme de sanction dans un acte de consécration aux déesses invoquées. Nous ne savons rien des formes du culte qui fut rendus par la suite dans ce mausolée. H. Wrede supposait qu'il ne différait guère de celui qui était célébré plus conventionnellement, avec des offrandes propres aux défunts et des banquets commémoratifs. (Wrede 1981, p. 88). Même si nous n'avons dans ce cas précis aucun élément pour en juger, et qu'il est impossible de savoir si les trois divinités associées recevaient elles aussi des honneurs religieux, cette proposition semble la plus vraisemblable.

Dans quelques cas pourtant, le culte du défunt semble s'être déroulé selon des modalités plus exceptionnelles. Les témoignages sur ce point sont épars et laconiques. Il vaut toutefois la peine de revenir sur une inscription notable provenant de Gabies, dans le Latium, et qui a parfois été rapprochée de l'ensemble précédent (CIL, XIV, $2793=I L S, 5449$; Wrede 1981, p. 85-86 ; SupplIt Imagines, Latium vetus, $\mathrm{n}^{\circ} 439$ ) (fig. 3) :

Veneri |Verae Felici Gabinae. | A(ulus) Plutius Epaphroditus, accens(us) uelat(us), negotiator sericarius, templum cum | signo aereo effigie Veneris item signis aereis n(umero) IIII dispositis in zothecis et $\left.\right|^{5}$ balbis (!) aereis et aram aeream et omni cultu a solo sua pecunia fecit; cuius ob|dedicationem diuisit decurionibus sing(ulis) (denarios) $V$ item (se)uir(is) Aug(ustalibus) sing(ulis) (denarios) III item taber|naris intra murum negotiantibus (denarium) I, et (sestertium) $X$ m(ilia) n(ummum) rei publ(icae) Gabinor(um) intulit, ita ut ex | usuris eiusdem summae quod annis IIII kal(endas) Octobr(es) die natalis Plutiae Verae | filiae suae decur(iones) et (se)uir(i) Aug(ustales) publice in triclinis suis epulentur. Quod si | facere neglexserint (!), tunc ad municipium Tusculanor(um) (sestertium) $X$ m(ilia) $n$ (ummum) pertineant, $\left.\right|^{10}$ quae confestim exigentur. L(ocus) d(atus) d(ecreto) d(ecurionum), | dedicata idibus Maias L(ucio) Venuleio Aproniano II, L(ucio) Sergio Paulo II co(n)s(ulibus).

«À Vénus Vera Felix Gabina Aulus Plutius Epaphroditus, accensus velatus, négociant en soie, a fait à ses frais ce temple depuis ses fondations, avec une statue de bronze à l'image de Vénus, des statues de bronze au nombre de quatre placées dans des niches, des portes de bronze, un autel de bronze et l'ensemble de sa décoration; pour sa dédicace il a fait distribuer cinq deniers à chaque décurion, trois deniers à chaque sévir augustal et un denier à chaque boutiquier dont 


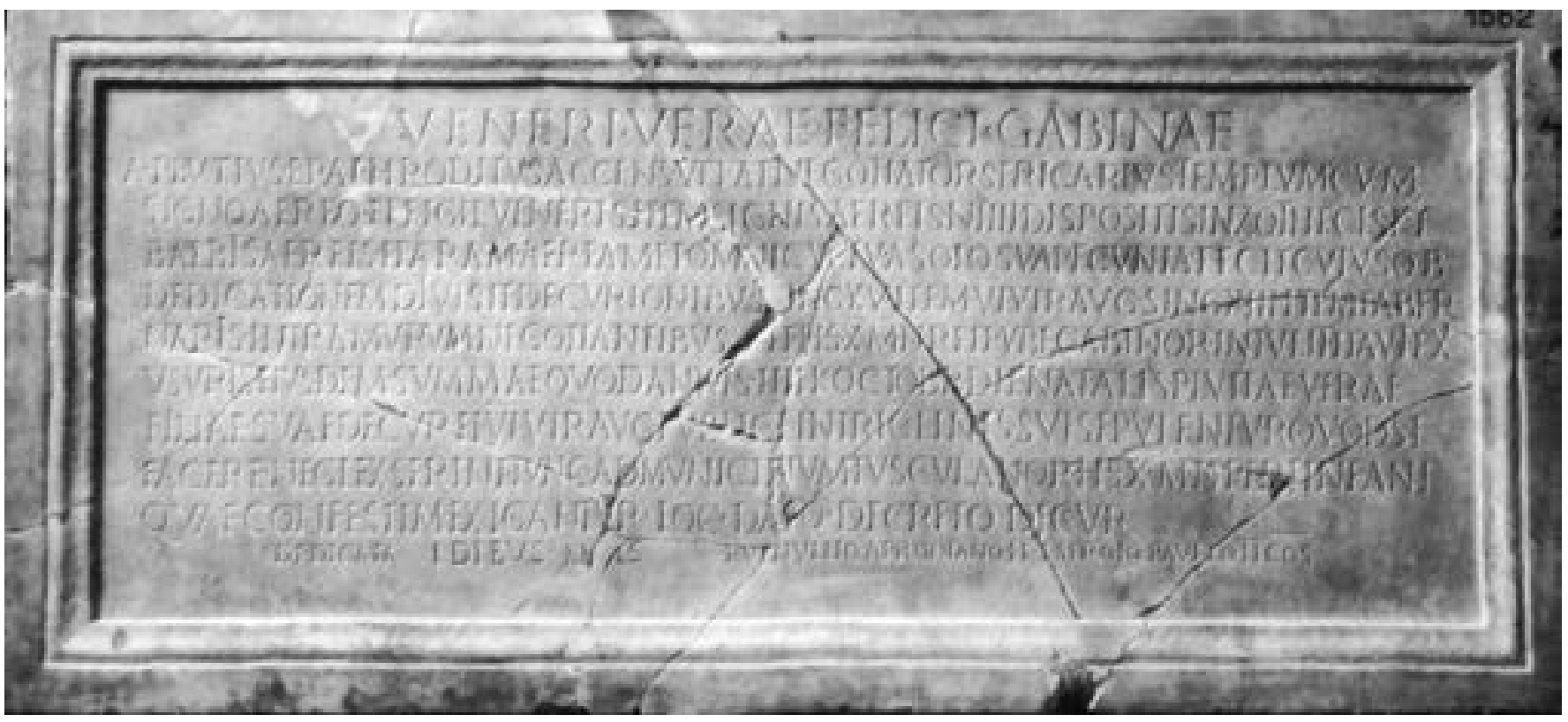

Fig. 3. Gabies, dédicace en l'honneur de Vénus Vera Felix Gabina (d'après M. Gr. Granino Cecere, Supplementa Italica. Imagines. Latium vetus (CIL, XIV ; Eph. Epigr. VII et IX). Latium vetus praeter Ostiam, Roma, Quasar, 2005, n429, cliché M. et P. Chuzeville).

les affaires se trouvent à l'intérieur de l'enceinte (de la ville) ; il a versé à la caisse de la communauté de Gabies la somme de dix mille sesterces, pour que chaque année, le quatrième jour des calendes d'octobre, au jour de l'anniversaire de Plutia Vera, les décurions et les sévirs augustaux célèbrent un repas public sur leurs banquettes. S'ils négligent de le faire, que les dix mille sesterces reviennent au municipe de Tusculum et ils seront réclamés sur le champ. Emplacement donné par décret des décurions ; dédié aux ides de mai, sous le second consulat de Lucius Venuleius Apronianus et le second consulat de Lucius Sergius Paulus ».

Ce texte a suscité des interprétations divergentes et mêmes discordantes. Les informations sont moins nombreuses que pour le tombeau de Claudia Semnè, car aucune trace matérielle de l'édifice où devait probablement être fixée la plaque n'a été retrouvée. Pour reconstituer le contexte monumental, nous sommes donc tributaires de la seule inscription, dont le contenu est néanmoins assez détaillé. L'édifice a parfois été considéré comme un monument funéraire dédié à Plutia Vera assimilée à Vénus (Wissowa [1882] 1904, p. 23 n. 4 : titulus sepulcralis; cf. Wissowa 1912, p. 291 n.9). Une telle définition ne va pourtant pas de soi. Le terme templum qui le qualifie désigne en effet un édifice consacré à un dieu et ne renvoie quasiment jamais à un tombeau ${ }^{28}$. Une seconde inscription de Gabies,

28. Le second sens d' « espace délimité par certains rites » apparaît nettement moins pertinent dans ce contexte : cf. Dubourdieu, Scheid relativement célèbre, fournit un parallèle intéressant $(C I L, \mathrm{XIV}, 2795=I L S 271)$. Elle atteste l'existence, en 140 ap. J.-C., d'un monument qualifié de templum et d'aedes construit en l'honneur de la mémoire de Domitia Longina par deux de ses affranchis. Sa construction se justifie probablement par la présence de possessions de l'ancienne épouse de Domitien dans cette cité, où on pourrait même supposer qu'elle était née (Chausson 2003, p. 128 n.63). Rien n'indique cependant qu'il se soit agi de son tombeau : la description livrée par l'inscription suggère plutôt un édifice voué à la mémoire familliale (Chausson 2003, p. 103-106) ${ }^{29}$. L'argument lexical n'est certes pas déterminant. Cicéron, par exemple, tenait particulièrement au terme de fanum et refusait celui de monumentum pour le sépulcre qu'il destinait à sa fille (Cic., Ad Att., 12, 35). Dans le monument édifié par A. Plutius Epaphroditus et tel qu'il est présenté par l'inscription de dédicace, la vocation cultuelle, soulignée aussi par la présence d'un autel, prédomine sur une éventuelle destination funéraire. L'ambiguïté est donc particulièrement notable.

Elle se retrouve aussi dans la divinité à qui il fut voué, Vénus. La présence du surnom de la défunte au second rang du théonyme complet marque un désir évident d'association voire d'identification avec la déesse. On

2000, p. 66-68. On trouve toutefois l'expression templum securitatis sur une inscription funéraire de Tunisie: ILTun 1715 (cf. aussi à Cagliari CIL, X, 7719).

29. On ignore où Domitia reçut une sépulture. 
considère généralement que le culte de Vénus Felix fut introduit à Rome par Sylla, mais cette épithète fut également attribuée à la Vénus qui partageait avec Roma la cella du grand temple bâti à Rome sur la Vélia par Hadrien ${ }^{30}$. La seconde épithète, Gabina, lui confère par ailleurs un ancrage local évident. Ces obscurités n'ont pas empêché de formuler diverses propositions pour éclairer la nature de la déesse. G.-Ch. Picard a voulu y voir la forme latinisée d'une divinité syrienne, Baâlat ou Astarté (Picard 1939, p. 129-130 ; cf. Schilling 1988, p. 172). C'est cette interpretatio, motivée par une quête de respectabilité auprès des autorités locales, qui justifiait selon lui l'adjonction de l'adjectif topique Gabina. Deux raisons le conduisaient à formuler cette hypothèse : d'une part, une prétendue origine orientale d'A. Plutius Epaphroditus ; d'autre part, les attributions funéraires de la déesse syrienne qui se trouvent particulièrement adaptées au contexte. En réalité, ces arguments sont loin d'être décisifs. Le surnom Epaphroditus marque en effet un lien privilégié avec Vénus, mais il est relativement banal à Rome avec au total plus de 300 occurrences, en particulier dans les milieux serviles ou affranchis (Solin 2003, I, p. 343-348). La racine grecque ne suffit pas à prouver que celui qui le portait venait de l'Orient méditerranéen, pas plus que sa profession de négociant en soie. En revanche, on notera que sa fonction d'accensus uelatus, c'est-à-dire d'appariteur et ministre du culte public romain lui faisait nécessairement entretenir des liens avec la ville de Rome et ses plus hauts dignitaires (Di Stefano Manzella 1994). Elle témoigne en outre, tout comme cette dédicace, de l'importance relative du personnage, dans la mesure où elle était confiée, sans doute de manière vagière, à des individus de rang notable, riches affranchis ou même chevaliers ${ }^{31}$. D'autre part, il semble très hasardeux de se lancer dans les spéculations autour d'un éventuel syncrétisme en avançant que la déesse serait en fait d'origine syrienne. En particulier, si l'on doit supposer à cette Vénus une sorte de patronage pour l'au-delà ou un rôle de psychopompe (Picard 1939; Schilling 1988, p. 178), on ne peut manquer de se demander pourquoi le dédicant ne s'est pas contenté

30. Sur cette déesse, voir toujours Wissowa 1882 [1904], p. 22-24 ; cf. aussi Schilling 1982, p. 283-289. Il existe à Rome deux dédicaces à Vénus Felix (CIL, VI, $781=30831$ et $782=I L S, 3166)$, ainsi qu'un texte mentionnant un adituus de son temple (CIL, VI, 8710). Elles ont été toutes attribuées au temple de Sylla, mais sans fondement assuré. Quoique non localisé par l'archéologie, il a été situé par certains chercheurs dans les environs des horti Sallustiani : cf. L. Chioffi, LTUR, V, p. 116. Hors de Rome, voir CIL, X, 4570 (Gaète) et CIL, IX, 3429 = ILS, 6110 (Peltuinum, datée de 242 ap. J.-C.). L'attribution de l'épithète Felix à la Vénus de Sylla a parfois été mise en doute et demeure de fait incertaine : Latte 1960, p. 188.

31. A. Plutius Epaphroditus est également connu à Gabies par une base de statue dédiée par ses affranchis : CIL, XIV, 2812. de l'honorer seule, mais est allé jusqu'à chercher l'identification avec la défunte ${ }^{32}$. Le corpus épigraphique de Gabies est relativement restreint et il n'existe aucune autre attestation d'un culte à Vénus à l'époque impériale. À tout prendre, on pourrait cependant se demander si ce n'est pas plutôt la déesse romaine qui est ici évoquée. Plutôt que de la Vénus protectrice de Sylla, il pourrait s'agir de celle du temple voulu par Hadrien. Cet empereur a entretenu des liens priviligiés avec Gabies, qui doit à sa munificence la reconstruction d'un aqueduc et d'un édifice non identifié ainsi que, sans doute, celle du temenos de Junon Gabina (Boatwright 1989, p. 261-262 et 271 ; Alföldy 1998) ${ }^{33}$. La volonté de l'insérer dans le paysage religieux municipal pourrait dans ce cas également justifier le recours à l'épithète Gabina, mais il faut reconnaître que l'écart chronologique de trente ans au moins rend un lien direct moins vraisemblable. Quoi qu'il en soit, la question de savoir si Plutia Vera fut associée à une déesse déjà honorée à Gabies ou à une divinité introduite pour l'occasion est probablement insoluble.

Un point qui a été moins souligné en revanche est le rôle joué par la cité de Gabies dans la fondation et le culte mis en place. En premier lieu, le templum fut édifié sur une parcelle du sol public cédé au fondateur par suite d'un décret des décurions. En outre, l'acceptation de la donation d'Epaphroditus et des conditions régissant son usage a dû être sanctionnée par une autre décision du sénat municipal. Cette procédure est en effet attestée par la dédicace de l'aeedes construite à la mémoire de Domitia Longina qui a été brièvement signalée plus haut (CIL, XIV, 2795). On a parfois avancé que cette évergésie des affranchis de l'ancienne épouse de Domitien avait servi de modèle au projet d'A. Plutius Epaphroditus

32. Il serait trop long et peu à propos de revenir ici sur l'intégralité du dossier de la «Vénus funéraire » sous l'Empire jadis constitué par G.-Ch. Picard. Comme j'essaie de le montrer ici, les deux principales inscriptions qui servaient à sa démonstration, celle de Claudia Semnè et celle de Plutia Vera, ne me semblent pas justifier de voir des interprétations eschatologiques dans l'invocation à Vénus. Il s'appuyait aussi sur des sarcophages, pour l'interprétation desquels on consultera maintenant Zanker, Ewald 2008, p. 207-212. On ne niera pas cependant que Vénus ait pu avoir affaire avec le monde des morts, jouant parfois un rôle psychopompe : ainsi, dans le poème épigraphique $C I L, \mathrm{VI}, 21521$ (CLE 1109), où le jeune défunt est conduit au ciel par la déesse. Il faut peut-êre le rapprocher de Tib. 1, 3, 57-58, où elle guide le poète disparu dans les Champs Élysées (cf. Grimal 1957- mais sa présence peut aussi bien s'expliquer par le contexte élégiaque). Delphes connaissait une Aphrodite $\dot{\varepsilon} \pi \imath \theta v \mu\left[0_{i} \alpha\right.$, mais rien ne dit qu'elle ait reçu un écho particulier à Rome : le rapprochement opéré par Plutarque $(Q R, 23)$ tient aussi aux spéculations d'antiquaire pour tenter d'éclairer la soi-disant Vénus Libitina (sur celle-ci, voir désormais les observations décisives de Scheid 2004).

33. Signalons que, dans l'inscription de l'ades de Domitia Longina (CIL, XIV, 2795), la curia de Gabies est surnommée AElia Augusta, mais ce nom pourrait venir aussi d'Antonin le Pieux. 
(Weinstock 1955, col. 926 ; Wrede 1981, p. 86). Pareille influence n'est pas impossible, mais rien ne permet de l'établir directement, d'autant plus que, même si les formes choisies pour la tutelle des monuments et du culte sont comparables, les deux édifices se distinguent en partie par leur dédicace. Par contre, les modalités d'institution des deux fondations furent probablement identiques, puisque c'était la même communauté qui en était bénéficiaire. La parenté se retrouve notamment dans la clause de transfert de la somme affectée à Tusculum en cas de manquement aux conditions posées par le donateur. Enfin, alors que la dédicace du monument a donné lieu à une distribution aux décurions, aux sévirs augustaux et aux boutiquiers, seuls les deux premiers groupes sont chargés de banqueter chaque année le jour anniversaire de la défunte. Même si ce choix est relativement récurrent dans de telles fondations (Andreau 1977), on relèvera malgré tout que ce sont les groupes situés au sommet de la hiérarchie de la société municipale. En dépit de ces dispositions, ni le temple ni le culte ne peuvent être définis à proprement parler comme un culte public du municipe, car, du point de vue du droit romain, il n'a pas été instauré par la communauté et n'était pas célébré pour elle (Van Andringa 2009, p. 25-26) ${ }^{34}$. Il est certain en revanche que le fondateur a voulu leur conférer une dimension publique - au sens non technique - et officielle aussi appuyée que possible.

Ces observations ne permettent malheureusement pas de spécifier plus avant la nature de l'édifice ou de la divinité, ou encore, en d'autres termes, de déterminer si ce templum était voué à une Vénus à laquelle Plutia Vera aurait été associée ou bien à Plutia Vera elle-même consacrée en Vénus Felix. Nous avons vu que le théonyme lui même marquait une évidente volonté d'association, voire d'assimilation. Celle-ci trouvait peut-être aussi une traduction plastique. La formulation signum aereo effigie Veneris, préférée au plus neutre signum Veneris, pourrait laisser entendre, comme cela a été quelquefois compris, que la statue adoptait les traits de Plutia Vera (Weinstock 1955, col.925). La fameuse statue du Belvédère au Musée du Vatican fournit un parallèle intéressant de représentation théomorphe d'une femme sous l'apparence d'une Vénus qualifiée de Felix par la dédicace (Wrede 1981, kat. 306 et $C I L$, VI, $782=I L S, 3166$ ). On ignore en revanche ce que représentaient les autres effigies (signa) placées dans des niches à l'intérieur de l'édifice ${ }^{35}$.

34. Sa classification comme «construction publique » me paraît donc très contestable : Jouffroy (H.) 1986, p. 116 et 121.

35. C'est en ce sens que l'on comprend le terme zotheca: cf. Plin., Epist., 2, 17, 21 ; CIL, XIV, $3543=I L S, 3452$ (Tivoli) et CIL, VIII, 7019 (Cirta).
L'un des moyens pour répondre à la question de la caractérisation du destinataire serait de connaître plus précisément les modalités du culte rendu. L'inscription fournit malheureusement peu d'indications à ce propos. La principale est la célébration d'un banquet annuel à l'anniversaire de Plutia, le 29 septembre. Bien que le texte ne le dise pas explicitement, ce repas devait s'accompagner d'un sacrifice, qui était une pratique usuelle dans ce contexte (Scheid 2005, p. 213-254). Or, deux solutions sont ici possibles : soit les rites s'adressaient à Vénus Felix, soit il s'agissait d'un sacrifice funéraire, une parentatio destinée aux Mânes de la défunte. Rien ne permet cependant de trancher. La date choisie, qui renvoie directement à la biographie de la morte, pourrait faire pencher pour la seconde solution. Le lieu des célébrations demeure en outre incertain. L'unique mention topographique est en effet le syntagme triclinia sua qui est vague : faut-il comprendre les banquettes qui sont réservées aux décurions dans le complexe ? Ou considérer qu'il s'agit plutôt de leurs propres salles de banquet où ils accomplissaient également les autres rites dont ils avaient normalement la charge ? Dans ce cas, le lieu du repas et le templum auraient pu être dissociés. Nous avons vu que ce dernier disposait d'un autel, mais le silence demeure évidemment sur les occasions pour lesquelles il était utilisé.

Faute de détails supplémentaires sur les modalités des rites, il n'est donc pas possible d'aller plus loin et, par conséquent, d'établir s'il s'agissait d'un culte funéraire, d'un culte rendu à une divinité céleste, ou encore d'une forme particulière de culte rendu à une morte déifiée. Le monument n'est pas sans rappeler, à une autre échelle, l'édifice qui fut construit par Néron à Poppée. Après la disparition de celle-ci, sa dépouille fut déposée dans le mausolée d'Auguste, et elle reçut des honneurs divins ${ }^{36}$. Le monument fut voulu par l'empereur et dédié par les

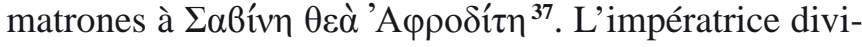
nisée y était donc identifiée à Vénus. Dion Cassius le qualifie d'îp̣̂ov, ce qui laisse entendre que le culte était destiné à la diua Poppaea plutôt qu'à Aphrodite ${ }^{38}$.

36. Tac., Ann., 16, 6 et 21. Cf. PIR ${ }^{2}$ P, 850 et Kienast (D.) 1996, p. 99. Le nom de diua Poppaea Augusta est attesté également par les inscriptions (e. g. CIL, XI, 1331) et par les monnaies.

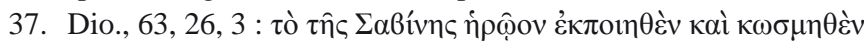

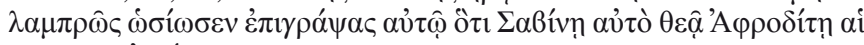

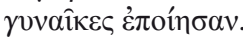

38. Chez Dion Cassius, ce terme n'est utilisé que pour désigner les monuments des diui et diuae, en particulier César $(47,18,4 ; 19$, $2 ; 51,19,2,22,2,22,4 ; 54,35,4)$, Auguste $(56,46,3$ et 59, 7, 1) et précisément, Poppée. Unique exception, une occurrence vient cependant qualifier le mausolée d'Auguste $(56,33,1)$. Cf. Lega 1996, p. 97. 
Dans le cas de Plutia Vera, tant la dédicace que les éléments architecturaux et même les données cultuelles marquent cette volonté d'identification entre la défunte et la déesse. Il se rapproche de ce fait des exemples précédemment analysés, mais dans un registre nettement plus hyperbolique, car il dépasse la simple assimilation plastique à valeur métaphorique. Il est ainsi possible de parler d'apothéose privée, dont la portée s'étend audelà du cadre domestique pour aller jusqu'à une forme de reconnaissance par la cité en raison des dispositions prises par le fondateur.

On constate par ailleurs que les considérations eschatologiques qui ont pu guider cette réalisation ne peuvent guère dépasser le rang de suppositions. Ce qui ressort avant tout, c'est la décision de conférer à la disparue des hommages de type divin. Si la destinataire du temple et du culte était bien Vénus et que la défunte devait se contenter de parentationes plus conventionnelles, l'association entre les deux contribuait malgré tout à glorifier sa mémoire. D'une certaine façon, nous serions face à une situation relativement comparable - mais non similaire - à celle des honneurs décidés par le Sénat et le peuple romain à la mémoire des princes impériaux, notamment pour L. et C. César ou Germanicus (Scheid 2005, p. 200-209 ; Fraschetti 2000). En revanche, la destinataire du templum pourrait tout aussi bien être Plutia Vera déifiée. Le changement onomastique est d'ailleurs l'une des marques de l'apothéose romaine (I. Gradel, ThesCRA, II, p. 186-187). Ce n'est pas inenvisageable, mais on pourrait avoir quelque réticence pour cette hypothèse car, bien que l'acte relève ici d'une initiative privée, on a vu que l'ampleur qui lui était conférée dépassait largement ce cadre : on doit alors se demander s'il était possible de donner une telle visibilité à ce qui demeurait, théoriquement du moins, un privilège impérial. On comprend que la question de savoir s'il s'agit d'une véritable déification ait été au cœur des préoccupations de ceux qui se sont penchés sur les discours ou les conceptions portant sur l'au-delà. Mais elle possède peut-être moins d'importance qu'on ne l'a cru. De fait, les morts sont indéniablement des dieux à Rome. Bien qu'il n'aient pas le même statut que les dieux « immortels » ou «de toujours » pour paraphraser les érudits latins, ils forment la communauté des dieux Mânes (di Manes). Varron en voyait un témoignage précisément dans les rites dont ils étaient destinataires, en particulier les jeux ${ }^{39}$. Si le trépas était marqué par une modification

39. Varr.,Ant.diu.210Cardauns(Aug., Сiu., 8,26) :Omnes... mortuos existimari Manes deos et [probat] per ea sacra, quae omnibus fere mortuis exhibentur, ubi et ludos commemorat funebres. Au passage, on relevèra que la preuve de la divinité des morts ne repose pas sur de statut de l'individu, une apothéose, au sens strict, n'aurait pas traduit par rapport au statut traditionnel des morts un changement de nature, mais plutôt de degré dans celui-ci. Cette différence trouvait des traductions très concrètes dans les modalités du culte, mais, comme nous l'avons dit, l'unique moyen pour en décider serait d'avoir plus de précisions sur les rites accomplis. Pourtant, plus encore que le statut post mortem, c'est le statut du défunt ici-bas, c'est-à-dire, sa mémoire dans la communauté qui était mise en valeur par ces pratiques, selon une conception bien romaine. Qu'un monument et un culte comme ceux instaurés pour Plutia Vera aient été une forme fastueuse de culte funéraire ou qu'ils aient voulu exprimer une déification, ils contribuaient, par une mise en scène de la piété, à la définition de la relation entre les vivants et le mort.

L'examen rapide des deux monuments de Claudia Semnè et Plutia Vera montre ainsi que ce que l'on a tendance à unifier sous l'idée de consecratio in formam deorum renvoie en réalité à des usages certes apparentés mais quelquefois disparates. Cette diversité n'est pas le propre de la sphère privée, car elle apparaît aussi dans le cadre des honneurs et du culte rendus à l'empereur et à sa famille. Les sources à notre disposition, souvent laconiques ou incomplètes, en font ressortir l'ambivalence ou l'ambiguïté. L'étude des inscriptions dans leur contexte, observé ou reconstitué, permet toutefois de combler partiellement ces silences, si du moins on prend conscience de leurs limites et du fait que ces monuments ne sont pas simplement l'expression de croyances, mais aussi et surtout les produits et le support de conduites. Pourtant, cette équivoque n'est peut-être pas uniquement un effet de la documentation et pourrait s'avérer un élément constitutif de ce phénomène, déjà sensible à l'époque impériale : c'est en tout cas elle qui a fourni à Tertullien, bon connaisseur des pratiques religieuses romaines, un argument supplémentaire lui permettant de plaider en faveur de la foi chrétienne.

une caractérisation théologique ou doctrinale, mais sur une sorte de raisonnement régressif qui donne la place déterminante à l'argument cultuel. 


\section{Bibliographie}

Alföldy 1998 : ALFÖLDY (G.) - Drei Bauinschriften aus Gabii. Arctos, 32, 1998, p. 27-44.

Altmann 1905 : ALTMANN (W.) - Die römischen Grabaltäre der Kaiserzeit. Berlin, Weidmannsche Buchhandlung, 1905, 305 p.

Andreau 1977 : ANDREAU (J.) - Fondations privées et rapports sociaux en Italie romaine ( ${ }^{\text {er-III' }}$ siècles). Ktèma, 2, 1977, p. 157-210.

Arnaldi 2003 : ARNALDI (A.) - Dediche a divinità in memoria di defunti nell'Italia romana. In : Angeli-Bertinelli (M.G.), Donati (A.), dir., Usi e abusi epigrafici. Atti del colloquio internazionale di epigrafia latina (Genova, 20-22 settembre 2001), Roma, G. Bretschneider, 2003, 534 p. (Serta antiqua et mediaevalia, 6), p. 463-488.

Bérard, Feissel, Laubry et al. 2010 : BÉRARD (F.), FEISSEL (D.), LAUBRY (N.), PETITMENGIN (P.), ROUSSET (D.), SÈVE (M.) - Guide de l'épigraphiste. Bibliographie choisie des épigraphies antiques et médiévales. Paris, $4^{e}$ éd., Éditions rue d'Ulm, 2010, 448 p.

Boatwright 1989 : BOATWRIGHT (M.T.) - Hadrian and Italian Cities. Chiron, 19, 1989, p. 235-271.

Boschung 1987 : BOSCHUNG (D.) - Antike Grabaltäre aus den Nekropolen Roms, Bern, Stämpfli, 1987, 136 p. et 61 pl. (Acta Bernensia, 10).

Boyancé 1944 : BOYANCÉ (P.) - L'apothéose de Tullia. REA, 46, 1944, p. 179-184.

Brelich 1937 : BRELICH (A.) - A halálszemlélet formai a Római birodalom sírfeliratain. Aspetti della morte nelle iscrizioni sepolcrali dell'Impero romano. Budapest, 1937, 88 p. (Dissertationes Pannonicae, I, 7).

Cesari 1998 : CESARI (P.) - In memoriam... in honorem : iscrizioni funerarie consacrate a divinità. Studi classici ed orientali, 46, 1998, p. 959-973.

Chausson 2003 : CHAUSSON (F.) - Domitia Longina. Reconsidération d'un destin impérial. $J S, 1,2003$, p. 101-129.

Cumont 1942 : CUMONT (F.) - Recherches sur le symbolisme funéraire des Romains. Paris, P. Geuthner, 1942, 543 p.

De Maria 1992: DE MARIA (S.) - Apoteosi private. In: Settis (S.), dir., Civiltà dei Romani 3. Il rito e la vita privata, Milano, Electa, 326 p., p. 292-304.

De Visscher 1963 : DE VISSCHER (F.) - Le droit des tombeaux romains. Milano, Giuffrè editore, 1963, 339 p.

Di Stefano Manzella 1994 : DI STEFANO MANZELLA(I.) - Accensi velati consulibus apparentes ad sacra. Proposta per la soluzione di un problema dibattuto. ZPE, 101, 1994, p. 261-279.

Dubourdieu, Scheid 2000 : DUBOURDIEU (A.), SCHEID (J.) - Lieux de culte, lieux sacrés : les usages de la langue. L'Italie romaine. In : Vauchez (A.), dir., Lieux sacrés, lieux de culte, sanctuaires. Approches terminologiques, méthodologiques historiques et monographiques, Rome, École française de Rome, 2000, 436 p. (Collection de l'EFR, 273), p. 59-80.

Ducos 1995 : DUCOS (M.) - Le tombeau, locus religiosus. In : Hinard (F.), dir., La mort au quotidien dans le monde romain. Actes du colloque de l'Université de Paris IV (Paris-Sorbonne, 7-9 octobre 1993), Paris, De Boccard, 1995, 257 p., p. 135-144.
Estienne 1997 : ESTIENNE (S.) - Statues de dieux «isolées » et lieux de culte : l'exemple de Rome. $C C G$, 8, 1997, p. 81-96.

Estienne 2008 : ESTIENNE (S.) - Éléments pour une définition rituelle des « espaces consacrés » à Rome. In : Dupré Raventós (X.), Ribichini (S.) et Verger (S.) dir., Saturnia Tellus. Definizioni dello spazio consacrato in ambiente etrusco, italico, fenico-punico, iberico e celtico, Roma, CNR, 2008, 724 p. 687-697.

Feraudi-Gruénais 2001 : FERAUDI-GRUÉNAIS (F.) - Ubi nobis diutius habitandum est. Die Innendekoration der kaiserzeitlichen Gräber Roms. Wiesbaden, Dr. Ludwig Reichert Verlag, 2001, 248 p. (Palilia, 9).

Feraudi-Gruénais 2003 : FERAUDI-GRUÉNAIS (F.) - Inschriften und 'Selbstsdarstellung' in stadtrömischen Grabbauten. Roma, Quasar, 2003, 221 p. (Libitina, 2).

Fraschetti 2000 : FRASCHETTI (A.) - L'eroizzazione di Germanico. In : Fraschetti (A.), dir., La commemorazione di Germanico nella documentazione epigrafica. Convegno internazionale di studi, Cassino, 21-24 ottobre 1991, Roma, G. Bretschneider, 2000, 300 p. (Saggi di storia antica, 14), p. 141-162.

Gabelmann 1978: GABELMANN (H.) - Tod und Apotheose in der römischen Grabkunst. In : Klimkeit (H.J.), dir., Tod und Jenseits im Glauben der Völker, Wiesbaden, Harrassowitz, 1978, 200 p., p. 111-129.

Gibson 2006 : GIBSON (B.), ed. - Statius Silvae 5. Oxford, Oxford University Press, 2006, 492 p.

Ginouvès 1988: GINOUVÈS (R.) - Dictionnaire méthodique de l'architecture grecque et romaine. Tome III. Espaces architecturaux, bâtiments et ensembles. Rome, École française de Rome, 1988, 492 p. (Collection de l'EFR, 84).

Gregori 1987-1988 : GREGORI (G.) - Horti sepulcrales e cepotaphia nelle iscrizioni urbane. BCAR, 92, 1987-1988, p. 175-188.

Grimal 1957 : GRIMAL (P.) - Vénus et l'immortalité (à propos de Tibulle, I, 3, 37 et suiv.). In : Hommages à Waldemar Deonna, Bruxelles, Latomus, 1957, 539 p. (Collection Latomus, 28), p. 258-262.

Gros 2001 : GROS (P.) - L'architecture romaine 2. Maisons, palais, villas et tombeaux. Paris, Picard, 2001, 527 p.

Helttula 2007 : HELTTULA (A.) - Le iscrizioni sepolcrali latine nell'Isola sacra. Roma, Quasar, 2007, 438 p. (Acta Instituti Romani Finlandiae, 30).

Hommel 1956 : HOMMEL (H.) - Euripides in Ostia. Epigraphica, 18, 1956, p. 109-164.

Jouffroy 1986 : JOUFFROY (H.) - La construction publique en Italie et dans l'Afrique romaine, Strasbourg, AECR, 537 p., p. 116 et 121.

Kammerer-Grothaus 1978 : KAMMERER-GROTHAUS (H.) - Zu den antiken Gräberstraßen unter San Sebastiano. MDAI(R), 85, 1978, p. 113-138.

Kienast 1996: KIENAST (D.) - Römische Kaisertabelle. Darmstadt, Wissenschaftliche Buchgessellschaft, 399 p., p. 99.

Latte 1960: LATTE (K.) - Römische Religionsgeschichte. München, C.H. Beck, 1960, XVI-445 p. (Handbuch der Altertumswissenschaft, 5, 4).

Laubry 2012 : LAUBRY (N.) - Des rites pour le faire, des mots pour le dire : désignations, conceptions et perceptions de l'espace funéraire à Rome ( ${ }^{\mathrm{er}}$ s. av. J.-C. - III ${ }^{\mathrm{e}}$ s. ap. J.-C.). In : De Souza (M.), Peters-Custot (A.), Romanacce (F.X.), dir. Le sacré dans tous ses états. Catégories du vocabulaire 
religieux et sociétés, de l'Antiquité à nos jours. Saint-Étienne, Publications de l’Université de Saint-Étienne, 2012, 429 p. (Travaux du CERHI, 10), p. 169-180.

Lega 1996 : LEGA (C.) - Frammento sepolcrale inedito con menzione di heroum. BMMP, 16, 1996, p. 93-112.

Lo Monaco 2011 : LO MONACO (A.) - Algide e belle come dee. Immagini private e apoteosi a Roma in età medio-imperiale. In : La Rocca (E.), Parisi Presicce (C.), Lo Monaco (A.) dir., Ritratti. Le tante facce del potere, Roma, Musei Capitolini, 2011, 431 p., p. 335-349.

Mielsch, von Hesberg 1995 : MIELSCH (H.), VON HESBERG (H.) Die heidnische Nekropole unter St. Peter in Rom. Die Mausoleen E-I und Z-PSI. Roma, «L'Erma » di Bretschneider, 1995, 275 p. et 39 pl. (Atti della Pontificia Accademia romana di archeologia, ser. 3, Memorie, 16-2).

North 1983 : NORTH (J.) - These He Cannot Take. JRS, 73, 1983, p. 169-174.

Orlandi 2004 : ORLANDI (S.) - Heredes, alieni, ingrati, ceteri. Ammissioni ed esclusioni. In : Libitina e dintorni. Atti dell'XI Rencontre franco-italienne sur l'épigraphie, Roma, Quasar, 2004, 652 p. (Libitina, 3), p. 359-384.

Panofsky 1964 : PANOFSKY (E.) - Tomb Sculpture. Its Changing Aspects from Ancient Egypt to Bernini. London, Thames and Hudson, 1964, 319 p.

Picard 1939 : PICARD (G.-C.) - La Vénus funéraire des Romains. Mélanges d'archéologie et d'histoire, 56, 1939, p. 121-135.

Ricci 2010 : RICCI (C.) - Sepulcrum e(s)t memoria illius. Una riflessioni sull'impiego del termine memoria negli epitafi latini di Roma. Scienze dell'Antichità, 16, 2010, p. 163-180.

Rothenhöfer 2010: ROTHENHÖFER (P.) - In formam deorum: Beobachtungen zu so gennanten Privatdeifikationen Verstorbener auf der Iberischen Halbinsel im Spiegel der Inschriften. In : Rüpke (J.), Scheid (J.), dir., Bestattungsritual und Totenkult in der römischen Kaiserzeit, Stuttgart, Franz Steiner Verlag, 2010, 298 p. (Postdamer Altertumswissenschaftliche Beiträge, 27), p. 259-280.

Scheid 2004 : SCHEID (J.) - Libitina, Lubentina, Venus Libitina et les morts. In : Libitina e dintorni. Atti dell'XI Rencontre franco-italienne sur l'épigraphie. Roma, Quasar, 2004, 652 p. (Libitina, 3), p. 13-20.

Scheid 2005 : SCHEID (J.) - Quand faire, c'est croire. Les rites sacrificiels des Romains. Paris, Albin Michel, 2005, 348 p.

Schilling 1982 : SCHILLING (R.) - La religion romaine de Vénus depuis les origines jusqu'au temps d'Auguste. Paris, 2e éd., De Boccard, 1982, X-442 p.

Schilling 1988 : SCHILLING (R.) - L'évolution du culte de Vénus sous l'Empire romain. In : Schilling (R.), Dans le sillage de Rome. Religion, poésie, humanisme. Paris, Klincksieck, 1988, 283 p. (Études et commentaires, 101), p. $152-183$.

Sinn, Freyberger 1996 : SINN (F.), FREYBERGER (K.S.) - Vatikanische Museen, Museo Gregoriano profano ex Lateranense. Katalog der Skulpturen.
Die Grabdenkmäler. 2, Die Austattung des Hateriergrabes. Mainz, Ph. von Zabern, 1996, 159 p. et 70 pl. (Monumenta Artis Romanae, 24).

Solin, Kajava 1992 : SOLIN (H.), KAJAVA (M.) - Iscrizioni rupestri nel Latium adiectum. In : Gasperini (L.), dir., Rupes loquentes. Atti del convegno internazionale di studio sulle iscrizioni rupestri di età romana in Italia, Roma 1992, p. 335-393.

Solin 2003 : SOLIN (H.) - Die griechischen Personennamen in Rom : ein Namenbuch. Berlin, New York, $2^{e}$ éd., W. de Gruyter, 2003, 3 vol., XLVI$1716 \mathrm{p}$.

Thomas 1999 : THOMAS (Y.) - Corpus aut ossa aut cineres. La chose religieuse et le commerce. Micrologus, 7, 1999, p. 73-112.

Toynbee 1971 : TOYNBEE (J.M.C.) - Death and Burial in the Roman World. London, Thames and Hudson, 1971, 336 p.

Turcan 1982 : TURCAN (R.) - Compte rendu de Wrede 1981. Gnomon, 54, 1982, p. 676-683.

Veyne 1983 : VEYNE (P.) - Titulus praelatus. Offrande, solennisation et publicité dans les ex-votos gréco-romains. $R A, 1983$, p. 281-300.

Visconti 1872 : VISCONTI (C. L.). - Due monumenti del culto della Fortuna sul Quirinale. BCAR, 1872, p. 201-211.

Van Andringa 2009 : VAN ANDRINGA (W.) - Quotidien des hommes et des dieux. La vie religieuse dans les cités du Vésuve à l'époque romaine. Rome, École française e Rome, 2009, XXIV-404 p. (BÉFAR, 337).

Von Hesberg 1992: VON HESBERG (H.) - Römische Grabbauten, Darmstadt, Wissenschaftliche Buchgesellschaft, 1992, 286 p.

Weinstock 1955: WEINSTOCK (S.) - Vera,1. RE, 2. reihe, 15, 1955, col. 923-926.

Wissowa 1882 [1904] : WISSOWA (G.) - De Veneris simulacris Romanis. Breslau, 1882 [= WISSOWA (G.), Gesammelte Abhandlungen zur römischen Religions- und Stadtgeschichte. München, C. H. Beck, 1904, 329 p., p. 1-62].

Wissowa 1912 : WISSOWA(G.) - Religion und Kultus der Römer. München, $2^{e}$ éd., C.H. Beck, 1912, XII-612 p.

Wrede 1971 : WREDE (H.) - Das Mausoleum der Claudia Semne und die bürgerliche Plastik der Kaiserzeit. $M D A I(R), 78,1971$, p. 125-166.

Wrede 1978 : WREDE (H.) - Die Austattung stadtrömischer Grabtempel unter Übergang zur Körperbestattung. $\operatorname{MDAI}(R), 85,1978$, p. 411-433.

Wrede 1981 : WREDE (H.) - Consecratio in formam deorum. Vergöttlichte Privatpersonen in der römischen Kaiserzeit. Mainz, Philipp von Zabern, 1981, X-373 p.

Zanker, Ewald 2008 : ZANKER (P.), EWALD (B.) - Vivere con i miti. L'iconografia dei sarcofagi romani. Torino, Bollati, 2008 [trad. de l'édition allemande 2004], $387 \mathrm{p}$. 



\title{
Esculturas e inscripciones del entorno funerario de Barcino
}

\author{
Montserrat Claveria \\ Universitat Autònoma de Barcelona \\ montserrat.claveria@vab.cat \\ Isabel Rodà \\ Universitat Autònoma de Barcelona \\ iroda@icac.cat
}

\begin{abstract}
Resumen
La mayor parte de las esculturas y de las inscripciones funerarias de Barcino proceden del interior de las torres y del lienzo externo de la muralla tardía de esta colonia, lugar donde fueron reutilizadas al construirse el recinto defensivo a partir le finales del siglo III. En el presente artículo se analizan los datos que aporta este material al conocimiento del entorno funerario barcinonense. A pesar de tratarse de disiecta membra hallados en un contexto de reutilización, estos materiales, en su mayoría labrados en piedra local de las canteras de Montjuïc, enriquecen considerablemente los escasos hallazgos de enterramientos in situ de época altoimperial, de los que los sepulcros exhumados en la plaza Vila de Madrid son los más representativos. Los epígrafes dan a conocer gentilicios itálicos, llevados en muchas ocasiones por individuos de ascendencia servil. Los restos escultóricos permiten discernir un número destacable de monumentos funerarios, predominando dos tipos, los turriformes y los grandes altares con pulvinos. En los relieves es patente la influencia itálica y la perduración del estilo triunviral.
\end{abstract}

Palabras clave: Barcino, epigrafía romana, escultura romana, iconografía, arte provincial, decoración arquitectónica romana, necrópolis romanas, arquitectura funeraria, piedra arenisca local de Montjuïc, reutilización.

\begin{abstract}
Most of the sculptures, and the funerary inscriptions of Barcino come from inside of the towers and the external stretch of the late wall of this colony. There they were re-used to build the defensive enclosure of the 4th century. This article analyzes the data that this material brings to the knowledge of the funeral environment of Barcino. In spite of being disiecta membra found in a context of reuse, these materials, in its majority carved in the local stone quarries of Montjuïc, enrich considerably the few findings in situ of burials of the highimperial period. Between them the tombs exhumed in the Vila de Madrid square are the most representatives. The epigraphs made know Italic names, brought on many occasions by individuals of servile descent. The sculptural remains allow us to discern a remarkable number of funerary monuments, predominantly two types: the mausoleums in form of tower and the big altars with pulvini. In the reliefs is evident the Italic influence and the persistence of the triumviral style.
\end{abstract}

Key-words: Barcino, roman epigraphy, roman sculpture, iconography, provincial art, roman architectural decoration, roman necropolis, funerary architecture, roman quarries of Montjuïc, reused material. 
$\mathrm{L}$ a ciudad de Barcino $^{1}$, parvum oppidum al decir de Pomponio Mela $(2,6,9)^{2}$, constituye un ejemplo de urbanismo romano en Hispania citerior. Nació, ya con la categoría jurídica de colonia, a finales del siglo I a.C., en el marco del proceso de reestructuración del norte de la Península, una vez finalizada la segunda campaña de las guerras cántabras en el año 19 a.C. $^{3}$

Se fundó así pues dentro de este contexto histórico, al igual que su hermana Caesar Augusta, hoy Zaragoza. Barcino fue una ciudad de nueva planta en el llano, pequeña pero con un trazado urbano absolutamente regular, con un circuito de murallas con los ángulos achaflanados que el duunviro Gayo Celio se encargó de construir en la etapa augustea ${ }^{4}$. Su titulación honorífica no le andaba a la zaga: Colonia Iulia Augusta Faventia Paterna Barcino ${ }^{5}$.

El papel de Barcino no era tanto servir de centro poblacional como de punto de control de un reducido pero denso territorio, articulado en torno al puerto del río Llobregat, antiguo Rubricatum, y rico en productos agrícolas, en especial el vino, y mineros.

En el mismo momento fundacional de Barcino se reestructuró la vía Augusta, procediendo a poner en marcha el tramo costero que unía ciudades republicanas como Iluro (Mataró) y Baetulo (Badalona) con la nueva Barcino $^{6}$. Se procedió dentro de este proceso a llevar a cabo grandes trabajos de infraestructura, como por ejemplo el puente de Martorell-Castellbisbal (ad Fines) que marcaba los límites territoriales entre las colonias de Tarraco y de Barcino. Este puente fue levantado por los componentes de las tres legiones que habían participado en la campaña militar del norte: la IV Macedonica, la VI Victrix y la $X$ Gemina ${ }^{7}$.

Son las mismas legiones que construyeron Caesar Augusta y que, de modo hipotético pero

1. Este artículo se ha realizado en el marco de los proyectos de investigación HAR 2009-35861 El retrato escultórico masculino en las colecciones anticuarias. Función, cronología y modos de restauración y HAR 2011-25011 La explotación y comercio de los recursos naturales en el norte de la Hispania romana: Lapis, metalla, aqua.

2. Ed. De Frick (C.) - Pomponii Melae de Chorographia libri tres, Stuttgart, 1968, p. 48.

3. Rodà 1998, 2005, 2006 a y b; Bost, Martín Bueno, Roddaz 2005.

4. IRC IV 1997, núm. 57.

5. IRC IV 1997, núm. 76.

6. Rodà 2011 , nota 7.

7. IRC I, 1984, núm. 1; IRC V, pp. 15-16; Gurt, Rodà 2005; Beltrán Lloris 2007-2008. probable, pudieron también intervenir en la edificación de Barcino $^{8}$. Tenemos, pues, el escenario a punto. Una vez más, Barcino, se nos presenta como ejemplo-tipo de lo que fue la colonización itálica en esta zona del litoral mediterráneo 9: los monumentos funerarios son prueba ello.

Tenemos una buena serie de restos escultóricos y epigráficos que nos permiten comprobar cómo la primera generación de barcinonenses se compuso esencialmente de gentes venidas de Italia, del centro de Italia sobre todo.

La excavación del interior de las torres de la muralla bajo-imperial permitió rescatar un número considerable y representativo de restos esculpidos e inscritos, conservados actualmente en el Museu d'Història de la Ciutat de Barcelona (MUHBA) y en el Museu d'Arqueologia de Catalunya (MAC). Todos fueron labrados en los talleres locales, con la piedra arenisca de Montjuïc, utilizada desde los orígenes de la colonia para los edificios urbanos, públicos y privados ${ }^{10}$. Se trata de elementos arquitectónicos, escultóricos y epigráficos desmembrados, que se usaron como material constructivo cuando ya las viejas necrópolis de la etapa fundacional habían quedado obsoletas y amortizadas ${ }^{11}$. Dado el contexto arqueológico de reempleo en el que las piezas fueron halladas, el conjunto nos ofrece un panorama dispar ya que se ha perdido una gran parte de los elementos arquitectónicos y todos los bloques no esculpidos sirvieron como sillares de la muralla tardorromana. Por esta razón, es muy difícil proponer la restitución original de estos monumentos, pero a pesar de ello Ana Garrido en su reciente tesis doctoral ha propuesto una integración de muchos de los disiecta membra en dos tipos principales de monumentos: los altares monumentales y los sepulcros turriformes ${ }^{12}$.

A este respecto cabe traer a colación un monumento funerario que no procede de Barcino, sino de la vecina Baetulo (Badalona), en concreto del yacimiento de Can Peixau (fig. 1). Se conservan dos fragmentos de friso dórico del primer cuerpo del edificio, que debió corresponder al tipo turriforme. Su editor, J. Guitart, restituyó su parte superior como un templete tetrástilo

8. IRC IV 1997, núm. 47; Rodà 2006b, p. 213; Gurt, Rodà 2005, p. 153; Beltrán Lloris 2007-2008.

9. Pons 1994, p. 90-126.

10. Àlvarez et al. 2009, p. 86-93.

11. Balil 1961, p. 80-103; Garrido 2011.

12. Garrido 2011, p. 349-384, cuadros 1-9. 


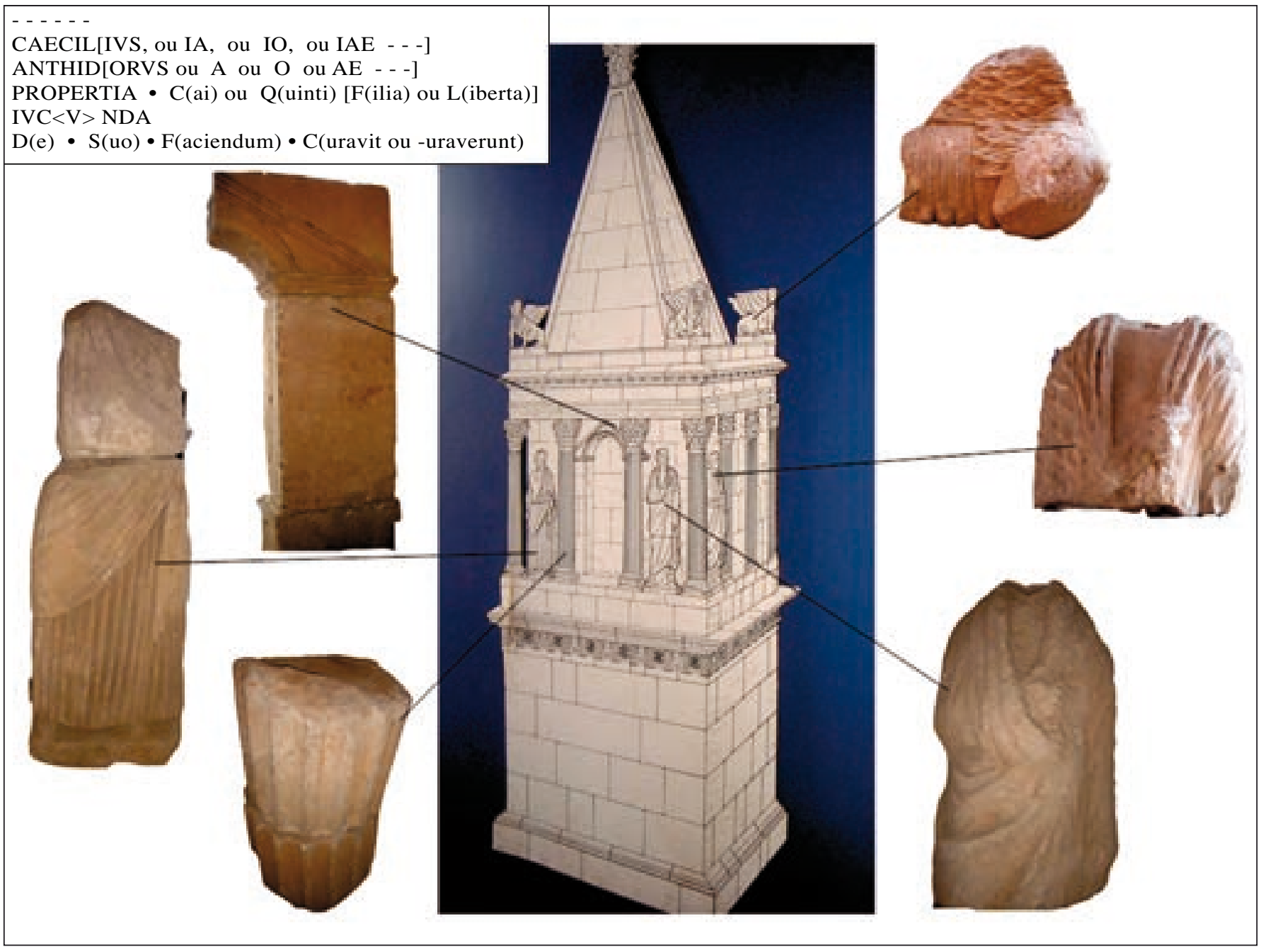

Fig. 1. Propuesta de restitución del mausoleo de Can Peixau (Badalona) expuesta en el Museu de Badalona (Fotos I. Rodà).

y coronamiento piramidal ${ }^{13}$, en el que se dispondrían las esculturas cuyos fragmentos han llegado hasta nosotros. Entre ellos estacan el de una esfinge y los de tres esculturas exentas ${ }^{14}$, una de ellas femenina, vestida con túnica y manto ${ }^{15}$ y las otras dos masculinas ${ }^{16}$ pertenecientes al "tipo pallium" según la terminología de H.R. Goette ${ }^{17}$, concretamente a un estadio avanzado del grupo A.b. que este autor diferenció dentro de esta categoría ${ }^{18}$.

\footnotetext{
13. Guitart 1976, p. 159-165.

14. Rodà 2009, p. 514-516.

15. Guitart 1976, p. 162-3, lám. 42, 2.

16. Guitart 1976, p. 160-162, láms. 42,1 y 43,1.

17. Goette 1989 , p. 24-26.

18. Cf. el pequeño umbo que se forma bajo la mano derecha de ambos ejemplares baetulonenses con el del togado de un relieve de la Villa Doria Pamphili de Roma y con los de dos retratos de Chiusi (Goette 1989, núms. 80 y 87-88, láms. 3, 1 y 3, 2-3, respectivamente), fechados por este autor en el último cuarto del siglo I a.C.
}

Este monumento de Baetulo fue labrado en la piedra arenisca procedente de las canteras de Montjuïc, que suministró asimismo la mayor parte de la materia prima para elaborar los elementos funerarios escultóricos y epigráficos barcinonenses, lo cual atestigua la difusión de sus producciones a las áreas funerarias de las urbes vecinas ${ }^{19}$. Pertenece al mismo monumento de Can Peixau la inscripción sepulcral de Caecilius Anthidorus y Propertia Iucunda, propietarios del mismo y de ascendencia libertina ambos ${ }^{20}$. Tipológicamente la cronología de este monumento se puede situar hacia el cambio de Era $^{21}$, lo cual coincide con las características tanto de los elementos escultóricos como epigráficos.

19. Claveria 2008, p. 378-380, notas 217-218; Rodà 2009 , p. 513-527.

20. IRC I 1984, núm. 147.

21. Guitart 1976, p. 165; Rodà 2009, p. 514-516. 
Centrándonos ya en Barcino y a pesar de la imposibilidad de establecer conexiones directas entre su material epigráfico, escultórico y arquitectónico, un examen de estos restos pone en evidencia distintos aspectos del entorno funerario de esta ciudad.

Constatamos, pues, que las producciones barcinonenses tuvieron un cierto radio de difusión ${ }^{22}$, denotando siempre un evidente carácter itálico, con la duda de cuando esta influencia llegó directamente de Italia o bien a través de la ciudad de Narbona (Narbo Martius) con la que Barcino presenta grandes concomitancias en el terreno de las producciones artísticas y del tejido social, sin descartar una vía de influencias ${ }^{23}$.

En primer lugar, estos materiales nos proporcionan una valiosa información sobre las necrópolis altoimperiales de la colonia, puesto que enriquecen considerablemente el parco panorama que nos ofrecen los hallazgos de enterramientos in situ de esta época ${ }^{24}$. Éstos se limitan por el momento a la cimentación de un monumento funerario de la segunda mitad del siglo I d.C. exhumado cerca de la puerta de la plaza Nova, en la calle dels Arcs (fig. $\mathbf{2} \mathbf{n}^{\mathbf{0}} \mathbf{2}$ ) ${ }^{\mathbf{2 5}}$, topónimo que perpetua el trazado de uno de los acueductos ${ }^{26}$. Además podemos

22. Además de los restos de este monumento funerario baetulonense, se conocen otros vestigios relativos a monumenta funerarios labrados en la misma piedra de Montjuïc en lugares externos a Barcino, pero relacionados con esta ciudad a través de las vías de comunicación. Tal es el caso del torso de una escultura femenina hallado en 1887 en Iluro y dos acróteras con máscaras procedentes de Llerona y conservadas en la finca de Can Santa Digna. De esta misma localidad, situada junto a la vía romana que enlazaba Barcino y Auso (Vic) remontando el río Congost, proceden dos fragmentos de pulvinos monumentales de mármol y un tercero de tamaño menor. Ambos, junto a otro altar monumental hallado en Iluro y el frente de un pulvino de Hospitalet de Llobregat - los dos también de mármol - denotan la influencia de los altares monumentales con pulvinos labrados en Barcino. Dos fragmentos de frisos de roleos exhumados en estratos de relleno del recinto de las iglesias de Egara (Terrassa) muestran el mismo estilo que los frisos trabajados en los talleres barcinonenses. Éstos y una acrótera de tema dionisíaco hallada en el mismo lugar son de piedra de Montjuïc, aunque no se puede asegurar si proceden de monumentos funerarios romanos erigidos en las proximidades de este lugar o si llegaron allí posteriormente a la antigüedad entre otros materiales destinados a la construcción de las iglesias egarenses. Para el conjunto de las piezas mencionadas en esta nota véase Claveria 2007, p. 3, Claveria 2008, p. 380, nota 218; Rodà 2009, p. 513-527.

23. Claveria 2011, p. 329-334; Rodà 2000, p. 173-179.

24. Beltrán de Heredia 2007, p. 18-20 y 2009, p. 12-14; Rodà 2011; Beltrán de Heredia, Rodà 2012.

25. Beltrán de Heredia 2007, p. 18 y 2009, p. 12; Granados 1991, p. 187; Granados, Rodà 1993, p. 30 y 37.

26. Mayer, Rodà 1977, p. 265-277; Granados 1991, p. 142; Palet, Rodà 2012, p. 33-34; Miró, Orengo 2010, p. 113-115 que ponen en duda la romanidad de este acueducto que quizás podría ser de época mencionar que otro monumento del paso del siglo I al siglo II d.C., localizado en la plaza de Joaquim Xirau (fig. $2 \mathbf{n}^{\mathbf{0}}$ ), se ha relacionado con una villa o una posible necrópolis meridional, cercana a una posible vía en dirección a la puerta de la calle Regomir, al igual que otros dos enterramientos monumentales hallados en la calle Nou de Sant Francesc /Rull y en la calle Ample (siglo II d.C.) ${ }^{27}$. En Sant Pau del Camp se excavó (fig. $2 \mathbf{n}^{\mathbf{0}} 3$ ), el mausoleo familiar del propietario de una villa suburbana, cercana a la vía principal que comunicaba la colonia cuyo trazado se ha perpetuado en la actual calle Hospital. Junto a esta vía se dispusieron también otras cinco inhumaciones, una de las cuales puede datarse entre el siglo II y la primera mitad del III d.C.; posteriores hallazgos han confirmado la presencia de nuevos sepulcros ${ }^{28}$ entre los que quisiéramos destacar la estructura excavada en el año 2006 de un monumento funerario en la calle Hospital 26-30 que ha proporcionado una gran placa fragmentaria con inscripción con la lista de los difuntos de condición libre pero cuya onomástica se encuentra incompleta; por la paleografía, la inscripción puede datarse en época julio-claudia, quizás en tiempos de Tiberio ${ }^{29}$. A finales de mayo de 2011 se los restos de un gran mausoleo del siglo II d.C. descubiertos gracias a los trabajos de remodelación del Museo Marítimo en las Reales Atarazanas ${ }^{30}$.

El conjunto más importante de los hallazgos funerarios in situ se conserva en la plaza de la Vila de Madrid (fig. $2 \mathbf{n}^{\mathbf{0}} \mathbf{1}$ ), donde, entre 1956-1957, se exhumó un tramo de una vía sepulcral romana que se dirigía la puerta de la plaza Nova. Fundamentalmente se sacaron a la luz monumentos funerarios sobre todo en forma de cupae y aras, cuyas inscripciones, tipología y material señalan una cronología a partir del siglo I d.C. y que tiene un punto álgido entre finales del siglo segundo y principios del tercero. En los últimos años se ha reexcavado esta necrópolis rozando los estratos fundacionales con presencia de numerosas cupae structiles que se remontan al siglo I, demostrando su mayor antigüedad respecto a las cupae solidae de aparición posterior, que permiten vislumbrar la posibilidad de la existencia de

posterior, tal y como se presenta en la exposición "La revolució de l'aigua a Barcelona" organizada por el MUHBA y presentada de marzo a septiembre de 2011 en el salón del Tinell (Miró, Orengo 2011).

27. Beltrán de Heredia 2007, p. 18-19 y 2009, p. 12-13.

28. Beltrán de Heredia 2007, p. 19-20 y 2009, p. 13-14.

29. Beltrán de Heredia 2007, p. 19-20 y 2009, p. 13-14; Pujades 2007, p. 194-195. Agradecemos la noticia al MUHBA y los datos a E. Revilla y a los directores de la excavación J. Alzina y R. Dehesa, Rodà 2013, p. 157-159.

30. Beltrán de Heredia, Rodà 2012, p. 87; Moreno 2014. 
un collegium funeraticium ${ }^{31}$. El estudio en profundidad de este yacimiento ha culminado en la creación de un centro de interpretación inaugurado a finales de 2009.

Se suma a los hallazgos in situ que acabamos de referenciar una gran cantidad de epígrafes, relieves y esculturas usados en la muralla. Aunque su lugar de reutilización no implica que el emplazamiento original de estas piezas tuviera que estar necesariamente en un lugar cercano $^{32}$, la concentración de piezas son indicadores a tener en cuenta. En la figura 3 situamos las piezas en el punto donde fueron reutilizadas y observamos una mayor densidad cerca de la puerta del Call, procedentes del derribo del convento de la Enseñanza. En este sector se hallaron unas treinta inscripciones, junto a una decena de bloques relivarios, que casi permitieron completar el coronamiento de un monumento funerario en forma de altar "a dado" (fig. 4 g) ${ }^{33}$ Otros frisos acantiformes (fig. $4 \mathbf{~ h - i ) , ~ c a p i t e l e s ~ y ~ f u s t e s ~ d e ~ c o l u m n a s ~ a t e s t i g u a n ~ l a ~}$ existencia de al menos 7 sepulcros monumentales del tipo turriforme, de los que A. Garrido ha podido realizar la reconstrucción arquitectónica del coronamiento y la planta de uno de ellos ${ }^{34}$.

Salta a la vista el gran número de monumentos a lo largo del lado noreste de la muralla (fig. 3), que representa la zona más investigada y visible de la misma ${ }^{35}$. En época tardía, en zonas extramuros próximas a este trazado, se han ido identificando abundantes restos funerarios, especialmente de enterramientos en tegulae ${ }^{36}$. Entre las torres 6 y 26 (fig. 4 a-f) se ha recuperado casi medio centenar de inscripciones y más de veinte fragmentos de pulvinos monumentales que permiten un cálculo de por lo menos 16 altares distintos, todos del tipo "a dado" ${ }^{37}$. En la calle de la Baixada de Viladecols se hallaron fragmentos de frisos dóricos (fig. 4 c-d), junto a capiteles y otros restos de esculturas exentas, que si bien no podemos atribuir al mismo monumento, nos

31. Beltrán de Heredia 2007 y 2009; Beltrán de Heredia, Rodà 2012. 32. Piénsese al respecto en el dispar hallazgo del busto y la cabeza de la escultura de personaje desconocido que en un primer momento fue considerado como de Antonino Pío (véase Balil 1991, p. 222223, fig. en p. 220).

33. Claveria 2008, p. 383, núm. 3, lám. 3; Garrido 2011, p. 356359, cuadro 3, monumento XVII.

34. Garrido 2011, p. 375-380, cuadros 7-9.

35. Los tramos de la muralla conservados están representados en la fig. 3 con trazos en negro con línea continua.

36. Rodà 1982, p. 232.

37. Claveria 2008, p. 369-372, 374-375; Garrido 2011, p. 352-356 у 375 . inducen a pensar en la existencia de otras clases de mausoleos como los de tipo turriforme ${ }^{38}$.

A. Garrido ha analizado recientemente este material, al igual que un importante conjunto de capiteles corintios, basas, fustes y otro friso dórico decorado por las dos caras, todos procedentes de la torre 25 , y otros restos arquitectónicos exhumados entre las torres 23 a la 26 y en los jardines de la calle Sotstinent Navarro. Esta autora ha podido diferenciar por lo menos 12 monumentos ${ }^{39}$ varios de ellos en forma de torre, de los que ha podido proponer la restitución de un mausoleo con edícula sobre podio ${ }^{40}$. Destaca también el relieve de piedra de Montjuïc hallado en la torre 26 (fig. 4 f), el cual representa a una ménade danzando tallada en un estilo y calidad superiores al resto de relieves elaborados en los talleres de la localidad ${ }^{41}$. Éste se ha relacionado con un conjunto de basas áticas y fustes, todos ellos de pilastra, reaprovechados como sillares en la parte inferior externa de la misma torre, donde actualmente todavía son visibles. Estos elementos de decoración arquitectónica también han sido interpretados como partes de un monumento turriforme, cuyo cuerpo inferior comprendería el mencionado relieve con la ménade y un fuste angular que conserva parte de otro relieve con las mismas características estilísticas y temáticas que el anterior ${ }^{42}$.

Además, en este sector se ha podido recuperar un gran número de elementos de cierre de recintos funerarios de una altura media de unos $30 \mathrm{~cm}$ y de coronamiento semicircular, con paralelos en las numerosas variantes de recintos sepulcrales que se desarrollaron en la primera época imperial en la Italia septentrional y sobre todo la central. Se relacionan con éstos otras piezas de mayor altura, en forma de cipo, altar o a veces ornamentados con gorgoneia, y seguramente correspondientes a los ángulos de dichos recintos ${ }^{43}$. La estructura de estos muretes de cierre indica una cronología temprana, que en otros lugares no debió ir más allá del siglo II, que es cuando se generalizaron los recintos de muros altos, más aptos para la celebración de los rituales funerarios en la intimidad familiar ${ }^{44}$.

38. Claveria 2008, p. 372; Garrido 2011, núms. 272-273, p. 274.

39. Garrido 2011, p. 366-375, cuadros 4-6.

40. Garrido 2011, cuadro 6.

41. Balil 1964, p. 149-150; Garrido, Rodà 2013.

42. Sanmartí 1984, p. 117; Garrido 2011, p. 371-373, monumento VII, cuadro 5 .

43. Claveria 2008 , p. 373 , nota 164 y especialmente nota 168 ; Garrido 2011, p. 384-386.

44. Hesberg 1994, p. 76; Gros 2001, p. 440-442. 


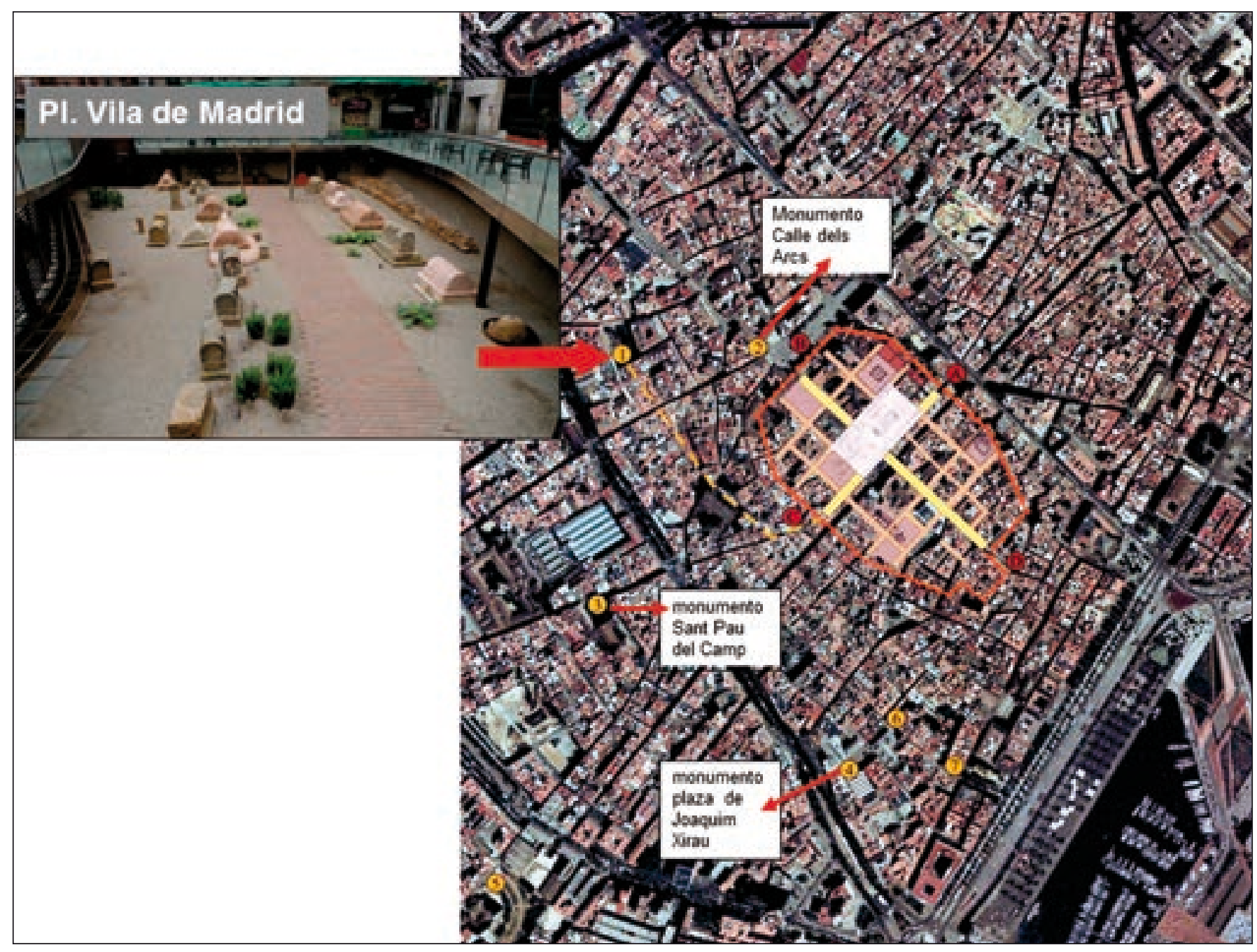

Fig. 2. Plano de Barcelona con la planta de la colonia romana Barcino y la localización de los enterramientos de la plaza Vila de Madrid según J. Beltrán de Heredia 2009, p. 117 (Fotos M. Claveria).

El conjunto de estos datos nos lleva a considerar que en Barcino debió ser habitual cerrar estos mausoleos tempranos dentro de estos recintos, que tenían la función de delimitar su espacio y, a la par, realzarlos a la vista del caminante. En ningún caso tenemos inscripciones que nos indiquen las dimensiones exactas que en otras zonas se determinan con las fórmulas habituales in agro pedes o similares ${ }^{45}$.

Si bien este examen nos permite deducir distintos aspectos sobre el entorno funerario de la colonia, desgraciadamente, en ningún caso, y como es de esperar en un contexto tal de reutilización, se ha podido hallar una correspondencia entre un elemento escultórico sepulcral y su inscripción.

45. Vaquerizo 2002, p. 168-171 y 2010, p. 110-112.
El análisis directo de estos elementos arquitectónicos, escultóricos y epigráficos desmembrados permite, por otro lado, distinguir varias series de ejemplares coherentes entre sí que nos llevan a contemplar otras consideraciones de orden tipológico, iconográfico y social.

Las inscripciones nos dan los nombres de los propietarios de los monumentos funerarios. Comprobamos que se trata de gentilicios centro-itálicos, llevados muy frecuentemente por individuos de ascendencia servil asentados en Barcino desde los primeros momentos de la ciudad y que se mostrarán como un auténtico poder fáctico en cuyas manos estaba una buena parte de la actividad económica y comercial ${ }^{46}$.

46. Rodà 2011 


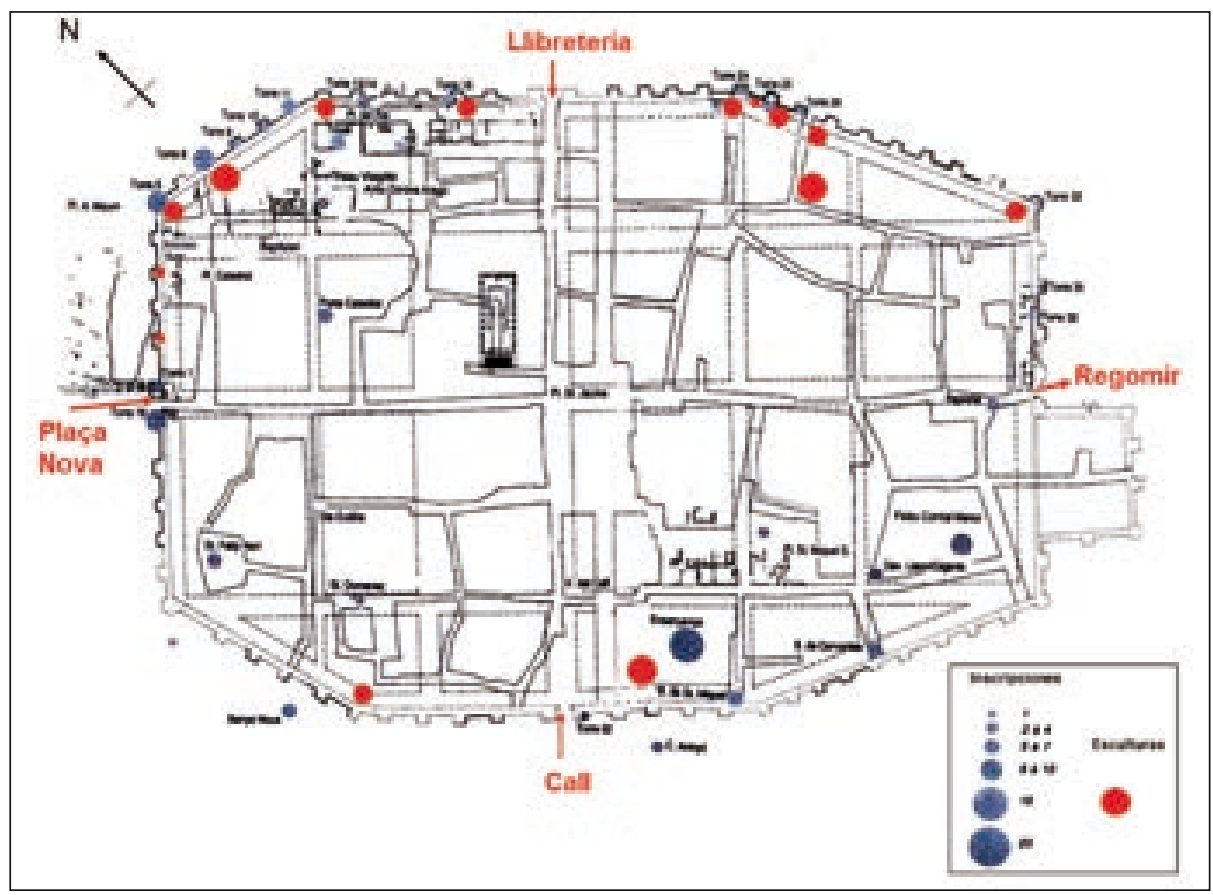

Fig. 3. Plano de Barcino con la señalización de los hallazgos escultóricos y epigráficos sobre el plano publicado en IRC IV 1997, pp. 54-55.

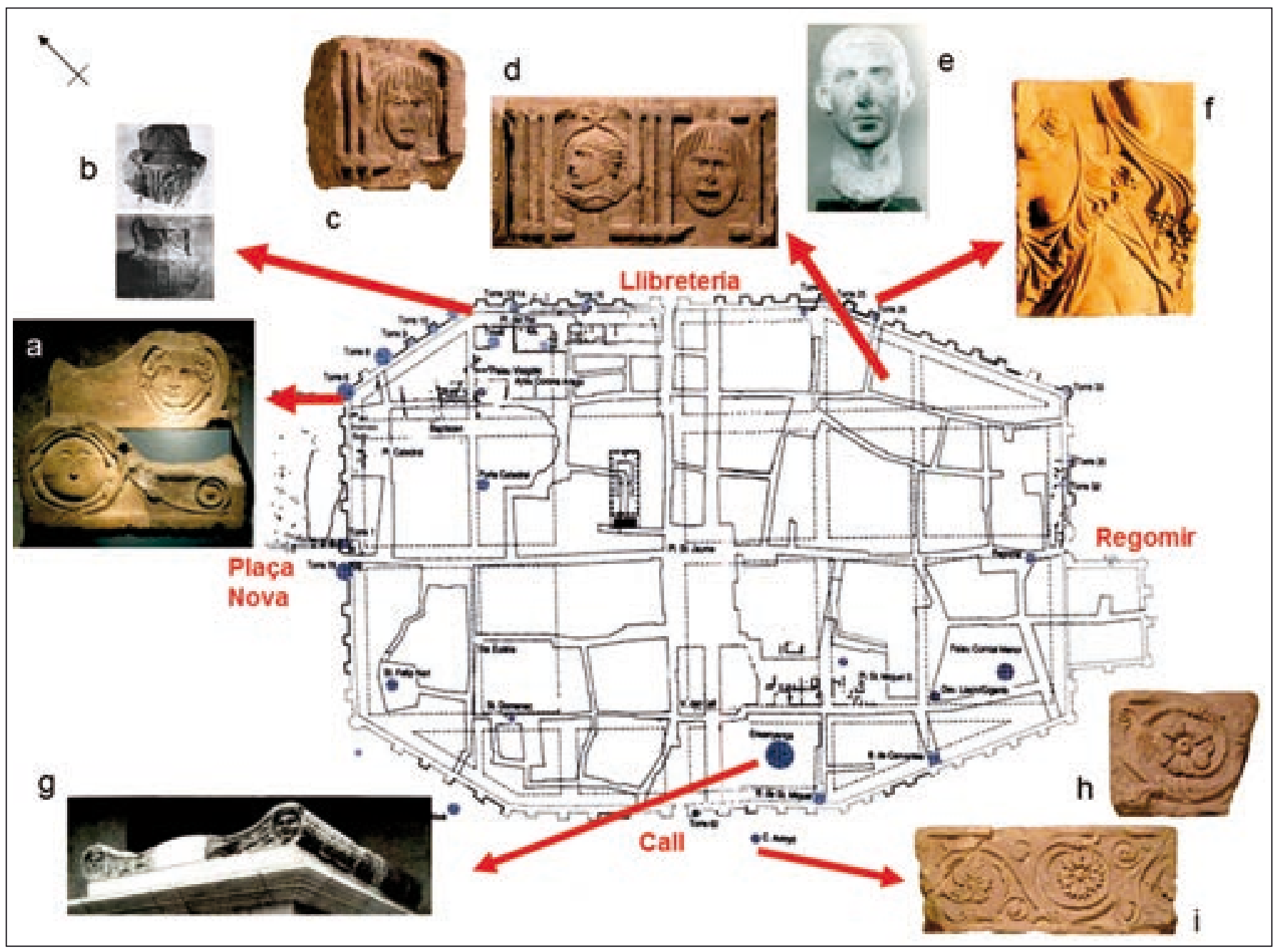

Fig. 4. Plano de Barcino con la señalización del punto de hallazgo de algunos fragmentos escultóricos (Fotos M. Claveria). 


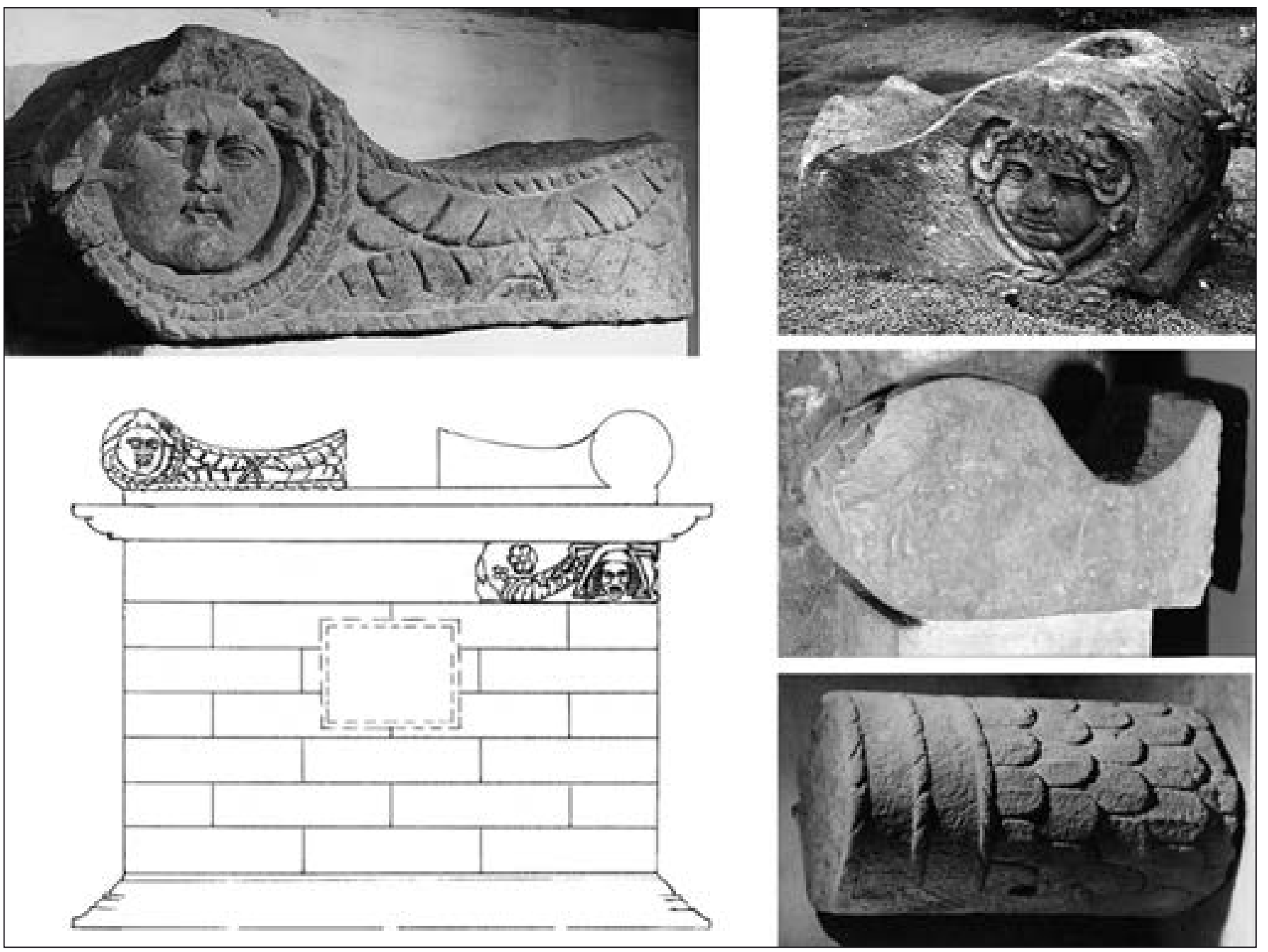

Fig. 5. Pulvinos y tallo lateral de altares monumentales de Barcino y propuesta de restitución (M. Claveria, Fotos MUHBA).

Comprobamos también cómo se siguen fielmente los modelos itálicos en los fragmentos de pulvinos monumentales, que constituyen la serie más nutrida, y por ende más representativa entre los restos arquitectónicos decorados conservados hasta hoy (fig. 5). Éstos están integrados por 16 frentes y 13 dorsos de pulvinos y por 39 fragmentos de tallos laterales ${ }^{47}$. Los frontales son en algunos casos cilíndricos, aunque por lo general tienen alargamientos laterales. Sus representaciones más características muestran gorgoneia y en mucha menor cantidad tienen motivos vegetales; sólo en el ejemplar más tardío se conserva un tema mítico, con la caza de Meleagro $^{48}$. Los dorsos suelen ser lisos y los tallos laterales presentan hojas de laurel superpuestas, imbricadas o fuertemente geometrizadas.

47. Garrido 2011, p. 307.

48. Claveria 2008, núm. 3, lám. 3.
Un análisis pormenorizado de la morfología, la iconografía y el estilo de cada una de estas piezas ${ }^{49}$ nos ha llevado a comprobar la directa recepción de sus modelos del medio centro-itálico, y ha permitido determinar que estos altares empezaron a producirse en una fecha próxima a la de fundación de la colonia, con una expansión de su uso durante el resto de la época julioclaudia. A partir de entonces su número decreció visiblemente, siendo los últimos ejemplares de mediados del siglo II ${ }^{50}$. Las características de estos fragmentos indican un tipo de altar en forma de dado (fig. 5), con los pulvinos separados entre sí y unas medidas que oscilarían entre los $2 \mathrm{~m}$. y los $4 \mathrm{~m}$. de profundidad. No faltaría la inscripción en su frente y posiblemente algunos se ornamentaron con frisos esculpidos con relieves ${ }^{51}$.

49. Claveria 2008, p. 349-378; Garrido 2011, p. 306-320, 352-365.

50. Claveria 2008, p. 378.

51. Claveria 2008, p. 376-378. 
Conservamos bastantes restos de estos frisos. Siete de ellos ${ }^{52}$ pertenecen al tipo dórico (figs. 4 c-d, 6 a-b), los demás, de índole vegetal, integran otra serie numéricamente representativa, encontrándose entre éstos 9 ejemplares con desarrollos acantiformes más o menos sencillos (figs. 4 h-i, 6 c-d) o conjugados con otras figuras (fig. 6 e) ${ }^{53}, 1$ friso de guirnaldas combinadas con máscaras(fig. 6 f $)^{54}$ y otros 3 con roleos de hiedra y uno de vid ${ }^{55}$.

Estos relieves, no sólo debieron formar parte de la decoración escultórica de altares monumentales, sino sobre todo de otros tipos de mausoleos de los que, según hemos referido más arriba, A. Garrido ha podido identificar al menos 19 monumentos distintos, varios de ellos turriformes. Los análisis de esta autora le han llevado a suponer que la mayoría de frisos dóricos (figs. 4 c-d, 6 a-b) pudieron relacionarse con edificios funerarios en forma de torre y que su cronología se desarrolló desde la fecha de fundación de Barcino a finales del siglo I a.C. hasta principios de época julioclaudia $^{56}$. Respecto a los frisos de índole vegetal, la misma autora ha llamado la atención sobre la afinidad estilística y formal de 4 de ellos decorados con roleos de acanto (figs. 4 h-i, 6 c-d) ${ }^{57}$. Su desarrollo, a base de un tallo principal continuo, estrecho y emanante de finos cálices acantiformes de doble hoja, sólo enriquecido por delgados vástagos y que discurre sobre un fondo bien visible, se ajusta al estilo de los frisos de este tipo característicos del segundo triunvirato ${ }^{58}$, como demostramos en una publicación de $2011^{59}$ en la que los comparábamos con varios relieves de Narbona ${ }^{60}$, un fragmento procedente de la tumba redonda de Ostia ${ }^{61} \mathrm{u}$ otros frisos acantiformes de Foligno, Aquino y Todi ${ }^{62}$. Sin embargo, A. Garrido, al catalogar y analizar el conjunto de piezas de decoración arquitectónica de Barcino, ha planteado con buenos argumentos la pertenencia de estos 4 ejemplares al entablamiento del cuerpo superior tipo naiskos próstilo de un mausoleo turriforme. Esta autora admite que su estilo se mantiene en la tradición del segundo triunvirato, no obstante, advierte que estos relieves y los

52. Garrido 2011, núms. 272-277.

53. Garrido 2011, núms. 278-286.

54. Garrido 2011, núm. 291.

55. Garrido 2011, núms. 287-290.

56. Garrido 2011, p. 274-277.

57. Garrido 2011, núms. 278-281.

58. Schörner 1995, p. 38-43.

59. Claveria 2011, p. 331-332.

60. Janon 1986, no .5-7, lám. II y núm. 30, lám. VIII.

61. Schörner 1995, núm. 130, lám. 14,2.

62. Schörner 1995, núm. 88 a-b, lám. 18, 5-6, núm. 31, lám. 13,4, núm. 294, lám. 19,3, respectivamente. capiteles asociados al mismo monumento denotan otras tendencias que, como el contacto asimétrico de los foliolos, indican su realización en un período posterior que debería situarse en la primera mitad del siglo I d.C. ${ }^{63}$ Los demás frisos con decoraciones acantiformes atestiguan la perduración de las corrientes augusteas hasta mediados del siglo I d.C., lo que significa una prueba más de la tendencia en Barcino de mantener modelos y modos de trabajar más antiguos, mientras que se incorporan con lentitud los nuevos estilos fijados en la metrópoli.

La presencia en algunos relieves sepulcrales de insignias propias de magistrados municipales, como los lictores o las fasces que parecen ser un indicio más del destacado papel, de sobra atestiguado por la epigrafía barcinonense, que desempeñaron los séviros augustales en la estructura social de la colonia ${ }^{64}$, aunque hemos de dejar la puerta abierta a que estos relieves puedan pertenecer también a tumbas de duoviros o ediles. Se trata de seis bloques con relieves (fig. 7) pertenecientes a dos o tres monumentos funerarios distintos. Muestran a veces sólo las faces (fig. 7 a) ${ }^{65}$, que, a juzgar por la distribución de los monumentos con este tipo de atributos, pudieron ocupar los extremos de una fachada, quizás con inscripción central ${ }^{66}$. Las representaciones restantes presentan a tunicati (fig. 7 b) muy mal conservados que podemos interpretar como lictores por el tipo laureado de las fasces que se erigen junto a ellos ${ }^{67}$. La austeridad de motivos, y el mal estado de los relieves merman la posibilidad de establecer una cronología orientativa a través de su análisis estilístico; a este respecto, nos preguntamos si la técnica del "relief cerné" podría constituir un indicio cronológico para estos ejemplares. E. Rosso ${ }^{68}$, al referirse a las distintas interpretaciones de autores que han tratado este estilo característico de los talleres de la Galia meridional, argumentó la posibilidad de que se tratara de un recurso de factura regional común a varias officinae de dicha zona del período julioclaudio. En Barcino, colonia de la que ya se ha puesto de manifiesto sus contactos escultóricos y epigráficos con la ciudad

63. Garrido 2011, p. 277-283, 376-378, cuadros 7-9.

64. IRC IV 1997, p. 412 para la relación de las inscripciones relativas a los seviros augustales de Barcino.

65. Schäfer 1989, p. 415, núm. C 111, lám. 117, 1-2; Rodà 2000, p. 176, lám. 4; Garrido, Rodà 2013.

66. Cf. la distribución de los fasces (fig. 7 a) en un relieve perteneciente a un monumento sepulcral empotrado en el campanario de la catedral de Aquino, con el altar funerario de Sulpicius Galba conservado en Roma o el fragmento de una tumba del Museo de Avellino - vid. Schäfer 1989, p. 250-252, núm. 7, lám.27,1 (Aquino), p. 363, núm. A.1, lám. 75,1 (Roma), p. 384, núm. C 1, lám. 92,1 (Avellino). 67. Schäfer 1989, p. 414, núm. C 110, lám. 117, 5-6; Rodà 2000, p. 176, láms. 5-6; Garrido, Rodà 2013.

68. Rosso 2006, p. 266-269. 


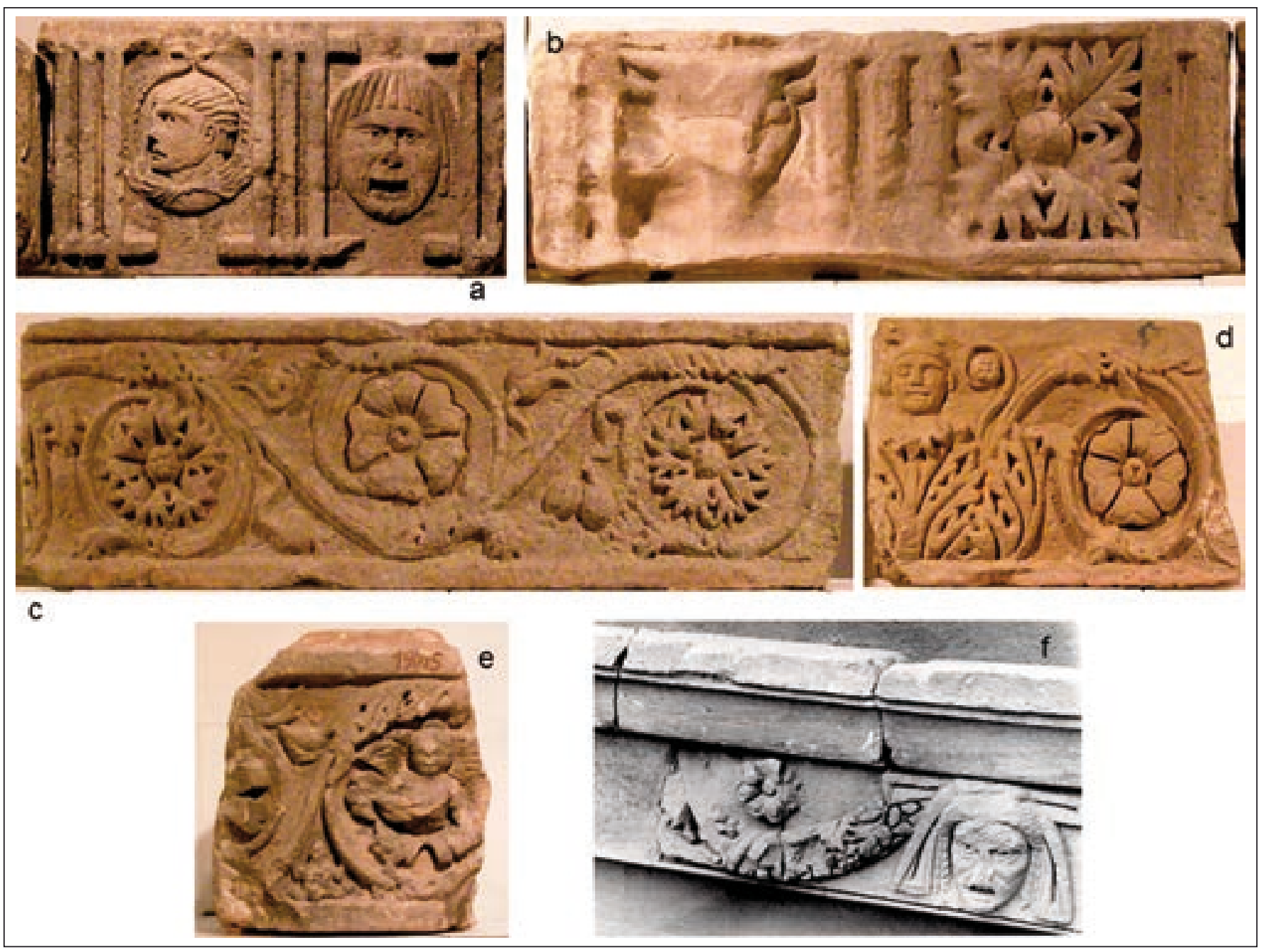

Fig. 6. Frisos dóricos y acantiformes de Barcino (Fotos a-e M. Claveria, Foto f MUHBA).

de $N a r b o^{69}$, este procedimiento técnico está muy presente en los frisos dóricos (figs. 4 c-d, 6 a-b), en varios pulvinos (fig. 5) y en los 4 fragmentos de relieves acantiformes mencionados más arriba (figs. 4 h-i, 6 c-d), todos ellos comprendidos en un período de tiempo que va desde finales del siglo I a.C. hasta mediados del siglo I d.C. y por tanto dentro de la cronología en la que se detecta el "relief cerné" en los talleres sudgalos. En algunas piezas barcinonenses, fechadas con posterioridad, todavía se observan reminiscencias de su uso, como en el pulvino procedente de Santa Eulàlia de Provençana (Hospitalet del Llobregat) ${ }^{70}$, de hacia mediados del siglo II, o en algunas cupae de finales de este siglo y principios del tercero ${ }^{71}$. En éstas, dicho recurso quizás esté presente como pervivencia de un modo de trabajar

69. Rodà 2000, p. 173-196; Rodà 2011.

70. Claveria 2008, núm. 2, lám. 2.

71. IRC IV 1997, núms. 165-166, lám. LXXX o núm. 192, lám. XCI. muy característico de los talleres de este lugar, o por tratarse de un procedimiento de talla muy inmediato, fácil de realizar y con vistosos resultados por el juego de luces y sombras que provoca. Esta técnica se observa en otros relieves funerarios barcinonenses que todavía no se han podido fechar. Por todo ello, de momento, no podemos considerar el estilo "cerné" como indicio cronológico; es necesario seguir avanzando en el conocimiento de la producción escultórica de Barcino para sacar conclusiones al respecto.

La autorepresentación de los propietarios de estos monumentos funerarios culmina en sus retratos. Aunque no podamos establecer conexiones directas, dado el contexto arqueológico de reempleo en el que las piezas fueron halladas, podemos imaginar que las figuras masculinas o femeninas labradas en piedra local (fig. 9) pudieran estar coronadas por los retratos tallados en la propia Barcino, empleando el mismo material o bien 


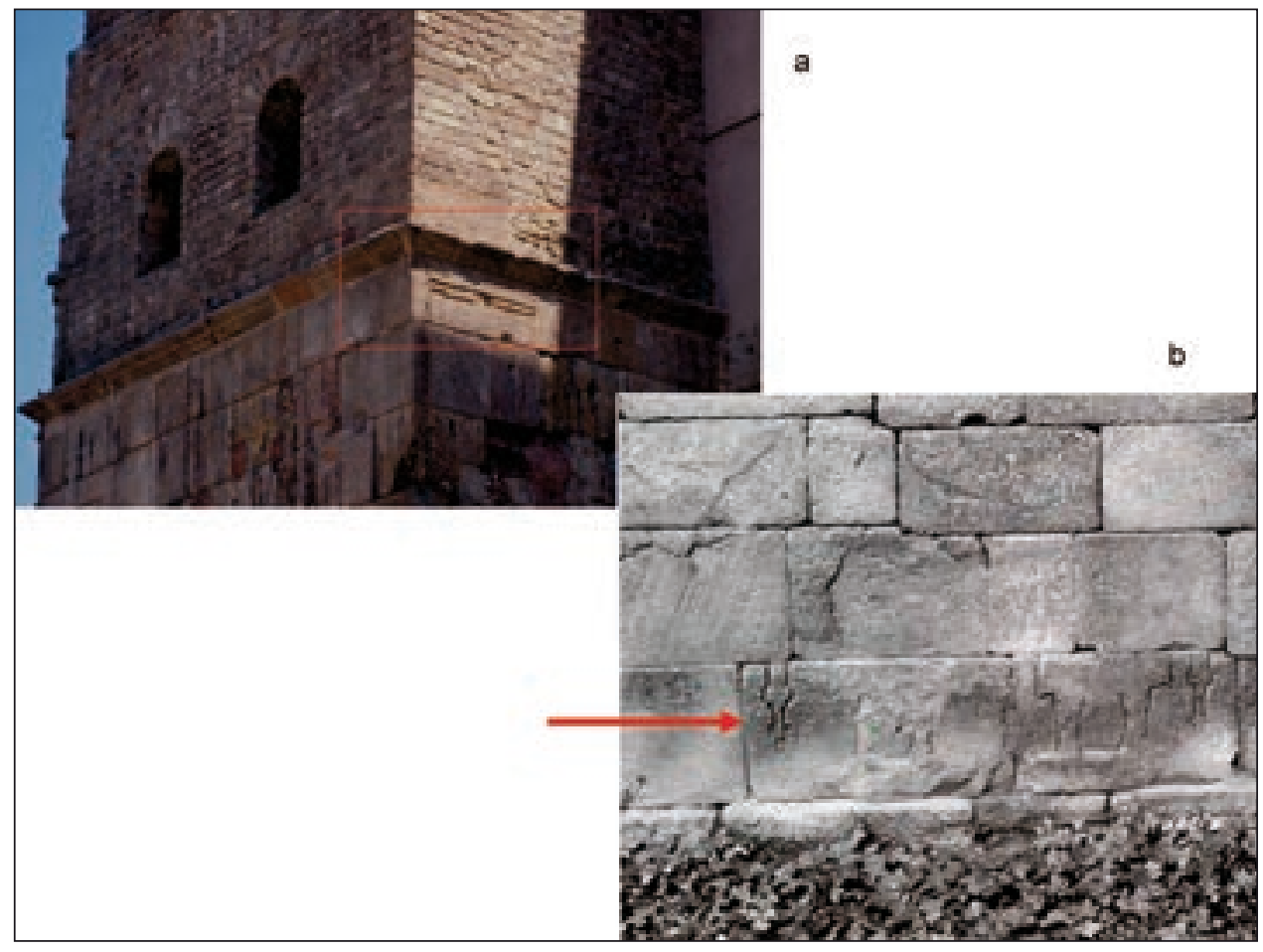

Fig. 7. Relieves con fasces (torre 3) y lictores (lienzo entre torres 24-25) (Fotos I. RODÀ).
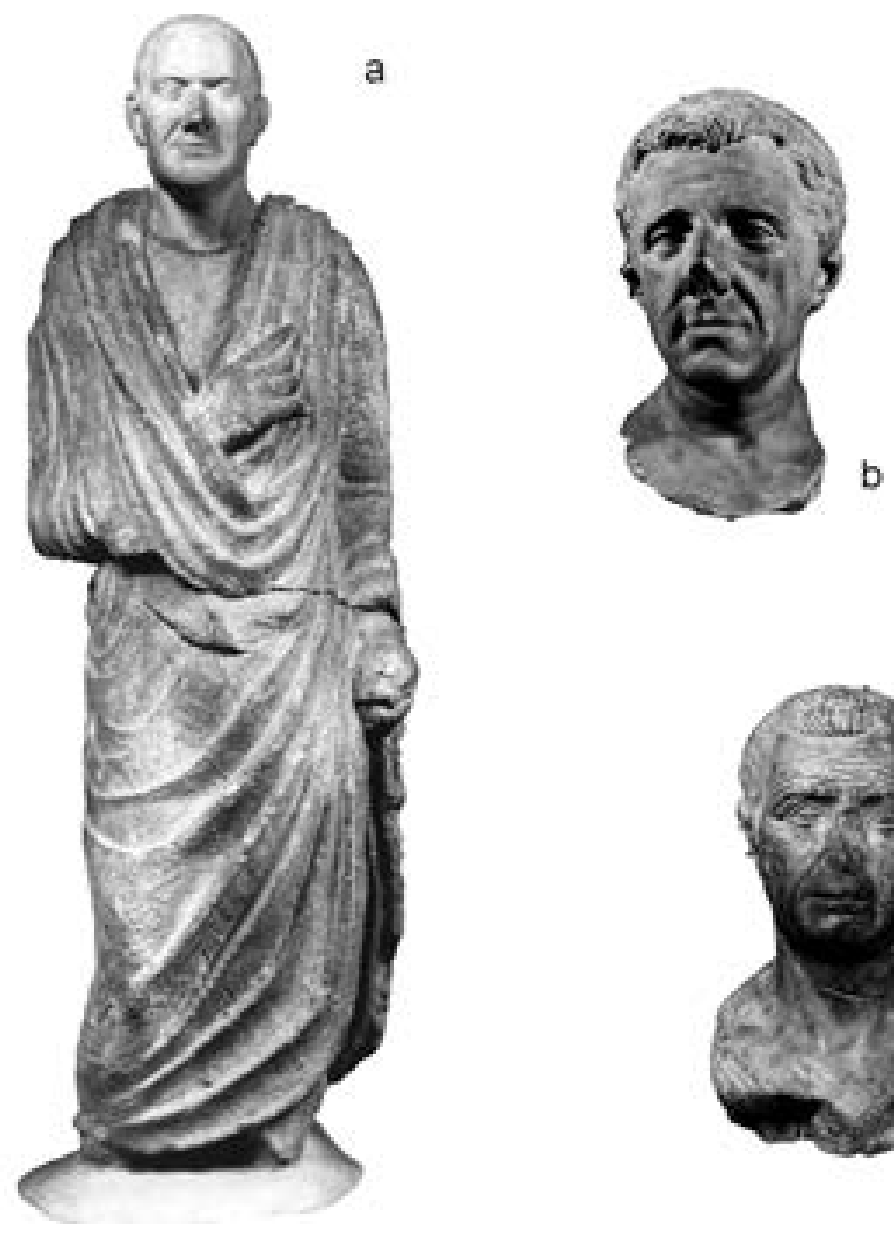

Fig. 8. Retratos funerarios de Barcino (Fotos MUHBA, Foto a: montaje fotográfico MUHBA). 

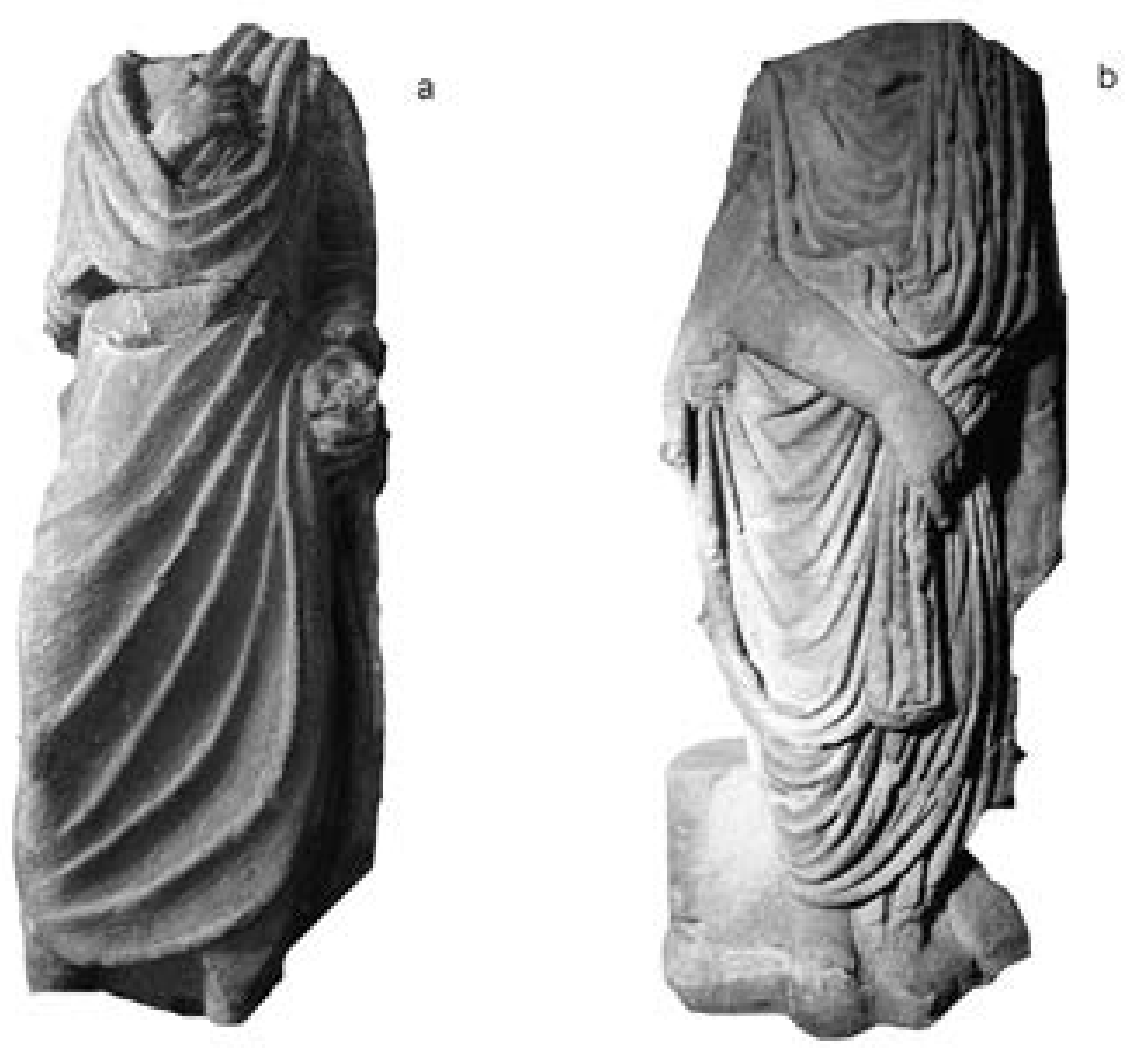

Fig. 9. Figura masculina com pallium y figura masculina com toga de Barcino (Fotos M. Claveria).

bloques de mármol de Luni-Carrara importados en bruto (fig. 8) ${ }^{72}$. Los rasgos de gran parte de estas cabezas son plenamente coincidentes con el estilo de transición de los años 50 a los 20 del siglo I a.C., como lo refleja la labra sintética de los volúmenes del rostro, las arrugas y los mechones del pelo de estos personajes, caracteres que todavía recuerdan la tradición fisiognómica republicana, pero que ya dejan traslucir unos rasgos más serenos y clásicos propios de la iconografía protoimperial ${ }^{73}$.

La mayoría de los togados (fig. 9 a-b) pertenecen al "Pallium-Typus" denominado por H.R. Goette, en su modalidad A.b. ${ }^{74}$, siendo también éstos exponentes de una producción temprana en relación al desarrollo de esta colonia. Los paralelos más ajustados a estos ejemplares se fechan entre el período triunviral y el último cuarto del siglo I a.C. ${ }^{75}$. Sin embargo, respecto a los frisos funerarios tratados más arriba, hemos constatado

72. Agradecemos la imagen al MUHBA y en especial a su conservadora Julia Beltrán de Heredia. El montaje fotográfico que aparece en ella se presenta en el centro de interpretación de la plaza de la Vila de Madrid.

73. Rodà 1980 y 1988.

74. Goette 1990, p. 24-26.

75. Vid. por ejemplo Goette 1990, núms. 39, 50, 87-88, láms. 2,4-5 y $3,2-3$, respectivamente. que en las producciones barcinonenses se mantenían modelos y estilos antiguos durante un tiempo más prolongado, por lo que sería plausible que aquellos retratos y las efigies de esta modalidad se mantuvieran hasta los primeros decenios del siglo I d.C. Más esporádicos son los togados que reproducen el modelo A.c. tipo palio "bracchio cohibito" con sinus ${ }^{76}$ y el B.a. con umbus en forma de $\mathrm{U}^{77}$ (fig. 9 b), característicos de las épocas augustea y tiberiana.

Sorprende constatar que tanto las inscripciones, como las distintas series de fragmentos escultóricos analizadas hasta aquí tienen como denominador común una cronología temprana, que arranca en la época de fundación de Barcino y se desarrolla fundamentalmente durante el período de Augusto y la época julioclaudia. Algunas producciones, como los altares monumentales con pulvinos, perduran con muy pocos ejemplares hasta mediados del siglo II. Sólo los altares funerarios no monumentales y las cupae, con sus inscripciones, vienen a llenar este vacío entre un momento avanzado

76. Por el momento sólo conocemos un ejemplar fragmentado con bulla conservado en el Museu d'Arqueologia de Catalunya sin número de inventario. Cf. Goette 1990, p. 27.

77. Goette 1990, p. 31-33. 
del siglo II y comienzos del III ${ }^{78}$; sin embargo en ningún caso se trata de una sustitución, puesto que ambos son tipos sepulcrales cuyos datos epigráficos nos remiten a las clases inferiores.

El parco panorama funerario que reflejan los epígrafes y las esculturas para la Barcino del siglo II contrasta vivamente con los datos que aportan las áreas públicas para el paisaje urbano. Entre la época flavia y mediados del siglo II, el foro se llena de pedestales tripartitos o monolíticos destinados a soportar estatuas, hoy desaparecidas; también tenemos epígrafes grabados sobre placas de mármol importado, destinados a ser empotrados en monumentos arquitectónicos. En esta época tenemos testimonios de las donaciones de evergetas que manifiestan así su deseo de colaboración en la vitalidad de la vida ciudadana y en su proceso de monumentalización ${ }^{79}$.

A modo de conclusión, quisiéramos destacar el abundante número de elementos funerarios recuperados en Barcino sobre todo en el dilatado proceso de excavación del recinto amurallado tardío, a los que se han sumado los localizados in situ a lo largo de fructíferas campañas arqueológicas. La mayoría de los restos escultóricos y buena parte de los epigráficos sepulcrales se concentran en época fundacional y en la primera mitad del siglo I, debido seguramente a que fueron los monumentos más antiguos los que estaban más próximos a la muralla y por ello estaban más a mano para ser usados como material de construcción, una vez que los monumentos funerarios habían quedado ya obsoletos. Manifiestan una evidentísima impronta itálica y una continuidad del llamado estilo triunviral, que se manifiesta tanto en los monumentos privados como en los públicos, de los que el máximo exponente es el llamado templo de Augusto que presidía el foro de Barcino. Evidentemente todos estos monumentos no pudieron erigirse antes de la fundación de la colonia que tenemos bien precisada en época augustea, con posterioridad al 19 a C. Mencionemos que esto no es un hecho aislado, sino que en el sur de la Galia Narbonense, el norte de la Hispania Citerior y diversos núcleos de la fachada levantina hasta la actual provincia de Jaén ${ }^{80}$, tenemos monumentos diversos que siguen los modelos itálicos y aplican asimismo las técnicas escultóricas que en Italia corresponden a época triunviral.

78. Beltrán de Heredia 2009, p. 24-52; Beltrán de Heredia, Rodà 2012.

79. IRC IV 1997, núms. 30, 33, 45, 109.

80. Baena del Alcázar, Beltrán Fortes 2002; Beltrán Fortes 2002, p. 233-255, especialmente p. 254-255; Ruiz de Arbulo, Mar, Domingo 2004, p. 130-132; Ramallo 2004, p. 170-171.

\section{Bibliografia}

Àlvarez et al. 2009 : ÀLVAREZ (A.), DOMÉNECH (A.), LAPUENTE (P.), PITARCH (À.), ROYO (H.) - Marbles and Stones of Hispania, Tarragona, 2009,142 p.

Baena del Alcázar, Beltrán Fortes 2002 : BAENA DEL ALCÁZAR (L.), BELTRÁN FORTES (J.) - Las esculturas romanas de la provincia de Jaén, Corpus Signorum Imperii Romani. España, t. 1, vol. 2, Murcia 2002.

Balil 1961 : BALIL (A.) - Las murallas bajoimperiales de Barcino, Madrid, 1961, $103 \mathrm{p}$.

Balil 1964 : BALIL (A.) - Colonia Iulia Augusta Paterna Faventia Barcino, Madrid, 1964, $180 \mathrm{p}$.

Balil 1991 : BALIL (A.) - Art i cultura. In : Sobrequès i Callicó (J.) dir., Història de Barcelona, 1 La Ciutat Antiga, Barcelona, 1991, p. 205-237.

Beltrán Fortes 2002 : BELTRÁN FORTES (J.) - La arquitectura funeraria en la Hispania meridional durante los siglos II a.C. - I d.C. In : Vaquerizo (D.) ed., Espacios y usos funerarios en el Occidente Romano, vol. I, Córdoba, 2002, p. 233-258.

Beltrán de Heredia 2007 : BELTRÁN DE HEREDIA (J.) - La via sepulchralis de la Plaza Vila de Madrid. Un ejemplo del ritual funerario durante el alto imperio en la necrópolis occidental de Barcino. Quarhis, 3, 2007, p. 11-63 (= La via sepulcral romana de la plaça de la Vila de Madrid, Documents Museu d'Història de Barcelona 3, Barcelona 2009, p. 7-57).

Beltrán de Heredia, Rodà 2012 : BELTRÁN DE HEREDIA (J.), RODÀ (I.) - Las cupae de la Hispania citerior: reflexiones sobre su origen y el caso de Barcino. En: Andreu (J.) ed. Actas del I Coloquio de Arqueología e Historia Antigua de Los Bañales. Las cupae hispanas: Origen, difusión, uso, tipología, Uncastillo (2012), p. 77-110.

Beltrán Lloris 2007-2008: BELTRÁN LLORIS (F.) - Marcas legionarias de la VI Victrix y de la X Gemina en el foro de Caesar Augusta. En: Homenaje a I. Barandiarán [Veleia 24-25], Vitoria, Universidad del País Vasco, p. 1069-1079.

Bost, Martín-Bueno, Roddaz 2005 : BOST (J.-P.), MARTÍN-BUENO (M.), y RODDAZ, (J.-M.) - L'Aquitaine et le Nord de l'Hispanie sous les empereurs Julio-Claudiens. En: L'Aquitaine et l'Hispanie Septentrionale à l'époque Julio-Claudienne. Organisation et exploitation des espaces provinciaux, Saintes (2003), Burdeos, Féderation Aquitanie, 2005, p. 17-50.

Claveria 2007 : CLAVERIA (M.) - Dos fragments de frisos acantiformes al Conjunt Monument de les Esglésies de Sant Pere de Terrassa. Merlet. Butlletí Informatiu del Museu de Terrassa, 29, 2007, p. 3.

Claveria 2008 : CLAVERIA (M.) - Los altares monumentales con pulvini del nordeste peninsular. En : Noguera (J.M.), Conde (E.) dir., Actas de la $V$ Reunión sobre escultura romana en Hispania, Murcia (2005), Murcia , 2008, p. 183-226.

Claveria 2011 : CLAVERIA(M.) - Recepción de modelos y creaciones locales en el relieve funerario del nordeste hispano. En : Nogales (T.), Rodà (I.) eds., Roma y las provincias: modelo y difusión, Actas del XI Coloquio Internacional de arte romano provincial, Mérida (2009), Roma, 2011, vol. II, p. 327-336.

Garrido 2011 : GARRIDO (A.) - Arquitectura y urbanismo de Barcino en época alto imperial: la decoración arquitectónica de edificios públicos y privados, tesis doctoral UAB leída en el ICAC, Tarragona en febrero de 2011, 419 p., 104 lám., 9 cuadros. http://www.tdx.cat/handle/10803/48641 
Garrido, Rodà 2013 : GARRIDO (A.), RODÀ (I.) - Los monumentos funerarios de Barcino con decoración figurada en relieve. En : VII Reunión de Escultura Romana en Hispania. Homenaxe ao Prof. Dr. Alberto Balil, Santiago de Compostela (2011), 2013, p. 131-147.

Goette 1989 : GOETTE (H.R.) - Studien zu römischen Togadarstellungen, Mainz am Rhein, 1989, 207 p., 94 lám.

Granados 1991 : GRANADOS (O.) - Estructura urbana de la ciudad romana. En : SOBREQUÈS I CALLICÓ (J.) dir., Història de Barcelona, 1 La Ciutat Antiga, Barcelona, 1991, p. 139-201.

Granados, Rodà 1993 : GRANADOS (O.), RODÀ (I.) - La Barcelona de l'època romana En: III Congrés d'Història de Barcelona, Barcelona, 1993, p. 11-46.

Gros 2001: GROS (P.) - Les monuments funéraires. En: GROS (P.), $L$ 'Architecture romaine. II. Maisons palais, villas et tombeaux, parte III, Paris, 2001, p. 379-467.

Guitart 1976 : GUITART (J.) - Baetulo. Topografía arqueológica, urbanismo e historia, Badalona, 1976, 291 p., 50 lám.

Gurt, Rodà 2005: GURT (J.M.), RODÀ (I.) - El pont del Diable. El monumento romano dentro de la política augustea, AEspA 78, 2005, p. $147-165$.

Hesberg 1994 : HESBERG VON (H.) - Monumenta. I sepolcri romani e la loro architettura, Milano, 1994, $331 \mathrm{p}$.

IRC I 1984 : FABRE (G.), MAYER (M.), RODÀ (I.) - Inscriptions romaines de Catalogne I. Barcelone (sauf Barcino), Paris, 1984, 249 p., 68 lám.

IRC IV 1997 : FABRE (G.), MAYER (M.), RODÀ (I.) - Inscriptions romaines de Catalogne IV. Barcino, Paris, De Boccard 1997, 422 p., 137 lám.

IRC V 2002 : FABRE (G.), MAYER (M.), RODÀ (I.) - Inscriptions romaines de Catalogne V. Suppléments aux volumes I-IV et instrumentum inscriptum, Paris, De Boccard 2002, 248 p., 91 lám.

Janon 1986 : JANON (M.) - Le décor architectonique de Narbonne. Les rinceaux, Revue Archéologique de Narbonnaise. Supplément 13, Paris, 1986, 91 p., 29 lám.

Joulia 1988 : JOULIA, (J.CL.) - Les frises doriques de Narbonne. Latomus. Revue d'études Latines, Bruxelles, 1988, 285 p., 114 láms.

Mayer, Rodà 1977 : MAYER (M.), RODÀ (I.) - El abastecimiento de aguas a la Barcelona romana. Reconstrucción de su trazado. En :Segovia y la arqueología romana Actas del Congreso Internacional de Arqueología romana, Segovia (1974), Barcelona, 1977, p. 265-277.

Miró, Orengo 2010 : MIRÓ (C.), ORENGO (H.) - El cicle de l'aigua a Barcino. Una reflexió entorn de les noves dades arqueològiques, Quarhis, 6, 2010, p. 109-133.

Miró, Orengo 2011 : MIRÓ (C.), ORENGO (H.) - La topografia de l'aigua en època romana. In : Guàrdia (M.) ed. La revolució de l'aigua de Barcelona, Barcelona 2011, p. 14-20

Moreno 2014 : MORENO (I.) - Drassanes reials. En : Anuari d'Arqueología i Patrimoni de Barcelona 2012, Barcelona 2014, p. 69-70.

Palet, Rodà 2012 : PALET (J.M.), RODÀ (I.) - Estructuración del territorio y gestión del agua en los llanos litorales del nordeste de la Tarraconensis. En : Nasti (F.), Reduzzi (F.) ed. Per una comune cultura dell'acqua. Dal
Mediterraneo all'America del Nord, Cassino-Napoli (2008), Cassino 2012 p. 27-57.

Pons 1994 : PONS (J.) - Territori i societat romana a Catalunya dels inicis al Baix Imperi, Barcelona, 1994, 439 p.

Pujades 2007 : PUJADES (J.) - Balanç actual de l'activitat arqueològica de la ciutat (2006), Quarhis 3, 2007, p. 181-213.

Ramallo 2004: RAMALLO ASENSIO (S.F.) - Decoración arquitectónica, edilicia y desarrollo monumental en Carthago Nova. En: Ramallo Asensio (S.F.) ed., La decoración arquitectónica en las ciudades romanas de Occidente, Cartagena (2003), Murcia, 2004, p. 153-218.

Rodà 1980 : RODÀ (I.) - Un retrat inèdit de Barcino i el taller escultòric local, Rivista di Studi Liguri XLVI, 1980, p. 41-52.

Rodà 1982 : RODÀ (I.) - Iconografia i distribució dels sarcòfags de tema pagà en les necròpolis de Barcino. En: II Reunió d'Arqueologia Paleocristiana Hispànica / IX Symposium de Prehistoria i Arqueologia Peninsular Montserrat (1978), Barcelona, 1982, p. 229-238.

Rodà 1988 : RODÀ (I.) - El retrato romano en el N.E. de la Tarraconense en: Quaderni di La Ricerca Scientifica. Ritratto ufficiale e ritratto privato. Conferenza internazionale sul ritratto romano (Roma 1984), Roma 1988, p. $453-462$

Rodà 1989 : RODÀ (I.) - Los primeros magistrados en colonias y municipios de la Hispania citerior (al norte de Sagunto). En: González (J.) ed., Estudios sobre Uso Colonia Iulia Genetiva, Sevilla, Alfar, 1989, p. 345-356.

Rodà 1998 : RODÀ (I.) - El papel de Agripa en la trama urbana de la Hispania augustea, en Rodríguez Colmenero (A.) coord., Los orígenes de la ciudad en el noroeste hispánico. I, Lugo (1996), Lugo, Diputación Provincial 1998, p. 275-293.

Rodà 2000 : RODÀ (I.) - La escultura del sur de la Narbonense y del norte de Hispania Citerior: paralelos y contactos. En : León (P.), Nogales (T.) dir., Actas de la III Reunión sobre escultura romana en Hispania, Córdoba (1997), Madrid, 2000, p. 173-196.

Rodà 2005 : RODÀ (I.) - La figura de Agripa en Hispania. En : PérezGonzález (C.), Illarregui (E.) coords., Arqueología militar romana en Europa/ Roman Military Archaeology in Europe, Segovia (2001), Segovia 2005, p. 319-331.

Rodà 2006a : RODÀ (I.) - Las guerras cántabras y la reorganización del norte de Hispania: fuentes literarias, epigrafía y arqueología / The Cantabrian Wars and the reorganization of north Hispania: between literary sources, epigraphy and archaeology. En : Morillo (Á.) ed., El ejército romano en Hispania. Guía arqueológica/The Roman Army in Hispania. An Archaeological Guide, León, Universidad de León 2006, p. 55-66.

Rodà 2006b : RODÀ (I.) - Militares en el área inerme de Hispania citerior. En : Morillo (Á.) ed. Arqueología militar romana en Hispania II. Producción y abastecimiento en el ámbito militar, León (2004), León, Universidad de León 2006, p. 205-218.

Rodà 2007 : RODÀ (I.) - Les inscripcions de la plaça de la Vila de Madrid, Quarhis 3, 2007, pp. 114-123, publicado también en La via sepulcral romana de la plaça de la Vila de Madrid, Documents Museu d'Història de Barcelona 3, Barcelona 2009, p. 107-115.

Rodà 2009 : RODÀ (I.) - Los talleres de la ciudad de Barcino (Barcelona). En: Gaggadis-Robin (V.), Hermary (A.), Reddé (M.), Sintes (C.) dir., Ateliers de sculpture régionaux: Techniques, styles et iconographie, Actes 
du $X^{e}$ Colloque Internacional sur l'Art Provincial Romain, Arles et Aix-enProvence (2007) Trav. du Centre C. Jullian, 11, Santander 2009, p. 513-529.

Rodà 2011 : RODÀ (I.) - Imago Mortis: consideraciones acerca de la escultura y el retrato funerarios en la Roma antigua. El ejemplo de Barcino. En : Andreu (J.), Espinosa (D.), Pastor (S.) coord., Actas del Seminario Internacional Mors omnibus instat. Aspectos arqueológicos, epigráficos y rituales de la muerte en el Occidente Romano, Tudela (2010), Madrid, Liceus 2011, p. 233-254.

Rodà 2013 : RODÀ (I.) - Darreres trobales epigrafiques en pedra de Barcino Quarhis, 9, 2013, p. 156-163.

Rosso 2006 : ROSSO (E.) - Le décor sculpté des mausolées de Narbonne : problèmes d'interpretation. À propos de l'auto-représentation des «élites » narbonnaises sous les julio-Claudiens. En: Moretti (J.CH.), Tardy (D.), L'architecture funéraire monumentale. La Gaule dans l'empire romain. Actes du colloque organisé par l'IRAA du CNRS et le musée archéologique HenriPrades, Lattes (2001), Paris, 2006, p. 254-271.

Ruíz de Arbulo, Mar, Domingo 2004 : RUíZ DE ARBULO (J.), MAR (R.), DOMINGO (J.), FIZ (I.) - Etapas y elementos de a decoración arquitectónica en el desarrollo monumental de la ciudad de Tarraco (s. II A.C.-I D.C.). En : Ramallo Asensio (S.F.) ed., La decoración arquitectónica en las ciudades romanas de Occidente, Cartagena (2003), Murcia, 2004, p. 115-151.

Sanmartí 1984 : SANMARTÍ (J.) - Edificis sepulcrals dels països catalans, Aragó i Múrcia, Fonaments, 4, 1984, p. 87-160.

Schäfer 1989 : SCHÄFER (T.) - Imperii insignia. Sella curulis und fasces. Zur Repräsentation römischer Magistrate, Mainz am Rhein, 1989, 457 p., 121 láms.

Schörner 1995 : SCHÖRNER (G.) - Römische Rankenfriese, Mainz am Rhein, 1995, 198 p., 87 láms.

Vaquerizo 2002: VAQUERIZO (D.) - Espacios y usos funerarios en Corduba. En : Vaquerizo (D.) ed., Espacios y usos funerarios en el Occidente Romano. Actas del congreso internacional, vol. II, Córdoba (2001), Córdoba, 2002, pp. 143-200.

Vaquerizo 2010 : VAQUERIZO (D.) - Necrópolis urbanas en Baetica, Documenta 15, Tarragona, ICAC 2010, 349 p., 286 láms. 



\title{
Épigraphie et mise en scène de la domination sociale dans la Gaule méridionale tardive (IV ${ }^{\mathrm{e}}-\mathrm{VI}{ }^{\mathrm{e}} \mathrm{s}$.)
}

\author{
Christian Stein \\ Maître de conférences en Histoire romaine, Université de Bourgogne \\ christian.stein@u-bourgogne.fr
}

\begin{abstract}
Résumé
On possède peu d'inscriptions gauloises qui mentionnent des membres des élites au IV s. Le corpus exploitable fait moins d'une quinzaine de textes et brille surtout par l'absence des clarissimes, ou du moins d'individus explicitement indiqués comme tels. Comme on sait par ailleurs que ce groupe est tout de même assez fourni en Gaule au IV ${ }^{\mathrm{e}} \mathrm{s}$., on en arrive vite à l'idée que l'épigraphie n'était pas à leurs yeux un moyen de se mettre en scène dans l'espace social. Il est cependant perceptible que les choses changèrent aux $\mathrm{V}^{\mathrm{e}}$ et $\mathrm{VI}^{\mathrm{e}} \mathrm{s}$. en Gaule méridionale : dans un contexte d'effondrement de l'Empire d'Occident, les inscriptions commémorant les membres des grandes familles galloromaines sont désormais relativement nombreuses. La lettre III, 12 de Sidoine Apollinaire, à propos de la tombe et de l'épitaphe de son grand père, permet de percevoir ce changement de sensibilité envers l'épigraphie.
\end{abstract}

Mots-clés : Élites, hiérarchie sociale, marqueurs sociaux, tombe privilégiée.

\begin{abstract}
We know only few inscriptions remembering members of the upper classes in IVth century Gaul. There are less than 15 usefull ones, in which we are surprised to notice an evident lack of clarissimi. As we know by other ways that clarissimi actually existed there in numbers, we must admit that epigraphy was not socially significant to them. This situation evolved during Vth and VIth centuries in southern Gaul. As the Western Empire collapsed, from this time on, we know numerous engraved stones speaking about members of major families of the Roman aristocracy. Thus, Sidonius Apollinaris' Epist. III, 12 about his grand-father's grave allows us to better perceive the new feeling towards epigraphy and some of its consequences.
\end{abstract}

Key-words: Ruling class, social ranks, markers of social status, elite burials. 
$\mathrm{L}$ 'ambition de cette contribution est de proposer une étude exploratoire consacrée à l'épigraphie de ces élites romaines tardives de Gaule, que l'on a pris aujourd'hui l'habitude de qualifier de 《gallo-romaines ${ }^{1}$. Mon propos consistera à formuler un certain nombre de remarques et d'hypothèses sur l'usage social de l'épigraphie par ces groupes qui culminaient au sommet de la pyramide sociale en Gaule méridionale aux $\mathrm{IV}^{\mathrm{e}}$ et $\mathrm{V}^{\mathrm{e}} \mathrm{s}$. ap. J.-C., avec l'analyse plus particulière du cas de la famille de Sidoine Apollinaire.

\section{Le corpus épigraphique des élites en Gaule au IV ${ }^{\mathrm{e}} \mathbf{s}$.}

Mon point de départ est une constatation empirique assez simple: on possède peu d'inscriptions du $\mathrm{IV}^{\mathrm{e}} \mathrm{s}$. qui mentionnent ou mettent en scène des membres des couches supérieures de la société en Gaule, bref les élites. Cette observation est évidemment aussi valable pour la Gaule méridionale, mais, à ce stade de l'enquête, il n'est guère pertinent d'identifier une région en particulier. Précisons aussi tout de suite qu'en parlant de « couches supérieures » de la société, ou élites, je reste volontairement assez vague, puisque la période tardive se caractérise par une évolution rapide des marqueurs sociaux. On sait par exemple qu'un clarissime tardif est en réalité souvent d'un rang social assez inférieur à celui d'un clarissime à l'époque d'Hadrien, et la signification sociale du titre même se modifie de manière significative entre le début et la fin du $\mathrm{IV}^{\mathrm{e}} \mathrm{s}$. ; autre exemple, le recrutement social des évêques gaulois en 300 est globalement inférieur à celui de leurs homologues en 400, etc. Dans ce contexte mouvant, disons pour l'instant que nous nous intéresserons d'abord à repérer des inscriptions qui mettent en valeur ou, à défaut, qui mentionnent des individus socialement dominants, au sens large, grâce à l'évocation explicite de leur rang ou de celui de leur famille.

Sans prétendre constituer un corpus exhaustif, à partir des grands outils que sont le premier volume de la Prosopography of the Later Roman Empire (PLRE), paru en 1971, la prosopographie de la Gaule tardoantique publiée en 1982 par Martin Heinzelmann dans la revue Francia et, pour les découvertes des années ultérieures, L'Année épigraphique, j' arrive à dresser une courte liste de treize documents qui mentionnent vingt individus, pour l'ensemble d'un grand $\mathrm{IV}^{\mathrm{e}} \mathrm{s}$. (puisque,

1. Par Gaule, j'entendrai désormais l'espace comprenant la Narbonnaise, les trois Gaules et les Germanies (mais sans les provinces alpines). comme d'habitude avec ce type de corpus, un certain nombre de documents sont datés dans une fourchette à cheval sur la fin $\mathrm{III}^{\mathrm{e}} / \mathrm{dé}^{\mathrm{b}} \mathrm{It}_{\mathrm{IV}}^{\mathrm{e}} \mathrm{s}$. et à l'autre extrémité fin $\mathrm{IV} /$ début $\mathrm{V}^{\mathrm{e}} \mathrm{s}$.) :

1) $C I L$, XIII, $7918=I L S, 7069$, Zülpich, près de Cologne, 352 ap. J.-C. : D(iis) M(anibus) \| Masclinio Materno, | dec(urioni) c(oloniae) A(grippinensis), aedilicio, du(u)mviral(icio), | curatoricio, sacerdotali, | ex comitibus, Masclinio Leo | patri benemerit[o] fecit, | Decentio Caesare et Paulo co(n)s(ulibus).

2) $A E, 1996,1095$, Trèves, sarcophage chrétien, datation par l'éditeur entre 293 et 310: Callosiae Clamosae co(n)iu|gi carissimae, quae vixit | annis XXVIIII et m(ensibus) V d(iebus) n(umero) XVIIII, $\mid$ cui Fl(avius) A[---], v(ir) p(erfectissimus), p(rae)p(ositus) v|inorum, coniux eius, faci|endum curavit.

3) CIL, XIII, 3672, Trèves, entre 293 et 305 : Indulgentissimo $\mid d($ omino) $n$ (ostro) Flavio Val(erio) | Constantio | nobilissimo $\{C\} \mid$ Caes(ari), Valerius Concordius, $\mid v($ ir) p(erfectissimus), dux, devo|tus numini | mai $\{i\}$ estati|que eorum.

4) $A E, 1978,503$, inscription métrique, Trèves, fin $\mathrm{III}^{\mathrm{e}}$-début $\mathrm{IV}^{\mathrm{e}} \mathrm{s}$. : $D($ is $)$ M(anibus). | Hic fecit cla[ $\left.r\right]$ o vigu[it qui] | nomin[e s]emper | doctor Rom[ani $n]$ $o b[i l i s] \mid$ eloqu[i]i | L(ucius) Terentius Iulianus qui et Concor $\mid[$ dius $], \quad v($ ir $)$ p(erfectissimus), magister $s[t]$ udiorum, gram|maticus Latinus.

5) Au milieu du $X^{\mathrm{e}}$ s., Flodoard (894-966) rapporte le texte d'une inscription versifiée qu'on pouvait lire à son époque dans l'église Saint Agricola de Reims. Elle mentionnait un Iovinus qui est identifié comme l'un des consuls ordinaires en 367 : il est vraisemblable qu'il s'agissait d'une épitaphe qui faisait en même temps office de dédicace de l'église ${ }^{2}$. Historia Remensis ecclesiae, I, 6 (= MGH, SS, XIII, p. 419) = CIL XIII, $3256=I L C V, 61:$ Felix militiae sumpsit devota Iovinus / cingula virtutum culmen provectus in altum/bisque datus meritis equitum peditumque magister / extulit aeternum saeclorum in saecula nomen. / Sed pietate gravi tanta haec praeconia vicit / insignesque triumphos religione dicavit, / ut quem fama dabat rebus superaret honorem

2. Une très ancienne tradition rémoise associe au nom du consul un sarcophage dit «de Jovin » aujourd'hui au musée Saint Remi ; ce sarcophage, qu'on date usuellement $\mathrm{du} \mathrm{III}^{\mathrm{e}} / \mathrm{IV}^{\mathrm{e}} \mathrm{s}$. ne comporte cependant aucune inscription ni marque chrétiennes. Voir la notice «Jovin » du Dictionnaire d'archéologie chrétienne et de liturgie, t. VII, col. 2745-2752 [H. Leclercq, 1926-1927]. 
/ et vitam factis posset sperare perennem. / Conscius hic sancto manantis fonte salutis / sedem vivacem moribundis ponere membris / corporis hospitium laetus metator adornat, / reddendos vitae salvari providet artus. / Omnipotens Christus, iudex venerabilis atque / terribilis, pie longanimis, spes fida precantum / nobilis eximios famulis non imputat actus / plus iusto fidei ac pietatis praemia vincant.

« Jovin embrassa avec succès le métier des armes : il parvint au comble des honneurs militaires, et élevé deux fois par ses services à la dignité de maître de la cavalerie et de l'infanterie, il s'est acquis un nom immortel pour les siècles des siècles. Mais sa haute piété mérite encore de plus grands éloges : il a sanctifié par la religion ses triomphes éclatants, il s'est élevé ainsi au-dessus de la gloire que la renommée accordait à ses hauts faits, et il s'est assuré par ses œuvres l'espérance de la vie éternelle. Il choisit ce lieu, où coulent les eaux saintes du salut, pour que ses restes y puisent une vie nouvelle, et c'est avec la joie de l'espérance qu'il embellit l'asile où ils doivent attendre la résurrection des corps. Le Christ tout-puissant, juge adorable et terrible, et cependant bon et miséricordieux, fidèle espoir de ceux qui l'emploient, ne tient pas compte à ses serviteurs de leurs actions d'éclat : mettons donc au premier rang les œuvres de la foi et de la piété. » (Trad. Leclercq)

6) $C I L$, XIII, $1796=I L C V, 89$, Lyon, épitaphe chrétienne, probablement fin $\mathrm{IV}^{\mathrm{e}}$ ou $\mathrm{V}^{\mathrm{e}} \mathrm{s}$. : Hic iacet Aelianus, | filius Pauli | viri praesidialis, | qui vixit anno $[s] \mid p l(u s)$ m(inus) XL, cives Remus.

7) $C I L$, XII, $1852=I L N, 5,1,43$, Vienne, probablement entre 312 et 337 : Virtute for|tissimo et pie|tate clementis|simo d(omino) $n$ (ostro) Fl(avio) | Constantino $\mid$ Maximo et $\mid$ Invict(o) Aug(usto) $\mid$ M(arcus) Alfius Apronia|nus, v(ir) p(erfectissimus), $p$ (raeses) p(rovinciae) Fl(aviae) Vienn(ensium), | $\operatorname{dev}($ otus $)$ n(umini) m(aiestati)q(ue) eius.

8) $C I L, \mathrm{XII}, 675=I L S, 1208=I L C V, 178$, Arles, sarcophage chrétien, fin $\mathrm{III}^{\mathrm{e}} / \mathrm{IV}^{\mathrm{e}} \mathrm{s}$. : Hydriae Tertullae, | c(larissimae) f(eminae), coniugi amantissi|mae, et Axiae Aelianae, |filiae dulcissimae, | Terentius Museus | hoc sepulchrum | posuit.

9) CIL, XII, 668, voir Heijmans 2004, p. 206-215, Arles, dédicace d'une réfection monumentale (les lettres sont identifiées à partir des trous d'ancrage dans la pierre) vers 324/326: [Dddddominis nnnn(ostris) Fl(avio) Val(erio) Constantino max(imo) vict(ori) semper Aug(usto) d]ivi Constanti filio divi Claudi nepoti | [bono rei publicae nato et Fl(avio) Iulio Crispo et Fl(avio) Claud]io Constantino et Fl(avio) Constantio | [nobbb(ilissimis) Caesss(aribus) et piissimae ac venerabili Aug(ustae) Flaviae Ma]ximae Faustae Augusti Caesarumque | [uxori matrique ---e]xo[r]natamque Arelatensium civitatem | [---dedic]avit cur(ante) Iul(io) Atheneo, v(iro) p(erfectissimo).

10) $A E, 1974,418$, Arles, sarcophage chrétien, après 328: XVII kal(endas) Apr|iles hic quiescet | in pace Marcia Roman|ia Celsa, c(larissima) f(emina), qu(a)e vixit a|nnos XXXVIII, m(enses) II, dies XI ; | Fl(avius) Ianuarinus, $v($ ir $) c($ larissimus $)$, ex $\mid$ cons(ule) $\operatorname{ord}(i)$ $n$ (ario) coniu|gi bene merenti posuit.

11) $C I L, \mathrm{XII}, 673=I L S, 2788=I L C V, 295$, Arles, sarcophage chrétien: Bene pausanti in pace, Fl(avio) Memorio, $v($ iro $) p($ erfectissimo), qui milit(avit) $\mid$ int(er) Iovianos annos XXVIII, pro(tectori) dom(esticorum) an(nos) VI; prae(fuit) lanciaris se[nioribus ---] rib[us] an(nos) III, comes ripe an(num) I, com(iti) Mauret(aniae) Ting(itanae) an(nos) IIII, | vix(it) an(nos) LXXV; Praesidia coni[unx] marito dulcissimo.

12) $C I L, \mathrm{XII}, 942=I L C V, 1117$, Arles, inscription métrique sur sarcophage chrétien, sans doute des années 380-390: Integer adque pius, vita et corpore purus, | aeterno hic positus vivit Concordius aevo, | qui teneris primum ministrum fulsit in annis, | post etiam lectus caelesti lege sacerdos. | Triginta et geminos decim vix reddidit annos. | Hunc cito sideream raptum omnipotentis in aulam et mater blanda et frater sine funere quaerunt.

«Chaste et pieux, pur par sa vie comme par son corps, Concordius, déposé ici, est vivant pour l'éternité. Il a d'abord, dans ses jeunes années, soutenu le ministre [de l'Église] et a ensuite été élu évêque par la loi céleste. Il a atteint à peine trente et deux fois dix ans. Lui qui a été tôt enlevé vers la demeure astrale du Tout-Puissant, sa mère affectueuse et son frère le cherchent sans en porter le deuil. » (Trad. Guyon-Heijmans)

13) $C I L, \mathrm{XII}, 674$ cf. p. $817=I L C V, 88$; cf. $A E, 1939$, p. 52 et $A E, 1948$, p. 171, Heijmans 2004, p. 380-381, Arles, sarcophage chrétien. La pierre étant perdue, le texte était connu grâce à des copies d'époque moderne ; par la suite la découverte de deux fragments a permis d'établir la mise en page: [Vir Agrippinen]sis [nomine Geminus | hic iacet, qui pos]t dignitatem | [praesidiatus admenistra]tor rationum | [quinque provinciarum dig] nus est | [habitus; hic post an(nos) XXXVIII, menses II | et dies sex, fedelis in fata concessit, | cuius insig]nem glo[riam cives sui sepulcri gratia adornaverunt.] 
Voyons maintenant rapidement les principales caractéristiques générales de ce corpus :

- Sur vingt individus, cinq femmes seulement qui n'apparaissent qu'associées à leur époux (ou leur père et mère dans le cas d'Axia Aeliana) : indiscutablement la pratique épigraphique reste, comme aux siècles précédents, une pratique masculine.

- D'un point de vue géographique, on note surtout la concentration des sites de découverte de notre petit corpus. Ce qui frappe est le caractère très « vertical » de cette répartition de ces treize documents : ils proviennent tous d'une sorte de couloir nord-sud, entre la région de Cologne et Arles ; couloir qui n'est finalement pas très large et qui correspond à peu près à un axe Rhône-Rhin. D'un autre côté, c'est aussi là que l'on trouve les grandes villes qui sont au cœur de l'histoire gauloise tardive. C'est d'ailleurs de ces villes que viennent la majorité de nos inscriptions, puisque, sur les treize documents, trois proviennent de Trèves et six d'Arles, qui - plus que Lyon - sont les grands centres administratifs et polarisent l'espace gaulois au $\mathrm{IV}^{\mathrm{e}} \mathrm{s} .{ }^{3}$.

- On remarque enfin que quatorze des vingt personnes mentionnées sont chrétiennes. L'échantillon est évidemment très faible, mais ce rapport entre inscriptions païennes et chrétiennes est à vrai dire assez surprenant - sauf à imaginer une christianisation vraiment très précoce de ces élites gauloises ou des pratiques épigraphiques différentes.

Pour être complet sur la constitution de ce corpus, il est également nécessaire de mentionner quelques inscriptions notables, mais considérées comme trop incertaines pour être utilisables :

- Le fragment de Trêves RICG, I, 191, que la PLRE, à la suite de quelques autres, identifie comme étant l'épitaphe de Flavius Merobaudes, le consul de 377 et 383 qui se suicida en 388 sur fond d'usurpation de Maxime (PLRE, I, p. 598-599, Merobaudes 2; Heinzelmann 1982, p. 652, M. 2) : le nom même du défunt est très restitué et l'épitaphe ne fait pas vraiment allusion à son rang social, ce qui la ferait pour le moins sortir du champ de notre étude ; en outre plusieurs éditeurs penchent pour une datation beaucoup plus tardive ${ }^{4}$.

3. Sur le développement d'Arles au IV e s., voir Heijmans 2004, p. $43-81$.

4. Ensemble du dossier dans la notice de Nancy Gauthier au RICG, I, 191.
- La fameuse et énigmatique épitaphe métrique de Nymfius de Valentine (Haute-Garonne), CIL, XIII, $128=I L C V, 391$. Si, à sa lecture, on comprend sans difficulté que le fameux Nymfius appartenait aux élites de sa région, le texte permet de distinguer en lui aussi bien un petit notable local très bien mis en valeur qu'un Ausone relativement discret ! Il y a certes des croix présentes sur la pierre, mais elles pourraient être postérieures, et le texte lui-même de l'épitaphe est assez elliptique pour que l'on puisse débattre longuement des convictions et choix religieux de Nymfius et de sa femme Serena (qui dédie l'inscription). Enfin, si tous les commentateurs s'accordent à penser qu'elle est assez tardive, elle ne comporte aucun élément précis de datation entre la fin du $\mathrm{III}^{\mathrm{e}}$ et le $\mathrm{V}^{\mathrm{e}} \mathrm{s}$. Si Jean-Marie Pailler penche pour le milieu du IV e s., Hagith Sivan, à partir d'éléments archéologiques, verrait plutôt le début du $\mathrm{V}^{\mathrm{e}} \mathrm{s}$. Le type d'éloge, très allusif, pourrait cependant très bien aussi se rapprocher de ce qui s'est fait plus loin encore dans le $\mathrm{V}^{\mathrm{e}} \mathrm{s}$., datation qui n'irait pas contre les dernières évaluations archéologiques (Heinzelmann 1982, p. 659 ; Pailler 1986 ; Sivan 1989).

- Le dossier CIL, XIII, 921a-c =ILS, $6117 ; 6117 \mathrm{a}$; $6117 \mathrm{~b}=I L C V, 80=I L A-$ Nitiobroges, $14-16$ comprend trois tablettes de bronze avec marques chrétiennes. Elles ont été offertes par trois cités, Sens, Auxerre et Orléans, en l'honneur de leur patron, Cl(audius) Lupicinus, clarissime, gouverneur consulaire de Maxima Senonia dans les années 383/388 (PLRE, I, p. 520, Lupicinus 5 ; Heinzelmann 1982, p. 640, L. 3). Les tablettes ont été retrouvées à Lacaussade, entre Bordeaux et Agen, dans ce qui semble être les ruines d'une villa : on peut donc formuler l'hypothèse que ces tablettes ont été remises au gouverneur Lupicinus qui les a ramenées chez lui après avoir exercé sa charge. Même si les inscriptions elles-mêmes n'en disent rien, Claudius Lupicinus est en conséquence très vraisemblablement un clarissime gaulois, ou en tout cas un clarissime qui s'est installé en Aquitaine. Toutefois, ces inscriptions relèvent d'une épigraphie de l'espace privé et n'étaient visiblement pas destinées à être exposées dans un lieu public ${ }^{5}$ : elles n'ont donc pas vocation à être intégrées à notre corpus.

- Une inscription sur sarcophage chrétien d'Arles est dédiée par un proconsul anonyme à un Breton

5. La cité d'Auxerre distingue ainsi très bien l'hommage privé et l'hommage public: Tantis pro meritis felix | provincia per $t[e] \mid$ que tribuit tabulas $\mid$ statuas decernere vellet (CIL, XIII, 921b = ILS, 6117a); voir aussi Chastagnol 1995. 
nommé Tolosanus, $A E, 2004,881=A E, 1939,53$ : Hic conditus i\|acet | nomine Tolo\|sanus | Britannus n\|atione | proconsul\|is dolor. Alors qu'on avait longtemps pensé que ce proconsul anonyme vivait à la fin du $\mathrm{IV}^{\mathrm{e}} \mathrm{s}$., Marc Heijmans a récemment repris le dossier et proposé de l'identifier au père anonyme du Camillus que Sidoine Apollinaire rencontra à Arles en présence de l'empereur Majorien vers 460. Si l'on suivait cette nouvelle proposition, l'épitaphe serait alors à dater des années 420/430 (PLRE, I, p. 921, Tolosanus ; Heinzelmann 1982, p. 706 ; Heijmans 2004, p. 381-384).

- Une épitaphe chrétienne de Lyon mentionne une Procula $\mid$ cl(arissima) femina $\mid$ famula Dei $\mid$ a terra ad martyres (CIL, XIII, $2423=I L C V, 3353)$. Évidemment tardive, rien ne permet de manière évidente de la situer là plutôt qu'au $\mathrm{V}^{\mathrm{e}}$ ou au $\mathrm{VI}^{\mathrm{e}} \mathrm{s}$. (PLRE, II, Procula 2, p. 923 ; Heinzelmann 1982, p. 674, P. 2). Dans le même ordre d'idées, une autre inscription chrétienne de Lyon mentionne une Merola clarissima femina (CIL, XIII, $2419=I L C V, 182 ;$ PLRE, II, p. 758 ; Heinzelmann 1982, p. 653) et un fragment métrique de Trèves une anonyme clarissima femina (CIL, XIII, $3675=I L C V$, 183, RICG, I, 192 ; PLRE, I, p. 1040, Anonyma $23=$ PLRE, II, p. 1238, A. 5) : dans ces deux cas la datation est très incertaine, et, par conséquent, probablement postérieure au $\mathrm{IV}^{\mathrm{e}} \mathrm{s}$.

\section{2. Épigraphie et domination sociale au IV ${ }^{\mathrm{e}}$ s. en Gaule}

Le moins que l'on puisse dire est que notre corpus du IV ${ }^{\mathrm{e}}$ s. donne un sentiment d'extrême modestie, pour un espace aussi vaste que l'ensemble des provinces de Gaule et des Germanies sur un siècle tout entier.

Modestie encore accentuée quand on se remémore que ce siècle n'est pourtant pas anodin pour cet espace. Depuis la Tétrarchie, en effet, sans parler de la création d'une préfecture spécifique, cette région de l'Empire est alors un secteur largement fréquenté par les Augustes et autres Césars, qui n'hésitent pas à s'y installer, en particulier à Trèves, avec leur cour et tous ceux qui gravitent habituellement autour de ces centres du pouvoir. Au Haut-Empire, la configuration avait été dans l'absolu bien moins favorable : nul empereur en tant que tel n'a jamais résidé en Gaule à cette époque, et c'est à peine si certains l'ont traversée. Sans compter également que les sénateurs issus des provinces étaient quasiment tenus de devenir italiens, et par là moins susceptibles de susciter dans leurs régions d'origine des inscriptions portant leur nom ou celui de leurs familles : une exigence qui a été assouplie au IV ${ }^{\mathrm{e}}$ s. $^{6}$.

Même si on sait que la pratique épigraphique décline de manière générale à partir du $\mathrm{III}^{\mathrm{e}} \mathrm{s}$. dans le monde latin, on aurait très bien pu attendre de cette situation socio-politique nouvelle, pour la Gaule du IV ${ }^{\mathrm{e}}$ s., qu'elle fût plus favorable à un acroissement sensible de la production d'inscriptions mettant en scène les élites ${ }^{7}$. Pourtant, avec treize inscriptions, c'est-à-dire finalement pas grand-chose, il n'en est rien ${ }^{8}$. À titre de comparaison indicative - la méthodologie est assez différente -, dans son ouvrage sur les chevaliers et sénateurs gaulois, Yves Burnand a identifié pour le $\mathrm{III}^{\mathrm{e}} \mathrm{s}$. onze clarissimes et quarante-sept chevaliers, dont pratiquement tous grâce à l'épigraphie (Burnand 2006, p. 513-614). La moisson d'un $\mathrm{III}^{\mathrm{e}} \mathrm{s}$. de crise est donc bien plus riche que celle d'un $\mathrm{IV}^{\mathrm{e}} \mathrm{s}$. dit de renouveau ! Et encore n'avons-nous pas tenu compte d'une des grandes limites de notre corpus : il est en effet certain que plusieurs des individus que nous avons identifiés ne sont même pas gaulois ou enracinés dans cette région, mais simplement de passage dans le cadre d'une carrière administrative.

On constate en outre que l'origine sociale de l'ensemble des individus identifiés n'apparaît pas particulièrement extraordinaire. Et on peut s'autoriser à penser cela même si notre population comporte deux consuls ordinaires, titre toujours impressionnant au IV $\mathrm{IV}^{\mathrm{e}} \mathrm{s}$.

La grande majorité de nos textes mentionne en effet de « simples » perfectissimes ou assimilables, membres d'un rang équestre qui avait certes beaucoup de lustre au $\mathrm{II}^{\mathrm{e}} \mathrm{s}$. mais qui a subi une forte érosion à partir de la fin du III ${ }^{\mathrm{e}}$ s., jusqu'à sa quasi-disparition de l'échelle des valeurs au début du $\mathrm{V}^{\mathrm{e}}$ : on observe d'ailleurs clairement dans le corpus la disparition au $\mathrm{IV}^{\mathrm{e}} \mathrm{s}$., comme ailleurs, des autres titres équestres inférieurs (Lepelley 1999).

Ceux qui s'en sortent le mieux sont bien entendu ceux qui ont obtenu leur perfectissimat à l'époque

6. Sur ce « déracinement des élites nobiliaires » au Haut-Empire : Burnand 2008, p. 221-241. Je laisse de côté la période très troublée de la crise du III e s. (Sivan 1993b).

7. Un phénomène analogue, en quelque sorte, à cette visibilité accrue des élites gauloises que l'on note dans les sources littéraires $\mathrm{du} \mathrm{IV}^{\mathrm{e}} \mathrm{s}$.

8. Avec cette réserve qui s'impose toujours à nous, qu'on dépend bien entendu aussi des multiples facteurs qui ont entraîné la conservation ou la destruction des inscriptions antiques et qui faussent sans doute parfois notre perception des choses. Néanmoins on peut postuler qu'il n'y a pas de raison de penser que les conditions de conservation des documents épigraphiques $d u \mathrm{IV}^{\mathrm{e}} \mathrm{s}$. étaient plus mauvaises que celles des siècles précédents. 
tétrarchique, quand cette érosion n'était pas encore trop marquée. Terentius Iulianus a occupé des fonctions palatines qui l'amenaient à côtoyer l'Auguste ou le César à Trèves (Heinzelmann 1982, p. 631, Iulianus 1), tandis que Valerius Concordius, avec un profil plus militaire, après avoir été gouverneur praeses de Numidie vers 295, fut $d u x$, c'est-à-dire responsable de district militaire, ou peut-être plutôt commandant d'une expédition militaire sous l'autorité de Constance (PLRE, I, p. 219, Concordius 4 ; Heinzelmann 1982, p. 585, C. 1). À la même époque cependant, Flavius A[---] n'avait d'autre responsabilité que celle d'être chargé (praepositus) des vins, sans doute une fonction liée à la logistique de la cour de Trèves ${ }^{9}$. Un peu plus tard, Alfius Apronianus fut lui aussi gouverneur de province, mais à un moment où les compétences du praeses étaient plus réduites et où son rang était le plus bas dans la hiérarchie des gouverneurs (PLRE, I, p. 86, Apronianus 4; Heinzelmann 1982, p. 557). Flavius Memorius, quant à lui, mit pratiquement 40 ans pour devenir finalement commandant des limitanei de la lointaine Maurétanie Tingitane (PLRE, I, p. 595, Memorius 2 ; Heinzelmann 1982, p. 652). De Iulius Atheneus, on ne sait pas s'il a obtenu son perfectissimat par l'exercice de fonctions administratives ou militaires, ou si ce fut le bâton de maréchal d'un notable arlésien en fin de carrière : ce qu'il faut remarquer en revanche, c'est que le fragment de dédicace le dit cur(ante), ce qui le situe derrière le vrai dédicant du monument, d'un rang certainement supérieur, et dont le nom est perdu (PLRE, I, p. 121 ; Heinzelmann 1982, p. 563, A. 2).

Outre tous ces perfectissimes, Paulus est vir praesidialis au plus tôt fin $\mathrm{IV}^{\mathrm{e}} \mathrm{s}$., ce qui indique qu'il a été gouverneur, mais peut-être aussi simplement praeses honoraire, le rang qui en découlait étant le perfectissimat puis un clarissimat déclassé à partir de la fin du $\mathrm{IV}^{\mathrm{e}} \mathrm{s}$. (PLRE, II, p. 851, Paulus 15 ; Heinzelmann 1982, p. 667, P. 3). On remarque au passage que l'épitaphe qu'il a dédiée à son fils Aelianus ne comporte aucune indication de rang ou de niveau social pour le défunt proprement dit, pourtant décédé à 40 ans : d'où la conclusion que le fils n'a pas vraiment réussi à égaler celui de son père (PLRE, II, p. 14, Aelianus 5 ; Heinzelmann 1982, p. 545). Masclinius Maternus était un grand notable de Cologne qui devint sacerdotalis, c'est-à-dire président du concilium de la province de Germanie seconde

9. C'est l'unique attestation de cette fonction : voir à ce propos $C T h, 11,1,6,(354)$ qui évoque le ravitaillement du cellier impérial en Italie, mais à une époque un peu plus tardive, cf VERA (D.) Aureliano, Valentiniano I e il vino del populus Romanus. Antiquité tardive, 13, 2005, p. 247-264.
(PLRE, I, p. 568, Maternus 3; Heinzelmann 1982, p. 648). Il obtint en récompense (avant 352) le rang de comte (sans doute) honoraire - le titre était peu de temps auparavant encore réservé aux clarissimes. Il devint ainsi un honoratus supérieur aux autres curiales de Cologne, mais son rang social réel n'était pas très différent de celui des perfectissimes : simplement, à son époque déjà, le perfectissimat lui-même était en perte de vitesse et moins attractif pour les notables qui se mirent à aspirer à d'autres dignités (Lepelley 1999, p. 642645). Rien n'est dit sur son fils qui dédie l'épitaphe ; aussi doit-on supposer un rang similaire ou (plutôt) inférieur, tant et si bien que la PLRE n'a même pas jugé pertinent de l'intégrer à ses listes (Heinzelmann 1982, p. 635, Leo 1). Geminus (PLRE, I, p. 389, Geminus 2 ; Heinzelmann 1982, p. 614) a visiblement été d'abord praeses honoraire, avant d'exercer un poste dans l'administration financière qui donnait le perfectissimat au moins jusqu'aux années 380, puis le clarissimat au début du $\mathrm{V}^{\mathrm{e}} \mathrm{s}$., lequel clarissimat qualifiait alors un rang social en réalité assez équivalent au perfectissimat un siècle auparavant (Delmaire 1989a, p. 28 ; Delmaire 1989b, p. 178-205).

Si l'on s'attache maintenant au consul ordinaire de 328, Flavius Ianuarinus, on grimpe là soudain à un rang social beaucoup plus élevé que le groupe précédent (PLRE, I, p. 453, Ianuarinus 2 ; Martindale 1980, p. 486 ; Heinzelmann 1982, p. 627). Toutefois, il est inconnu par ailleurs : par principe, une telle obscurité pour un consul ordinaire est un mauvais signe sur son extraction... C'est sans doute cela qui justifie le rapprochement avec un homonyme connu un peu avant, vers 320, et qui avait la fonction de vicaire (PLRE, I, p. 453, Ianuarinus 1). On reconstitue alors le parcours d'un très grand serviteur de Constantin d'origine relativement médiocre, qui aura fait une belle carrière dans l'administration civile avec des fontions importantes, même si la plupart d'entre elles nous échappent, avant d'être récompensé par un très beau et très rare consulat ordinaire ${ }^{10}$. L'épitaphe précise que sa femme Marcia Romana Celsa était $c$ (larissima) $f($ emina $)$, mais il n'est en fait pas possible de dire si elle était d'origine clarissime ou si son clarissimat lui fut accordé en marge de la promotion de son mari (Martindale 1980, p. 480 ; Heinzelmann 1982, p. 577, Celsa 2,).

10. On peut sans doute mettre cette carrière en parallèle avec celles - certes un peu moins brillantes - de deux contemporains qui ont également servi Constantin comme fonctionnaires civils et dont on a la chance de connaître les carrières complètes : PLRE, p. 875-876, Tatianus 4, et PLRE, I, p. 806-808, Saturninus 9. 
Avec le consul ordinaire de 367 Iovinus (PLRE, I, p. 462-463, Iovinus 6 ; Heinzelmann 1982, p. 630, I. 2), on a cette fois-ci un militaire brillant et sans doute politiquement habile, puisque son soutien actif à Julien ne brisa pas sa carrière ni ne l'empêcha d'obtenir de Valentinien le consulat ordinaire. Néanmoins, depuis le milieu du $\mathrm{III}^{\mathrm{e}} \mathrm{s}$., les grands généraux romains n'étaient plus guère issus de grandes familles bien installées, et on assista même à l'ascension de généraux d'origine barbare, tels Nevitta ou Dagalaifus - consuls ordinaires en 362 et 366 et par ailleurs contemporains et collègues de Iovinus. Certaines légendes locales voudraient faire du consul de 367 un Rémois d'origine, mais aucun indice ne pointe en ce sens : la présence de sa tombe à Reims s'explique beaucoup moins par une très hypothétique origine locale que, plus simplement, par le fait que la ville servait à l'époque de quartier général en Gaule. Il n'est pas non plus inutile de noter, au passage, le paradoxe de voir là un général, qui fut l'un des principaux soutiens de Julien dit l'Apostat, dédicacer une église avec une épitaphe composée sur le mode de l'éloge chrétien le plus vibrant. Que ce soit par tactique politique ou par conviction religieuse, Iovinus, à la fin de sa vie, a visiblement affiché ouvertement son (nouveau ?) christianisme, ce qui a certainement aussi contribué à la consolidation de sa situation dans la hiérarchie sociale (Pietri 1970) ${ }^{11}$.

Reste, enfin, un cas un peu à part qui est celui de cet Arlésien sacerdos, Concordius, qui est généralement identifié avec l'évêque du même nom attesté en 374 au concile de Valence. Rien dans l'épitaphe elle-même ne permet de déterminer son origine sociale, et à vrai dire on ne sait pratiquement rien de l'évêque par ailleurs ${ }^{\mathbf{1 2}}$. Toutefois, on notera que la grande qualité des motifs qui décorent son sarcophage en marbre du Proconnèse est de même nature que celle des sculptures qui ornent les sarcophages de la femme de Ianuarinus et de quelques autres (Benoit 1954, p. 35). C'est donc ici surtout par l'addition entre le titre de sacerdos et la richesse du tombeau qu'on en arrive à l'idée que Concordius était un évêque issu d'une famille aisée et désireuse de manifester cette

11. Le consul Iovinus a-t-il pour autant réussi à faire souche ou pas ? Certains le pensent, et la PLRE l'identifie à ce priscus Iovinus mentionné par Sidoine Apollinaire et ancêtre (avus) par sa mère de son ami Consentius de Narbonne (Sidon., Carm, XXIII ; voir en particulier v. 170-177). En revanche, d'autres, comme Martin Heinzelmann, verraient plutôt en Consentius le petit-fils de l'usurpateur Iovinus qui, issu d'une grande famille gauloise, se proclama Auguste en Germanie seconde entre 411 et 413 .

12. Gallia Christiana novissima. Histoire des archevêchés, évêques et abbayes de France, t. 3, Arles, par J.-H. Albanès, Montbéliard, 1900, col. 17-18. situation : de fait, il s'agit là d'un des premiers, sinon du premier, évêques gaulois dont on a conservé le tombeau (Heinzelmann 1976, 66-73 \& Heijmans 2004, p. 247).

Si l'on prend maintenant pour point de comparaison l'album de Timgad, qui renseigne bien sur les hiérarchies sociales d'une petite cité africaine dans les années 360, nos Gaulois appartenaient pour l'essentiel à la frange supérieure de la curie ou se situaient juste au-dessus de cette dernière (Chastagnol 1978, p. 22-28), mais, en dehors des deux consuls, le groupe des clarissimes n'est pas vraiment représenté. En cela, il y a comme un hiatus social dans le corpus épigraphique des élites gauloises entre les perfectissimes et le sommet tout de même exceptionnel atteint par nos deux consuls ordinaires : entre les deux, il manque tout le groupe des clarissimes et sénateurs intermédiaires dont on connaît pourtant la présence en Gaule grâce aux sources littéraires ${ }^{13}$.

La seule exception apparente à cette constatation dans le corpus, le cas de l'Arlésienne Hydria Tertulla $c$ (larissima) $f($ emina $)$, a en réalité plutôt tendance à renforcer mon propos (PLRE, I, p. 882 ; Heinzelmann 1982, p. 700). En effet, le sarcophage en marbre de Carrare et du Proconnèse qu'elle partage avec sa fille Axia Aeliana est dédié par le mari et père Terentius Museus, pour lequel aucune indication de rang n'est inscrite (Benoit 1954, p. 34 ; PLRE, I, p. 611 ; Heinzelmann 1982, p. 654, M. 1) ${ }^{14}$. Deux interprétations sont alors possibles. Soit l'on considère, avec André Chastagnol, que le mariage avait été socialement très inégal et que Terentius Museus n'était ni clarissime ni chevalier, contrairement à sa femme clarissime de naissance ${ }^{15}$ : dans ce cas on devra remarquer qu'entre les deux extrêmes - le groupe des perfectissimes d'une part, les deux consuls de l'autre -, nous ne pouvons identifier que deux femmes clarissimes (Hydria Tertulla et l'épouse de Ianuarinus), pour toute la Gaule, ce qui en soi mettrait largement en exergue

13. Quelques exemples parmi d'autres : Amm., XVI, 8, 8 ; Sulp. Sev., Dial., III, 7, 1-3 ; III, 14, 3-6 ; Sym., Epist., IV, 30, etc. Claudius Lupicinus à la fois clarissime et gouverneur de rang consulaire en 383/388, mais que nous avons écarté du corpus, en serait aussi un exemple.

14. La PLRE date le sarcophage de la deuxième moitié du $\mathrm{III}^{\mathrm{e}} \mathrm{s}$. tandis que Martin Heinzelmann propose la fin du $\mathrm{III}^{\mathrm{e}} \mathrm{s}$ avec un point d'interrogation: cette datation est sans doute influencée par l'établissement d'un lien avec le procurateur Q. Axius Aelianus connu par une inscription de Dacie en $238\left(P I R^{2}, \mathrm{H}, 236\right)$. Se fondant en revanche sur les thèmes iconographiques très chrétiens du sarcophage, Jean-Pierre Caillet date le tombeau du milieu du IV $\mathrm{e}$ (Caillet 1993, p. 134) : il est évident que le lien avec Axius Aelianus est alors plus difficile à proposer.

15. Suivant les règles régissant le mariage des femmes clarissimes : voir Chastagnol 1992, p. 230-231 et 296-297. 
l'absence des hommes de ce même rang dans le matériel épigraphique. Soit, plus vraisemblablement, Terentius Museus était bien clarissime lui-même, voire de rang équestre, mais il n'a tout simplement pas jugé essentiel de faire figurer ce rang sur l'épitaphe de sa femme et de sa fille, se conformant ainsi en quelque sorte à l'usage épigraphique de son groupe social à cette époque : il s'inscrirait alors parfaitement dans le hiatus social qui vient d'être relevé dans la documentation.

Cela amène maintenant aussi à préciser l'idée avancée plus tôt, que le niveau social de notre corpus n'est pas « extraordinaire ». Ce serait, certes, faire une caricature que d'affirmer que ces hommes et femmes n'étaient que des médiocres. Ils ont tous, en effet, sans aucun doute possible, appartenu aux niveaux supérieurs de la société gauloise du $\mathrm{IV}^{\mathrm{e}} \mathrm{s}$.

En revanche, sans négliger le fait déjà signalé qu'un certain nombre n'étaient même pas originaires de Gaule ni implantés dans cette région, aucun - y compris les deux consuls - ne semble correspondre au profil de ces grands chevaliers et clarissimes du Haut-Empire, issus de puissantes familles de notables, qui avaient accumulé localement au fil des générations un capital économique et social très important et qu'on sentait ancrées dans le terroir. Je compare par exemple avec le cas, sans doute un peu extrême, que fut le Viennois Q. Valerius Macedo. Hadrien lui octroya l'adlectio et la questure, mais il déclina pourtant cet honneur. Macedo avait donc une surface sociale suffisante pour attirer l'attention de l'empereur (ou de ses agents) et intégrer l'élite impériale, mais aussi pour s'accorder le luxe de choisir de rester un grand notable à Vienne plutôt que de devenir un sénateur ordinaire à Rome. Il ne fit d'ailleurs pas cela sans un certain snobisme, puisque, s'il déclina l'honneur sénatorial, il autorisa quand même ses clients à inscrire toute l'affaire dans une inscription qui lui fut dédiée : de l'art de se valoriser avec des titres que finalement on n'a pas ${ }^{16}$ ! C'est ce type de profil qui manque dans notre corpus gaulois du $\mathrm{IV}^{\mathrm{e}} \mathrm{s}$., corpus qui semble rester socialement un cran en retrait par rapport à ce sommet de la hiérarchie sociale qu'étaient les clarissimes et, à partir des années 360, les spectabiles et autres illustres.

16. CIL, XII, $1783=I L S, 6998=I L N, 5,1,303: Q($ uinto $)$ Val(erio $)$ C(ai) fil(io) Volt(inia) | Macedoni, | flam(ini) iuvent(utis), q(uaestori) c(oloniae) V(iennensium), | IIvir(o) aer(arii), auguri, | IIIvir(o) $[1($ ocorum $)]$ p(ublicorum) p(ersequendorum). Huic|divos Hadrianus | latum clavom cu $[\mathrm{m}] \mid$ quaest(ura) optuli $[t] \mid$ et petentis | excusationem acc[epit].| Vicani Boxs[ani] | et Noiomagens[es]|patrono.
Notre perception sociale est peut-être erronée ou faussée, mais tout semble indiquer que, pour la plupart des grandes familles gallo-romaines de rang sénatorial, l'épigraphie n'était pas vraiment un moyen de se mettre en valeur au $\mathrm{IV}^{\mathrm{e}} \mathrm{s}$. En tout cas, on ne connaît pour la Gaule de cette époque rien de comparable aux inscriptions de ces grandes familles italiennes et romaines qui fleurissent à la même époque et qui vantent longuement, au-delà des carrières proprement dites, les mérites et les vertus des membres de ce que l'on nomme couramment l'aristocratie sénatoriale romaine.

Cela ne signifie pas que ces grandes familles galloromaines ne se mettaient pas en scène, mais, pour la plupart d'entre elles, elles ne le faisaient pas au moyen de l'épigraphie. Par exemple, à Arles, le texte de l'épitaphe datée du IV ${ }^{\mathrm{e}} \mathrm{s}$. d'Optatinia Reticia sive Pascasia, dédiée par son époux Ennius Filterius sive Pompeius, n'attire en rien l'attention ${ }^{17}$. Et le couple est d'ailleurs ignoré par les grandes prosopographies des élites - rien dans la PLRE ni dans Heinzelmann 1982. C'est le monument où elle figure qui était en réalité socialement signifiant, puisqu'il s'agit d'une partie de couvercle de sarcophage en marbre importé de Carrare, finement décorée de représentations de scènes de l'Ancien Testament et qui donne une petite idée de ce qu'avait été le sarcophage initial. C'est donc le coût du monument et son degré de finition qui indiquent que ce couple appartenait très certainement aux élites d'Arles, même s'il n'est pas possible de dire exactement avec quel rang ${ }^{18}$. Autres exemples, le sarcophage de Marcia Romana Celsa, la femme du consul Ianuarinus, a été découvert en 1974 en compagnie de deux autres sarcophages décorés, datés de la même époque, mais sans inscriptions, qu'on appelle depuis sarcophage «de la Trinité » ou «des époux » et sarcophage « de la chasse » (Rouquette 1974). Dans les deux cas, il est évident qu'on a aussi des sépultures de membres des élites; le sarcophage «des époux» paraît même être la tombe d'un couple de clarissimes. Pourtant, les cartouches en forme de médaillon sont vides d'inscriptions. Cela ne signifie pas nécessairement

17. CIL, XII, 956 : Optatin(a)e Retici|ae sive Pascasi(a)e, coni|ugi amantissimae, En|nius Filterius sive|Pompeius maritus | posuit sepulcru|m, cum qua vixit $\mid$ annis octo men|sibus novem et $\mid$ diebus duobus.

18. Certains considèrent que tout sarcophage décoré avec inscription marque la sépulture d'un membre des élites (par exemple Wood 1996, p. 14), mais Noël Duval reste un peu plus prudent sur la question du prix et par conséquent des commanditaires de sarcophages (Duval 1993, p. 34) ; voir aussi Dresken-Weiland 2003, p. 307, qui suppose un niveau social élevé de la grande majorité des commanditaires (mais semble également osciller un peu sur cette question, puisqu'un peu plus loin, p. 312, il n'y a plus de lien évident entre le rang social et le choix de l'inhumation en sarcophage). 
qu'ils l'ont toujours été. Il est probable que les commanditaires de ces monuments funéraires ont fait peindre des textes assez brefs dans ces cartouches, mais, à la différence de Ianuarinus, sans les faire graver: au fil des années, les pigments sont partis et les inscriptions se sont évanouies. Toutefois, le choix même de la peinture, seule et sans gravure, révèle que ces riches commanditaires n'accordaient tout simplement pas une importance prépondérante aux inscriptions elles-mêmes, dont ils savaient pertinemment bien, consciemment ou non, qu'elles allaient assez rapidement disparaître si elles n'étaient pas gravées dans la pierre ${ }^{19}$. Ainsi, dans deux sarcophages sur trois découverts, le faible soin apporté au texte et surtout à sa longévité tranche avec celui apporté au monument lui-même ${ }^{20}$. Ce point est capital, car la présence durable ou non d'écrits sur ces sarcophages, ou d'autres monuments, affecte toute la dimension mémorielle de ces objets ${ }^{21}$.

\section{Une rupture au $\mathrm{V}^{\mathrm{e}} \mathrm{s}$. : la tombe du grand-père de Sidoine Apollinaire}

Ainsi donc, si on se limite à la documentation épigraphique, on peut légitimement se demander où sont ces grandes familles gallo-romaines $\mathrm{du} \mathrm{IV}^{\mathrm{e}} \mathrm{s}$. dont on a pourtant conservé bien des traces dans d'autres sources (Sivan 1993a ; Balmelle, Van Ossel 2001). Où sont les Ausone et autres Lachanius? Mon propos n'est toutefois pas d'entrer dans la longue discussion sur les origines

19. On retrouve bien ce rapport particulier à l'épigraphie avec le sarcophage de Tolosanus, dont le texte est « manifestement secondaire » (Heijmans 2004, p. 381).

20. Impossible de dire si cette proportion de deux sur trois est significative de quelque chose ou pas. Balmelle, Van Ossel 2001, p. 549, notent le caractère anépigraphe des nombreux sarcophages d'Aquitaine et les difficultés à déterminer pour qui ces derniers avaient été réalisés.

21. Dans un article qui résume une vaste recherche, Jutta DreskenWeiland exprime l'avis que les inscriptions et décorations éventuelles des sarcophages, païens comme chrétiens, s'adressaient généralement aux morts et non aux vivants (Dresken-Weiland 2003). Elle conclut que « les personnes qui pouvaient se permettre une telle sépulture étaient plus intéressées par l'inhumation dans un sarcophage que par la décoration de ce dernier. Ils étaient assez indifférents au spectateur. » (p. 319). Il est sûr que dans cette perspective, la dimension mémorielle de ces monuments et de leurs inscriptions serait assez réduite. Même si cette étude soulève des questions importantes, je ne suis pourtant guère convaincu par la démarche et ses conclusions : par exemple, à propos de la question des sarcophages avec inscription à l'intérieur (tout de même très peu nombreux dans l'ensemble des sarcophages conservés), il me paraît assez périlleux de vouloir mettre en série l'épitaphe d'un sénateur mort en 13 av. J.-C. et celle d'un évêque du $\mathrm{IV}^{\mathrm{e}} \mathrm{s}$. pour appuyer l'argumentation. des grandes familles gallo-romaines tardives ${ }^{22}$, mais seulement de relever cette absence de visibilité épigraphique de ceux qui dominaient la société gallo-romaine au $\mathrm{IV}^{\mathrm{e}} \mathrm{s}$., afin de pointer le contraste majeur avec la situation des $\mathrm{V}^{\mathrm{e}}$ et $\mathrm{VI}^{\mathrm{e}} \mathrm{s}$.

À cette époque-là, en effet, à rebours d'une pratique épigraphique dont le déclin s'accélère, la Gaule - et cette fois singulièrement la Gaule méridionale - devient ainsi (relativement) riche d'inscriptions qui évoquent des individus dont certains gravitent dans des sphères qui paraissent bien plus implantées et élevées que celles du corpus du IV ${ }^{\mathrm{e}} \mathrm{s}$. Il s'agit non seulement de tous ces évêques étudiés par Martin Heinzelmann, mais encore de laïcs comme Dardanus, le fondateur de Theopolis vers 410, de Pantagathus de Vaison-la-Romaine qui décéda en 515, peut-être de Petrus d'Arles mort en 530, et, bien entendu, d'Apollinaris, grand-père de Sidoine Apollinaire et préfet des Gaules en 408 dont il va bientôt être question.

La majorité de ces inscriptions plus tardives sont des épitaphes métriques assez longues et souvent plutôt bien faites : pendant longtemps le carmen funéraire de Sidoine Apollinaire, connu d'abord par un manuscrit $\mathrm{du} \mathrm{X}^{\mathrm{e}} / \mathrm{XI}^{\mathrm{e}} \mathrm{s}$., a paru trop bien composé pour que certains lui attribuent une datation antérieure à l'époque carolingienne (RICG, VIII, 21). Toujours liées à la religion chrétienne d'une manière ou d'une autre, ces inscriptions insistent sur les hautes origines du défunt, ses vertus, ses fonctions laïques et/ou religieuses, même si ces derniers éléments n'apparaissent souvent que de manière allusive. On perçoit alors le développement d'un véritable mouvement de mise en valeur par l'épigraphie profondément différent de ce qu'on a pu observer au IV ${ }^{\mathrm{e}}$ s., même si l'épitaphe rémoise de Iovinus, longue, métrique, liée à un monument religieux et qui assume ostensiblement être plus portée sur la valorisation des qualités - ici très religieuses - du défunt que sur l'évocation précise de sa carrière publique était peut-être déjà un précurseur de ce nouveau style épigraphique qui a pris de l'ampleur aux $\mathrm{V}^{\mathrm{e}}$ et $\mathrm{VI}^{\mathrm{e}} \mathrm{s} .{ }^{23}$.

C'est désormais cette transition d'une pratique épigraphique vers une autre que je propose d'explorer à partir du cas de la famille de Sidoine Apollinaire, car il me semble qu'une anecdote ou plutôt un fait divers

22. Étude détaillée de cette question par Hagith Sivan qui mentionne plusieurs des personnes dont il est question ici.

23. Je préfère privilégier l'idée de mouvement plutôt que celle de politique de mise en valeur : il y a dans le second terme une dimension volontaire et calculée que je ne perçois pas. 
raconté dans une lettre de Sidoine présente un jalon dans ce processus de transformation des pratiques épigraphiques des élites gauloises tardives (Sidon., Ep., III, 12). La lettre en question est datée (sans doute) de 469 et elle est adressée à son neveu Secundus - inconnu par ailleurs - qui réside à Lyon.

Sidoine est alors au sommet de sa gloire : il vient d'exercer la préfecture de la Ville à Rome l'année précédente et il est devenu patrice (PLRE, II, p. 115-118, Apollinaris 6 ; Heinzelmann 1982, p. 556, A 3). Devant se rendre à Clermont, il quitte Lyon et prend la route de la ville des Arvernes. À quelques distances de cette route se trouve la nécropole abandonnée où repose son grandpère qui fut préfet des Gaules en 408. Or, que voit-il de loin, horrifié ? Des fossoyeurs sont en train de réoccuper le site!

« Le champ funéraire où il repose, rempli depuis des années tant de cendres funéraires que de corps, ne recevait plus depuis longtemps de nouvelles fosses ; mais la terre qui surmonte la tombe des morts avait repris son niveau primitif, désagrégée par le poids de la neige ou par l'action continuelle des pluies sur les tertres croulants : c'est la raison pour laquelle les croque-morts (baiuli), regardant l'emplacement comme disponible, eurent l'audace de le souiller de leurs bêches funestes. Bref! déjà le gazon vert disparaissait sous la terre noire; déjà des mottes toutes fraîches recouvraient l'antique tombeau [...]. » (Ep., III, 12, 1-2 ; trad. Loyen)

Comme il le raconte lui-même, le sang du patrice ne fait alors qu'un tour et il se précipite au galop pour mettre in extremis un terme au forfait. Le récit est assez savoureux, dramatisé à souhait, et on n'insistera sans doute jamais assez sur le hasard absolument extraordinaire de la situation décrite : les croque-morts sont passés à l'action au moment précis où Sidoine est sorti de Lyon, réussissant donc l'exploit de fâcher contre eux l'un des individus les plus puissants - peut-être le plus puissant - de la région ! Est-il besoin d'ajouter que lesdits fossoyeurs ont ensuite passé un mauvais quart d'heure ? Visiblement pressé, Sidoine reprend alors sa route pour Clermont, mais prend aussi le temps de contacter trois personnes à Lyon pour régler définitivement cette affaire.

Il y a en premier lieu un problème juridique à régler si possible rapidement. C'est pourquoi, encore en route, Sidoine écrit d'abord à l'évêque de Lyon afin de s'excuser d'avoir empiété sur la juridiction en punissant lui-même sur le champ les fossoyeurs, plutôt que de les déférer devant lui. On pouvait s'y attendre : l'évêque absout Sidoine et lui donne raison, le flagrant délit, le rang de son interlocuteur ainsi que sa courtoisie lui laissant sans doute peu d'autres options.

Vient ensuite le problème toujours en suspens de la tombe de l'aïeul qui tourmente encore Sidoine. Afin de le régler, il souhaite faire restaurer la tombe et y installer une pierre gravée d'un carmen funéraire. Pour cela, distinguant les tâches, il charge dans un premier temps un certain Gaudentius de s'occuper matériellement de cette pierre et sans doute de son installation. Puis, peu après, il écrit à son neveu pour lui transmettre le texte du carmen à graver sur la pierre, avec la responsabilité de contrôler la réfection de la tombe, et surtout de vérifier que le lapicide n'a pas commis d'erreur lors de la gravure :

Serum post patruos patremque carmen / haud indignos avo nepos dicavi, I ne fors tempore postumo, viator, / ignorans reverentiam sepulti / tellurem tereres inaggeratam. I Praefectus iacet hic Apollinaris, I post praetoria recta Galliarum / maerentis patriae sinu receptus, / consultissimus utilissimus / ruris, militiae forique cultor, / exemploque aliis periculoso I liber sub dominantibus tyrannis. / Haec sed maxima dignitas probatur, I quod frontem cruce, membra fonte purgans / primus de numero patrum suorum / sacris sacrilegis renuntiavit. / Hoc primum est decus, haec superbia virtus, /spe praecedere quos honore iungas, / quique hic sunt titulis pares parentes, / hos illic meritis supervenire.

«Petit-fils non indigne de mon grand-père, je lui ai consacré, après mes oncles et mon père, ce poème tardif, pour qu'à l'avenir tu n'ailles point, voyageur, ignorant le respect dû à ce mort, fouler la terre de ce tertre. Ici gît le Préfet Apollinaris, qui, après avoir géré la préfecture du prétoire des Gaules, a été reçu dans le sein de sa patrie en larmes. Profondément versé et efficace dans les choses de la terre, du service public et du barreau, il les cultiva tous, et, par un exemple périlleux pour d'autres, resta libre sous le règne des tyrans. Mais le plus grand mérite qu'on lui reconnaisse, c'est d'avoir été le premier, de toute la lignée de ses ancêtres, en purifiant son front par le signe de la croix, son corps par l'eau du baptême, à renoncer à un culte sacrilège. La première gloire, la vertu par excellence, c'est de surpasser en espérance ceux qui vous égalent par le rang et de venir là-haut par ses mérites au-dessus de ceux qui sont ici-bas vos parents égaux par les titres. » (Ep., III, 12, 5 = CIL, XIII, 2352 ; trad. Loyen)

Il en profite ensuite pour émettre également un commentaire sur cette nouvelle épitaphe : 
«Certes, je sais que la qualité de l'épitaphe n'est pas digne de la science de notre ancêtre, mais l'âme d'un homme cultivé ne rejette pas un chant offert aux mânes. Il convient qu'à toi non plus ne paraisse pas trop tardive la dette que nous acquittons comme héritiers à la troisième et quatrième génération, quand nous avons appris à l'école qu'un cycle de tant d'années s'écoula avant qu'Alexandre le Grand sacrifiât aux mânes d'Achille et que Jules César rendît les honneurs funèbres à Hector, comme à l'un de ses ancêtres. » (Ep., III, 12, 6 ; trad. Loyen)

Il est remarquable que Sidoine a choisi de conserver la lettre à Secundus en l'incluant dans la publication de sa correspondance, contrairement à la lettre adressée à l'évêque qui n'a pas été préservée. Cette anecdote avait donc à ses yeux une importance suffisante pour être transmise, et sa relation est pour nous riche d'enseignements sur les pratiques funéraires et épigraphiques d'une des grandes familles gallo-romaines $\mathrm{du} \mathrm{V}^{\mathrm{e}} \mathrm{s}$.

Rappelons d'abord qu'en 469 ladite famille est illustre depuis longtemps, au moins un siècle environ. Le père anonyme de Sidoine fut préfet des Gaules en 448-449 (PLRE, II, p. 1220, Anonymus 6), le grand-père Apollinaris occupa un poste similaire en 408 (PLRE, II, p. 113, A 1 ; Heinzelmann 1982, p. 556, A 1), et le père de ce dernier, à nouveau un anonyme pour nous, aurait aussi exercé des responsabilités importantes et qui restent imprécises dans le dernier quart du $\mathrm{IV}^{\mathrm{e}} \mathrm{s}$.

Au moment de son décès, Apollinaris n'avait donc rien d'un homme nouveau et, pourtant, on observe avec surprise que la tombe du préfet des Gaules de 408 était complètement anonyme au milieu des autres dans cette fameuse nécropole lyonnaise : si les fossoyeurs avaient été conscients qu'ils étaient sur le point d'attaquer la sépulture d'une famille contemporaine aussi connue et aussi puissante, il est certain que leur instinct de conservation les aurait promptement incités à vite aller creuser ailleurs. Cette tombe portait-elle au moins une pierre qui aurait pu l'identifier? Manifestement non, et il n'y a pas de raison de croire qu'il y en ait jamais eu une. Sidoine n'en mentionne pas et explique sans l'occulter la véritable raison de l'erreur tragique des fossoyeurs : au fil du temps le tertre de la tombe a tout simplement disparu, aplani par des intempéries qui n'auraient certainement pas altéré une stèle. On peut d'ailleurs aussi raisonnablement estimer que, si les fossoyeurs avaient ignoré l'avertissement qu'aurait constitué une quelconque stèle, Sidoine ne se serait pas privé de l'indiquer dans sa relation, comme circonstance aggravante de la violation de sépulture. Cette violation n'était donc en réalité pas aussi évidente que cela dans les faits tels qu'ils sont rapportés, les coupables pouvant plaider leur bonne foi.

Ce qu'il y a d'important à retirer dans tout cela, c'est la constatation que, dans cette puissante et ancienne famille, la génération qui a précédé Sidoine (et enterré Apollinaris) admettait parfaitement l'idée qu'une sépulture de préfet des Gaules puisse être équivalente à celle d'un simple quidam ${ }^{24}$. Mieux, la mention du tertre montre qu'on ne faisait pas de tombe destinée à marquer le paysage ni même à durer dans le temps : clairement, avant Sidoine, aucun effort n'avait été consenti au fil des années pour restaurer le tertre qui s'affaissait. Dans la mesure où il est question d'une famille qui, économiquement, aurait pu financer tout type de monument, tout cela implique qu'on avait accepté, de manière plus ou moins consciente, l'idée qu'à terme la tombe allait disparaître.

Cette acceptation d'une tombe anonyme et éphémère était-elle ancienne ou non? On pourrait arguer qu'Apollinaris était le premier chrétien de la famille et qu'il s'est peut-être conformé aux recommandations de plus d'un théologien de l'époque vantant la modestie dans la mort, mais l'argument n'est guère convaincant : notre corpus du $\mathrm{IV}^{\mathrm{e}} \mathrm{s}$. ne concerne-t-il pas essentiellement des chrétiens (Lauwers, Treffort 2009)? En outre, la discrétion évidente de la tombe d'Apollinaris fait directement écho à une constatation archéologique plus large, à savoir que les rapports sociaux apparaissent peu dans les sépultures tardives, tout comme «la topographie sociale de la mort» nous échappe encore pour cette époque (Raynaud 2006, p. 144 ; L'inhumation privilégiée, p. 10-11) ${ }^{25}$. Tous ces éléments incitent donc à estimer que la manière de gérer la tombe d'Apollinaris correspondait non pas à une innovation ou à une décision ponctuelle, mais bien à la prolongation de la tradition familiale en la matière - en tout cas au moins jusqu'à la génération de Sidoine Apollinaire.

D'un autre côté, Sidoine et peut-être son neveu et correspondant étaient tout à fait capables d'identifier le lieu de cette tombe devenu quasi invisible, et sans doute

24. L'affaire de la tombe d'Apollinaris est assez connue pour être régulièrement citée (par exemple dernièrement : Pietri 1986, p. 136 ; Wood 1996, p. 13 ; Raynaud 2006, p. 137-139). Les commentaires, assez brefs, se limitent néanmoins en général à constater la situation et à s'intéresser à la génération de Sidoine, sans la mettre en rapport avec ce qu'avait fait la génération précédente.

25. Ce qui ne signifie cependant pas qu'il n'y avait absolument pas de différences dans les sépultures (et les spécificités funéraires locales) : pour un exemple du $\mathrm{IV}^{\mathrm{e}} \mathrm{s}$., voir le bilan récent des fouilles de la nécropole de Lisieux (Paillard et al. 2009). 
longtemps après l'inhumation. Cela signifie donc que, depuis les funérailles - auxquelles Secundus n'avait d'ailleurs sans doute pas lui-même assisté -, la tombe d'Apollinaris était demeurée un «lieu de mémoire» familial ${ }^{26}$. Cependant, ce lieu appartenait exclusivement à la géographie intime de cette famille et de ses proches, une géographie que Sidoine et les siens ne partageaient pas avec leurs contemporains et qui n'avait aucune dimension publique ${ }^{27}$. Corollaire de tout cela, la sépulture n'avait pour cette famille aucune fonction de marqueur social.

Bref, jusqu'à Sidoine, sa famille n'a pas cherché à mettre en scène sa puissance à travers la sépulture du préfet des Gaules de 408, a fortiori à travers son épitaphe inexistante : on retrouve là une situation qui est directement dans la ligne de ce que nous avions constaté à propos de la discrétion épigraphique des élites galloromaines au $\mathrm{IV}^{\mathrm{e}} \mathrm{s}$.

\section{Manifestation de la hiérarchie sociale et mémoire familiale}

Or, il est manifeste que Sidoine Apollinaire a très consciemment rompu avec cette pratique familiale ${ }^{28}$. Sa lettre à Secundus montre en effet que s'est imposée à lui l'idée non seulement de restaurer le tertre, mais bien de garantir la longévité de la tombe, en particulier par l'adjonction d'une inscription funéraire soigneusement

26. Martin Heinzelmann a très justement souligné l'importance, pour la vie sociale des familles, des funérailles proprements dites, indépendamment de la longévité de la tombe ou des accessoires qu'on pouvait y mettre (L'inhumation privilégiée, p. 52, en marge d'une intervention d'Alain Dierkens sur les tombes privilégiées tardives de Belgique) ; idée développée par Michel Lauwers et Cécile Treffort qui insistent sur la distinction à faire dans les pratiques funéraires entre ce qui était de l'ordre de l'éphémère et ce qui allait être durable, mais aussi entre ce qui était visible et ce qui n'était pas voué à le rester (Lauwers, Treffort, 2009, p. 443-444).

27. À la différence du tombeau lyonnais (conditorium) du consul de 382 Flavius Afranius Syagrius qui, deux générations après sa mort, pouvait servir à l'occasion de point de chute pour les élites locales, et qui était situé à quelques pas de l'église des Maccabées (qui abritait depuis 390 environ le tombeau de Saint Just), comme le rapporte Sidoine (Ep., V, 17, 4, datée sans doute de 469). La lettre de Sidoine est cependant muette quant à la manière dont se présentait cette tombe, qui avait visiblement surtout pour caractéristique d'être $a d$ sanctum : était-elle monumentale (éventuellement avec inscription) ou bien n'était-elle devenue qu'un lieu-dit, du fait de sa proximité avec le tombeau du saint?

28. Contra: «Vieille habitude que cette célébration écrite, destinée autant à la mémoire du défunt qu'à la notoriété de ses descendants, qu'il importe de signifier au passant. Ainsi se perpétuent les pratiques de la piété ostensible qui depuis les siècles de la République entouraient la sépulture. » (Raynaud 2006, p. 139). composée. On perçoit là une sensibilité nouvelle qui enjoint, beaucoup plus que par le passé, de préserver la tombe, et aussi, de facto, le corps qui y repose. Cela amènerait évidemment à s'interroger sur la raison de tous ces efforts nouveaux, auxquels les générations précédentes n'avaient pas consenti, mais, à quinze siècles de distance, il ne nous est guère possible ici de sonder les cœurs dans cette affaire; on peut seulement faire quelques observations.

La première concerne la tombe elle-même. Le but affiché de la réfection et surtout de la pierre gravée est de s'assurer contre tout nouveau risque de violation de sépulture. Toutefois, en monumentalisant ainsi la tombe, cette dernière change en quelque sorte de nature en abandonnant son invisibilité, ce qui, mécaniquement, hiérarchise socialement l'espace funéraire où elle se situe (Lauwers, Treffort 2009, p. 440-442). Nulle part le futur évêque Sidoine n'évoque en effet la sécurité des tombes voisines de celle de son grand-père : alors qu'auparavant cet espace funéraire était égalitaire, pourrait-on dire, il y a désormais la tombe d'Apollinaris, qui a vocation à perdurer, et l'ensemble des tombes ordinaires, qui sont condamnées à l'oubli.

Les fossoyeurs sauront désormais à l'avenir de manière claire qu'il ne faut pas toucher à cette tombe-ci. Néanmoins, que penser de l'inscription? Il est douteux que ces croque-morts de la fin $\mathrm{du} \mathrm{V}^{\mathrm{e}} \mathrm{s}$. aient été aptes à lire et surtout à apprécier une longue épitaphe métrique comme celle que Sidoine fait graver. On en déduit alors que ce qui doit les retenir à l'avenir, c'est le monument lui-même : une pierre de taille respectable ainsi qu'un texte gravé garantiront que repose à cet endroit un individu important et puissant qu'il convient de ne pas déranger. Paradoxalement, cette inscription s'adresse donc sans doute aussi aux illéttrés : la taille du texte, quel que soit son contenu, fonctionnera très bien comme un marqueur culturel, avec le sous-entendu qu'une pierre, même relativement simple, comportant autant de mots et de lettres, ne peut appartenir qu'à une famille importante. En propre, l'inscription même deviendrait un document d'histoire de l'art, indépendamment du contenu du texte lui-même.

Mais il n'y a pas là qu'une mesure conservatoire. L'épitaphe s'adresse en effet à un autre public que les illettrés quand elle vante les mérites privés et publics du défunt ainsi que son attitude religieuse : pour celui qui savait lire, elle faisait la publicité à la fois et du rédacteur du carmen. Ce dernier instaure un dialogue avec les éventuels passants, curieux de découvrir ce que cette pierre avait à leur proposer et appartenant aux happy few 
capables de goûter ce texte. Il serait d'ailleurs intéressant de savoir si cette pierre était dressée ou couchée, malheureusement... ${ }^{29}$

Cependant le public naturel et privilégié de cette épitaphe me semble être surtout la propre famille de son rédacteur, car la question familiale est centrale dans cette lettre à Secundus: le carmen lui-même inclut un commentaire sur le rapport entre les générations, même si le nom de Sidoine Apollinaire est absent. La dimension mémorielle de la tombe d'Apollinaris est en effet fortement renforcée par la pierre et son inscription. Jusqu'alors la tombe n'était destinée à durer qu'une ou deux générations, le temps, sans doute, que ceux qui avaient connu le défunt s'effacent à leur tour. En la restaurant au moment où elle aurait normalement dû disparaître, Sidoine Apollinaire relance un nouveau cycle de vie pour ce qui, de lieu de mémoire temporaire, devient maintenant un vrai monument familial, destiné à préserver pour les générations ultérieures le souvenir du fait qu'Apollinaris avait été préfet des Gaules et premier de sa famille à se convertir au christianisme. C'est là une manière à la fois de faire la publicité de sa famille et de mettre sur la place publique, sur un support durable, plusieurs éléments importants des archives familiales.

À vrai dire, la décision d'installer cette pierre gravée au nom de la piété envers les anciens place Sidoine dans une situation un peu délicate. En effet, tout le discours sur les devoirs envers le grand-père pourrait être interprété comme une critique de la génération intermédiaire, coupable de ne pas avoir tout entrepris pour la tombe d'Apollinaris. On perçoit bien cette gêne chez Sidoine Apollinaire à travers le soin qu'il met dans sa lettre à justifier sa démarche auprès de Secundus, afin d'emporter l'adhésion de celui-ci ; un Secundus qui luimême n'a certainement pas connu celui qui avait été son arrière-grand-père. Dans le fond, Sidoine innove. Il doit donc se justifier auprès de son parent de ce non-respect de la tradition familiale en la matière. La manière d'y arriver est d'ailleurs assez classique ; pour excuser le caractère tardif de son hommage épigraphique funéraire, il renvoie tout simplement à des exemples illustres et anciens que Secundus partage avec lui : l'hommage, par delà les siècles, d'Alexandre le Grand

29. Contra (sans doute): Jutta Dresken-Weiland soulevait la question du public auquel étaient destinées les inscriptions des sarcophages (Dresken-Weiland 2003 ; voir supra n.21). Il faudrait en fait élargir la question à l'ensemble de l'épigraphie funéraire : en tout cas il ne me paraît pas que l'épitaphe d'Apollinaris composée par Sidoine Apollinaire ait été destinée au défunt. à Achille (cf Cic. Arch., 24) et celui de César à Hector (cf. Luc. IX, 974-977). Ainsi, plutôt que de dénoncer la tradition léguée par son père (ce qui serait une impiété), il l'éclipse par une tradition supérieure dont il s'institue l'héritier. Décision qu'il a assumée pleinement : après tout, c'est lui qui a pris la décision de faire la publicité de cette affaire en faisant le choix d'insérer cette lettre dans sa correspondance publiée. L'argumentation de Sidoine a d'ailleurs dû porter, puisque lui aussi a bénéficié à la fin de sa vie d'un beau et grand carmen funéraire à Clermont.

Si l'on rassemble maintenant les éléments de ce dossier, on observera que la pratique épigraphique de la famille de Sidoine Apollinaire correspond d'assez près à ce que l'on observe par ailleurs plus généralement pour l'épigraphie des élites gauloises des $\mathrm{IV}^{\mathrm{e}}$ et $\mathrm{V}^{\mathrm{e}} \mathrm{s}$. Si on accepte de lui donner un caractère représentatif, on a peut-être là un aperçu partiel sur la transition vers les pratiques épigraphiques du $\mathrm{V}^{\mathrm{e}}$ et $\mathrm{VI}^{\mathrm{e}} \mathrm{s}$ : d'abord un certain désintérêt puis une réappropriation du média qu'était l'épigraphie, en particulier funéraire, dans la moitié sud de la Gaule. La façon dont ces élites méridionales se percevaient ou percevaient leurs relations avec leur environnement social a indubitablement changé, par rapport au siècle précédent et aussi par rapport à ce qui se passait dans la partie septentrionale. Est-ce lié à la recomposition de ces élites, due elle-même à la christianisation, aux mouvements de populations et à l'effondrement de l'Empire romain ? En tout cas, en mobilisant les morts, à travers l'épigraphie et de nouvelles pratiques funéraires, ces élites méridionales ont manifesté plus ouvertement la hiérarchie sociale et leur domination, en exposant d'une nouvelle manière leur différence et en préservant leur nom de l'oubli ; tout cela- et paradoxalement -en contradiction flagrante avec l'humilité requise par le christianisme que leurs inscriptions affichaient.

Un dernier mot : l'innovation de Sidoine a finalement été au moins partiellement payante. Quinze siècles plus tard, en effet, cette nouvelle manière de mettre en scène les morts et leur souvenir a réussi à sauver de l'oubli le nom de son grand-père et ses titres les plus glorieux. Néanmoins, cette stratégie mémorielle a également bénéficié d'une ruse de l'Histoire, qu'on a parfois un peu tendance à négliger. Car si cette épitaphe a bien été conservée à travers les siècles, c'est de manière indirecte et sur un autre support : malgré les efforts de Sidoine, le matériau funéraire a péri, ou bien se trouve aujourd'hui inaccessible, enterré ou intégré à quelque mur lyonnais. Ce qui a permis à ce texte de résister au temps est sa transposition épistolaire. C'est sans doute une certaine fierté envers sa création qui a poussé Sidoine à intégrer 
le carmen à la publication de sa correspondance : d'écrit épigraphique, il est donc devenu littéraire et a été préservé comme tel. Avait-il alors en tête l'avertissement de Martial ?

Impossible désormais à la renommée de me donner davantage : partout mon livre est dans toutes les mains. Et lorsque les pierres de Messala ne seront plus que des débris et que le marbre orgueilleux de Licinius ne sera plus que poussière, il y aura encore des bouches pour déclamer mes vers, et bien des étrangers les rapporteront au séjour de leurs pères. (VIII, 3, 6 ; trad. Izaac)

Force est de constater que de nombreuses autres inscriptions tardives du même type ont suivi un chemin similaire, en particulier beaucoup d'épitaphes d'évêques. Qu'on se rappelle ainsi le carmen consacré au général Flavius Iovinus, que nous considérions dans notre corpus du $\mathrm{IV}^{\mathrm{e}} \mathrm{s}$. comme un précurseur de ce qui allait se passer au siècle d'après : l'église rémoise où il se situait a disparu, mais il est malgré tout parvenu jusqu'à nous par le biais d'un intermédiaire, Flodoard, qui l'avait entretemps trouvé remarquable et transcrit dans son œuvre. Exactement le chemin qu'a suivi l'épitaphe de Sidoine Apollinaire. Ce ne sont certainement pas les quelques fragments découverts à Clermont en 1991 qui auraient pu permettre de reconstituer le texte de l'épitaphe (Montzamir 2003). Si nous la possédons toujours, c'est bien parce qu'un copiste du $\mathrm{X}^{\mathrm{e}}$ ou du $\mathrm{XI}^{\mathrm{e}} \mathrm{s}$. a jugé bon et souhaitable de la transcrire en marge d'un manuscrit de l'œuvre de l'évêque de Clermont (Prévot 1993, p. 223). Et rien ne dit qu'il n'y a pas eu encore un autre intermédiaire encore entre la pierre proprement dite et ce copiste anonyme. Ces remarques ajoutent un nouvel élément au débat séculaire sur l'articulation entre littérature et épigraphie, particulièrement épineux, par exemple, à propos des épitaphes dites «littéraires » de Venance Fortunat, mais c'est là un autre sujet.

\section{Bibliographie}

Les corpus épigraphiques sont indiqués par les sigles utilisés par L'Année épigraphique, les sources littéraires sont citées avec les abréviations du nouveau Gaffiot.

Balmelle, Van Ossel 2001 : BALMELLE (C.), VAN OSSEL (P.) - De Trèves à Bordeaux. La marque des élites dans les campagnes de la Gaule romaine aux IV et $\mathrm{V}^{\mathrm{e}}$ siècles. In : Ouzoulias (P.), Pellecuer (Chr.), Raynaud (Cl.), van ossel (P.), Garmy (P.) dir., Les campagnes de la Gaule à la fin de l'Antiquité, Actes du IV ${ }^{e}$ colloque de l'association AGER, Montpellier, 11-14 mars 1998, Antibes, Éditions APDCA, 2001, p 535-552.

Benoit 1954: BENOIT (F.) - Sarcophages paléochrétiens d'Arles et de Marseille, Paris, CNRS, 1954, 88 p., 49 pl. (Supplément à Gallia, V).

Burnand 2006 : Burnand (Y.), Primores Galliarum. - Sénateurs et chevaliers romains originaires de la Gaule de la fin de la République au III siècle, II, Prosopographie, Bruxelles, Éd. Latomus, 2006, 630 p. (Collection Latomus 302).

Burnand 2008 : Burnand (Y.), Primores Galliarum - Sénateurs et chevaliers romains originaires de la Gaule de la fin de la République au III siècle, III, Étude sociale, 2. Les horizons de vie, Éd. Latomus, Bruxelles, 2008, 382 p. (Collection Latomus 319).

Caillet 1993 : CAILLET (J.-P.) - Les sarcophages chrétiens en Provence (III ${ }^{\mathrm{e}}-\mathrm{V}^{\mathrm{e}} \mathrm{s}$.). Antiquité tardive, 1, 1993, p. 127-142.

Chastagnol 1978 : CHASTAGNOL (A.) - L'album municipal de Timgad, Bonn, Habelt, 1976, 109 p., 16 p. de pl.

Chastagnol 1992 : CHASTAGNOL (A.) - Le Sénat romain à l'époque impériale, Paris, Les Belles Lettres, 1992, 484 p.

Chastagnol 1995: CHASTAGNOL (A.) - Le chrisme des tablettes de patronat. In : Orbis Romanus Christianusque ab Diocletiani aetate usque ad Heraclium. Travaux sur l'Antiquité Tardive rassemblés autour des recherches de Noël Duval, Paris, De Boccard, 1995, 322 p., p. 33-39.

Delmaire 1989a : DELMAIRE (R.) - Les responsables des finances impériales au Bas-Empire romain (IV $V^{e} V I^{e} \quad$ s. .). Études prosopographiques, Bruxelles, Éd. Latomus, 1989, 321 p. (Collection Latomus 203).

Delmaire 1989b: DELMAIRE (R.) - Largesses sacrées et res privata. L'aerarium impérial et son administration du IVe au VI e siècle, Rome, École française de Rome, 1989, XVII-759 p. (Collection de l'École française de Rome 121).

Dresken-Weiland 2003: DRESKEN-WEILAND (J.) - Recherches sur les sépultures paléochrétiennes en sarcophage (occident, $\mathrm{IV}^{\mathrm{e}}-\mathrm{VI}^{\mathrm{e}}$ siècles. Antiquité tardive, 11, 2003, p. 305-319.

Duval 1993 : DUVAL (N.) - La notion de «sarcophage » et son rôle dans l'Antiquité tardive. Antiquité Tardive, I, 1993, p. 29-34.

Heijmans 2004 : HEIJMANS (M.) - Arles durant l'Antiquité tardive. De la Duplex Arelas à l'Urbs Genesii, Rome, École française de Rome, 2004, XII446 p. (Collection de l'École française de Rome 324).

Heinzelmann 1976 : HEINZELMANN (M.) - Bischofsherrschaft in Gallien. Zur Kontinuität römischer Führungsschichten vom 4. Bis zum 7. Jahrhundert. Soziale, prosopographische und bildungsgeschichte Aspekte, Munich, Artemis, 1976, 280 p. (Beihefte der Francia, Band 5). 
Heinzelmann 1982 : HEINZELMANN (M.) - Gallische Prosopographie 260-527 (Prosopographica IV). Francia, 10, 1982, p. 531-714.

Lauwers, Treffort 2009 : LAUWERS (M.), TREFFORT (C.) - De l'inhumation privilégiée à la sépulture de prestige. In: Inhumation de prestige, p. 439-450.

L'inhumation privilégiée : DUVAL (Y.), PICARD (J.-Ch.) éd. - L'inhumation privilégiée du IVe au VIII siècle en occident, Actes du colloque de Créteil les 16-18 mars 1984, De Boccard, Paris, 1986, 260 p.

Inhumation de prestige : ALDUC-LE BAGOUSSE (A.) dir. - Inhumation de prestige ou prestige de l'inhumation? Expressions du pouvoir dans l'au-delà ( $I V^{e}-X V^{e}$ siècle), Caen, Publications du CRAHM, 2009, 452 p.

Lepelley 1999 : Lepelley $(\mathrm{Cl}$.) - Du triomphe à la disparition. Le destin de l'ordre équestre de Dioclétien à Théodose. In: L'ordre équestre. Histoire d'une aristocratie (II siècle av. J.-C. - III e siècle ap. J.-C.), Actes du colloque international organisé par Ségolène Demougin, Hubert Devijver et MarieThérèse Raepsaet-Charlier (Bruxelles-Leuven, 5-7 octobre 1995), Rome, École française de Rome, 1999, 694 p. (Collection de l'École française de Rome 257), p. 629-646.

Martindale 1980 : MARTINDALE (J.R.) - Prosopography of the Later Roman Empire : addenda et corrigenda to Volume I. Historia, 29, 1980, p. 474-497.

Montzamir 2003 : MONTZAMIR (P.) - Nouvel essai de reconstitution matérielle de l'épitaphe de Sidoine Apollinaire (RICG, VIII, 21). Antiquité tardive, 11, 2003, p. 321-327.

Paillard et al. 2009: PAILLARD (D.), ALDUC-LE BAGOUSSE (A.), BUCHET (L.), BLONDIAUX (J.), NIEL (C.) - Identité sociale ou miroir d'une société en évolution ? Les tombes remarquables de la seconde moitié du IVe siècle dans la nécropole Michelet à Lisieux (Calvados). In : Inhumation de prestige, p. 1-22.
Pailler 1986 : Pailler (J.-M.) - L'énigme Nymfius. Gallia, 1986, p. 151-165.

Pietri 1970 : PIETRI (L.) - La conversion en Belgique seconde d'un ancien officier de l'armée de Julien, Jovin. Revue du Nord, 52, 1970, p. 443-453.

Pietri 1986 : PIETRI (L.) - Les sépultures privilégiées en Gaule d'après les sources littéraires. In : L'inhumation privilégiée, p. 133-142.

PLRE : JONES (A.H.M.), MARTINDALE (J.R.), MORRIS (J.) - The prosopography of the later Roman empire, Cambridge, CUP, t. I, A.D. 260-395, 1971, XXII-1151 p., t. II, A.D. 395-527, 1992, XLI-1342 p.

Prévot 1993 : PREVOT (Fr.) - Prolégomènes à RICG, VIII. Deux fragments de l'épitaphe de Sidoine Apollinaire découverts à Clermont-Ferrand. Antiquité tardive, 1, 1993, p. 223-229.

Raynaud 2006 : RAYNAUD (Cl.) - Le monde des morts. In : Heijmans (M.), Guyon (J.) dir., Antiquité tardive, haut Moyen Âge et premiers temps chrétiens en Gaule méridionale, I, Réseau des cités, monde urbain et monde des morts. Gallia, 63, 2006, p. 137-156.

Rouquette 1974 : Rouquette (J.-M.) - Trois nouveaux sarcophages chrétiens de Trinquetaille (Arles). CRAI, 118/2, 1974, p. 254-277.

Sivan 1989 : SIVAN (H.S.) - Town Country and Province in Late Roman Gaul : The Example of CIL XIII 128. ZPE, 79, 1989, p. 103-113.

Sivan 1993a : SIVAN (H.S) - Ausonius of Bordeaux. Genesis of a Gallic Aristocracy, Londres, Routledge, 1993, 243 p.

Sivan 1993b : SIVAN (H.S) - Numerian the Intellectual. A Dynastic Survivor in Fourth Century Gaul. Rheinische Museum, 136, 1993, p. 360-365.

Wood 1996 : WOOD (I.) - Sépultures ecclésiastiques et sénatoriales dans la vallée du Rhône (400-600). Médiévales, 31, automne 1996, p. 13-27. 

Troisième Partie

\section{Espaces de la religion}

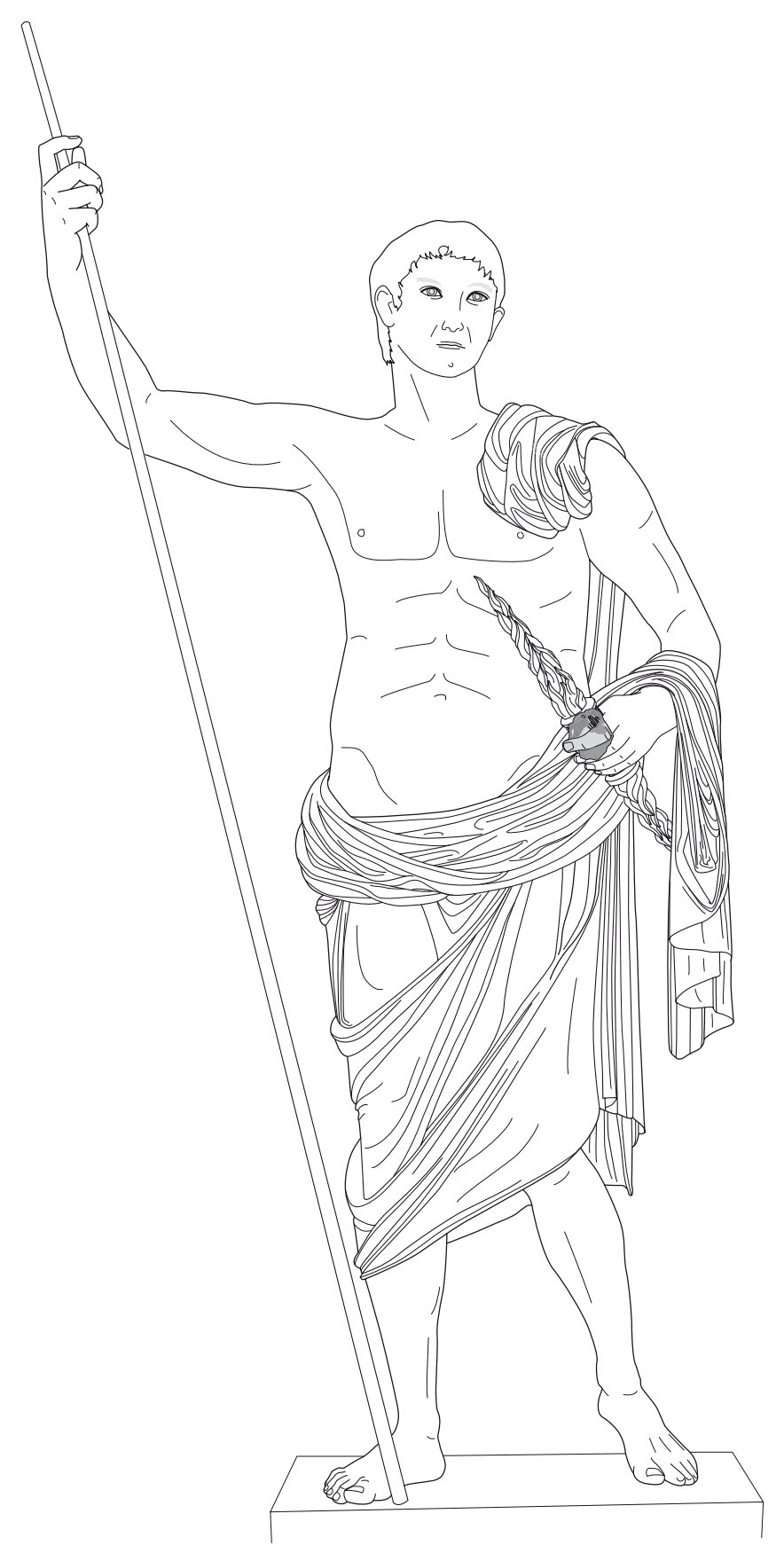




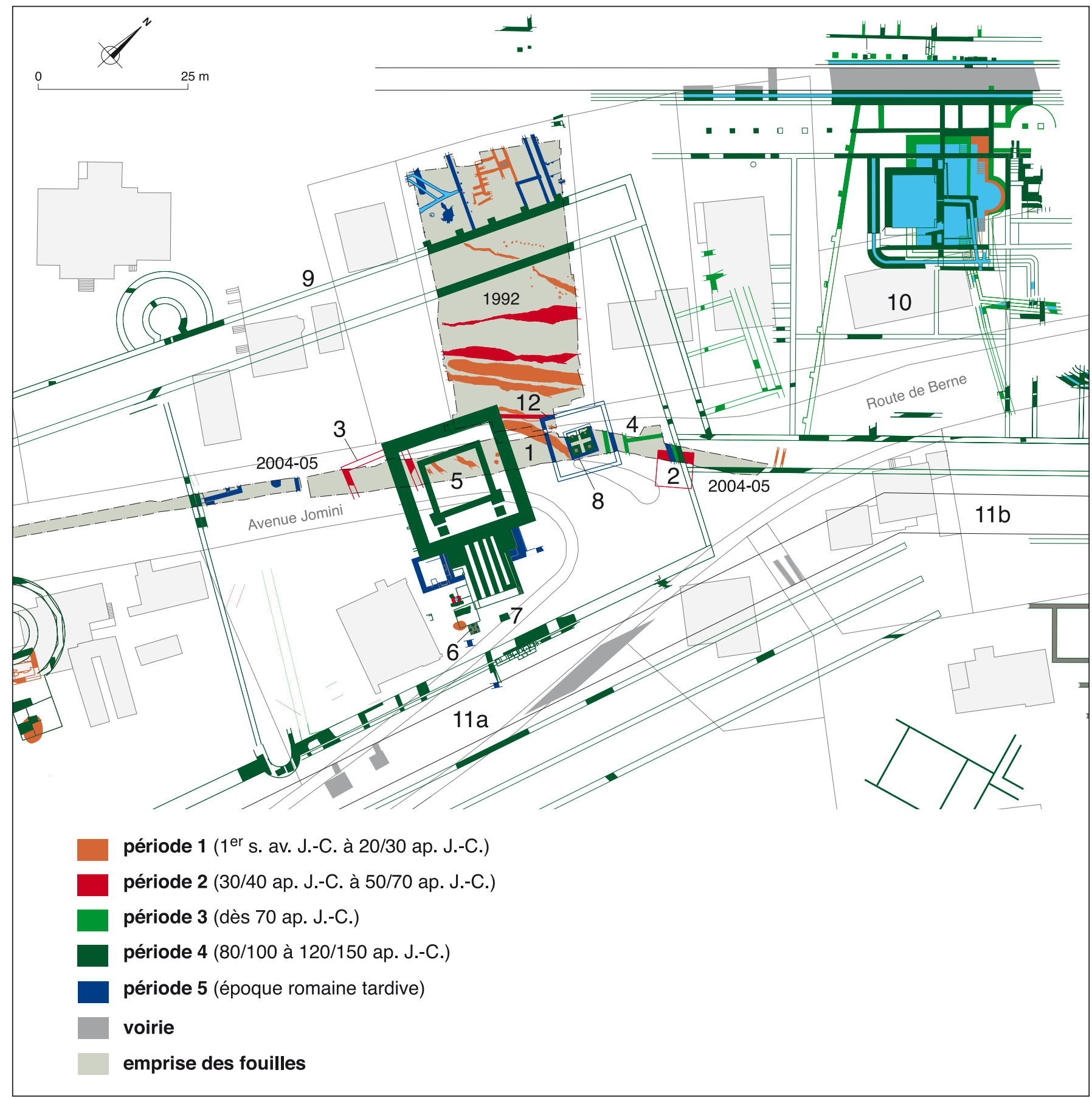

Fig. 1. Plan de l'aire sacrée de la Grange des Dîmes (périodes 1 à 5). 1-3: monuments période $2 ; 4$ : bâtiment quadrangulaire période 3 ; 5-9: monuments période 4 ( $5:$ temple, $6:$ tétrastyle, $7:$ autel, $8:$ monument tétrapyle, 9 : enclos sacré) ; $10:$ thermes de l'insula 19 périodes $2-4$; $11 \mathrm{a}$ : voie décumane ; $11 \mathrm{~b}$ : decumanus maximus ; 12 : mur M21 dans lequel ont été découvertes les restes d'une inscription.

Crédit des illustrations :

Fig. 1 à 5,7 et 8 : tiré de Bossert, Meylan Krause 2007, fig. 2, 20, 30, 24, 16, 15, 14.

Fig. 6 : d'après Mazur 2006, réélaborée par Jean-Paul Dal Bianco, Site et Musée romains d'Avenches.

Fig. 9 à 11 : tiré de Bridel 2011. 


\title{
Signa in templo
}

\section{Où situer le nouveau groupe statuaire de la famille impériale dans le sanctuaire de la Grange des Dîmes (Avenches, Suisse) ?}

\author{
Philippe Bridel \\ Site et musée romains d'Avenches, Suisse \\ philippe.bridel@MUSRAV.vd.ch
}

\section{Résumé}

La découverte de fragments de statues en marbre de la famille impériale du $2^{\mathrm{e}}$ quart du $\mathrm{I}^{\mathrm{er}} \mathrm{s}$. a relancé la question du culte dynastique dans le sanctuaire de la Grange des Dîmes, où ils ont été retrouvés. La comparaison avec le groupe julio-claudien du forum de la ville, daté du milieu du règne de Tibère a révélé une grande similitude des deux groupes.

Le cycle dynastique du forum avait été restitué par hypothèse sur le podium du temple attribué au culte civique de Rome et Auguste. Le lieu et la forme des honneurs rendus à la maison impériale restent cependant conjecturaux.

Le cycle de la Grange des Dîmes serait à situer sur une base multiple érigée au deuxième tiers du $\mathrm{I}^{\text {er }} \mathrm{s}$. dans la cour du sanctuaire, qui compte alors deux autres édifices, l'un de caractère héroïco-funéraire probablement, l'autre étant un petit temple dédié sans doute à Mercure. Le contexte de sa découverte atteste cependant qu'il a été intégré au programme architectural du temple de plan gallo-romain édifié à la fin du $\mathrm{I}^{\mathrm{er}} \mathrm{s}$. On s'interroge enfin sur le statut des divers lieux où semble attesté le culte impérial : forum, sanctuaires de la Grange des Dîmes et du Cigognier.

Mots-clés : Architecture sacrée, Avenches, Aventicum, sanctuaire du Cigognier, sanctuaire de la Grange des Dîmes, culte dynastique, statues, temples, forum, développement urbain.

\begin{abstract}
The discovery of fragments of marble statues of the imperial family of the 2nd quarter of the Ist century has raised the question of dynastic cult in the sanctuary of the Cigognier (Avenches), where they were found. The comparison with the Julio-Claudian group forum in the city, dated from the middle of the reign of Tiberius, revealed high similarity of the two groups.

The dynastic cycle found on the forum had been restored by hypothesis on the podium of the temple attributed to the civic cult of Roma and Augustus. However, the location and shape of the honors paid to the imperial house remain conjectural.

The cycle of the sanctuary of "Grange des Dîmes" would be located on a multiple basis erected in the second period of the first century, in the courtyard of the shrine, which then has two other buildings: one seems to have an heroic-funerary function, the other is a small temple dedicated probably Mercury. However, the context of its discovery certifies that it has been integrated into the architectural program of the temple of the Gallo-Roman plan built at the end of the first century. It also questions the status of the various locations where the imperial cult seems attested: forum, sanctuaries of "Grange des Dîmes" and of "Cigognier".
\end{abstract}

Key-words: Sacred architecture, Avenches, Aventicum, sanctuary of Cigognier, sanctuary of Grange des Dîmes, dynastic cult, statues, temples, forum, urban development. 


\section{Introduction}

Les fouilles d'urgence de 2004, menées pour permettre l'ouverture d'une importante tranchée technique traversant le périmètre classé du sanctuaire de la Grange des Dîmes, sont venues renouveler et compléter nos connaissances d'un secteur monumental (fig. 1) dont le développement a pu être précisé à l'occasion du colloque Topographie sacrée et rituels, le cas d'Aventicum, capitale des Helvètes (Morel, Blanc 2006 [2008], p. 39-50). Alors encore toute récente, l'identification par Martin Bossert, d'une trentaine d'éléments de statues monumentales en marbre de Luni mêlés aux nombreux fragments architecturaux récoltés, n'avait pu être présentée comme elle le méritait. Ces membra disjecta ont été depuis reconnus comme ceux d'un groupe de statues de la famille impériale du $2^{\mathrm{e}}$ quart du $\mathrm{I}^{\mathrm{er}} \mathrm{s}$., composé de cinq individus au moins; une attentive étude stylistique et comparative permet de considérer cet ensemble comme contemporain et homologue du groupe julio-claudien, bien mieux conservé, du forum d'Aventicum (Bossert, Meylan Krause 2007).

Celui-ci, situé tout d'abord vers 49/50, sous Claude (Bossert, Kaspar 1974 ; Bossert 1983) et attribué à l'exèdre centrale du portique de l'area sacra du forum, a été finalement daté du milieu du règne de Tibère (Bossert 1998, p. 113, 128) et restitué par hypothèse en couronnement du podium du temple du forum, qui serait dédié au culte impérial, sur la base d'une comparaison serrée avec la série de portraits tibériens du temple de Rome et Auguste sur l'ancien forum de Leptis Magna (Kaspar 1995). Il aurait été érigé à l'occasion de l'accession de la cité pérégrine d'Avenches à un nouveau statut, sanctionné par un nouvel appellatif: Forum Tiberii (Lieb 1989, Rapin 2003). Il figurait, à trois échelles différentes, Divus Augustus en pied, torse dénudé, tenant le foudre et la lance, un colosse de $4 \mathrm{~m}$ (fig. 2), Germanicus cuirassé (?) (fig. 3) et Agrippine Majeure (3,10 $\mathrm{m}$ et 2,75 $\mathrm{m}$ de hauteur restituée, fig. 4), et peutêtre l'empereur régnant Tibère, Drusus Minor, son successeur pressenti, et Claudia Livilla, tous trois plus grands que nature.

Le contexte architectural de l'area sacra du forum, encore mal connu puisque le podium de son temple n'a pas été fouillé, resterait cependant déterminant pour décider où situer ces statues et si elles constituent un monument honorifique ou sont l'objet d'un culte officiel. La divinité éponyme de l'aedes demeure en outre inconnue, faute d'inscription, même si la proposition

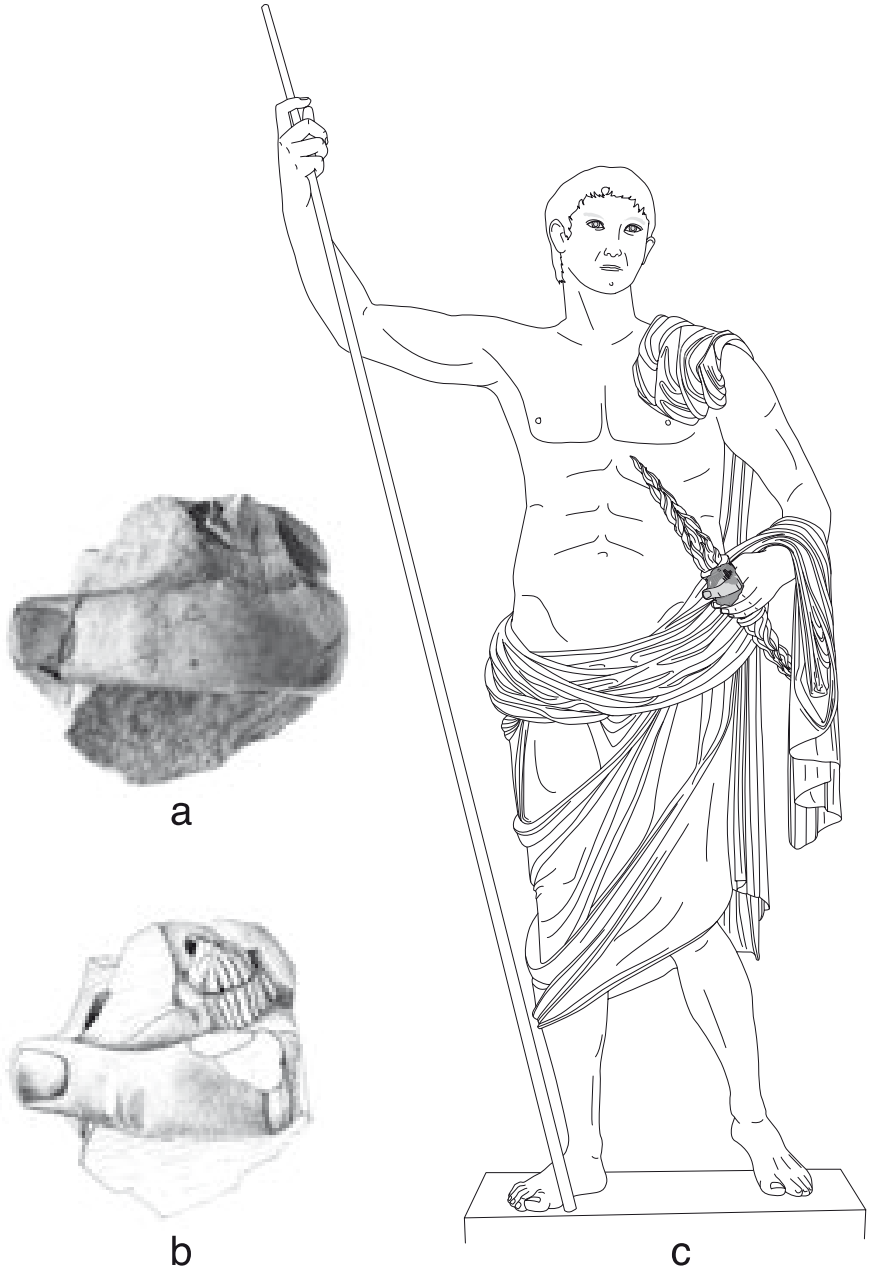

Fig. 2. Forum d'Avenches. a-b. Fragment de main gauche avec foudre d'une statue colossale d'Auguste divinisé. c. Restitution. H. env. 4 m.

d'un temple à Rome et Auguste est vraisemblable ${ }^{1}$. Le cadre architectural et l'organisation des espaces, la distribution des monuments font donc ici encore problème, en dépit des comparaisons possibles.

M. Bossert a restitué le cycle de la Grange des Dîmes à partir de neuf fragments identifiés parmi les trente conservés, certains très imposants il est vrai, qu'il a comparés très savamment avec ceux du forum. Parmi au moins cinq statues plus grandes que nature, on trouvait celle d'un empereur divinisé, identifié par un fragment de manteau retombant sur son épaule gauche ; elle devait atteindre une hauteur de $3,5 \mathrm{~m}$ s'il s'agit d'une statue en pied comme celle d'Herculanum, en bronze, figurant l'empereur Auguste. Mais le prince pourrait aussi trôner assis, statue de culte comme à Leptis Magna.

1. J. Scheid renvoie à un culte au moins pour Agrippine, ou plutôt sa Juno d'après le type statuaire, sans se prononcer sur le problème sa localisation sur le forum (Scheid 2008, p. 331). 


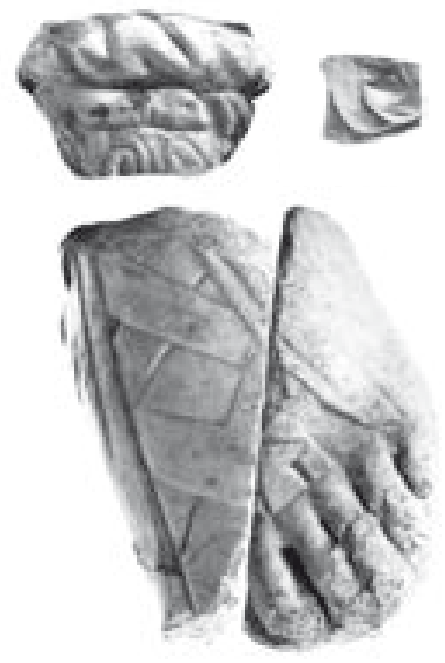

a

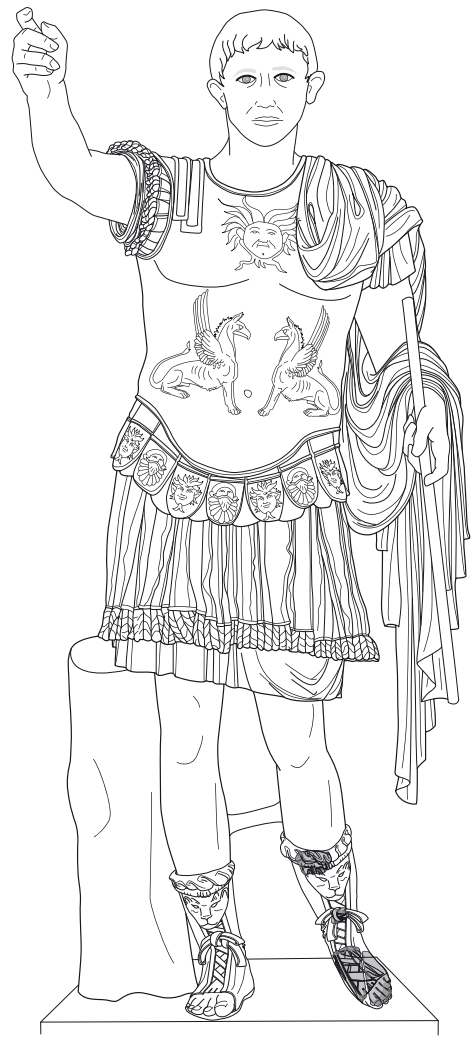

b

Fig. 3. Forum d'Avenches. a. Fragments d'une statue cuirassée. b. Restitution, Germanicus ? H. 3,10 m env.
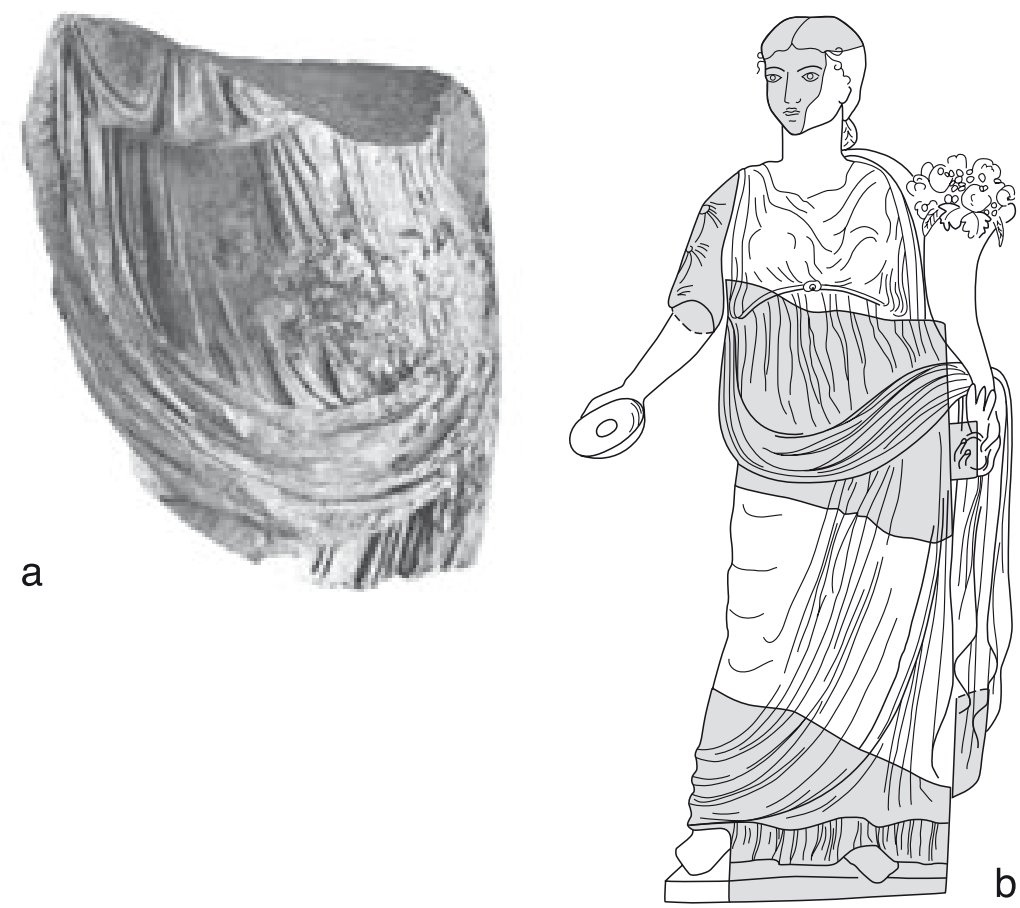

Fig. 4. Forum d'Avenches. a. Fragment de bassin d'Agrippine Majeure. b. Restitution. H. 2,75 m avec plinthe. 


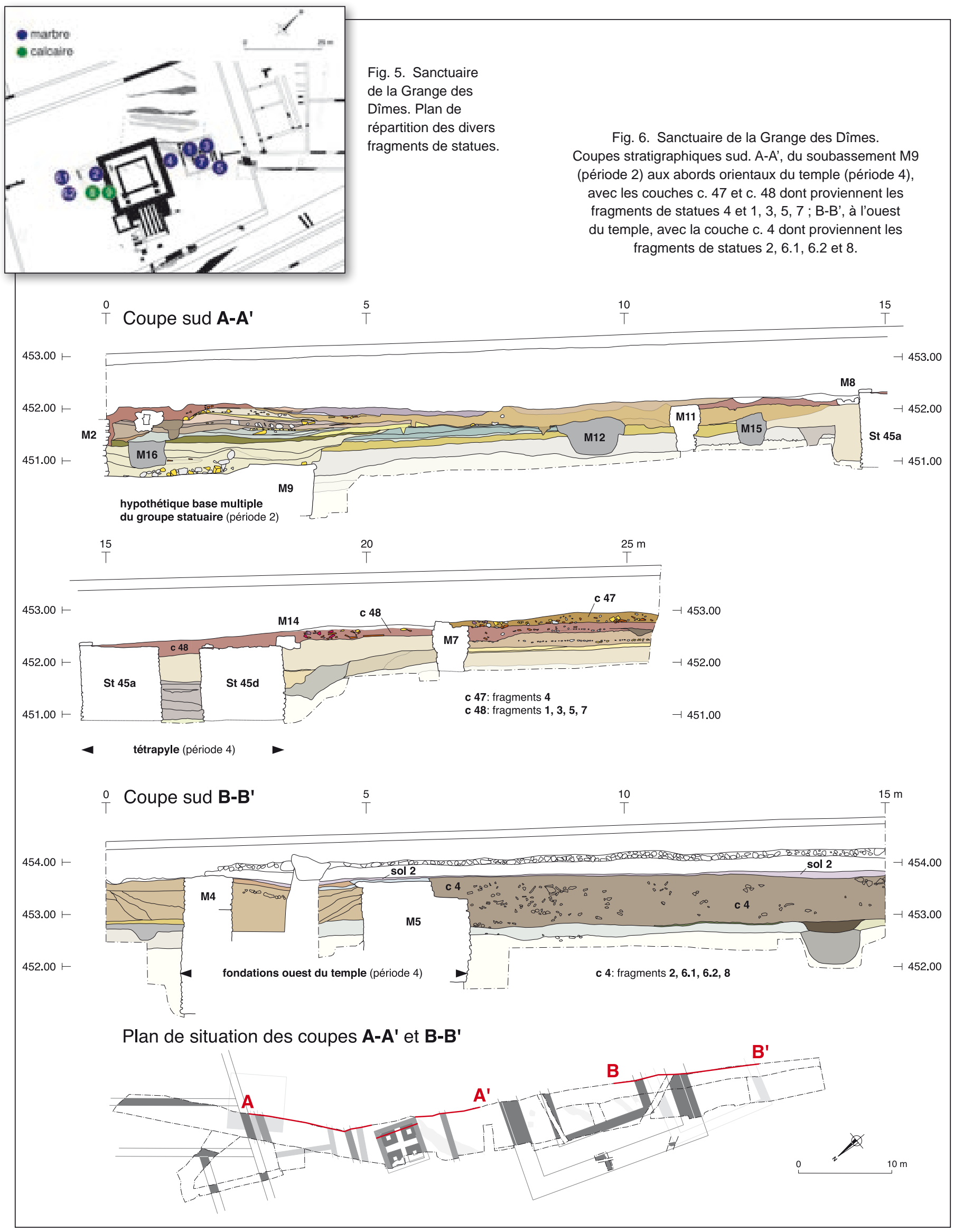


On ignore donc en fait le nombre et l'aspect exact de ces statues, que le seul parallèle avec celles du forum permet de dater et de considérer, par hypothèse, comme une réplique, personnage pour personnage, du cycle dynastique julio-claudien de l'area sacra.

Face à des signa sine titulis, c'est en fin de compte leur position dans le dispositif architectural du sanctuaire qui pourrait donner tout leur sens à ces effigies impériales ; il nous faut donc examiner au plus près le contexte archéologique de leur découverte pour tenter d'en restituer l'emplacement, tout au long de l'évolution du bâti.

\section{Le contexte de découverte}

Une carte de répartition des principaux fragments (fig. 5) montre bien qu'ils ont été retrouvés mêlés aux vestiges de l'architecture du temple de la fin du $\mathrm{I}^{\mathrm{er}} \mathrm{s}$., de part et d'autre de son podium démantelé. Mais les niveaux de circulation du temple sont ici perdus et la faible surface fouillée, la dispersion des fragments dans des contextes «tombés en place», perforés par des tombes médiévales parfois, invitent à la prudence quant à la précision planimétrique à conférer à de tels indices. La stratigraphie très minutieusement relevée et interprétée par la responsable de la fouille (Mazur 2006) permet d'écarter l'hypothèse, un temps avancée, d'un apport extérieur de ces morceaux de marbre, qui auraient été tardivement réunis pour finir dans un four à chaux. Les fragments 2, 6.1, 6.2, 8 proviennent de la couche de démolition romaine c. 4 (fig. 6), scellée elle-même par la couche c. 3 et par la route bernoise du milieu du $\mathrm{XVIII}^{\mathrm{e}}$ s. (sol 2). Le fragment 4 provient de la couche de démolition romaine c. 47 , scellée par le remblai de la route actuelle ; les fragments 1, 3, 5, 7 se trouvaient dans la couche de démolition romaine en place c. 48, également scellée par un remblai moderne (Bossert, Meylan Krause 2007, p. 175).

Le cycle statuaire semble donc bien avoir appartenu au sanctuaire de la Grange des Dîmes, et subsister jusqu'au démantèlement du temple érigé à la fin du $\mathrm{I}^{\mathrm{er}}$ ou au début du $\mathrm{II}^{\mathrm{e}} \mathrm{s}$. Mais comme ce cycle remonte au $2^{\mathrm{e}}$ quart du $\mathrm{I}^{\mathrm{er}} \mathrm{s}$., il nous faut tenter ici de retrouver son emplacement d'origine dans le cadre de l'aménagement et du fonctionnement du sanctuaire tels qu' on peut aujourd'hui les entrevoir pour cette époque.

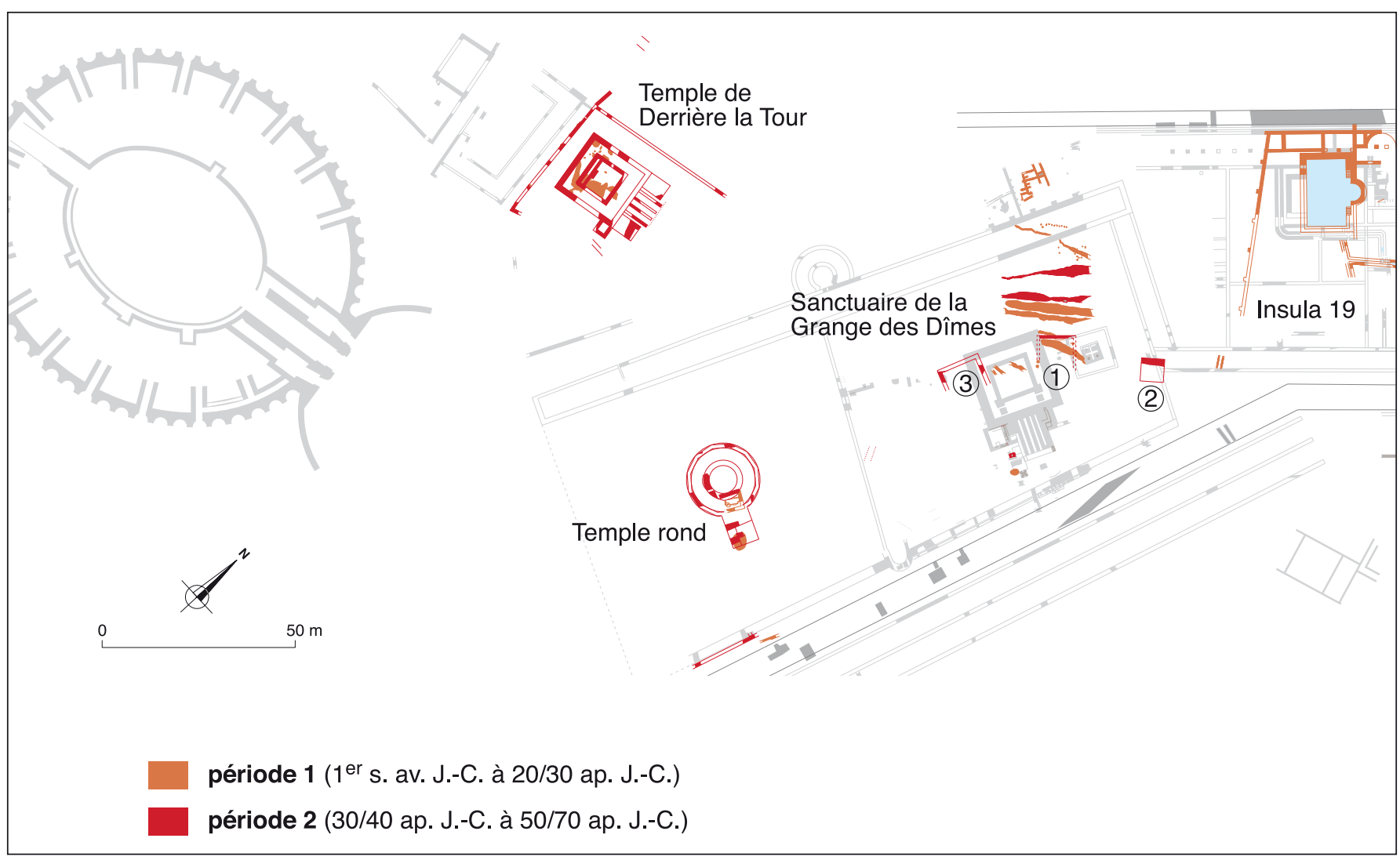

Fig. 7. Aventicum. Plan du quartier religieux occidental du flanc est de la colline durant la première moitié du ler s. ap. J.-C. En orange, période 1 (Ier S. av. J.-C. à 20/30 ap. J.-C.) ; en rouge, période 2 (30/40 à 50/70 ap. J.-C.). 


\section{La restitution dans le cadre du sanctuaire du $2^{\mathrm{e}}$ quart du $\mathrm{I}^{\mathrm{er}} \mathrm{s}$ et de Forum Tiberii} $(30 / 40-50 / 70)$

Une première occupation du secteur est attestée sous forme d'un probable enclos de tradition celtique, avec palissade et fossé contenant dans son comblement les restes osseux de ce qui pourrait être des repas rituels. Restitué par hypothèse comme un espace rectangulaire clos de $12,5 \mathrm{~m}$ de côté, il a semble-t-il abrité un petit édifice à structure légère de bois dont les trous de poteaux ont été retrouvés. Cette occupation qu'on hésite à interpréter comme funéraire ou cultuelle, se développe entre la fin du ${ }^{\text {er }}$ s. av. J.-C. et les années 20 à 30 ap. J.-C., dans un contexte général encore mal connu mais qui pourrait déjà, sous forme d'un sanctuaire " héroïque », combiner rituels funéraires et vénération d'une divinité protectrice, comme on a pu le proposer pour un dispositif comparable, mais mieux connu, du site périurbain d'Avenches-En Chaplix (Castella 1993, Castella 2008, Bossert, Meylan Krause 2007, p. 162-167, en particulier p. 165 et n.21 et 22 pour cette interprétation). L'exiguïté des surfaces explorées et conservées en bon état pour cette période empêche cependant de conclure définitivement.

Dans un second temps, entre les années 30 à 40 et jusque vers 50 à 70 ap. J.-C., un second enclos, plus vaste mais de même orientation, vient se substituer au premier, qui disparait sous un vaste empierrement de galets. Les vestiges de trois constructions maçonnées ont été repérés (fig. 7) et deux blocs d'architecture en grès molassique, un chapiteau de pilier et un chaperon de mur, trouvés dans le comblement du fossé nord de ce nouvel enclos (Bossert, Meylan Krause 2007, p. 167-173).

L'un de ces édifices contemporains du groupe de statues en marbre pourrait n'être qu'un enclos à ciel ouvert venu remplacer le premier aménagement à poteaux de bois, perpétuant peut-être ainsi le souvenir du premier « héros » vénéré en ces lieux (fig. 7, 1). Un dispositif de ce type a été récemment étudié à Yverdon (Menna, Schöpfer 2004).

Le troisième édifice, connu par quelques vestiges des tranchées de fondation de ses murs (fig. 7, 3), pourrait avoir été un bâtiment couvert, peut-être le temple de la divinité protectrice du héros honoré dans l'édifice 1, un Mercure autochtone probablement, mais à l'aspect et au culte désormais conformes aux canons romains, à en croire les indices relevés de sa présence dans le sanctuaire à la période suivante de son développement.
Même s'il a pu atteindre $11 \mathrm{~m}$ de largeur hors tout, il est trop mal connu pour qu'on puisse prétendre qu'il abritait à la fois la statue de culte de Mercure et les six effigies impériales de marbre que nous cherchons à replacer dans leur contexte original.

C'est bien plutôt à l'édifice 2 qu'il faut s'intéresser ici (fig. 7, 2), imposante plate-forme massive de maçonnerie dont la hauteur conservée atteint $0,80 \mathrm{~m}$, pour une extension connue de $6 \mathrm{~m}$ d'est en ouest, et sans doute d'au moins autant du nord au sud. Elle a été arasée au niveau du sol de construction et de circulation, et son élévation a totalement disparu, abattue pour permettre la construction vers 72 ap. J.-C. de la nouvelle clôture occidentale des thermes de l'insula 19, alors agrandis (fig. 6a, M9, M10. Il pourrait s'agir ici de l'une de ces bases multiples, connues au forum de Ruscino par exemple (Rosso 2006, p. 115). La date de construction est assurée par le mobilier et les monnaies retrouvés dans les niveaux de construction et d'occupation, tout comme dans le comblement du fossé de récupération du massif maçonné ; c'est de ce dernier contexte que proviennent un important mobilier métallique et quatre monnaies, les plus récentes du règne de Caligula. Parmi elles, un sesterce frappé à Rome en 37-38 dont le revers illustre le sacrifice pratiqué à l'occasion de l'inauguration du Templum Divi Augusti de Rome, construit sous Tibère mais achevé par Caligula (fig. 8).

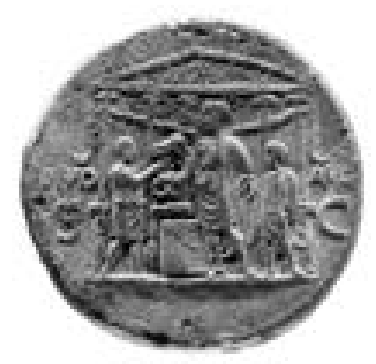

Fig. 8. Aire sacrée de la Grange des Dîmes. Fouilles 2004. Sesterce représentant l'inauguration du Templum Divi Augusti à Rome, construit sous Tibère mais inauguré sous Caligula.

Cette pièce exceptionnelle, sans doute ici un don votif, vient à point nommé conforter l'hypothèse qui fait de cet édifice la base d'un monument (honorifique ou cultuel ?) célébrant la famille impériale. Quant à son exact dispositif architectural, nous resterons prudent; il combinait sans doute le grès calcaire et molassique dans les parties basses et le calcaire hauterivien en élévation, si l'on en croit les déchets de taille trouvés dans les divers niveaux du chantier de construction. S'agissait-il d'une base simple constituée d'un podium de 1,2 m de hauteur? ou 
l'ensemble se développait-il plus largement, sous forme d'un autel monumental, les statues disposées à l'arrière ? C'est là toute la question, qui souligne l'ambiguïté, ou mieux la polyfonctionnalité, à la fois honorifique et cultuelle, des effigies de la famille impériale. En l'absence d'inscription qui nous éclairerait à ce sujet, nous resterons prudent. Comment d'ailleurs se représenter la disposition des statues de ce groupe posthume, dont on a vu qu'elles ne sont pas toutes à la même échelle ? Faut-il les aligner, les regrouper sur deux rangs ? Et dans quel ordre hiérarchique ? Faute d'indice archéologique, nous laisserons la question ouverte, tout en relevant que le lieu d'érection de ces statues est particulièrement bien choisi pour les mettre en valeur, qu'elles aient regardé vers l'est, dans l'axe du decumanus maximus en provenance de l'entrée du forum, ou vers le sud, s'alignant sur la façade de l'édifice 1 et accueillant le passant qui, venant de l'ouest, se dirigeait vers le centre civique de la cité.

En 72, on l'a dit, le groupe statuaire est démantelé et sa base arasée en raison d'importants travaux entrepris dans ce secteur, conséquence du développement des thermes de l'insula 19 et d'une réorganisation du sanctuaire de la Grange des Dîmes et des ses cultes. Durant cette période de transition mal connue, qui voit même l'édification d'un bâtiment artisanal semble-t-il, on ignore quel est le sort des statues.

\section{La nouvelle présentation dans le cadre du sanctuaire de la fin du $\mathrm{I}^{\mathrm{er}} \mathrm{s}$. et de la Colonia} (80/100-120/150)

Retrouvés mêlés aux décombres de l'architecture du temple érigé à la fin du $\mathrm{I}^{\mathrm{er}}$ ou au début du $\mathrm{II}^{\mathrm{e}}$ s., les fragments du cycle statuaire julio-claudien de la Grange des Dîmes ont dû nécessairement y trouver leur place. Cet édifice est désormais mieux connu et plus aisé à restituer (fig. 9, 10, 11, Bridel 2011); ses fondations présentent un plan à carrés emboîtés dit de tradition gallo-romaine, qui implique une haute cella entourée d'un ambitus plus bas, contrairement aux restitutions proposées jadis par M. Verzár (Verzár 1978, Verzár-Bass 1995). Mais le tout se dresse sur un haut podium desservant un porche monumental à fronton, éléments empruntés à l'architecture romaine la plus classique. Un long escalier frontal, peut-être constitué de plusieurs volées, mène de la cour au porche, rachetant selon une faible pente la dénivellation du podium.

Mais où faut-il placer les statues de la famille impériale héritées de l'état précédent du sanctuaire ? Restent-elles d'ailleurs groupées en un ensemble cohérent ?
Pour les mêmes raisons qu'à l'état antérieur, on laissera à Mercure, considéré comme divinité principale du sanctuaire, le fronton, où il apparaît en haut-relief (Bossert 1998, p. 47-48) et la cella, qui devait abriter sa statue de culte, sans ménager cependant assez d'espace pour tout le groupe d'effigies impériales ; on renoncera également aux entrecolonnements de la façade de l'ambitus (largeur 1,04 m entre bases) ou du pronaos (largeur 2,08 $\mathrm{m}$ de part et d'autre, 2,38 $\mathrm{m}$ dans l'axe), trop étroits à notre avis. C'est pourtant dans une telle galerie que W. Van Andringa, se fondant sur l'étude du vase de Sains-du-Nord (Van Andringa 2000, p. 38-41),

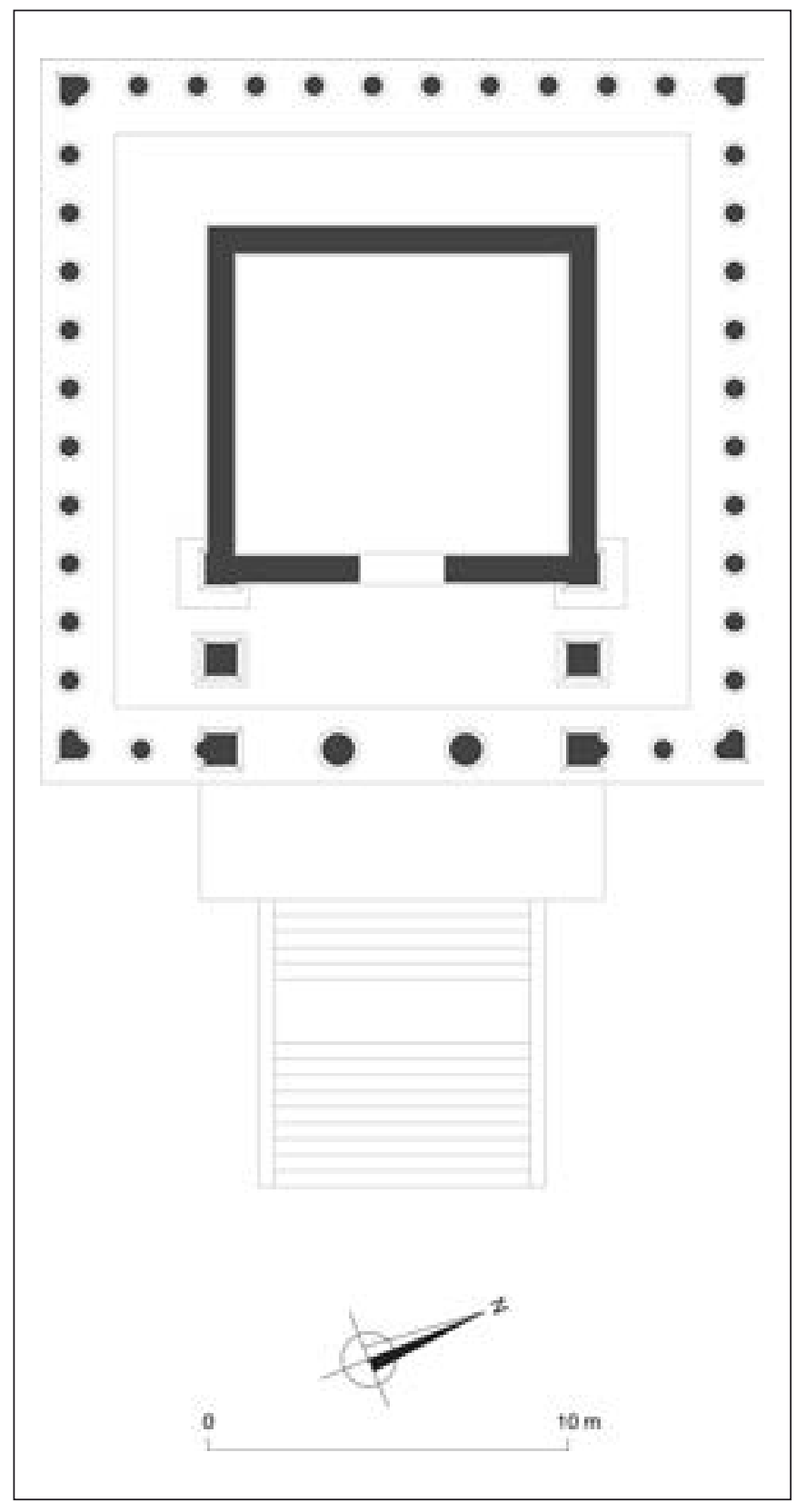

Fig. 9. Avenches, temple de la Grange des Dîmes. Plan de restitution. $1 / 250$. 
réunit les statues des divinités secondaires ou des empereurs non encore divinisés auxquels on rendait un culte ou qu'on voulait simplement honorer (Van Andringa 2002, p. 178-179). Aurait-on alors dissocié le groupe et distribué les statues en plusieurs emplacements, avec le divin Auguste abrité par le mystérieux édifice à quatre piles qui jouxte le temple à l'est ? Cela semble difficile, l'espace libre entre les quatre poteaux de bois de son élévation, 1,60 x 1,60 m, y suffisant à peine. Nous voyons plutôt dans ce mystérieux édifice le lieu où se perpétuerait la fonction héroïco-funéraire à l'origine du sanctuaire, qui pourrait prendre ici la forme d'un monument de type trophée (Bridel 2011). M. Verzár supposait une statue de l'empereur sous le baldaquin du petit tétrastyle érigé au pied de l'escalier (Verzár 1978, p. 26, fig. 8, p. 30) : la surface disponible entre les colonnettes mesurant $0,70 \times 0,70 \mathrm{~m}$, la statue dont le fragment d'épaule a été retrouvé ne saurait y trouver place, du fait de ses dimensions colossales.

C'est finalement dans une position comparable à celle du groupe de Leptis Magna et rappelant sa situation dans le dispositif d'origine du sanctuaire de la Grange des Dîmes qu'il faudrait restituer cet ensemble statuaire, dont l'unité méritait à notre avis d'être préservée pour des raisons rituelles; on recherchera donc une situation en hauteur, face à l'entrée du sanctuaire désormais délimité par un haut mur, in templo à défaut d'être in aede. Le long escalier menant au podium pourrait l'accueillir sur l'un de ses paliers, plus probablement sur le dernier, élargi de part et d'autre aux deux avancées latérales du podium ; disposées à l'air libre, en avant des colonnades de façade, ces statues ne laisseraient peut-être libre que l'entrecolonnement central du porche. L'espace disponible de part et d'autre de l'accès axial desservant la cella et l'ambitus, mesurant deux fois 4,5 $\mathrm{m}$ de longueur environ, y suffirait largement, les statues disposées en ordre de taille décroissant. Statues honorifiques ou statues honorées d'un culte rendu à la domus divina ? On en sait trop peu sur l'organisation des cultes dans ce sanctuaire, sans doute multiples et de statuts divers, pour pouvoir trancher, la situation ayant pu d'ailleurs évoluer au cours des ans.

Les médaillons à tête de Zeus Amon, Méduse ou Achéloos (Verzár 1978, p. 34-46, Bossert 1998, p. 44-57) peuvent être aujourd'hui attribués à notre avis au décor à clipei de l'attique de l'ambitus. On retrouve là, près d'un siècle après leur apparition en couronnement des portiques flanquant le Forum d'Auguste, un motif sans doute désormais banalisé (Casari 2004, p. 29-36, Gros 2003, p. 116-117) et dont il est difficile d'interpréter la signification dans un contexte aussi particulier que celui

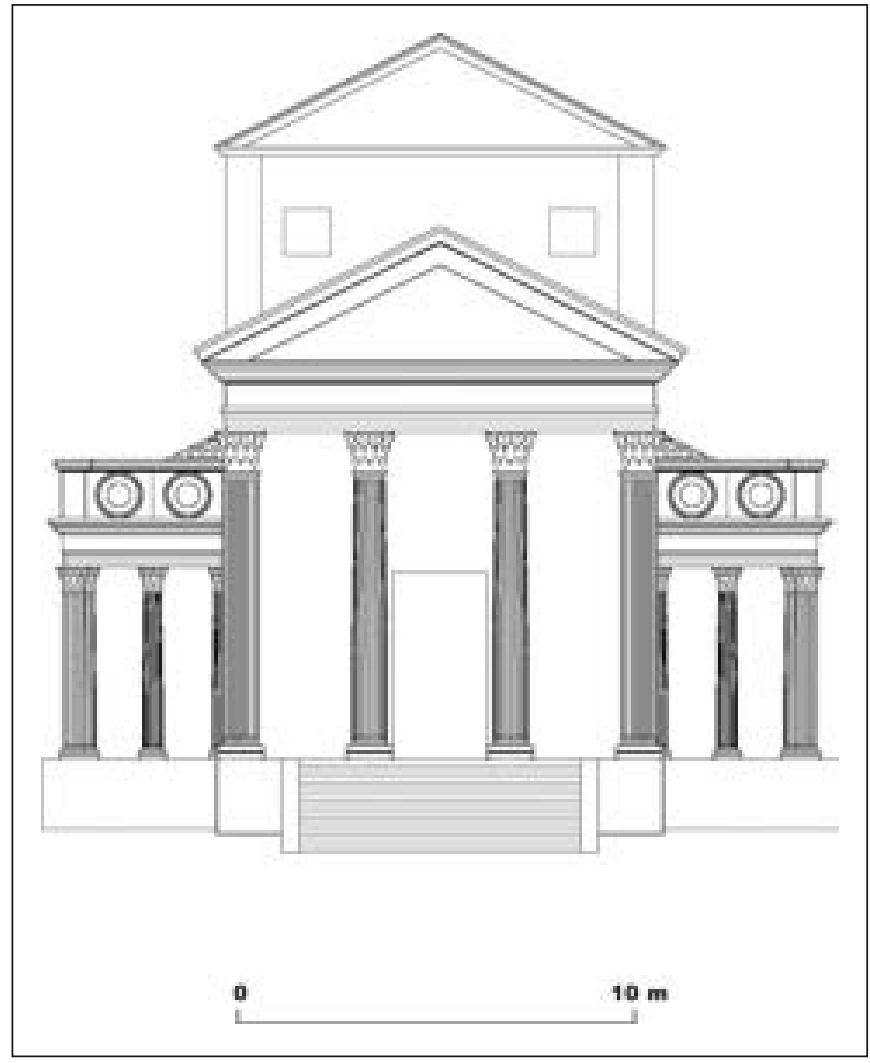

Fig. 10. Avenches, temple de la Grange des Dîmes. Façade orientale restituée. 1/250.

du sanctuaire de la Grange des Dîmes. On reste bien sûr dans une ambiance et un vocabulaire iconographique qui glorifient le prince. Mais ces clipei essentiellement marins ou fluviaux, ne trouvent-ils pas un écho dans les frises de griffons et de monstres marins affrontés ornant les corniches à cavet du sanctuaire du Cigognier, à peine plus ancien, qui abrite sans doute lui aussi, à côté du culte éponyme d'une grande divinité helvète comme Mars, une forme nouvelle de culte de la maison impériale ? (Bridel, Matter 2006 [2008], p. 53-54). Dans ce cas-là aussi, l'exégèse iconographique reste ardue, mais une piste a été récemment ouverte par M. Fuchs, étudiant une mosaïque de Münsingen (Fuchs 2010, p. 130-133).

La restitution de l'ensemble du cadre monumental et rituel du sanctuaire de la Grange des Dîmes, qui va sans doute se peupler encore au cours des quelque deux siècles de son existence, demeure sur bien des points lacunaire à ce jour. On ne peut exclure que d'autres emplacements soient possibles dans sa cour pour ces statues dont nous n'avons retrouvé que quelques fragments ou pour de nouvelles effigies impériales, ou encore pour des statues honorifiques de notables évergètes. Il y a peu à espérer de nouvelles fouilles, mais les surfaces nonbâties offrent d'importantes réserves. 


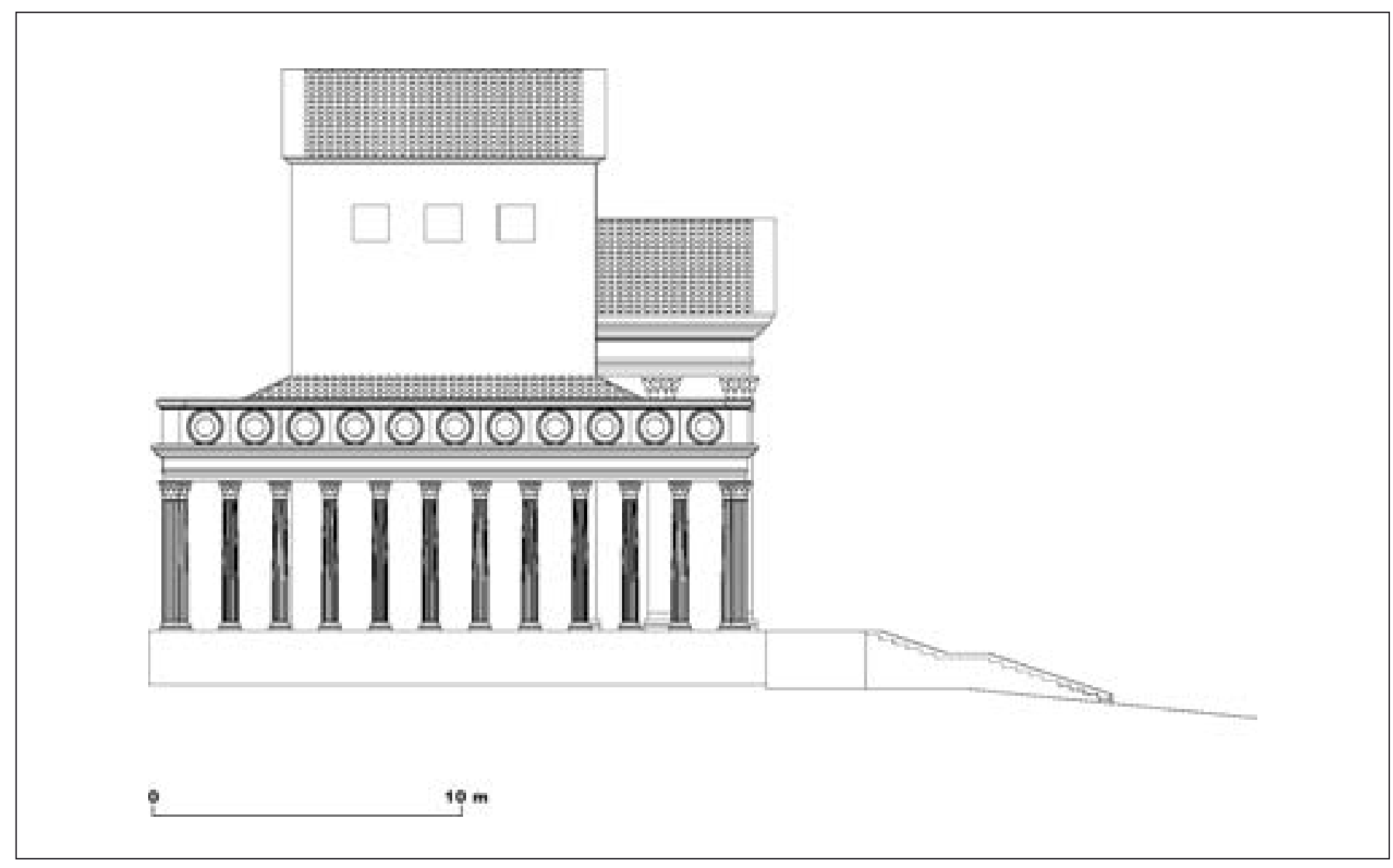

Fig. 11. Avenches, temple de la Grange des Dîmes. Façade méridionale restituée. 1/250.

\section{Conclusion}

Élargissant notre propos aux formes plus ou moins clairement attestées du culte de la famille impériale, il faut nous demander ici pourquoi deux groupes statuaires restitués par hypothèse comme identiques, auraient été érigés à la même époque l'un dans un lieu civique par excellence, le forum, et l'autre dans un espace religieux plus traditionnel, probablement funéraire à l'origine, mais bientôt consacré à Mercure, le sanctuaire de la Grange des Dîmes ?

Les commanditaires des deux groupes de sculptures, qui proviennent probablement d'un seul et même atelier, pourraient être les mêmes représentants des élites helvètes romanisées, intervenant d'une part comme magistrats et évergètes au cœur politique et civique de Forum Tiberii dont ils ont assuré la promotion, d'autre part comme héritiers d'un rituel à l'origine héroïque et quasi tribal, pratiqué dans un sanctuaire traditionnel, qui leur est propre, au sein de ce quartier religieux occidental de la colline où se sont regroupés les cultes indigènes peu à peu intégrés au panthéon romanisé de toute la civitas Helvetiorum. Au sanctuaire de la Grange des Dîmes, une forme de culte dynastique a pu très tôt se développer autour de statues de la famille impériale réunies sur une base multiple, sans nécessiter les mêmes autorisations officielles qu'un culte public, et manifester l'allégeance au prince d'une élite helvète fraîchement romanisée; bien décidée à conserver son identité propre, ses cultes distincts, elle a pu s'organiser un peu à la façon d'un collège ou d'une corporation, face aux nouveaux arrivants avec lesquels elle a dû partager magistratures et cultes officiels de la cité. Peut-être ce « collège » d'un culte particulier a-t-il dû s'en remettre à un patronus ou à un évergète pour être reconnu. Serait-ce Afranius Professus, venu de Narbonnaise, et qui offre la curie vers 50 ? (Fuchs, Margueron 1998, p. 137).

Ce rôle et cette identité particulière des élites autochtones se voient à notre avis réaffirmés avec éloquence dans le cadre institutionnel renouvelé de la colonia flavienne, par la construction dans le sanctuaire de la Grange des Dîmes, à la fin du I ${ }^{\text {er }} \mathrm{s}$. au plus tôt, d'un véritable temple de plan «indigène » ou plutôt proprement gallo-romain, avec haute cella carrée et ambitus. Avant Tibère, on n'en connaît que fort peu d'exemples dans nos régions, et ceux connus à Avenches restent difficiles à restituer en élévation. Celui qui vient se substituer au modeste édifice tibérien consacré à 
Mercure présente cependant un aspect architectural témoin d'une romanisation très profonde, avec son haut podium, son pronaos à fronton, la colonnade au rythme serré de son ambitus, son escalier monumental particulièrement développé, et enfin le décor sculpté en attique de l'ambitus, réplique en quelque sorte en miroir de celui des portiques du Forum d'Auguste à Rome. Les commanditaires réaffirment ainsi tout à la fois leur identité helvète et leur allégeance aux modèles de Rome, dans une synthèse architecturale originale et particulièrement explicite. Les honneurs ou le culte à rendre à la famille impériale y trouvent à nouveau une place de choix, plus intimement liés que jamais à la divinité éponyme du temple. Tout cela alors même que s'édifie non loin de là le nouvel ensemble monumental du sanctuaire du Cigognier et du théâtre. Symbole de l'unité et de la fidélité de la civitas tout entière ce complexe gigantesque accueille, dans un espace politique et religieux bien distinct du forum, l'ensemble de la nation réunie autour de tous ses dieux assemblés sous l'égide du prince victorieux, garant de la Paix universelle, auquel elle rend sans doute un culte public d'un nouveau type encore (Bridel, Matter 2006, p. 57-58).

Tout l'intérêt, mais aussi toute la difficulté de notre enquête sur l'évolution architecturale du sanctuaire de la Grange des Dîmes tiennent en fin de compte, à nos yeux, dans cette possibilité, entrevue et à peine esquissée, de saisir dans la durée l'évolution de l'une des formes du culte ou des honneurs rendus à la famille impériale par une catégorie civique bien particulière selon notre hypothèse, soucieuse de maintenir son image et son pouvoir au travers de l'évolution institutionnelle de la cité et de sa capitale.

L'évergésie ou le patronat de grandes familles, Afranius Professus ou les Camillii sous Tibère (FreiStolba 1996), les Otacillii ou Q. Cluvius Macer après l'élévation au rang de colonie, sont sans doute mis à contribution pour payer des statues importées d'Italie et financer la construction du cadre architectural qui leur donne un sens. L'extension du sanctuaire, qui englobe bientôt le temple rond, la création d'un vaste portique (à deux étages et rotonde) en limite nord, la monumentalisation de tout le site, couronné finalement par l'amphithéâtre, montrent bien l'importance du secteur sacré occidental de la ville, face au forum, comme lieu de représentation du pouvoir des élites traditionnelles sur la civitas entière. De nouveaux cultes continueront d'ailleurs à s'agréger à ce secteur bien avant dans le $\mathrm{II}^{\mathrm{e}} \mathrm{s}$., traditionnels à en croire l'architecture des temples qui les hébergent au Lavoex, mais exprimant toujours, à leur manière, leur adhésion à l'Empire et la vénération de la famille impériale, garante de sa stabilité.

Telles sont du moins les hypothèses que nous tentons d'approfondir dans le cadre de la publication systématique, en préparation. Elles sont à la merci de nouvelles découvertes sur le terrain, peu probables à brève échéance, mais pourraient, espérons-le, bénéficier des avancées marquées de la recherche sur d'autres sites comparables et mieux conservés. La voie ouverte par W. Cart lors de la découverte du site en 1905 reste ouverte (Cart 1907), mais que de chemin parcouru en un siècle...

\section{Bibliographie}

Bossert 1983 : BOSSERT (M.) - Die Rundskulpturen von Aventicum. Bern, 1983, 82 p. et 62 pl. (Acta Bernensia, 9).

Bossert 1998: BOSSERT (M.) - Die figürlichen Reliefs von Aventicum. Lausanne, 1998, 224 p. dont 49 pl. (Cahiers d'archéologie romande, $69=$ CSIR, Schweiz I,1).

Bossert, Kaspar 1974 : BOSSERT (M.), KASPAR (D.) - Eine julisch-claudische Kaiserkultgruppe in Avenches. BProAvent, 22, 1974, p. 17-26.

Bossert, Meylan Krause 2007 : BOSSERT (M.), MEYLAN KRAUSE(M.-F.) - Aventicum. Présence impériale dans les sanctuaires de la Grange des Dîmes et de Derrière la Tour. BProAvent, 49, 2007, p. 159-205.

Bridel 2011 : BRIDEL (Ph.) - Le sanctuaire de la Grange des Dîmes, témoin de l'évolution de l'architecture religieuse d'Aventicum, du $\mathrm{I}^{\mathrm{er}}$ au début du $\mathrm{II}^{\mathrm{e}} \mathrm{s}$. In : Reddé (M.) dir., Les sociétés antiques dans l'Est de la Gaule, Mutations politiques, socio-économiques et environnementales à la fin de l'Âge du Fer et au début de l'époque romaine, IV, Architecture et matériaux de construction, Actes de la table ronde de Bibracte (16 et 17 avril 2009), Collection Bibracte 21, Glux-en-Glenne, 2011, p. 287-298

Bridel, Matter 2006 [2008] : BRIDEL (Ph.). MATTER (G.) - Sanctuaire du Cigognier, théâtre vantique et temples du Lavoëx : un cas particulier. In : Castella (D.), Meylan Krause (M.-F.) dir., Topographie sacrée et rituels. Le cas d'Aventicum capitale des Helvètes, Actes du colloque d'Avenches (4-6 novembre 2006) (Antiqua, 43), Bâle, 2008, p. 51-58.

Cart 1907 : CART (W.) - Le temple gallo-romain de la « Grange du Dîme » à Avenches, Anzeiger für Schweizerische Altertumskunde - Indicateur d'Antiquités Suisses, 9, 1907, p. 293-312. Repris plus brièvement dans BProAvent, 9, 1907, p. 3-23.

Casari 2004: CASARI (P.) - Iuppiter Ammon e Medusa nell'Adriatico nordorientale. Simbologia imperiale nella decorazione architettonica forense. Rome, 2004, 190 p. et 63 pl. (Studi e ricerche sulla Gallia cisalpina, 18 ; Antichità altoadriatiche, monografie, 1).

Castella 1993 : CASTELLA (D.) - Un sanctuaire augustéen autour d'une sépulture à incinération à Avenches, canton de Vaud, Suisse. In : Struck (M.), éd., Römerzeitliche Gräber als Quellen zu Religion, Bevölkerungsstruktur und Sozialgeschichte. Internationale Fachkonferenz vom 18.-20. Februar 1991. (Archäologische Schriften des Instituts für Vor- und Frühgeschichte der Johannes Gutenberg-Universität Mainz, 3), Mainz, 1993, p. 229-244. 
Castella 2008 : CASTELLA (D.) - «Mon père, ce héros ! ». Sanctuaires liés à des structures funéraires à Avenches et dans les provinces du nord-ouest de l'Empire In : Castella (D.), Meylan Krause (M.-F.) dir., Topographie sacrée et rituels. Le cas d'Aventicum capitale des Helvètes, Actes du colloque d'Avenches (4-6 novembre 2006) (Antiqua, 43), Bâle, 2008, p. 103-120.

Frei-Stolba 1996 : FREI-STOLBA (R.) - Claude et les Helvètes. Le cas de C. Iulius Camillus. BProAvent, 38, 1996, p. 59-72.

Fuchs, Margueron 1998 : FUCHS (M.), MARGUERON (G.) - Les estampilles sur tuiles d'Avenches : Afranius, la légion XXI, Cornelius, Camillius et les autres. BProAvent, 40, 1998, p. 105-172.

Fuchs 2010: FUCHS (M.E.) - L'Océan de Münsingen BE: une mosaïque entre l'air et l'eau. Annuaire d'archéologie suisse, 93, 2010, p. $123-127$.

Gros 2003 : GROS (P.) - Le «modèle » du forum d'Auguste et ses applications italiques ou provinciales. État de la question après les dernières découvertes. In : Navarro Caballero (M.), Roddaz (J.-M.), La transmission de l'idéologie impériale dans l'Occident romain. Actes du $18^{\mathrm{e}}$ colloque CTHS, Bastia 2003, Bordeaux, 2005, p. 115-127.

Kaspar 1995 : KASPAR (D.) - Senatus Consultum, Domus Augusta und Forum Tiberii. In : Koenig (F.E.), Rebetez (S.), Arculiana. Recueil d'hommages offerts à Hans Bögli, Avenches, 1995, p. 5-13.

Lieb 1989 : LIEB (H.) - Forum Tiberii, BProAvent, 31, 1989, p. 107-108.

Mazur 2006 : MAZUR (A.) - Rapport sur les investigations réalisées à la Grange des Dîmes en 2004 et 2005. (Document inédit déposé aux archives du Musée romain d'Avenches). Avenches-Cracovie, 2006, 1 vol. de texte de 79 p., 1 vol. d'annexes, coupes stratigraphiques et répertoires sous forme de tableaux.
Menna, Schopfer 2004 : MENNA(F.), SCHOPFER(A.) - Un sanctuaire galloromain du début du Haut-Empire à l'entrée ouest du vicus d'Eburodunum/ Yverdon VD, JbSchwUrgech, 87, 2004, p. 303-312.

Morel, Blanc 2006 [2008] : MOREL (J.), BLANC (P.) - Les sanctuaires d'Aventicum. Évolution, organisation, circulations. In : Castella (D.), Meylan Krause (M.-F.) dir., Topographie sacrée et rituels. Le cas d'Aventicum capitale des Helvètes, Actes du colloque d'Avenches (4-6 novembre 2006) (Antiqua, 43), Bâle, 2008, p. 35-50.

Rapin 2003 : RAPIN (C.) - La Suisse et l'arc alpin dans la carte de Ptolémée. Sur Aventicum-Forum Tiberii. JbSchwUrgech, 86, 2003, p. 137-145.

Rosso 2006: ROSSO (E.) - L'image de l'empereur en Gaule romaine. Portraits et inscriptions. Paris, 2006, 612 p.

Scheid 2008: SCHEID (J.) - Conclusion. In : Castella (D.), Meylan Krause (M.-F.) dir., Topographie sacrée et rituels. Le cas d'Aventicum capitale des Helvètes, Actes du colloque d'Avenches (4-6 novembre 2006) (Antiqua, 43), Bâle, 2008, p 329-333.

Van Andringa 2000 : VAN ANDRINGA (W.) - Le vase de Sains-du-Nord et le culte de l'imago dans les sanctuaires gallo-romains. In : Van Andringa (W.), éd., Archéologie des sanctuaires en Gaule romaine. Saint-Etienne, 2000, (Centre Jean-Palerne, Mémoires, 22), p. 27-44.

Van Andringa 2002 : VAN ANDRINGA (W.) - La religion romaine. Piété et politique (Ir-III s. ap. J.-C.). Paris, Errance, 2002, 335 p.

Verzár 1978: VERZÁR (M.) - Un temple du culte impérial. Avenches, Lausanne, 1978. (Cahiers d'archéologie romande, 12, Aventicum, II).

Verzár-Bass 1995 : VERZÁR-BASS (M.) - Bemerkungen zum Problem der Kaiserkultstätte in Aventicum. In : Koenig (F.E.), Rebetez (S.), Arculiana. Recueil d'hommages offerts à Hans Bögli, Avenches, 1995, p. 15-32. 


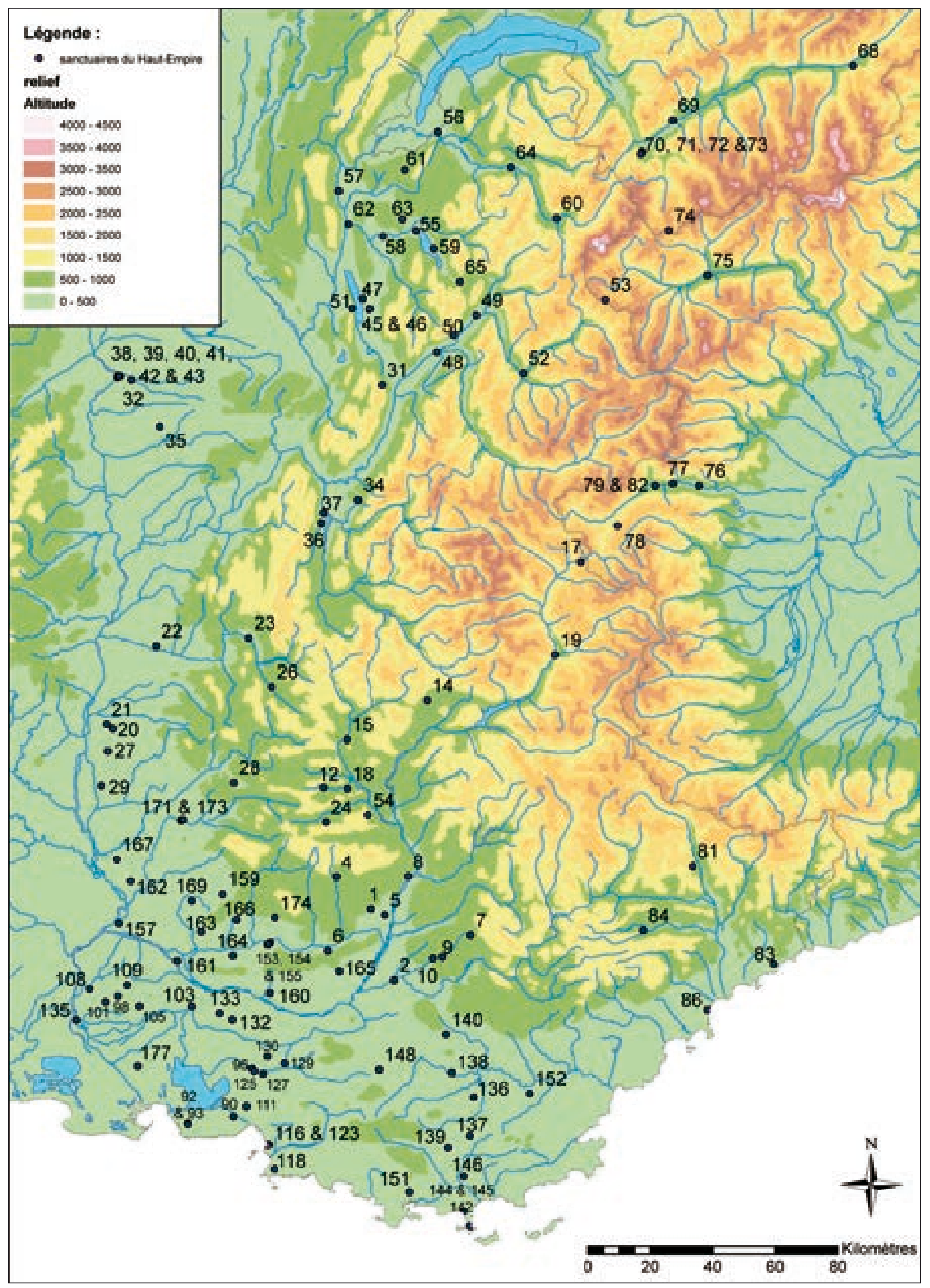

Fig. 1. Carte de localisation des sanctuaires du Haut-Empire dans le Sud-Est de la Gaule ; $n^{\circ} 20$ : Allan, Beauvoir ; $n^{\circ} 29$ : Saint-Vincent, Saint-Paul-Trois-Châteaux (Cartographie R. Golosetti). 


\title{
Deux lieux de culte de domaine foncier sous le regard croisé de l'archéologie, de la sculpture et de l'épigraphie : Saint-Vincent (Saint-Paul-Trois-Châteaux) et Beauvoir (Allan)
}

\author{
Raphaël Golosetti \\ docteur en archéologie \\ golosetti.raphael@gmail.com
}

\begin{abstract}
Résumé
Ces deux modestes sanctuaires dédiés aux Mères et établis sur un domaine foncier mettent en évidence la pertinence d'une démarche combinant l'étude des données épigraphiques et iconographiques dans leur contexte archéologique.

Ils alimentent également la réflexion sur le rôle des lieux de culte établis à proximité immédiate des établissements ruraux : la nature des cultes rattache ces sanctuaires à la fois au monde agraire, aux espérances personnelles voire au monde des ancêtres des divers membres de la communauté vivant dans l'établissement. Ce dossier conduit aussi à rouvrir une piste de recherche stimulante quant à la relation entre le culte des Mères et d'autres divinités collectives féminines telles que les Proxsumes.

Enfin une ouverture vers le reste de la Gaule démontre la fréquence de ce type de lieu de culte associé à une uilla, par ailleurs très souvent destiné à des cultes et pratiques très proches.
\end{abstract}

Mots-clés : Sanctuaire, monde rural, déesses Mères, vallée du Rhône.

\begin{abstract}
These two small shrines dedicated to Matres/Matrae goddesses and established on a land area highlight the relevance of an approach that combines the study of epigraphic and iconographic data in their archaeological context.

They also feed the debate on the role of places of worship established in the immediate vicinity of rural settlements: the nature of religion connects these shrines to the agrarian world, personal expectations and perhaps to the world of the ancestors of various members of the community living in the settlement. This corpus also invites to reopen a stimulating research question on the relationship between worship of these goddesses and other collective female divinities such as Proxsumae.

Finally an opening to the rest of Gaul shows the frequency of this type of place of worship associated with a uilla otherwise very often for cults and practices closely.
\end{abstract}

Key-words: Sanctuary, rural world, Matres/Matrae, Rhône valley. 


\section{Introduction}

L'objectif premier de ce travail est de répondre, dans le monde rural et dans le domaine cultuel, à la question centrale de ce colloque sur les « rapprochements entre blocs sculptés et textes épigraphiques provenant d'un même monument, d'un même complexe monumental ou d'un même site ». Le but second est d'insister sur le fait que blocs sculptés et/ou inscrits doivent être perçus comme des objets archéologiques et que par conséquence ils doivent toujours être replacés, quand cela est possible, dans leur contexte archéologique. Nous irons donc un petit peu plus loin que la démarche de ce colloque en précisant qu'on ne doit pas dissocier étude épigraphique et étude des blocs sculptés d'une analyse archéologique.

Face à ce double objectif, le choix s'est alors porté sur deux sites voisins de Gaule Narbonnaise, plus précisément de la moyenne vallée du Rhône (fig. 1) parce qu'ils mêlaient ces trois sources dans un cadre commun, celui des lieux de culte établis sur des domaines fonciers. Ils offraient aussi l'opportunité de sortir de l'espace de représentations usuellement présenté qu'est le monde urbain et de s'intéresser aux initiatives privées et individuelles.

De ce dossier extrait d'une thèse récente (Golosetti 2009), nous souhaitons débuter par le site de SaintVincent (Saint-Paul-Trois-Châteaux ; Drôme) avant de présenter celui du quartier Beauvoir à Allan (Drôme). Nous ouvrirons ensuite par une démarche comparative aussi bien sur la question des monuments sculptés, de la place du culte des déesses-Mères que des lieux de culte en relation avec des établissements ruraux.

\section{Saint-Vincent : confrontation des sources iconographiques et du contexte archéologique}

À seulement $600 \mathrm{~m}$ des remparts augustéens du chef-lieu Augusta Tricastinorum, colonie latine (Odiot, Bois 1992, 23), il a été reconnu, à proximité d'une uilla observée tout d'abord sur des photographies aériennes de L. Monguilan puis par une fouille au début des années 80 (Odiot, Raynaud 1992, 117), un édifice quadrangulaire $(5,45 \times 5,6 \mathrm{~m})$ interprété comme un « fanum ${ }^{1}$ »

1. Nous employons avec précaution mais pour des commodités de langage le terme de «fanum » (entre guillemet et sans italique pour le différencier du terme latin) en raison de son utilisation courante dans le discours archéologique et en particulier pour ce site. Nous par les fouilleurs, l'absence de galerie pouvant résulter de l'arasement des niveaux de sol (fig. 2). Il s'installe à l'époque augustéenne (état I) à proximité d'un édifice $\mathrm{A}$ $(66,8 \times 16 \mathrm{~m})$ dont le plan est à rapprocher des petites uillae connues dans la Somme. La uilla connaît une extension à la période flavienne avec l'ajout d'une aile, définissant un espace de $1700 \mathrm{~m}^{2}$ dont le plan à cour centrale, la porte charretière et la présence de deux bassins suggéreraient la fonction agricole mais l'éventuel lieu de culte (bâtiment B) perdure sans modifications visibles jusqu'à l'abandon de l'ensemble dans la seconde moitié du II s. ap. J.-C. (Odiot, Raynaud 1992, 118-121).

Les données archéologiques sont insuffisantes pour caractériser un lieu de culte : le plan n'est guère pertinent et le mobilier ${ }^{2}$ recueilli uniquement dans les tranchées de fondation du bâtiment ne l'est pas davantage. L'interprétation cultuelle de l'édifice B provient surtout de la découverte, en remploi dans les murs d'une construction moderne (Odiot, Raynaud 1992, 17), de quatre bas-reliefs composés des scènes de trois personnages féminins assis dans une niche ou en buste, parfois porteurs de corbeille de fruits et parfois accompagnés d'un autel (Blanc 1967, 67-69) (fig. 3). D'après surtout une des ses représentations sculptées, ce sanctuaire a été rattaché au culte des déesses-Mères jusqu'à très récemment (Odiot, Raynaud 1992 ; Lert et alii 2009, 152-153). Or une reprise de la documentation et du parallèle effectué déjà par $\mathrm{A}$. Blanc $(1967,69)$ avec le lieu de culte de Beauvoir (Allan) destiné aux Mères victorieuses s'avère nécessaire.

Alors que l'édifice de Beauvoir à Allan est sans conteste destiné à un culte aux déesses-Mères, le rôle de ces dernières à Saint-Vincent ne repose que sur la similarité entre un seul des monuments de Saint-Paul-Trois-Châteaux et un monument représentant trois déesses-Mères à Allan (Espérandieu 1907, n⿳327 ; fig. 4) : ce bloc ${ }^{3}$ en molasse calcaire supporte la représentation de trois personnages féminins assis dans une niche profonde et vêtus d'une tunique longue, alors que des corbeilles de fruits ronds sont posées sur leurs genoux (Blanc 1967, 67). Par conséquent, ce bas-relief renvoie sans doute possible à une image de déesses-Mères, représentation confirmée d'une manière claire au sein de l'édifice de Beauvoir par l'épigraphie si besoin était.

précisons ici que nous comprenons ce terme dans son acception archéologique soit synonyme de temple de tradition gallo-romaine ou à plan centré ou encore à galerie périphérique selon les différentes expressions empruntées.

2. Céramique sigillée de type italique et sud-gauloise, céramique commune.

3. $0,4 \mathrm{~m}$ de haut pour $0,55 \mathrm{~m}$ de large. 


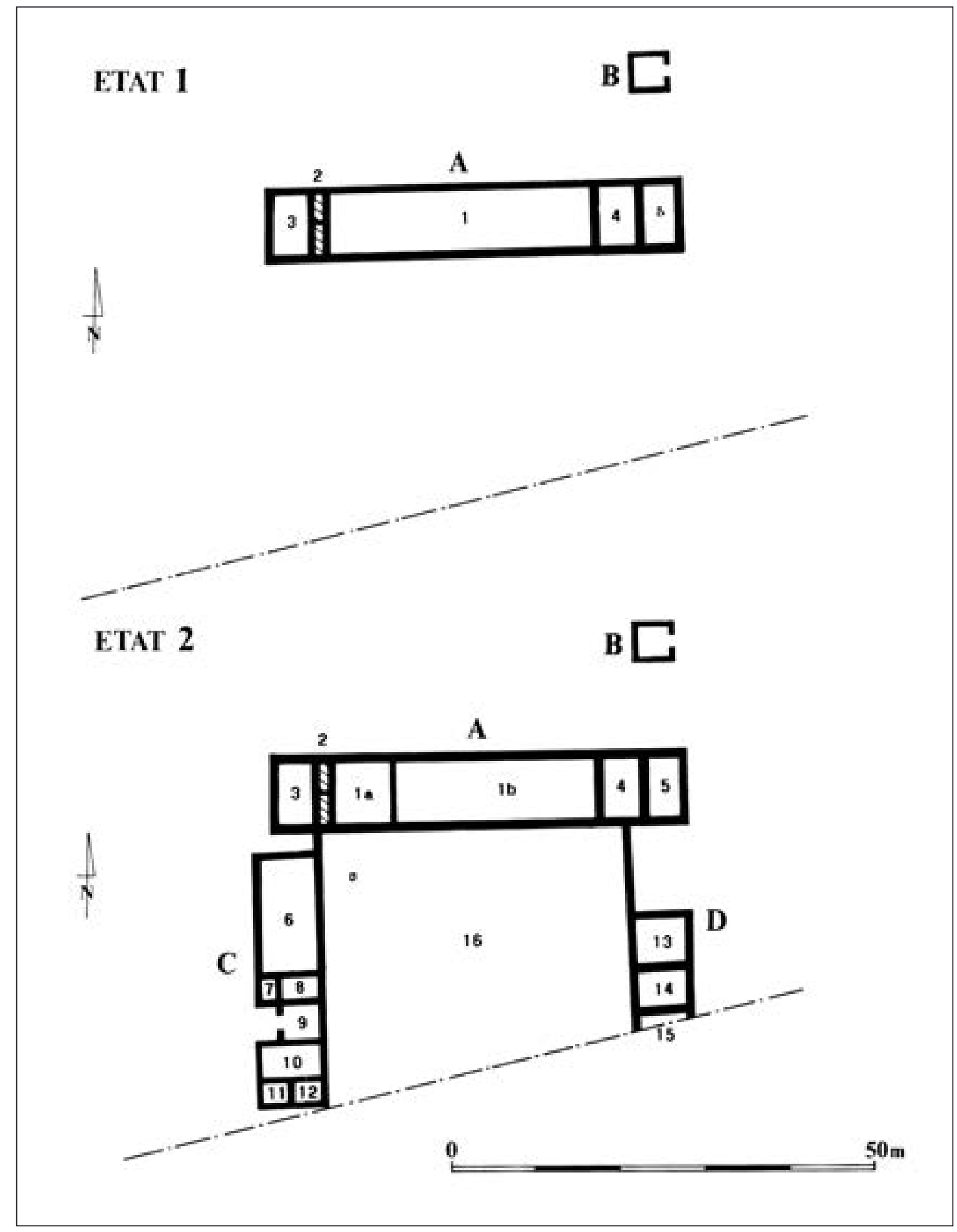

Fig. 2. Plan des structures du site de Saint-Vincent (Saint-Paul-Trois-Châteaux, Drôme) (dans Odiot, Raynaud 1992, 120, fig. 82). 
La seule présence, réelle, d'un bas-relief représentant les déesses-Mères à Saint-Paul-Trois-Châteaux n'est néanmoins pas suffisante pour assimiler les autres monuments découverts en remploi à ses côtés comme relevant d'une même référence.

Tout d'abord décrivons ces monuments (fig. 3) :

Une niche «en pierre à grain grossier » à sommet triangulaire de $0,53 \mathrm{~m}$ de haut et $0,42 \mathrm{~m}$ de large livre dans sa partie inférieure la représentation en bas-relief d'un autel avec base et couronnement et dans sa partie supérieure trois bustes de personnages féminins drapés et voilés (Blanc 1967, 69).

Une autre niche $(0,40 \times 0,27 \mathrm{~m})$ très semblable à la précédente et réalisée dans le même matériau, avec fronton triangulaire portant une rosace à sept pétales et bouton central, possède dans son registre inférieur un autel avec base et couronnement et dans son registre supérieur quatre têtes mutilées (Blanc 1967, 69).

Enfin une dernière niche $(0,52 \times 0,35 \mathrm{~m})$, à fronton triangulaire également, présentait un autel avec base et couronnement en bas et en haut quatre têtes mutilées portant les traces d'une coiffure (Blanc 1967, 69).

Depuis A. Blanc (1967) et jusqu'à récemment (Odiot, Raynaud 1992, 117, Rouillon 1996, 103-104 ; Lert et alii 2009, 152), ces monuments étaient interprétés comme des représentations de déesses-Mères, à l'appui du premier monument. S'agit-il réellement de déesses-Mères ? Le nouvel examen de ces bas-reliefs conduit à nuancer l'identification.

Tout d'abord, en Narbonnaise, S. Rouillon (1996) ne comptabilise que six représentations de déesses-Mères dont trois correspondent à celles d'Allan et Saint-Paul. Hormis un bas-relief de Saint-Paul-Trois-Châteaux, toutes les autres figurations de déesses-Mères qu'elle recense n'associent jamais la représentation d'un autel aux déesses-Mères et surtout ces dernières sont le plus souvent assises, parfois debout mais jamais en buste. Outre la statue en calcaire d'une déesse-Mère (Lantier 1966, 20, $\mathrm{n}^{\circ} 8687$ ) tenant une corbeille contenant des fruits ronds et découverte en place dans une niche aménagée aux abords de la voie conduisant à la source à Glanum (Rolland 1953, 12-13) ${ }^{4}$, on peut évoquer l'autel

4. On l'associera au fragment d'un avant-bras tenant des épis (Rolland 1958, 87) et surtout on qualifiera ces Mères de Mères Glaniques à la lecture d'une stèle de 1,65 m de haut découverte en place au pied de la niche (Rolland 1953, 13 et 17) et surtout d'un découvert à Vaison (Espérandieu 1907, n²83; Rouillon 1996, 105-106 ; Provost, Meffre 2003, 112 fig. 69-70) ou encore un autel de Vienne ${ }^{5}$ en calcaire blanc sur lequel sont représentés trois personnages féminins : l'un assis, les deux autres debout.

Face à ces représentations en buste, la première démarche a été d'aller chercher dans le domaine funéraire des représentations comparables car les bustes d'au moins deux bas-reliefs de Saint-Vincent rappelaient les stèles à portraits ${ }^{6}$. Par ailleurs, la forme générale de ces monuments avec leur fronton triangulaire renvoyait bien à une stèle. Enfin la présence de la rosace au centre d'un fronton sur un des documents se retrouve par exemple sur les exemplaires de stèles funéraires du Piémont (Mercando, Paci 1998, pl. CXXIV).

Une recherche dans la Base Nesp sur les stèles funéraires dans le Sud-Est de la Gaule offre alors toute une série de stèles et bas-reliefs ${ }^{7}$ avec une telle représentation de bustes. Doit-on comprendre ces trois monuments de Saint-Vincent comme des monuments funéraires ? F. Benoit $(1970,16)$ les interprétait d'ailleurs comme des «stèles-maisons » représentant le laraire familial avec bustes des défunts.

Cette hypothèse d'une référence au monde funéraire n'est pas totalement satisfaisante: à aucun moment, nous ne trouvons dans les stèles à portraits la présence d'un autel en association dans le registre inférieur. Par ailleurs, on peut noter avec prudence que les têtes représentées sur les monuments dont il est question ici sont frustes : or généralement l'art funéraire exige un certain effort pour reconnaître le genre du personnage voire quelques détails anatomiques ${ }^{8}$.

Ne renvoyant guère ni aux représentations usuelles des déesses-Mères ni aux stèles à portraits, ces basreliefs en remploi avec celui des déesses-Mères dans une dépendance d'une ferme du quartier Saint-Vincent

autel en calcaire découvert sur le sol de la voie portant une inscription en gallo-grec aux Mères Glaniques (Lejeune 1985, 76, G-64)

5. Vu longtemps au-dessus de la porte d'une petite tour s'élevant au-dessus des ruines romaines à Sainte-Blandine (Lavagne et alii 2003, n¹00, pl. 113).

6. Je profite de ce point pour remercier de leur aide sur cette question de l'identification, E. Rosso et V. Gaggadis-Robin, CCJ/UMR 7299.

7. On évoquera sans exhaustivité des stèles funéraire à portraits de Narbonne (NARB 054, 057, 63), de Nîmes (NIM 461 et 462) ou encore de Lyon (LYO 277). Les numéros renvoient à la Base Nesp. http://nesp.mmsh.univ-aix.fr/

8. Renseignement oral E. Rosso. 


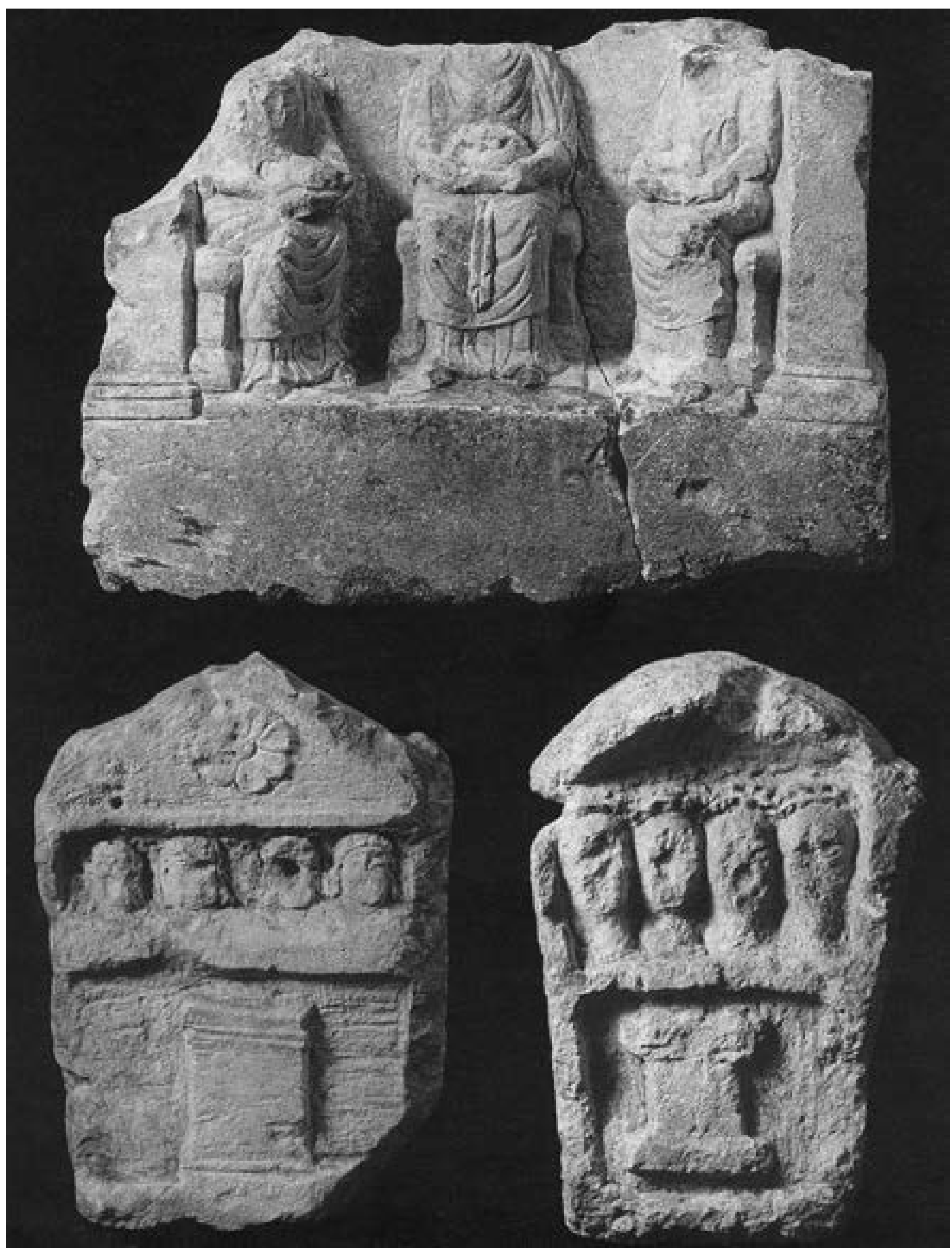

Fig. 3. Bas-reliefs de Saint-Vincent (Saint-Paul-Trois-Châteaux, Drôme) (cliché musée SPTC dans Odiot, Raynaud 1992, 119, fig. 79-81 et Blanc 1967, 70, fig. 3). 


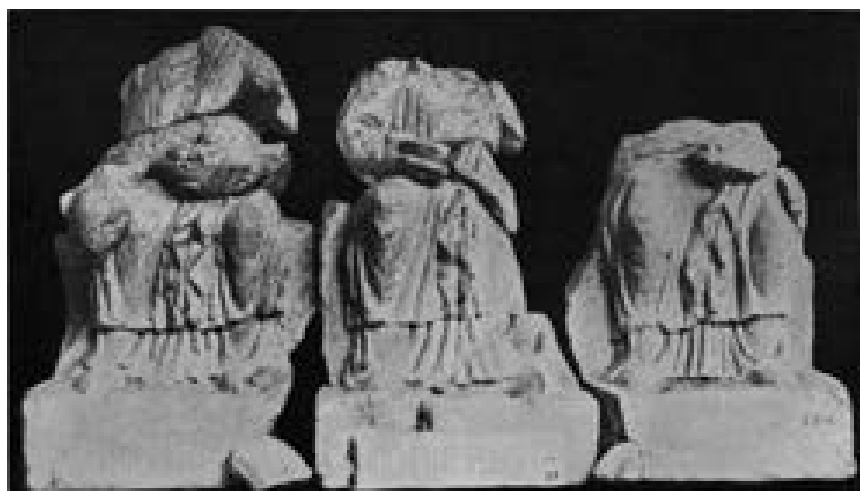

Fig. 4. Monument sculpté aux déesses-mères de l'édifice du quartier de Beauvoir à Allan (Drôme) (d'après Espérandieu 1907, 241, n³27).

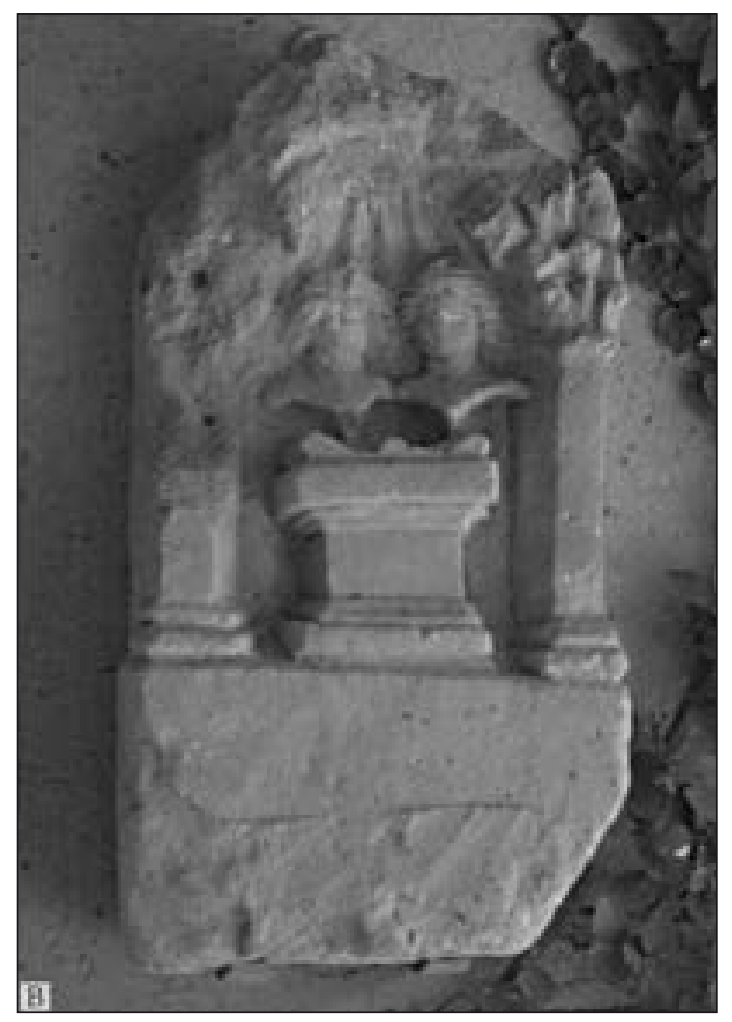

Fig. 5. Monument découvert sur la colline Sainte-Juste à Saint-Paul-Trois-Châteaux

(cliché M. Lert ; Lert et alii 2009, fig. 244B).

forment donc des documents originaux. Or une découverte jusque là inédite a été récemment publiée: provenant du côté nord-ouest de la colline Saint-Juste à Saint-Paul-Trois-Châteaux, il s'agit d'un monument très proche des précédents ayant la forme d'une stèle (la base dégrossie signalant sans doute la partie enterrée) portant la représentation, entre deux pilastres, d'un autel au-dessus duquel apparaissent deux bustes surmontés d'une coquille (Lert et alii 2009, 153 et fig. 244B ; fig. 5).
Nous trouvons ainsi un premier monument proche ${ }^{9}$ des précédents, malgré des bustes au nombre de deux seulement, et provenant d'un secteur très proche puisque la colline Sainte-Juste se situe à un peu plus de $1 \mathrm{~km}$ au sud-est du quartier Saint-Vincent, à environ $600 \mathrm{~m}$ au sud de Saint-Paul-Trois-Châteaux. Malheureusement ce nouveau document est anépigraphe et sans contexte archéologique: il ne permet guère d'avancer dans l'identification.

Face à l'originalité des monuments à bustes de Saint-Paul-Trois-Châteaux, nous avons recherché des représentations équivalentes : or cela a permis de comparer des documents jusque là jamais rapprochés entre eux. Pourtant anciennement découverte (Espérandieu 1928, X, n 7453 ), une petite stèle en marbre de $0,42 \mathrm{~m}$ de haut et $0,31 \mathrm{~m}$ de large en forme de niche cintrée vient avantageusement enrichir notre réflexion (fig. 6). Provenant de Bollène (Vaucluse), plus exactement de l'oppidum de Barry, à environ $4 \mathrm{~km}$ au sud de SaintPaul-Trois-Châteaux, cette stèle porte la représentation de trois bustes de femmes en haut relief au-dessus d'un petit autel (Buisson 1997; Roumégous 2009, 147). La même composition que pour les monuments de Saint-Paul-Trois-Châteaux apparaît à nouveau dans un rayon proche : mais au-delà, ce document est intéressant par l'inscription ${ }^{\mathbf{1 0}}$ qu'il porte : Beratiae p? ur ?iiiai [.]roxsumas / sibi et suis. Pour la première fois, nous pouvons associer un culte à ce type de représentation : il s'agit des Proxsumes. Or comme le fait remarquer A. Buisson (1997, 271), le caractère funéraire de la formule sibi et suis semble confirmer une référence au monde funéraire de ces représentations, hypothèse déjà plus ou moins formulée. Mais les différentes hypothèses relatives aux Proxsumes (Buisson 1997 pour une synthèse) rendent compte indirectement de la difficulté à définir ce culte.

Quoi qu'il en soit, si on estime que les monuments en remploi dans le mur moderne de Saint-Vincent formaient un ensemble cohérent de représentation, nous devons supposer un espace cultuel juxtaposant un culte aux déesses-Mères et un culte aux Proxsumes. Cette juxtaposition est tout à fait admissible puisque généralement ces divinités féminines collectives, sont rapprochées des déesses-Mères.

9. A. Blanc $(1967,69)$ rapprochait un autre monument (Espérandieu 1907, n³29) provenant du quartier Saint-Vincent : certes on y retrouve entre deux colonnes la figuration d'un autel et de quatre personnages placés dans une niche en forme de coquille mais ces derniers sont debout et parfaitement identifiables (deux femmes et deux hommes). La similitude est donc bien moins forte.

10. CIL XII, 1251 et AE. 1997, 1046. 

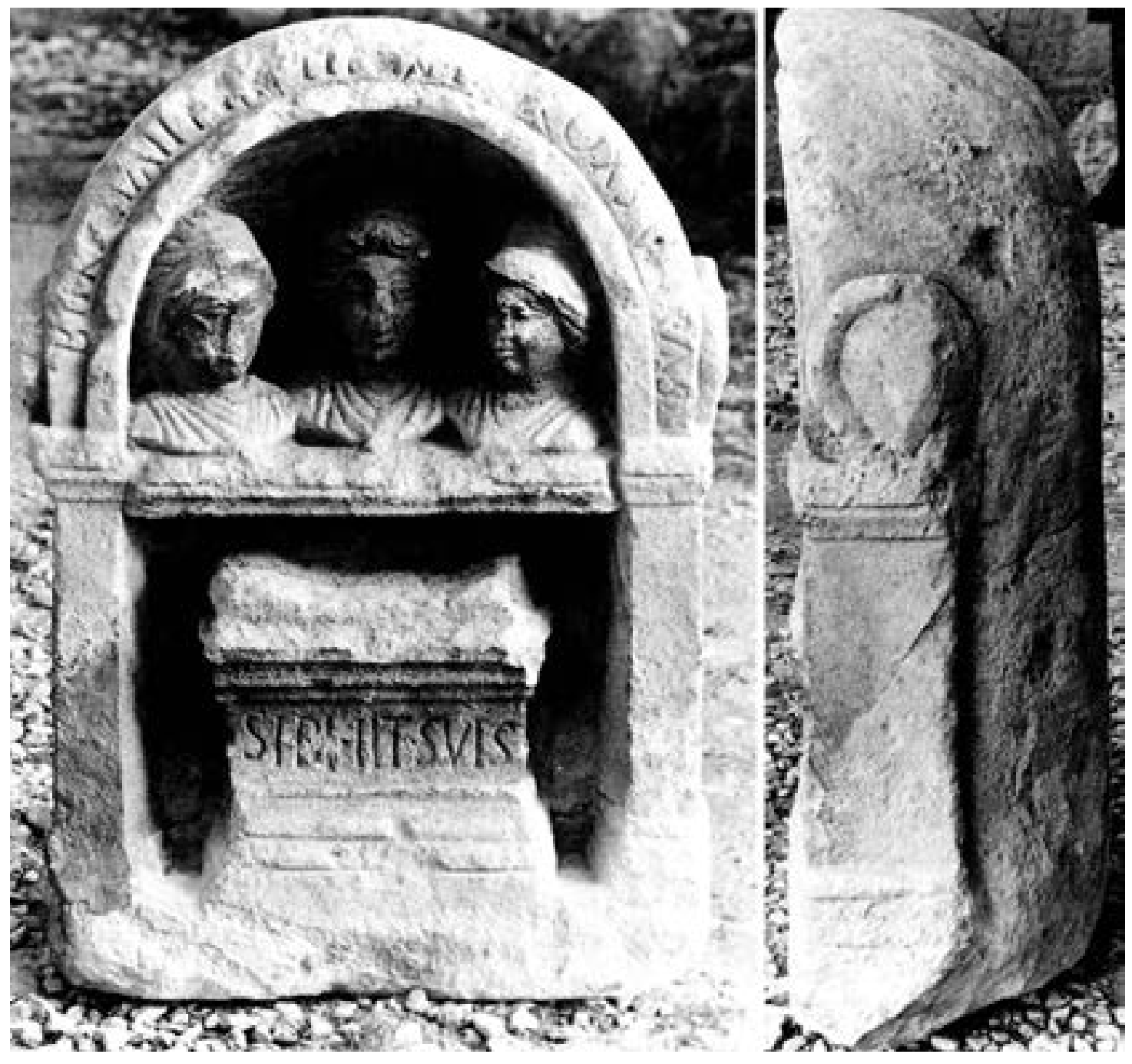

Fig. 6. Vue de face et de profil du monument découvert à Bollène (84) (Buisson 1997, 270, fig. 1-2).

A. Buisson (1997, 272-273) a réétudié le monument de Bollène et a recherché des comparaisons mais n'a jamais fait le rapprochement avec ceux de Saint-PaulTrois-Châteaux. Néanmoins, il semble que tout cela forme un dossier cohérent concentré géographiquement autour d'Orange et Saint-Paul-Trois-Châteaux et caractérisé par ces représentations de trois bustes de divinités au-dessus d'un autel. Le monument de Bollène permet d'identifier ces divinités, comme les Proxsumes et d'interpréter ces représentations comme un type de monument bien circonscrit jusqu'à présent au sein d'une zone plus vaste où se concentre le culte aux Proxsumes à savoir la basse vallée du Rhône.

Ce culte aux Proxsumes ferait-il donc écho au basrelief aux déesses-Mères en remploi aux côtés des monuments de Saint-Vincent? Doit-on revenir à l'idée d'une représentation en bustes de déesses-Mères ? Nous l'avons évoqué, H. Lavagne $(1979,192)$ rapproche
Matrae et Proxusmae (avec d'ailleurs les Fatae, Junones et Nymphes) notamment en raison de leurs « ressemblances iconographiques ». Mais ces divinités féminines collectives, généralement représentées par trois comme les déesses-Mères, que sont les Proxsumes sont comprises par H. Lavagne comme des « genii familiers qui protègent l'individu dans sa vie quotidienne ». Le rapprochement que font M. Christol et M. Janon $(1986,267)$ entre les Parques honorées dans les inscriptions du sud de la Gaule et les Proxsumes est intéressant sur ce point : car ces Parques correspondraient en fait à des divinités indigènes collectives, comme le sont les Proxsumes, qui auraient été réinterprétées dans le Sud de la Gaule sous la forme romaine des Parques. Il a été mis en parallèle la triade des Parques avec celle usuelle des déesses-Mères pour expliquer ce phénomène d'interpretatio mais on ne peut penser que la société indigène de Narbonnaise n'ait pas pris en compte également dans cette réinterprétation le rôle dans le monde romain des Parques, à 
savoir la destinée. On peut ainsi penser que Parques ou Proxsumes renvoient à des divinités indigènes domestiques liées à la destinée de l'individu ${ }^{11}$. Le nom même des Proxsumae, «les plus proches", va dans ce sens puisqu'on évoquera jusqu'à une intimité entre dédicants et Proxsumes, « la dédicante [faisant] elle-même presque partie des Proxsumes » (Buisson 1997, 271). De plus, l'association des Proxsumes avec le culte du Numen sur un autel d'Orange (AE 1940, ${ }^{\circ} 137$; Buisson 1997, 274) confirme l'interprétation de divinités personnelles. Si la sociologie des dédicants marque une dominante féminine, les hommes ne sont pas absents dans le culte que ce soit comme dédicants ou comme bénéficiaires de l'intervention divine (Buisson 1997, 274). Les monuments de Saint-Vincent semblent donc renvoyer à des pratiques privées, dans le cadre d'une sorte de laraire familial. Le contexte de découverte de ces monuments, à proximité d'une uilla, est d'ailleurs tout à fait en accord avec celui le plus souvent au sein d'habitats antiques, des dévotions aux Proxsumes.

Bien qu'elles soient également représentées au nombre de trois, on ne peut sur ce simple fait les assimiler avec les déesses-Mères. Certes, elles pourraient être associées au sein du lieu de culte de Saint-Vincent mais cela n'est pas vérifié et surtout leur association au sein d'un même sanctuaire ne les définit pas comme similaires.

Nous serions tenté de penser que ces monuments de Saint-Vincent marquent bien une sorte de laraire familial où se côtoieraient les cultes domestiques en référence aux entités personnelles des habitants (Proxsumes) et un culte aux Mères dont le caractère agraire a dû sembler essentiel pour les résidents de l'établissement agricole. Ce type d'espace sacré ${ }^{12}$ est à l'image des lieux de culte domestiques décrits par W. Van Andringa (2009, 220221 et 267) dans la région du Vésuve où on retrouvait au sein d'un même aménagement les cultes aux divinités personnelles comme le Génie du maître de la maison (paterfamilias), les dieux Lares, divinités de la maisonnée et d'autres divinités en relation avec la vie quotidienne des résidents.

Une nuance cependant doit être apportée : ces lieux de culte domestiques étaient situés à l'intérieur de l'habitation et non, comme dans les cas de ce dossier,

11. Néanmoins, elles ont été également définies comme des «âmes divinisées des aïeuls » (citation reprise dans Buisson 1997, 271) ce qui renvoie toujours à une dimension funéraire.

12. Nous ne revenons pas sur la définition de l'espace sacré dans le monde romain. De tels lieux de culte n'étaient pas reconnus juridiquement comme des espaces sacrés ; le propriétaire était responsable du respect du lieu de culte (Van Andringa 2009, 239). à l'extérieur. De plus, leurs dimensions sont généralement plus réduites et lorsqu'ils prennent une envergure certaine, par exemple la "véritable chapelle ouvrant sur l'atrium » de la villa de San Marco à Stabies (Van Andringa 2009, 222), nous sommes loin des édifices de Saint-Vincent, de Beauvoir ou des quelques cas de Gaule que nous allons évoquer ci-après.

Par conséquent, doit-on réduire ces lieux de culte à proximité des uillae à des lieux de culte domestiques ou étaient-ils destinés à une communauté plus large que la familia qui honorait les Lares (Van Andringa 2009, 244)?

Enfin, revenons avec une extrême prudence sur le rapport avec le monde funéraire de ces stèles. Nous avons rappelé l'hypothèse de F. Benoit $(1970,16)$ d'un laraire familial avec bustes des défunts. Certes, un autel découvert à Laumellum (Italie) ${ }^{13}$ supporte, dans une même composition, une scène de sacrifice (représentation d'un autel, d'un taureau et d'un officiant) et la représentation de plusieurs bustes au-dessus de la scène et interprétés comme des imagines maiorum dans le cadre d'un culte des ancêtres (Maccabruni 1988 ; fig. 7). Nous retrouverions dans cette composition l'association singulière retrouvée dans le sanctuaire de la maison de Ménandre : dans une exèdre de l'angle sud-ouest du portique de cette domus, étaient associées deux statuettes encadrant trois bustes grossièrement sculptés (Van Andringa 2009, 267). Les statuettes auraient représenté Mercure et éventuellement un dieu Lare alors que les bustes auraient été des imagines maiorum. Mais W. Van Andinrga (2009, 269) insiste sur le fait qu'aucun témoignage littéraire ou archéologique atteste d'un culte des ancêtres célébré dans le cadre domestique. Par conséquent, l'hypothèse d'un laraire familial dans lequel auraient été présents des références aux ancêtres ne trouve pas de confirmation.

Par ailleurs il faut insister sur le fait que l'autel de Laumellum est un monument votif puisque l'inscription ${ }^{14}$ qu'il porte comporte la formule $u$ (otum) s(oluit) l(ibens) $m$ (erito) usuelle. Malheureusement, si nous connaissons le dédicant, la divinité honorée n'est signalée que par l'initiale $M(. .$.$) qui laisse certes la possibilité$ de $M$ (atrae) ou M(atronae) mais bien d'autres divinités sont envisageables. Si on accepte l'idée que les bustes représentés soient réellement des portraits d'ancêtres, plus qu'un culte des ancêtres sur lequel des doutes sont émis, nous aurions sur ce monument la représentation

13. Je tiens à remercier Matteo Cadario (Università degli studi di Milano) pour m'avoir communiqué cette information.

14. CIL V, 6471. 


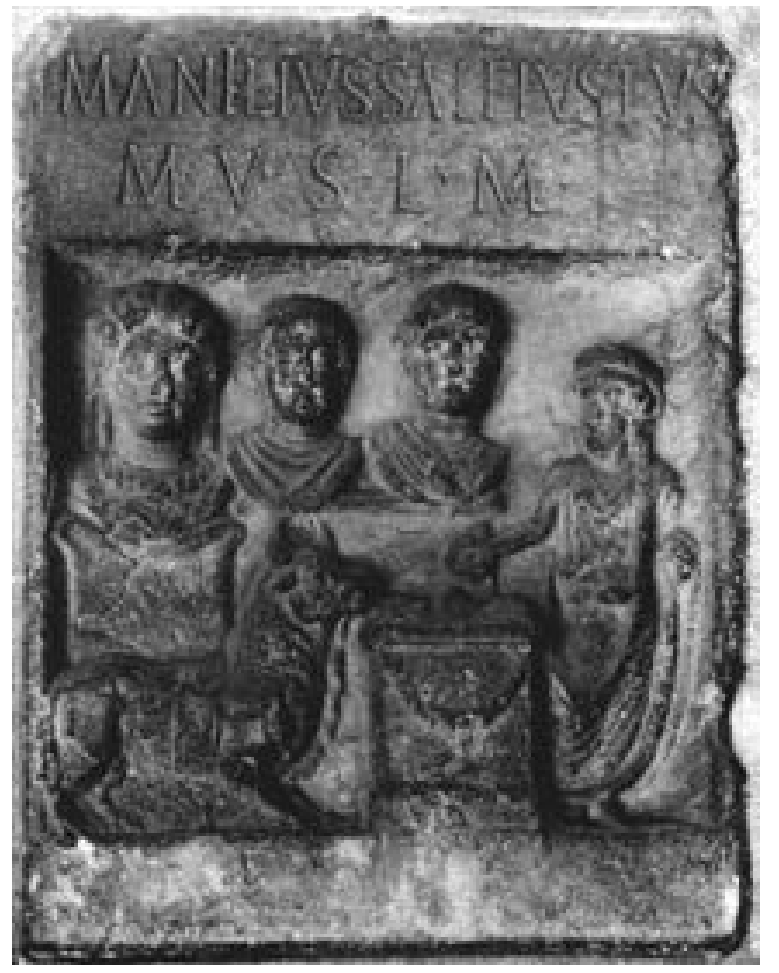

Fig. 7. Autel de Manilius lustus (C.I.L. V 6471) découvert à Laumellum (Italie) (d'après Massara 2002, p. 52, fig. 11).

d'une scène usuelle d'un culte domestique auprès duquel les imagines maiorum auraient été amenées. Lorsque W. Van Andringa (2009, 244) évoque la situation des laraires dans la maison, il précise que les Lares pouvaient être situés « au côté du génie du paterfamilias dans l'atrium près des portraits de famille ». Nous aurions donc sur cet autel la représentation d'un sacrifice dans le cadre d'un culte domestique auquel assistaient les portraits des ancêtres sans pour autant en déduire un culte des ancêtres.

Nous voyons donc que la question soulevée par ces monuments est loin d'être résolue. Alors que l'identification des bustes comme une représentation de déesses-Mères n'est pas certaine, la référence à des bustes des ancêtres n'est pas satisfaisante non plus. Nous nous en tenons donc à des monuments offerts aux divinités domestiques, les Proxsumes, agissant pour le bien des individus de la uilla, un peu à l'image des dieux Lares, dieux principaux de la maison, gardiens de la famille (Van Andringa 2009, 256). Il demeure le problème de la référence au domaine funéraire que laissent entrevoir aussi bien la forme du monument que le formulaire de l'inscription de Bollène. Pourquoi une telle proximité avec le monde funéraire qu'un laraire ou un culte à des divinités de la destinée ou du génie personnel ne légitimeraient pas?
En conclusion, le lieu de culte à proximité immédiate de l'établissement rural de Saint-Vincent, à seulement $10 \mathrm{~m}$ au nord du bâtiment $\mathrm{A}$, et dont la contemporanéité plaide en faveur d'un lieu de culte attaché à l'établissement rural, a pu accueillir des cultes personnels (Proxsumes par exemple) ainsi que des cultes liés aux besoins des habitants (déesse-Mère). On peut alors s'interroger sur la cohabitation voire l'association des cultes aux Proxsumes et aux Mères au sein d'un même lieu de culte.

Malgré cette révision de l'analyse des bas-reliefs de Saint-Vincent, la comparaison avec le lieu de culte de Beauvoir, à environ $19 \mathrm{~km}$ au nord-est, demeure très pertinente.

\section{Le lieu de culte du quartier Beauvoir à Allan : un dossier riche}

Le site nous est connu sous la forme d'un édifice (fig. 8) de 9,6 x 4,10 m comportant deux salles symétriques de part et d'autre d'une salle de dimensions plus réduites. Cette salle centrale donnait accès aux deux autres et était ornée d'une colonne de part et d'autre de l'entrée (deux bases de colonnes ayant été retrouvées en place).

Il a été interprété comme un espace cultuel, malgré un plan original, en raison de la découverte de dix exvoto $^{15}$ aux Mères Victorieuses inscrits sur des plaques en marbre ou en calcaire tendre et dédiés par le même individu, Niger, esclave de Caius Satrius Silus, intendant du cellier du domaine Anarias, de fragments d'autel (Vallentin du Cheylard 1957, 71) et de trois fragments d'un même monument représentant trois déesses-Mères (fig. 4). Il ne fait ainsi aucun doute que cet édifice accueillait un culte aux Mères et le statut du dédicant met en évidence la relation de ce lieu de culte avec un domaine rural. Par contre, l'identification par F. Benoit

15. ILGN, 257a-i \& AE 1907, 39-40 \& Planchon, Bois, ConjardRéthoré 2010, 151-152:

- Matris [Vic]tricibus / [u(otum)] s(oluit) [l(ibens)] m(erito) / Niger, C(ai) Satri Sili (seruus), / cellarius[s] Anariate /d(e) [s(uo)]d(edit)

- [Matri]s Victricibus Niger / ---

- Matris Victric[ibus] / N[iger ---] / ---

- Matris V[ictricibus] / dedica[uit Niger ? ---] / ---

- Matris [---]/---

- Matris / Niger Sili (seruus) / ---

- [Ma]tris [---]/ ---

- -- Niger C(ai) S(atri) S(ili) (seruus) d(e) s(uo) d(edit)

- --- / [---]CI+[---] / [---]+[---]+T XIIII k(alendas) M[---] /

[---]an[o ---]to co (n)s(ulibus) $+/[---d(e) s($ uo $) d]$ edit

- [Si?]li 
$(1970,16)$ et G. Barruol $(1994,55)$ d'un «fanum » à double cella est discutable tant le plan de l'édifice est original et ne présente en rien la caractéristique d'une cella entourée d'une galerie. Par ailleurs, la figuration sur le plan de Vallentin du Cheylard (1957, 70, fig. 1) de deux murs sectionnés reste énigmatique.

On notera la présence d'un bassin de "grandes briques » au fond de la salle centrale. Il était alimenté par une conduite extérieure et «s'écoulait par un canal ouvert dans un fossé longeant l'ensemble de la façade ». Le rôle de ce bassin dans l'activité rituelle pourrait être marqué par la répartition des plaques mutilées adressées aux Mères selon les propos de Vallentin du Cheylard $(1957,71)$ mais la fig. 8 ne permet pas de relier directement les plaques au bassin tout en démontrant la situation centrale de celui-ci. Il convient de signaler également la qualité de l'édifice dont témoignent, outre les bases de colonnes déjà mentionnées, des « fragments de stuc colorié », d'une inscription en marbre, d'un dallage de marbre dans la pièce centrale (Vallentin du Cheylard 1957, 70).

Au plan non caractéristique d'un lieu de culte, s'ajoute un mobilier ${ }^{16}$ pas toujours pertinent pour l'interprétation cultuelle même si plusieurs éléments récemment examinés (une quarantaine de lampes dont des miniatures, figurines en terre cuite, une vingtaine de monnaies) demeurent évocateurs. En revanche, point de doute avec les dix plaques mutilées inscrites découvertes en contexte, un fragment d'autel avec la légende ex uoto ainsi que des fragments d'autels anépigraphes découverts près de l'entrée de la salle de droite, à côté d'une statue des Mères (Vallentin du Cheylard 1957, 71).

16. La description du fouilleur évoque des «Plats en terre cuite», des lampes, des monnaies non décrites sauf une de Vespasien et une de Philippe un "plat et une «asperge» (sic) de bronze, des pommes de pin » (Valletin du Cheylard 1957, 71) et un «fragment d'une caisse en plomb» signalé uniquement sur le plan de l'édifice (Valletin du Cheylard 1957, 70, fig. 1) et enfin des ossements de faune. Un réexamen du mobilier de la collection Vallentin du Cheylard à Montélimar a permis de mieux qualifier certains objets votifs : la quarantaine de lampes de taille normale mais surtout la présence des lampes miniatures (avec nombreux ratés de cuisson), de petits vases votifs, de nombreuses figurines anthropomorphes et zoomorphes en terre rouge ou blanche et la vingtaine de monnaies d'Auguste à Constance II caractérisent relativement bien des pratiques votives. On signalera également la conservation, assurée par le milieu humide due à une source toute proche, d'offrandes végétales dans des écuelles. Il a été identifié des pommes de pin pignon ou pin parasol (pinus pinea) et des pignons avec leur coquille, des graines de légumineuses.(Planchon, Bois, Conjard-Réthoré 2010, 153).
En effet, dans «l'angle supérieur droit de la salle de gauche » (Vallentin du Cheylard 1957, 71), plusieurs fragments en pierre commune (Espérandieu 1907, $\mathrm{n}^{\circ} 327$ ) de trois personnages féminins assis et portant de longues tuniques appartenaient à un même monument sculpté (Ht : 0,8 m ; Larg. : 1,31 m ; Ep. : 0,33 m). La figuration féminine de gauche porte sur ses genoux une corbeille de fruits et tenait dans la main gauche un objet rond non identifié. Celle de droite connaît la même position avec la corbeille de fruits sur les genoux. Le personnage central soutient une patère (avec un " osselet » au fond ?) (Vallentin du Cheylard 1957, 71).

Parmi le matériel épigraphique, on évoquera tout d'abord la plaque moulurée de marbre blanc (haut. 0,40 m; larg. 0,70 m; épais. 0, $05 \mathrm{~m}$ ), brisée en plusieurs fragments avec un encadrement mouluré portant un texte très intéressant ${ }^{17}$ : Matris [Vic]tricibus / [u(otum)] s(oluit) [l(ibens)] m(erito) / Niger, C(ai) Satri Sili (seruus), / cellarius[s] Anariate / D(e) [s(uo)] d(edit). Le cellarius est défini comme le chef de l'office, (Gaffiot 1998) ou comme esclave de confiance, chargé de surveiller l'office (cella penonia) et le cellier (cella vinaria) appartenant à la classe des Ordinarii (serui) (Darembert, Saglio 1873-1919). Les autres plaques sont toutes offertes par le même dédicant Niger et honorent les Mères Victorieuses. Néanmoins, l'une d'entre elles se révèle plus intéressante: il s'agit d'une plaque incomplète de calcaire tendre, brisée en trois fragments et portant le texte ${ }^{18}$ : --- / [---]CI+[---] / [---]+[---]+T XIIII $k$ (alendas) $M[---] /$ [---]an[o ---]to co $(n) s($ ulibus $)+/$ [--- d(e) s(uo) d]edit. À la première ligne conservée, on peut envisager de restituer [Matris Victri]cib[us]; à la ligne 2, il faut penser au mois de mars (M[artias]) ou au mois de mai (M[aias]), sans pouvoir trancher entre les deux hypothèses; à la ligne 3 , le vestige de lettre pourrait être le $\mathrm{N}$ de N[iger]. Mais surtout le document pourrait conduire à une datation par le nom des consuls. A. Blanc avance " avec une certaine réserve » les noms de Iulianus et Torquatus, consuls en 148. Cela doit rester une hypothèse, car d'autres noms sont possibles (Planchon, Bois, Conjard-Réthoré 2010, 152). H. Desaye (1992, 30) souligne que la graphie ne s'oppose pas à cette datation mais d'autres dates consulaires restent néanmoins plausibles. Sur la

17. «Aux Mères victorieuses. S'est acquitté de son vœu volontiers et à juste titre Niger, esclave de Caius Satrius Silus, intendant du cellier du domaine Anarias. Il a donné (ce monument) à ses frais. » (Trad. Planchon, Bois, Conjard-Réthoré 2010, 151).

18. «... le 14 des kalendes de mars (ou de mai) ..., sous le consulat de ... a donné (ce monument) à ses frais ». 
question de la chronologie, la fourchette des monnaies recueillies (d'Auguste à Constance II) atteste tout d'abord d'une certaine durée de fréquentation qui dépasse la durée de vie de Niger. Par ailleurs, les formes des céramiques attestent bien un maximum de fréquentation entre 50 et 150 ap. J.-C. (Planchon, Bois, Conjard-Réthoré 2010, 153). On comprendra donc que le lieu de culte était certainement implanté anciennement et qu'il est abandonné peu de temps après sa fréquentation par l'intendant Niger.

En définitive, l'épigraphie livre l'évidence de la relation de ce petit lieu de culte à un domaine agricole privé dont on connaît le nom mais dont on ne sait où situer l'habitat. Si l'ancien inventaire disponible (Sautel 1939) ne recense aucun habitat rural dans un rayon de $5 \mathrm{~km}$, la parution récente de la carte archéologique de la Drôme permet d'évoquer quelques sites dans les environs : tout d'abord, le lieu-dit Beauvoir semble une zone d'exploitation antique d'après le matériel romain observé lors de sondages dans des niveaux de colluvions de cette cuvette de piémont d'environ 8 ha (Planchon, Bois, Conard-Réthoré 2010, 151). Mais l'établissement antique exploitant cette zone et en relation avec le sanctuaire installé sur la pente nord de la colline de la Ramette, n'est pas localisé. On signalera également, à environ $2 \mathrm{~km}$ au nord-ouest du sanctuaire, l'établissement agricole romain à cour de La Barque/La Grange Neuve 3, occupé de la deuxième moitié du ${ }^{\text {er }} \mathrm{s}$. jusqu'au début du III ${ }^{\mathrm{e}}$ s. ap. J.-C. (Planchon, Bois, ConardRéthoré 2010, 150-151). Enfin, trois autres sites antiques sont signalés sur la seule commune d'Allan (aux quartiers de Roibi, des Coudoulis et à la chapelle Barbara) (Planchon, Bois, Conard-Réthoré 2010, 153). Sur la commune d'Espeluche, aucun établissement antique ne semble fonctionner là encore avec ce sanctuaire : les quelques sites antiques évoqués sont éloignés de la zone (Planchon, Bois, Conard-Réthoré 2010, 360-361). L'agglomération la plus proche est proposée à 2,5 km au nord-ouest, au niveau des thermes de Bondonneau (Allan). Par conséquent, il est attesté un second exemple de lieu de culte accueillant un culte aux Mères et en relation avec un domaine privé.

En première conclusion, ces deux exemples mettent en évidence le développement de sanctuaires répondant aux besoins religieux d'un domaine rural. On peut d'ailleurs se demander si la présence du culte aux Mères se comprend par sa dimension agraire, culte somme toute logique dans un domaine agricole. Mais l'assimilation des déesses-Mères aux Proxsumes que proposent certains auteurs pourrait aussi renvoyer à une dimension de protection des individus.
L'intérêt de ces deux sites réside dans le parfait exemple de la complémentarité des sources qu'ils illustrent, offrant un contexte archéologique aux données épigraphiques et aux blocs sculptés. En outre ils offrent un dossier cohérent sur des lieux de culte de domaine foncier dans la cité des Tricastins et dans lesquels la référence aux déesses-Mères prend toute sa place.

Il est intéressant de mettre ces occurrences en parallèle avec l'évocation de Pline le Jeune (Lettres, IX, 39) d'un temple à Cérès situé sur un de ces domaines et fréquenté une fois par an par une foule nombreuse. Tout d'abord car avec Cérès, nous retrouvons la dimension agraire qui expliquerait le développement de ce culte sur un domaine agricole. Mais un autre point est également soulevé. En effet, la présence d'un seul dédicant ainsi que son statut sur le site de Beauvoir et le culte éventuellement en relation avec un culte des ancêtres ou en tout cas des Proxsumes sur Saint-Vincent nous situeraient dans le cadre de sanctuaires privés individuels/familiaux. Mais l'exemple du temple que Pline souhaite restaurer sur ces terres démontre qu'un sanctuaire de gestion privée, établi sur un domaine rural, a pu être fréquenté par une population dépassant le simple cadre domestique. Est-ce le cas pour ces deux exemples rhodaniens ?

\section{Lieux de culte et uillae : démarche comparative}

Dans le Sud-Est de la Gaule, la seule comparaison pertinente de la relation d'un lieu de culte avec un établissement rural est l'ensemble de La Valette, au sudouest d'Aix-en-Provence. Ce «fanum » dans la plaine alluviale de l'Arc (fig. 9), non dégagé par des fouilles, correspond à une structure composée de deux carrés concentriques $(15,9 \mathrm{~m}$ de côté - Soyer 1968, 201) et implantée au nord-est d'une importante construction de 31,8 x $53 \mathrm{~m}$ (uilla) et d'un tracé rectiligne d'une probable voie ancienne. Une prospection au sol n'a livré que de nombreuses tuiles et divers fragments non décrits (Soyer 1968, 205). La chronologie de l'occupation de l'ensemble (uilla et «fanum ») est située au HautEmpire d'après le matériel de surface recueilli (Marco, Mocci 1989, 110).

Si l'hypothèse d'un «fanum » (Marco, Mocci 1989, 110) n'est pas sans pertinence, d'autres interprétations ne sont pas écartées, par exemple un mausolée (Mocci, Nin 2006, 481). Par ailleurs, on insistera sur la prudence nécessaire dans l'identification de «fanum » à partir de photographies aériennes : ainsi à Lambesc, sur le site du Grand Verger: l'hypothèse d'un temple à double cella 


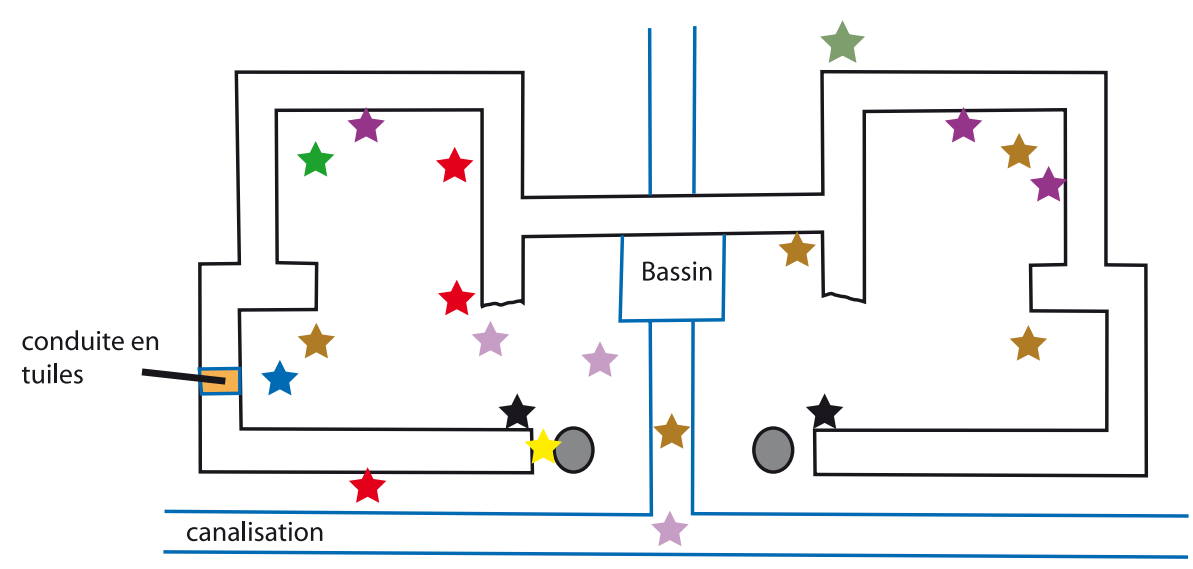

base de colonne

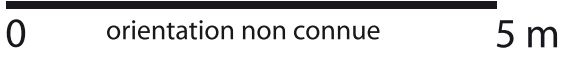

DAO R. Golosetti 2009

fragments de statue

fragments d'inscriptions aux Mères

fragments de tablettes inscrites

t> autel

autel avec inscription ex uoto

lampes, monnaies, vases, clous

1 plateau en bronze

fragments d'une caisse en plomb

Lames de plomb

Fig. 8. Plan de l'édifice de Beauvoir (Allan, Drôme) avec répartition des points de découverte d'une partie du mobilier (Dessin R. Golosetti d'après Vallentin du Cheylard 1957, 70, fig. 1).

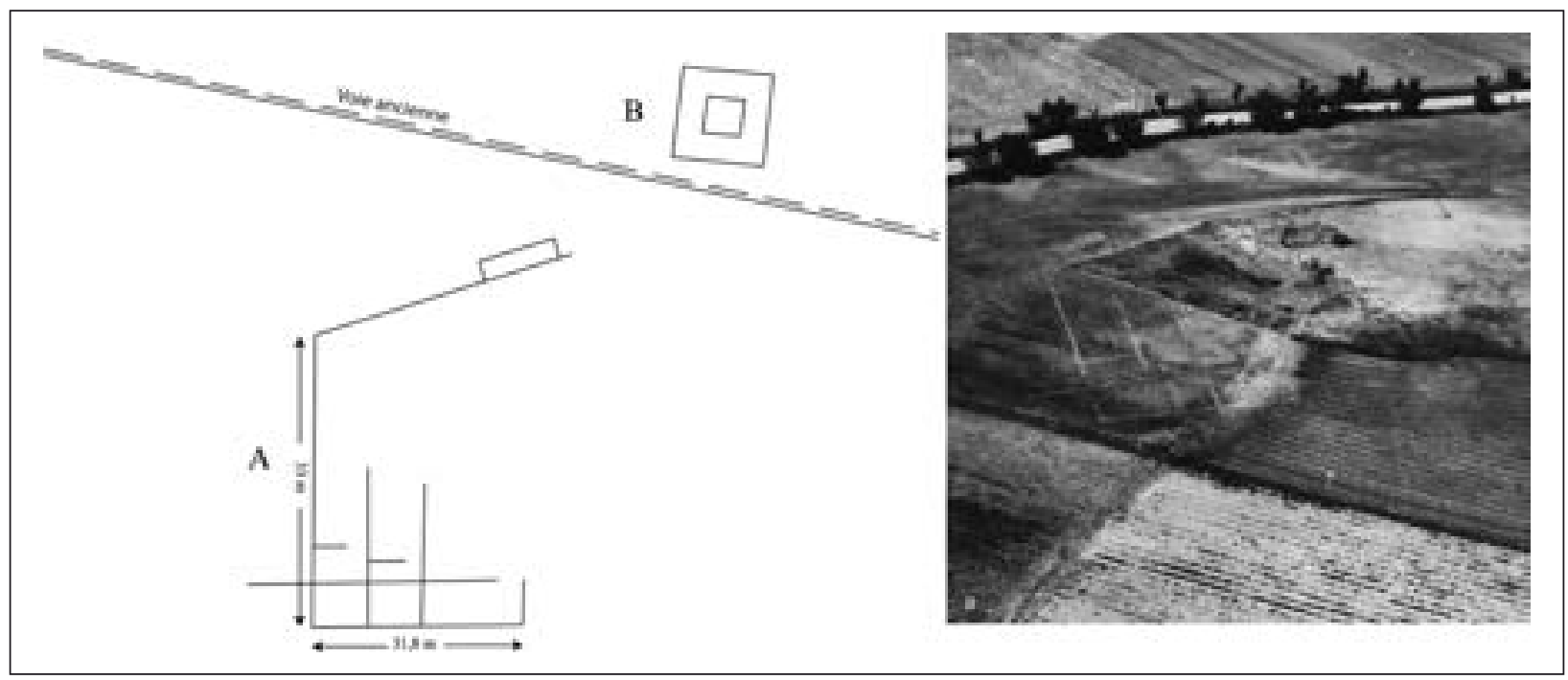

Fig. 9. Plan redressé de la vue aérienne (L. Monguilan) du site de La Valette à Aix-en-Provence (B.-du-Rh. ; Soyer 1968, 204, fig. 4) et cliché de L. Monguilan (Mocci, Nin 2006, fig. 626a-b). 
(Gauthier 1986, 411) reconnu dans la partie sud-est du site et reprise plus récemment (Mocci, Nin 2006, 571) doit plutôt être abandonnée au profit de l'identification de structures (bassin ?) de la pars rustica. De même, l'identification d'un «fanum » à l'entrée de la villa de la Trébillane à Cabriès (Mocci, Nin 2006, 531-532) à partir de l'observation sur le plan d'une structure de deux carrés concentriques n'est pas pertinente puisque cet aménagement est complètement inséré au nord et à l'ouest dans l'ensemble résidentiel : nous croyons davantage y reconnaître une petite cour à péristyle. Le «fanum » sur le site de la uilla de Saint-Pancrace à Puyloubier (13) est tout aussi incertain (Mocci, Nin 2006, 626-627).

Suite à ces nuances, le possible temple de type galloromain ayant dû fonctionner avec l'établissement rural de la Valette demeure en tout cas une illustration potentielle d'un sanctuaire lié à la uilla et fréquenté par la population des environs.

Ce type de lieu de culte modeste à proximité immédiate de uilla connaît des exemples plus évidents dans le reste de la Gaule ou les Germanies. A. Ferdière (1988, 251) précise cependant que l'observation de véritables sanctuaires privés dans les exploitations rurales est rare si ce n'est dans les très vastes et riches villas. Y. Barat (1999, 148) reprend cette idée en affirmant que les « sanctuaires privés sur les sites ruraux » sont « rarement attestés ». Néanmoins, il est intéressant de mettre en évidence dans la uilla ${ }^{19}$ de Chatillon-sur-Seiche (Ille-etVilaine) l'existence au $\mathrm{II}^{\mathrm{e}} \mathrm{s}$. ap. J.-C. d'un temple à plan centré à l'extérieur de la cour principale, mais à proximité immédiate d'une aile de bâtiment (Leroux, Provost 1990, 270) (fig. 10). La découverte d'une soixantaine de fragments de figurines en terre blanche ${ }^{20}$ sur le sol environnant et les déblais du «fanum » (Leroux, Provost 1990, 271) conduit à y voir le lieu de culte de la « population laborieuse du domaine » (Mohen 1989, 314, site $\mathrm{n}^{\circ} 183$ ). Une telle interprétation est-elle transférable aux deux cas qui nous intéressent? L'occupation antérieure aux actes votifs de Niger sur le site d'Allan plaide bien en faveur d'une fréquentation dépassant ce seul individu ou sa famille.

La uilla de Richebourg (Yvelines) livre également un « fanum » (cella) dès la phase $\mathrm{I}^{21}$ à seulement $30 \mathrm{~m}$ de l'habitation et dans le cadre d'un jardin clôturé (fig. 11).

19. Datation vers 20 av. - 20/40 ap. - III' $\mathrm{s}$.

20. Vénus anadyomène, Vénus sous édicule, déesse mère, Minerve, cheval et chien.

21. Seconde moitié du ${ }^{\text {er }}$ S. av. J.-C. au plus tôt.
Ce modeste lieu de culte poursuit son existence pendant les phases 2 et 3 (julio-claudienne et flavienne) avec une restructuration (ajout d'une galerie périphérique à la cella) et la réalisation de trois nouveaux édicules mais à aucun moment les divinités honorées ne sont explicitement définies. On notera cependant là encore la découverte de statuettes de Vénus anadyomènes en terre blanche de l'Allier (Barat 1999).

Nous évoquons là les exemples les plus frappants de lieux de culte situés à proximité immédiate d'établissements ruraux : mais d'autres cas pourraient enrichir le corpus. La uilla gallo-romaine de Montmaurin (HauteGaronne) avec son lieu de culte à Tutela notamment (Fouet 1969, 164) est intéressante : la situation d'un premier petit édifice octogonal (fin $\mathrm{I}^{\mathrm{er}}-\mathrm{II}^{\mathrm{e}} \mathrm{s}$. ap.) à l'intérieur de la cour d'entée de la uilla mais surtout la présence d'un temple ${ }^{22}$, au plan très original et ayant livré un autel central hexagonal, dans la cour d'honneur vers la moitié du $\mathrm{IV}^{\mathrm{e}} \mathrm{s}$. ap. J.-C. à mi-distance sur l'allée centrale entre l'entrée de l'habitat et le portique d'entrée, sont intéressants dans le cadre de notre réflexion. Parmi les six autels découverts non loin de cet édifice, un monument de 0,36 $\mathrm{m}$ de haut était dédié à dea Tutela $^{23}$ alors que la moitié supérieure d'un petit autel de $10 \mathrm{~cm}$ de haut portait une dédicace à Iuppiter Optimus Maximus et qu'un dernier monument anépigraphe possède la représentation d'une rouelle. À l'exception de la dédicace à Jupiter, nous ne connaissons pas le statut des dédicants, le matériel ${ }^{24}$ découvert n'étant pas d'une grande aide. Néanmoins, les fouilleurs interprètent cet espace comme "le lieu de rassemblement pour des cérémonies des colons et visiteurs du domaine » voire comme un «lieu de culte public, pour les colons ou la clientèle du maître » (Fouet 1969, 164). Mais le statut public de ce lieu de culte n'est absolument pas à retenir; tout au plus pouvons-nous suggérer un caractère collectif dépassant le cadre domestique mais cela est tout à fait incertain. La divinité Tutela ${ }^{25}$, sorte de Vesta pour G. Fouet $(1969,166)$ renvoie plutôt à un culte domestique, qui n'est pas véritablement comparable

22. On précisera cependant qu'une étude récente de J.-L. SchenkDavid (2005, 18 ; repris dans Sablayrolles, Beyrie 2006, 205) fait de ce temple hexagonal un simple bassin de captage et de dérivation des eaux de drainage.

23. CIL XIII, 159.

24. Une statuette en bronze, « croissant » en bronze, une pomme de pin, pots et coupelles, lampes, fragments de vasque avec l'inscription Deo marquée à la pointe, 62 monnaies (Fouet 1969, 159-163).

25. Ecartons-nous tout de suite de l'interprétation sans argument de la divinité honorée Tutela comme d'une «vieille divinité probablement de la source voisine de la Hillère incluse dans le domaine ». 


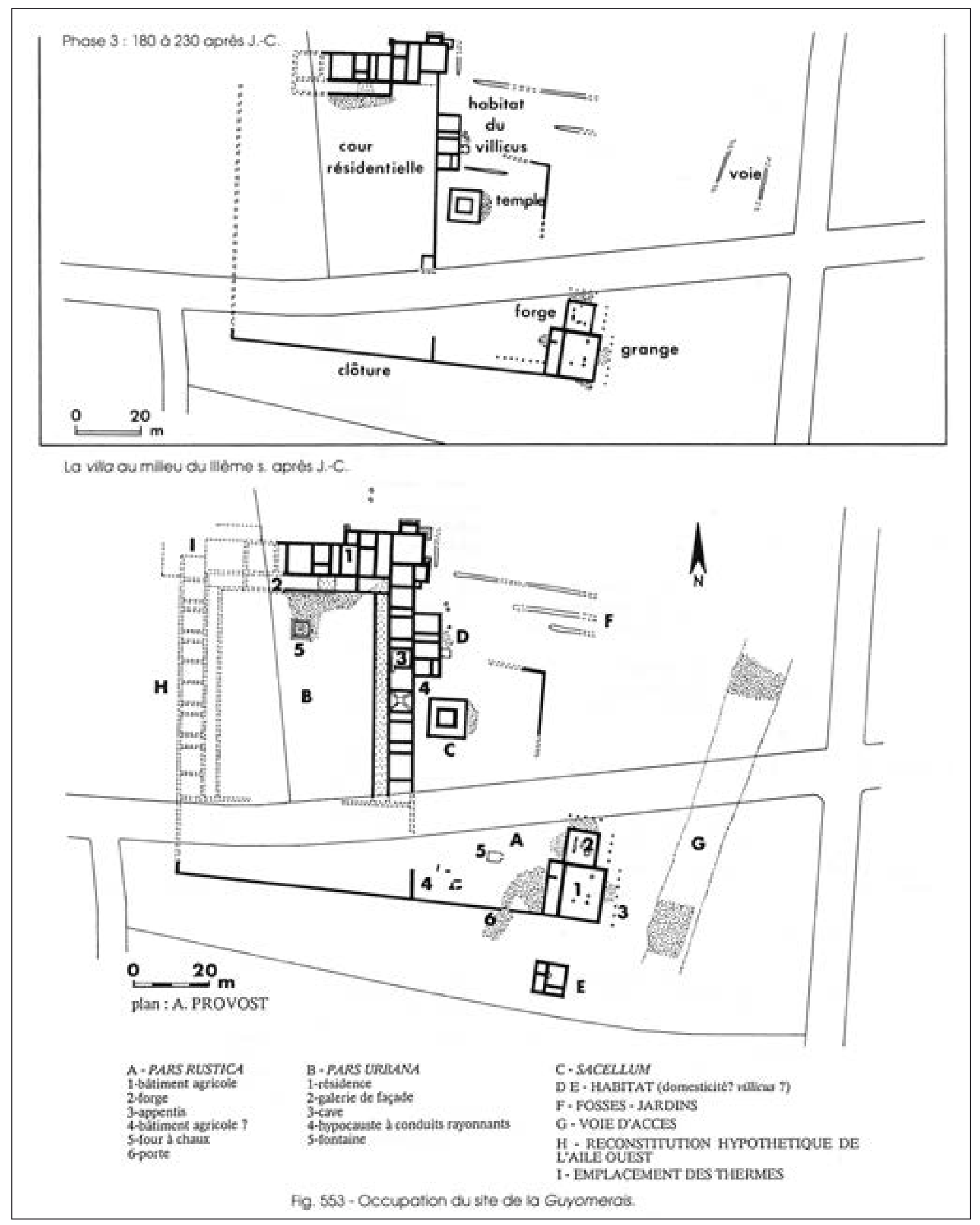

Fig. 10. Plan de la uilla de la Guyonnerais à Chatillon-sur-Seiche, (35) (dans Leroux, Provost 1990, 273 fig. 553). 


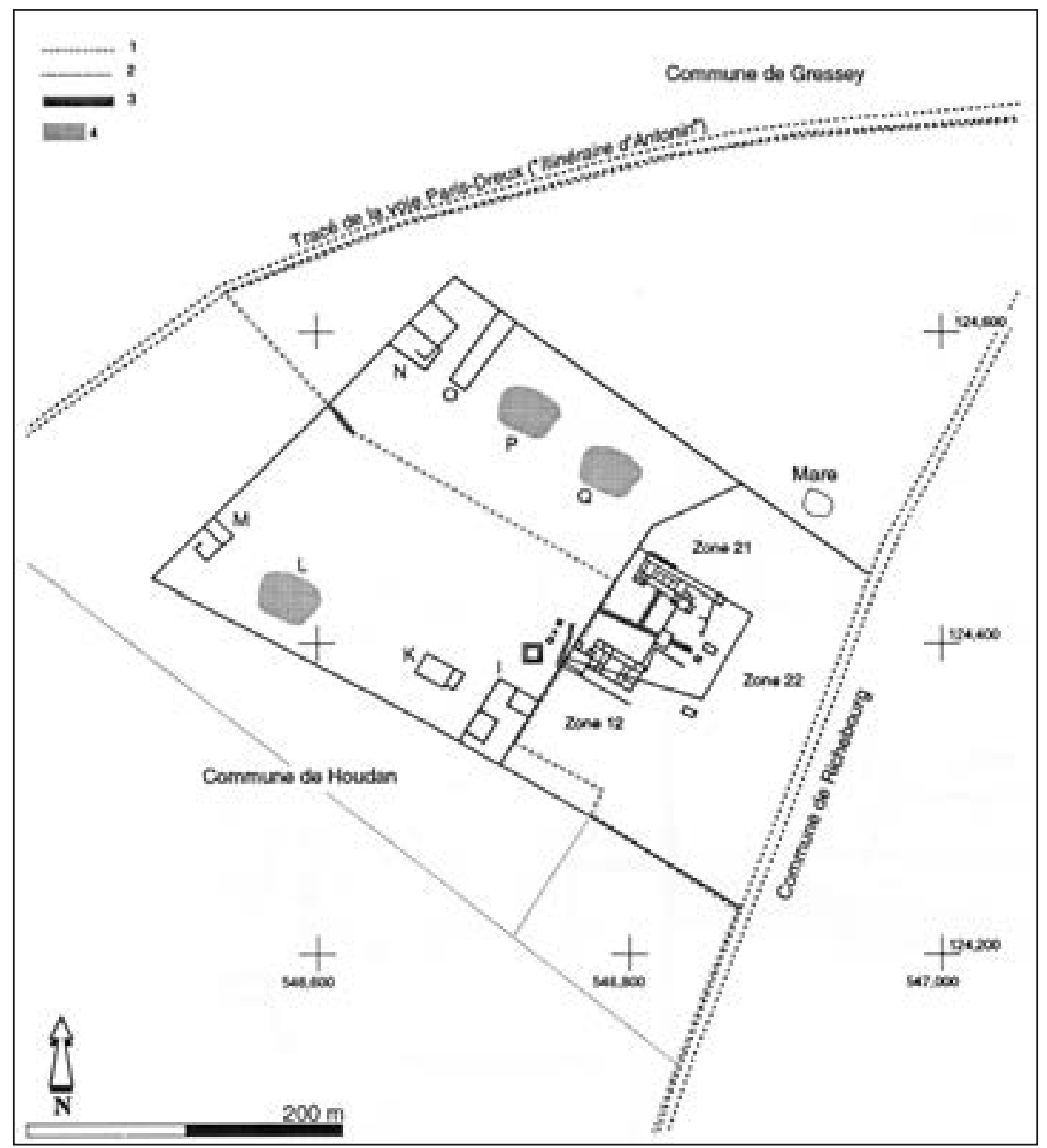

Fig. 11. Plan de la uilla de Richebourg (78) : 1 . : limites communales ; 2. : limites cadastrales ;

3. : tronçon de voie antique ; 4. : concentrations de mobilier en surface des labours (bâtiments de bois ?) (dans Barat 1999, 121 fig. 3).

aux déesses-Mères ${ }^{26}$ ou aux Proxsumes qui nous intéressent ici. Tutela correspond davantage à une figure allégorique ou divine liée à la puissance protectrice tutélaire veillant sur la maison, la famille. Certes la statue d'une déesse Mère découverte dans le sous-sol d'une maison d'Alesia (Côte-d'Or) pourrait illustrer la Mère domestique veillant sur le bien-être de la maisonnée (Deyts 1992, 61) mais le rapprochement entre DéesseMère et Tutela ne semblent pas se justifier.

Le « fanum » dans la cour résidentielle de la grande uilla de Touffréville (Calvados), l'édifice à double cella à $100 \mathrm{~m}$ au nord-est de la uilla du Champ des Pois à Levet (Cher) (Chevrot, Troadec 1992, 240-241) ou encore

26. On ne peut faire d'une Tutela une déesse-Mère mais on notera tout de même que S. Deyts (1992, 60-61) observe l'emprunt dans la représentation des Mères aux images de Tutela ou de la Fortune. le temple à galerie au nord-est de la uilla de St-Jean à Sainte-Colombe-de-Villeneuve (Lot-et-Garonne) (Fages 1995, 282-283) enrichissent le dossier de ces sanctuaires établis auprès d'établissements ruraux.

L'exemple donné par A. Ferdière (1988, 254) et repris depuis par X. Lafon (1988) ou Y. Barat (1999) à Chiragan (Martres-Tolosanes ; Haute-Garonne) est nettement plus discutable car le plan et la situation particuliers du BAT. XVI ${ }^{27}$ sur le plan de L. Joulin (1902, pl. 1 et 2) ne sauraient permettre d'identifier à eux seuls un sanctuaire alors que les découvertes de sept tombes d'enfants (?) dans des amphores et une tombe sous tuiles (Joulin 1902, 267 et 284), d'un grand cippe

27. Et non XIV comme donné par A. Ferdière (1988, 254). 
ou autel en marbre incomplet, de deux inscriptions « païennes » et de deux sarcophages chrétiens auxquels s'ajoutent de nombreuses petites poteries non décrites et des monnaies (Joulin 1902, 284) ne forment pas des arguments en faveur d'un lieu de culte. Par ailleurs, une hypothèse récente interprète cet édifice comme une construction liée au passage de la voie (mansio ou mutatio) (Massendari 2006, 264).

Nous terminerons ce tour d'horizon par le sanctuaire formé d'au moins trois « fanums » et de plusieurs édicules sur le site de Margerides (Corèze) : en effet, au-delà de l'enceinte, au nord, d'autres édifices pourraient souligner la présence d'un habitat mais l'absence d'une description précise empêche d'identifier de quel type d'habitat (rural, groupé, agglomération ?) il s'agit (Lintz 1992, 64-65). Mais ce site nous intéresse surtout par la présence d'une représentation de déesse-Mère qui nous invite à revenir sur la place de ce culte au sein des domaines ruraux.

\section{Culte des déesses-Mères et uillae}

Dans le Sud-Est de la Gaule, zone privilégiée de notre étude, nos deux exemples demeurent quelque peu isolés. Nous souhaitons tout d'abord revenir sur l'identification, que nous jugeons abusive, d'un «fanum à double cella » (Tallah 2004, 327) au quartier Saint-Just à Saint-Christol (84) : l'édifice établi sur un petit mamelon a certes livré un autel de $0,53 \mathrm{~m}$ de haut (Allmer 1874, 367) mais son plan quadrangulaire de $15 \times 7 \mathrm{~m}$ divisé par un mur de refend, l'épaisseur des murs (2 m) et surtout le mobilier ${ }^{28}$ mentionné (Chrestian 1866-1867, 117-122) ne militent pas en faveur d'un lieu de culte. D'ailleurs, l'autel aurait été trouvé à 2-3 m à l'extérieur dans un contexte imprécis. G. Barruol $(1965,93)$ interprète davantage ce site comme une uilla et ce serait donc dans ce contexte qu'il faudrait replacer la dédicace aux Mères ${ }^{29}$ inscrite sur l'autel.

Nous connaissons dans le Sud-Est une seconde occurrence d'une dédicace aux Mères dans le cadre d'un établissement rural. À Auriol (13), au lieu-dit La Moricaude, outre un monument semi-circulaire ${ }^{30}$, a été

28. Verrerie, clous en fer, fragments de douille en cuivre, une défense de sanglier, monnaie de Valérien.

29. CIL XII, 1174; Matribus / Elitnis / Capellatessi / u(otum) s(oluit) l(ibens) m(erito) (Chrestian 1866-1867, 117-122). Cette inscription aux Matres Elitiuae (Sautel 1939, 19 n³9; Barruol 1965, 93) comporte toujours des problèmes de développement.

30. Trop rapidement interprété comme un temple par F. Benoit (1936, 11, n40). découverte une inscription aux Matres Ubelnae ${ }^{31}$ sur un autel en calcaire de $30 \mathrm{~cm}$ de haut exhumé vers 1740 sur les bords de l'Huveaune (Rothé, Tréziny 2005, 774). Or la présence en surface d'une céramique abondante (notamment des fragments de sigillée et d'amphore), de tuiles, de dolium, de meule en basalte et l'évocation de mosaïque et colonne de chapiteau (Rothé, Tréziny 2005, 774) replace cet acte de dévotion aux Mères dans un contexte de villa.

Notre recherche sur l'association d'un culte aux Mères et d'un établissement rural nous renvoie vers la uilla du Grand Verger (Lambesc, 13) déjà évoquée, car la découverte d'un autel de $0,3 \mathrm{~m}$ de haut indique la présence d'un culte à des divinités féminines ${ }^{32}$ que J. Gascou (1995, 322 n²56) rapproche, dans le cadre de divinités tutélaires, des Matres, Matrae, Matronae, Iunones, Proxumae car on connait des Matres Suleuiae et des Iunones Suleuiae. Nous sommes ici confrontés à nouveau à la perception difficile de ces divinités féminines rapprochées aussi bien des Mères que des divinités liées à des individus telles que Proxsumes, Iunones.

Pour compléter la présentation de ce site, on évoquera la découverte dans les niveaux de remblai supérieurs de l'antiquité tardive, à l'angle de la parcelle et en dehors de toute structure, de quatre autels anépigraphes devant prendre place dans cette uilla de 2 ha occupée de la fin $\mathrm{du} \mathrm{I}^{\mathrm{er}} \mathrm{s}$. av. au $\mathrm{IV}^{\mathrm{e}} \mathrm{s}$. ap. J.-C. et à laquelle succèdera une basilique funéraire au $\mathrm{V}^{\mathrm{e}} \mathrm{s}$. On notera par ailleurs le remploi de chaperons en calcaire dans la basilique mais aussi dans les fondations de pièces de la partie nord de la uilla, notamment l'abside au nord : cela indique le démontage d'un édifice monumental mais nous ne pouvons sur la base des données actuelles l'interpréter comme un sanctuaire et encore moins en relation avec les autels découverts. L'hypothèse d'un mausolée démoli et réemployé lors d'une phase de construction ${ }^{33}$ de la uilla est tout aussi probable.

Si nous nous intéressons à l'ensemble de la Gaule, la nature des cultes en relation avec les domaines ruraux est, selon A. Ferdière (1988, 250-251), est liée à la fécondité essentielle pour les cultures : il évoque alors Jupiter, dieu de la foudre et intempéries, et surtout les déessesMères pour lesquelles les représentations en pierres et en

31. CIL XII, 333 : Matribus / Vb[el]nabus / u(otum) s(oluit) l(ibens) m(erito) / [Sex(tus) Lici]nius / Successus.

32. IILN Aix, 256: [S]extus /S[u]leuiabus / u(otum) s(oluit) l(ibens) $m$ (erito)

33. D'après la fouille et le phasage de 2006 (Almès 2006, 128), les murs réemployant les blocs sont de l'état $3 \mathrm{du} \mathrm{V} \mathrm{V}^{\mathrm{e}} \mathrm{s}$. ap. J.-C. 
terre cuite dans les uillae sont nombreuses. Par ailleurs, T. Derks (1997, 143-144) privilégie une corrélation entre les dédicaces à Mars et le réseau des uillae en Gaule du Nord : il suggère que l'intervention de Mars se place dans le domaine agraire dans le cadre de la plurifonctionnalité des divinités. Néanmoins, ce même auteur $(1998,126)$ et d'autres après lui (Spickermann 2002, 156) ont noté que le développement du culte matronal en Rhénanie est notamment conditionné par la mise en place du système d'exploitation en villae dans le sud de la Germanie inférieure, ce qui contribue à accentuer le caractère agraire de ce culte fortement attaché, d'après les épithètes associées, au nom de lieux et de groupes humains, d'ethnies, de pagi ou de curiae (Spickermann 2002, 145). On retrouve alors dans ces Matronae, « divinités aux compétences polyvalentes pour des groupes sociaux de caractère rural » (Spickermann 2002, 146), une relation privilégiée avec le développement d'établissements ruraux. Mais si la majorité des sanctuaires devait être en relation immédiate avec un établissement ou uilla rustica (Spickermann 2002, 165), le caractère tribal évoqué pour ces matronae de Germanie paraît nous éloigner des cultes rencontrés à proximité des établissements agricoles de notre dossier. De plus, le principal vecteur de diffusion du culte matronal en Germanie, sous une forme iconographique romaine, serait le fait de vétérans romains, ce qui ne convient guère à nos deux lieux de culte précédemment évoqués puisque tous deux sont situés dans la cité de Saint-Paul-Trois-Châteaux/ Augusta Tricastinorum qui ne relève pas d'une fondation de vétérans.

\section{Conclusion}

Ces deux sites paraissent former un dossier cohérent sur deux modestes sanctuaires dédiés aux Mères et établis sur un domaine foncier et surtout ont le mérite de démonter la pertinence d'une démarche combinant une étude des blocs sculptés et une analyse des textes épigraphiques tout en insistant sur le contexte archéologique.

Ils mettent aussi en lumière quelques pistes de recherche insuffisamment exploitées. Tout d'abord, ils illustrent ces nombreux exemples de sanctuaires établis à proximité immédiate de uillae. Les sanctuaires privés participent également au paysage religieux du monde rural et il serait opportun de développer davantage l'étude de ce type de lieux de culte privés. On s'aperçoit aussi que l'étude des cultes domestiques reste à faire face à la difficile interprétation des cultes des Mères, des Proxsumes ou des Junons qui apparaissent dans des contextes différents : sanctuaire public, sanctuaire privé établi sur un domaine ou simple culte domestique à l'intérieur de l'habitation.

La place du culte aux Mères dans les domaines ruraux reste ainsi à définir car s'il apparaît à plusieurs reprises en association avec des uillae, d'autres dieux sont aussi présents dans les cultes domestiques. Le culte des Mères apparaît par sa relation avec la fécondité comme tout à fait légitime dans son lien avec des établissements agricoles mais il ne faudrait pas le réduire à ce simple caractère car l'association de ce culte avec d'autres divinités féminines davantage liées au destin des individus (Proxsumes par exemple) sur certains sites ou le répertoire iconographique proche de ces différentes divinités témoignent de son éventuelle complexité. Nous en profitons pour insister sur la difficulté de prouver la relation des Mères aux sources comme a l'habitude de le souligner pourtant la bibliographie. Certes, les Mères Glaniques prennent place auprès de la source monumentalisée, une source (non localisée) est évoquée dans les environs de la uilla de Saint-Vincent tout comme à proximité de l'édifice de Beauvoir mais cela ne permet pas de systématiser cette relation à l'eau. Par ailleurs, la présence d'une dévotion aux Mères à Glanum mais aussi attestée à Nîmes ou encore à Vienne ${ }^{34}$ indique bien que ce culte matronal prend aussi toute sa place dans le monde urbain.

34. Une aedes est notamment évoquée par l'épigraphie : ILN Vienne, 13-16 et Lavagne et alii 2003, nº8, pl. 112 et n ${ }^{\circ} 100$, pl. 113. 


\section{Bibliographie}

Allmer 1874 : ALLMER (A.) - Deuxième promenade d'un épigraphiste (suite). Bulletin de la Société Archéologique de la Drôme, 8, 1874, p. 347-371.

Almès 2006 : ALMES (G.) - Lambesc, Saint-Victor/Grand Verger. B.S.R.P.A.C.A., 2006, p. 128-129.

Barat 1999 : BARAT (Y.) - La villa gallo-romaine de Richebourg (Yvelines). $R A C F, 38,1999$, p. 117-167.

Barat 2007 : BARAT (Y.) - Carte archéologique de la Gaule, 78. Les Yvelines. Paris, académie des Inscriptions et Belles-Lettres, 2007, 429 p.

Barruol 1965 : BARRUOL (G.) - Les Origines. A.L., 37 (Sites et monuments de Haute-Provence, Val de Sault et Pays d'Albion, II, Les hommes), automne 1965, p. 89-96.

Barruol 1994 : BARRUOL (G.) - Les sanctuaires gallo-romains du midi de la Gaule. In : Goudineau (C.), Fauduet (I.), Coulon (G.) dir., Les sanctuaires de tradition indigène en Gaule romaine, Actes du colloque d'Argentomagus (Argenton-sur-Creuse, Saint-Marcel, Indre, 8-10/10/1992). Paris, Ed. Errance, 1994, p. 49-72.

Benoit 1936 : BENOIT (F.) - Forma Orbis Romani. Carte archéologique de la Gaule romaine, V. Département des Bouches-du-Rhône. Paris, E. Leroux, 1936, 232 p., 3 plans h.t., 7 pl.

Benoit 1970 : BENOIT (F.) - Le symbolisme dans les sanctuaires de la Gaule. Bruxelles, Ed. Latomus, 1970, 108 p. (Latomus, 105).

Blanc 1967 : BLANC (A.) - Nouveaux bas-reliefs des déesses-mères et du dieu au maillet chez les Tricastins. Gallia, 25, 1967, p. 67-74.

Buisson 1997: BUISSON (A.) - Un monument dédié aux Proxsumae retrouvé dans la vallée du Rhône. $R A N, 30,1997$, p. 269-280.

Chevrot, Troadec 1992 : CHEVROT (J.-F.), TROADEC (J.) - Carte archéologique de la Gaule, 18. Le Cher. Paris, académie des Inscriptions et Belles-Lettres, 1992, $370 \mathrm{p}$.

Chrestian 1866-1867 : CHRESTIAN (H.) - Note sur une inscription votive aux déesses-mères faisant connaître le nom d'une ancienne peuplade habitant le plateau de Sault. Annales de la société littéraire, scientifique et artistique d'Apt, $4^{e}$ année, 1866-1867, p. 114-127.

Christol, Janon 1986 : CHRISTOL (M.), JANON (M.) - Révisions d'inscriptions de Nîmes, II, C.I.L. XII 5890. RAN, 19, 1986, p. 259-267.

Darembert, Saglio 1873-1919: DAREMBERT (C.), SAGLIO (E.) Dictionnaire des antiquités grecques et romaines d'après les textes et les monuments, contenant l'explication des termes qui se rapportent aux mœurs, aux institutions... et en général, à la vie publique et privée des anciens. Paris, Hachette, 1873-1919, 10 vol.

Derks 1997 : DERKS (T.) - The transformation of landscape and religious representations in Roman Gaul. Archaeological Dialogues, 4, fasc. 2, décembre 1997, p. 126-163.

Derks 1998 : DERKS (T.) - Gods, temples and ritual practices, the transformation of religious ideas and values in Roman Gaul. Amsterdam, Amsterdam University Press, 1998, 325 p.

Desaye 1992: DESAYE (H.) - L'épigraphie latine des Tricastins. In : Odiot (T.), Bel (V.) et Bois (M.) dir., D'Augusta Tricastinorum à
Saint-Paul-Trois-Châteaux (Drôme). Lyon, diffusion ALPARA, 1992, (D.A.R.A. n ${ }^{\circ}$ ), p. 27-39.

Deyts 1992 : DEYTS (S.) - Images des dieux de la Gaule. Paris, Errance, $1992,159 \mathrm{p}$.

Espérandieu 1907: ESPERANDIEU (E.) - Recueil général des basreliefs de la Gaule romaine, t. I. Alpes maritimes, Alpes Cottiennes, Corse, Narbonnaise. Paris, imprimerie nationale, 1907, (rééd. Ridgewood, The Gregg Press Incorporated, 1965), 489 p.

Espérandieu 1928 : ESPERANDIEU (E.) - Recueil général des bas-reliefs, statues et bustes de la Gaule romaine, t. X. Supplément (suite) et Tables Générales du recueil. Paris, imprimerie nationale, 1907, (rééd. Ridgewood, The Gregg Press Incorporated, 1965), 291 p.

Fages 1995 : FAGES (B.) - Carte archéologique de la Gaule romaine, 47. Le Lot-et-Garonne. Paris, académie des Inscriptions et Belles-Lettres, 1995, $365 \mathrm{p}$.

Ferdière 1988 : FERDIERE (A.) - Les campagnes en Gaule romaine. Paris, Errance, 2 vol., 301 et 284 p.

Fouet 1969 : FOUET (G.) - La villa gallo-romaine de Montmaurin. Paris, éd. C.N.R.S., 1969, 392 p. (XXe suppl. à Gallia).

Gaffiot 1998 : GAFFIOT (F.) - Dictionnaire Latin-Français. Paris, Hachette, 1998, (réimpr. éd. 1934), 1720 p.

Gascou 1995 : GASCOU (J.) - Inscriptions Latines de Narbonnaise (I.L.N.). III. Aix-en-Provence. Paris, éd. C.N.R.S., 1995, 396 p. (XLIV ${ }^{\text {e }}$ suppl. à Gallia).

Gauthier 1986 : GAUTHIER (M.) - Informations archéologiques, circonscription de Provence-Alpes-Côte-d'Azur. Gallia, XLIV, 1986, p. 375-483.

Golosetti 2009 : GOLOSETTI (R.) - Géographie du Sacré du Sud-Est de la Gaule, de la Protohistoire récente au Haut-Empire. Aix-en-Provence, thèse de doctorat sous la dir. de D. Garcia, université de Provence, 2009, vol. 1 et 2 (texte : 806 p.) et vol. 3 (annexe : tableaux, planches, cartes et figures : 290 pl.).

Joulin 1902 : JOULIN (L.) - Les établissements gallo-romains de la plaine de Martres-Tolosanes. Mémoires présentés par divers savants à l'Académie des Inscriptions et Belles-Lettres de l'Institut de France, $1^{\text {ère }}$ série, t. XI, $1^{\text {ère }}$ partie, 1902, p. 220-511.

Lafon 1988 : LAFON (X.) - À propos de Saint-Ulrich : villas et lieux de culte dans la Gaule du Nord-Est. In : Aspects de la religion celtique et gallo-romaine dans le Nord-Est de la Gaule à la lumière des découvertes récentes, Actes de la rencontre archéologique en hommage au professeur J.-J. Hatt (SaintDié-des-Vosges ; 7-9/10/1988). Saint-Dié-des-Vosges, Société Philomatique Vosgienne, 1988, p. 59-71.

Lantier 1966 : LANTIER (R.) - Recueil général des bas-reliefs de la Gaule romaine, t. XV. Suppléments (suite). Paris, P.U.F., 1966, 173 p.

Lavagne 1979: LAVAGNE (H.) - Les dieux de la Gaule Narbonnaise, « romanité » et romanisation. Journal des Savants, juil-sept., 1979, p. $155-197$.

Lavagne et alii 2003 : LAVAGNE(H.) dir., TERRER(D.), LAUXERROIS (R.), ROBERT (R.), GAGGADIS-ROBIN (V.), HERMARY (A.), JOCKEY (P.), Recueil général des sculptures sur pierre de la Gaule, Vienne (Isère). Paris, Académie des Inscriptions et Belles-Lettres, 2003, 251 p., 269 pl. (coll. Nouvel Espérandieu, I). 
Lejeune 1985 : LEJEUNE (M.) - Recueil des Inscriptions Gauloises (R.I.G.), vol. I. Textes gallo-grecs. Paris, éd. C.N.R.S., 1985, 459 p. (XLVe suppl. à Gallia).

Leroux, Provost 1990 : LEROUX (G.), PROVOST (A.) - Carte archéologique de la Gaule, 35. L'Ille-et-Vilaine. Paris, académie des Inscriptions et Belles-Lettres, 1990, 304 p.

Lert et alii 2009 : LERT (M.), BOIS (M.), BLANC-BIJON (V.), BEL (V.) - Atlas topographique des villes de Gaule méridionale, 3. Saint-Paul-TroisChâteaux. Lattes, Ed. Association de la R.A.N., 2009, 211 p. (suppl. à la R.A.N., 39).

Lintz 1992 : LINTZ (G.) - Carte archéologique de la Gaule romaine, 19. La Corrèze. Paris, académie des Inscriptions et Belles-Lettres, 1992, $223 \mathrm{p}$.

Maccabruni 1988 : MACCABRUNI (C.) - Testimonianze di scultura celebrativa privata a Laumellum. Quaderni Ticinesi di Numismatica e Antichità classica, 17, 1988, p. 241-255.

Marco, Mocci 1989: MARCO (V.), MOCCI (F.) - Histoire de l'habitat et occupation du sol dans la moyenne vallée de l'Arc de la préhistoire à l'antiquité tardive. Carte archéologique de la commune de Gardanne et des quartiers d'Aix-en-Provence, Luynes et Les Milles, de la préhistoire au $X V I I I^{e} s$. Aix-en-Provence, mémoire de maîtrise sous la dir. de P. Leveau, université de Provence, 1989, 3 vol.

Massara 2002 : MASSARA (P.) - L'iconografia del sacrificio cruento nei rilievi scultorei di età romana in Italia settentrionale. In : Saletti (C.) dir., Mito, rito e potere in Cisalpina. Firenze, All'insegna del giglio, 2002 p. 31-106 (Flos Italiae, 2).

Massendari 2006 : MASSENDARI (J.) - Carte archéologique de la Gaule, 31/1. La Haute-Garonne (hormis le Comminges et Toulouse). Paris, académie des Inscriptions et Belles-Lettres, 2006, 399 p.

Mercando, Paci 1998 : MERCANDO (L.), PACI (G.) - Stele romane in Piemonte. Roma, éd. Bretschneider, accademia nazionale dei Lincei, monumenti antichi, 1998, serie Miscellanea (vol. V ; LVII della serie generale ; 1998), $345 \mathrm{p}$.

Mocci, Nin 2006 : MOCCI (F.), NIN (N.) dir. - Carte archéologique de la Gaule, 13/4. Aix-en-Provence, Pays d'Aix, Val de Durance. Paris, académie des Inscriptions et Belles-Lettres, 2006, 781 p.

Mohen 1989 : MOHEN (J.-P.) dir. - Archéologie de la France, 30 ans de découvertes. Paris, éd. de la Réunion des musées nationaux, catalogue d'exposition (Galeries nationales du Grand Palais, 27/09-31/12/1989), 1989, $495 \mathrm{p}$.

Odiot, Bois 1992 : ODIOT (T.), BOIS (M.) - Les limites du Tricastin galloromain. In : Odiot (T.), Bel (V.) et Bois (M.) dir., D'Augusta Tricastinorum à Saint-Paul-Trois-Châteaux (Drôme). Lyon, diffusion ALPARA, 1992, (D.A.R.A., 7), p. 18-23.

Odiot, Raynaud 1992 : ODIOT (T.), RAYNAUD (C.) - Saint-Vincent, un site rural. In : Odiot (T.), Bel (V.) et Bois (M.) dir., D'Augusta Tricastinorum à Saint-Paul-Trois-Châteaux (Drôme). Lyon, diffusion ALPARA, 1992, (D.A.R.A., 7), p. 115-139.
Planchon, Bois, Conjard-Réthoré 2010 : PLANCHON (J.), BOIS (M.), CONJARD-RETHORE (P.) dir. - Carte archéologique de la Gaule, 26. La Drôme. Paris, académie des Inscriptions et Belles-Lettres, 2010, 783 p.

Provost, Meffre 2003 : PROVOST (M.), MEFFRE (J.-C.) - Carte archéologique de la Gaule, 84/1. Vaison-la-Romaine et ses campagnes. Paris, académie des Inscriptions et Belles-Lettres, 2003, 553 p.

Rémy et alii 2004 : REMY (B.) dir., BRETRANDY (F.), KAYSER (F.), PELLETIER (A.), WIBLE (F.) - Inscriptions latines de Narbonnaise (I.L.N.), V. 1. Vienne. Paris, CNRS éd., 2004, 407 p. (XLIV suppl. à Gallia).

Rolland 1953 : ROLLAND (H.) - Fouilles de Glanum (1951-1952) compterendu sommaire. Gallia, XI, fasc. 1, 1953, p. 3-17.

Rolland 1958 : ROLLAND (H.) - Fouilles de Glanum, 1947-1956. Paris, éd. C.N.R.S., 1958, 135 p. (XI ${ }^{\mathrm{e}}$ suppl. à Gallia).

Rothé, Tréziny 2005 : ROTHE (M.-P.), TREZINY (H.) (dir.) - Carte archéologique de la Gaule, 13/3. Marseille est ses alentours. Paris, académie des Inscriptions et Belles-Lettres, 2005, 925 p.

Rouillon 1996: ROUILLON (S.) - Le culte des déesses-mères en Gaule Narbonnaise d'après les monuments épigraphiques. Aix-en-Provence, mémoire de maîtrise sous la direction de D. Julia-Pralon, université de Provence, 1995-1996, $152 \mathrm{p}$.

Roumégous 2009 : ROUMEGOUS (A.) - Carte archéologique de la Gaule, $84 / 3$. Orange et sa région. Paris, académie des Inscriptions et Belles-Lettres, $2009,371 \mathrm{p}$.

Sablayrolles, Beyrie 2006 : SABLAYROLLES (R.), BEYRIE (A.) - Carte archéologique de la Gaule, 31/2. Le Comminges (Haute-Garonne). Paris, académie des Inscriptions et Belles-Lettres, 2006, 515 p.

Sautel 1939 : SAUTEL (J.) - Forma Orbis Romani. Carte archéologique de la Gaule romaine, VII. Vaucluse. Paris, académie des Inscriptions et Belles Lettres, 1939, $160 \mathrm{p}$.

Schenk-David 2005: SCHENK-DAVID (J.-L.) - L'archéologie de trois sanctuaires des Pyrénées Centrales. Contribution à l'étude des religions antiques de la cité des Convènes. Saint-Bertrand-de-Comminges, Musée archéologique départemental, 2005, 128 p. (Pirénéica, 1)

Spickermann 2002 : SPICKERMANN (W.) - Nouvelles réflexions relatives à la genèse et aux vecteurs du culte matronal dans la région du Rhin inférieur. CCG, XII, 2002, p. 141-167.

Soyer 1968 : SOYER (J.) - Découvertes d'emplacements d'habitat galloromain dans la plaine d'Aix. $R A N, 1,1968$, p. 201-218.

Tallah 2004: TALLAH (L.) - Carte archéologique de la Gaule, 84/2. Le Lubéron et le Pays d'Apt. Paris, académie des Inscriptions et Belles-Lettres, 2004, $431 \mathrm{p}$.

Vallentin du Cheylard 1957 : VALLENTIN DU CHEYLARD (R.) - Sacellum consacré aux Mères victorieuses. Cahiers rhodaniens, IV, 1957, p 67-72.

Van Andringa 2009 : VAN ANDRINGA (W.) - Quotidien des dieux et des hommes. La vie religieuse dans les cités du Vésuve à l'époque romaine. Rome, E.F.R., 2009, 404 p. (BEFAR, 337). 
Achevé d'imprimer en janvier 2015 par l'imprimerie SEPEC à Peronnas

Dépôt légal : mars 2015

$\mathrm{n}^{\circ} \mathrm{d}^{\prime}$ imprimeur :

Imprimé en France 